\title{
Synthesis of Biological Research on Juvenile Fish Passage and Survival at Bonneville Dam through 2005
}

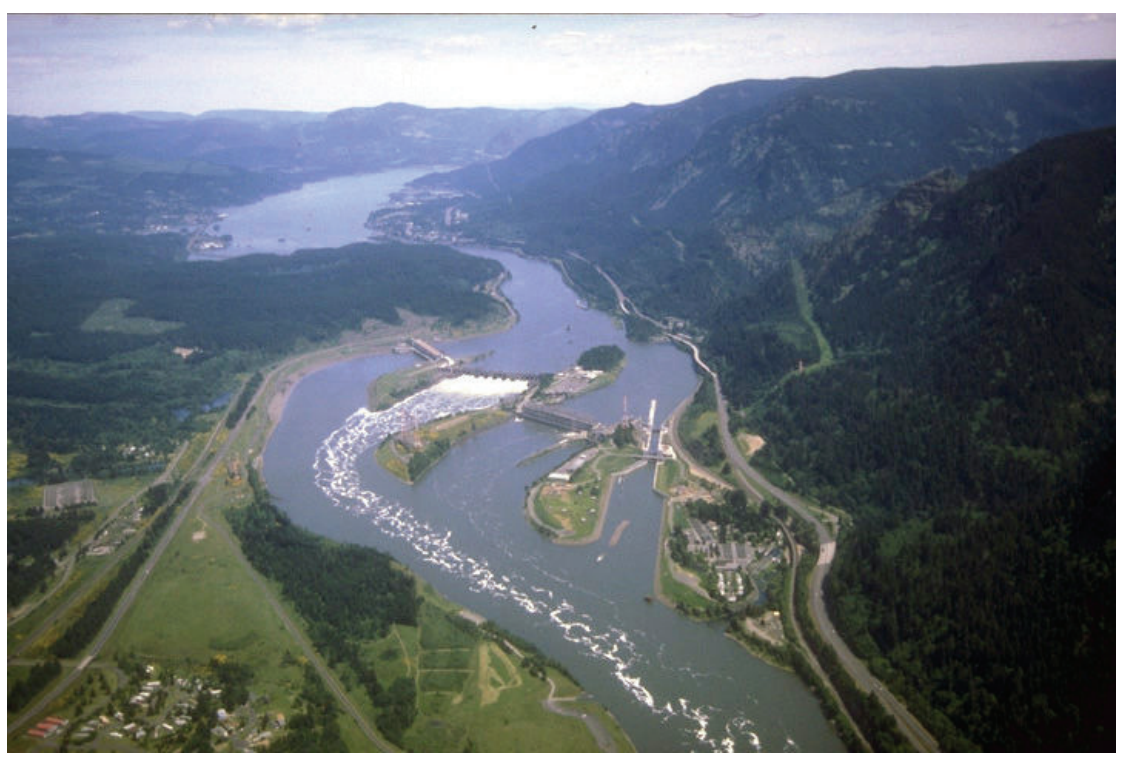
G. R. Ploskey
G. E. Johnson
A. E. Giorgi
R. L. Johnson
J. R. Stevenson
C. R. Schilt
P. N. Johnson
D. S. Patterson

FINAL REPORT

July 2007

Prepared for the

U.S. Army Corps of Engineers

Under a Related Services Agreement

With the U.S. Department of Energy

Contract DE-AC05-76RLO1830

\section{Pacific Northwest National Laboratory}

Operated by Battelle for the U.S. Department of Energy 
This report was prepared as an account of work sponsored by an agency of the United States Government. Neither the United States Government nor any agency thereof, nor Battelle Memorial Institute, nor any of their employees, makes any warranty, express or implied, or assumes any legal liability or responsibility for the accuracy, completeness, or usefulness of any information, apparatus, product, or process disclosed, or represents that its use would not infringe privately owned rights. Reference herein to any specific commercial product, process, or service by trade name, trademark, manufacturer, or otherwise does not necessarily constitute or imply its endorsement, recommendation, or favoring by the United States Government or any agency thereof, or Battelle Memorial Institute. The views and opinions of authors expressed herein do not necessarily state or reflect those of the United States Government or any agency thereof.

\author{
PACIFIC NORTHWEST NATIONAL LABORATORY \\ operated by \\ BATTELLE \\ for the
}

UNITED STATES DEPARTMENT OF ENERGY

under Contract: DE-AC06-75RLO1830

Printed in the United States of America

Available to DOE and DOE contractors from the

Office of Scientific and Technical Information,

P.O. Box 62, Oak Ridge, TN 37831-0062;

ph: (865) 576-8401

fax: (865) 576-5728

email: reports@adonis.osti.gov

Available to the public from the National Technical Information Service, U.S. Department of Commerce, 5285 Port Royal Rd., Springfield, VA 22161

ph: (800) 553-6847

fax: (703) 605-6900

email: orders@ntis.fedworld.gov

online ordering: http://www.ntis.gov/ordering.htm 


\title{
Synthesis of Biological Research on Juvenile Fish Passage and Survival at Bonneville Dam through 2005
}

\author{
G. R. Ploskey \\ G. E. Johnson \\ A. E. Giorgi ${ }^{(1)}$ \\ R. L. Johnson \\ J. R. Stevenson ${ }^{(1)}$ \\ C. R. Schilt ${ }^{(2)}$ \\ P. N. Johnson ${ }^{(2)}$ \\ D. S. Patterson ${ }^{(2)}$
}

\section{FINAL REPORT}

July 2007

Prepared for

the U.S. Army Corps of Engineers

Portland District, Portland, Oregon

Under a Related Services Agreement

With the U.S. Department of Energy

under Contract DE-AC05-76RLO1830

Pacific Northwest National Laboratory

P.O. Box 999

Richland, Washington 99352

\footnotetext{
(1) BioAnalysts, Inc., Seattle, Washington

(2) BAE Systems, Inc., Stevenson, Washington
} 



\begin{abstract}
This document provides a synthesis of biological research on juvenile salmonid passage and survival at Bonneville Dam from 1939 to 2005. This review of available literature was prepared by the Pacific Northwest National Laboratory for the U.S. Army Corps of Engineers (USACE). It involved acquiring a copy of every pertinent report or journal article through 2005, writing an annotated bibliography, and then writing a report that summarizes and synthesizes available information in a decision-support document. Studies of interest and the arrangement of chapters after the Chapter 1-Introduction include Chapter 2Forebay Distribution and Approach; Chapter 3-Passage, including sections on Major Metrics, Surface Flow Outlets, Fish-Guidance Efficiency, and Fine-Scale Distributions; Chapter 4-Survival, and Chapter 5-Optimizing Fish Passage Strategies at Bonneville Dam.
\end{abstract}


Synthesis of Biological Research on Juvenile Salmonid Passage and Survival at Bonneville Dam through 2005 


\section{Summary}

This document provides a synthesis of biological research on juvenile salmonid passage and survival at Bonneville Dam from 1939 to 2005. This review of available literature was prepared by the Pacific Northwest National Laboratory for the U.S. Army Corps of Engineers (USACE). It involved acquiring a copy of every pertinent report or journal article through 2005, writing an annotated bibliography, and then writing a report that summarizes and synthesizes available information in a decision-support document. Studies of interest include those on project-wide route-specific passage (and related efficiency and effectiveness metrics), fish survival (direct and indirect), fish-guidance efficiency (FGE) of powerhouses and units, predation in the forebay and tailrace, fish behavior on forebay approach and egress, and surface passage. The chapter on juvenile salmonid passage includes a review of available passage distribution data (horizontal, vertical, and diel) for juvenile salmon.

\section{Forebay Distribution and Approach}

Fish approach the Bonneville Project following bulk flow, and the distribution of fish passage among the Bonneville Dam First Powerhouse (B1), the spillway, and the Bonneville Dam Second Powerhouse (B2) is well correlated with the discharge distribution. Dam operations affect the distribution of fish passage among structures because fish movement from one forebay to another is minimal after the initial distribution by bulk flow. Vertical distributions of fish in forebay areas upstream of dam structures are highly skewed toward the water's surface, and therefore surface flow bypasses have potential to be efficient and effective. Horizontal distribution in forebays of the two powerhouses revealed areas of concentration. At B1 these areas were upstream of units 4-6 in spring and upstream of units 4-6 and toward the north end of the powerhouse in summer. At B2 fish concentrated primarily in the south end near or in a large eddy and in a smaller eddy on the north side of the forebay.

Average travel rates from release sites to the project were relatively quick. In kilometers per hour, rates averaged 2.1 for subyearling Chinook salmon, 2.3 for yearling Chinook salmon, and 2.6 for steelhead. These results indicate that radio-tagged fish are actively moving downstream and not holding for prolonged periods of time.

Average hourly residence times in forebays were short except for B1, when B2 was assigned the generation priority for the project after 2000 or for steelhead at either powerhouse (Table S.1). Short residence times at the spillway and $\mathrm{B} 2$ reduce the risk of predation.

Table S.1. Average Hours of Forebay Residence for Chinook Salmon and Steelhead

\begin{tabular}{|lccc||}
\hline Species / Age Class & B1 & Spillway & B2 \\
\hline \hline Yearling Chinook salmon & 2.2 & 0.2 & 0.5 \\
Steelhead & 5.4 & 0.3 & 3.0 \\
Subyearling Chinook salmon & 4.4 & 0.4 & 0.2 \\
\hline
\end{tabular}

\section{Juvenile Salmonid Passage}

\section{Major Passage Metrics}

Maximizing fish passage by non-turbine routes (fish passage efficiency or FPE) may or may not be the best goal to maximize project survival depending upon the ranking of survival of all major routes at 
Bonneville Dam. Prioritizing routes by survival rate would seem to be a logical first step toward the goal of maximizing project survival, and therefore a thorough understanding of route-specific survival is critical for choosing the best routes for fish. After routes are ranked from highest to lowest survival, the next step would be to adjust project operations to maximize passage through the safest routes. In the survival chapter, we made an effort at ranking routes, as follows:

- Survival was always highest through the B2 Corner Collector (B2) - all species.

- The B2 Juvenile Bypass System (B2 JBS) typically ranked second or tied for first - all species.

- Ranking among the other three routes, the B1 JBS, spillway, and B1 sluiceway, varied substantially, with no consistent pattern evident.

These rankings were determined by inspecting summary tables and figures appearing in the reports (Counihan et al. 2005, 2006). Depending on the species and prevailing condition, spillway survival was often low, ranking 4th or 5 th of the five routes available. This may suggest that spill is not particularly beneficial for enhancing passage survival for the population at large. However, spilling water also enhances egress conditions in the tailrace and likely contributes to the high survival realized at the corner collector.

If turbines sometimes provide a safer route than some spill bays, then using spill to maximize FPE may not be consistent with the goal of maximizing project survival. However, if the safest routes turned out to be non-turbine routes, and the goal was to maximize passage by non-turbine routes, then the discussion and recommendations in the next two paragraphs make sense.

The most efficient approach to increase non-turbine passage is to optimize percent flow to the B1sluiceway and the B2 Corner Collector (B2CC) because these routes can reduce turbine passage by outcompeting adjacent turbines for fish. The spillway cannot compete directly with turbines for fish. Spill should not be eliminated, but it may be possible to reduce reliance on spill to pass juvenile salmonids by fully realizing all potential benefits of surface passage through structural and operational changes at the powerhouses. Turbines are about as efficient as the spillway at any percent of project flow (Ploskey et al. 2006b), but surface routes are much more efficient than turbines at low percent flow. The average percent of B1 flow through the B1 sluiceway (1\%-2\%) is well below an optimum amount of $10 \%$, but hopefully planned improvements in that system will greatly increase its performance in the future. Given the very high effectiveness of surface routes at the lowest flows, we recommend testing the use of many low-flow surface outlets at B1 versus the use of a few outlets passing equivalent flow. Regressions indicated that increasing surface-flow percentages of B1 flow from $1 \%$ to $10 \%$ could increase B1 sluiceway-passage efficiency from $40 \%$ to $83 \%$, and this clearly indicates that juvenile salmonids preferentially select surface outlets over adjacent turbines. Increasing B2 flow to the B2 sluiceway from $4 \%$ to $15 \%$ could increase fish passage from $31 \%$ to $62 \%$. The high effectiveness of surface outlets and their proximity to turbines should make them the first choice of managers for optimizing flow to increase non-turbine passage, rather than spill. Without structural modification, attaining 10\% B1 flow to the sluiceway requires shutting down turbines, which is how $50 \%$ to $100 \%$ of B1 flow to the sluiceway was possible at times.

Given the B2 powerhouse priority, it is difficult to imagine increasing the percent of B2 flow to the B2CC much above the median baseline of 4\% observed in 2004 and 2005. Previous observations of 10\% to $15 \%$ of B2 flow to the B2CC always occurred at night when turbines were shut down to accommodate increased spill at night. The installation and testing of a smolt guidance device in the B2 forebay may be a viable alternative to increasing percent flow from $4 \%$ to $15 \%$. We also recommend testing ways to 
reduce shedding of turbulence from piers at units 11 and 12 as these turbulent cells tend to push lateral flow away from the face of the powerhouse. An economical approach would be to cover spare trash racks with a plywood veneer and install them into trash-rack slots on top of existing un-blocked trash racks to assess potential benefits to B2CC efficiency and effectiveness.

The percent of spill clearly has an overriding influence on spill and fish-passage efficiency and likely will always be an important tool to improve spill and fish-passage efficiency, but spill effectiveness is nearly constant at just over 1:1 over a wide range of percent spill. Spill has been and probably will continue to be used to increase non-turbine passage at Bonneville Dam, but it is not an efficient use of water because the project has two islands that isolate spillway flow from powerhouse flow before fish can select a preferred route. Consequently, spill efficiency will always be directly proportional to percent spill, with effectiveness ranging from about 0.7 to 1.3 .

\section{Surface Flow Outlets}

\section{PSC}

Based on the collective data during the 1998-2000 Prototype Surface Collector (PSC) evaluation period (summarized by Johnson and Carlson 2001), researchers found that the surface bypass concept as applied at B1 was an efficient way to collect juvenile salmonids and minimize turbine passage. Fish collection efficiency estimates from hydroacoustics, radio telemetry, and acoustic telemetry methods comported reasonably well. The highest quality and most applicable data for fish collection efficiency are from the 2000 evaluation, because of the large sample sizes and because the PSC covered units 1-6 that year. The PSC only covered units 3 and 4 in 1998, and units 3 through 6 in 1999. For the purposes of planning and analysis for constant turbine operations, at one PSC slot opening, the following fish collection efficiency estimates should be used:

$\begin{array}{lr}\text { Yearling Chinook salmon } & 76 \% \\ \text { Steelhead trout } & 82 \% \\ \text { Subyearling Chinook salmon } & 84 \%\end{array}$

Fish collection efficiency for the PSC was similar between spring and summer, i.e., it did not decrease in summer but stayed largely unchanged while the run composition changed. This is not true of other smolt bypass approaches that have decreasing efficiency as the season progresses. Fish collection efficiency for the B1 PSC was higher than that for the surface bypass and collector SFO at Lower Granite Dam and comparable to that for the Wells Dam SFO. Extending the PSC to units 1 and 2 in 2000 was worthwhile because the surface bypass entrances at units 1 and 2 passed a substantial proportion of total PSC fish passage (23\%-28\%). According to radio telemetry data from 2000, the PSC would have increased fish passage efficiency at Bonneville Dam 18\% for steelhead and 10\% for Chinook salmon had it been a functional bypass system. The PSC was twice as effective (percentage fish divided by percentage water) as spill at passing fish at Bonneville Dam in 2000.

The B1 PSC showed promise as a powerhouse retrofit SFO, but it was not followed by a full production structure, a state it remains in to this day. The main reasons for this included

- uncertainty about fish response to forebay flow fields from a ramped entrance structure

- complexity of the conveyance and outfall structures

- uncertainty about fish injury rates at high flow outfalls 
- commitment to the $\mathrm{B} 2$ Corner Collector and associated designation of $\mathrm{B} 2$ as the priority powerhouse at Bonneville Dam

- $\operatorname{cost}(\sim 200 \mathrm{M})$.

The PSC evaluations demonstrated the efficacy of a powerhouse retrofit SFO for B1. Lessons learned from the PSC will be applicable to any future SFO development efforts at B1.

\section{B1 Sluiceway}

Based upon all available seasonal estimates from hydroacoustic and radio telemetry studies, the efficiency of the B1 sluiceway relative to B1 was correlated with the percent of B1 flow to that route. Within-season day and night estimates show the full range of effect much more clearly. B1 sluiceway efficiency increased very rapidly at low levels of percent flow. On average, the percent of B1 passage through the B1 sluiceway was about $40 \%$ at $1 \%$ of B1 flow (the minimum flow), $73 \%$ at $5 \%$ flow, $83 \%$ at $10 \%$ flow, and $88 \%$ at $15 \%$ flow.

Future SFO development at B1 is underway with the planned removal of the wall between the current sluiceway and the old juvenile bypass channel in 2007. This will increase channel capacity and allow all outlets above Unit 1 to be left fully open without limiting channel capacity for several gates further upstream. There also are plans to install floating gates to follow forebay elevation and produce a constant discharge. There are also possibilities for a new powerhouse retrofit SFO. Options would entail new conveyance and outfall structures, perhaps for a partial or full powerhouse Alternative A, a B1 corner collector with or without an associated behavioral guidance structure. Preliminary engineering is available for most of these options. We strongly recommend evaluating changes to the sluiceway system including its efficiency and effectiveness and fish survival after improvements are made. The survival study should include reference releases of fish from the existing outfall and potential alternative outfalls.

\section{B2CC}

Collection efficiency and effectiveness of the $\mathrm{B} 2 \mathrm{CC}$ relative to $\mathrm{B} 2$ was highest for steelhead trout (66\%-74\%) and reasonably similar for the run-at-large (31\%-32\% in spring and $40 \%-44 \%$ in summer, as estimated by hydroacoustic sampling) to the estimate for Chinook salmon by radio telemetry (30\%-37\% in spring and 37\%-40\% in summer). For spring 2004 and 2005, fish-collection effectiveness relative to B2 averaged 7.3 for the run-at-large in spring, 6.5 for yearling Chinook salmon, and 13.7 for steelhead. In summer of those years, $\mathrm{B} 2 \mathrm{CC}$ effectiveness relative to $\mathrm{B} 2$ was 7.3 according to the hydroacoustic estimate and 6.5 for subyearling Chinook salmon, according to the radio telemetry estimate.

There were too few seasonal estimates of $\mathrm{B} 2 \mathrm{CC}$ efficiency for regression on percent of $\mathrm{B} 2$ flow to the B2CC, but daily hydroacoustic data from 2004 and 2005 show a trend similar to that observed for the B1 sluiceway. The percent of B2 passage through the B2CC was $30 \%$ at $4 \%$ of B2 flow (the minimum flow), $36 \%$ at $5 \%$ flow, $52 \%$ at $10 \%$ flow, and $62 \%$ at $15 \%$ flow. The remaining percentages of B1 or B2 passage at any percent flow represent what would pass through adjacent turbines.

The B2 Corner Collector is a permanent, long-term surface flow outlet at the B2 powerhouse. It has a state-of-the-art conveyance channel and outfall that passes juvenile salmonids with utmost safety into environs downstream of the dam. The B2CC takes advantage of the location of the old sluice chute relative to the forebay eddy to pass surface-oriented emigrants. The intention is for the $\mathrm{B} 2 \mathrm{CC}$ not to be a stand-alone route, but rather to complement the intake screen system to protect fish at B2.

The reason for the higher collection efficiency and effectiveness for steelhead than for Chinook salmon is unknown, but efforts should be made to improve the collection of the latter species. As 
recommended above, we support testing of lateral flow modifications along the south face of the B2 powerhouse and a behavioral guidance device, given that it would be difficult to increase percent flow to the $\mathrm{B} 2 \mathrm{CC}$ much above the median baseline of $4 \%$ without shutting down turbines. The installation and testing of a smolt guidance device in the B2 forebay was scheduled for 2007 but postponed.

\section{Fish Guidance Efficiency}

Fishery managers and analysts require estimates of FGE for certain evaluations, such as those involving fish passage models. FGE estimates are just one of many input parameters that are used to populate a passage model. Selecting a representative value for the species of interest can be challenging as witnessed by the variability in measured values and ever-changing screen systems. The difficulty is magnified if retrospective analyses are pursued, which requires establishing what effective FGE was at some point in history. Often such details are ignored or cannot be reasonably determined. In most cases a generic value that is considered representative is applied across dam configuration eras. This can result in rather coarse assessments.

The most recent generic FGE values for B1 and B2 were reported by Ferguson et al. (2005) as shown in Table S.2.

Table S.2. FGE Values for B.1 and B.2

\begin{tabular}{||l|c|c|c|c||}
\hline & \multicolumn{2}{|c|}{ PATH } & \multicolumn{2}{c||}{ NOAA - 1999 Configuration } \\
\hline \hline Species & B1 & B2 & B1 & B2 \\
\hline Yearling Chinook & 41 & 43 & 38 & 44 \\
\hline Subyearling Chinook & --- & --- & 16 & 18 \\
\hline Steelhead & --- & --- & 41 & 48 \\
\hline
\end{tabular}

These values were distilled from the complex of fyke net-based FGE estimates in the historical database. Staff used their judgment in selecting values that they believed were most representative of the general dam configuration pre-Biological Opinion (BiOp). Some of those estimates were then adjusted based on side-by-side PIT tag and fyke net data obtained at Snake River dams.

In viewing the collective FGE information obtained with fyke nets, hydroacoustics, and radiotelemetry, we submit the following synthesis and conclusions.

Establishing reliable, representative estimates of powerhouse FGE for use in retrospective passage modeling analyses for either B1 or B2 will be difficult. We could not readily identify any preferred set of estimates. Results vary by turbine unit, configuration, operations, and monitoring tool. There is no correct or best estimate of FGE available for application across all years. Furthermore, across and within years, so many conditions have been explored and tested that no typical or standard FGE can easily be distilled from the information. Managers seeking such estimates will have to make value judgments regarding the suitability of year-specific estimates for use in retrospective model analyses. Action Agencies, National Oceanic and Atmospheric Administration National Marine Fisheries Service (NOAA Fisheries), and state and tribal biologists are currently engaged in such an effort as part of the 2006 remand process for the BiOp. Managers must determine what the further monitoring objectives are for Bonneville Dam and select the appropriate tool and method to satisfy them. 
The fyke net method for estimating FGE seems best suited for evaluating different screen configurations in side-by-side comparisons. Since such evaluations involve only monitoring one or two units, this technique is not well suited for generating FGE estimates that represent performance across the entire powerhouse.

Hydroacoustic monitoring seems well suited for providing season-wide estimates of FGE if temporal and spatial coverage of the powerhouse is adequate. It is also the only practical method for documenting temporal changes in FGE over the migration period. An obvious shortcoming is the lack of speciesspecific information, but depending on management objectives, this may not be a handicap.

The radio-telemetry method provides sound estimates of the effective FGE across the entire powerhouse during the period tagged fish are passing the project. This may be the most representative estimate of FGE that could be adopted and applied in model analyses. Even so, only a few estimates from recent years are available. Estimates are best for units where the most fish are passing but numbers may be insufficient for units with the least passage.

\section{Horizontal Distributions}

The proportion of fish passage through B1, the spillway, and B2 was nearly proportional to discharge at each location. This observation was consistent throughout five years of full-project-passage assessment based upon both radio telemetry and hydroacoustic techniques.

Distributions of fish associated with passage through various routes within B1, the spillway, and B2 depend on discharge in that fish cannot pass through routes that are closed. This is why patterns of fish passage through B1 turbines varied a lot after the powerhouse priority was shifted to B2 in 2001 and thereafter. Different units were running in different years depending upon unit priority and outages for retrofitting or maintenance. The general correspondence between fish passage and discharge can be seen in route-specific plots of fish and flow passage for 2004 and 2005.

Horizontal distributions should always be plotted with route-specific discharge and interpreted in that context, something that was not always done in reports before 2004. The addition of discharge to distribution plots allows readers to get a sense of whether or not distributions were driven by project operations. Without plotting or considering the route-specific distribution of discharge, one might conclude that the fish passage distributions across B1 from 1996 to 2002 were simply not uniform or consistent.

However, the general relation between discharge and fish passage breaks down for surface flow outlets, because juvenile salmonids preferentially select these routes over other routes, and this selection leads to high measures of effectiveness (high efficiency with low water proportions). This is quite evident in lots of the density of fish passage by route. Surface passage routes have much higher efficiency at low flow proportions than do either the spillway or turbines.

Like the sluiceway at B1, the B2CC is a highly effective route of passage, clearly passing many more fish than any turbine unit and exponentially more on the basis of fish-per-unit of discharge. Lateral passage into the $\mathrm{B} 2 \mathrm{CC}$ is not uniform. A majority of fish pass in the middle relative to the north and south sides, at least near the water's surface, where most fish are distributed. Intake piers from units 11 through 13 shed vortices and create turbulence that has an unknown effect on B2CC performance. Spare trash racks with plywood blocks on the upstream surfaces could be dropped into trash-rack slots in units 11 and 12 on top of existing trash racks to reduce shedding of turbulent flow. The blocked racks would act as cheap fillers for the space between the piers and could be put in and removed to create treatments 
that could be evaluated. The turbulence shed from the piers tends to push flow away from the powerhouse face and this could increase passage of fish into the north eddy instead of into the $\mathrm{B} 2 \mathrm{CC}$.

Non-uniformity of passage across openings to surface-flow outlets also was typical. Distributions of fish passing over chain gates at B1 sluiceway outlets sometimes favored the middle and sometimes the edges near piers according to video camera counts and later according to hydroacoustic counts after hydroacoustic sampling became reliable (after 2001). Acoustic camera (DIDSON) images of fish entering these outlets reveal a dynamic, seemingly unpredictable process mediated by time of day, vortices to the turbine below the opening, and other hydraulic characteristics, as well as the original direction of approach by fish (Ploskey et al. 2006c). The same was true for the lateral distribution of fish entering the PSC and the $\mathrm{B} 2 \mathrm{CC}$, where lateral distribution sometimes varied with depth.

The distribution of fish passage among bays with different spill deflector types may be more important than north or south skews in spillway passage distributions, both of which have been reported. Survival data suggest that fish passing through bays with older 14-ft-elevation deflectors may have lower survival than fish passing through bays with the new 7-ft-elevation deflectors (Counihan et al. 2003, 2006a). If passage among bays were uniform, we would expect $67 \%$ of fish to pass through bays with the older, apparently less fish-friendly deflectors. However, 2004 and 2005 operations apparently reduced the percentage passing through Bays $4-15$ by $6 \%-9 \%$ over what would be expected. Hydroacoustic data indicated that $57 \%-60 \%$ of fish passage was through bays $4-15$ instead of $67 \%$. Since discharge patterns appear to be partially responsible for trends in spillway passage distributions, some tweaking of discharge to reduce the percent passing through bays with old spill deflectors may be warranted.

Numbers of radio tagged fish detected at the spillway each season between 1996 and 1999 were only sufficient to provide a broad description of passage trends by north and south halves of the structure, and estimates in later studies were reported only as a proportion of total project passage. At best, skews in spillway passage distributions could be described as weak in most years, with just over $50 \%$ to $65 \%$ of fish favoring one half of the spillway or the other.

Almost all hydroacoustic and radio telemetry studies reflect a strong skew toward the south end of the powerhouse. With very few exceptions across season, year, or methodology, units 11-14 (especially units 11 and 12) passed the majority of fish as compared to units 15-18 on the north half of B2. As with lateral fish passage across intakes at B1, distributions across turbine intakes at B2 were not uniform. Leaving turbine intake extensions (TIEs) out from units 11 through 14 undoubtedly facilitates a strong southerly flow of water along the powerhouse face toward the $\mathrm{B} 2 \mathrm{CC}$, and this is highly desirable for increasing fish passage at the B2CC. The TIEs retained on every other intake from Intake 15A through 18B help break up the flow toward the north eddy and likely increase passage and FGE at intakes between TIEs.

Turbine-intake extensions have created some predictable patterns in passage among intakes at B2, although horizontal distributions across intakes of the same turbine typically were not uniform nor predictable based on hydroacoustic sampling at B1. Discharge through Bonneville Dam turbines typically is highest at the south (A) intakes, intermediate at the middle (B) intake, and lowest at the north (C) intakes, but passage seldom follows the discharge pattern. Hydroacoustic data have sometimes shown about $10 \%$ higher passage through intakes between TIES than intakes behind TIEs at B2 (e.g., Ploskey et al. 2002c; Ploskey et al. 2003). Monk et al. (1999b) noted that FGE for yearling Chinook increased 20\% for intakes between TIEs. 


\section{Vertical Distributions}

A number of investigators have assessed vertical distribution of fish upstream of passage structures, but those data do not accurately reflect distributions of fish committed to passage. About $100 \mathrm{ft}$ upstream of trash racks at B2, fish were distributed very high in the water column, and those distributions seemed inconsistent with low in-turbine estimates of FGE (Ploskey et al. 2002a) but were fairly consistent with vertical distribution estimates for the B2CC (Ploskey et al. 2005, 2006c). Fish upstream of the PSC and immediately upstream of B2 trash racks were less highly skewed toward the water's surface (Ploskey et al. 2002a and 2002c).

The vertical distribution at surface flow outlets first depends upon the depth of the outlet. The B1 sluiceway is very shallow and yet highly efficient, consistently passing over $33 \%$ of B1 fish passage. When the 40- to 45-ft-deep PSC took fish at all depths although slightly more entered in the upper half than in the lower half, and the PSC also was highly efficient and effective. Given that vertical distributions of fish in B1 turbines are not skewed toward the top of the intake and fish occur at many depths, the depth of the PSC was not wasted. At the PSC, entrance depths varied by species and time of day according to radio telemetry sampling. The vertical distribution of passage at the $\mathrm{B} 2 \mathrm{CC}$ was highly skewed toward the surface of the water, even though about $24 \mathrm{ft}$ of depth is available for passage.

At the spillway, the vertical distribution of passage peaks within a few feet above the elevation of the ogee crest, and this could be undesirable in terms of survival. Fish passing deep and close to the ogee sometimes experience higher incidence of injury and mortality than fish passing from higher in the water column (Thomas Carlson, Personal Communication).

In-turbine distributions at both B1 and B2 are not highly skewed toward higher elevations as they often are at upstream hydropower projects. There also is evidence of a skew toward both higher and lower elevations at B1 intakes, especially in summer (e.g., Ploskey et al. 2002c). In-turbine vertical distribution data are generally consistent with FGE estimates for each powerhouse where FGE is often $50 \%$ or less.

\section{Diel Distributions}

It is easiest to talk about diel distribution by type of passage route (turbines, spillway, and surface passage outlets) because trends are more apparent and consistent than they are by structure (B1, B2, and the spillway). However, it is very important to differentiate between diel patterns that are driven by diel shifts in project operations and discharge and natural patterns that occur when operations are relatively constant.

The diel patterns of passage through turbines and the spillway suggest that some fish may be holding in forebay areas during the day and passing at night, although short radio telemetry residence times suggest that holding cannot be prolonged (a few hours at most). Nevertheless, the crepuscular peaks in passage in bypass systems, fyke net samples, and hydroacoustic samples would only result if some delay occurred. The loss of visual position cues may be responsible for increased fish passage into turbines just after sunset because smolt passage at turbine units is not a function of increased flow at that time.

\section{Turbines}

When turbines run 24 hours per day, fish passage usually is crepuscular with peaks occurring after sunset and about dawn, and passage usually is higher at night than it is during the daytime. These trends are not unlike what can be observed for juvenile bypass structure (JBS) data except that there is a delay of 
several hours in the observed peaks for JBS data since fish may delay in gatewell slots. When turbines dominate project operations, as they did in 2001, similar diel patterns can be observed for total project passage, but in general a single turbine running the same discharge 24-hours per day provides the best look at a typical diel pattern.

Atypical diel patterns of passage at turbines result from turbines not running consistently over a diel cycle, so it is important to show discharge on diel plots, if turbine operations are unknown. Turbine discharge and fish passage at B1 in spring and summer 2005 provide a good example of an atypical diel pattern driven by turbine operations. These diel patterns are of interest because they show the degree to which diel patterns can be altered by operations. Another atypical example of a diel trend for turbine passage was observed in B2 turbine passage in summer 2005, when most turbines between unit 11 and 18 were shut down to provide water for increased spill at night.

\section{Spillway}

In a couple of cases when discharge was held constant throughout 24-hour periods (e.g., during the drought of 2001 and for six days in summer 2004), hourly passage estimates clearly indicate that nighttime-dominated diel patterns are not entirely due to increased discharge at night. In the drought year of 2001, when spill was nearly constant 24 hours per day, Ploskey et al. (2002c) described diel trends with a decline during daylight hours, an increase at 2100 hours in spring and 2200 hours in summer. Except for those periods of constant discharge for 24 hours, separating a natural diel pattern of passage at the Bonneville Dam spillway has been difficult because discharge usually is much higher at night and spill efficiency is directly correlated with discharge. With the exception of yearling Chinook salmon in 2000, all other studies of radio-tagged fish showed higher hourly rates of spillway passage at night than during the day.

\section{Surface Flow Outlets}

Most research indicates that a majority of fish pass surface-flow outlets during daylight hours, unlike passage through turbines and the spillway described above. Netting data by Willis and Uremovich (1981), hydroacoustic data collected after 2001, and Dual Frequency Identification Sonar (DIDSON) video clips all indicate that B1 sluiceway passage is higher at night than it was during the day. Results at the 20-ft-wide slot at the PSC showed higher passage at night than during the day based upon hydroacoustic sampling (Ploskey et al. 2001b, 2002a and b) and radio telemetry sampling (Evans et al. 2001a; Evans et al. 2001b). The B2 sluiceway outlet (B2 sluice chute before 2004 and B2CC thereafter) had a daytime-dominated diel pattern of fish passage (Magne et al. 1986; BioSonics 1998; Ploskey et al. 2001a; Ploskey et al. 2005, 2006c).

The predominance of fish passage through surface routes during the day indicates that smolts are readily entering those outlets, but DIDSON video indicates that smolts often are holding upstream of outlets at night. Day and night DIDSON recordings of smolt behavior upstream of the B1 sluiceway in 2005 (Ploskey et al. 2006c) certainly support the nighttime holding hypothesis for that location. Not only were smolts holding in large loose schools at night, they were subjected to intensive predation, whereas during the daytime tight schools of smolts readily entered B1 Sluiceway Outlet 3C, and predation events were relatively rare. Similar recordings showing increased holding and predation at night in the south eddy upstream of the B2CC were recorded in 2004. 


\section{Survival}

The safest passage routes at Bonneville Dam are the B2CC and the B2 JBS. Operations that maximize passage through these routes are advantageous to juvenile salmonid populations tested so far. The ranking of survival among the three other routes reveals no clear and consistent pattern. Survival at the B1 sluiceway should be re-evaluated after improvements are made in 2007 and 2008 and reference releases downstream should include the existing outfall and another potential outfall site. In our opinion, the affects of deflector elevation on spillway survival are becoming clearer. Based on radio tag data, the lower deflector yielded higher (or equivalent) survival than the 14-ft deflector, regardless of the spill level, species, or season. The only exception may be for steelhead under gas cap spill levels. It appears that the lowered deflector is the preferred configuration, although another year of testing may be prudent. Survival through minimum gap runner (MGR) turbines tested at Bonneville appears equivalent to that realized for smolts passing through standard units. Thus, the MGR provides no discernable improvement in turbine passage survival. Balloon tag survival estimates are clear on this point, although the potential for some delayed effects associated with injury could be manifested well downstream from the dam. Radio tag-based survival estimates did not shed light on this potential effect. Telemetry estimates of survival through a standard unit were not available for direct comparison with the MGR estimate.

Comparisons of survival estimates from assorted investigations can be confusing at times. Nearly every treatment estimate reported is probably best viewed as a relative estimate of survival. The control release sites establish the reference point, and the recovery of control fish constitutes the tag recovery proportions for the condition specific to that time and space.

Not all studies have released controls in the same locations. Even within a multi-year study conducted by the same investigation team, the location of control release sites can vary. Similarly, the location where, and the means by which, treatment groups are released has varied across studies. These attributes can, in turn, affect the survival estimates. Managers must select those estimates that best reflect the zone of interest and the set of conditions that are of primary concern and then focus on survival estimates that best bracket those parameters. We have attempted to provide that information in this report to guide those management decisions.

The absolute values of a number of survival estimates that were obtained using radio telemetry are suspicious, since they approach or exceed $100 \%$. Indications are that they were likely biased high. This was because, in several instances, a key assumption was violated. Independent tests revealed that some known dead fish bearing active tags released in the tailrace were subsequently detected at downstream detection transects. This raises the possibility that some smolts killed during dam passage could have drifted to the detection sites and been logged as live fish. The extent to which this actually occurred cannot be accurately determined. Perhaps relocating the downstream detection sites could avert this problem in the future.

Despite the uncertainty regarding bias associated with the absolute values of some telemetry estimates, the technique can still be used to generate acceptable estimates of relative survival. Thus, use of this tool for determining optimal passage routes or operations appears sound if based on relative estimates. Conversely, it may require caution on the part of managers to rely on these telemetry-based survival estimates as input for passage modeling at Bonneville, because they may be mischaracterizing the true magnitude of passage effects.

Radio tags provide a sound means to evaluate the effects of recent operations, using dam survival estimates derived from route-specific estimates. Furthermore we see this as an instructive performance 
index. A consistent pattern was evident in both 2004 and 2005. During the gas cap-night condition, survival was highest for all species. The only qualification being that, in 2004, survival of subyearling Chinook was uniform across the spill conditions. If future conditions need to be evaluated, a fruitful analytical approach is at hand. Again, we suggest the readers consider these relative survival estimates, not absolute survival probabilities.

Other mark-recapture approaches may not experience the difficulties unique to telemetry, but they are not without limitations. The absolute values of survival estimates obtained using freeze brands varied widely depending on the location at which the controls were released. As a consequence, those investigators expressed results as relative differences in recovery proportions to avoid the complication (Dawley et al. 1993b).

Absolute values generated using balloon tags appear sound and are readily interpretable. But of course they only reflect direct effects. Managers intent on analyzing the full passage effects through the Federal Columbia River Power System (FCRPS) desire estimates that reflect total passage effects. For such purposes, managers will be forced to select judiciously from the estimates reported to date and select those that best reflect the zones and class of effects they wish to incorporate in their analyses. We cannot identify a best universal set of estimates that are suitable for all applications. 
Synthesis of Biological Research on Juvenile Salmonid Passage and Survival at Bonneville Dam through 2005 


\section{Preface}

This report was prepared by the Pacific Northwest National Laboratory (PNNL), Richland, Washington; BioAnalysts, Inc.; and BAE Systems, Inc. The U.S. Army Corps of Engineers, Portland District (USACE - Portland) provided funding, and Blaine Ebberts and Dennis Schwartz provided oversight.

\section{Acknowledgments}

Randy Lee and Dennis Schwartz (USACE - Portland) provided historical information from their report, Fish Guidance Efficiency Improvements 1995-2002 Prototype Design and Evaluations. Scott Evans, Rachael Reagan, and Tim Counihan (U.S. Geological Survey [USGS], Columbia River Research Laboratory, Cook, Washington) graciously provided radio telemetry reports on fish passage and survival. Rudd Turner graciously provided portable document files (PDFs) of the USACE Reservoir Control Center's Annual Fish Passage Plans for 1984-2005) and the annual reports of the Columbia River Water Management Group's Committee on Fishery Operations for 1978-1983, which preceded the annual fish passage plans. These plans provided valuable information about changes in dam structure and operations since 1978. The USACE Portland District Library loaned many of the reports that were scanned into PDFs for the digital video disk (DVD) accompanying this report. Eric Fischer (Pacific States Marine Fisheries Commission or PSMFC), added a few abstracts to the annotated bibliography, standardized the abstracts, and requested permission to reproduce copyrighted materials. Jina Kim, also with PSMFC, checked figure numbering and assembled the list of figures and tables. Mary Ann Simmons helped with editing, and Theresa Gilbride was the editor. 
Synthesis of Biological Research on Juvenile Salmonid Passage and Survival at Bonneville Dam through 2005

xviii 


\section{Acronyms and Abbreviations}

\begin{tabular}{|c|c|}
\hline AFEP & USACE Anadromous Fish Evaluation Program \\
\hline AT & Acoustic Telemetry \\
\hline B1 & Bonneville Dam First Powerhouse \\
\hline B2 & Bonneville Dam Second Powerhouse \\
\hline $\mathrm{B} 2 \mathrm{CC}$ & B2 Corner Collector \\
\hline $\mathrm{BiOp}$ & Biological Opinion reports published by NOAA Fisheries \\
\hline BPA & Bonneville Power Administration \\
\hline $\mathrm{CBE}$ & combined bypass efficiency \\
\hline CENWP & U.S. Army Corps of Engineers - Portland District \\
\hline CFD & computational fluid dynamics \\
\hline $\mathrm{cfs}$ & Cubic feet per second \\
\hline CWT & coded wire tags \\
\hline $\mathrm{DE}$ & discovery efficiency \\
\hline DIDSON & Dual Frequency Identification Sonar \\
\hline DSM & demand side management \\
\hline DVD & digital video disk \\
\hline ESBS & extended length submerged bar screens \\
\hline FCRPS & Federal Columbia River Power System \\
\hline FGE & fish guidance efficiency \\
\hline FPE & fish-passage efficiency \\
\hline $\mathrm{H}$ & hour \\
\hline HA & Hydroacoustic \\
\hline $\mathrm{HRB}$ & Hood River Bridge \\
\hline ID & identification \\
\hline ITC & B2 ice/trash sluice chute \\
\hline JBS & juvenile bypass system \\
\hline JDA & John Day Dam \\
\hline $\mathrm{kcfs}$ & thousands of cubic feet per second \\
\hline $\mathrm{km}$ & kilometer \\
\hline MGR & minimum gap runner \\
\hline NOAA Fisheries & NOAA National Marine Fisheries Service (formerly called NMFS) \\
\hline NOAA & National Oceanic and Atmospheric Administration \\
\hline PATH & Plan to analyze and test hypotheses \\
\hline
\end{tabular}




$\begin{array}{ll}\text { PCC } & \text { Prototype Corner Collector at B2 sluiceway } \\ \text { PDF } & \text { Adobe Portable Document Files } \\ \text { PIT } & \text { passive integrated transponder } \\ \text { PNNL } & \text { Pacific Northwest National Laboratory } \\ \text { PSC } & \text { Prototype Surface Collector } \\ \text { PSMFC } & \text { Pacific States Marine Fisheries Commission } \\ \text { RCK } & \text { Rock Creek } \\ \text { RT } & \text { radio telemetry } \\ \text { SFO } & \text { surface flow outlet } \\ \text { STS } & \text { submerged traveling screens } \\ \text { TDA } & \text { The Dalles Dam } \\ \text { TDG } & \text { total dissolved gas } \\ \text { TIEs } & \text { turbine intake extensions } \\ \text { USACE } & \text { U.S. Army Corps of Engineers } \\ \text { USGS } & \text { U.S. Geological Survey } \\ \text { VBS } & \text { vertical barrier screen }\end{array}$




\section{Contents}

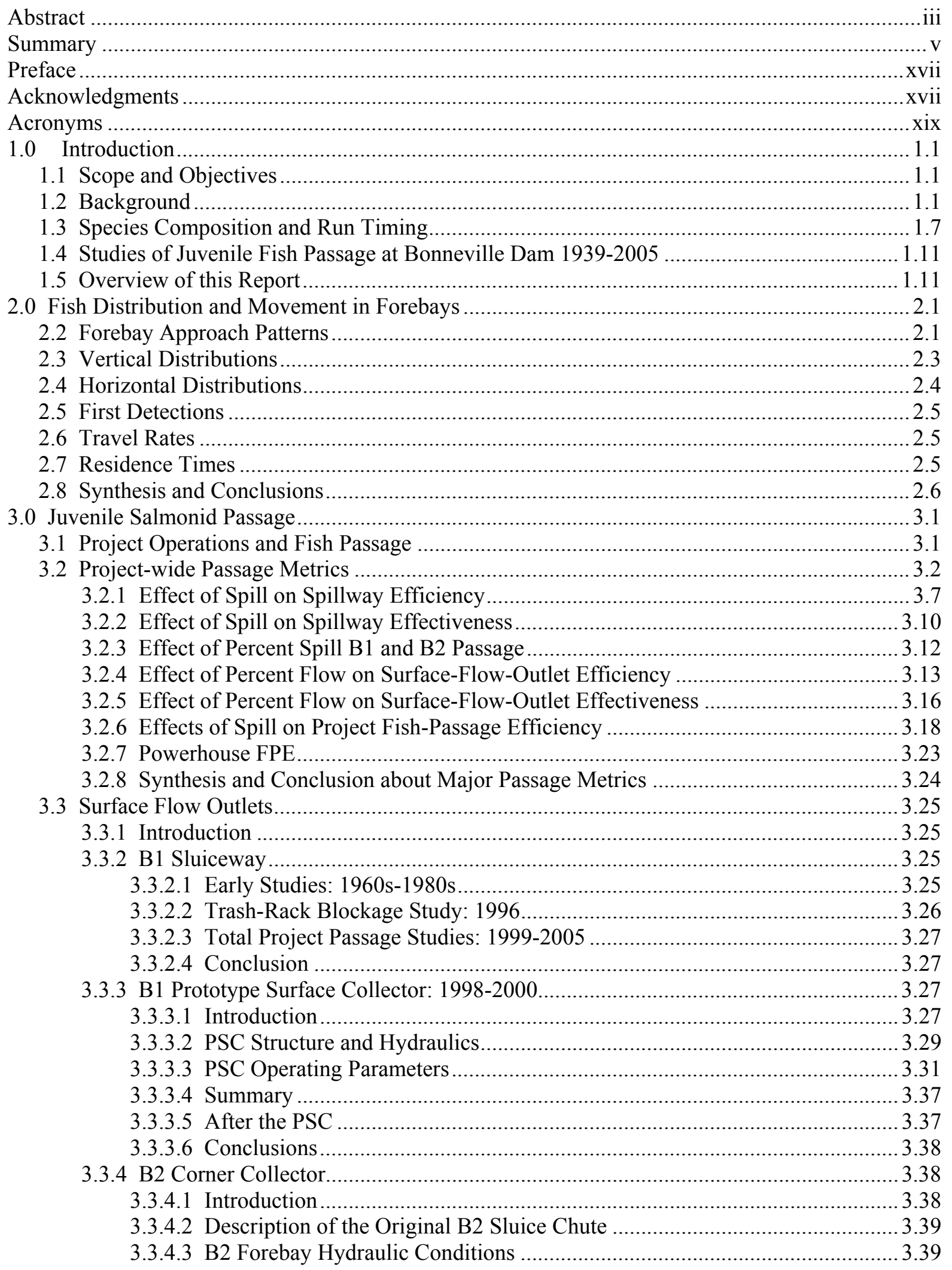


3.3.4.4 Early Studies: 1980s

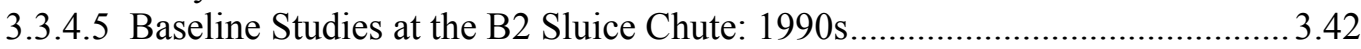

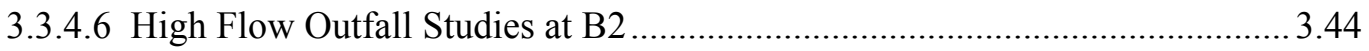

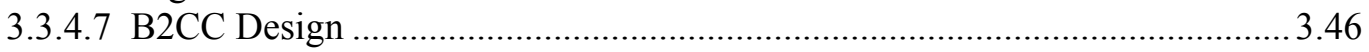

3.3.4.8 Post-Construction Evaluation of the B2 Corner Collector: 2004-2005 ...........3.47

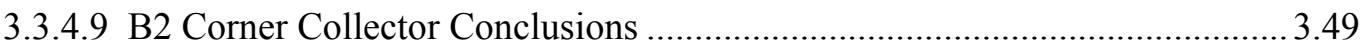

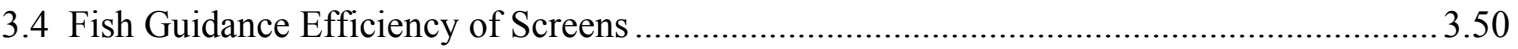

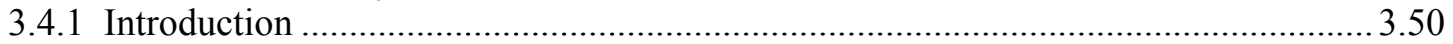

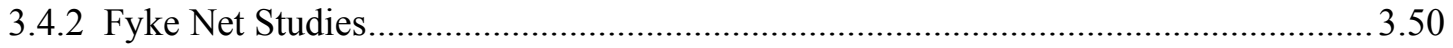

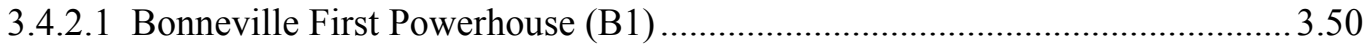

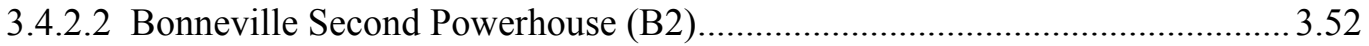

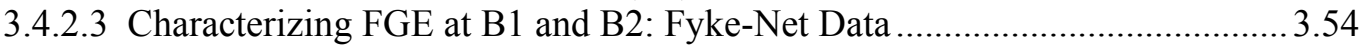

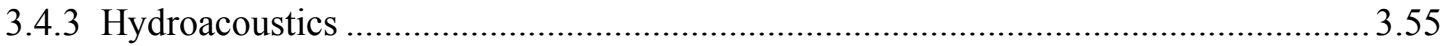

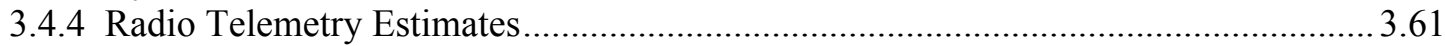

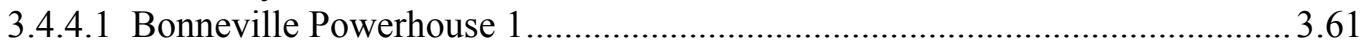

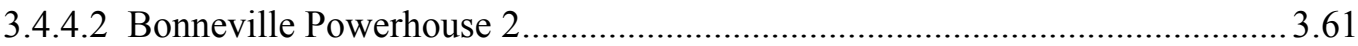

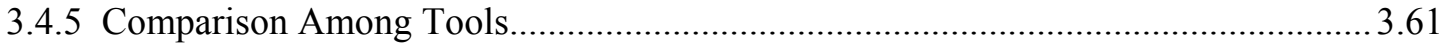

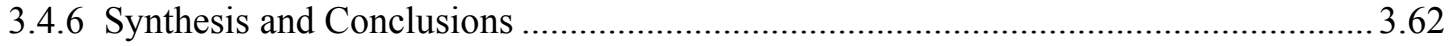

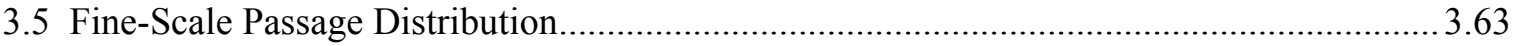

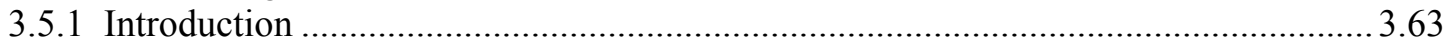

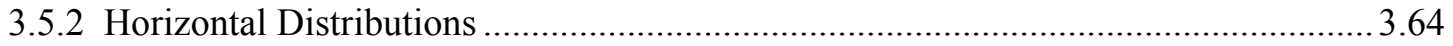

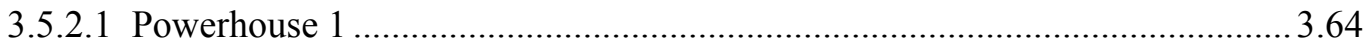

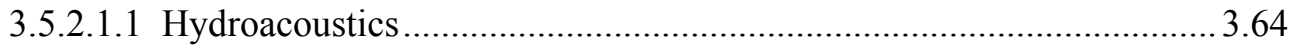

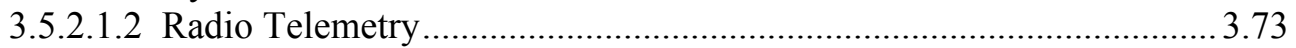

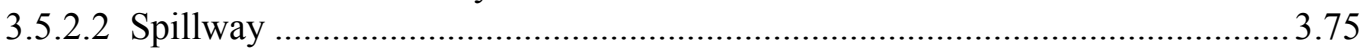

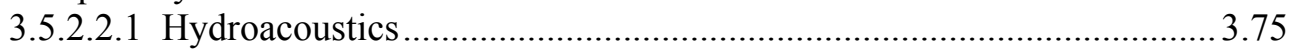

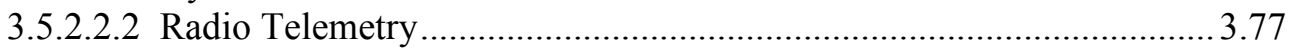

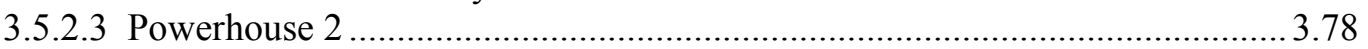

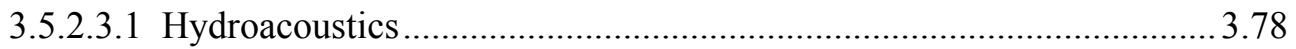

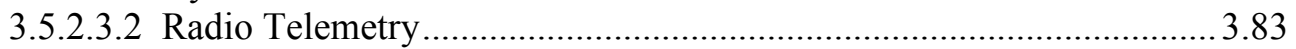

3.5.2.5 Comparison of Hydroacoustics and Radio Telemetry Estimates ..................... 3.84

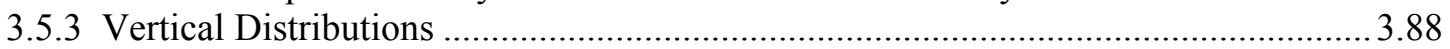

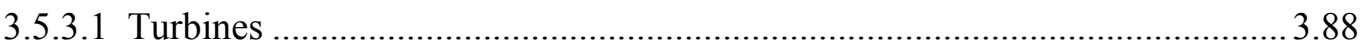

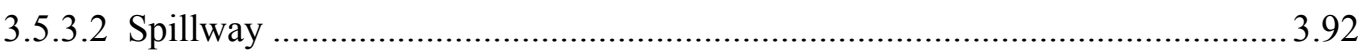

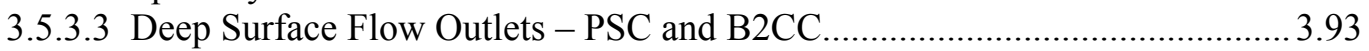

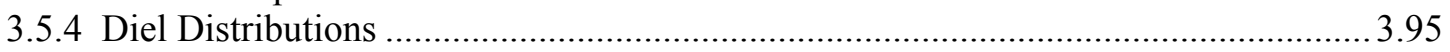

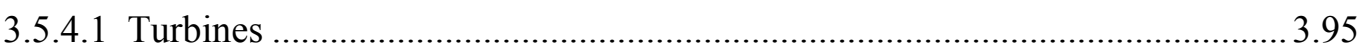

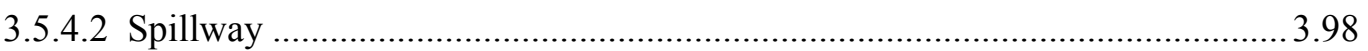

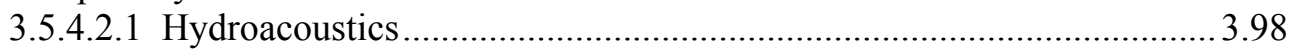

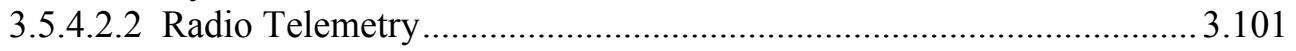

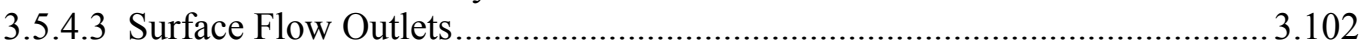

3.5.4.3.1 B1 Sluiceway ......................................................................... 3.102

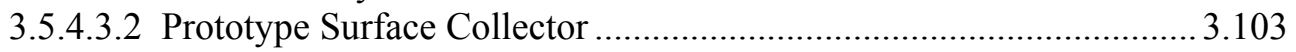

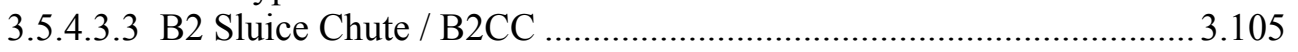

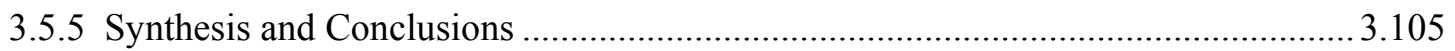

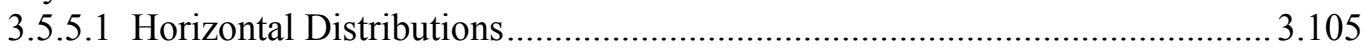

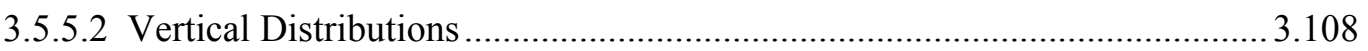

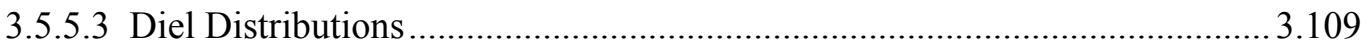

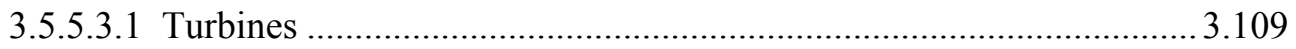

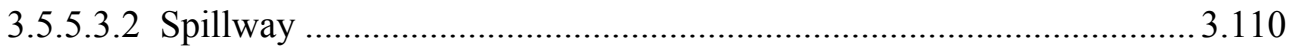

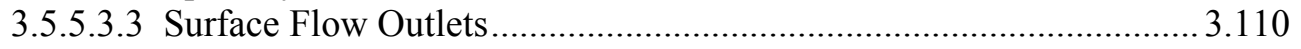

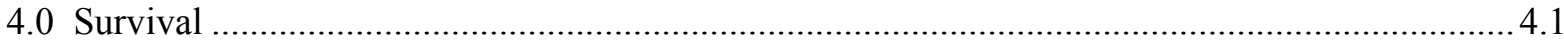




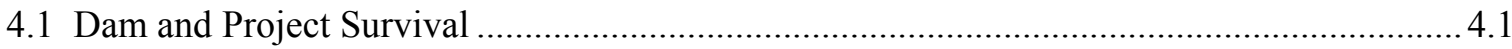

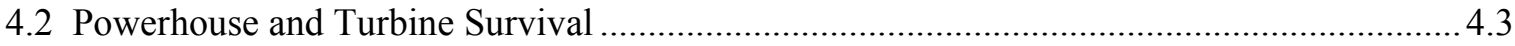

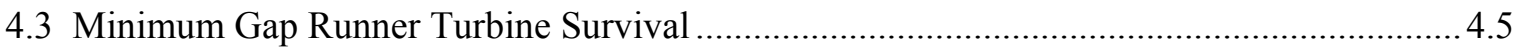

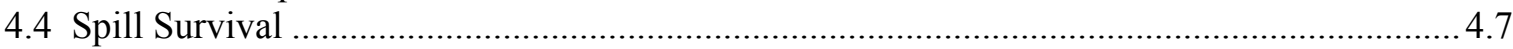

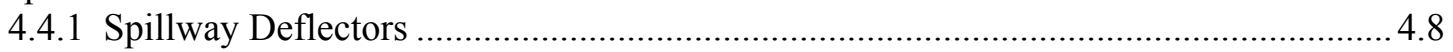

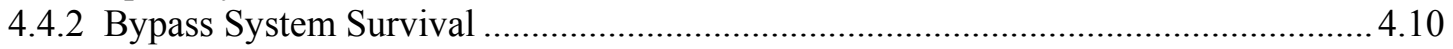

4.4.2.1 Powerhouse 2; Original Bypass System …….............................................. 4.10

4.4.2.2 Powerhouse 2; New JBS ......................................................................... 4.10

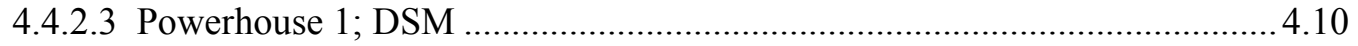

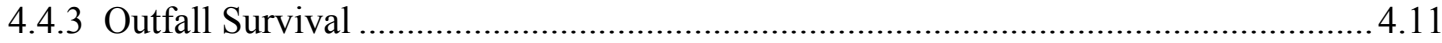

4.4.4 Route-Specific Survival- Recent Evaluations .......................................................... 4.11

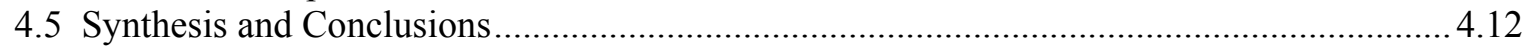

5.0 Optimizing Juvenile Fish Passage Strategies at Bonneville Dam .............................................. 5.1

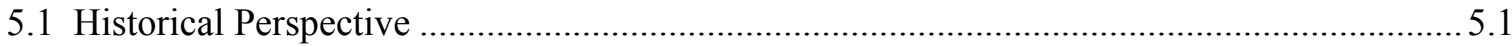

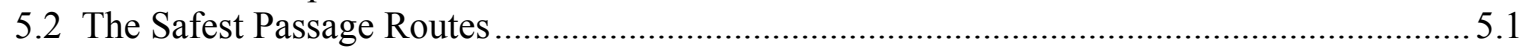

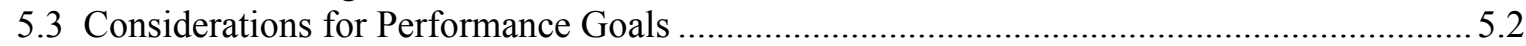

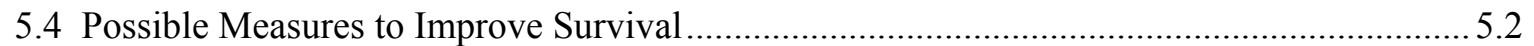

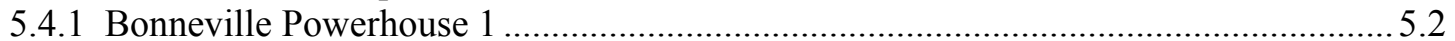

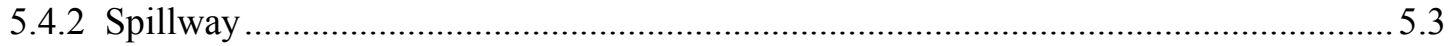

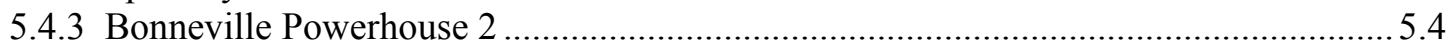

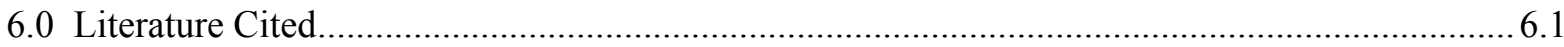

Appendix A - References with Hyperlinks to Portable Document Files Containing Copies

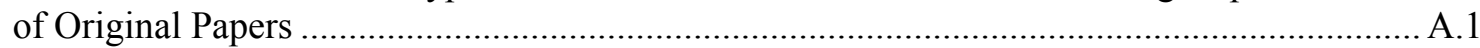

Appendix B - Annotated Bibliography with Hyperlinks to Portable Document Files ...................... B.1 
Synthesis of Biological Research on Juvenile Salmonid Passage and Survival at Bonneville Dam through 2005

xxiv 


\section{Figures}

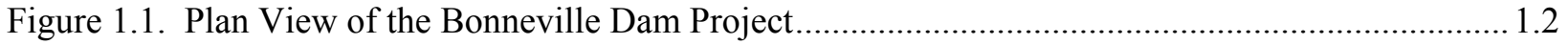

Figure 1.2. Historical Record of Percent Spill (Upper Plot) and Project and Spill Discharge Volume (Lower Plot) During the Spill Season at Bonneville Dam through 2005

Figure 1.3. Species Composition and Run Timing based upon the Smolt Passage Index at the Bonneville Dam B1 Smolt Monitoring Facility in 1996, a Year of Above-Average Flow and Spill Discharge

Figure 1.4. Species Composition and Run Timing based upon the Smolt Passage Index at the Bonneville Dam B2 Smolt Monitoring Facility in 2001, a Year of Below-Average Flow and Percent Spill

Figure 1.5. Species Composition and Run Timing based upon the Smolt Passage Index at the Bonneville Dam B2 Smolt Monitoring Facility in 2004, a Year of Average Flow and Percent Spill

Figure 2.1. Approach Locations and Final Passage Routes of 70 Radio-Tagged Hatchery Steelhead at Bonneville Dam in Spring 1997.

Figure 2.2. Approach Locations and Final Passage Routes of 46 Radio-Tagged Yearling Chinook Salmon at Bonneville Dam in Spring 1997.

Figure 2.3. Approach Locations and Final Passage Routes of 77 Radio-Tagged Subyearling Chinook Salmon at Bonneville Dam in Summer 1997

Figure 2.4. Bulk Flow Effectiveness for Bonneville Dam 1st and 2nd Powerhouse and Spillway Plotted from 1999 to 2005 Data

Figure 2.5. Movement between Areas Data for Bonneville Dam 1st and 2nd Powerhouse and Spillway Plotted from 1999-2005 Data

Figure 3.1. Total Discharge from The Dalles Dam, which Constitutes Most Inflow to the Bonneville Dam Project, for the Last Ten Fish Passage Seasons (April through July). ......... 3.2

Figure 3.2. Plot of Spill Efficiency Estimates on Percent Spill based on Data in Tables 3.2-3.5 ............3.8

Figure 3.3. Regression of Day and Night Estimates of Spillway Efficiency on Percent Spill................. 3.9

Figure 3.4. Regression of Spill Efficiency on Percent Spill by Year of Study at Bonneville Dam ........ 3.10

Figure 3.5. Plot of Spill Effectiveness Estimates on Percent Spill based on Data in Tables 3.2-3.5 ...... 3.11

Figure 3.6. Plot of Day and Night Spill Effectiveness Estimates on Percent Spill.

Figure 3.7. Trends in the Percent Fish and Flow Passing B1 as a Function of Percent Spill 3.12

Figure 3.8. Trends in the Percent of Fish and Flow Passing B2 as a Function of Percent Spill

Figure 3.9. Regression of Seasonal Estimates of B1 Sluiceway Efficiency Relative to B1 on Percent of B1 Flow into the Sluiceway

Figure 3.10. Logit Regression of Day and Night Estimates of B1 Sluiceway Passage Efficiency on Percent of B1 Flow Passing the B1 Sluiceway

Figure 3.11. Logit Regression of Day and Night Estimates of the B2CC Passage Efficiency on Percent of B2 Flow Passing into the B2CC

Figure 3.12. Logit Regression of Day and Night Estimates of Percent of Project Fish Passage through Surface Flow Outlets on Percent of Project Flow through the Same Routes 
Figure 3.13. Logit Regressions Lines Summarizing Percent of Project Passage by Route as a Function of Percent of Project Flow through the Same Route.

Figure 3.14. B1 Sluiceway Effectiveness as a Function of the Percent of B1 Flow into the B1 Sluiceway

Figure 3.15. Regression of Day and Night Estimates of B1 Sluiceway Effectiveness on Percent of B1 Flow.

Figure 3.16. Regression of Day and Night Estimates of B2CC Effectiveness on Percent of B2 Flow. The trend for spill effectiveness as a function of percent spill also is shown for reference.

Figure 3.17. Regression of Seasonal Estimates of Fish-Passage Efficiency on Percent Spill

Figure 3.18. Regression of Fish-Passage Efficiency on Percent Spill for Bonneville Dam

Figure 3.19. Regression of Fish-Passage Efficiency on Percent Spill by Year for Bonneville Dam...... 3.21

Figure 3.20. Distribution of Proportions of Total Project Discharge and Total Estimated Fish Passage through Different Structures at Bonneville Dam in Spring and Summer of 2004.

Figure 3.21. Project FPE, Spill Efficiency, and Sluiceway Efficiency $(B 1+$ B2CC) during Three Operational Conditions Presented to Fish from the Spring Creek Hatchery Release in March 2004

Figure 3.22. The Prototype Surface Collector at B1 3.28

Figure 3.23. Side View of the PSC at B1. 3.28

Figure 3.24. B1 Forebay and Powerhouse Showing the PSC Upstream of Turbines 1-6.

Figure 3.25. B1 Forebay Bathymetry Relative to Sea Level 3.30

Figure 3.26. Sectional View of the PSC Showing Water Velocity from a CFD Model and a 1:25 Scale Physical Model

Figure 3.27. Vertical Distribution and Passage of Radio-Tagged Juvenile Steelhead during Day (Top) and Night (Bottom) at the B1 PSC in 2000

Figure 3.28. Daily PSC Fish Collection Efficiency (Left Panel) Compared to Fish Guidance Efficiency for a Prototype Extended Length Bar Screen in Unit 8 (Middle Panel) and a Submersible Traveling Screen in Units 7, 9, 10 (Right Panel)

Figure 3.29. Fish Budgets Reflecting Discovery, Entrance, and Fish Collection Efficiencies for Radio-Tagged Steelhead (Top) and Yearling Chinook Salmon (Bottom)

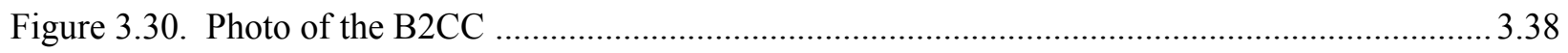

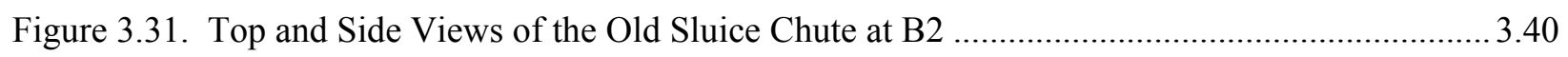

Figure 3.32. Computational Fluid Dynamic Model Display of Bonneville Powerhouse 2 Forebay Circulation.

Figure 3.33. One-Dimensional Spot Velocities (fps) as Measured at the B2 Sluice Chute Entrance in the 1:40 Physical Model at the Engineering Research and Development Center.

Figure 3.34. Injury and Mortality Rates from Experiments Conducted in a High Velocity Jet in a Laboratory Flume.

Figure 3.35. Plan View of the B2 Corner Collector Showing the Entrance (Far Right), Transportation Channel, and Outfall (Far Left) 


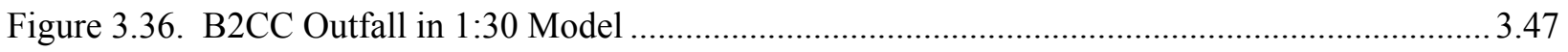

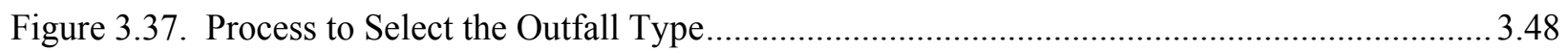

Figure 3.38. Schematic of the B2 Corner Collector Outfall: Mid-Level Cantilever............................... 3.48

Figure 3.39. Map of Bonneville Dam Showing the Various Alternatives Studied during the B2CC Outfall Site Selection Process ............................................................................................... 3.49

Figure 3.40. FGE of an Extended-Length Bar Screen at Intake 8b Estimated by Fixed Aspect

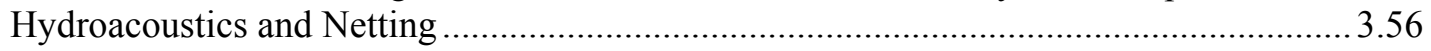

Figure 3.41. Plot of FGE Estimates Made from all Nighttime Hours of Hydroacoustic Sampling

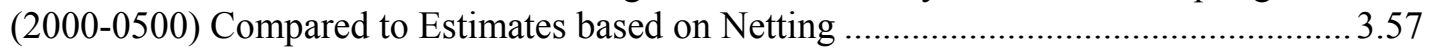

Figure 3.42. Estimates of FGE and 95\% Confidence Limits for Turbine Units at Bonneville Dam

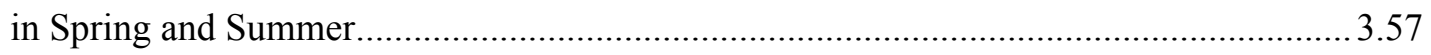

Figure 3.43. Comparison of FGE among Types of Units with STS at Powerhouse 1, Powerhouse 2, and at Modified Unit 15 by Date.

Figure 3.44. Comparison of FGE and Fish Passage among Turbines at Bonneville Dam in Spring and Summer 2002 .

Figure 3.45. Plots of Seasonal Trends of Intake-Specific FGE for B2 in 2002 with Labels Indicating the Intakes that were Behind, as Opposed to, Between TIES.....

Figure 3.46. Relative Fish Passage at each Intake in Turbine Units 3 and 5 in 1996 .......................... 3.64

Figure 3.47. Lateral and Vertical Distribution of Fish Passing through 20-ft-wide Slots in the Prototype Surface Collector (PSC) at Intakes 3b and 5b in 1998

Figure 3.48. Percent of Fish Passage among and within Intakes of Unit 5 in Spring and Summer 1999

Figure 3.49. Horizontal Distribution of Total Fish Passage at Turbines and Spillway in Spring and Summer 2000

Figure 3.50. Horizontal Distribution of Fish Passage through Turbines (Gray Bars) and Spill Bays (Black or Striped Bars) in Spring (Top) and Summer (Bottom) 2001 ...

Figure 3.51. Horizontal Distribution of Fish Passage through Bonneville Dam in Spring (Top) and Summer (Bottom) 2002......

Figure 3.52. Horizontal Distribution of Fish Density through Bonneville Dam in Spring (Top) and Summer (Bottom).

Figure 3.53. Plots of Horizontal Distribution of Fish Passage into Sluiceway Entrance 7A in Spring and Summer 2002 based on Video (Top) and Hydroacoustic Sampling (Middle and Bottom).

Figure 3.54. Estimated Fish Passage and Flow through All Sampled Routes at Bonneville Dam in Spring and Summer 2004.

Figure 3.55. Fish Passage Density by Route in Spring and Summer 2004.

Figure 3.56. Estimated Fish Passage and Flow through all Sampled Routes at Bonneville Dam in Spring and Summer 2005.

Figure 3.57. Fish Passage Density by Route in Spring and Summer 2005.

Figure 3.58. Fish Passage Distribution Based on a Three-year Mean of Spring and Summer Estimates from 2002 through 2005 under New Spill Patterns 
Figure 3.59. Percentage of Fish Passage and Discharge at Each Major Passage Structure in Spring (Top) and Summer (Bottom) 2005.

Figure 3.60. Proportional Fish Passage Across All Sampled Units at B2 in 1996 by Season and Time of Day.....

Figure 3.61. Horizontal Distribution of Fish Passage Density, in Fish per Million Cubic Meters of

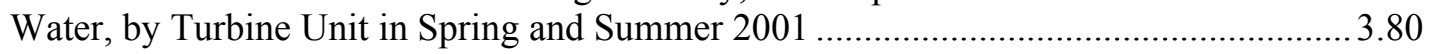

Figure 3.62. Horizontal Distribution of Fish Passing through the B2CC in Spring and Summer, 2004

Figure 3.63. Horizontal Distribution of Fish Passing through the B2CC in Spring and Summer through July 3, 2004.

Figure 3.64. Horizontal and Vertical Distribution of Smolt-Sized Fish Upstream of the B2CC Entrance in Spring and Summer 2004

Figure 3.65. Horizontal Distribution of Fish Passage at the B2CC

Figure 3.66. Plots of the Percent of Total Passage Estimated by Hydroacoustics and Radio Telemetry at B2 in Spring and Summer 2002.

Figure 3.67. Correlations between Hydroacoustic and Radio Telemetry Estimates of Percent Passage by Route at B2 in 2004 and 2005

Figure 3.68. Distribution in Percent Passage Among B2 Routes in Spring and Summer of 2004 and 2005, as Estimated by Radio-Telemetry and Hydroacoustic Methods

Figure 3.69. Vertical Distributions of In-Turbine Fish Passage Estimates during 5-ft Slot Treatments for Spring and Summer 1999

Figure 3.70. Vertical Distribution of Smolt-Sized Fish Detected Inside Intake 10B in Spring 2001 ..... 3.88

Figure 3.71. Vertical Distribution of Smolt-Sized Fish Detected Inside Intake 10B in Summer 2001

Figure 3.72. Vertical Distribution of Smolt-Sized Targets Inside Modified Intake 15B for Spring and Summer 2001

Figure 3.73. Estimates of Vertical Distributions of Fish within Turbine Intakes at Bonneville Dam First Powerhouse in Spring and Summer 2004 3.90

Figure 3.74. Vertical Distributions of Fish Within Turbine Intakes at B1 in 2005 3.90

Figure 3.75. Average Vertical Distributions of Fish Passage within B1 Turbine Intakes in Spring and Summer 2005, after Standardizing Sampling Elevation

Figure 3.76. Average Vertical Distributions of Fish Passage Within B1 Turbine Intakes in Spring and Summer 2002

Figure 3.77. Vertical Distributions of Fish within B2 Turbine Intakes in Spring and Summer 2005 ....3.92

Figure 3.78. Vertical Distributions of Fish Passage at Spillway in 2004 (Left) and 2005 (Right) ......... 3.92

Figure 3.79. Plot of All Fish as Dots Where They were Detected within Acoustic Sample Volumes of Split-Beam Transducers to Illustrate Sampling Coverage at the B2CC Entrance in Spring and Summer, 2004

Figure 3.80. Vertical Distribution of Fish Passing through the B2CC in Spring and Summer 2004 ..... 3.93

Figure 3.81. Vertical Distribution of Fish Passing through the B2CC in Spring and Summer through July 4, 2004, Only. 
Figure 3.82. Vertical Distributions of Fish at the B2CC Entrance in 2005 ..........................................94

Figure 3.83. Diel Trend in Mean Hourly Passage in 1996 at Two B1 Turbines..................................... 3.95

Figure 3.84. Diel Trends in Fish Passage Above (Guided) and Below (Unguided) an ESBS at

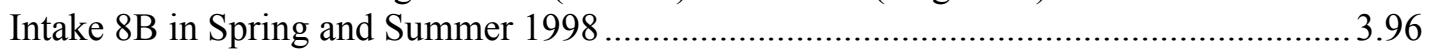

Figure 3.85. Diel Trends in Total Project Passage in 2001, when Spill Passage was Low Relative

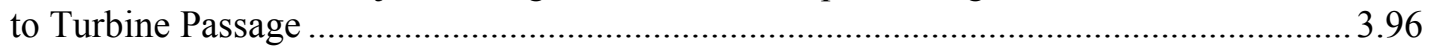

Figure 3.86. Average Diel Trend in Fish Passage through Turbine 18 in Spring 2005 ........................ 3.97

Figure 3.87. Diel Trends in Fish Passage Above (Guided) and Below (Unguided) an ESBS at

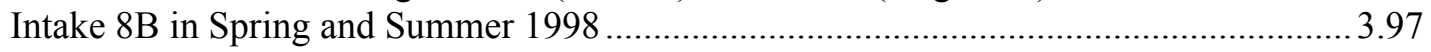

Figure 3.88. Diel Trends in Fish Passage in B2 Turbine Passage in Summer 2005 ............................ 3.98

Figure 3.89. Hourly Patterns in the Mean Number of Fish Spilled per Hour in Spring and Summer 2000.

Figure 3.90. Estimates of Diel Trends in Spilled Fish and Spillway Discharge in Spring and Summer 2002 .

Figure 3.91. Estimated Hourly Spillway Passage and Discharge at Bonneville Dam in Spring and Summer of 2004

Figure 3.92. Estimated Hourly Spillway Passage and Discharge at Bonneville Dam in Spring and Summer of 2005

Figure 3.93. Estimates of Diel Trends in Spillway Fish Passage and Spillway Discharge in Spring and Summer 2001 Under Nearly Constant Spill

Figure 3.94. Estimated Hourly Spillway Passage and Discharge at Bonneville Dam during Six Days in Summer 2004...

Figure 3.95. Diel Trends in B1 Sluiceway Passage in Spring (Top) and Summer (Bottom) 2004.......3.102

Figure 3.96. Diel Trends in B1 Sluiceway Passage in Spring (Top) and Summer (Bottom) 2005.......3.103

Figure 3.97. Estimated Mean Hourly Passage into the 20-ft and 5-ft Wide Slots in the PSC in 1998.

Figure 3.98. Estimated Mean Hourly Passage into the 20-ft Wide Slot in the PSC in 2000

Figure 3.99. Number of Steelhead and Yearling Chinook Salmon that Entered the PSC by Hour of Day during Spring 2000.

Figure 3.100. Diel Trends in Hourly Passage of Fish through the Sluice Chute at B2 in Spring and Summer 1998

Figure 3.101. Diel Trends in Hourly Passage of Fish through the B2CC in Spring and Summer of 2004 and 2005 
Synthesis of Biological Research on Juvenile Salmonid Passage and Survival at Bonneville Dam through 2005 


\section{Tables}

Table 1.1. Listing of PDF Identification Numbers and Associated Citations

Table 1.2. Summary of Juvenile Fish-Passage Research at Bonneville Dam from 1939 through 2005

Table 2.1. Vertical Distribution Expressed as Approximate Depth (ft) of the Uppermost 80th Percentile

Table 2.2. Fish Distribution, Travel Rate, and Residence Times in the Forebay of Bonneville Dam from 1999 to 2004

Table 3.1. Definitions of Major Fish-Passage Metrics

Table 3.2. Estimates of Major Flow and Passage Metrics $\pm 1 / 295 \%$ Confidence Limits for Spring Based upon Hydroacoustic Sampling in 2000, 2001, 2002, 2004, and 2005

Table 3.3. Estimates of Major Flow and Passage Metrics $\pm 1 / 295 \%$ Confidence Limits for Summer Based upon Hydroacoustic Sampling in 2000, 2001, 2002, 2004, and 2005

Table 3.4. Passage Performance Metrics for Yearling Chinook Salmon and Steelhead at Bonneville Dam during Spring Study Periods in 2000, 2001, 2002, 2004, and 2005

Table 3.5. Passage Performance Metrics for Subyearling Chinook Salmon at Bonneville Dam during Summer Study Periods of 2000, 2001, 2002, 2004, and 2005

Table 3.6. Spring and Summer 2002 Spill Efficiency Estimates

Table 3.7. Spring and Summer 2002 Fish Passage Efficiency Estimates

Table 3.8. Characteristics of the PSC for 5-ft and 20-ft-Wide Entrances

Table 3.9. Discovery Efficiency Estimates based on Radio and Acoustic Telemetry at B1 in 2000......3.32

Table 3.10. Entrance Efficiency Estimates based on Radio and Acoustic Telemetry at B1 in 2000......3.34

Table 3.11. Fish Collection Efficiency Estimates based on Hydroacoustics, and Radio and Acoustic Telemetry at B1 in 2000

Table 3.12. Results from Monitoring Radio-Tagged Fish Passage at the B2 Sluice Chute and Intake Screen System at B2 in 1998

Table 3.13. Combined Bypass Efficiency for the Sluice Chute and Screens at Units 11-13 when the Sluice Chute was Open and Closed in Spring and Summer 1998

Table 3.14. Estimates of FGE for Bonneville Dam Powerhouse 1

Table 3.15. Mean FGE Estimates for the ESBS (1998) and the STS (1988, 1989, and 1991) by Species

Table 3.16. Estimates of FGE at the Bonneville Dam Powerhouse 2

Table 3.17. Generic FGE Values for B1 and B2 Calculated by NOAA Staff for the 1999 Dam Configuration Compared with Those Used Last in the PATH Modeling Forum

Table 3.18. Hydroacoustic and Radiotelemetry Estimates of FGE at B1 and B2 in 2001

Table 3.19. Season-Wide FGE Estimates for each Entire Powerhouse as Determined Using Radio Telemetry and Hydroacoustics.

Table 3.20. Results from Wilcoxon Sign Rank Test 
Table 3.21. Proportion of Total Passage (in percent) through the Three Primary Passage Routes at Bonneville Dam

Table 3.22. Proportion of Fish Passed (\%) by Season, Time Period and Passage Route in 1989

Table 3.23. Proportion of Fish Passed (\%) by Season, Time Period and Passage Route in 1989, for each Intake

Table 3.24. Radio Telemetry Rates of Spillway Passage During the Day and at Night

Table 4.1. Smolt Survival Passing Bonneville Dam, or Partial-Project Survival .....

Table 4.2. Differences in Relative Survival between Fish Passing through the Bypass Systems and other Passage Routes at Bonneville Dam based upon Juvenile Recovery Data from Estuarine Sampling.

Table 4.3. Mean Percent Direct Survival in 1999 for Balloon-Tagged Chinook Salmon Passed through a MGR and a Standard Turbine

Table 4.4. Comparison of Turbine Passage Survival Estimates from Several Studies, Reflecting either Direct or Total Effects

Table 4.5. Survival Estimates for balloon-tagged Chinook at Two Deflector Elevations and Spill Levels

Table 4.6. Survival Estimates (\%) through Spillbays at Different Spill Regimes

Table 4.7. Dam Survival Estimates (\%) as Derived from Route-Specific Estimates at Bonneville Dam in 2004 and 2005 


\subsection{Introduction}

This document provides a synthesis of biological reports on downstream fish passage and survival at Bonneville Dam from 1939 to 2005. The document was prepared for the U.S. Army Corps of Engineers (USACE) - Portland District under the Anadromous Fish Evaluation Program (AFEP) by the Pacific Northwest National Laboratory (PNNL), Richland, Washington, BioAnalysts, Inc., and BAE Systems, Inc.

\subsection{Scope and Objectives}

The review of available literature for juvenile salmonid passage at Bonneville Dam involved acquiring a copy of every pertinent report or journal article written between 1939 and 2005, writing an annotated bibliography, and then writing a report that summarizes and synthesizes available information in a decision-support document. Studies of interest were on project-wide route-specific passage (and related efficiency and effectiveness metrics), fish survival (direct and indirect), fish-guidance efficiency (FGE) of powerhouses and units, predation in the forebay and tailrace, fish behavior on forebay approach and egress, and surface passage. The fish passage part includes a review of available distribution data (horizontal, diel, and vertical) for juvenile salmon. This report does not repeat the results of previous review and synthesis studies but cites them, includes Adobe portable document files (PDF) of the reviews, and then summarizes subsequent reports. Where no previous review exists for a subject area, all reports were reviewed and synthesized. This review does not cover hydraulic studies. This report consists of three parts:

1. this document, which summarizes and synthesizes research on juvenile salmonid passage at Bonneville Dam from 1939 through 2005

2. an annotated bibliography summarizing each report we reviewed

3. a digital video disk (DVD) containing PDFs of more than 170 papers and reports reviewed and an HTML index with hyperlinks to these documents. The index is sorted by authors and date.

\subsection{Background}

Bonneville Lock and Dam consists of several dam structures that together complete a span of the Columbia River between Oregon and Washington at River Mile 146.1, about 40 miles east of Portland, Oregon. From the Oregon shore north toward Washington, the current project is composed of a navigation lock, a 10-turbine-unit First Powerhouse (B1), Bradford Island, an 18-gate spillway, Cascades Island, and an 8-turbine-unit Second Powerhouse (B2; see Figure 1.1).

Bonneville Dam was formally authorized by Congress in the Rivers and Harbor Act of 30 August 1935. This act also provided the authority for the construction of additional hydroelectric generation facilities when requested by the Administrator of the Bonneville Power Administration (BPA). The spillway and B1 were constructed between 1933 and 1937 without specific regard for protecting juvenile salmonids migrating downstream. Public Law 329 by the 75th Congress, August 20, 1937, provided authority for the completion, maintenance, and operations of Bonneville Dam. Administrative letters of 
BPA in January and February 1965 stated the need for the construction of B2. Construction of turbine units 11 through 18 and two fishway units began in 1974 and was completed in 1982.

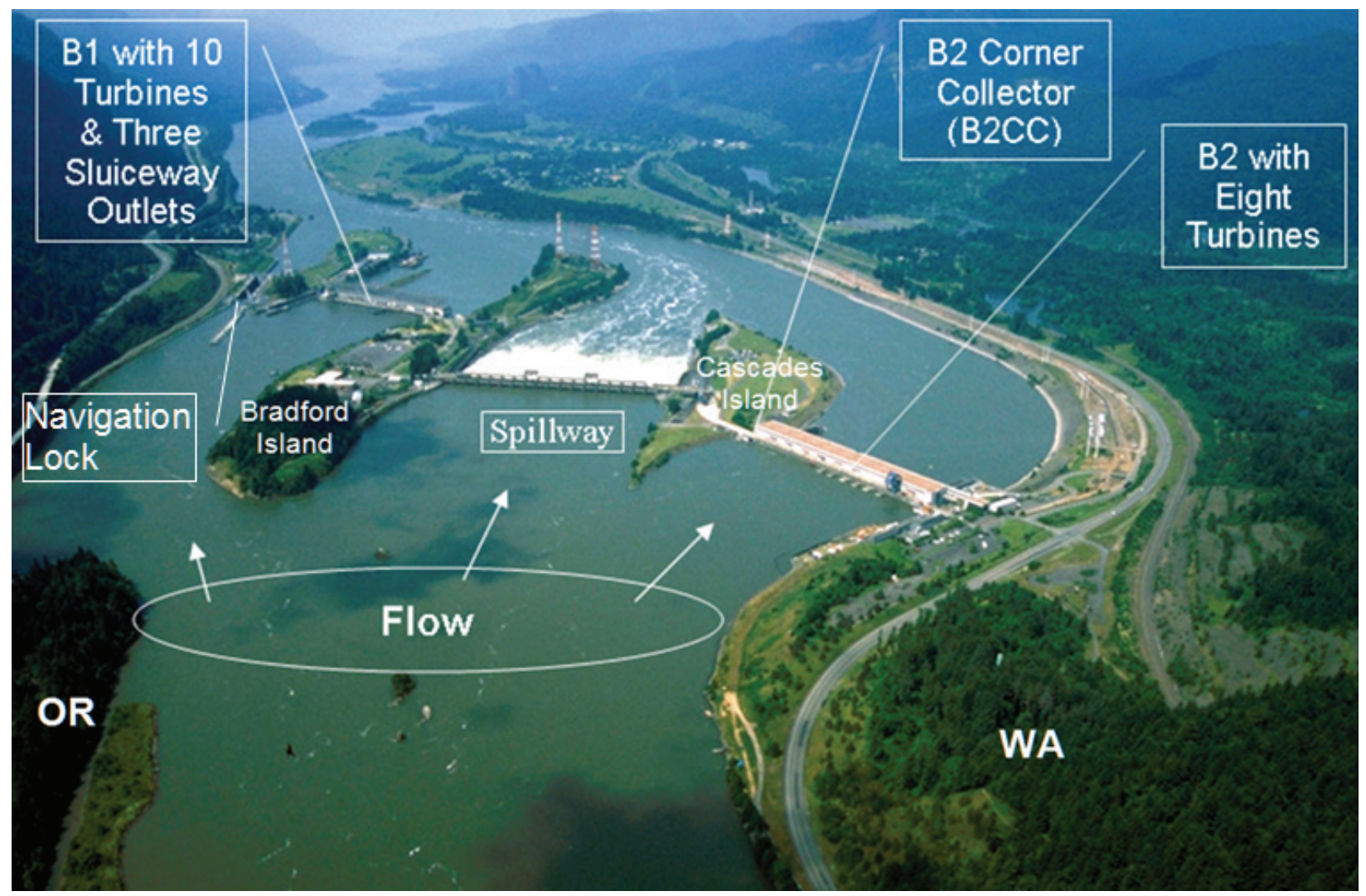

Figure 1.1. Plan View of the Bonneville Dam Project. The B1 sluiceway outlets and the B2 Corner Collector (B2CC) are surface overflow passage routes.

Principal fish passage routes include the spillway and two powerhouses, but within each powerhouse, passage can be through ice-trash sluiceways, turbines, or the juvenile bypass system (JBS). Smolts enter the JBS after encountering screens in the upper part of the turbine intakes. Screens divert fish to gatewell slots where they pass through orifices opening into a bypass channel which carries them to an outfall downstream of the dam. The JBS system at B1 was removed in 2004 because other routes are safer for fish. In 2003, the ice-trash sluiceway channel at B2 was modified and lengthened so that water was discharged downstream from the tip of Cascades Island. The modified sluiceway is hereafter referred to as the B2 Corner Collector (B2CC). All modifications were specifically designed to maximize nonturbine passage and survival of juvenile salmonids.

The following background information is intended to provide a brief history of changes to juvenile fish passage routes at Bonneville Dam and a general chronology of smolt-passage research. The intent is to provide an overview of structural and operational changes that have been evaluated.

There has been a long history of juvenile salmonid research at Bonneville Dam (see Tables 1.1 and 1.2, which are presented at the end of this chapter due to length). Initial survival studies on juvenile salmonids were conducted by the U.S. Fish and Wildlife Service from 1938 through 1944 using gossamer bags and balloons; these studies estimated turbine passage survival for juvenile fall Chinook salmon to be from $85 \%$ to $89 \%$. In 1953,1954 , and 1956 additional direct survival studies, generally referred to as 
"balloon experiments" because auto-inflating balloons were used to retrieve fish introduced into turbines, below spill gates, or downstream of the dam, were conducted by the USACE's Resident Biologist and the U.S. Fish and Wildlife Service. There also was considerable work on the diel distribution of smolt passage in the late 1940s and early 1950s. In 1970 and 1971 two studies were conducted regarding hydraulic effects on egress and forebay pool and tailwater effects, respectively. In 1969, 1971, 1980, and 1981 the sluiceway at B1 was studied by the Fish Commission of Oregon with funding from the USACE Portland District.

Research on juvenile fish passage was relatively sparse during the 36-year period from 1939 through 1974, but it increased substantially in the 1980s, especially after the Bonneville Second Powerhouse was completed in 1982, and it remained high through 2005 (Table 1.1). Starting in 1981, submerged traveling screens (STS) that were designed in the 1960s and 1970s were tested at B1 to determine fish guidance efficiency (FGE) at various screen angles (Krcma et al. 1982). The relatively high FGE estimates ended most fish-guidance research at B1 until the new navigation lock was completed in 1988. Guidance levels from May 30 to June 5, 1988 were considerably less than in 1981 (Gessel et al. 1989); these results and other low estimates for turbines at Powerhouse 2 sparked a lot of research. The B1 STS have been studied by netting in the late 1980s and 1990s and since the late 1990s by hydroacoustics and radio telemetry methods.

A prototype extended length submerged bar screen (ESBS) was installed in 1999 and specifically tested in 2000 and 2001. It was still present during the 2002 studies but was removed in 2003 because both netting and hydroacoustic sampling revealed a significant decline in FGE in summer that made the screen no more effective than existing STS. In 2004, the STS at B1 were not deployed for the first time in many years because studies indicated that survival was better for fish passing through turbines than for fish screened at B1 and passed through the existing juvenile bypass system. Other survival data has raised questions about whether bypass systems increase smolt survival (Dawley et al. 1993a and b). New minimum gap runners were installed in Unit 6 and survival was evaluated in 2000; remaining B1 turbines should all have these new runners by 2008 (Portland District 2002).

In winter 1997, the Portland District installed a Prototype Surface Collector (PSC) with deep variable width slots at units 3 through 6 of B1, and the efficiency and effectiveness of 5- and 20-ft slots at Units 5 and 6 were extensively studied by fixed-aspect hydroacoustics, multi-beam acoustics, and radio telemetry in 1998 (see Johnson and Giorgi 1999 for a review). PSC entrances were 40- to 46-ft deep depending upon forebay level, and the mean velocity at the entrance ranged from 3.8 to $8.3 \mathrm{fps}$, depending on slot width, resulting in flows of 1,700 $\mathrm{cfs}$ for 5 - $\mathrm{ft}$ slots and 3,300 $\mathrm{cfs}$ for 20 -ft slots. Unit 5 was studied again in 1999, and the PSC was extended to units 1 through 6 and tested with the above mentioned methods and with acoustic telemetry in 2000 (see Johnson and Carlson 2001 for a synthesis of results).

Over the years, the Portland District has developed spill patterns and rates to facilitate egress of smolts from the spillway tailrace, but structural changes to benefit fish were limited to installation of spill deflectors in 13 of 18 bays in 1975 and of six new deep deflectors at bays 1-3 and 16-18 in 2001. Spill deflectors reduce gas supersaturation by directing flow along the surface of the tailrace rather than allowing it to plunge. The new deflectors added in 2001 were submerged $7 \mathrm{ft}$ deeper than the existing ones, and generated considerably lower total dissolved gas (TDG) pressures than the old deflectors for low tailwater conditions ranging from 10.2 to $13.7 \mathrm{ft}$. For example, the difference in the mean TDG 
saturation (old deflector minus new deflector) for a specific discharge of 7,000 cfs per bay was $6.1 \%$ (Schneider et al. 2003). The two types of spillway deflectors have been studied in direct survival studies using balloon tags (Normandeau et al. 1996 and 2003) and indirect survival studies using radio telemetry (Counihan et al. 2006a and 2006b). In both cases, trends were apparent, although usually not significant. There are a number of factors governing spill at Bonneville, including TDG limitations and effects of spill on adult passage. The former may preclude the ability to spill 100,000 cfs all of the time in spring.

After completion of B2 in 1982, it took researchers about a decade of hard work to maximize FGE by adjusting the deployment depths of the STS and recommending structural modifications (Gessel et al. 1991). The Portland District had added three streamlined trash racks in the upper part of the turbine intake and turbine intake extensions (TIEs) to every other intake across the powerhouse by 1993. Nevertheless, guidance rates were still less than desirable in spring and poor in summer. The TIEs are still removed by early July because they do not facilitate subyearling guidance in summer as well as they guide yearling salmonids in spring. Performance of various measures tested from 1983 to 1994 (Gessel et al. 1991) were highly variable among years, seasons, species, intake slot, and unit and powerhouse operation. The number of fish entering and being guided by the non-TIE intake slots was higher under four and six than eight-unit operation; this suggested that powerhouse load (number of units on) has an effect on the strength of the lateral flows directed toward each corner of the powerhouse, and that TIEs produce a varying effect on intake distribution that decreases from four to six units of operation, and disappears with eight units (Portland District 2002).

Based upon a review of FGE results, researchers with the National Marine Fisheries Service of the National Oceanic and Atmospheric Administration (NOAA Fisheries) concluded 1) the flow field above the STS and into the gatewell slot is restricted and needs to be increased, and 2) the bulk flow moving laterally across both the north and south ends of the powerhouse in the near forebay needs to be redirected into the intake because the forebay hydraulic environment greatly complicates the sensory cues presented to the fish. Researchers recommended that subsequent hydraulic evaluations need to be examined to look at the complex interactions between bulk forebay flow and the flat face and intake structures for clues on how to improve FGE.

In response to these findings, the USACE Portland District started research in 1998 to collaborate and support the construction of two new fish passage improvement projects at B2 (as described in Portland District 2002). The first of the two improvements included modifications to the current gatewell intake structure to direct more flow up into the gatewell slot. These modifications included new vertical barrier screens (VBS), a gap closure device, and a turning vain. With these improvements, the hydraulic capacity of the gatewell slot went from $270 \mathrm{cfs}$ to $480 \mathrm{cfs}$, and the STS top gap flows were reduced from $215 \mathrm{cfs}$ to 90 cfs. Research was conducted in 2001 to measure the FGE improvements in modified Unit 15, and netting and hydroacoustic results were very encouraging. The netting estimates were the highest FGE values measured at B2 since testing began in the early 1980s (Monk et al. 2002). Summer FGE for subyearling Chinook salmon averaged 57\%. Hydroacoustic FGE estimates for all run-of-river salmonids combined was $72 \%$ for spring and $50 \%$ for summer. In 2002, the USACE modified Unit 17 to be similar to modified Unit 15. Netting and hydroacoustic results again were encouraging in 2002 (Monk et al. 2004; Ploskey et al. 2003, respectively) although there was greater variation among intakes of Unit 17 than there was among intakes of Unit 15 and FGE was lower at Unit 17 than at Unit 15. 
The ice and trash sluice chute at B2 was recognized as an exceptionally effective way to pass juvenile fish by Fishery Field Unit researchers in the 1980s, but fish managers limited its use in the 1990s and from 2000 through 2003 because of egress problems and predation in the tailrace downstream of the original ice and trash sluice chute outfall. Exceptions included sluice-chute tests in 1998 and the B2CC evaluation in 2004. In both of these years, TIEs were removed from units 11 through 14 in spring and summer to facilitate flow toward the south corner of B2. Since the sluice chute channel was modified in late 2003 and early 2004 to discharge fish at the downstream end of Cascades Island, poor egress is no longer a problem, and the $\mathrm{B} 2 \mathrm{CC}$ is operated full time during the spring and summer emigration periods.

Since 1977, annual fish passage plans prepared by the Columbia River Water Management Group's interagency Committee on Fish Operations from 1979 to 1984 and prepared by the USACE Northwest Division's Reservoir Control Center from 1984 through 2005 (Committee on Fishery Operations 19791985; Reservoir Control Center 1985a,b - 2005) have dictated operations deemed necessary to protect and enhance anadromous fish species. Many of the operations are highly specific (such as chain gate adjustments at B1, gatewell or STS inspection frequencies, or the precise spill pattern for any level of spill discharge) and will not be summarized by year in this report. From 1960 until B2 was operational in 1982, spill was common and rarely planned because river flows usually greatly exceeded the discharge capacity of the single powerhouse at B1 (Figure 1.2). Most non-drought years before B2 was finished in 1982 had as high or higher percent spill than years after B2 was operational, even though spill for juvenile fish passage was not mandated until 1996 by the 1995 Biological Opinion (BiOp) of the National Marine Fisheries Service (NOAA Fisheries 1995). Project discharge has generally declined over the historical period of record, although there was a lot of year-to-year variability (Figure 1.2). From about 1960 through 1990, spill discharge and percent spill have exhibited a general downward trend, which paralleled Project discharge. The discharge estimates in Figure 1.2 are from the DART web site, and spill discharge has not been corrected to address underestimates for spill $<75,000 \mathrm{cfs}$.

Biological opinions in 1995 and 2000 called for continuous spill at Bonneville Dam during the spring and summer migrations since 1996 (NOAA Fisheries 1995 and 2000) and consisted of the following elements:

1. Spill for juvenile fish passage will begin on April 10 and end August 31. These are planning dates and are flexible according to specific requirements relating to fish abundance.

2. The daytime spill amount is $75 \mathrm{kcfs}$ in order to reduce adult fallback even though this exceeded the $2000 \mathrm{BiOp}$ minimum spill level of $50 \mathrm{kcfs}$.

3. At night, the spill amount will be up to the $120 \%$ gas cap. 


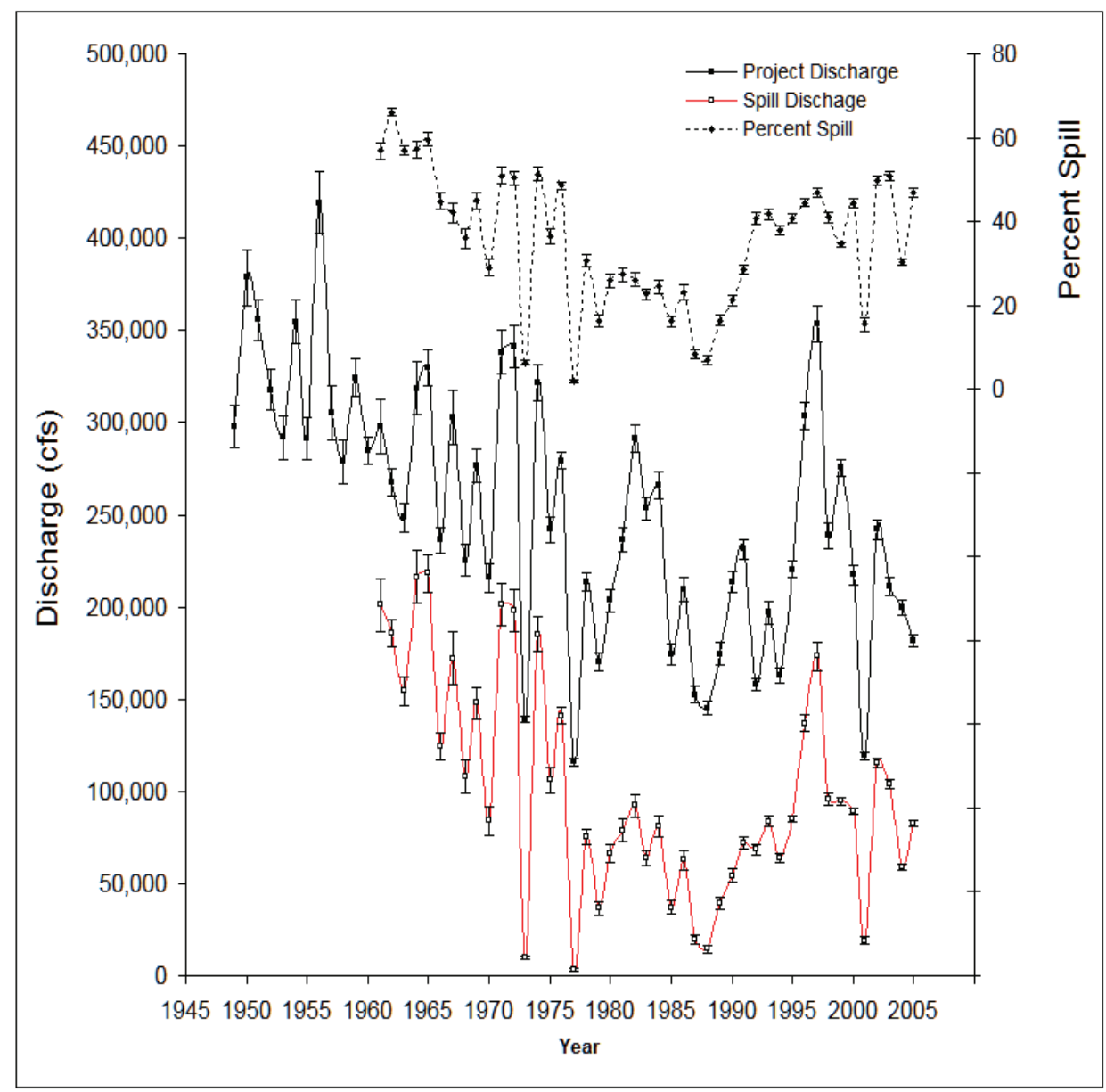

Figure 1.2. Historical Record of Percent Spill (Upper Plot) and Project and Spill Discharge Volume (Lower Plot) During the Spill Season at Bonneville Dam through 2005. Percent spill was calculated as spill discharge / total discharge for the period April 20 through August 31 each year.

After B2 came on line in 1982 and especially after fish guidance efficiency problems were identified in 1983, fish passage plans from 1984 through 2000 called for B1 to be the priority powerhouse. In general, B2 units were not operated except for research purposes unless they were needed to limit spill to $75,000 \mathrm{cfs}$ during daylight hours. Units 11,17 , and 18 were the priority units in most years, after B1 units. It was not until 2001 that the fish passage plan switched the powerhouse priority from B1 to B2. This change in priority was made possible by a new switch that allowed the two powerhouses to operate independently and by new data suggesting that survival of fish passing B2 was higher than previously thought. Some managers have hypothesized that a B2 priority would produce higher spill efficiencies than a B1 priority because of smoother flows entering the spillway and B2 forebays. Research on powerhouse priorities also played an important role in the switch from B1 to B2 priority. The B2 likely will remain the priority powerhouse since the Portland District redesigned the B2 ice/trash sluice chute (ITC) outfall to discharge fish near the downstream tip of Cascades Island in winter 2003-2004, and since researchers documented very high efficiency and effectiveness for the B2CC in 2004. 
Methods of research also have changed over the years. Researchers have long used nets and traps to assess fish passage, injury, and survival, and these are still used today, although perhaps not as often as remote sensing techniques like fishery hydroacoustics that were developed in the 1980s and 1990s, passive integrated transponder (PIT) tag detection developed since the 1980s, and radio telemetry, which has been used for tracking smolts since the mid 1990s. Since 2000, radio telemetry of juvenile salmonids has been used to estimate route-specific passage and survival. Acoustic telemetry, which has been used once to track fish in three dimensions in the B1 forebay in 2000 (Faber et al. 2001), likely will be more widely used in the future.

\subsection{Species Composition and Run Timing}

The following salmonid species migrate downstream past Bonneville Dam:

Oncorhynchus tshawytscha Chinook salmon (yearling and subyearling)

O. mykiss steelhead trout

O. nerka sockeye salmon

O. kisutch coho salmon.

Peaks in migration timing for each species of juvenile salmon may shift by 1-2 weeks depending upon the exact timing of releases from hatcheries upstream of Bonneville Dam and the magnitude of river discharge (Figures 1.3, 1.4, and 1.5). Species composition also may vary widely among years. We selected 1996 (Figure 1.3), 2001 (Figure 1.4), and 2004 (Figure 1.5) to represent very wet, very dry, and average flow conditions for the lower Columbia River, respectively. In 1996, river discharge and percent spill were both high (Figure 1.2), and the ranking of species by abundance in spring was $42 \%$ subyearling Chinook salmon, $28 \%$ coho, $15 \%$ yearling Chinook salmon, $14 \%$ steelhead, and $1 \%$ sockeye. In the drought year of 2001, river discharge and percent spill were far below average (Figure 1.4), and the ranking of species by abundance in spring was $42 \%$ coho, $30 \%$ yearling Chinook salmon, only $18 \%$ subyearling Chinook salmon, 9\% steelhead, and $<1 \%$ sockeye. In 2004, when discharge and percent spill were more average (Figure 1.5), subyearling Chinook salmon again dominated the springtime species composition (46\%) like they did in 1996. Yearling Chinook salmon were the second most abundant in spring 2004 (30\%), followed by coho (19\%), a weak run of steelhead (3\%), and a relatively strong run of sockeye (2\%). Subyearling Chinook salmon dominated the summer run in all years, making up $86 \%$ of all species in $1996,63 \%$ in 2001 , and $89 \%$ in 2004 . Subyearlings appear to be at a disadvantage during summers of drought if 2001 was a representative drought year.

Variations in species composition among weeks in spring and among years (Figure 1.3-1.5) have important implications for acoustic and radio tagging studies and their conclusions. Neither method provides much statistical inference for the majority of juvenile salmonids migrating in spring. Only yearling Chinook salmon and steelhead were tagged in spring, and in most years those species make up < $40 \%$ of the spring run. For example, yearling Chinook salmon and steelhead only make up $29 \%, 40 \%$, and $33 \%$ of the run in spring 1996, 2001, and 2004, respectively. Results of tagging studies are very useful for assessing species-specific effects of structural changes or operations, but they provide no inference for the other species or age groups that are not tagged and that, in this case, made up $61 \%$ to $71 \%$ of the spring run in most years. Tagging of subyearling Chinook salmon provides inference for the majority of the juvenile salmonids migrating in summer ( $>86 \%$ of migrants in normal to wet years). 


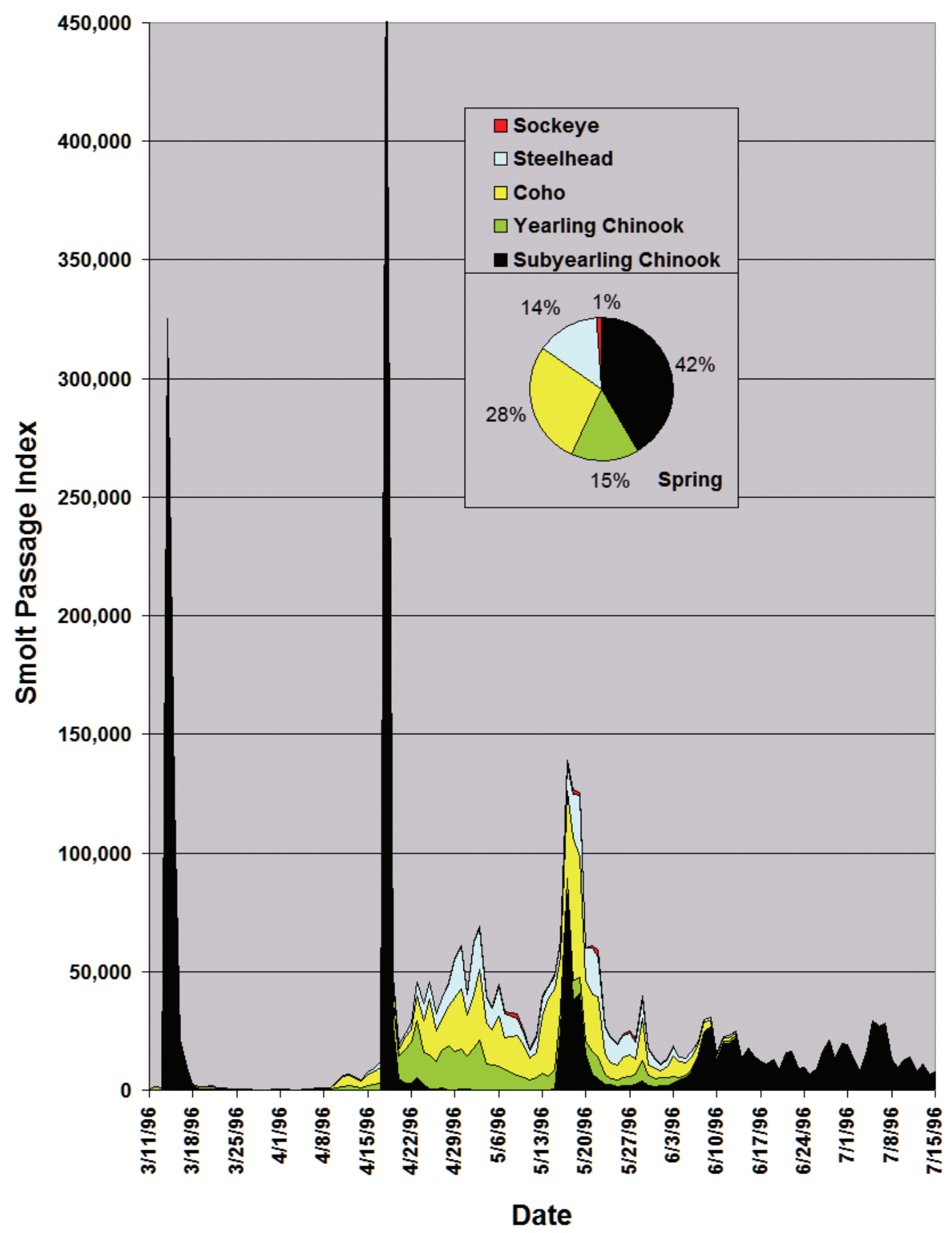

Figure 1.3. Species Composition and Run Timing based upon the Smolt Passage Index at the Bonneville Dam B1 Smolt Monitoring Facility in 1996, a Year of Above-Average Flow and Spill Discharge 


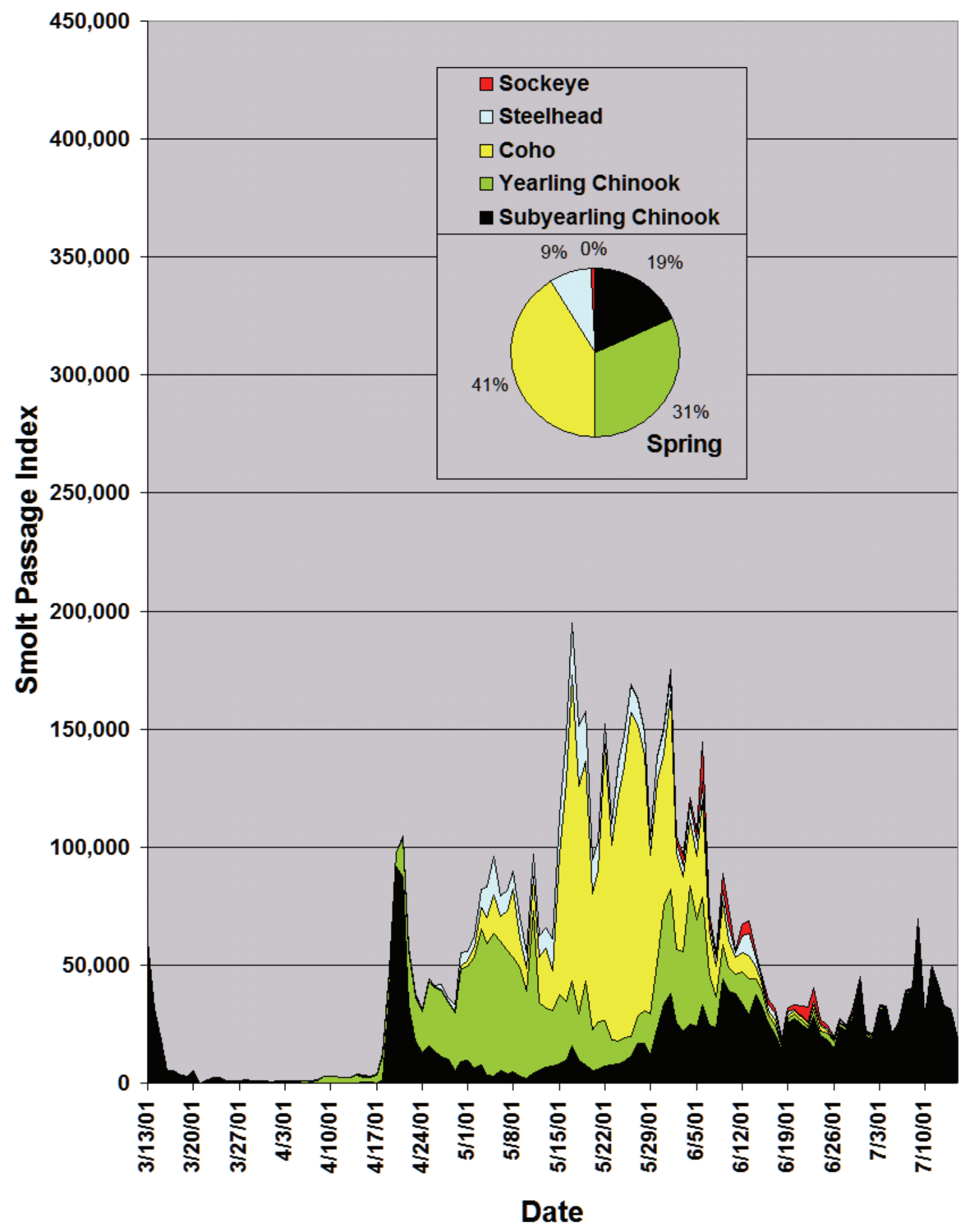

Figure 1.4. Species Composition and Run Timing based upon the Smolt Passage Index at the Bonneville Dam B2 Smolt Monitoring Facility in 2001, a Year of Below-Average Flow and Percent Spill 


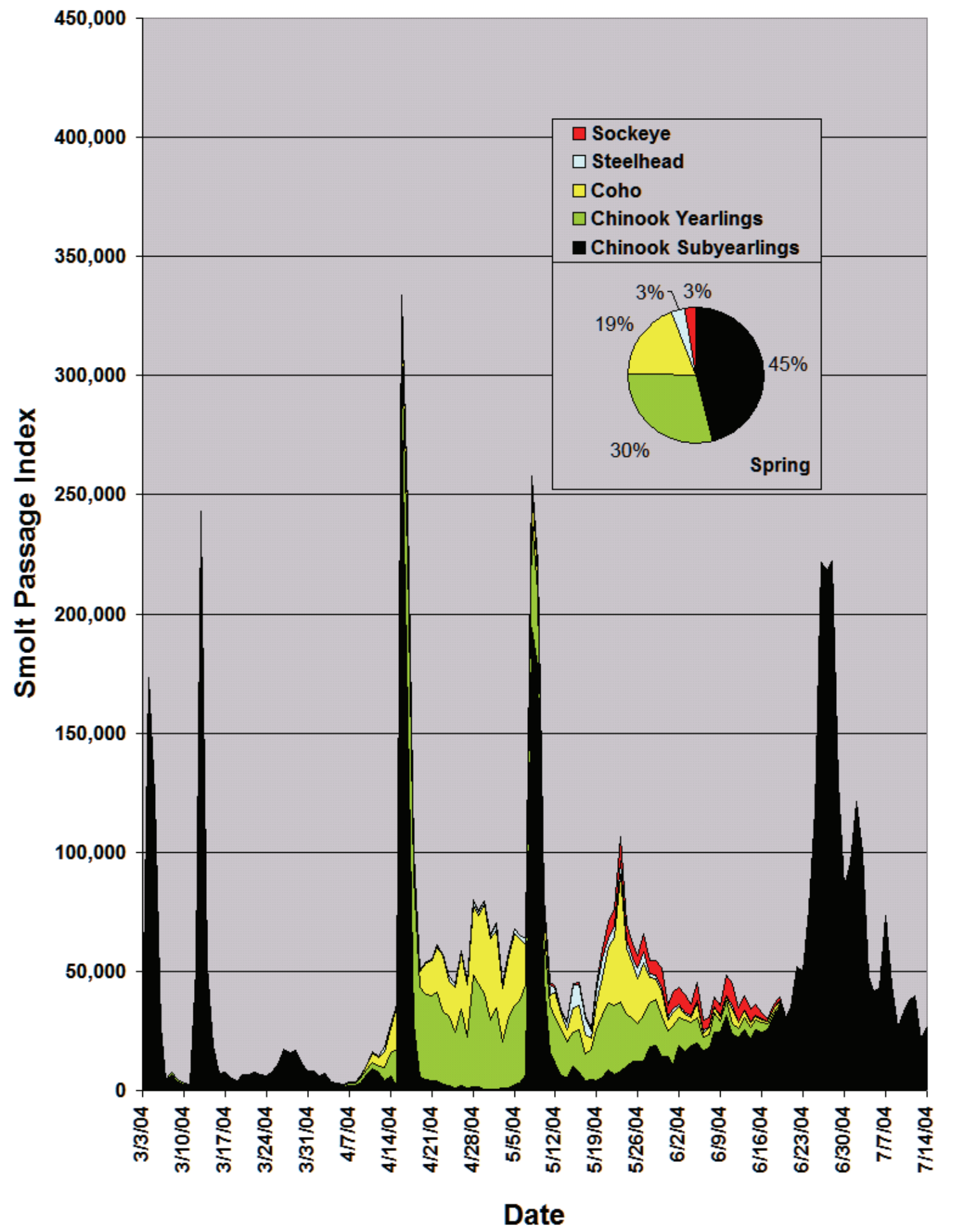

Figure 1.5. Species Composition and Run Timing based upon the Smolt Passage Index at the Bonneville Dam B2 Smolt Monitoring Facility in 2004, a Year of Average Flow and Percent Spill 


\subsection{Studies of Juvenile Fish Passage at Bonneville Dam 1939-2005}

Each of the studies that we reviewed was assigned an identification number. Table 1.1 lists all of the reports and their corresponding ID numbers. (These reference numbers also appear in Appendix A as the hyperlinks for each report.) Table 1.2 is a comprehensive matrix indicating which reports pertain to which dam structures or topics of study and which year of dam operation from 1939 through 2005.

\subsection{Overview of this Report}

This report contains six chapters and two appendixes. Chapter 1 is this introduction. Chapter 2 describes fish distribution and movement in the forebays above both powerhouses and the spillway. Chapter 3 describes passage characteristics including major passage metrics, surface flow outlets, fish guidance efficiency, and the distribution of passage including horizontal, vertical, and diel distributions. Chapter 4 summarizes survival research. Chapter 5 is a synthesis and conclusions. Chapter 6 is a list of references cited in this report. Appendix A is a list of the references with hyperlinks to full PDF versions of each of the reports, which are contained on the accompanying DVD. Appendix B is an annotated bibliography which provides an abstract of each report listed in Appendix A and included on the DVD. The abstracts are provided for readers who are less familiar with the research by title. For convenience, citations with more than two authors are arranged by first author, year, and if necessary, by an assigned alphabetic letter whenever there were multiple papers per year with the same lead author, regardless of the order of the coauthors (e.g., Evans et al. 2003a,b; Evans et al. 2006a,b,c).

Table 1.1. Listing of PDF Identification Numbers and Associated Citations. Not all numbers between 1 and 182 were used because some reports were dropped before publication.

\begin{tabular}{llll} 
ID. No. & \multicolumn{1}{c}{ Citation } & ID. No. & \multicolumn{1}{c}{ Citation } \\
BS001 & Ploskey et al. 2003 & BS085 & Ledgerwood et al. 1990 \\
BS002 & Normandeau et al. 2003 & BS086 & Gessel et al. 1990 \\
BS003 & Monk et al. 2002 & BS087 & Ferguson1991 \\
BS004 & Ploskey et al. 2002c & BS088 & Dawley et al. 1989 \\
BS005 & Evans et al. 2001d & BS089 & Gessel et al. 1989 \\
BS006 & Evans et al. 2001c & BS090 & Dawley et al. 1988 \\
BS007 & BioAnalysts, ENSR, INCA. 2001 & BS091 & Michimoto 1971 \\
BS008 & Holmberg et al. 2001 & BS092 & Jensen 1987. \\
BS009 & Monk \& Sandford 2001 & BS093 & Nagy \& Magne 1986 \\
BS010 & Wertheimer, Dalen, Madson 2001 & BS094 & Magne 1987a \\
BS011 & Ploskey et al. 2002a & BS095 & Krcma, Long, \& Thompson 1978 \\
BS012 & Ploskey et al. 2002b & BS096 & Long \& Krcma 1977 \\
BS013 & Evans et al. 2001b & BS097 & Long \& Krcma 1977 \\
BS014 & Evans et al. 2001a & BS098 & Johnson 1970 \\
BS015 & Johnson \& Giorgi 1999 & BS099 & Michimoto \& Korn 1969 \\
BS016 & Holmberg et al. 2001 & BS102 & Dawley et al. 1993a \\
BS017 & Plumb et al. 2001 & BS103 & Holmes 1952. \\
BS018 & Monk, Sandford, \& Dey 1999 & BS104 & McConnell \& Muir 1982 \\
BS019 & Ploskey et al. 2001a & BS105 & Jones, Starke, \& Stansell 1997 \\
BS020 & Hanks and Ploskey 2000 & BS106 & Jones, Starke, \& Stansell 1999 \\
BS021 & Ploskey et al. 2000 & BS107 & Fisheries Eng. Res. Prog. 1957 \\
BS022 & Bickford \& Skalski 2000 & BS108 & Jones, Starke, \& Stansell 1996 \\
& & &
\end{tabular}


BS023 Hawkes et al. 1991

BS024 BioSonics 1998

BS025 Gessel et al. 1991

BS027 Johnson et al. 2000

BS028 Gessel, Monk, \& Williams 1988

BS029 Gessel et al. 1987

BS030 Johnson, Moursund, Simmons 1999

BS031 Gessel et al. 1986

BS032 Gessel et al. 1985

BS033 Krcma et al. 1984

BS035 Hensleigh et al. 1999

BS036 Holmberg et al. 1996

BS037 Evans et al. 2003a

BS038 Hansel et al. 1999

BS039 Krcma et al. 1982

BS040 Ploskey et al. 1998

BS042 Magne, Rawding, \& Nagy 1986

BS043 Magne 1987b

BS044 Magne, Stansell, \& Nagy 1989

BS045 Muir et al. 1989

BS047 Thorne \& Kuehl 1989

BS048 Ploskey et al. 2001b

BS049 Thorne \& Johnson 1993

BS050 Stansell et al. 1990

BS051 Uremovich et al. 1980

BS054 Monk, Gessel, \& Ferguson 1999

BS055 Monk, Sandford, \& Dey 1993

BS056 Monk, Sandford, \& Dey 1995

BS062 Willis \& Uremovich 1981

BS063 Mebane, Maret, \& Hughes 2003

BS064 Smith et al. 2000 (1998)

BS066 Zimmerman \& Ward 1999

BS067 Muir et al. 2001

BS069 NW Fisheries Science Center 2000

BS072 Zabel et al. 2001

BS073 Smith et al. 2000 (1999)

BS074 Muir et al. 2003

BS075 Giorgi \& Stevenson 1995

BS077 Normandeau 2000

BS078 Nagy 1997

BS079 Ledgerwood et al. 1994

BS080 Monk et al. 1993

BS081 Gilbreath et al. 1993

BS082 Monk, Varney, \& Grabowski 1992

BS083 Ledgerwood et al. 1991
BS109 Magne 1987c

BS110 Magne 1984

BS112 Bell 1971

BS114 Dawley et al. 1998

BS115 Simmons et al. 2001

BS116 Martinson et al. 1997

BS117 Monan \& Liscom 1974

BS118 Gessel et al. 1994

BS119 Shrank, Dawley, \& Ryan 1997

BS120 Toner, Ryan, \& Dawley 1995

BS121 Toner \& Dawley 1995

BS122 Gauley, Anas, Schlotterbeck 1958

BS123 Normandeau et. al. 2001

BS124 Johnson et al. 2001

BS125 Johnson \& Carlson 2001

BS126 Normandeau et al. 1996

BS127 Snelling \& Mattson 1996

BS128 Johnson, Giorgi, \& Erho 1997

BS129 Dawley et al. 1992

BS130 Dawley et al. 1993a

BS131 Gessel et al. 1986b

BS132 Petersen, Gadomski, \& Poe 1994

BS133 Dawley et al. 1991

BS134 Portland Dist. COE 2001

BS135 Ward, Petersen, \& Loch 1995

BS136 Counihan et al. 2003

BS137 Evans et al. 2003b

BS139 Counihan et al. 2002

BS140 Ploskey et al. 2004

BS141 Faber et al. 2001

BS142 Monk et al. 2004

BS170 Skalski et al. 2002

BS171 Johnsen and Dawley 1974

BS172 Counihan et al. 2006a

BS173 Counihan et al. 2006b

BS174 Ploskey et al. 2005

BS175 Ploskey et al. 2006c

BS176 Adams et al. 2006

BS177 Evans et al. 2006a

BS178 Evans et al. 2006b

BS179 Reagan et al. 2006

BS180 Evans et al. 2006c

BS181 Ploskey et al. 2006a

BS182 Ploskey et al. 2006b 
Table 1.2. Summary of Juvenile Fish-Passage Research at Bonneville Dam from 1939 through 2005. Identification numbers in Table 1.2 correspond to ID numbers for references listed in in Table 1.1 and to full papers on an accompanying DVD.

\begin{tabular}{|c|c|c|c|c|c|c|c|c|c|c|c|c|c|c|c|c|c|}
\hline \multirow[t]{2}{*}{ Area } & \multicolumn{17}{|c|}{ Year } \\
\hline & 39 & 40 & 41 & 42 & 43 & 44 & 45 & 46 & 47 & 48 & 49 & 50 & 51 & 52 & 53 & 54 & 55 \\
\hline \multicolumn{18}{|l|}{ B1 Forebay } \\
\hline \multicolumn{18}{|l|}{ B1 Sluiceway } \\
\hline B1 Turbines & \multicolumn{7}{|c|}{ 103; 107} & & & & & & & & 107 & 107 & \\
\hline \multicolumn{18}{|l|}{ B1 JBS } \\
\hline \multicolumn{18}{|l|}{ B1 STS } \\
\hline \multicolumn{18}{|l|}{ B1 ESBS } \\
\hline \multicolumn{18}{|l|}{ B1 PSC } \\
\hline \multicolumn{18}{|l|}{ B1 MGRs } \\
\hline Spillway & \multicolumn{7}{|c|}{$103 ; 107$} & & & & & & & & 107 & 107 & \\
\hline \multicolumn{18}{|l|}{$\begin{array}{l}\text { Flow Deflector } \\
\text { Tests }\end{array}$} \\
\hline \multicolumn{18}{|l|}{ Gas Cap Tests } \\
\hline \multicolumn{18}{|c|}{ B2 Sluice Chute } \\
\hline \multicolumn{18}{|l|}{ B2 Turbines } \\
\hline \multicolumn{18}{|l|}{ B2 STS } \\
\hline \multicolumn{18}{|l|}{ B2 JBS } \\
\hline \multicolumn{18}{|l|}{$\begin{array}{l}\text { B2 JBS Outfall } \\
\text { Relocation }\end{array}$} \\
\hline \multicolumn{18}{|l|}{$\begin{array}{l}\text { B2 Gatewell } \\
\text { Improvements }\end{array}$} \\
\hline \multicolumn{18}{|l|}{$\begin{array}{l}\text { Hydraulic } \\
\text { Effects }\end{array}$} \\
\hline \multicolumn{18}{|l|}{$\begin{array}{l}\text { Total Project } \\
\text { FPE and Spill } \\
\text { Efficiency }\end{array}$} \\
\hline Survival & \multicolumn{7}{|c|}{ 103; 107} & & & & & & & & 107 & & \\
\hline Predation & & & & & & & & & & & & & & & & & \\
\hline $\begin{array}{l}\text { Forebay } \\
\text { Approach }\end{array}$ & & & & & & & & & & & & & & & & & \\
\hline Horizontal Dist & & & & & & & & & & & & & & & & & \\
\hline Vertical Dist. & & & & & & & & & & & & & & & & & \\
\hline Diel Dist. & & & & & & & & 122 & & & 122 & 122 & & 122 & 122 & & \\
\hline
\end{tabular}


Table 1.2. (Cont)

\begin{tabular}{|c|c|c|c|c|c|c|c|c|c|c|c|c|c|c|c|c|c|c|c|}
\hline \multirow[t]{2}{*}{ Area } & \multicolumn{19}{|c|}{ Year } \\
\hline & 56 & 57 & 58 & 59 & 60 & 61 & 62 & 63 & 64 & 65 & 66 & 67 & 68 & 69 & 70 & 71 & 72 & 73 & 74 \\
\hline B1 Forebay & & & & & & & & & & & & & & & & & & & \\
\hline B1 Sluiceway & & & & & & & & & & & & & & 99 & & 91 & & & \\
\hline B1 Turbines & 107 & & & & & & & & & & & & & & & & & & \\
\hline B1 JBS & & & & & & & & & & & & & & & & & & & \\
\hline B1 STS & & & & & & & & & & & & & & & & & & & \\
\hline B1 ESBS & & & & & & & & & & & & & & & & & & & \\
\hline B1 PSC & & & & & & & & & & & & & & & & & & & \\
\hline B1 MGRs & & & & & & & & & & & & & & & & & & & \\
\hline Spillway & 107 & & & & & & & & & & & & & & & & 171 & 171 & \\
\hline $\begin{array}{l}\text { Flow Deflector } \\
\text { Tests }\end{array}$ & & & & & & & & & & & & & & & & & 171 & 171 & \\
\hline Gas Cap Tests & & & & & & & & & & & & & & & & & & & \\
\hline B2 Sluice Chute & & & & & & & & & & & & & & & & & & & \\
\hline B2 Turbines & & & & & & & & & & & & & & & & & & & \\
\hline B2 STS & & & & & & & & & & & & & & & & & & & \\
\hline B2 JBS & & & & & & & & & & & & & & & & & & & \\
\hline $\begin{array}{l}\text { Hydraulic } \\
\text { Effects }\end{array}$ & & & & & & & & & & & & & & & 98 & 112 & & & \\
\hline $\begin{array}{l}\text { Total Project } \\
\text { FPE and Spill } \\
\text { Efficiency }\end{array}$ & & & & & & & & & & & & & & & & & & & \\
\hline Survival & 107 & & & & & & & & & & & & & & & & & & \\
\hline Predation & & & & & & & & & & & & & & & & & & & \\
\hline $\begin{array}{l}\text { Forebay } \\
\text { Approach }\end{array}$ & & & & & & & & & & & & & & & & & & & \\
\hline Horizontal Dist. & & & & & & & & & & & & & & & & & & & \\
\hline Vertical Dist. & & & & & & & & & & & & & & & & & & & \\
\hline Diel Dist. & & & & & & & & & & & & & & & & & & & \\
\hline
\end{tabular}


Table 1.2. (Cont')

\begin{tabular}{|c|c|c|c|c|c|c|c|c|c|c|c|c|c|c|c|c|c|c|}
\hline Area & \multicolumn{18}{|c|}{ Year } \\
\hline & 75 & 76 & 77 & 78 & 79 & 80 & 81 & 82 & 83 & 84 & 85 & 86 & 87 & 88 & 89 & 90 & 91 & 92 \\
\hline B1 Forebay & & & & & & & & & & & & & & & & & & \\
\hline B1 Sluiceway & & & & & & 51 & $\begin{array}{l}39 \\
62 \\
\end{array}$ & & & & & & & & & & & \\
\hline B1 Turbines & 97 & & 95 & & & & 39 & & & & & & 90 & $\begin{array}{l}47 \\
88\end{array}$ & 86 & & 82 & $\begin{array}{r}7980 \\
102\end{array}$ \\
\hline B1 JBS & & 95 & 95 & & & & $\begin{array}{l}39 \\
62\end{array}$ & 104 & & 32 & 31 & 29 & $\begin{array}{l}28 \\
90\end{array}$ & 88 & 85 & 23 & 82 & $\begin{array}{r}7980 \\
102\end{array}$ \\
\hline B1 STS & & & & & & & 39 & & & & & & & $\begin{array}{l}47 \\
89 \\
\end{array}$ & 86 & & 82 & 80 \\
\hline B1 VBS & & & & & & & 39 & & & & & & & & & & & \\
\hline B1 Bar screen & & & $95^{1}$ & & & & & & & & & & & & & & & \\
\hline Spillway & & & & & & & & & & & & & & & $\begin{array}{r}81 \\
85 \\
102 \\
129 \\
\end{array}$ & & & \\
\hline B2 Forebay & & & & & & & & & & 110 & & & & & & & & \\
\hline B2 Sluice Chute & & & & & & & & & & & & 42 & $\begin{array}{r}43 \\
94 \\
109 \\
\end{array}$ & 44 & 50 & & & \\
\hline B2 Turbines & & 96 & & & & & & & $\begin{array}{l}25 \\
33 \\
54\end{array}$ & $\begin{array}{l}25 \\
32 \\
54\end{array}$ & $\begin{array}{l}25 \\
31 \\
54 \\
93\end{array}$ & $\begin{array}{l}25 \\
29 \\
42 \\
54\end{array}$ & $\begin{array}{r}25 \\
28 \\
43 \\
54 \\
81 \\
87 \\
94 \\
102 \\
129\end{array}$ & $\begin{array}{r}25 \\
44 \\
45 \\
54 \\
81 \\
87 \\
89 \\
102 \\
129\end{array}$ & $\begin{array}{r}25 \\
50 \\
54 \\
81 \\
85 \\
86 \\
87 \\
102 \\
129\end{array}$ & $\begin{array}{r}81 \\
83 \\
87 \\
102 \\
129\end{array}$ & & 79 \\
\hline B2 Bar screen & & & & & & & & & & & & & & 89 & 86 & & & \\
\hline B2 STS & & & & & & & & & $\begin{array}{l}25 \\
33 \\
54\end{array}$ & $\begin{array}{l}25 \\
32 \\
54\end{array}$ & $\begin{array}{l}25 \\
31 \\
54 \\
93\end{array}$ & $\begin{array}{l}25 \\
29 \\
42 \\
54\end{array}$ & $\begin{array}{r}25 \\
28 \\
43 \\
54 \\
94 \\
109 \\
\end{array}$ & $\begin{array}{l}25 \\
44 \\
45 \\
54 \\
89\end{array}$ & $\begin{array}{l}25 \\
45 \\
50 \\
54 \\
86\end{array}$ & & & \\
\hline B2 TIEs & & & & & & & & & & & & 29 & 28 & 89 & 86 & & & \\
\hline B2 VBS & & & & & & & & & & 32 & & & & & & & & \\
\hline B2 JBS & & $96^{2}$ & & & & & & 104 & 33 & 32 & 31 & 29 & $\begin{array}{r}81 \\
87 \\
102\end{array}$ & $\begin{array}{r}87 \\
102\end{array}$ & $\begin{array}{r}85 \\
87 \\
102\end{array}$ & $\begin{array}{r}23 \\
83 \\
87 \\
102 \\
114\end{array}$ & $\begin{array}{l}114 \\
133\end{array}$ & 114 \\
\hline Trash-rack effects & & 96 & & & & & & & & 32 & 31 & 29 & & & & & & \\
\hline Effect of Lights & & & & & & & & & & 32 & & & 28 & 89 & 86 & & & \\
\hline $\begin{array}{l}\text { Total Project FPE } \\
\text { and Spill } \\
\text { Efficiency }\end{array}$ & & & & & & & & & & & & & & & & & & \\
\hline Survival & & & & & & & & 104 & & & & & $\begin{array}{r}81 \\
90 \\
102 \\
129\end{array}$ & $\begin{array}{r}81 \\
88 \\
102 \\
129\end{array}$ & $\begin{array}{r}81 \\
85 \\
102 \\
129\end{array}$ & $\begin{array}{r}81 \\
83 \\
102 \\
114 \\
129\end{array}$ & $\begin{array}{l}114 \\
133\end{array}$ & $\begin{array}{r}79 \\
102 \\
114\end{array}$ \\
\hline Predation & & & & & & 51 & & & & & & & & & $118^{3}$ & $\begin{array}{l}132 \\
135 \\
\end{array}$ & 135 & 135 \\
\hline Forebay Approach & & & & & & & & & & & & & & & & & & \\
\hline Horizontal Dist. & & & & & & & $\begin{array}{l}39 \\
62\end{array}$ & & & 110 & & & & & & & & \\
\hline Vertical Dist. & 97 & & & & & & 39 & & & $\begin{array}{r}321 \\
10 \\
\end{array}$ & $\begin{array}{l}31 \\
93 \\
\end{array}$ & $\begin{array}{l}29 \\
42 \\
\end{array}$ & & 89 & 86 & & & \\
\hline Diel Dist. & & 96 & & & & & 62 & & & & 31 & 29 & & & 50 & & & \\
\hline
\end{tabular}

${ }^{1}$ Small prototype bar screen near gatewell entrance

${ }^{2}$ Orifice passage efficiency

${ }^{3}$ Northern pikeminnow population estimate 
Table 1.2. (Cont')

\begin{tabular}{|c|c|c|c|c|c|c|c|c|c|c|c|c|c|c|}
\hline Area & & & & & & & Year & & & & & & & Reviews \\
\hline & 93 & 94 & 95 & 96 & 97 & 98 & 99 & 00 & 01 & 02 & 03 & 04 & 05 & \\
\hline B1 Forebay & & & 21 & 3640 & 2435 & 38 & & & 56 & 37137 & & & & \\
\hline B1 Sluiceway & & & 126 & 40 & 35 & & & 13141 & 56 & $\begin{array}{r}1237 \\
137\end{array}$ & & & 182 & 1575128134 \\
\hline B1 Turbines & & & 21 & 40 & 20 & 1938 & 17140 & $\begin{array}{r}1112 \\
1377 \\
141 \\
\end{array}$ & $\begin{array}{r}456 \\
139\end{array}$ & $\begin{array}{r}137 \\
136 \\
137 \\
\end{array}$ & & & 182 & 134170 \\
\hline B1 MGR & & & & & & & & 77 & 77 & 136 & & & & \\
\hline B1 JBS & 130 & & & 116 & & 18 & 140 & 13 & 56139 & $\begin{array}{r}13637 \\
137\end{array}$ & & & & 134 \\
\hline B1 STS & & & & 40 & 20 & 19 & & 1112 & 456 & $\begin{array}{r}137 \\
137\end{array}$ & & & & 2 \\
\hline B1 ESBS & & & & & & 1819 & & $\begin{array}{r}91112 \\
115\end{array}$ & 4 & 1 & & & & 2 \\
\hline B1 PSC & & & & & & $\begin{array}{r}1930 \\
38\end{array}$ & $\begin{array}{r}1727 \\
48\end{array}$ & $\begin{array}{r}1112 \\
13124 \\
141\end{array}$ & & & & & & 1575125134 \\
\hline Spillway & & & 126 & 36 & 2435 & 38 & & 1113 & $\begin{array}{r}456 \\
139\end{array}$ & $\begin{array}{r}1237 \\
136 \\
137\end{array}$ & & $\begin{array}{l}174179 \\
180182\end{array}$ & $\begin{array}{l}175 \\
176 \\
182\end{array}$ & 134 \\
\hline Flow Deflector & & & 126 & & & & & & & & & & & 134 \\
\hline Gas Effects & 121 & 120 & 119 & & & & & & & & & & & \\
\hline B2 Forebay & & & & 3640 & 2435 & 38 & & 13 & 56 & 37137 & & & & 1 \\
\hline B2 Sluice Chute & & & 126 & 3640 & 2435 & 1938 & & 123 & & & & & & 11575128 \\
\hline $\mathrm{B} 2 \mathrm{CC}$ & & & & & & & & & & & & 181 & 182 & $\begin{array}{r}775128 \\
134 \\
\end{array}$ \\
\hline B2 Turbines & 55 & 56 & & 40 & 24 & 1938 & 1754 & 1113 & $\begin{array}{r}3456 \\
139\end{array}$ & $\begin{array}{r}137 \\
136 \\
137\end{array}$ & & $\begin{array}{r}174179 \\
180\end{array}$ & $\begin{array}{l}175 \\
176\end{array}$ & ${ }^{1} 2554 \quad 134$ \\
\hline B2 STS & 55 & 56 & & 40 & 24 & 19 & 54 & 1113 & 456 & $\begin{array}{r}137 \\
137\end{array}$ & 140 & & & ${ }^{1} 2554$ \\
\hline B2 TIEs & 55 & 56 & & 40 & & & 54 & 11 & 4 & 1 & & 174 & 175 & 1 \\
\hline B2 VBS & & & & & & & & & & & & & & 1 \\
\hline B2 JBS & & 56 & & 116 & & & 16 & 813 & $\begin{array}{c}56 \\
139\end{array}$ & $\begin{array}{r}13637 \\
137\end{array}$ & & & & 1 \\
\hline B2 JBS Relocated & & & & & & & 16 & 8 & & & & & & \\
\hline Tailrace egress & & & & 127 & & & 16 & 8 & & & & & & \\
\hline $\begin{array}{l}\text { B2 Gatewell } \\
\text { Improvements }\end{array}$ & & & & & & & & & 34 & $\begin{array}{r}1 \\
142\end{array}$ & 140 & 174 & 175 & 1134 \\
\hline Total Project FPE & & & & & & & & $\begin{array}{r}1113 \\
182\end{array}$ & $\begin{array}{r}456 \\
182\end{array}$ & $\begin{array}{r}137 \\
137 \\
177 \\
178 \\
182\end{array}$ & & $\begin{array}{l}174179 \\
180182\end{array}$ & $\begin{array}{l}175 \\
176 \\
182\end{array}$ & 183 \\
\hline Spill Efficiency & & & & 36 & 35 & 38 & 17 & 1113 & 456 & $\begin{array}{r}137 \\
137\end{array}$ & & $\begin{array}{r}174179 \\
180\end{array}$ & $\begin{array}{l}175 \\
176 \\
182 \\
\end{array}$ & \\
\hline Survival & 130 & & 126 & & & & & 77123 & 139 & $\begin{array}{r}2 \\
136 \\
173\end{array}$ & 171 & 172 & 173 & $\begin{array}{r}226787102 \\
170\end{array}$ \\
\hline Predation & 135 & 66 & 66108 & $\begin{array}{rl}66 & 105 \\
127\end{array}$ & & 106 & & & & & & & & \\
\hline Forebay Approach & & & 21 & 3640 & 2435 & 3038 & 1727 & $\begin{array}{r}1113 \\
124\end{array}$ & 56 & 37137 & & & & \\
\hline Horizontal Dist. & & & & 3640 & 2435 & 1938 & & $\begin{array}{r}1112 \\
13\end{array}$ & 456 & $\begin{array}{r}137 \\
137 \\
\end{array}$ & & $\begin{array}{r}174 \\
179180 \\
\end{array}$ & $\begin{array}{l}175 \\
176\end{array}$ & \\
\hline Vertical Dist. & & & & 40 & 24 & 1930 & 2748 & $\begin{array}{r}1112 \\
124\end{array}$ & 4 & 1 & & 174 & 175 & \\
\hline Diel Dist. & & & 21 & 40 & 2435 & 19 & 48 & $\begin{array}{r}1112 \\
13\end{array}$ & 456 & $\begin{array}{r}137 \\
137\end{array}$ & & $\begin{array}{r}174179 \\
180\end{array}$ & $\begin{array}{l}175 \\
176\end{array}$ & \\
\hline
\end{tabular}

${ }^{1}$ INCA Engineers, Inc. et al. (1999)

${ }^{2}$ Lee, R. and D. Schwartz (2003) 


\subsection{Fish Distribution and Movement in Forebays}

\subsection{Forebay Approach Patterns}

Before 1995, there are no data on fish distribution and movements in the forebays of Bonneville Dam (Giorgi and Stevenson 1995). After 1995, forebay research occurred in two primary periods:

- 1995-1998: approach patterns and vertical and horizontal distributions

- 1999-present: first detection among the three main passage routes (B1, spillway, and B2), travel rates, and residence times.

Data on fish distribution and movement began to be collected in earnest in 1995 as part of the USACE Portland District's Program on Surface Flow Bypass. Forebay research to support the Surface Flow Bypass Program was undertaken in 1995-1998 using radio telemetry to determine approach paths and hydroacoustic techniques to determine vertical and horizontal distributions. The radio telemetry tool also provided data on travel rates, distribution among the three forebays, and residence times during 1995-1998. However, because of small sample sizes, these data are not as robust as radio telemetry data collected from 1999 to the present and thus are not used in favor of the latter data on those topics. Forebay migration characteristics were studied as part of the extensive radio telemetry efforts in 1999present for the program on Total Project Fish Passage Efficiency. These research efforts provided useful data on travel rates between the upriver release locations and Bonneville Dam, distribution among the three migration routes, and forebay residence times.

\subsection{Forebay Approach Patterns}

In 1996, 1997, and 1998, investigators coupled data describing the location of radio-tagged smolts upstream of Boat Rock with data identifying the location where these tagged fish passed the dam (Holmberg et al. 1996; Hensleigh et al. 1999; Hansel et al. 1999). Most radio-tagged smolts moved quickly downstream to Boat Rock where they branched into the three main forebay regions of Bonneville Dam. Lateral smolt distribution on approach to Bonneville Dam influenced whether the ultimate passage route was B1, the spillway, or B2 (e.g., Hensleigh et al. 1999). Fish distributed to the south side of the channel were likely to pass the dam at B1 or the spillway (e.g., Figures 2.1 and 2.2). Fish distributed to the north side of the channel were likely to pass the dam at B2 or the spillway.

Smolt distribution in the narrow river channel between the Bridge of the Gods and Boat Rock was somewhat species-specific and always variable depending on river conditions (e.g., Hensleigh et al. 1998). Yearling Chinook salmon and steelhead were generally distributed in the southern portion of the channel (Figures 2.1 and 2.2). Subyearling Chinook salmon tended to migrate in the northern portion of the channel (Figure 2.3). 


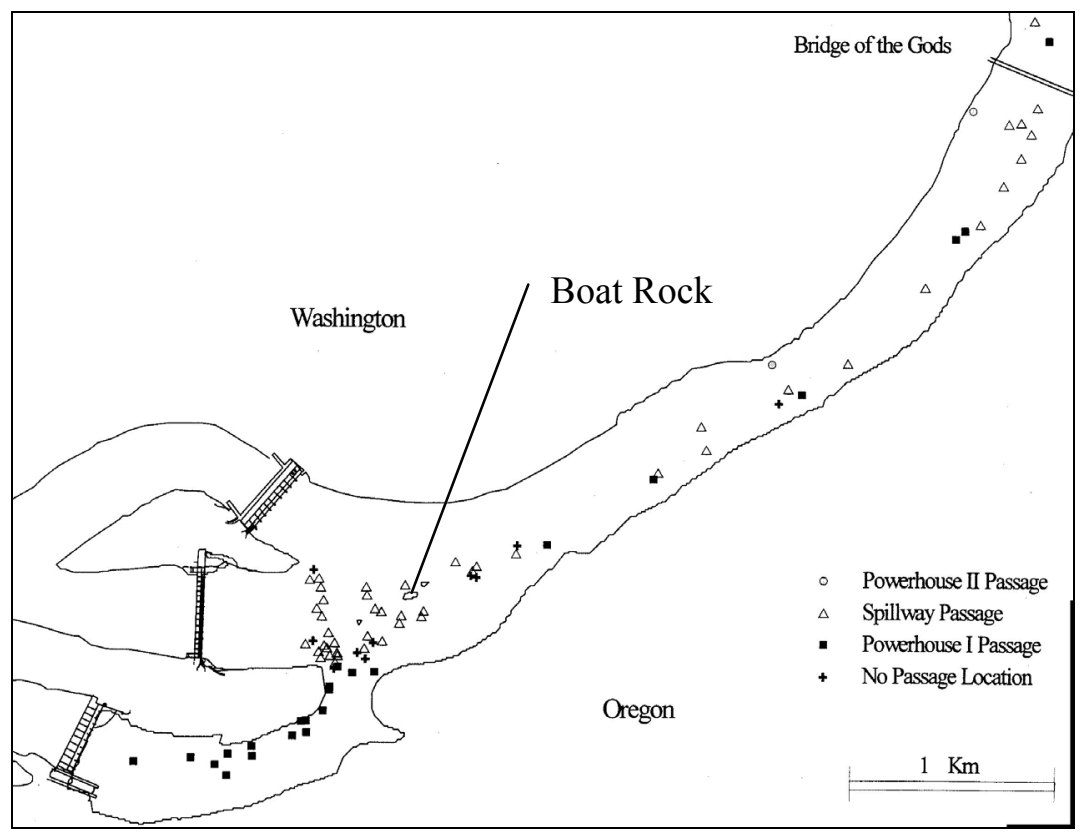

Figure 2.1. Approach Locations and Final Passage Routes of 70 Radio-Tagged Hatchery Steelhead at Bonneville Dam in Spring 1997. During the study, flows were about $80 \mathrm{kcfs}$ at B1, $110 \mathrm{kcfs}$ at B2, and 100-365 kcfs at the spillway. Data are from Hensleigh et al. (1999; Figure 17).

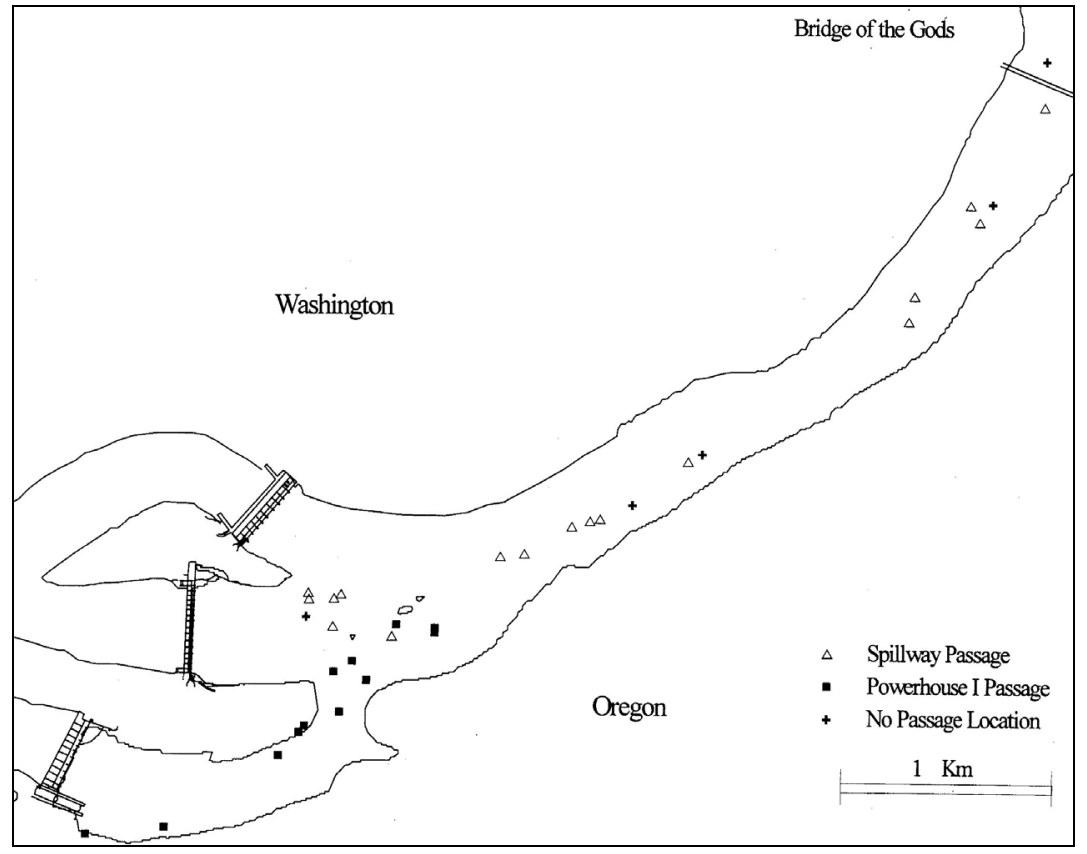

Figure 2.2. Approach Locations and Final Passage Routes of 46 Radio-Tagged Yearling Chinook Salmon at Bonneville Dam in Spring 1997. Spring 1997 flows were as described in Figure 21 of Hensleigh et al (1999). Data are from Hensleigh et al. (1999; Figure 18). 


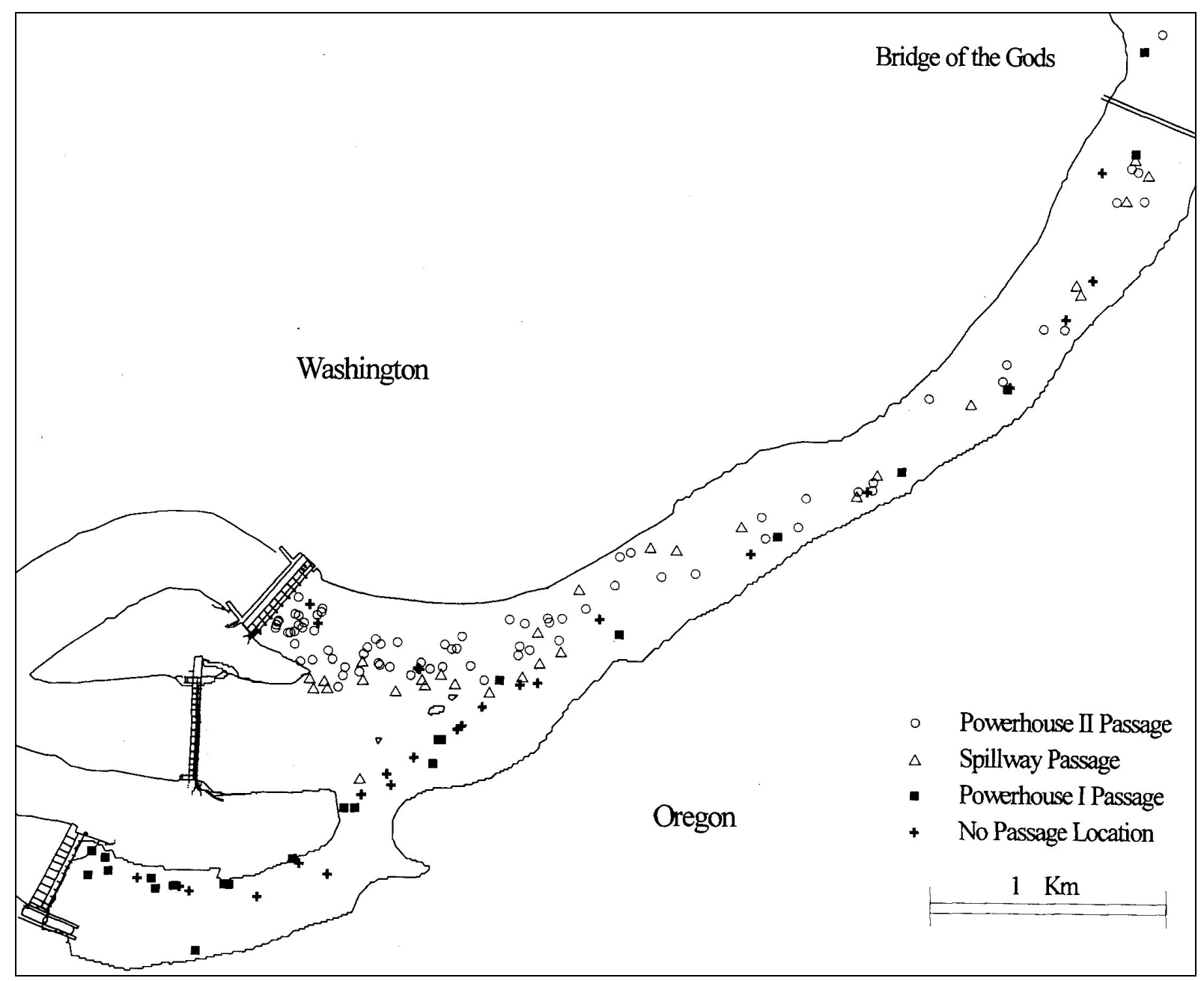

Figure 2.3. Approach Locations and Final Passage Routes of 77 Radio-Tagged Subyearling Chinook Salmon at Bonneville Dam in Summer 1997. During the study, flows were about $80 \mathrm{kcfs}$ at B1, $110 \mathrm{kcfs}$ at B2, and 85-120 kcfs at the spillway. Data are from Hensleigh et al. (1999; Figure 19).

\subsection{Vertical Distributions}

In spring and summer 1996 and 1997 at B1 and B2, researchers used mobile hydroacoustics to study forebay vertical distributions. Vertical distribution varied between B1 and B2, day and night, spring and summer, and study years (Ploskey et al. 1998 and BioSonics 1998). Vertical distribution at B1 was generally 5 to $16 \mathrm{ft}$ deeper than at B2 (Table 2.1). This might be due to the deeper bathymetry at B1 than B2. Fish were distributed deeper during day than night, except during spring 1996 (Table 2.1). This is contrary to typical behavior observed at mainstem dams, which is for fish to be deeper at night than day (e.g., Thorne and Johnson 1993). Spring migrants were generally distributed deeper than summer migrants, especially in 1997 (Table 2.1). 
Table 2.1. Vertical Distribution Expressed as Approximate Depth ( $\mathrm{ft}$ ) of the Uppermost $80^{\text {th }}$ Percentile. Data are from mobile hydroacoustic transects 30-60 ft from the dam in spring and summer 1996 by Ploskey et al. (1998) and 1997 by BioSonics (1998).

\begin{tabular}{ccccc}
\hline Year & Season & Powerhouse & Day & Night \\
\hline 1996 & Spring & B1 & 39 & 43 \\
& & B2 & 34 & 67 \\
& \multirow{2}{*}{ Summer } & B1 & 46 & 23 \\
& & B2 & 30 & 23 \\
\hline \multirow{2}{*}{1997} & \multirow{2}{*}{ Spring } & B1 & 69 & 59 \\
& & B2 & 69 & 59 \\
& \multirow{2}{*}{ Summer } & B1 & 36 & 30 \\
& & B2 & 28 & 23 \\
\hline
\end{tabular}

Vertical distribution can change as fish get closer to each powerhouse. Ploskey et al. (1998) noted that the depth of the 80th percentile was 6 to $17 \mathrm{ft}$ shallower at transects 30 to $60 \mathrm{ft}$ from B1 than at transects 150 to $225 \mathrm{ft}$ from the dam. On the other hand, at B2 Ploskey et al. (1998) noticed that vertical distribution in the forebay at night got deeper the closer one got to the dam (80th percentile had a 21-ft change). They surmised this was probably due to rapid increases in forebay depth near B2 and increasing downward currents. BioSonics (1998) observed that vertical distribution shifted downward in both B1 and B2 forebays as they got closer to the powerhouses in spring 1997, but the opposite was true in summer 1997. Thus, vertical distributions changed as smolts neared the powerhouses, but this change was variable seasonally and annually with no consistent trend.

\subsection{Horizontal Distributions}

In 1996, Ploskey et al. (1998) studied horizontal distribution with mobile and fixed hydroacoustic surveys at both powerhouses. In 1997, BioSonics (1998) and Hensleigh et al. (1999) applied mobile hydroacoustic and radio telemetry techniques, respectively. The following horizontal distribution data reflect trends where fish were actually located at the dam. They have not been adjusted for turbine operations. Most available units at Bonneville Dam, however, were on in spring 1996 and 1997.

In 1996 at B1, baseline data on fish distributions from mobile hydroacoustics in the B1 forebay indicated that the highest average fish densities occurred upstream of units 4 through 6 in spring and upstream of units 4, 5, 6, 8, and 9 in summer (Ploskey et al. 1998). These data supported the location of a prototype surface collector in the central part of B1.

In 1997 at B1, fish tended to concentrate in the forebay of the central and northern sections of the dam (BioSonics 1998), confirming the finding by Ploskey et al. (1998). Similarly, Hensleigh et al. (1999) reported a proportionately high number of contacts of radio-tagged fish in the same region of the B1 forebay, which may reflect a concentration of fish there since residence times were short (Table 2.2). 
In 1996 at B2, smolt densities were highest at the south end of the forebay (Ploskey et al. 1998). Fish passage rates were significantly higher at the sampled intakes at units 11,12, 13, and 18 than at the others. These data indicated that the south end of the powerhouse where the sluice chute is currently located is, in general, an appropriate location for a surface bypass because of the horizontal concentration of fish there. Furthermore, they observed dense concentrations of smolts near the face of B2, suggesting that large numbers of smolts should encounter a corner collector entrance at its current location next to the powerhouse.

In 1997 at B2, fish density was high in the south eddy (BioSonics 1998), as observed by Ploskey et al. (1998) in 1996. The distribution of radio-tagged subyearling Chinook salmon in the B2 forebay in 1997 appeared to shift to the south toward the sluice chute when it was open (Hensleigh et al. 1999).

\subsection{First Detections}

Table 2.2 summarizes studies of first detection, travel rate, and residence times in the forebay of Bonneville Dam from 1999 to 2005. This research was extensive as thousands of yearling and subyearling Chinook salmon and steelhead were typically tagged each year during this period for the purposes of survival studies, except for 2003 when no study was conducted.

The pattern for first detection of radio-tagged fish among the three main routes (B1, spillway, B2) was dependent on project operations and discharge. In 1999-2000, 29\% of the fish were first detected at B1, whereas during 2001-2005 only 4\%-9\% of the total passing Bonneville dam was detected first there (Table 2.2). At the spillway, 23\%-57\% of first detections were recorded. The highest percentages of first detections were attained at B2 (23\%-71\% of total first detections).

\subsection{Travel Rates}

Travel rates from the release sites upstream at John Day and The Dalles dams were comparable among the three species outfitted with radio transmitters (Table 2.2). The ranges for the median rates of the annual studies were $1.8-2.7,2.5-2.8$, and $1.5-2.3 \mathrm{~km} / \mathrm{h}$ for yearling Chinook salmon, steelhead, and subyearling Chinook salmon, respectively.

\subsection{Residence Times}

Forebay residence time was typically an order of magnitude longer at B1 than at either the spillway or B2 (Table 2.2). In the B1 forebay, residence times ranged from 0.9 to $9.7 \mathrm{~h}$ depending on species and study-year. In the spillway forebay, the range was $0.03-1.3 \mathrm{~h}$. In the B2 forebay, tagged fish resided for 0.1 to $3.9 \mathrm{~h}$, except for the $6.4 \mathrm{~h}$ observed for steelhead in 2000 . 
Table 2.2. Fish Distribution, Travel Rate, and Residence Times in the Forebay of Bonneville Dam from 1999 to 2004. Studies were not conducted in 2003. Steelhead smolts were not tagged in 2001. Chinook salmon subyearlings were not tagged in 1999.

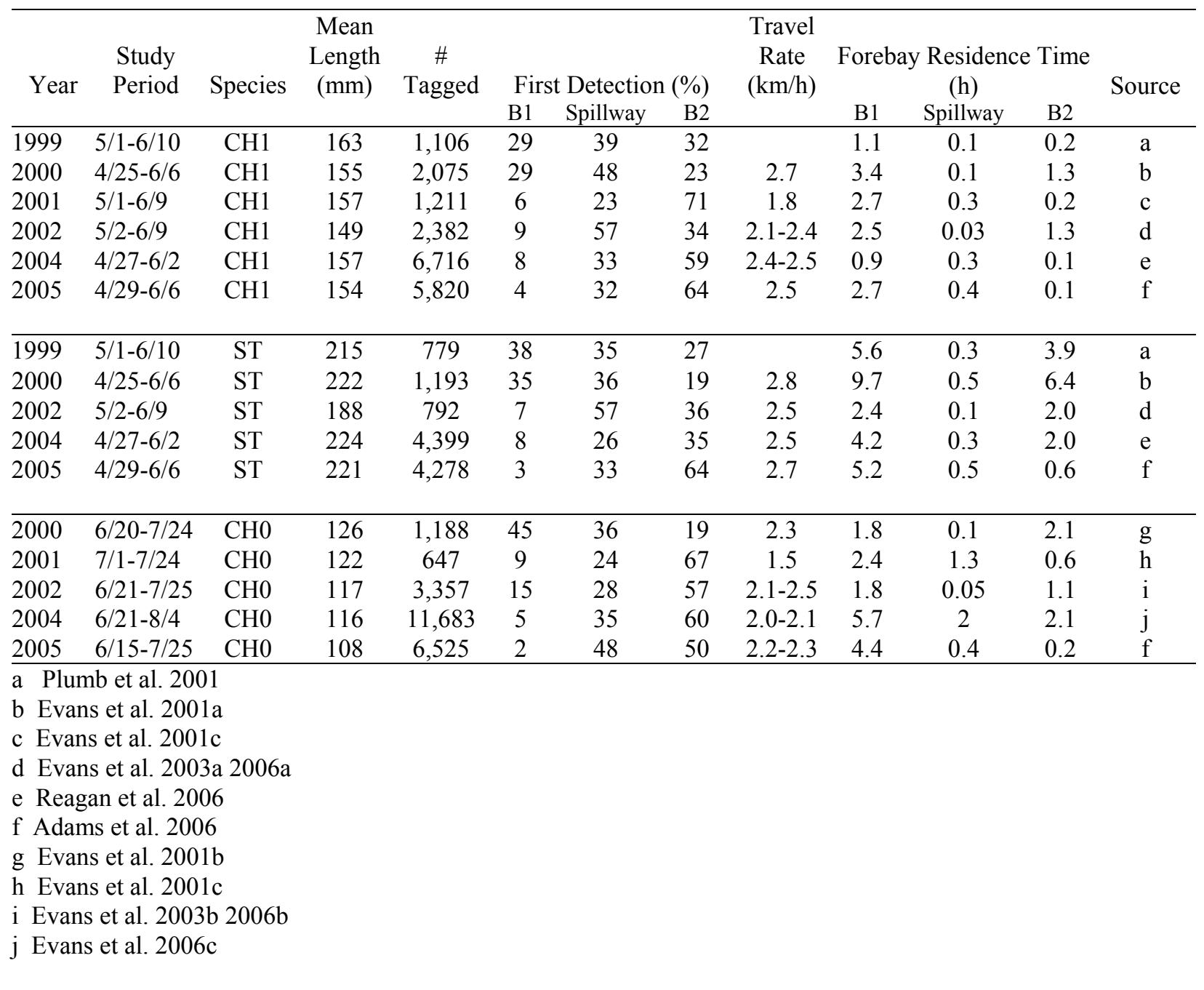

\subsection{Synthesis and Conclusions}

Two new metrics were developed to synthesize data on forebay migration characteristics: Bulk Flow Effectiveness and Movement Among Areas.

Bulk Flow Effectiveness is the proportion of first detections for a given area (B1, Spill, or B2) divided by the proportion of water discharged at that area. Values near 1 indicate radio-tagged fish were following the bulk flow into that particular area. Values less than 1 indicate radio-tagged fish were not following bulk flow. Values greater than 1 indicate fish might have been attracted to the bulk flow. Bulk flow effectiveness data is plotted in Figure 2.4 for studies conducted between 1999 and 2005. 


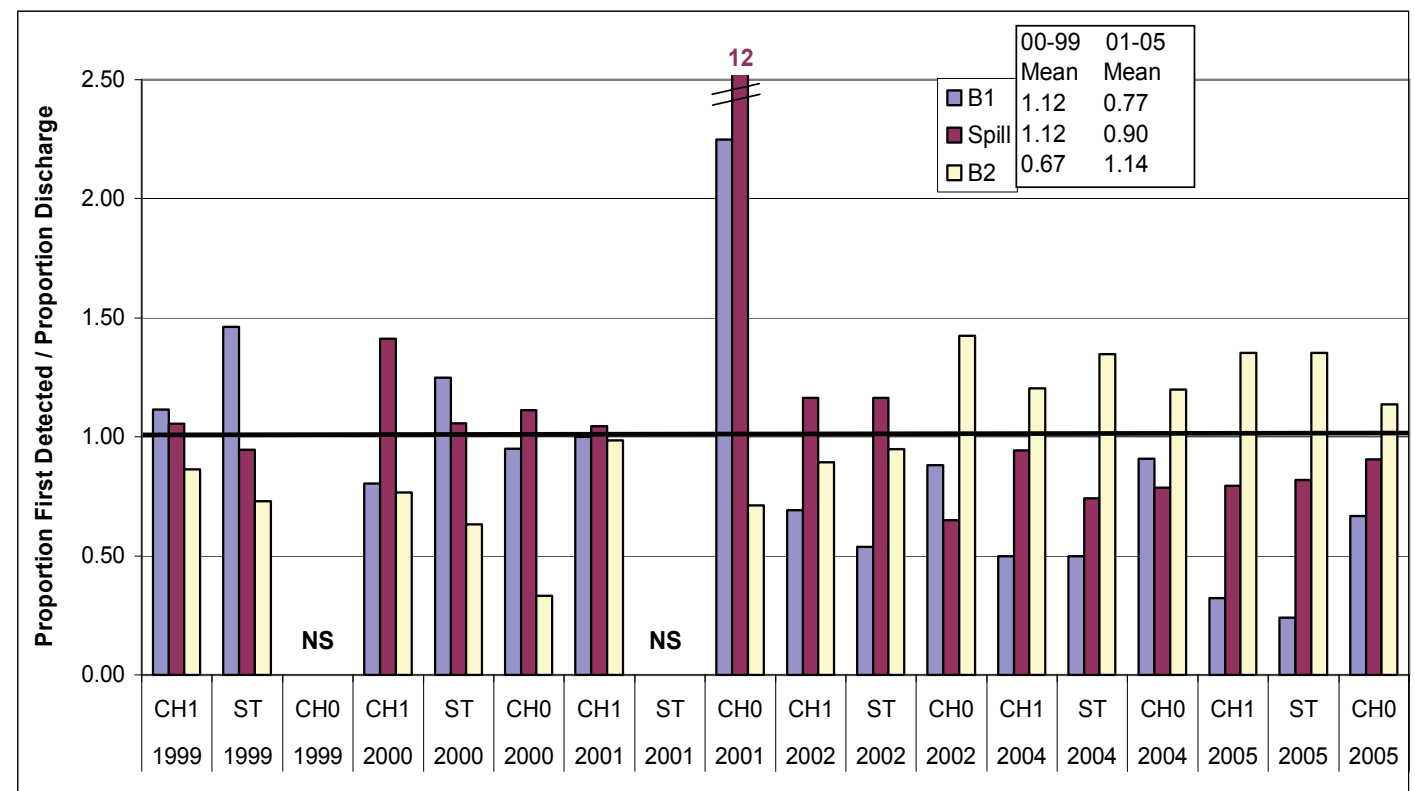

Figure 2.4. Bulk Flow Effectiveness for Bonneville Dam 1st and 2nd Powerhouse and Spillway Plotted from 1999 to 2005 Data

Movement between Areas Indicator is the proportion of first detections for a given area (B1, Spill, or B2) divided by the proportion of fish that passed at that area. Values near 1 indicate radio-tagged fish were staying in a particular area once they entered it. Values less than 1 indicate some of the radio-tagged fish moved to that particular area to pass the dam. Values greater than 1 indicate some of the fish moved out of that particular area to pass the dam. Data on movement between areas (B1, B2, and Spillway) is charted in Figure 2.5, and means near 1 indicate that movement from one area to another is low.

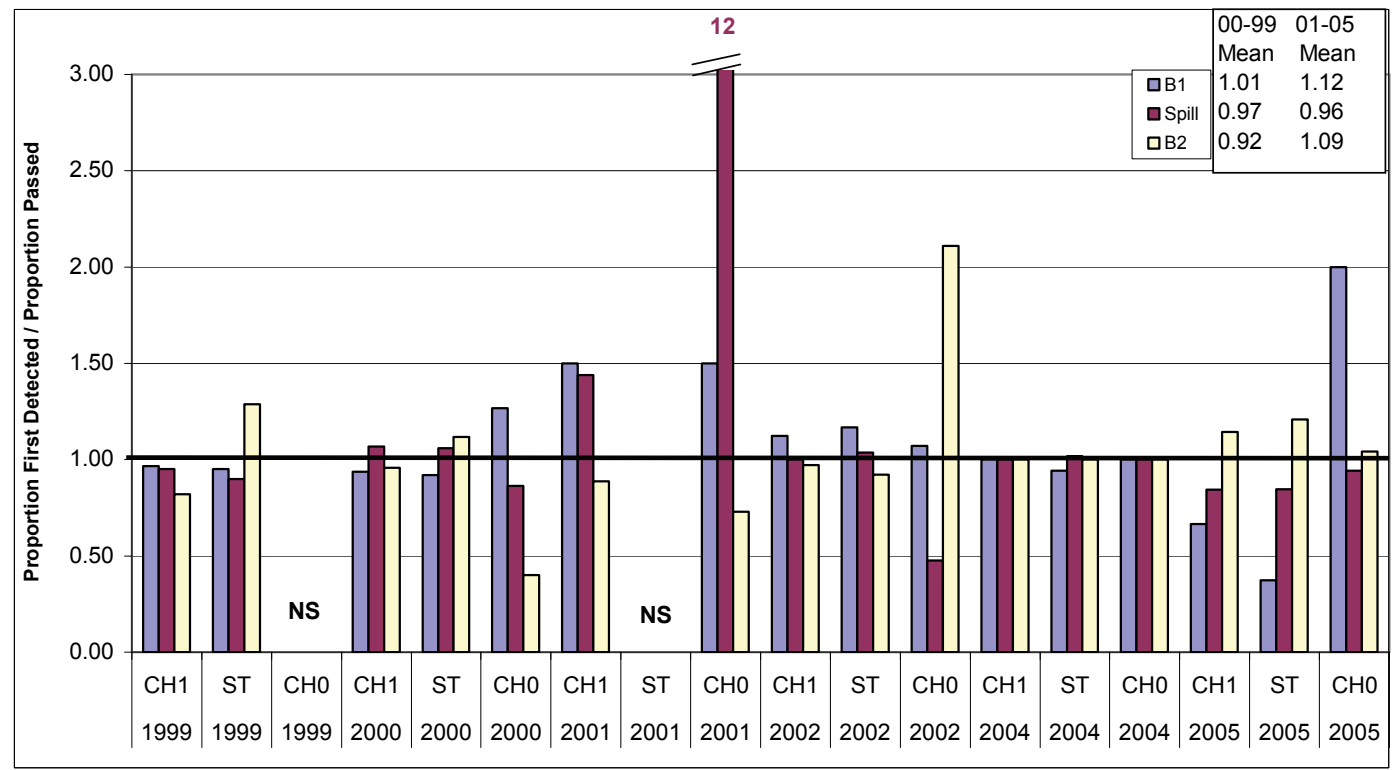

Figure 2.5. Movement between Areas Data for Bonneville Dam 1st and 2nd Powerhouse and Spillway Plotted from 1999-2005 Data 
- Fish approach the dam following bulk flow, and the split in fish passage is correlated with the split in discharge among the corresponding structures. Therefore, dam operations affect fish movements in the forebay and where they subsequently pass the dam.

- Vertical distributions of fish upstream of dam structures are highly skewed toward the water's surface and, therefore, surface flow bypasses have the potential to be efficient and effective.

- Horizontal distribution in the forebays of the two powerhouses revealed areas of concentration. At B1, these areas of concentration were upstream of Units 4-6 in spring and upstream of units 4, $5,6,8$, and 9 in summer. At B2, fish concentrated primarily at the south end of the forebay near or in a large eddy and in a smaller eddy on the north side of the forebay.

- Average travel rates (km / hours) from release sites to the project were relatively quick:

\begin{tabular}{||ll|}
\hline \multicolumn{1}{|c|}{ Species / Age Class } & Travel Rate \\
\hline \hline Yearling Chinook salmon & 2.3 \\
Steelhead & 2.6 \\
Subyearling Chinook salmon & 2.1 \\
\hline
\end{tabular}

- Average hourly residence times in forebays were short except for B1 when B2 had the generation priority:

\begin{tabular}{||lccc||}
\hline \multicolumn{1}{|c}{ Species / Age Class } & B1 & Spillway & B2 \\
\hline \hline Yearling Chinook salmon & 2.2 & 0.2 & 0.5 \\
Steelhead & 5.4 & 0.3 & 3.0 \\
Subyearling Chinook salmon & 4.4 & 0.4 & 0.2 \\
\hline
\end{tabular}




\subsection{Juvenile Salmonid Passage}

Section 3.1 of this chapter describes factors that control project operations and affect major fish passage metrics at Bonneville Dam. Section 3.2 describes project-wide fish-passage metrics, as estimated by fixed-aspect hydroacoustic and radio-telemetry methods. The approach was to tabulate estimates of all major passage metrics by method and then to describe effects in subsections. Under Section 3.2, we examine detailed effects of flow distributions among routes on spillway efficiency (Subsection 3.2.1), spillway effectiveness (Subsection 3.2.2), powerhouse passage proportions (3.23), surface-passage outlet efficiency and effectiveness (3.2.4), and fish-passage efficiency (3.2.5). Section 3.2 relies exclusively on five years of project-wide study, conducted from 2000 through 2005 (excluding 2003). Remaining sections of this chapter review studies on surface-flow outlets (Section 3.3), fish-guidance efficiency (3.4), and fine-scale passage distribution studies including horizontal, vertical, and diel distribution (3.5).

\subsection{Project Operations and Fish Passage}

During any year or passage season, there are predictable and unpredictable circumstances that affect the passage of fish at a hydropower project. Water availability and demand for electricity are of prime importance and cannot be rigorously controlled. Project operations, such as spill level or powerhouse priority, may be dictated by policies or experimental designs aimed at elucidating patterns in fish passage under different operating regimes. In addition, equipment issues, such as turbine outages, are important in determining operating regimes. Operations are more flexible at average or below-average river flows and diminish as river flow approaches flood stage.

During the five years (2000-2005, excluding 2003) of the Total Project Fish Passage Efficiency Study, there were a variety of hydrologic conditions, power demands, and experimental circumstances that have complicated the understanding of fish passage. In 2000, B1 was given generation priority while a prototype surface collector (PSC) installed across 18 intakes of Units 1 through 6 was evaluated. After 2000 , there was no PSC and power generation priority was switched to B2. There was a drought and high demand for electricity from outside the region in 2001, and this resulted in severely restricted spill, both in level and duration. During 2001, the spill discharge (around $50 \mathrm{kcfs}$ ) did not vary with time of day (i.e., higher spill at night) as is normally the case. The following year, 2002, was a fairly high water year. During that year, three different spill levels (two in daytime and one at night) were tested. The gatewell slots of Unit 15 were modified for 2001 and those of Unit 17 were modified for 2002, and modifications to increase flow up submerged traveling screens and FGE were present thereafter. In some years, specific turbine units were operated to facilitate netting, including netting for intake modification tests at B2.

In 1996 and 1998, the B2 sluice chute was tested as a fish-passage route and was opened or closed according to a prescribed sampling design. In many other years it was opened to pass trash. In 2004, the B2 sluiceway channel was modified as the B2 Corner Collector to route water from the forebay to the downstream tip of Cascades Island, and it operated all spring and summer of 2004 and 2005, unlike earlier years when it operated rarely. During B2CC operations in 2004, TIEs were not installed at units 11-14 on the south half of B2 to increase lateral flow toward the south and the $\mathrm{B} 2 \mathrm{CC}$, a major departure from previous operations. In 2005, the configuration of the project was similar to that in 2004, except that $\mathrm{B} 1$ sluiceway gates $1 \mathrm{C}, 3 \mathrm{C}$, and $6 \mathrm{C}$ were opened and sampled whereas in 2004 gates $2 \mathrm{C}$, 4C, and $6 \mathrm{C}$ 
were opened and were sampled. All of these factors make comparisons across passage years difficult but some generalizations are possible that provide insight regarding future study needs and operational/design modifications to improve passage conditions for juvenile salmon and steelhead.

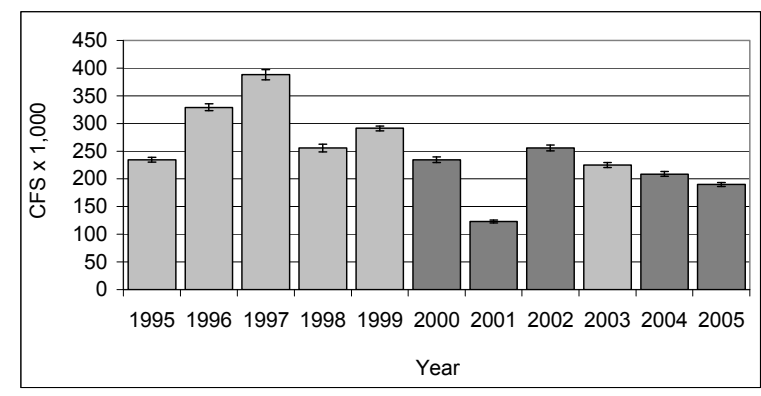

Figure 3.1. Total Discharge from The Dalles Dam, which Constitutes Most Inflow to the Bonneville Dam Project, for the Last Ten Fish Passage Seasons (April through July). (Data are from Data Access in Real Time http://www.cbr.washington.edu/dart/). Dark gray bars indicate years with Project fish-passage efficiency estimates.

\subsection{Project-Wide Passage Metrics}

We did not truncate sampling seasons for hydroacoustic or radio-telemetry studies so that estimates of passage metrics would be for the same periods of time. We also did not pool species-specific radio telemetry estimates to make comparisons with run-of-river (non-species specific) hydroacoustic estimates. Those truncated and smoothed comparisons are available for 2001 (Ploskey et al. 2002c; Evans 2001c; Evans 2001d), 2002 (Evans et al. 2003a and 2006a), 2004 (Evans et al. 2006c; Reagan et al. 2006), and 2005 (Ploskey et al. 2006c; Adams et al. 2006). A direct comparison of the hydroacoustic estimates and radio telemetry estimates can help to better understand the strengths and weaknesses of each method. This insight may be used to develop more accurate passage estimates in the future. These comparisons are useful to see how well the methods compare, but not for much else, because the exercise throws out a lot of data to match the sampling seasons and applies weighting factors that are incomplete because they cannot account for untagged species in the run at large. Pooling steelhead and yearling Chinook salmon estimates gives up the species-specific estimates that represent a strength of radio telemetry. Readers should remember that estimates by the two methods are based upon samples of different populations in spring. Differences in estimates may result from differences in sampled species composition in spring, temporal differences in either season, and bias, which is independent of the precision of estimates. Bias is much more insidious than lack of precision because it is very difficult to identify or quantify without detailed and very accurate information about detectability. However, for the most part, estimates comport fairly well for radically different methods that did not sample the same composition of fish.

Because of the variety of fish-passage routes associated with Bonneville Dam, a correspondingly large number of passage metrics have been developed to measure the efficiency and effectiveness for passing juvenile salmonids. Definitions of all metrics used in this chapter are presented in Table 3.1. 
Table 3.1. Definitions of Major Fish-Passage Metrics. Efficiency and effectiveness metrics are relative to the entire project unless a subscript indicates otherwise. Names of individual variables are underlined when used in equations to avoid term confusion.

\begin{tabular}{|c|}
\hline Project passage $=($ Spillway + B1 Sluiceway + B2CC + B1 Guided + B1 Unguided + B2 Guided + B2 Unguided $)$ \\
\hline $\begin{array}{l}\text { Project passage } \\
\text { Variable names refer to the route of passage. } \\
\text { fish are screened from turbine intakes and routed to a juvenile bypass system (JBS) channel. Unguided fish passed through } \\
\text { turbines. Variables may be zero if a route was not open in a specific year. }\end{array}$ \\
\hline 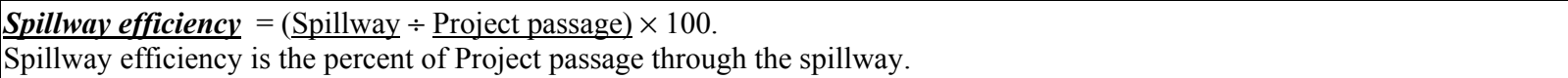 \\
\hline $\begin{array}{l}\text { Fish-passage efficiency }=[(\underline{\text { Spillway }}+\underline{B 1 \text { Sluiceway }}+\underline{\mathrm{B} 2 \mathrm{CC}}+\underline{\mathrm{B} 1 \text { Guided }}+\underline{\mathrm{B} 2 \text { Guided }}) \div \underline{\text { Project passage }}] \times 100 \text {. Fish- } \\
\text { passage efficiency }(\mathrm{FPE}) \\
\text { is the percentage of fish passing the Project by non-turbine routes. Variables may be zero if a route } \\
\text { was not }\end{array}$ \\
\hline
\end{tabular}

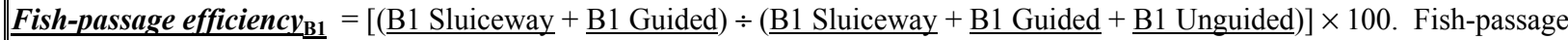
efficiency $_{\mathrm{B} 1}\left(\mathrm{FPE}_{\mathrm{B} 1}\right)$ is the percentage of fish passing B1 by non-turbine routes. Guided and Unguided terms do not apply when in-turbine screens were not deployed, as in 2004 and 2005, when this metric was equivalent to B1 Sluiceway Efficiency ${ }_{B I}$. If the sluiceway was not sampled, this metric equals fish-guidance efficiency ${ }_{\mathrm{B} 1}$.

Fish-guidance efficiency $\left._{\underline{B} 1}=[\underline{B 1 \text { Guided }}) \div(\underline{B 1 \text { Guided }}+\underline{B 1 \text { Unguided }})\right] \times 100$. Fish-guidance efficiency $y_{\mathrm{B} 1}\left(\mathrm{FGE}_{\mathrm{B} 1}\right)$ is the percentage of fish in B1 turbines that were intercepted by intake screens and routed to the B1 JBS channel.

Fish-guidance efficiency $_{\underline{B} 2}=[\underline{B} 2$ Guided $) \div(\underline{B} 2$ Guided $+\underline{B} 2$ Unguided $\left.)\right] \times 100$. Fish-guidance efficiency ${ }_{\mathrm{B} 2}\left(\mathrm{FGE}_{\mathrm{B} 2}\right)$ is the percentage of fish in B2 turbines that were intercepted by intake screens and routed to the B2 JBS channel.

Fish-passage efficiency $\underline{B}_{2}=[(\underline{B} 2 \mathrm{CC}+\underline{B} 2$ Guided $) \div(\underline{B} 2 \mathrm{CC}+\underline{B} 2$ Guided $+\underline{B} 2$ Unguided $)] \times 100$. Fish-passage efficiency ${ }_{\mathrm{B} 2}$ $(\mathrm{B} 2 \mathrm{FPE})$ is the percentage of fish passing $\mathrm{B} 2$ by non-turbine routes. If the $\mathrm{B} 2 \mathrm{CC}$ was not operational, this metric equals $\mathrm{FGE}$ (above).

$\underline{\text { Fish-passage efficiency }}_{\underline{B 2} \text { \& Spillwav }}=[(\underline{\text { Spillway }}+\underline{\mathrm{B} 2 \mathrm{CC}}+\underline{\mathrm{B} 2 \text { Guided }}) \div(\underline{\text { Spillway }}+\underline{\mathrm{B} 2 \mathrm{CC}}+\underline{\mathrm{B} 2 \text { Guided }}+\underline{\mathrm{B} 2 \mathrm{Unguided}})] \times$ 100.

Fish-passage efficiency ${ }_{\mathrm{B} 2 \& \text { Spillway }}$ is the percentage of fish passing B2 and the spillway by non-turbine routes. This metric ignores B1 passage, which was low from 2001 through 2005 because of an assigned B2 generation priority.

$\underline{\text { SFO efficiency }}=(\underline{B 1}$ Sluiceway $+\underline{B} 2 \mathrm{CC}) \div$ Project passage $\times 100$.

Surface-flow-outlet efficiency (SFO efficiency) is the percentage of fish passing the project through surface flow outlets, including B1 sluiceway and B2CC.

B1 sluiceway efficiency $=\underline{B 1}$ Sluiceway $\div$ Project passage $\times 100$.

B1 Sluiceway efficiency is the percent of fish passing the project through the B1 sluiceway.

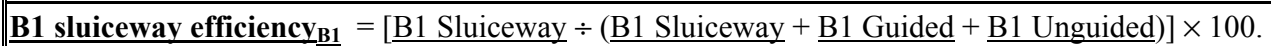

$\mathrm{B} 1$ sluiceway efficiency $\mathrm{B}_{1}$ is the percentage of fish passing B1 through the B1 sluiceway. This is the same as B1 FPE when no screens were deployed in turbines (2004 and 2005).

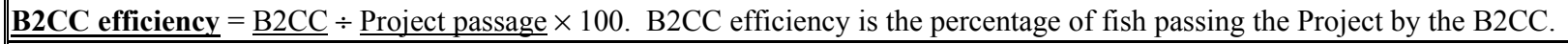

$\underline{B 2 C \boldsymbol{C} \text { efficiency }} \underline{\mathrm{B} 2}=[\underline{\mathrm{B} 2 \mathrm{CC}} \div(\underline{\mathrm{B} 2 \mathrm{CC}}+\underline{\mathrm{B} 2 \text { Guided }}+\underline{\mathrm{B} 2 \text { Unguided })}] \times 100$

$\mathrm{B} 2 \mathrm{CC}$ efficiency $\mathrm{B}_{\mathrm{B} 2}$ is the percentage of fish passing B2 through the B2CC after 2003.

$\underline{\text { Spillway effectiveness }}=\underline{\text { Spillway efficiency }} \div$ Percent Spill

Spillway effectiveness is the ratio of spillway efficiency to the percent of Project discharge through the spillway.

$\underline{\text { SFO effectiveness }}=\underline{S F O \text { efficiency }} \div$ Percent SFO Flow

Surface-flow-outlet effectiveness (SFO effectiveness) is the ratio of percent fish passage through surface flow outlets to the percent of Project flow through the same outlets (Percent SFO Flow).

$\underline{B} 1$ sluicewav effectiveness $=\underline{B 1}$ Sluiceway efficiency $\div \underline{\text { Percent B1 sluiceway Flow }}$

B1 sluiceway effectiveness is the ratio of the percentage of fish to the percentage of flow passing the Project through the B1 sluiceway.

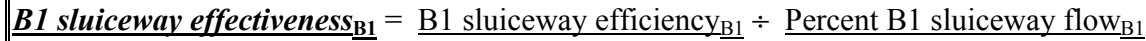

B1 sluiceway effectiveness ${ }_{\mathrm{B} 1}$ is the ratio of the percentage of fish to the percentage of flow passing B1 through the B1 sluiceway.

$\underline{B 2 C C \text { effectiveness }}=\underline{B 2 C C \text { Efficiency } \div \text { Percent B2CC Flow }}$

$\mathrm{B} 2 \mathrm{CC}$ effectiveness is the ratio of the percentage of fish to the percentage of flow passing the Project through the B2CC.

$\underline{B 2 C C \text { effectiveness }} \underline{\mathrm{B}}_{2}=\underline{\mathrm{B} 2 \mathrm{CC} \text { Efficiency }} \underline{\mathrm{B} 2}_{2} \div \underline{\text { Percent B2CC Flow }}_{\mathrm{B} 2}$

$\mathrm{B} 2 \mathrm{CC}$ effectiveness $\mathrm{B}_{\mathrm{B}}$ is the ratio of the percentage of fish to the percentage of flow passing B2 through the B2CC. 
In 2006, Ploskey et al. (2006b) re-analyzed the five years of project-wide hydroacoustic data and compiled estimates of all major fish passage metrics for spring and summer in Tables (Tables 3.2 and 3.3), and Adams et al. (2006) compiled the estimates based upon radio telemetry (Tables 3.4 and 3.5).

Table 3.2. Estimates of Major Flow and Passage Metrics $\pm 1 / 295 \%$ Confidence Limits for Spring Based upon Hydroacoustic Sampling in 2000, 2001, 2002, 2004, and 2005. Headings list some important differences in conditions or sampling methods among years. STS = submerged traveling screen. After a table in Ploskey et al. (2006b).

\begin{tabular}{|c|c|c|c|c|c|}
\hline Major Passage Metric & $\begin{array}{c}2000 \\
\text { PSC at Units 1-6 } \\
\text { B1 Priority } \\
\text { No Sluiceway } \\
\text { Sampled; } \\
\text { No STS in PSC } \\
\text { Screens in 7-10 }\end{array}$ & $\begin{array}{c}2001 \\
\text { Severe Drought } \\
\text { B2 Priority } \\
\text { No Sluiceway } \\
\text { Sampled; } \\
\text { B1 Screens } \\
\text { Installed }\end{array}$ & $\begin{array}{c}2002 \\
\text { B2 Priority } \\
\text { B1 Sluiceway } \\
\text { Sampled; } \\
\text { B1 Screens } \\
\text { Installed }\end{array}$ & $\begin{array}{c}2004 \\
\text { B2 Priority } \\
\text { B1 Sluiceway \& } \\
\text { B2CC Sampled } \\
\text { No B1 Screens }\end{array}$ & $\begin{array}{c}2005 \\
\\
\text { B2 Priority } \\
\text { B1 Sluiceway \& } \\
\text { B2CC Sampled } \\
\text { No B1 Screens }\end{array}$ \\
\hline Dates Sampled & $4 / 20-6 / 01$ & $4 / 20-6 / 05$ & $4 / 20-6 / 02$ & $4 / 15-5 / 31$ & $4 / 16-5 / 31$ \\
\hline B1 Percent of Project Flow & $37.8 \%$ & $7.5 \%$ & $12.3 \%$ & $12.6 \%$ & $11.6 \%$ \\
\hline B1 Percent of Project Passage & $33.2 \%$ & $6.8 \%$ & $17.9 \%$ & $16.8 \pm 0.9 \%$ & $16.3 \pm 0.6 \%$ \\
\hline Spillway Percent of Project Flow & $31.5 \%$ & $14.7 \%$ & $44.6 \%$ & $33.5 \%$ & $40.3 \%$ \\
\hline Spillway Efficiency & $47 \pm 0.1 \%$ & $15.0 \pm 0.2 \%$ & $54.0 \pm 0.5 \%$ & $41.2 \pm 0.9 \%$ & $39.7 \pm 1.1 \%$ \\
\hline B2 Percent of Project Flow & $32.1 \%$ & $78.2 \%$ & $42.6 \%$ & $51 \%$ & $48.2 \%$ \\
\hline B2 Percent of Project Passage & $20.3 \%$ & $78.5 \%$ & $27.9 \%$ & $42.0 \pm 1.2 \%$ & $44.1 \pm 1.6 \%$ \\
\hline Fish-Passage Efficiency & $80 \pm 0.1 \%$ & $63 \pm 0.3 \%$ & $79 \pm 0.1 \%$ & $74 \pm 1.2 \%$ & $73.4 \pm 2.0 \%$ \\
\hline Fish-passage efficiency ${ }_{B 1}$ & $67 \pm 0.1 \%$ & $49 \pm 2.3 \%$ & $58 \pm 0.4 \%$ & $33.3 \pm 2.0 \%$ & $37.4 \pm 0.8 \%$ \\
\hline Fish-guidance efficiency ${ }_{B 1}$ & $54 \pm 0.1 \%$ & $49 \pm 2.3 \%$ & $37 \pm 0.4 \%$ & N/A & N/A \\
\hline Fish-guidance efficiency ${ }_{\mathrm{B} 2}$ & $55 \pm 0.1 \%$ & $57 \pm 0.3 \%$ & $53 \pm 0.3 \%$ & $48 \pm 3.3 \%$ & $45.0 \pm 4.3 \%$ \\
\hline Fish-passage efficiency ${ }_{\mathrm{B} 2}$ & $55 \pm 0.1 \%$ & $57 \pm 0.3 \%$ & $53 \pm 0.3 \%$ & $64.0 \pm 2.1 \%$ & $62.8 \pm 3.9 \%$ \\
\hline Fish-passage efficiency ${ }_{\mathrm{B} 2} \&$ Spillway & N/A (B1 Priority) & $64 \pm 0.3 \%$ & $84 \pm 0.1 \%$ & $82 \pm 0.01 \%$ & $80.4 \pm 0.1 \%$ \\
\hline$\%$ of Project flow through surface flow outlets & N/A & N/A & 0.03 & $3.3 \%$ & $3.2 \%$ \\
\hline Surface-flow-outlet efficiency & N/A & N/A & $6.0 \pm 0.1 \%$ & $18.8 \pm 0.4 \%$ & $20.2 \pm 0.6 \%$ \\
\hline B1 Sluiceway efficiency & $\mathrm{N} / \mathrm{A}$ & N/A & 5.9 & $5.6 \pm 0.1 \%$ & $6.08 \pm 0.2 \%$ \\
\hline B1 sluiceway efficiency ${ }_{B 1}$ & N/A & N/A & $33.2 \pm 0.9 \%$ & $33.3 \pm 2.0 \%$ & $37.4 \pm 0.8 \%$ \\
\hline B2CC efficiency & N/A & N/A & N/A & $13.2 \pm 0.3 \%$ & $14.1 \pm 0.4 \%$ \\
\hline $\mathrm{B} 2 \mathrm{CC}$ efficiency $\mathrm{B}_{\mathrm{B} 2}$ & $\mathrm{~N} / \mathrm{A}$ & N/A & N/A & $31.4 \pm 1.4 \%$ & $31.9 \pm 2.0 \%$ \\
\hline Spillway effectiveness & $1.49 \pm 0.01$ & $1.02 \pm 0.00$ & $1.21 \pm 0.01$ & $1.13 \pm 0.03$ & $0.98 \pm 0.03$ \\
\hline Surface-flow-outlet effectiveness & N/A & N/A & $19.7 \pm 0.01$ & $5.7 \pm 0.12$ & $6.3 \pm 0.18$ \\
\hline B1 sluiceway effectiveness & N/A & N/A & $19.7 \pm 0.01$ & $10.1 \pm 0.23$ & $10.7 \pm 0.3$ \\
\hline $\mathrm{B} 1$ sluiceway effectiveness $\mathrm{B}_{\mathrm{B} 1}$ & $\mathrm{~N} / \mathrm{A}$ & N/A & $13.5 \pm 0.06$ & $7.6 \pm 0.5$ & $7.6 \pm 0.2$ \\
\hline B2CC effectiveness & N/A & $\mathrm{N} / \mathrm{A}$ & N/A & $4.8 \pm 0.1$ & $5.3 \pm 0.2$ \\
\hline $\mathrm{B} 2 \mathrm{CC}$ effectiveness $\mathrm{B}_{\mathrm{B}}$ & N/A & N/A & N/A & $5.8 \pm 0.03$ & $5.8 \pm 0.4$ \\
\hline
\end{tabular}


Table 3.3. Estimates of Major Flow and Passage Metrics $\pm 1 / 295 \%$ Confidence Limits for Summer Based on Hydroacoustic Sampling in 2000, 2001, 2002, 2004, and 2005. Headings list some important differences in conditions or sampling methods among years. After a table in Ploskey et al. (2006b). STS = submerged traveling screen.

\begin{tabular}{|c|c|c|c|c|c|}
\hline Major Metric & $\begin{array}{c}2000 \\
\text { PSC at Units 1-6 } \\
\text { B1 Priority } \\
\text { No Sluiceway } \\
\text { Sampled; } \\
\text { No STS in PSC } \\
\text { Screens in 7-10 }\end{array}$ & $\begin{array}{c}2001 \\
\text { Severe Drought } \\
\text { B2 Priority } \\
\text { No Sluiceway } \\
\text { Sampled; } \\
\text { B1 Screens } \\
\text { Installed }\end{array}$ & $\begin{array}{c}2002 \\
\text { B2 Priority } \\
\text { B1 Sluiceway } \\
\text { Sampled; } \\
\text { B1 Screens } \\
\text { Installed }\end{array}$ & $\begin{array}{c}2004 \\
\text { B2 Priority } \\
\text { B1 Sluiceway } \\
\& \\
\text { B2CC } \\
\text { Sampled } \\
\text { No B1 } \\
\text { Screens }\end{array}$ & $\begin{array}{c}2005 \\
\text { B2 Priority } \\
\text { B1 Sluiceway } \\
\text { \& } \\
\text { B2CC Sample } \\
\text { No B1 } \\
\text { Screens }\end{array}$ \\
\hline Dates Sampled & $06 / 05-07 / 15$ & $06 / 06-7 / 15$ & $6 / 03-7 / 15$ & $6 / 05-7 / 15$ & $6 / 02-7 / 15$ \\
\hline B1 Percent of Project Flow & $48.9 \%$ & $8.7 \%$ & $22.0 \%$ & $13.5 \%$ & $3.7 \%$ \\
\hline B1 Percent of Project Passage & $40.9 \%$ & $7.4 \%$ & $34.7 \%$ & $15.8 \%$ & $7.2 \pm 0.3 \%$ \\
\hline Spillway Percent of Project Flow & $43 \%$ & $9.8 \%$ & $40.2 \%$ & $33.5 \%$ & $51.6 \%$ \\
\hline Spillway Efficiency & $52.0 \pm 0.2 \%$ & $22.0 \pm 0.3 \%$ & $45.0 \pm 0.6 \%$ & $34.1 \pm 0.7 \%$ & $44.2 \pm 1.3 \%$ \\
\hline B2 Percent of Project Flow & $10.1 \%$ & $81.7 \%$ & 37.2 & $53.0 \%$ & $44.8 \%$ \\
\hline B2 Percent of Project Passage & $6.8 \%$ & $71.0 \%$ & $19.8 \%$ & $50.1 \pm 0.4 \%$ & $48.6 \pm 1.5 \%$ \\
\hline Fish-Passage Efficiency & $80 \pm 0.1 \%$ & $54 \pm 0.4 \%$ & $76 \pm 0.2 \%$ & $71 \pm 1.2 \%$ & $81 \pm 2.1 \%$ \\
\hline Fish-passage efficiency ${ }_{\mathrm{B} 1}$ & $61 \pm 0.1 \%$ & $40 \pm 1.8 \%$ & $61 \pm 0.3 \%$ & $37.6 \pm 1.5 \%$ & $70.9 \pm 1.3 \%$ \\
\hline Fish-guidance efficiency ${ }_{\mathrm{B} 1}$ & $39 \pm 0.1 \%$ & $40 \pm 1.8 \%$ & $45 \pm 0.5 \%$ & 0 (No STSs) & 0 (No STSs) \\
\hline Fish-guidance efficiency ${ }_{\mathrm{B} 2}$ & $35 \pm 1 \%$ & $42 \pm 0.4 \%$ & $46 \pm 0.1 \%$ & $36 \pm 2.9 \%$ & $37 \pm 4.4 \%$ \\
\hline Fish-passage efficiency ${ }_{\mathrm{B} 2}$ & $35 \pm 1 \%$ & $42 \pm 0.4 \%$ & $46 \pm 0.1 \%$ & $61 \pm 2.0 \%$ & $64.6 \pm 3.5 \%$ \\
\hline Fish-passage efficiency ${ }_{\mathrm{B} 2} \&$ Spillway & N/A (B2 Priority) & $55 \pm 0.4 \%$ & $84 \pm 0.5 \%$ & $77 \pm 0.02 \%$ & $82 \pm 0.02 \%$ \\
\hline $\begin{array}{l}\% \text { of Project flow through surface } \\
\text { flow outlets }\end{array}$ & N/A & N/A & 0.24 & $3.3 \%$ & $3.5 \%$ \\
\hline Surface-flow-outlet efficiency & N/A & N/A & $10.0 \pm 0.1 \%$ & $25.8 \pm 0.5 \%$ & $26.2 \pm 0.7 \%$ \\
\hline B1 Sluiceway efficiency & N/A & N/A & $10.0 \pm 0.1 \%$ & $5.9 \pm 0.1 \%$ & $5.13 \pm 0.2 \%$ \\
\hline B1 sluiceway efficiency ${ }_{\mathrm{B} 1}$ & N/A & N/A & $29.1 \pm 0.7 \%$ & $37.6 \pm 1.5 \%$ & $70.9 \pm 1.2 \%$ \\
\hline B2CC efficiency & N/A & N/A & N/A & $19.9 \pm 0.4 \%$ & $21.1 \pm 0.6 \%$ \\
\hline B2CC efficiency ${ }_{\mathrm{B} 2}$ & N/A & N/A & N/A & $39.6 \pm 1.5 \%$ & $43.5 \pm 2.5 \%$ \\
\hline Spillway effectiveness & $1.21 \pm 0.01$ & $2.25 \pm 0.01$ & $1.12 \pm 0.01$ & $1.02 \pm 0.02$ & $0.86 \pm 0.03$ \\
\hline Surface-flow-outlet effectiveness & N/A & N/A & $42.8 \pm 0.03$ & $7.9 \pm 0.15$ & $7.60 \pm 0.22$ \\
\hline B1 sluiceway effectiveness & N/A & N/A & $42.8 \pm 0.03$ & $10.9 \pm 0.2$ & $8.6 \pm 0.3$ \\
\hline B1 sluiceway effectiveness ${ }_{\mathrm{B} 1}$ & N/A & N/A & $26.9 \pm 6.6$ & $9.3 \pm 0.4$ & $4.3 \pm 0.08$ \\
\hline B2CC effectiveness & N/A & N/A & N/A & $7.3 \pm 0.14$ & $7.4 \pm 0.21$ \\
\hline $\mathrm{B} 2 \mathrm{CC}$ effectiveness $\mathrm{B}_{\mathrm{B}}$ & N/A & N/A & N/A & $7.7 \pm 0.28$ & $6.8 \pm 0.4$ \\
\hline
\end{tabular}


Table 3.4. Passage Performance Metrics for Yearling Chinook Salmon and Steelhead at Bonneville Dam during Spring Study Periods in 2000, 2001, 2002, 2004, and 2005 based on Radio Telemetry. B1 = first powerhouse and B2 = second powerhouse. Adapted from a table by Adams et al. (2006)

\begin{tabular}{|c|c|c|c|c|c|}
\hline Species and Passage Metric & 2000 & 2001 & 2002 & 2004 & 2005 \\
\hline Dates Sampled & $4 / 25-6 / 6$ & $5 / 1-6 / 9$ & $5 / 2-6 / 9$ & $4 / 29-6 / 7$ & $5 / 1-6 / 12$ \\
\hline \multicolumn{6}{|c|}{ Yearling Chinook Salmon } \\
\hline Spillway Percent of Project Flow & $34 \%$ & $22 \%$ & $49 \%$ & $35 \%$ & 40.3 \\
\hline Spillway efficiency & $44 \%$ & $16 \%$ & $57 \%$ & $33 \%$ & $37 \%$ \\
\hline Spillway effectiveness & 1.3 & 0.7 & 1.2 & 0.9 & 0.9 \\
\hline Fish-guidance efficiency ${ }_{B 1}$ & $50 \%$ & $45 \%$ & $50 \%$ & $\mathrm{a}$ & $\mathrm{a}$ \\
\hline Fish-guidance efficiency ${ }_{\mathrm{B} 2}$ & $39 \%$ & $46 \%$ & $37 \%$ & $33 \%$ & $36 \%$ \\
\hline Fish passage efficiency & $73 \%$ & $56 \%$ & $76 \%$ & $71 \%$ & $71 \%$ \\
\hline Fish-passage efficiency ${ }_{\mathrm{B} 1}$ & $65 \%$ & $87 \%$ & $69 \%$ & $54 \%$ & $35 \%$ \\
\hline Fish-passage efficiency ${ }_{\mathrm{B} 2}$ & $39 \%$ & $46 \%$ & $37 \%$ & $57 \%$ & $55 \%$ \\
\hline $\mathrm{B} 1$ sluiceway efficiency ${ }_{\mathrm{B} 1}$ & $29 \%$ & $77 \%$ & $35 \%$ & $53 \%$ & $33 \%$ \\
\hline $\mathrm{B} 1$ sluiceway effectiveness ${ }_{\mathrm{B} 1}{ }^{\mathrm{b}}$ & & & 18.6 & 14.6 & 8.8 \\
\hline $\mathrm{B} 2 \mathrm{CC}$ efficiency ${ }_{\mathrm{B} 2}$ & & & & $37 \%$ & $30 \%$ \\
\hline $\mathrm{B} 2 \mathrm{CC}$ effectiveness $\mathrm{B}_{\mathrm{B}}$ & & & & 7.0 & 5.9 \\
\hline B2CC efficiency & & & & $22 \%$ & $17 \%$ \\
\hline B2CC effectiveness & & & & 8.4 & 7.0 \\
\hline \multicolumn{6}{|c|}{ Steelhead } \\
\hline Spillway efficiency & $33 \%$ & $\mathrm{c}$ & $55 \%$ & $26 \%$ & $39 \%$ \\
\hline Spillway effectiveness & 1.0 & $\mathrm{c}$ & 1.2 & 0.7 & 1.0 \\
\hline Fish-guidance efficiency ${ }_{B 1}$ & $59 \%$ & $\mathrm{c}$ & $75 \%$ & $\mathrm{a}$ & $\mathrm{a}$ \\
\hline Fish-guidance efficiency ${ }_{\mathrm{B} 2}$ & $55 \%$ & $\mathrm{c}$ & $59 \%$ & $40 \%$ & $40 \%$ \\
\hline Fish passage efficiency & $78 \%$ & $\mathrm{c}$ & $84 \%$ & $86 \%$ & $83 \%$ \\
\hline Fish-passage efficiency ${ }_{\mathrm{B} 1}$ & $77 \%$ & $\mathrm{c}$ & $91 \%$ & $58 \%$ & $30 \%$ \\
\hline Fish-passage efficiency ${ }_{\mathrm{B} 2}$ & $55 \%$ & $\mathrm{c}$ & $59 \%$ & $84 \%$ & $79 \%$ \\
\hline B1 sluiceway efficiency $y_{B 1}$ & $44 \%$ & $\mathrm{c}$ & $65 \%$ & $55 \%$ & $29 \%$ \\
\hline $\mathrm{B} 1$ sluiceway effectiveness ${ }_{\mathrm{B} 1}^{\mathrm{b}}$ & & & 34.1 & 15.1 & 7.5 \\
\hline $\mathrm{B} 2 \mathrm{CC}$ efficiency $\mathrm{B}_{\mathrm{B}}$ & & & & $74 \%$ & $66 \%$ \\
\hline $\mathrm{B} 2 \mathrm{CC}$ effectiveness $\mathrm{B}_{\mathrm{B}}$ & & & & 14.2 & 13.2 \\
\hline B2CC efficiency & & & & $49 \%$ & $35 \%$ \\
\hline B2CC effectiveness & & & & 19.1 & 14.7 \\
\hline
\end{tabular}


Table 3.5. Passage Performance Metrics for Subyearling Chinook Salmon at Bonneville Dam during Summer Study Periods of 2000, 2001, 2002, 2004, and 2005 based on Radio Telemetry. Adapted from a table by Adams et al. (2006).

\begin{tabular}{|c|c|c|c|c|c|}
\hline Metric & 2000 & 2001 & 2002 & 2004 & 2005 \\
\hline Dates Sampled & $6 / 20-7 / 24$ & $7 / 1-7 / 24$ & $6 / 21-7 / 25$ & $6 / 21-8 / 4$ & $6 / 15-7 / 25$ \\
\hline Spillway Percent of Project Flow & $54 \%$ & $2.4 \%$ & $43 \%$ & $44.5 \%$ & $53 \%$ \\
\hline Spillway efficiency & $65 \%$ & $2 \%$ & $58 \%$ & $35 \%$ & $51 \%$ \\
\hline Spillway effectiveness & 1.2 & 0.8 & 1.3 & 0.9 & 1.0 \\
\hline Fish-guidance efficiency ${ }_{\mathrm{B} 1}$ & $29 \%$ & $57 \%$ & $43 \%$ & $\mathrm{a}$ & $\mathrm{a}$ \\
\hline Fish-guidance efficiency ${ }_{\mathrm{B} 2}$ & $25 \%$ & $35 \%$ & $47 \%$ & $22 \%$ & $24 \%$ \\
\hline Fish passage efficiency & $91 \%$ & $40 \%$ & $82 \%$ & $68 \%$ & $78 \%$ \\
\hline Fish-passage efficiency ${ }_{B 1}$ & $77 \%$ & $89 \%$ & $72 \%$ & $52 \%$ & $70 \%$ \\
\hline Fish-passage efficiency $y_{\mathrm{B} 2}$ & $25 \%$ & $35 \%$ & $47 \%$ & $50 \%$ & $55 \%$ \\
\hline $\mathrm{B} 1$ sluiceway efficiency $\mathrm{B}_{\mathrm{B}}$ & $29 \%$ & $77 \%$ & $35 \%$ & $53 \%$ & $59 \%$ \\
\hline B1 sluiceway effectiveness ${ }_{B 1}{ }^{b}$ & & & 18.6 & 14.5 & 2.8 \\
\hline $\mathrm{B} 2 \mathrm{CC}$ efficiency ${ }_{\mathrm{B} 2}$ & & & & $37 \%$ & $40 \%$ \\
\hline $\mathrm{B} 2 \mathrm{CC}$ effectiveness $\mathrm{B}_{\mathrm{B} 2}$ & & & & 7.0 & 5.9 \\
\hline B2CC efficiency & & & & $22 \%$ & $19 \%$ \\
\hline $\mathrm{B} 2 \mathrm{CC}$ effectiveness & & & & 5.9 & 6.4 \\
\hline
\end{tabular}

\subsubsection{Effect of Spill on Spillway Efficiency}

Percent spill is the primary factor affecting spill efficiency. This variable explains most of the variation among years, seasons, species, and even spill treatments. On the other hand, spill effectiveness at Bonneville Dam is near 1:1 and mostly independent of percent spill. If we plot all 24 estimates of spill efficiency versus percent spill in Tables 3.2 through 3.5, percent spill explains $85 \%$ of the variation in spill efficiency (Figure 3.2), regardless of sampling method, year, season, or species. Accordingly, the lowest estimates came from the studies during the drought of 2001 and estimates from the wettest study (2002) produced among the highest estimates. This plot is similar to many that have been presented on daily or hourly time scales in the hydroacoustic studies, but is unique in that it integrates estimates from all studies (hydroacoustic and radio-telemetry). Seasonal estimates have the advantage of being more precise than daily or hourly estimates, and they are available for both methods, whereas radio telemetry cannot provide robust daily or hourly estimates because of sample size limitations. However, seasonal estimates do not capture the full range in percent spill at Bonneville Dam because strong diel and treatment variations are averaged out. Therefore, it is advantageous to examine results of some spilltreatment studies and plots of day and night estimates from hydroacoustic studies. 


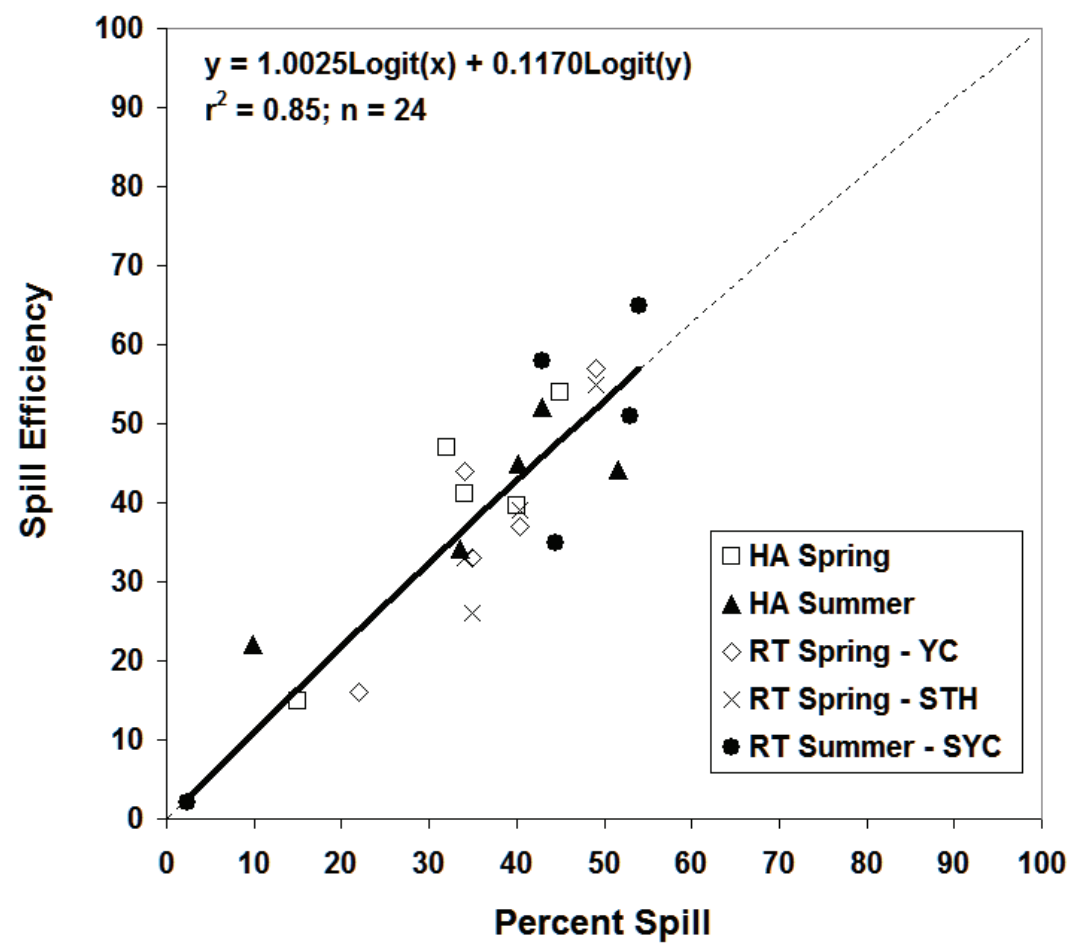

Figure 3.2. Plot of Spill Efficiency Estimates on Percent Spill based on Data in Tables 3.2-3.5. Abbreviations include $\mathrm{HA}=$ hydroacoustics, $\mathrm{RT}$ = radio telemetry, $\mathrm{YC}=$ yearling Chinook salmon, STH = steelhead, and SYC = subyearling Chinook salmon.

In 2002, two spill treatments were defined for their effects on spill efficiency:

1) The Day Cap Treatment was a typical diel spill treatment of about 57,000 cfs during the day and spill to the gas cap at night. Mean discharge was about 80,000 cfs in spring and 81,000 cfs in summer. The range was from $57,000 \mathrm{cfs}$ during the day to $210,000 \mathrm{cfs}$ at night in spring and from $57,000 \mathrm{cfs}$ during the day to $171,000 \mathrm{cfs}$ at night in summer.

2) The Total Dissolved Gas Cap Treatment was day and night spill to the TDG limit and averaged $128,000 \mathrm{cfs}$ in spring and $118,000 \mathrm{cfs}$ in summer. The range was about 75,300 cfs to $210,000 \mathrm{cfs}$ in spring and from about $63,000 \mathrm{cfs}$ to $171,000 \mathrm{cfs}$ in summer.

For spring, estimates of spill efficiency for the two treatments are reasonably close to what would be predicted from the regression equation in Figure 3.2, given average estimates of percent spill (Table 3.6). In summer, the regression line in Figure 3.2 would forecast estimates that would be close to the hydroacoustic estimates but lower than radio-telemetry estimates. Evans et al. (2006b) found no significant difference in spill efficiency between the two treatments for subyearling Chinook salmon, although they did find differences between high spill during the day or night and low spill during the daytime part of the Day Cap treatment. Spill to the gas cap at night occurred in both defined treatments, and this may be partially responsible for confounding the results because the predominant arrival time of fish at the Project on a given treatment day could be the determining factor affecting spill efficiency. For example, if most fish arrived and passed at night during the high spill part of the Day Cap treatment, then spill efficiency would be inflated for that treatment. 
Table 3.6. Spring and Summer 2002 Spill Efficiency Estimates

\begin{tabular}{|c|c|c|c|}
\hline \multirow[t]{2}{*}{ Spill Treatment } & \multirow[t]{2}{*}{$\begin{array}{l}\text { Hydroacoustic } \\
\text { Estimate }^{\mathrm{a}}\end{array}$} & \multicolumn{2}{|c|}{$\begin{array}{c}\text { Radio Telemetry } \\
\text { Estimates }^{\mathbf{b}}\end{array}$} \\
\hline & & $\begin{array}{l}\text { Yearling } \\
\text { Chinook }\end{array}$ & Steelhead \\
\hline \multicolumn{4}{|l|}{ Spring } \\
\hline Overall & $54 \%$ & $56 \%$ & $55 \%$ \\
\hline Day Cap $($ mean $=80,000 \mathrm{cfs} ; 36 \%)$ & $44 \%$ & $46 \%$ & $37 \%$ \\
\hline TDG $\quad($ mean $=128,000 \mathrm{cfs} ; 55 \%)$ & $64 \%$ & \multirow{2}{*}{\multicolumn{2}{|c|}{ Subyearling Chinook }} \\
\hline Summer & & & \\
\hline Overall & $45 \%$ & & $3 \%$ \\
\hline Day Cap $($ mean $=81,000 \mathrm{cfs} ; 32 \%)$ & $38 \%$ & & $5 \%$ \\
\hline TDG $=118,000 \mathrm{cfs} 47 \% ; 47 \%)$ & $52 \%$ & & $\%$ \\
\hline $\begin{array}{l}\mathrm{a} \\
{ }^{\mathrm{b}}\end{array}$ & & & \\
\hline
\end{tabular}

Ploskey et al. (2006b) reanalyzed all previous project-wide hydroacoustic data after percent spill estimates for 2000-2004 were corrected because of an error in the rating curve. They found a highly significant relationship between day and night estimates of spill efficiency and percent spill (Figure 3.3). A lot of the scatter in Figure 3.3 resulted from among-year differences in estimates, and regressions from three of the five years day and night estimates of percent spill explained over $75 \%$ of the variation in spill efficiency (Figure 3.4). Regressions for three of the five years 4 had significantly higher $r^{2}$ values than did the pooled regression in Figure 3.3. Similar types of plots have been made using hourly data (e.g., Ploskey et al. 2003; Ploskey et al. 2005) but there is a greater risk of autocorrelation in those estimates than there is in using day and night estimates.

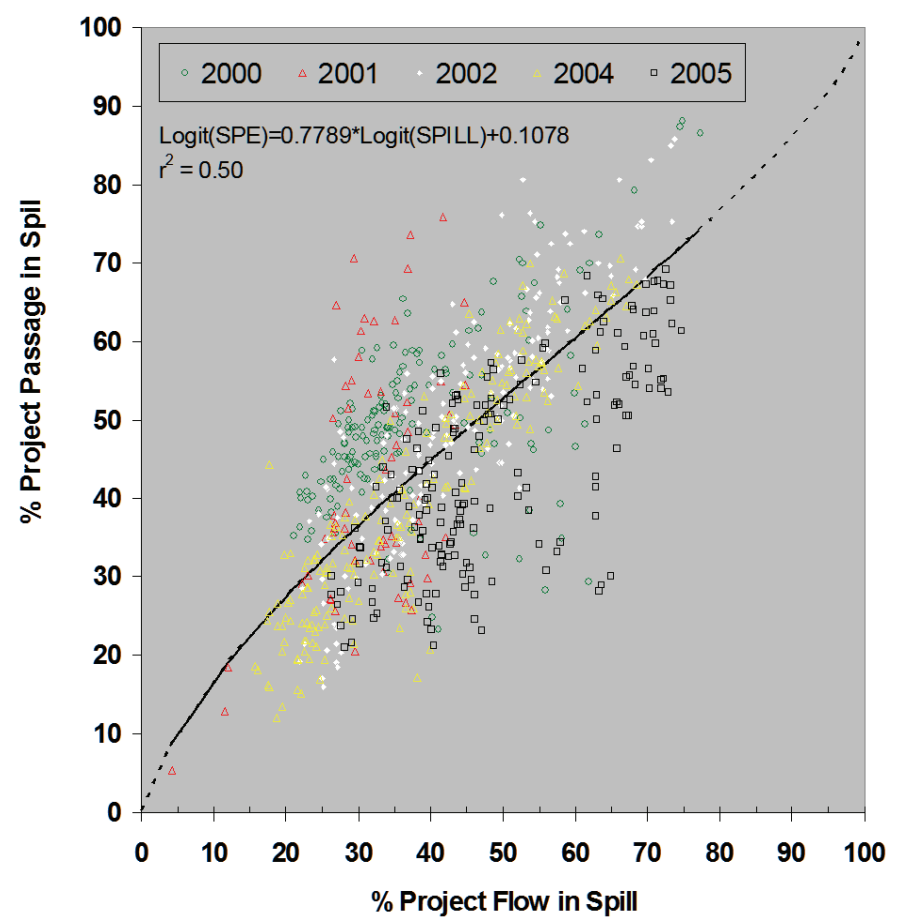

Figure 3.3. Regression of Day and Night Estimates of Spillway Efficiency on Percent Spill 


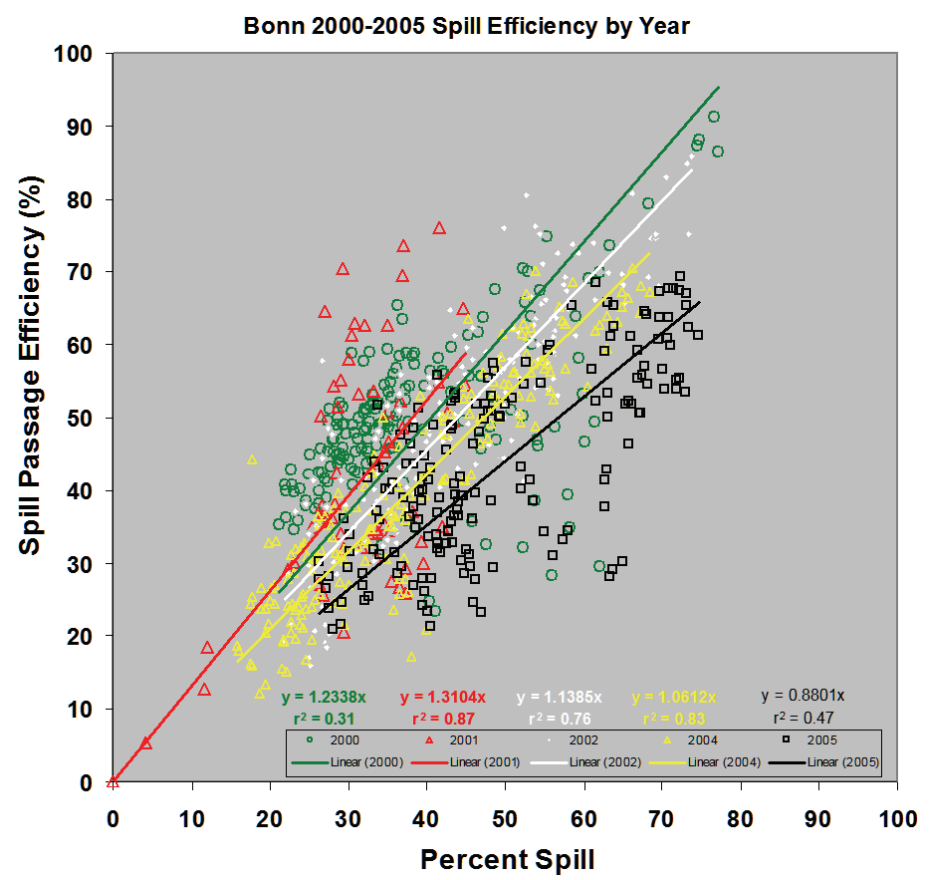

Figure 3.4. Regression of Spill Efficiency on Percent Spill by Study Year at Bonneville Dam. Points are from five different years and were estimated for day and night period of each day sampled.

\subsubsection{Effect of Spill on Spillway Effectiveness}

Another composite plot based on estimates from hydroacoustics and radio-telemetry shows that spill effectiveness is mostly independent of percent spill and is near 1:1 over most of the range in percent spill (Figure 3.5), as expected given the 1:1 slope of the regression in Figure 3.2. The plot of all data points is similar to trends observed in the reanalysis of day and night estimates from hydroacoustic studies (Figure 3.6). At best, there is a weak negative relationship between spill effectiveness and percent spill. The variation in point estimates tends to decrease and estimates converge with increasing percent spill.

The weak negative relationship between spill effectiveness and percent spill at Bonneville Dam probably results from the isolation of the spillway from powerhouses. Spill effectiveness at Columbia River dams typically is higher than the average at Bonneville Dam. For example, spill effectiveness at Lower Granite Dam in spring 2002 ranged from 1.8 to 3.3 and averaged 2.2 (Anglea et al. 2003). Overall spill-passage effectiveness at John Day Dam was 2.7 in spring and 2.3 in the summer of 2002 (Moursund et al. 2003). In both examples, project operations and the proximity of the project powerhouse to the spillway contributed to the spillway being able to take fish away from the powerhouse and concentrate them in spillway passage. For effectiveness to be much above 1:1 at Bonneville Dam, fish would have to preferentially select the spillway over either powerhouse. Unfortunately, islands funnel fish to the three forebays before fish are exposed to forebay conditions that might allow them to make a selection (see Chapter 2). Telemetry estimates of spill effectiveness generally were slightly lower than hydroacoustic estimates for Bonneville Dam, and those results also support the hypothesis that spillway isolation from both powerhouses prevents the spillway from attracting fish from either powerhouse forebay. This point is consistent with the data on movement between areas (B1, spillway, B2) presented near the end of Chapter 2. 


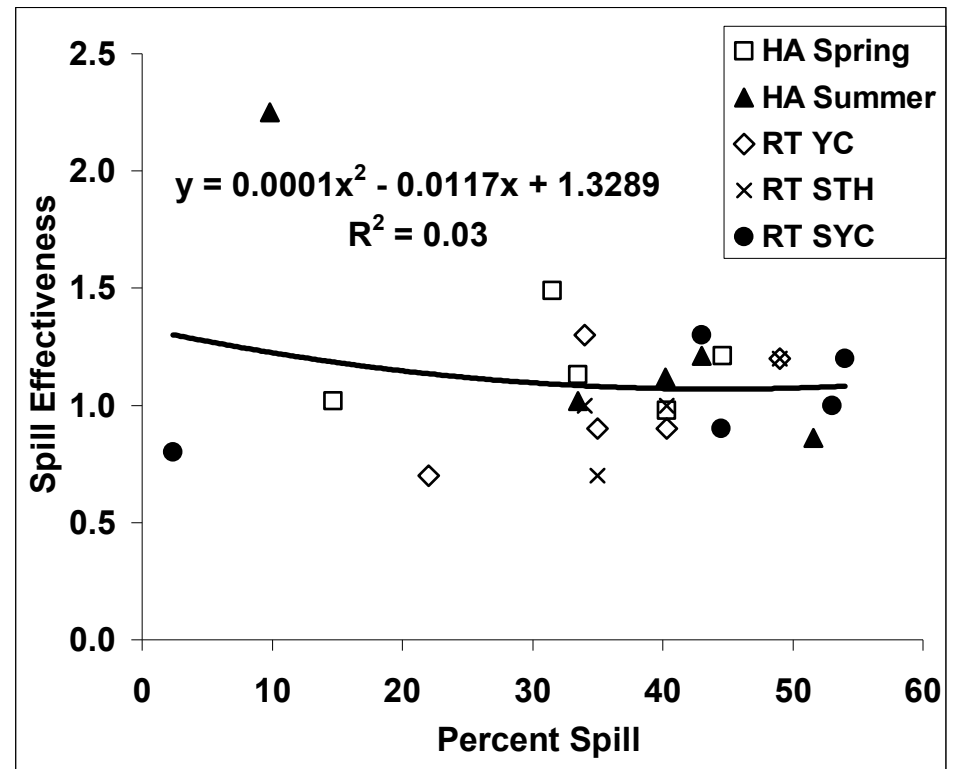

Figure 3.5. Plot of Spill Effectiveness Estimates on Percent Spill based on Data in Tables 3.2-3.5. Abbreviations include $\mathrm{HA}=$ hydroacoustics, $\mathrm{RT}=$ radio telemetry, $\mathrm{YC}=$ yearling Chinook salmon, $\mathrm{STH}=$ steelhead, and SYC = subyearling Chinook salmon.

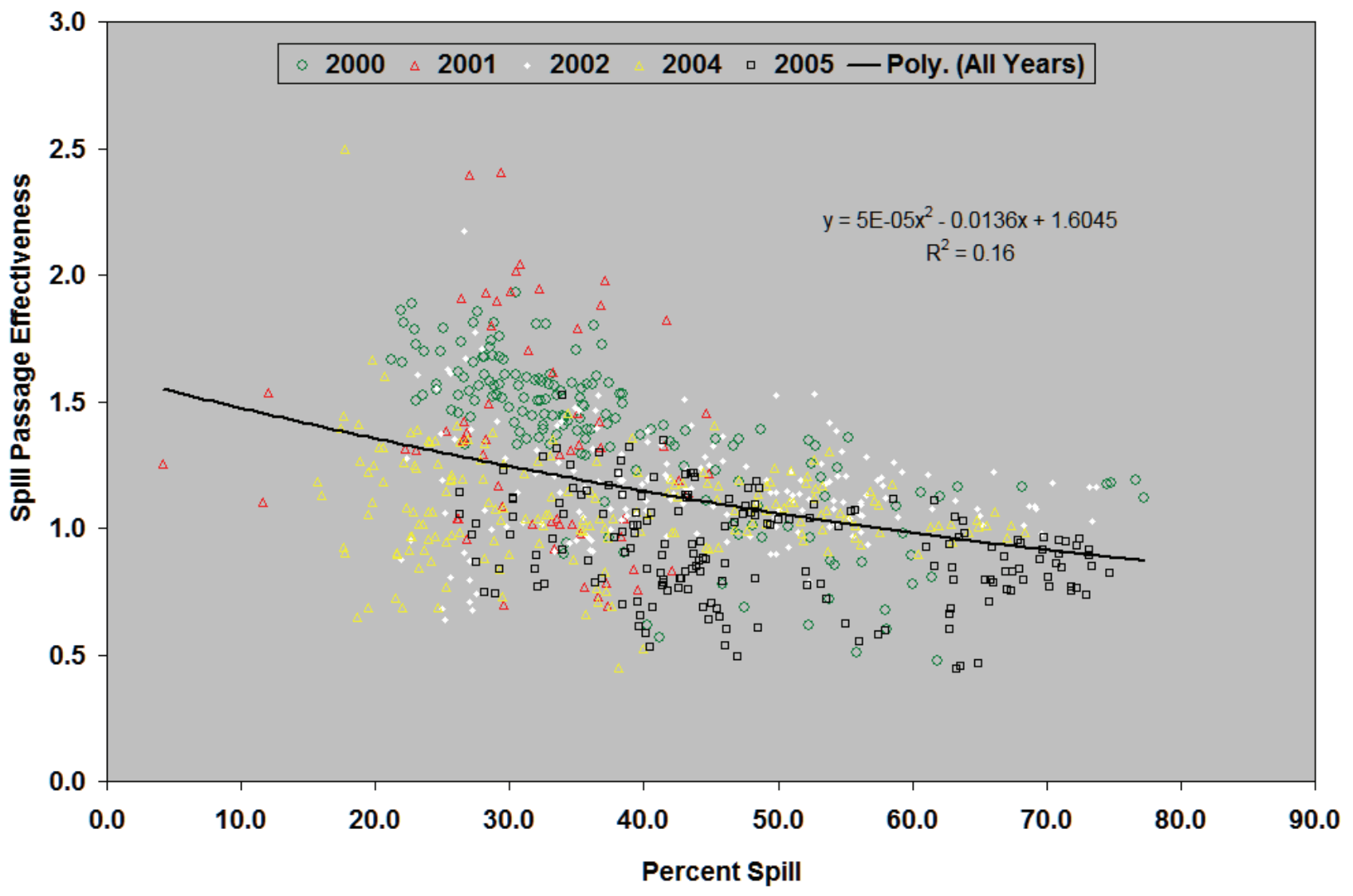

Figure 3.6. Plot of Day and Night Spill Effectiveness Estimates on Percent Spill (from Ploskey et al. 2006b) 
Radio telemetry data also indicate that few fish detected in one of the three forebays move to a different forebay before passing the project. Lateral smolt distribution on approach to Bonneville Dam influenced whether the ultimate passage route was B1, the spillway, or B2 (e.g., Hensleigh et al. 1999). In 1996, 1997, and 1998, investigators coupled data describing the location of radio-tagged smolts upstream of Boat Rock with data identifying the location where these tagged fish passed the dam (Holmberg et al. 1996, Hensleigh et al. 1999, Hansel et al. 1999). Fish distributed to the south side of the channel were likely to pass the dam at B1 or the spillway. Fish distributed to the north side of the channel were likely to pass the dam at B2 or the spillway.

\subsubsection{Effect of Percent Spill B1 and B2 Passage}

Increasing spill to increase fish passage takes flow and fish from B1 and B2, both of which include non-turbine, surface-flow routes. The magnitude of effect when the respective powerhouses are impacted depends upon the assigned generation priority. For example, in 2005 when B2 was the priority powerhouse for generation, the percentage of fish and flow passing the Project through B1 declined precipitously as the percent spill increased from $25 \%$ to $40 \%$ (Figure 3.7). Although spills above $40 \%$ had little effect on fish passing B1 because it had nearly bottomed out, there was a significant decrease in fish passing B2 (Figure 3.8).

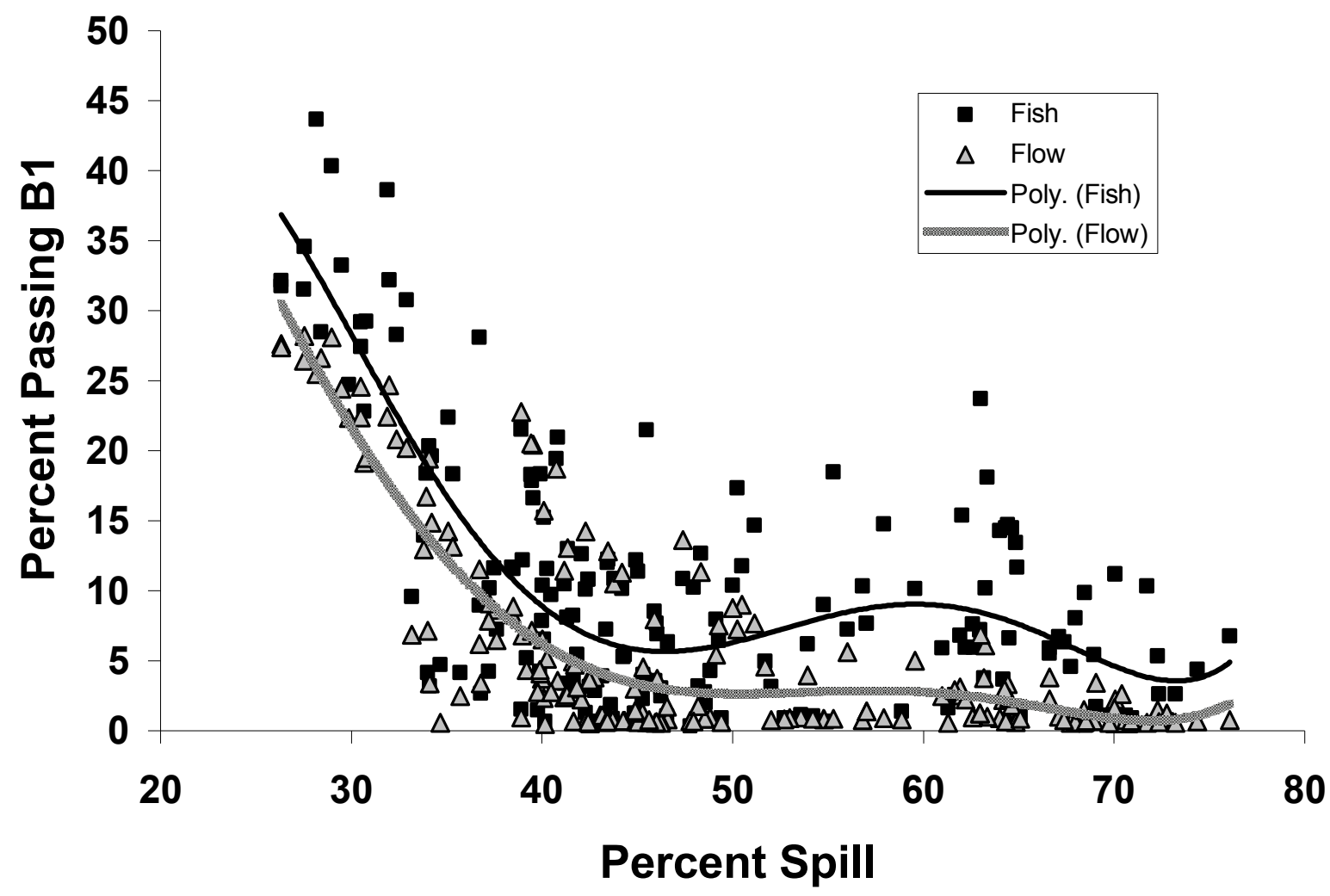

Figure 3.7. Trends in the Percent Fish and Flow Passing B1 as a Function of Percent Spill. Points include all day and night estimates from both passage seasons (from Ploskey et al. 2006c). 


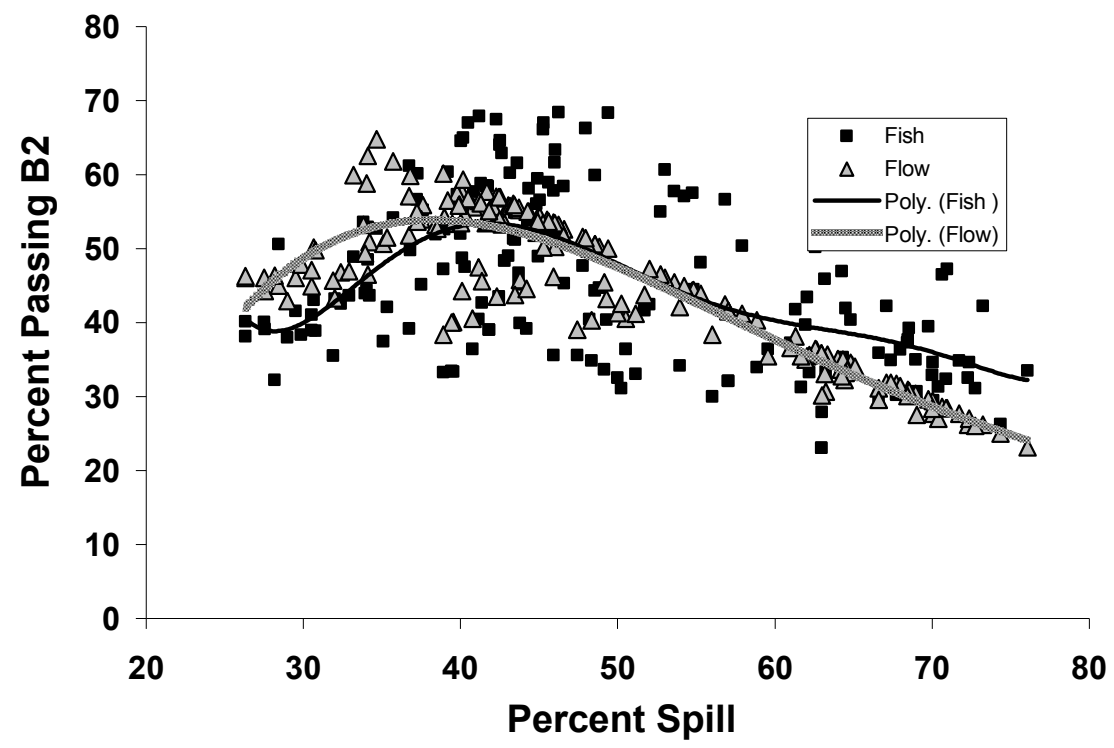

Figure 3.8. Trends in the Percent of Fish and Flow Passing B2 as a Function of Percent Spill. Points include all day and night estimates from both passage seasons in 2005 . From Ploskey et al. (2006c).

\subsubsection{Effect of Percent Flow on Surface Flow Outlet Efficiency}

Based upon all available seasonal estimates from hydroacoustic and radio telemetry studies (Tables 3.2 through 3.5), the efficiency of the B1 sluiceway relative to B1 was correlated with the percent of B1 flow to that route (Figure 3.9). Within-season day and night estimates show the full range of effect much more clearly (Figure 3.10). B1 sluiceway efficiency increased very rapidly at low levels of percent flow. On average, the percent of B1 passage through the B1 sluiceway was about $40 \%$ at $1 \%$ of B1 flow (the minimum flow), $73 \%$ at $5 \%$ flow, $83 \%$ at $10 \%$ flow, and $88 \%$ at $15 \%$ flow.

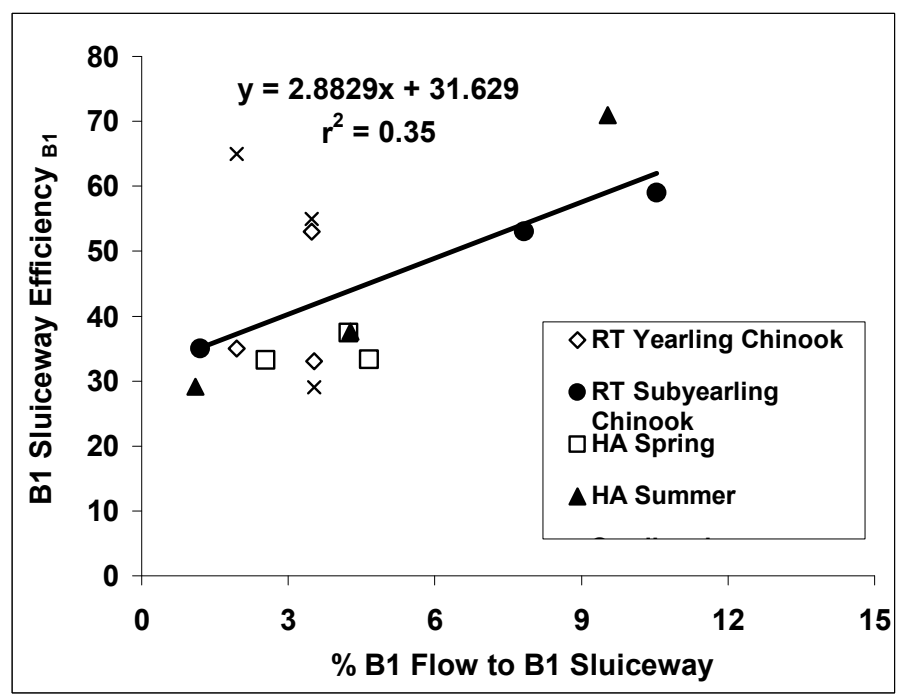

Figure 3.9. Regression of Seasonal Estimates of B1 Sluiceway Efficiency Relative to B1 on Percent of B1 Flow into the Sluiceway 


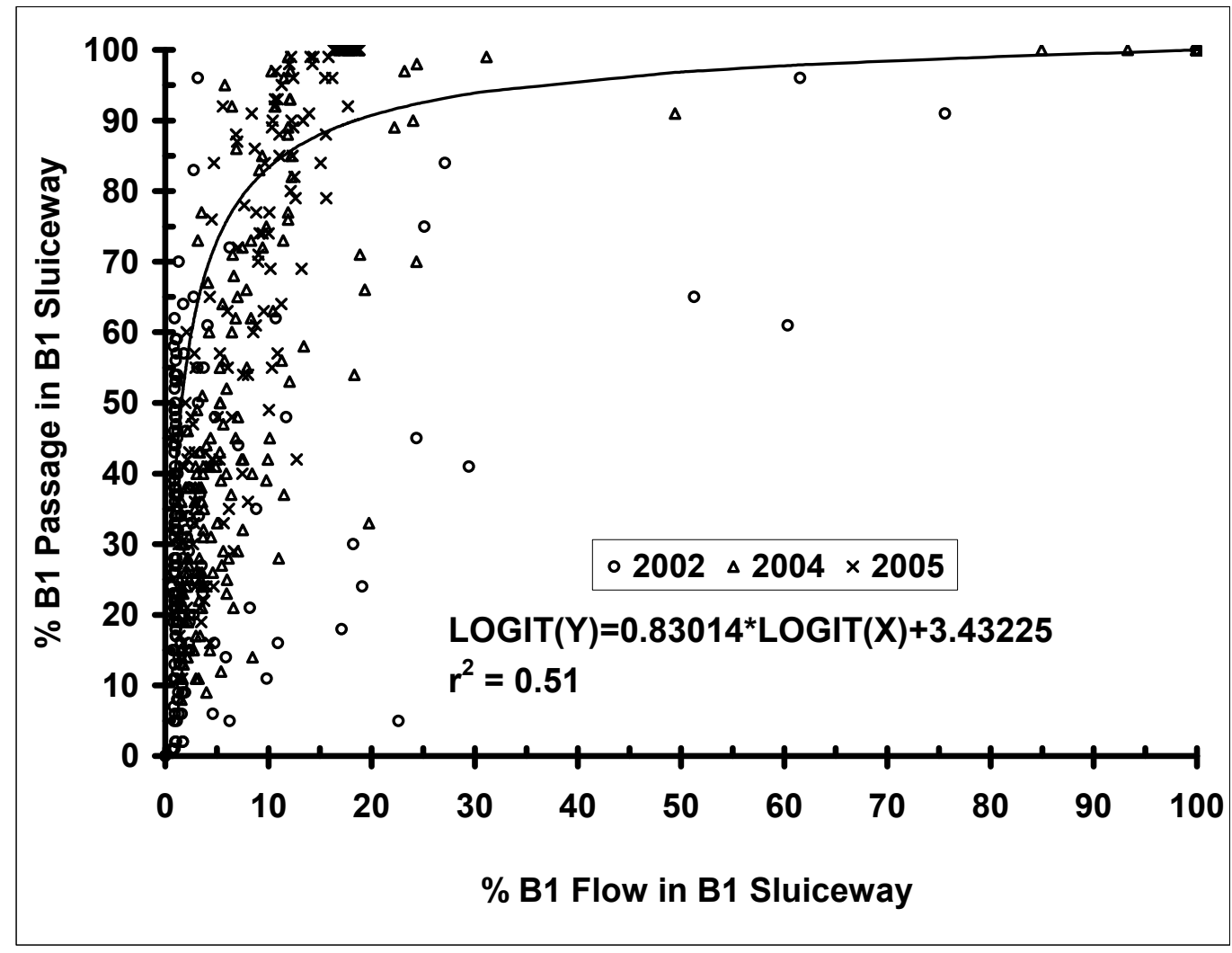

Figure 3.10. Logit Regression of Day and Night Estimates of B1 Sluiceway Passage Efficiency on Percent of B1 Flow Passing the B1 Sluiceway (from Ploskey et al. 2006b)

Examination of the B2CC efficiency estimates in Tables 3.4 and 3.5 clearly indicate that steelhead are much more likely than juvenile Chinook salmon to pass into the $\mathrm{B} 2 \mathrm{CC}$ outlet and that hydroacoustic estimates are closer to estimates for juvenile Chinook salmon. The average $\mathrm{B} 2 \mathrm{CC}$ efficiency relative to B2 was 70\% for steelhead, compared with just 34\% for yearling Chinook salmon and 39\% for subyearling Chinook salmon. Hydroacoustic estimates averaged 32\% in spring and $42 \%$ in summer, both of which are similar to respective estimates for Chinook salmon yearlings in spring and subyearlings in summer. This tendency of higher steelhead efficiency was only apparent in one year of B1 sluiceway data, perhaps because B1 outlets have low discharge compared with the $\mathrm{B} 2 \mathrm{CC}$.

There were too few seasonal estimates of $\mathrm{B} 2 \mathrm{CC}$ efficiency for regression on percent of $\mathrm{B} 2$ flow to the B2CC, but daily hydroacoustic data from 2004 and 2005 show a trend similar to that observed for the B1 sluiceway (Figure 3.11). The percent of B2 passage through the $\mathrm{B} 2 \mathrm{CC}$ was $30 \%$ at $4 \%$ of $\mathrm{B} 2$ flow (the minimum flow), $36 \%$ at $5 \%$ flow, $52 \%$ at $10 \%$ flow, and $62 \%$ at $15 \%$ flow (Figure 3.11 ). The remaining percentages of $\mathrm{B} 1$ or $\mathrm{B} 2$ passage at any percent flow represent what would pass through adjacent turbines.

At just $6 \%$ of project flow, predicted passage of all surface-flow outlets was over $30 \%$ of project passage (Figure 3.12), and this was at least three times higher than percent passage predicted for spill at that level (Figure 3.13). Percent of project flow through all surface-flow outlets explained $44 \%$ of the variation in project fish passage there (Figure 3.12). 

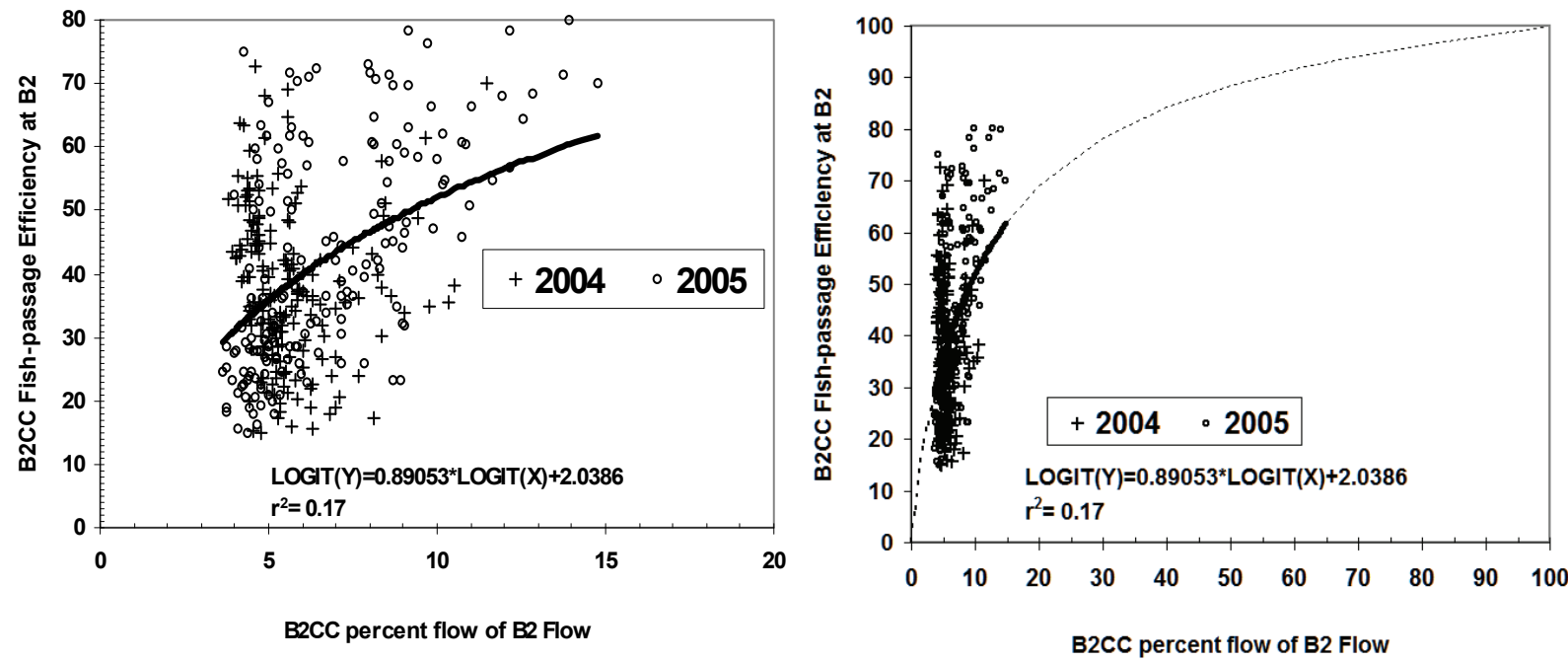

Figure 3.11. Logit Regression of Day and Night Estimates of the B2CC Passage Efficiency on Percent of B2 Flow Passing into the B2CC. The right plot shows full extrapolation to known endpoints as a dashed Line. From Ploskey et al. (2006b).

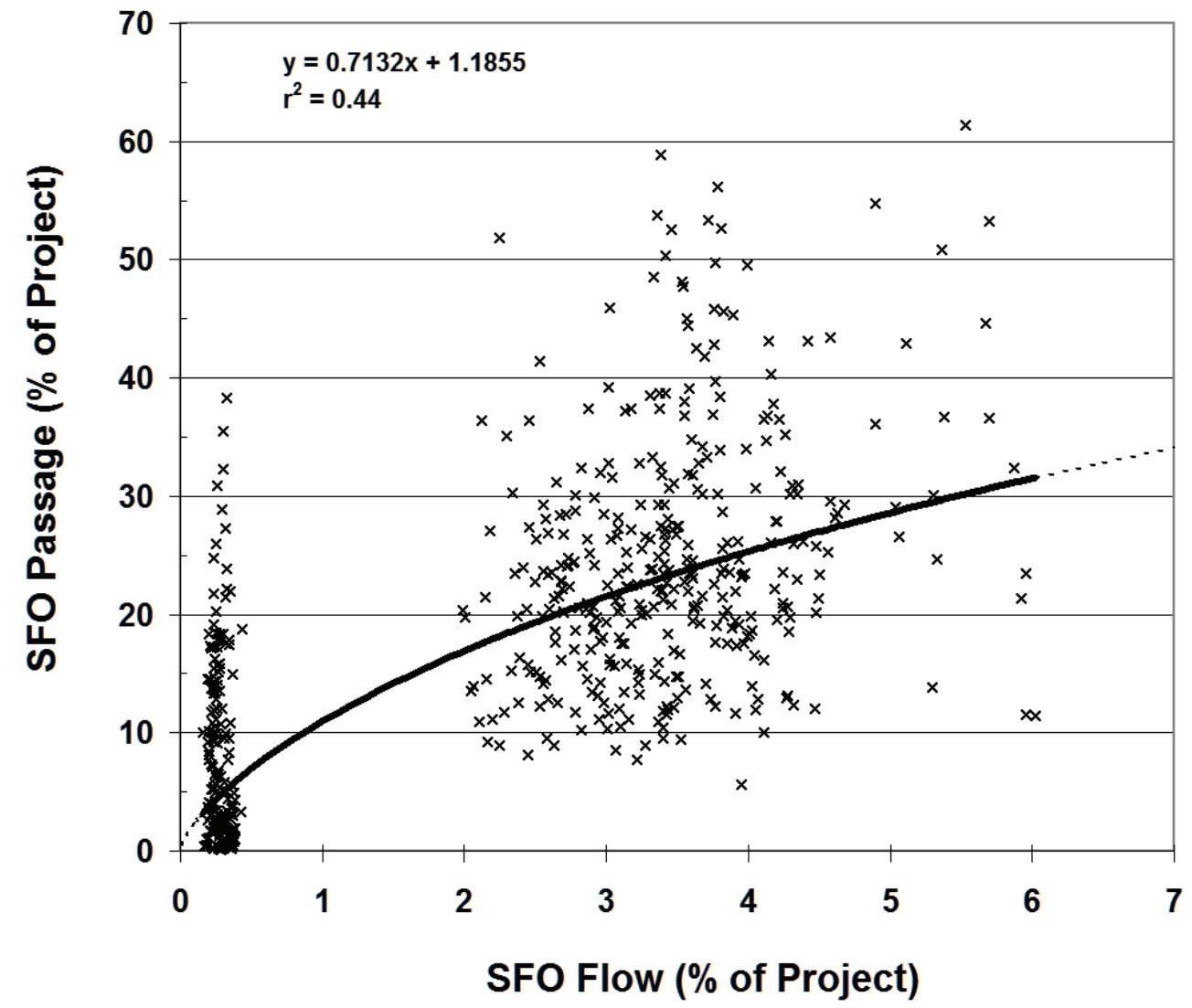

Figure 3.12. Logit Regression of Day and Night Estimates of Percent of Project Fish Passage through Surface Flow Outlets (SFO = B1 Sluiceway and B2CC Combined) on Percent of Project Flow through the Same Routes. The dashed portion of the line is an extrapolation toward known endpoints $(0,0$ and 100,100). From Ploskey et al. 2006b. 


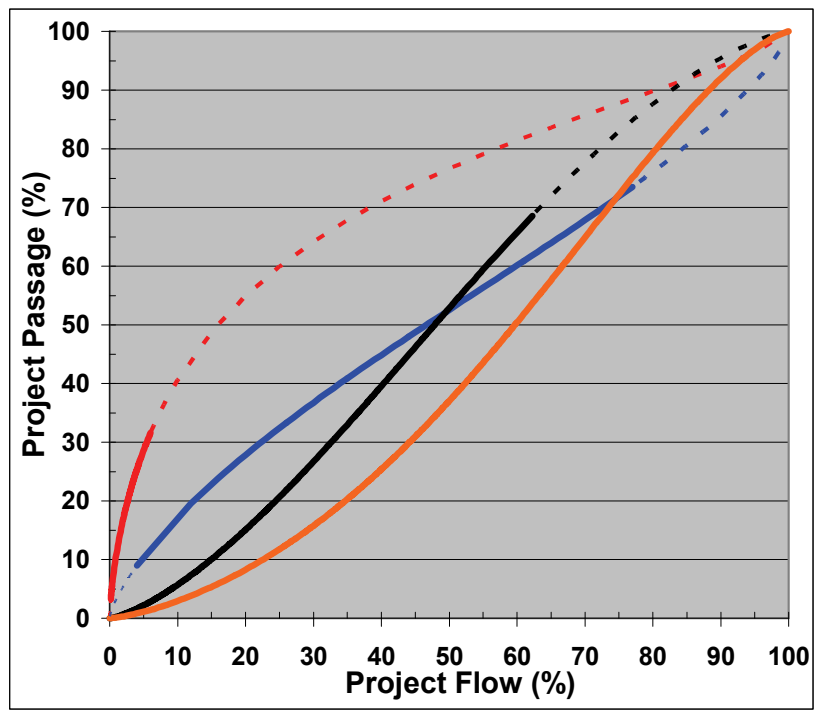

Figure 3.13. Logit Regression Lines Summarizing Percent of Project Passage by Route as a Function of Percent of Project Flow through the Same Route. The red line is the predicted response for surface flow outlets, blue is for spill, black is for B1 turbines, and orange is for B2 turbines. Lightly dashed portions of lines are extrapolations to known endpoints. From Ploskey et al. (2006b).

\subsubsection{Effect of Percent Flow on Surface Flow Outlet Effectiveness}

The effectiveness of the B1 sluiceway had a highly significant negative correlation with the percent of B1 flow passing that route (Figure 3.14) based upon all seasonal hydroacoustic and radio telemetry estimates in Tables 3.2 through 3.5. This trend is similar to that observed by Ploskey et al. (2006b) based upon day and night estimates from hydroacoustic studies (Figure 3.15), although the daily estimates afford a look at responses over a much wider range of percent flow than do the seasonal estimates.

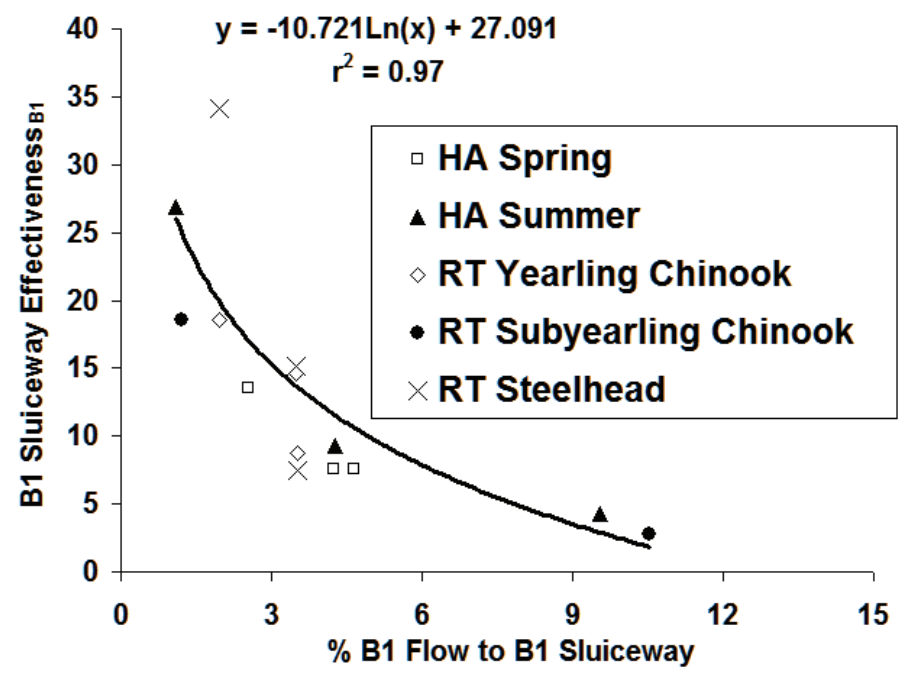

Figure 3.14. B1 Sluiceway Effectiveness as a Function of the Percent of B1 Flow into the B1 Sluiceway. Seasonal estimates are from Tables 3.2 through 3.5. 
Percent of B1 flow into the B1 sluiceway explained $67 \%$ of the variation in B1 sluiceway effectiveness, mostly because the effectiveness of the B1 sluiceway was very high at low flow percentages and then declined exponentially, something that was not observed for the spillway (Figure 3.15). Differences between predicted estimates of effectiveness for the B1 sluiceway and the spillway based upon percent flow through the respective routes were much larger at low percent flow (20:1 at $1 \%$ flow) than they were at high percent flow (2:1 at $80 \%$ flow).

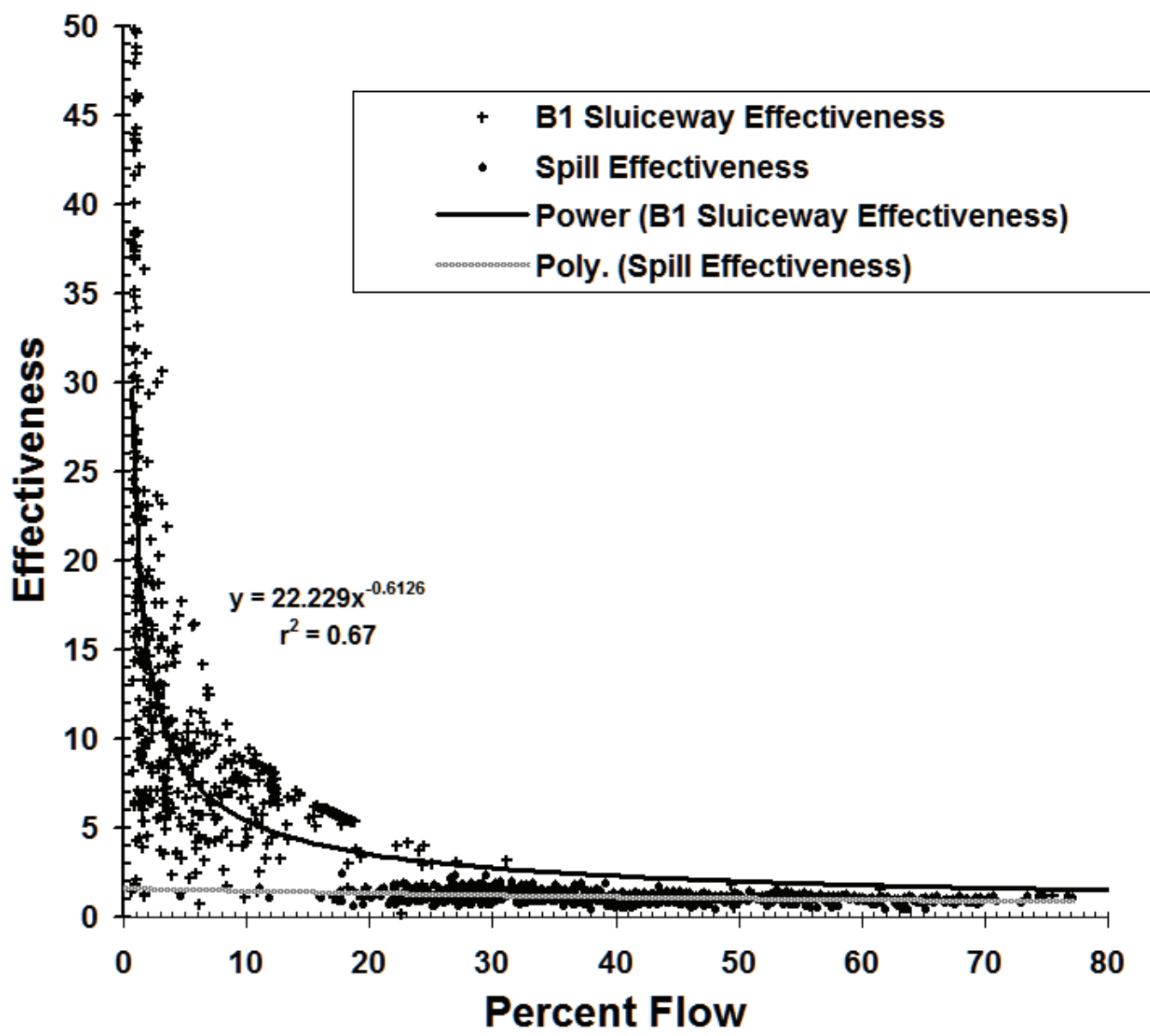

Figure 3.15. Regression of Day and Night Estimates of B1 Sluiceway Effectiveness on Percent of B1 Flow. The trend for spill effectiveness is shown for reference. From Ploskey et al. 2006b.

Based upon seasonal estimates of effectiveness relative to B2 (Tables 3.2-3.5), the B2CC was much more effective for steelhead (13.2-14.2) than it was for yearling or sub-yearling Chinook salmon (5.9-7.0) or for the run at large (5.8-7.7). In fact, radio telemetry data indicate that the $\mathrm{B} 2 \mathrm{CC}$ passed $35 \%$ (2004) and $49 \%$ (2005) of the steelhead at the entire Project in just $4 \%$ of the flow.

There were insufficient seasonal estimates to plot B2CC effectiveness as a function of the percent of B2 flow into the collector, so we relied on day and night estimates from hydroacoustic studies (Figure 3.16). A similar trend of high effectiveness at low flow percentage was observed for the $\mathrm{B} 2 \mathrm{CC}$, where predicted effectiveness was about 8:1 at 4\% of B2 flow through the $\mathrm{B} 2 \mathrm{CC}$ and about $4: 1$ at 15\% flow (Figure 3.16). The range of percent flow for the B2CC (4-15\% of B2 flow) was much narrower than it 
was for the B1 sluiceway (1\%-100\% of B1 flow) and the spillway (4\%-80\% of project flow), and this probably explains the low $\mathrm{r}^{2}$ of $14 \%$ for the B2CC data. At $4 \%$ flow, the normal operating percentage for the B2CC, effectiveness was about 5.33 times higher than spill effectiveness (Figure 3.16).

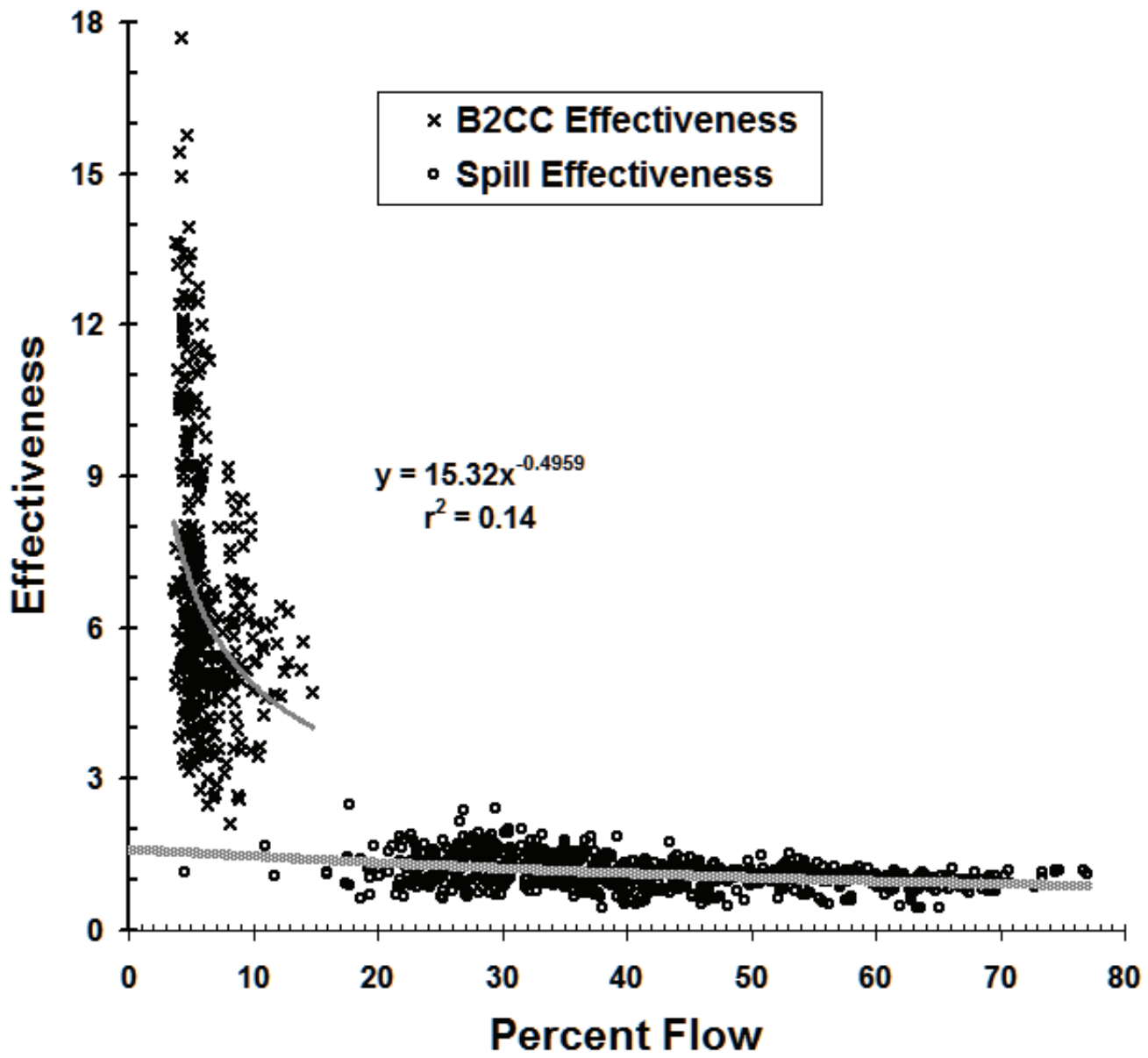

Figure 3.16. Regression of Day and Night Estimates of B2CC Effectiveness on Percent of B2 Flow. The trend for spill effectiveness as a function of percent spill also is shown for reference. From Ploskey et al. 2006b.

\subsubsection{Effects of Spill on Project Fish-Passage Efficiency}

When the management goal is to maximize fish passage through non-turbine routes, the combined effect of management is reflected in both the project-wide and powerhouse FPE. Estimated project FPE has varied substantially during the five years of project study. In a typical water year the goal of maximizing project FPE has substantially guided project operations. High spill discharge rates are considered necessary to compensate for low fish guidance rates at both powerhouses, especially in summer. The spill level and percent of total discharge spilled are restricted by water availability and power demand and by the legally set downstream total dissolved gas (TDG) cap of $120 \%$ of saturation that is meant to limit gas-related damage and mortality downstream. In a typical year, spill is set to between 50 and $75 \mathrm{kcfs}$ during the day and 100 to $140 \mathrm{kcfs}$ at night. Night spill can be higher because upstream migrating adult salmonids are not thought to move much at night and are unlikely to be swept 
back down through the spillway, whereas smolts move through deeper passage (under spill gates or through turbines) at night than during daytime (Thorne and Johnson 1993).

A plot of all seasonal FPE estimates in Tables 3.2 through 3.5, without regard to sampling method, season, or species, provided a scatter plot and regression that explained $71 \%$ of the variation in FPE (Figure 3.17). This plot had a similar intercept but steeper slope than one based upon day and night estimates of FPE from hydroacoustic studies (Figure 3.18). According to Figure 3.17, each 1\% increase in percent spill buys a $0.7 \%$ increase in FPE. However, a known endpoint for Figure 3.17 is 100\% FPE at $100 \%$ spill, which indicates that the true relationship must be curvilinear. There was a lot of variation in slopes and intercepts of regression lines among the five years (Figure 3.19). Regression lines varied a lot among years, with percent spill explaining from $47 \%$ to $79 \%$ of the day and night variation in fishpassage efficiency (Figure 3.19). Slopes in 2000 and 2002 (0.29 and 0.38) were less than slopes in 2001, 2004, and 2005. Intercepts also varied widely, from lows in 2004 (37\%) and 2005 (28\%) to highs in 2000 (69\%) and 2002 (62\%). However, data acquired during days of low spill and no spill in 2001 were most important for defining the intercept, which was about $49 \%$ when there was no spill. There were no data collected when spill was $<15 \%$ in other years so the intercepts are backward extrapolations beyond available data.

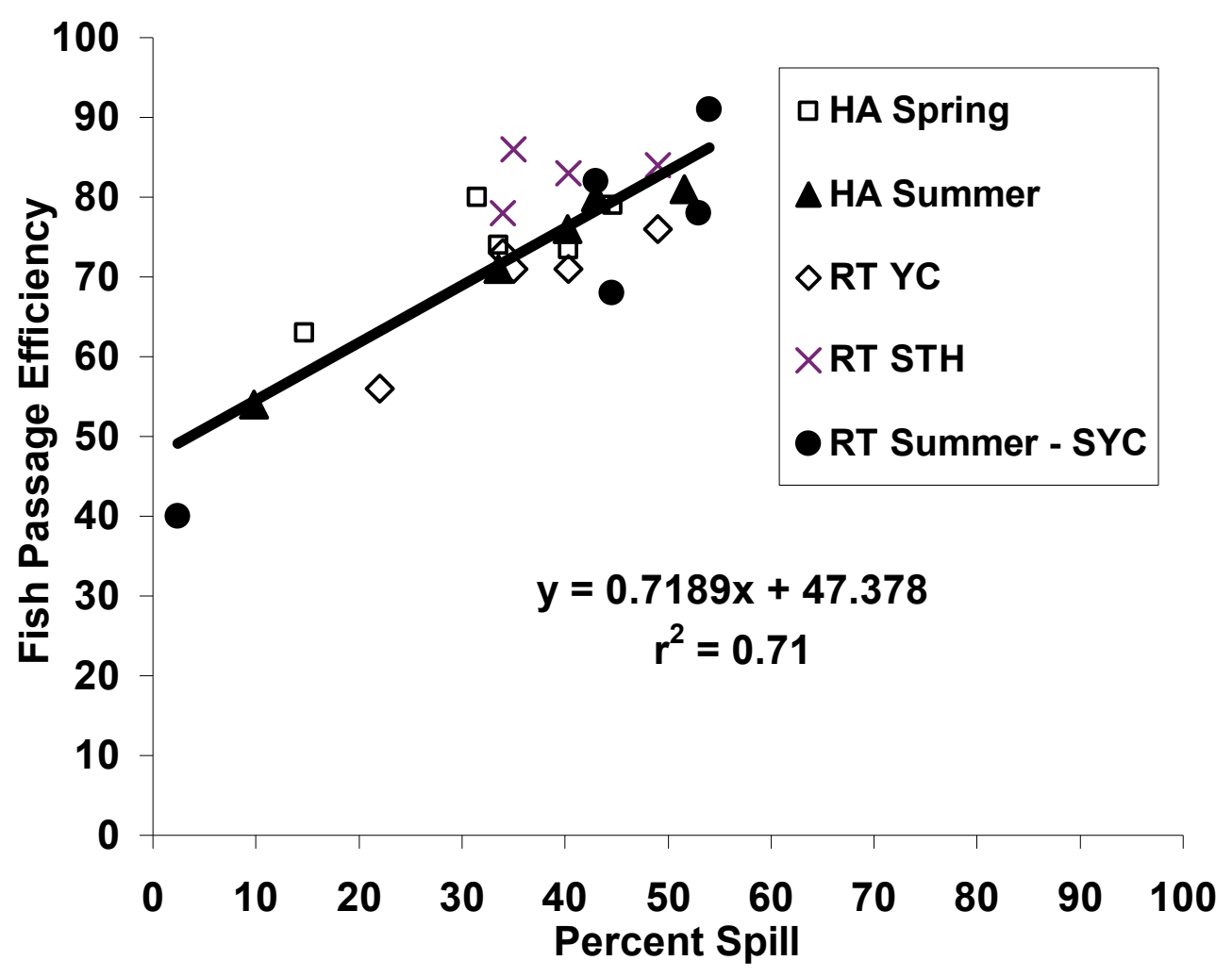

Figure 3.17. Regression of Seasonal Estimates of Fish-Passage Efficiency on Percent Spill. Data are from Tables 3.2 through 3.5 . 


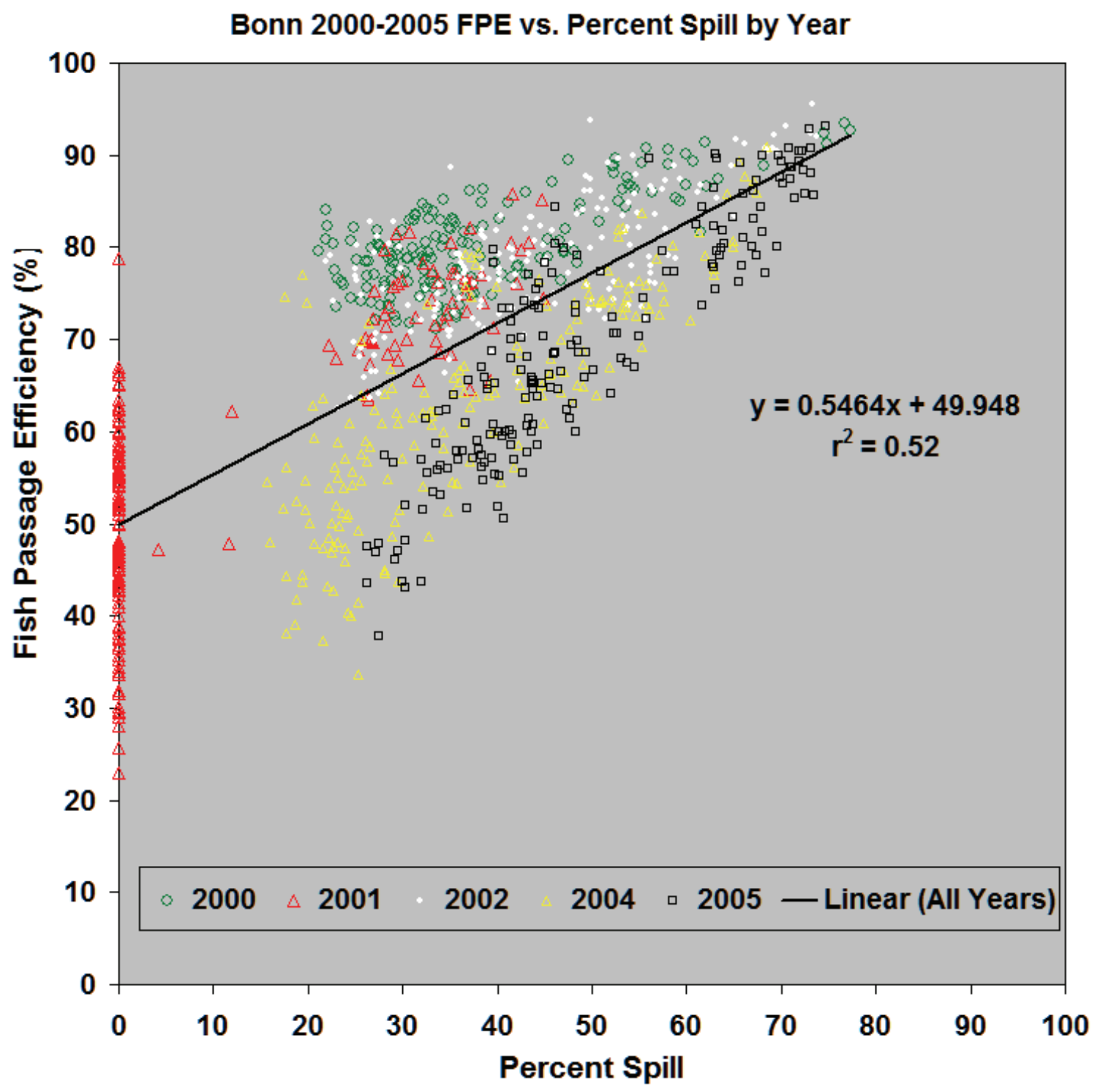

Figure 3.18. Regression of Fish-Passage Efficiency on Percent Spill for Bonneville Dam. Points are from five different years and were estimated for day and night periods. From Ploskey et al. (2006b).

Given relations between FPE and percent spill at Bonneville Dam (Figures 3.17 and 3.18), it was not surprising that spring FPE was higher during a TDG spill treatment than it was during a Day Cap treatment (Table 3.7). However, we were surprised that neither method showed expected increases in FPE in summer. In fact, Evans et al. (2006b) found a significant difference but with higher FPE for the Day Cap treatment. As Evans et al. (2006b) correctly pointed out, spill to the gas cap at night occurred in both treatments, and this may be partially responsible for confounding the results because the predominant arrival time of fish at the spillway on a given treatment day could be the determining factor affecting FPE. For example, if most fish arrived and passed at night during the high spill part of the Day Cap treatment, then FPE would be inflated for that treatment. 


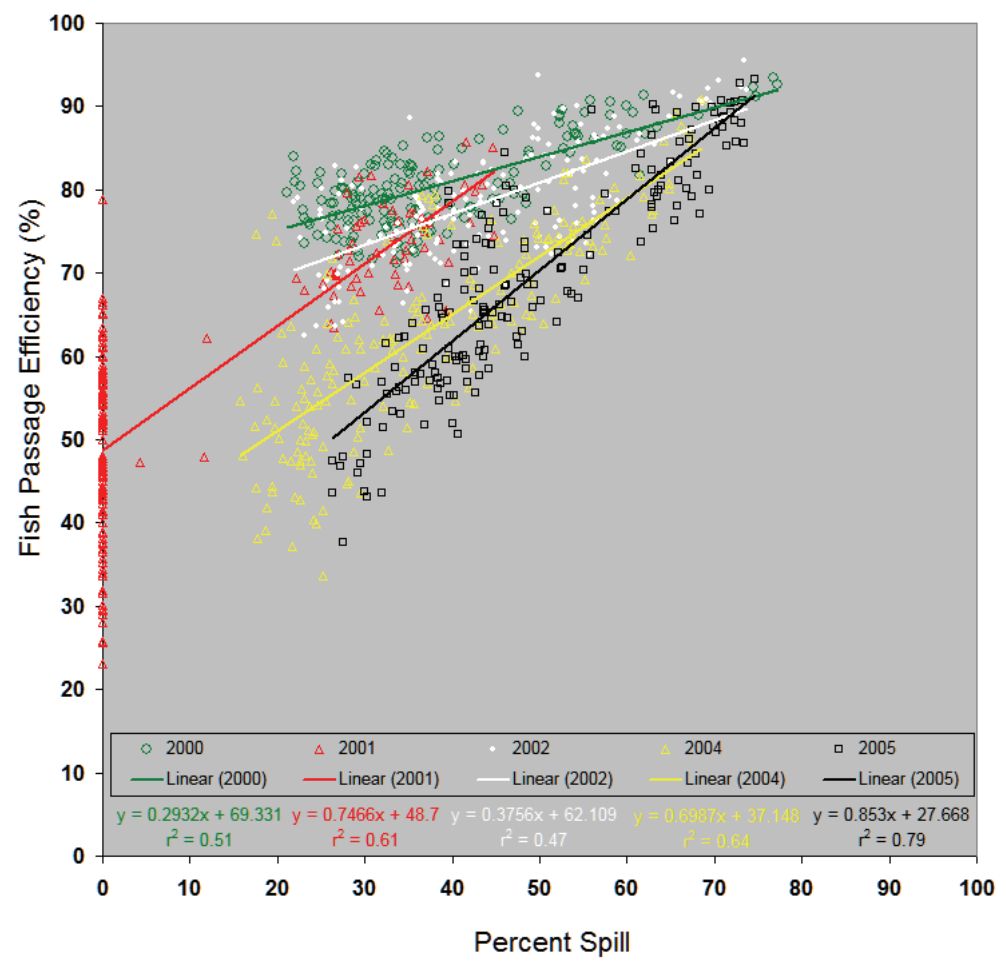

Figure 3.19. Regression of Fish-Passage Efficiency on Percent Spill by Year for Bonneville Dam. Points are from five different years and were estimated for day and night periods. From Ploskey et al. (2006b).

Table 3.7. Spring and Summer 2002 Fish Passage Efficiency Estimates

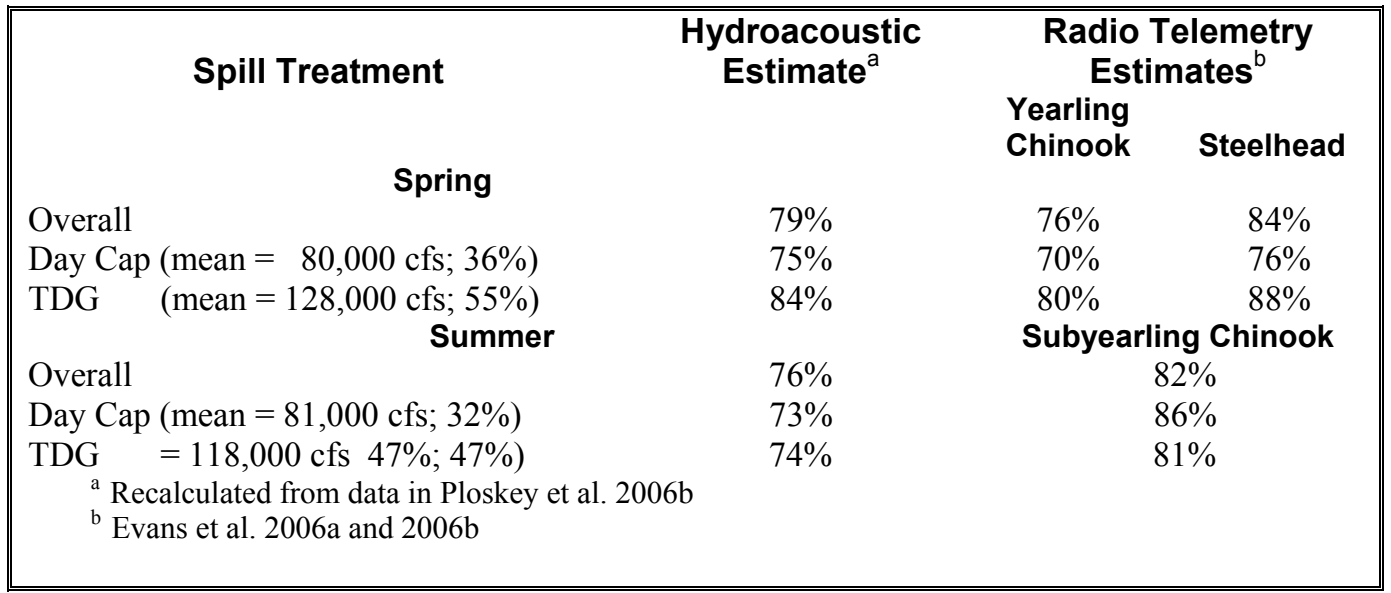

Total Project FPE estimates of 74\% in spring and 71\% in summer 2004 were made possible primarily by surface passage routes (Ploskey et al. 2005). There were no traveling screens (STS) deployed at B1 in 2004, spill efficiency was below average, and B2 FGE was about average for non-drought years. Fish passage efficiency is functionally a result of differences in structure and operations. For instance, the B1 sluiceway and $\mathrm{B} 2 \mathrm{CC}$ were responsible for a large proportion of the estimated total project fish passage relative to the amount of water discharged through those surface routes (Figure 3.20). Although the contribution of surface passage routes to FPE did not completely make up for the absence of screens at B1 or below-average spill efficiency, it did keep spring FPE within 6\% of estimates in 2000 and 2002 and 
summer FPE within 9\% of 2000 levels and $4 \%$ of 2002 levels, two non-drought years. Surface passage was especially important in maintaining a relatively high (71\%) FPE estimate in late summer, when Project FPE often declines. Project FPE calculated with no surface-passage component was about $67 \%$ in spring and 60\% in summer. In 2004, B2 screen guidance was about average for that structure (just under $50 \%$ in spring and just over $35 \%$ in summer) and Project spill efficiency was the lowest of the three nondrought years sampled.

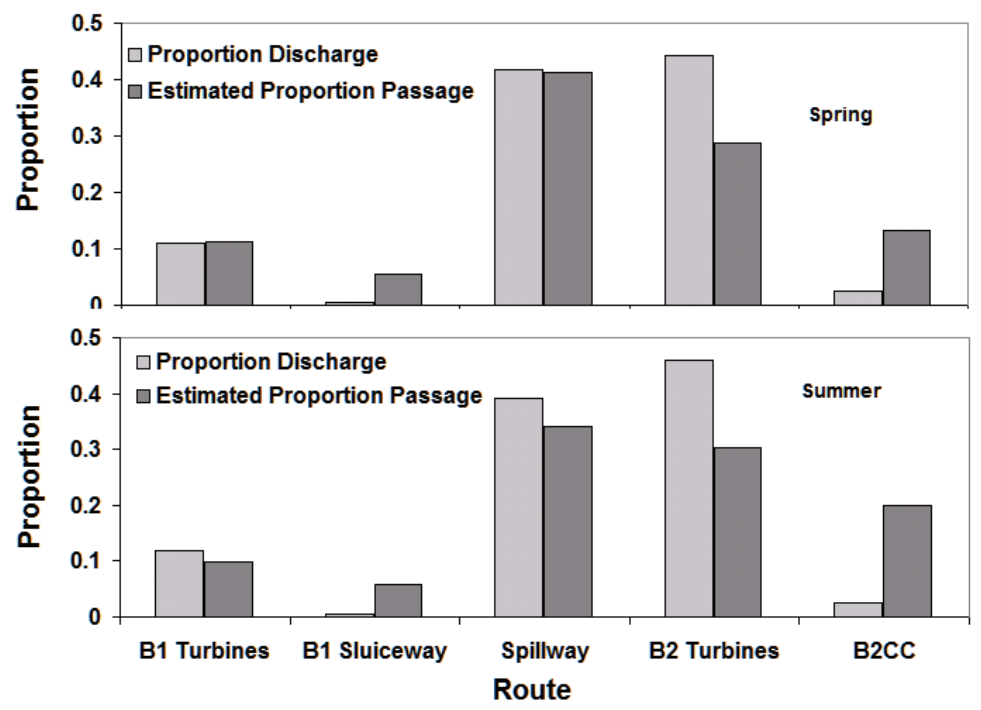

Figure 3.20. Distribution of Proportions of Total Project Discharge and Total Estimated Fish Passage through Different Structures at Bonneville Dam in Spring and Summer of 2004. (from Ploskey et al. 2005)

Adams et al. (2006) also noted that spillway efficiency was lower in 2004 and 2005 because more fish passed at B2, specifically through the corner collector. Although the addition of the corner collector did not increase Project FPE, it did achieve a Project FPE similar to that attained in previous years, mainly through spill. Furthermore, the corner collector helped achieve similar Project FPE with far less water than would have been used to attain the same FPE without the corner collector. The spillway discharged an average of 17 times more water than the corner collector.

An additional special study FPE evaluation of the early Spring Creek Releases of subyearling Chinook salmon was undertaken using three operational treatments in March 2004 (Ploskey et al. 2005). Bonneville Dam was operated according to the following three operational scenarios:

1. five days of $31,400 \mathrm{cfs}$ spill with no $\mathrm{B} 2 \mathrm{CC}$ operations

2. four days of $\mathrm{B} 2 \mathrm{CC}$ operation with no spill

3. approximately seven days of no spill and no B2CC operation.

Spill was supposed to be 50,000 cfs but because of gauging errors it was actually only about 31,400 cfs and about $23 \%$ of project discharge during the spill treatments. Project power generation continued as usual during all three scenarios, with clear B2 priority, and all three B1 sluiceway entrances open. Results for project FPE, spill efficiency, and sluiceway efficiency during the three operational conditions are shown in Figure 3.21. Project FPE was about 54\% during the spill and no B2CC operation, 45\% during no spill-B2CC operation, and only $32 \%$ under the no-spill, no-B2CC condition. The radio 
telemetry estimate of FPE for summer 2001 was $40 \%$ under similar spill conditions because of a severe drought, although the B2CC was not functioning in 2001. The hydroacoustic estimate for summer 2001 was $54 \%$. Passage of fish at the B1 sluiceway contributed from $1.7 \%$ to $5.1 \%$ to project FPE. Over three years of summer hydroacoustic estimates when subyearling Chinook salmon predominated, the B1 sluiceway passed an average of $7 \%$ of project passage. The B2CC accounted for about $17.1 \%$ of the Spring Creek hatchery fish that passed the Project and 24\% of fish that passed at B2 during the no spillB2CC operation.

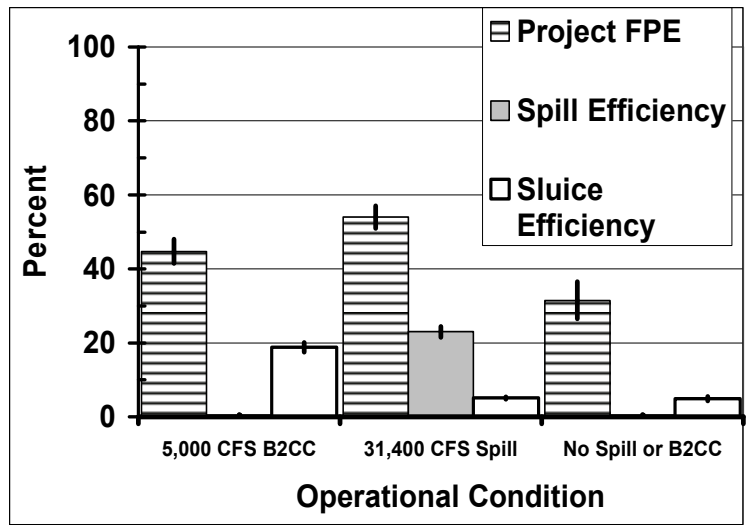

Figure 3.21. Project FPE, Spill Efficiency, and Sluiceway Efficiency $(B 1+B 2 C C)$ during Three Operational Conditions Presented to Fish from the Spring Creek Hatchery Release in March 2004. Vertical bars are the $95 \%$ confidence limits on the estimates.

Running the B1 sluiceway and $\mathrm{B} 2 \mathrm{CC}$ without spill produced a Project FPE that was nearly as high as that provided by 50,000 cfs of spill, B1 sluiceway operation, and no $\mathrm{B} 2 \mathrm{CC}$, and this was despite a poorly performing B1 sluiceway. Project FPE was as high during two of the days of B2CC-only operation as it was during the five days of spill. Under the other two days of $\mathrm{B} 2 \mathrm{CC}$ only operation, Project FPE was only about $12 \%$ lower than average FPE under spill. In contrast, four of seven days of no spill and no B2CC produced an FPE that ranged from 16\% to 39\% lower than FPE during spill at this early point in the season.

\subsubsection{Powerhouse FPE}

Powerhouse-specific FPE estimates were made for the years 2000 through 2005 (except for 2003) using both hydroacoustics and radio telemetry methods, but estimates were only comparable for a few of the five years. When surface routes were functional and sampled and in-turbine screens were deployed, powerhouse FPE reflected the combined efficiency of surface-passage routes and screens. These combined efficiencies included hydroacoustic estimates of B1 FPE in 2002 only and of B2 FPE in 2004 and 2005 only, and radio-telemetry estimates of B1 FPE in 2000, 2001, and 2002 only and of B2 FPE in 2004 and 2005 only). From 2000 through 2002, B1 FPE averaged 74\% for yearling Chinook salmon, $84 \%$ for steelhead, and 79\% for subyearling Chinook salmon. In 2004 and 2005, B2 FPE averaged 56\% for yearling Chinook salmon, $81.5 \%$ for steelhead, and $52.5 \%$ for subyearling Chinook salmon. The higher B2 FPE for steelhead was largely owing to the high B2CC efficiency. Hydroacoustic estimates of B2 FPE for 2004 and 2005 averaged 63\% for both seasons. When no surface routes were sampled (B1 in 2001 by hydroacoustics) or functioning (B2CC was closed in 2000, 2001, and 2002), powerhouse FPE 
was the same as powerhouse FGE, which is described in Section 3.4 below. When screens were not deployed at B1 in 2004 and 2005, powerhouse B1 FPE was equivalent to B1 sluiceway efficiency relative to $\mathrm{B} 1$, which was described in Section 3.2.4 above.

\subsubsection{Synthesis and Conclusion about Major Passage Metrics}

Prioritizing routes by survival rate would seem to be a logical first step toward the goal of maximizing Project survival, and therefore a thorough understanding of route-specific survival is critical for choosing the best route for fish. After routes are ranked from highest to lowest survival, the next step would be to adjust project operations to maximize passage through the safest routes. If turbines were a safer route than some spill bays, then using spill to maximize FPE may not be consistent with the goal of maximizing Project survival. However, if the safest routes turned out to be non-turbine routes, and the goal was to maximize passage by non-turbine routes, then the discussion and recommendations of Ploskey et al. (2006b), which are paraphrased in the next paragraph, also make sense.

The most efficient approach to increase non-turbine passage is to optimize percent flow to the B1sluiceway and $\mathrm{B} 2 \mathrm{CC}$ because these routes can reduce turbine passage by out-competing adjacent turbines for fish. The spillway cannot compete directly with turbines for fish. Spill should not be eliminated, but it may be possible to reduce reliance on spill to pass juvenile salmonids by fully realizing all potential benefits of surface passage through structural and operational changes at the powerhouses. Turbines are about as efficient as the spillway at any percentage of project flow, but surface routes are much more efficient than turbines at low percent flow (Figure 3.13). The average percent of B1 flow through the B1 sluiceway (1\%-2\%) is well below an optimum amount of $10 \%$ (see Figure 3.10), but hopefully planned improvements in that system will greatly improve its performance in the future. Given the very high effectiveness of surface routes at the lowest flow (Figures 3.15 and 3.16), we recommend testing the use of many low-flow surface outlets at B1 versus the use of a few outlets passing equivalent flow. Responses of percent of adjacent powerhouse passage through surface flow outlets like the B1 sluiceway increased very rapidly at low levels of percent flow, and this clearly indicates that juvenile salmonids preferentially select surface outlets over adjacent turbines. The high effectiveness of surface outlets and proximity to turbines should make them the first choice of managers for optimizing flow to increase nonturbine passage rather than spill. Without structural modification, attaining $10 \% \mathrm{~B} 1$ flow to the sluiceway requires shutting down turbines, which is how $50 \%-100 \%$ of B1 flow to the sluiceway was possible at times. Given the B2 powerhouse priority, it is difficult to imagine increasing percent of B2 flow to the B2CC much above the median 4\% observed in 2004 and 2005. The installation and testing of a smolt guidance device in the B2 forebay may be a viable alternative to increasing percent flow from $4 \%$ to $15 \%$. Previous observations of $10 \%-15 \%$ of B2 flow to the B2CC always occurred at night when turbines were shut down to accommodate increased spill at night.

Percent spill clearly has an overriding influence on spill and fish-passage efficiency and is an important tool to improve spill and fish-passage efficiency, but spill effectiveness is nearly constant at just over 1:1 over a wide range of percent spill. Spill has been used to increase non-turbine passage at Bonneville Dam, but it is not an efficient use of water because the project has two islands that isolate spillway flow from powerhouse flow before fish can select a preferred route. Consequently, spill efficiency will always be directly proportional to percent spill, with effectiveness ranging from about 0.7 to 1.3 . 


\subsection{Surface Flow Outlets}

\subsubsection{Introduction}

Surface flow outlet (SFO) technology is a primary management strategy to safely pass juvenile salmonids at Bonneville Dam. An SFO is a non-turbine, water-efficient passage route with an overflow structure through which flow and fish pass over a dam. The Biological Opinions on operation of the Federal Columbia River Power System (FCRPS) (NOAA Fisheries 1995, 1998; 2000; 2004) mandated development of surface bypasses at Bonneville Dam, because FGE and smolt survival associated with turbine intake screens was substandard (e.g., Dawley et al. 1992; Gilbreath et al. 1993; Monk et al. 1999a). In the mid-1990s the USACE instituted a formal Surface Flow Bypass Program whose goal was to "develop and evaluate surface bypass and collection prototype concepts that will lead, if justified by prototype test results, to permanent systems for improving survival of juvenile salmon..." (USACE 1995). The Independent Scientific Advisory Board reviewed and supported this initiative (Bisson et al. 1999). Synthesis reports on SFO development at Bonneville Dam can be found in Giorgi and Stevenson (1995), Johnson et al. (1997), Dauble et al. (1999), and Johnson and Dauble (2006).

At Bonneville Dam, three surface flow outlets have been studied: the B1 Sluiceway, the B1 Prototype Surface Collector, and the B2 Corner Collector. Our purpose in this section is to describe physical, hydraulic, and biological characteristics of these three structures as juvenile salmonid passage routes.

\subsubsection{B1 Sluiceway}

For over 30 years, the Bonneville Dam First Powerhouse (B1) sluiceway has been operated as a nonturbine passage route for juvenile salmonids. An ice-trash sluiceway extends along the surface of the forebay side of the B1 powerhouse. There is a leaf gate above each turbine intake. Flow through sluice gates is strongly influenced by forebay elevation. Maximum total capacity of the sluiceway is about $2,100 \mathrm{cfs}$. A gate at the south end of the sluiceway controls sluiceway channel flow. At this point, flow plunges into a raceway, which turns downstream and discharges into the tailrace at the south end of the $\mathrm{B} 1$ powerhouse. The following material covers investigations of the B1 sluiceway as a passage route for downstream migrants, including the early studies of the 1960s-1980s, the 1996 trash-rack blockage study, and the total project passage studies in 1999-2005.

\subsubsection{Early Studies: 1960s-1980s}

Michimoto and Korn (1969) investigated the potential for passing smolts through the B1 sluiceway. Using mark-recapture techniques, they estimated that hundreds of thousands of smolts passed the dam via the sluiceway. These authors surmised that many more would have passed through the sluiceway had its flow been maximized at 1,500 cfs instead of the $832 \mathrm{cfs}$ necessary for their sampling operations. Michimoto and Korn (1969) concluded that sluiceway passage was more similar to spillway passage than turbine passage because of the hydraulic and physical characteristics of each passage route. They recommended full-time B1 sluiceway operation at 1,500 cfs during the downstream migration period.

A decade later, Uremovich et al. (1980) found that juvenile salmonid passage in spring and summer at the sluiceway was significantly $(\mathrm{P}<0.01)$ higher with "split" gates $(4 \mathrm{~B}, 6 \mathrm{~B}, 7 \mathrm{~A}, 10 \mathrm{C})$ than with "adjacent" gates $(6 \mathrm{~A}, 6 \mathrm{~B}, 6 \mathrm{C})$. They observed the highest concentrations of fish in gatewells where the 
intakes are near or adjacent to walls (6B, 7A, and 10C). This suggested that forebay walls or shorelines, and possibly associated vortices or eddies, might serve to guide and concentrate smolts.

Willis and Uremovich (1981) continued sluiceway research at B1 in 1981. Their goal was to provide estimates of sluiceway efficiency under their proposed optimum operating conditions. Fisheries managers considered this information when they decided which smolt bypass alternative was preferred (STS, sluiceway, or both). Willis and Uremovich (1981) found that passage per sluice gate at 6B and 7A, respectively, was 6.1 and 3.7 times higher at full flow ( $\sim 75 \mathrm{cfs}$ per gate) than at half flow ( $\sim 240 \mathrm{cfs}$ per gate). This implied that "fish attraction" was positively related to the amount of water entering a sluice gate. They estimated sluiceway bypass efficiencies (sluice passage divided by total powerhouse passage) to be $83 \%$ for steelhead, $58 \%$ for yearling Chinook salmon, $50 \%$ for coho salmon, $42 \%$ for sockeye salmon, $10 \%$ for subyearling Chinook salmon "migrating naturally," and $4 \%$ for hatchery subyearling Chinook salmon. Given these results, Willis and Uremovich (1981) recommended the sluiceway at B1 be operated in conjunction with a STS bypass system. They felt a "hybrid" system would reduce delay and decrease turbine passage over either the STS or sluiceway as a stand-alone smolt bypass. A combination of sluiceway and STS has been operated routinely at B1 since the early 1980s.

Collectively, the early sluiceway research demonstrated that surface routes would pass appreciable numbers of smolts at B1. However, fisheries managers felt the sluiceway system was inadequate as a stand-alone system because sluiceway flow was limited to about 2,100 cfs, and conveyance and outfall conditions were poor. Therefore, an intake screen system was installed at B1.

\subsubsection{Trash-Rack Blockage Study: 1996}

In 1996 at B1, trashracks at units 3 and 5 were blocked to El. $33 \mathrm{ft}$ (about $41 \mathrm{ft}$ deep) as an inexpensive, preliminary surface bypass test. The purpose of the blockages was to occlude part of the intake entrance area to intensify and deepen the "zone of separation" between the turbine flow and surface sluiceway flow. The intent was to determine if surface-oriented smolts would exhibit an enhanced proclivity to resist sounding if a large zone of separation could be established.

The primary results of the evaluation of trash rack blockages at B1 in 1996 come from fixed hydroacoustics. Too few radio-tagged fish were present in the area of interest during the experimental treatments to provide meaningful radio telemetry estimates of passage. Blocking in spring increased sluiceway passage at Gate 3B by $14.6 \%$ and at Gate 5B by $12.8 \%$; however, neither increase was statistically significant because the tests lacked sufficient statistical power (Ploskey et al. 1998). In summer 1996, blocking did not significantly increase sluice passage or sluice passage efficiency (Ploskey et al. 1998).

Split-beam transducers aimed upward about 10-15 ft upstream of Gates 3B and 5B were used to monitor the direction of fish movement. A ratio of upward-moving to downward-moving fish was used to characterize effects of the blockages. A ratio near 1 implies no effect, greater than 1 implies a positive effect, and less than 1 implies a negative effect. In front of Gate $3 \mathrm{~B}$, the ratio of upward-moving to downward-moving fish was significantly greater with the blockages in (mean ratio 4.0) than with them out (mean ratio 1.9). No significant difference in the upward/downward ratio was found at Gate 5B. In general, ratios of mean sluice passage rates with and without blockages were 4.8 for Gates $3 \mathrm{~B}$ and $5 \mathrm{~B}$ pooled, 6.8 for Gate 3B, and 2.2 for Gate 5B (Ploskey et al. 1998). The same ratio for turbine passage at 
3B and 5B pooled was 0.56 (Ploskey et al. 1998). Daily passage was highly variable, which affected the ability to statistically detect differences in passage with and without blockages. In conclusion, the experiment with trash rack blockages at B1 in 1996 did not reveal negative impacts from the blockages.

\subsubsection{Total Project Passage Studies: 1999-2005}

Efficiency and effectiveness at the B1 Sluiceway, relative to the B1 powerhouse, were estimated as part of the total project passage studies designed to estimate fish passage efficiency for Bonneville Dam as a whole during 2000-2005. Recall, 2001 was a drought year, so the B1 turbines were operated sparingly during the downstream migration period. No passage studies were conducted in 2003 . Except for 2000, B2 was the priority powerhouse for power production. Approximately one-third of the yearling and subyearling Chinook salmon passing B1 used the sluiceway during studies in 2000-2005; for steelhead, about one-half used the sluiceway and one-half used the B1 turbines (Tables 3.4 and 3.5). For the run-at-large during spring and summer, sluiceway efficiencies were also about one-third of total B1 passage (Tables 3.2 and 3.3). Seasonal effectiveness estimates for the B1 sluiceway average 9.6 in spring and 13.5 in summer for the run at large (Tables 3.2 and 3.3), 14 for yearling Chinook salmon, 18.9 for steelhead (Table 3.4), and 12 for subyearling Chinook salmon (Table 3.5).

\subsubsection{Conclusion}

The B1 sluiceway continues to be a valued passage route for juvenile salmonids at Bonneville Dam. It could provide the basis to develop a more extensive surface flow outlet at B1.

\subsubsection{B1 Prototype Surface Collector: 1998-2000}

\subsubsection{Introduction}

The USACE Surface Bypass Program started in 1995 with development of alternatives for SFOs at B1 (Harza and ENSR 1996a). The alternatives included a full powerhouse collection structure (called Alternative A), a high-flow corner collector at the south end of the powerhouse, and a bypass channel attached to intakes with extended bar screens. To test the SFO concept for Alternative A, a prototype surface collector (PSC, Figure 3.22) was retrofitted to the upstream face of B1 at units 3-6 in 1998.

The purpose of the PSC was to provide a field site to investigate hydraulic and biological performance for a potential surface bypass at B1. Fish entering the PSC passed through the structure into the turbine intake behind the PSC (Figure 3.23). The PSC was not designed to actually bypass fish around turbines. The intent was to use the PSC to examine entrance hydraulics and to examine the efficacy of surface bypass at B1 before building a large-scale prototype or full production surface bypass facilities at B1. An extensive biological evaluation was undertaken in 1998. In 1999, limited research occurred to prepare for culminating tests in 2000.

In 2000, the PSC was extended beyond units 3 through 6 to also cover units 1 and 2, because a noticeable number of smolts were observed in 1998 and 1999 to move obliquely from north to south across the forebay of the PSC. The PSC was thoroughly evaluated in 2000. The objectives for SFO research at B1 in 2000 were to 1) confirm proof-of-concept for the surface bypass at B1 that was established in 1998, 2) estimate PSC performance; and 3) study behavioral processes and mechanisms that affect performance to aid future surface bypass designs. The PSC results presented below will focus 
on the 2000 study because it was the most extensive and the PSC was at its highest level of structural development.

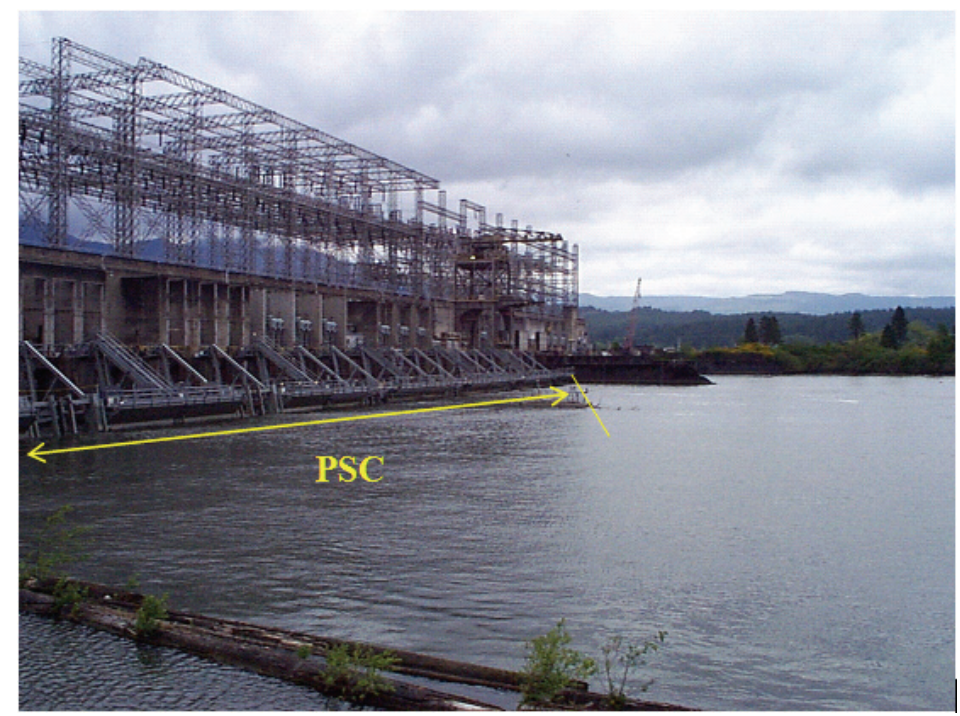

Figure 3.22. The Prototype Surface Collector at B1. (Photograph courtesy of M. Weiland)

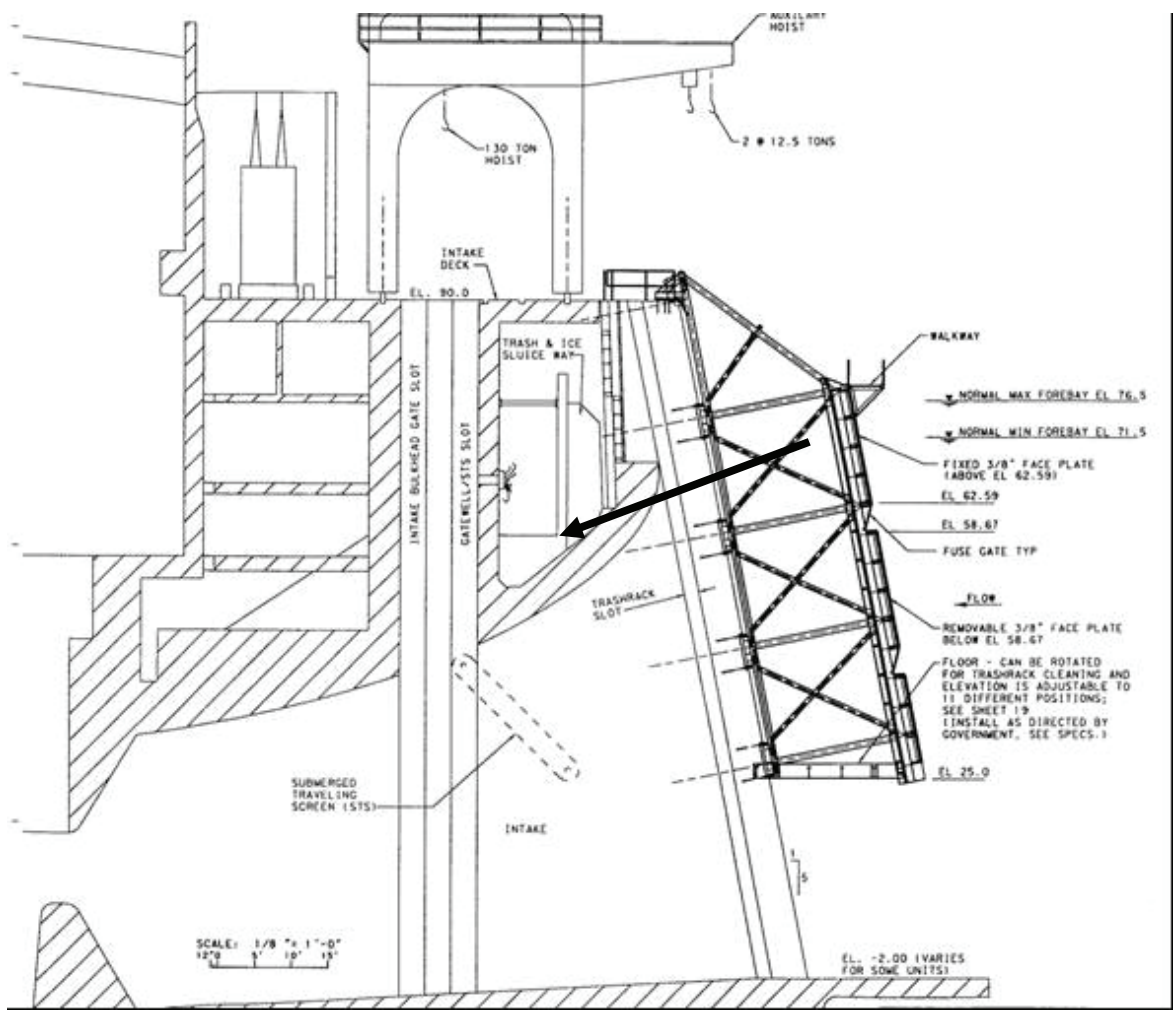

Figure 3.23. Side View of the PSC at B1. Arrow depicts flow into and through the PSC and into the turbine intake behind. PSC floor was actually installed at El. $30.5 \mathrm{ft}$, not $25.0 \mathrm{ft}$. Modified from Plate 4 in Harza and ENSR (1996a). 


\subsubsection{PSC Structure and Hydraulics}

The PSC was retrofitted to the upstream face of B1 at units 1-6 (Table 3.8; Figures 3.22, 3.23, and 3.24). A detailed description of the PSC test structure can be found in Harza and ENSR (1996a). The PSC was located in the thalweg of the Columbia River at B1 (Figure 3.25). Vertical slots in the PSC in front of middle (B) intakes at each unit were configured to have 5-ft- or 20-ft-wide openings. Slot width during the evaluation was set according to a randomized block design. These widths were chosen to maximize differences in flows and velocities between the configurations to increase the likelihood of detecting differences in smolt response to PSC slot widths. PSC entrances were 40 to $46 \mathrm{ft}$ deep depending on forebay level (the PSC floor was at El. $30.5 \mathrm{ft}$ ). The mean velocity at the entrance ranged from 3.8 to $8.3 \mathrm{fps}$, depending on slot width (Table 3.8). Flow through the entrances was 1,700 cfs for 5$\mathrm{ft}$ slots and 3,300 cfs for 20-ft slots. Water velocity in the B1 forebay is generally higher in the north half than in the south half. Flow relatively close to units 1 to 6 (within $100 \mathrm{ft}$ ) had a southerly component. At the PSC, water velocities were about 4 to $7 \mathrm{fps}$ and had a downward component (Figure 3.26).

Table 3.8. Characteristics of the PSC for 5 -ft- and 20 -ft-wide Entrances. The forebay was at El. $75 \mathrm{ft}$, the PSC floor was at El. $30.5 \mathrm{ft}$, and turbine discharge was 10,000 cfs / unit. Data are from the 1:25 scale physical model.

\begin{tabular}{|lcc|}
\hline Characteristic & 5-ft & 20-ft \\
\hline \hline PSC flow (cfs) & 1,700 & 3,300 \\
Area $\left(\mathrm{ft}^{2}\right)$ & 223 & 890 \\
Velocity (fps) & $7.1-8.3$ & $3.8-4.6$ \\
\hline
\end{tabular}

Throughout the USACE Surface Bypass Program, physical models have been used to investigate specific design elements in the development process. For the PSC, several design elements were investigated on the B1 1:25 scale sectional and 1:40 scale general models. Also, Alternative A (described above) was modeled in the 1:40 scale physical model of B1. In general, developers observed some differences and similarities in water velocities for the 5 - $\mathrm{ft}$ and $20-\mathrm{ft}$ configurations for the conditions studied. Approach velocity was higher for the 20 - $\mathrm{ft}$ than for the 5 - $\mathrm{ft}$ configuration, although mean entrance velocities at the PSC slot were higher for the 5-ft than for the 20-ft width. Downward velocity components become pronounced deeper in the water column for the $20-\mathrm{ft}$ than for the 5 - $\mathrm{ft}$. See Sweeney et al. (2007) for summary of hydraulic modeling for the PSC and Alternative A.

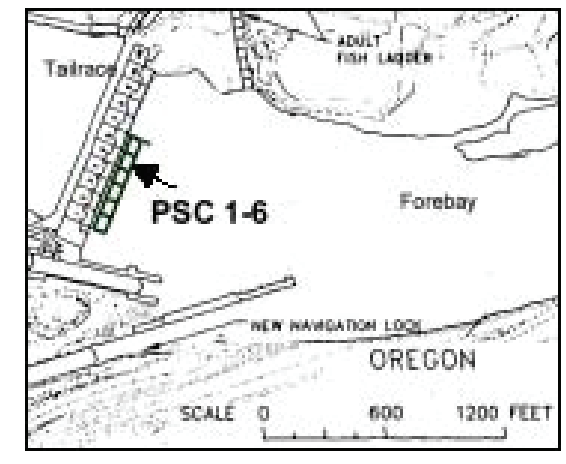

Figure 3.24. B1 Forebay and Powerhouse Showing the PSC Upstream of Turbines 1-6 


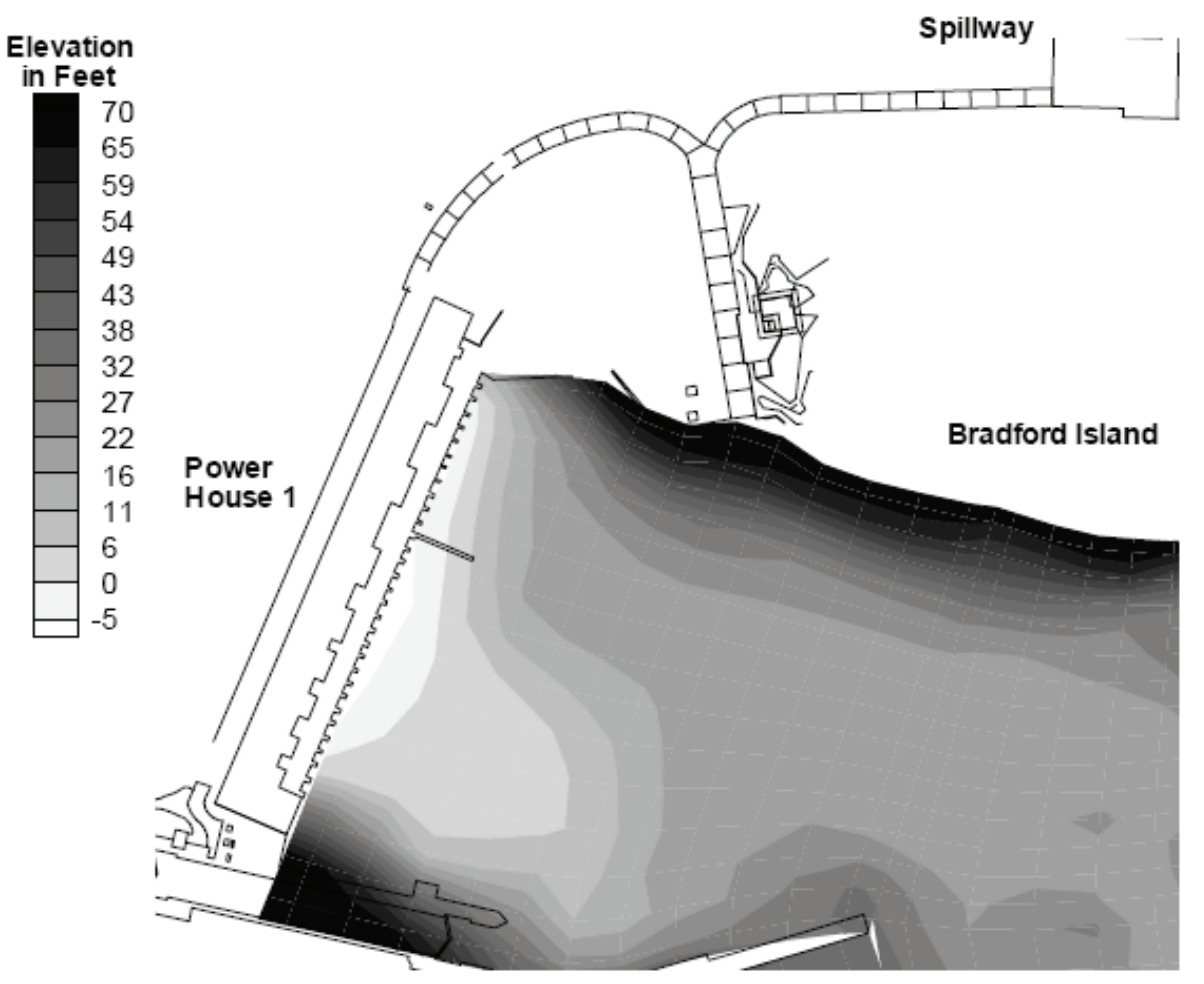

Figure 3.25. B1 Forebay Bathymetry Relative to Sea Level. Figure courtesy of C. Rakowski, PNNL, December 5, 2000.

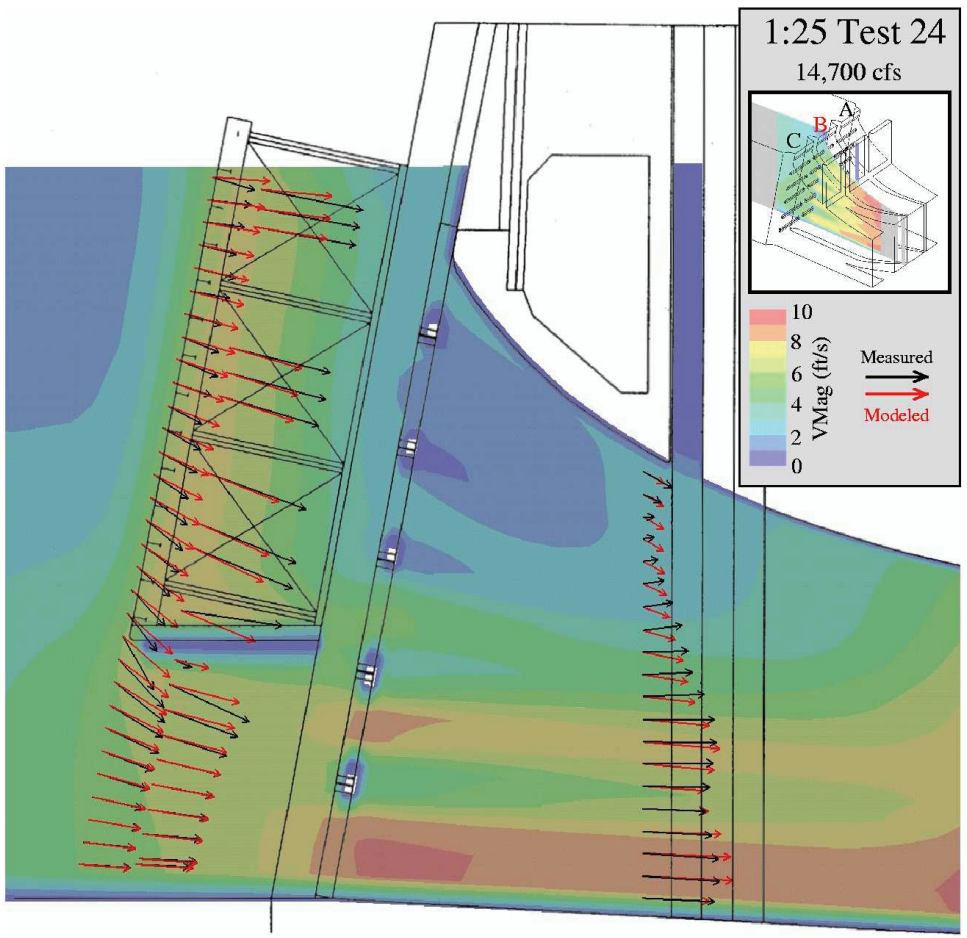

Figure 3.26. Sectional View of the PSC Showing Water Velocity from a CFD Model and a 1:25 Scale Physical Model. Figure courtesy of L. Ebner, CENWP. 


\subsubsection{PSC Operating Parameters}

Operation of the PSC in 2000 involved the following parameters: PSC trashracks, entrance widths, entrance locations, turbine operations, sluiceway operations, forebay elevation, intake screens, and experimental design.

PSC Trashracks - The PSC trashracks were in place during the 1998 and 1999 tests. However, project maintenance did not require them because there are trashracks at the turbine intakes. Also, it was possible the PSC trashracks could cause some smolts to avoid the PSC entrances, so the PSC trashracks were removed for the 2000 test.

PSC Entrance Widths - During the 1998 and 1999 tests, PSC performance and fish behavior were compared for 5-ft vs. 20-ft-wide vertical entrances at PSC 3 and PSC 5. In 1998, the 20-ft entrance was more efficient than the 5-ft entrance in spring (Hensleigh et al. 1998 and Ploskey et al. 2001a). In summer 1998, Ploskey et al. (2001a) using hydroacoustics found that the collection efficiencies for 5-ft and 20-ft entrances were similar, while Hensleigh et al. (1998) using radio telemetry reported that the 20$\mathrm{ft}$ entrance had much higher efficiency than the 5-ft entrance. Results from the 1999 hydroacoustic study (Ploskey et al. 2001b) were similar to those in 1998 (Ploskey et al. 2001a). Given the 1998-1999 results, it did not seem necessary to continue to compare 5 -ft and 20 - $\mathrm{ft}$ entrance widths in 2000 . Thus, PSC entrance width was a constant $20 \mathrm{ft}$ in 2000 .

PSC Entrance Locations - The PSC had the capability for six entrances, one in front of the B-intake of each unit at units 1-6. To maximize PSC passage, all six entrances were opened.

Turbine Operations - For purposes of the PSC evaluation, turbine units 1-6 were priority units at B1 in 2000 to reduce hydraulic variability at the PSC. Units 1-6 were all operational for PSC tests in spring and summer 2000.

Sluiceway Operations - Open sluice gates at the B-slots behind the PSC entrances improved hydraulics inside the PSC, at least at the surface. Sluiceway flow probably had little effect on hydraulic conditions at depths below about $2 \mathrm{~m}$ within the PSC. For example, without an open sluice gate, surface flow was sometimes moving upstream and out of the PSC in the B slot. Upstream flow inside the PSC was considered undesirable because smolt passage through the PSC may be reduced. Thus, B-slot sluice gates behind each PSC entrance were opened with the weir crest at El. $72 \mathrm{ft}$ for the 2000 study.

Forebay Elevation - Forebay elevation affected PSC inflows because the PSC was fixed in place. To minimize this effect on the PSC test in 2000, forebay elevation was constrained at $\pm 1 \mathrm{ft}$ around El. $74.5 \mathrm{ft}$.

Intake Screens - Intake screens were deployed at units 1-6 during the PSC evaluations.

\section{Biological Evaluations}

The 2000 PSC evaluation encompassed PSC efficiency and forebay fish migration patterns, including the following biological research methods:

- radio telemetry to determine species-specific PSC performance and movement patterns for yearling Chinook salmon and steelhead (Evans et al. 2001a, b) 
- acoustic telemetry to study three-dimensional movement patterns and PSC performance for yearling Chinook salmon and steelhead (Faber et al. 2001)

- fixed hydroacoustics to estimate fish passage rates and determine PSC performance for the run at large during spring and summer (Ploskey et al. 2002a and 2002b)

- multi- and split-beam hydroacoustics to assess fish movements near the PSC (Johnson et al. 1999, 2000, and 2001)

- physical scale and computational fluid dynamics modeling to document forebay hydraulic conditions (Rakowski et al. 2001, 2005)

The key findings of the 2000 PSC evaluation presented below are organized by location, from approach in the forebay to passage at the dam.

The downstream migrants that entered the B1 forebay tended to follow the bulk flow as they approached the dam. For example, Faber et al. (2001) tracked acoustic-tagged fish within $100 \mathrm{~m}$ of the dam and found that "as fish approach the dam they hold to the thalweg..." (p. 19). More tagged fish approached the dam at units 4-6 than any other region at B1 (Evans et al. 2001a, b, p. 38; Faber et al. 2001, p. 20). However, fish generally ceased to follow the bulk flow once they encountered the dam.

Discovery efficiency ${ }^{\mathrm{a}}$ represents the percentage of tagged fish entering the B1 forebay that actually encountered the PSC flow nets. Radio telemetry estimates of discovery efficiency were $74 \%$ for steelhead and $63 \%$ for yearling Chinook salmon (Table 3.9). Acoustic telemetry estimates of discovery efficiency were $79 \%$ for steelhead and $90 \%$ for yearling Chinook salmon (Table 3.9). A relatively large percentage of fish entering the B1 forebay migrated within close proximity $(<6 \mathrm{~m})$ to PSC entrances at Units 1-6 even though passage was usually possible at the entire powerhouse, units 1-10. Thus, most smolts seemingly had opportunity to discover the PSC flow nets.

Table 3.9. Discovery Efficiency Estimates based on Radio and Acoustic Telemetry at B1 in 2000. Sample sizes of tagged fish are given in parentheses (number detected within $6 \mathrm{~m}$ of a PSC entrance out of the total entering the B1 forebay). Radio telemetry data were obtained from Evans et al. (2001; p. 27). Acoustic telemetry data were obtained from Faber et al. (2001; modified from data on p. 15).

\begin{tabular}{|c|c|c|}
\hline Species & Radio Telemetry & $\begin{array}{l}\text { Acoustic } \\
\text { Telemetry }\end{array}$ \\
\hline Steelhead & $74 \%(356$ of 481$)$ & $79 \%$ (110 of 139$)$ \\
\hline Yearling Chinook & $63 \%(341$ of 545$)$ & $90 \%(28$ of 31$)$ \\
\hline
\end{tabular}

${ }^{a}$ Discovery efficiency is estimated by dividing the number of tagged juveniles detected within $6 \mathrm{~m}$ of the PSC entrances by the total number of tagged fish entering the B1 forebay. 
The vertical distribution of tagged and untagged smolts approaching and encountering the PSC was surface oriented (Evans et al. 2001a, b; Ploskey et al. 2001a and 2002b). Depth of approach of radiotagged fish to the PSC was determined by the vertical position of the antenna recording the first detection for a particular tagged specimen. The vertical distribution of radio-tagged fish was classified as shallow $(<6.5 \mathrm{~m})$ or deep $(>6.5 \mathrm{~m})$. Radio-tagged steelhead were distributed shallower than yearling Chinook salmon (steelhead 76\% shallow and 24\% deep; Chinook salmon 53\% shallow and 47\% deep; Evans et al. 2001a; p. 32). In hydroacoustics evaluations at the face of the PSC (1-3 m away) in 2000, Ploskey et al. (2002b; p. xxi) detected 92\%-99\% of the targets above the floor of the PSC (El. $30.5 \mathrm{ft}$ ) in spring. In summer, $85 \%-96 \%$ were above the depth of the PSC floor. The vertical distribution of fish approaching the PSC corresponded well with the vertical position of the PSC entrances (Figure 3.27).

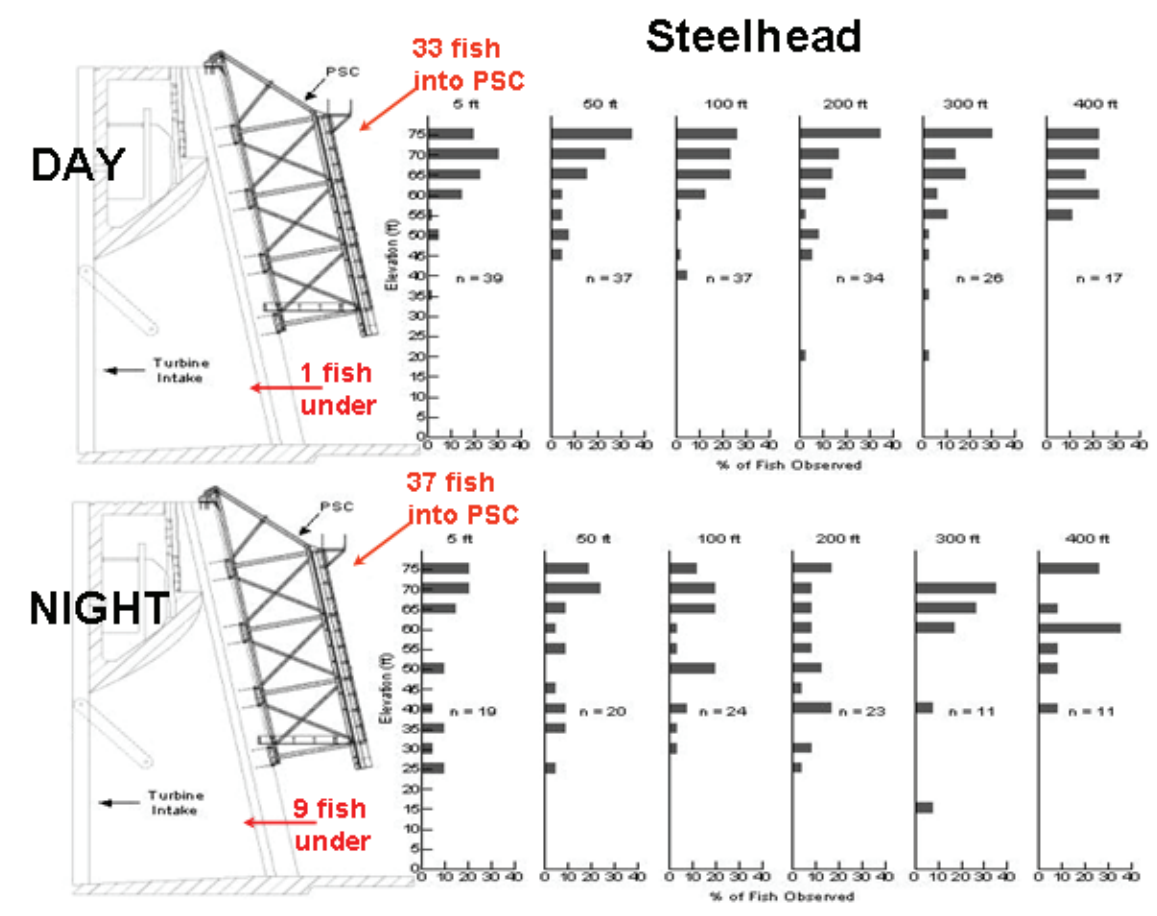

Figure 3.27. Vertical Distribution and Passage of Radio-Tagged Juvenile Steelhead during Day (Top) and Night (Bottom) at the B1 PSC in 2000. Figure from Faber et al 2001.

Radio telemetry estimates of entrance efficiency ${ }^{\mathrm{a}}$ were $60 \%$ for steelhead and $72 \%$ for yearling Chinook salmon (Table 3.10). Acoustic telemetry estimates of entrance efficiency were $64 \%$ for steelhead and 79\% for yearling Chinook salmon (Table 3.10). Entrance efficiency was higher for yearling Chinook salmon than for steelhead. Many tagged fish that appeared to get close enough to encounter (discover) the PSC flow nets seemed to eventually pass through the structure, but others apparently passed elsewhere (under the PSC, Units 7-10, or back out of the B1 forebay).

Three general movement patterns were displayed by radio- and acoustic-tagged fish: direct passage, searching, and milling. Direct passage was characterized by short forebay residence time $(<1 \mathrm{~h})$ before

\footnotetext{
${ }^{a}$ Entrance efficiency is estimated by dividing the total number of tagged juveniles entering the PSC by the total number detected within $6 \mathrm{~m}$ of the PSC entrances.
} 
passing into B1. Searching was displayed as active movement back and forth along B1, including the PSC, resulting in longer residence times (1-4 h) than observed for direct passage fish. Milling was defined as relatively long residence times $(>4 \mathrm{~h})$. Of the radio-tagged fish, $31 \%$ of the steelhead (61 of 200 ) and $47 \%$ of the Chinook salmon (100 of 214) passed directly, i.e., they passed at the first PSC entrance they encountered (Evans et al. 2001a, b). Results were similar for acoustic-tagged fish. Acoustic-tagged steelhead and Chinook had a higher percentage of direct passage at night than they did during the day. Non-direct movement was also exhibited in the hydroacoustic data (Johnson et al. 2001).

Table 3.10. Entrance Efficiency Estimates based on Radio and Acoustic Telemetry at B1 in 2000. Sample sizes of tagged fish are given in parentheses. Radio telemetry data were obtained from Evans et al. (2001a; p. 27, revised June 12, 2001). Acoustic telemetry data were obtained from Faber et al. (2001; modified from data on p. 15).

\begin{tabular}{|ccc|}
\hline Species & Radio Telemetry & Acoustic Telemetry \\
\hline \hline Steelhead & $60 \%(214$ of 356$)$ & $64 \%(70$ of 110$)$ \\
Yearling Chinook & $72 \%(246$ of 341$)$ & $79 \%(22$ of 28$)$ \\
\hline
\end{tabular}

Fish tracked with multi-beam hydroacoustics tended to move upstream and downstream equally, indicating milling behavior (Johnson et al. 2001). Milling behavior was also revealed as fish movements became more variable the closer the fish got to the PSC. Movements of fish tracked with hydroacoustics in the region $18 \mathrm{~m}$ in front of the PSC entrance at Unit 3 were generally obliquely downstream and southerly toward the dam (Johnson et al. 2001). In addition, Evans et al. (2001; p. 31) reported "that, in general, both steelhead and Chinook salmon moved laterally from north to south along the face of the PSC before passing into it."

Some acoustic-tagged fish and fish tracked with multi-beam hydroacoustics exhibited positive rheotaxis within $\sim 6 \mathrm{~m}$ of PSC entrances (Faber et al. 2001; Johnson et al. 2001). That is, when some fish got relatively close to the PSC entrances they apparently turned and oriented upstream into the flow. Also, Johnson et al. (2001) observed that fish swam strongly upward in the water column in response to the downward component of the PSC flow net at the sample site at Unit 3. As determined by acoustic telemetry, fish classified as milling held at the sides of the B1 forebay and were oriented into the flow. Positive rheotaxis indicated that fish responded to environmental stimuli at the PSC, probably related to hydraulic conditions.

The forebay residence time of tagged fish that passed at B1 was about 4 to $10 \mathrm{~h}$. Yearling Chinook salmon passed the dam a little faster (by a few hours) than steelhead. Some tagged fish resided for a considerable amount of time in the forebay before passing (e.g., several days), as indicated by the relatively low median values compared to the means.

In spring 2000, the fish collection efficiency ${ }^{a}$ of the PSC was estimated on a species-specific basis for yearling migrant steelhead and Chinook salmon using radio and acoustic telemetry and for the run at large using fixed-location hydroacoustics (Table 3.11). During the hydroacoustic summer study, subyearling Chinook salmon dominated the out-migration. (The study ended before shad became prevalent in the

- $\quad{ }^{a}$ Fish collection efficiency is defined as PSC passage divided by PSC passage plus passage under the PSC. 
forebay.) Thus, the hydroacoustic results for summer can be ascribed to subyearlings. Species-specific estimates of collection efficiency are important to decision-makers because different species may respond differently to smolt protection measures.

Radio telemetry estimates of collection efficiency were $82 \%$ for steelhead and $76 \%$ for yearling Chinook salmon (Table 3.11). Acoustic telemetry estimates of collection efficiency were $88 \%$ for steelhead and $96 \%$ for yearling Chinook salmon. For the purposes of passage modeling and planning, we believe the species-specific collection efficiency estimates from radio telemetry should be used, because the relatively large sample sizes for radio telemetry likely yielded more precise estimates than those from acoustic telemetry.

Table 3.11. Fish Collection Efficiency Estimates based on Hydroacoustics, and Radio and Acoustic Telemetry at B1 in 2000. Sample sizes are in parentheses. Hydroacoustic data from Ploskey et al. (2002b); adjusted for passage into the sluiceway behind the PSC entrances which was not sampled by hydroacoustics. Radio telemetry data from Evans et al. $(2001 ; \mathrm{p}$. 30 , revised June 12, 2001). Acoustic telemetry data from Faber et al. (2001; p. 15).

\begin{tabular}{|llccc||}
\hline Population & Season & Hydroacoustics & Radio Telemetry & Acoustic Telemetry \\
\hline \hline Steelhead & Spring & ---- & $82 \%(200$ of 258$)$ & $88 \%$ (70 of 80$)$ \\
Yearling Chinook & Spring & ---- & $76 \%(214$ of 312$)$ & $96 \%$ (22 of 23$)$ \\
Run-at-Large & Spring & $83 \%$ & ---- & ---- \\
Subyearling Chinook & Summer & $84 \%$ & ---- & --- \\
\hline \hline
\end{tabular}

Hydroacoustic estimates of collection efficiency (unadjusted for sluiceway passage behind the PSC) were $72 \%$ for both spring and summer (Figure 3.28). Note that the hydroacoustic process underestimated collection efficiency because passage into the sluiceway was not sampled at the gates open behind the PSC entrances (B-slots). The radio telemetry data, however, indicated that roughly $50 \%$ of PSC passage for both tagged species combined was via the sluiceway (S. Evans, pers. comm.). Thus, after adjusting the data for 50\% sluiceway passage in the PSC, the hydroacoustic estimates of collection efficiency were $83 \%$ for spring and $84 \%$ for summer 2000 (Table 3.11 ).
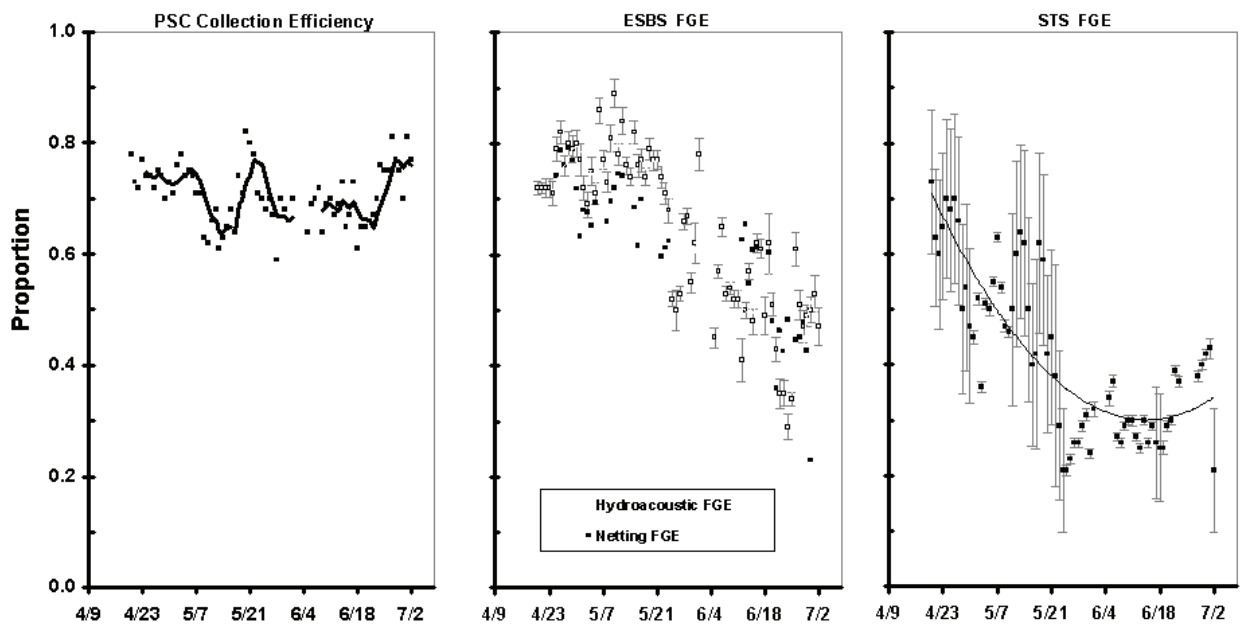

Figure 3.28. Daily PSC Fish Collection Efficiency (Left Panel) Compared to Fish Guidance Efficiency for a Prototype Extended Length Bar Screen in Unit 8 (Middle Panel) and a Submersible Traveling Screen in Units 7, 9, 10 (Right Panel). From Ploskey et al. (2002b) 
PSC fish collection effectiveness ${ }^{\mathrm{a}}$, as determined in the radio telemetry study, was 2.49 for steelhead and 2.30 for yearling Chinook salmon (Evans et al. 2001; p. 30, revised June 12, 2001). Acoustic telemetry estimates of effectiveness were 2.63 for steelhead and 2.87 for yearling Chinook salmon (Faber et al. 2001; p. 15). Based on hydroacoustics, PSC effectiveness was 2.15 in spring and 2.23 in summer. An effectiveness of 2 means that the percentage of fish moving into the PSC out of total passage was twice the percentage of water passing into the PSC. Trends in effectiveness were similar to those of collection efficiency because the percentage of water passing into each PSC entrance was fairly uniform.

The fish budgets for steelhead and yearling Chinook salmon based on radio telemetry were linked to the PSC performance metrics (Figure 3.29). This figure summarizes B1 passage and PSC performance for radio-tagged fish. We used radio telemetry data for this summary rather than acoustic telemetry because larger sample sizes were available for radio telemetry.

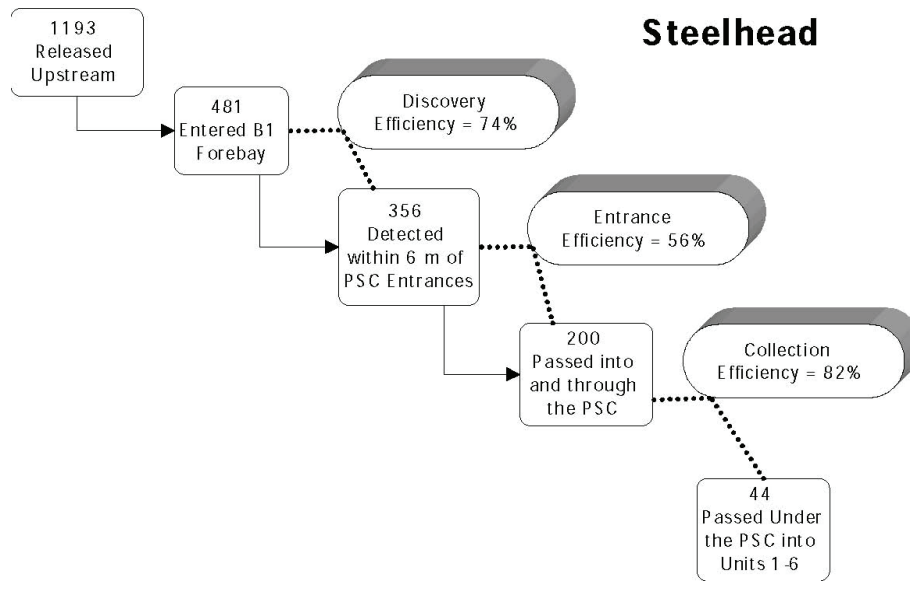

Chinook Salmon

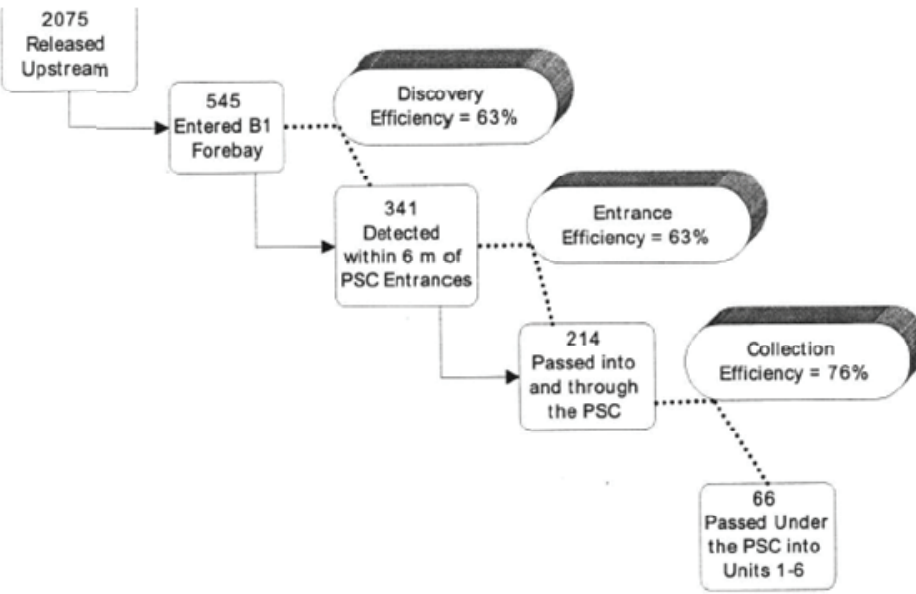

Figure 3.29. Fish Budgets Reflecting Discovery, Entrance, and Fish Collection Efficiencies for RadioTagged Steelhead (Top) and Yearling Chinook Salmon (Bottom). The fish budgets are based on data from Evans et al. (2001a, b), prior to the revisions in the data shown in Table 3.10 .

\footnotetext{
${ }^{\text {a }}$ Fish collection effectiveness is defined as PSC fish collection efficiency divided by proportion of water passing
} into the PSC out of total discharge at units 1-6. 
The fish collection efficiency of the PSC remained high in both the spring and summer seasons in 2000, unlike the fish guidance efficiency of the extended length bar screens and submersible traveling screens, which declined significantly from spring through summer (Figure 3.28). The daily collection efficiency data for the PSC varied between $60 \%$ and $80 \%$. Fish guidance efficiency for the two types of intake screens was about $20 \%$ to $90 \%$. The decline in summer for intake screen guidance efficiency is a recurring pattern (Ferguson et al. 2005).

\subsubsection{Summary}

Based on the collective data during the 1998-2000 PSC evaluation period (summarized by Johnson and Carlson 2001), researchers found that the surface bypass concept as applied at B1 was an efficient way to collect juvenile salmonids and minimize turbine passage. Fish collection efficiency estimates from hydroacoustics, radio telemetry, and acoustic telemetry methods comported reasonably well. The highest quality and most applicable data for fish collection efficiency, because of large sample sizes and the PSC covered units 1-6 are from the 2000 evaluation. For the purposes of planning and analysis for constant turbine operations, at one slot opening, the following fish collection efficiency estimates should be used:

$$
\begin{array}{ll}
\text { Yearling Chinook salmon } & 76 \% \\
\text { Steelhead trout } & 82 \% \\
\text { Subyearling Chinook salmon } & 84 \%
\end{array}
$$

Fish collection efficiency was similar between spring and summer, i.e., it did not decrease in summer but stayed largely unchanged while the run composition changed. This is not true of other smolt bypass approaches that have decreasing efficiency as the season progresses. Fish collection efficiency for the B1 PSC was higher than that for the surface bypass and collector SFO at Lower Granite Dam, and comparable to that for the Wells Dam SFO. Extending the PSC to Units 1 and 2 in 2000 was worthwhile because the surface bypass entrances at Units 1 and 2 passed a substantial proportion of total PSC fish passage (23\% to $28 \%$ ). According to radio telemetry data from 2000, the PSC would have increased fish passage efficiency at Bonneville Dam $18 \%$ for steelhead and $10 \%$ for Chinook salmon had it been a functional bypass system. The PSC was twice as effective (percentage fish divided by percentage water) as spill at passing fish at Bonneville Dam in 2000.

\subsubsection{After the PSC}

The B1 PSC showed promise as a powerhouse retrofit SFO, but it was not followed by a full production structure. The main reasons for this included

- uncertainty about fish response to forebay flow fields from a ramped entrance structure

- complexity of the conveyance and outfall structures

- uncertainty of fish injury rates at high flow outfalls

- commitment to the B2 Corner Collector and associated designation of B2 as the priority powerhouse at Bonneville Dam

- $\operatorname{cost}(\sim 200 \mathrm{M})$ 
Future SFO development at B1, however, is a possibility. Such SFO work could involve the B1 Sluiceway where the wall for the juvenile bypass screen system in the sluiceway channel is scheduled for removal in 2007. Other sluiceway improvements would be to increase sluiceway discharge, install automated gates to follow forebay elevation to produce a constant discharge, and evaluate fish survival at the existing outfall to examine if a new outfall is necessary. There are also possibilities for a new powerhouse retrofit SFO. Options would entail new conveyance and outfall structures, perhaps for a partial or full powerhouse Alternative A. Another idea is a B1 corner collector SFO with or without an associated behavioral guidance structure. Preliminary engineering is available for most of these options. We strongly recommend evaluating changes to the sluiceway system including its efficiency and effectiveness and fish survival after improvements are made. The survival study should include reference releases of fish from the existing outfall and potential alternative outfalls.

\subsubsection{Conclusions}

The PSC evaluations demonstrated the efficacy of a powerhouse retrofit SFO for B1. Lessons learned from the PSC will be applicable to any future SFO development efforts at B1.

\subsubsection{B2 Corner Collector}

\subsubsection{Introduction}

At Bonneville Second Powerhouse, the ice and trash sluice chute has been developed as a surface flow outlet for juvenile salmonids called the B2 Corner Collector (B2CC). There have been two phases to development pre-B2CC and post-B2CC. In the pre-B2CC era during the 1980s and 1990s, managers were motivated to study the ice-trash sluice chute as a non-turbine passage route by the substandard fish guidance efficiency of the intake screen bypass system at B2 (e.g., Monk et al. 1999a). During this time, the sluice chute was not typically operated for juvenile passage. However, based on forebay hydraulic patterns and fish distribution observations by USACE biologists, ${ }^{\mathrm{a}}$ a strategy was developed to use the sluice chute as a surface flow outlet (Figure 3.30 courtesy of G. Ploskey)

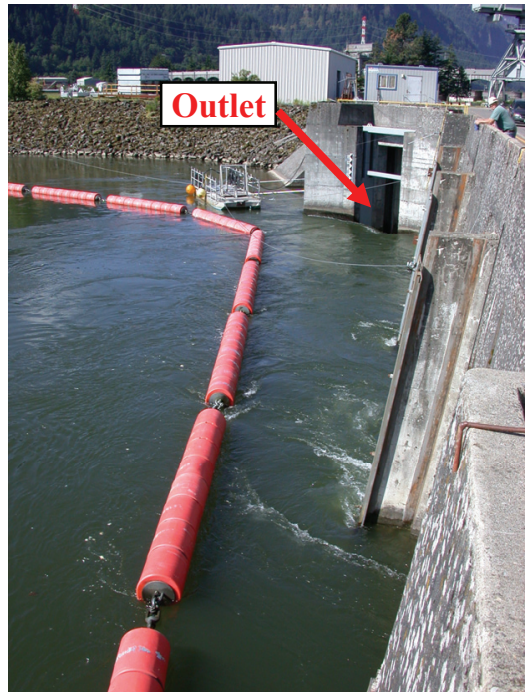

Figure 3.30. Photo of the B2CC.

The USACE engineering process commenced in 1995 to develop a formal SFO at B2. In the feasibility phase of the USACE process, Harza and ENSR (1996a,b), under direction of the Portland District, identified a number of surface flow outlet alternatives for B2. Development of the sluice chute was one of the alternatives. INCA et al. (1997) used physical scale models to study hydraulic and structural aspects of the sluice chute as a surface flow outlet from biological and engineering perspectives. Consideration was also given to a physical guidance device at the beginning of the B2 forebay channel (CH2M-Hill et al. 1998). In 1997 and 1998, the sluice chute was opened for biological research using an improved monitoring methodology to re-evaluate its passage potential. Given the encouraging results of

\footnotetext{
${ }^{a}$ The late Jim Kuskie, Project Biologist for Bonneville Dam, noted that juvenile salmonids passed into the ice and trash sluice chute when it was opened during migration seasons in the 1980s.
} 
the 1998 biological studies (presented below), fisheries managers and the Corps committed to development of the $\mathrm{B} 2 \mathrm{CC}$. In the design phase of the engineering process, the District performed a $\mathrm{B} 2 \mathrm{CC}$ outfall type and site selection study. Concurrently, Johnson et al. (2000) studied biological and hydraulic characteristics of high flow outfalls (>1,000 cfs), like the one being developed at the time for the B2CC. The engineering phase concluded with the Design Documentation Report by the District. ENSR et al. (1999) reviewed alternatives for dewatering and outfall location at B1; some of the findings were applicable to B2. The construction phase for the new entrance gates, conveyance channel, and outfall for the B2CC was completed in 2004. After this, PNNL and USGS evaluated B2CC biological performance during 2004 and 2005. Today, the B2CC is a permanent, functional surface flow outlet that is routinely operated as a complement to the intake screen system for smolt protection at B2. The purpose of this section is to describe $\mathrm{B} 2 \mathrm{CC}$ development in detail.

\subsubsection{Description of the Original B2 Sluice Chute}

The ice and trash sluice chute is located on the southwest corner of the B2 powerhouse. It is oriented $45 \mathrm{deg}$ off the horizontal axis of the powerhouse, a purposeful design to pass ice and trash from the forebay to the tailrace below the dam. The entrance is $15 \mathrm{ft}$ wide. Bottom and top vertical weir gates (Figure 3.31) controlled flow into the sluice chute. The bottom weir gate rested on a concrete sill at El. $52 \mathrm{ft}$. It could be raised (undershot flow) to El. $61 \mathrm{ft}$. The top weir gate can be lowered (overflow) to El. $59.5 \mathrm{ft}$. Typically, the top gate is lowered to dog-off points that result in the weir crest at El. 61 or $68 \mathrm{ft}$. After passing over the weir gate, water drops about $45 \mathrm{ft}$ to the channel floor at El. $29 \mathrm{ft}$ (Figure 3.31). The chute channel turned $45 \mathrm{deg}$ to the right about $25 \mathrm{ft}$ downstream of the weir gate. The radius of the turn in the 15-ft-wide channel was about $32 \mathrm{ft}$, which corresponded to a curvature of about 2 diameters. The distance from the curve to the terminus of the chute (outfall) was about $400 \mathrm{ft}$. Sluice chute discharge was about 3,000 cfs with the weir gate at El. $61 \mathrm{ft}$ and the forebay at El. $75 \mathrm{ft}$.

\subsubsection{B2 Forebay Hydraulic Conditions}

Hydraulic conditions in the B2 forebay and at the sluice chute entrance are important to the surface flow outlet there. From qualitative observations in both the field and the 1:40 scale physical model, B2 hydraulics were unsteady with eddies and boils appearing sporadically. The dominant feature of the forebay hydraulics is the large eddy that forms in the entire half of the forebay in front of the sluice chute (Figure 3.32). This eddy turns counterclockwise and increases in intensity as powerhouse loading increases. It dissolves when one or two units are operating. The B2 forebay eddy serves to concentrate fish and debris at the southwest corner of the forebay at the sluice chute entrance.

Limited water velocity measurements were available from physical model (1:40 general) or field work in the forebay near the B2 sluice chute entrance. With the weir at El. $61 \mathrm{ft}$ and forebay at El. $73 \mathrm{ft}$, calculated flow was about 2,800 cfs. Entrance velocity varied by depth; velocities were faster than shown at El. 67 and $70 \mathrm{ft}$ and less for El. 64, 61, and $58 \mathrm{ft}$. Overall, entrance velocities ranged from 9 to $16 \mathrm{fps}$ (Figure 3.33).

During model investigations, engineers observed distinctive hydraulic patterns with and without turbine intake extensions (TIEs). With the TIEs removed, lateral movement across the face of the powerhouse was smooth with minimal disruption before encountering the "zone of influence" of the 
collector entrance. With the TIEs installed, significant amounts of dye become entrained in eddies between adjacent TIEs and general turbulence levels increased.

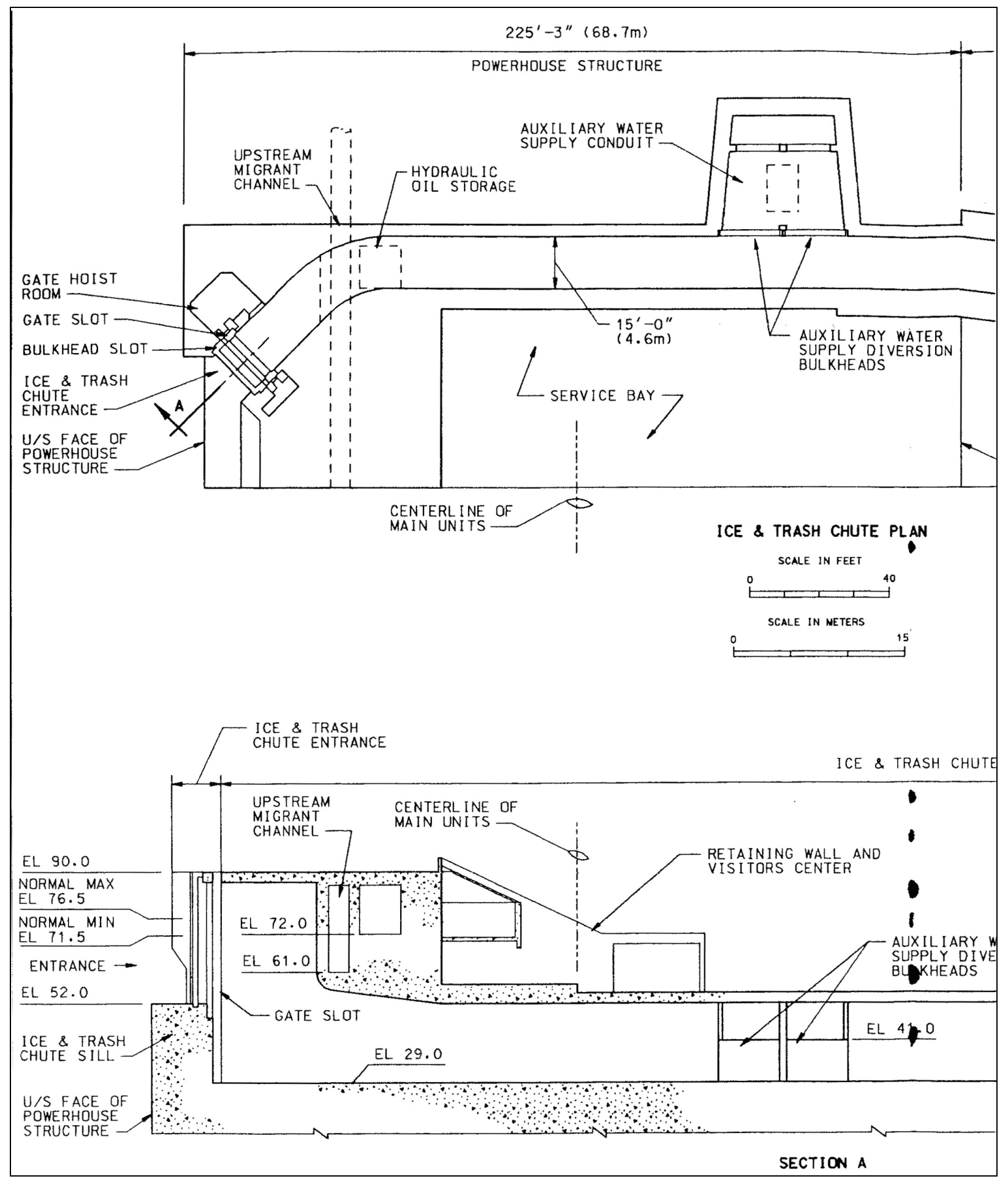

Figure 3.31. Top and Side Views of the Old Sluice Chute at B2. Modified from Plate 2 in INCA et al. (1997). 


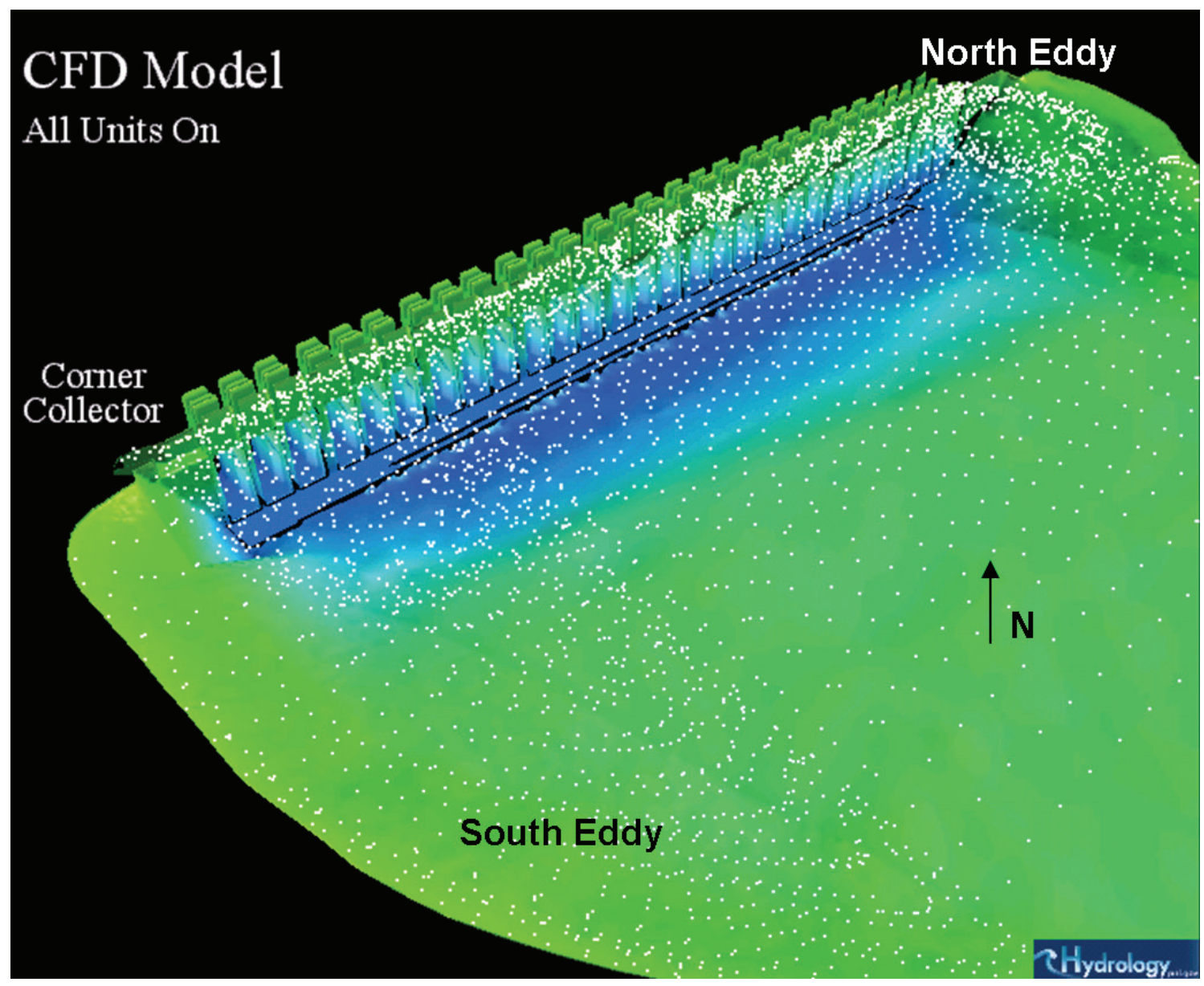

Figure 3.32. Computational Fluid Dynamic Model Display of Bonneville Powerhouse 2 Forebay Circulation. Dots represent particles suspended in surface flow and concentrations indicate flow patterns such as upwelling at the dam face and north and south eddies.

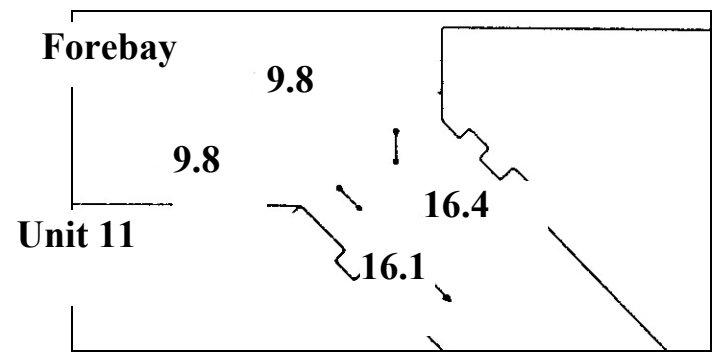

Figure 3.33. One-Dimensional Spot Velocities (fps) as Measured at the B2 Sluice Chute Entrance in the 1:40 Physical Model at the Engineering Research and Development Center. Weir gate was at El. $61 \mathrm{ft}$, forebay was at El. $73 \mathrm{ft}$, and calculated B2 sluice chute flow was at 2,800 cfs.

\subsubsection{Early Studies: 1980s}

INCA et al. (1997) summarized research conducted in the 1980s at the B2 sluice chute with respect to its potential as a surface bypass. Studies by Nagy and Magne (1986), Magne (1987a,b,c), Magne et al. (1989), and Stansell et al. (1990) documented that the B2 sluice chute passed substantial numbers of 
juvenile salmonids. None of these studies, however, was able to make a direct estimate of sluice chute efficiency (i.e., sluice chute passage relative to passage elsewhere at the B2 powerhouse) because of sampling difficulties. Clearly the potential was evident, but questions remained regarding forebay collection, conveyance, and outfall conditions.

\subsubsection{Baseline Studies at the B2 Sluice Chute: 1990s}

The hiatus in research on the B2 sluice chute between 1989 and 1995 ended with establishment of the Surface Bypass Program for Bonneville Dam. To provide baseline data for the new program, forebay distribution studies were conducted in 1995 (see Section 2). In addition, the B2 sluice chute was tested as a prototype SFO. In 1996, 12 radio-tagged yearling and 25 subyearling Chinook salmon were contacted in the vicinity of the sluice chute entrance, but none apparently entered it (Holmberg et al. 1996). That same year, fixed hydroacoustic estimates of fish passage at the sluice chute were problematic, because of excessive acoustic noise associated with turbulent surface currents created by the turbine intake extensions (Ploskey et al. 1998). In 1997, BioSonics (1998) sampled fish passage at the sluice chute and Turbine Intake $11 \mathrm{~A}$ to provide baseline data on chute efficiency. They also reported excessive acoustic noise from the TIEs with the weir gate at El. 61 ( 3,300 cfs), but not at El. 68 ( $\sim 1,100 \mathrm{cfs})$. INCA et al. (1997) recommended that the sluice chute be evaluated as a prototype corner collector in 1998, with the TIEs removed to allow for hydroacoustic monitoring of fish passage into the sluice chute with the gate at El. 61.

The most influential biological test of the original B2 ice and trash sluice chute took place in 1998. During the 1998 test, the weir crest was at El. $61 \mathrm{ft}$ (Figure 3.31). Thus, the entrance was $15 \mathrm{ft}$ wide and about $14 \mathrm{ft}$ high with discharge of 3,000 cfs, depending on forebay level. The approximate mean velocity upstream of the gate was $15.4 \mathrm{fps}$. Turbine intake extensions were removed at Units 11-14 to reduce turbulence at the sluice chute entrance. Removal of the TIEs also made the southerly, lateral flow lines at the face of powerhouse Units 11-14 less variable and more uniformly directed to the sluice chute entrance weir. In 1998, the B2 sluice chute was opened and closed according to a randomized block experimental design to compare passage rates at the adjacent units (Unit 11-13). The B2 sluice chute and B2 intakes were monitored and evaluated using fixed radio telemetry and fixed hydroacoustics.

In the 1998 radio telemetry study, about $3 / 4$ of the steelhead and $1 / 2$ of the yearling Chinook salmon that passed B2 were detected within $10 \mathrm{ft}$ of the B2 sluice chute entrance; this means discovery efficiency (DE) was high (overall $\mathrm{DE}=61 \%$; Table 3.12). After relatively few detections of PIT tagged fish for a survival study at The Dalles Dam just upstream were detected in the B2 juvenile bypass system, the sluice chute was closed most of summer 1998, so few data on subyearlings could be collected.

In 1998, entrance efficiency (\# entering/total \# within $10 \mathrm{ft}$ of antenna detection range), according to radio telemetry data, was also high (Table 3.12). It was $71 \%$ for steelhead (42 of 59) and $76 \%$ for yearling Chinook salmon (25 of 33). Since water velocity within $10 \mathrm{ft}$ of the B2 sluice chute entrance was relatively high ( $\sim 12$ fps at the weir gate), the radio telemetry detection zone was presumably this was within the B2 sluice chute flow net. Thus, these data indicate that relatively few radio-tagged fish avoided the B2 sluice chute entrance. 
Table 3.12. Results from monitoring radio-tagged fish passage at the $B 2$ sluice chute and intake screen system at B2 in 1998. Discovery efficiency is \# within $10 \mathrm{ft}$ of B2 sluice chute divided by total. Entrance efficiency is \# into B2 sluice chute divided by \# within $10 \mathrm{ft}$. Forebay collection efficiency is \# into B2 sluice chute divided by total B2 passage. CBE is B2 sluice chute plus guided fish passage divided by total B2 passage. n/a $=$ not applicable. Data are from Hensleigh et al. (1998).

\begin{tabular}{||lllllll||}
\hline \multicolumn{1}{|c}{ Metric } & \multicolumn{2}{c}{ CH1 } & \multicolumn{2}{c}{ ST } & \multicolumn{2}{c|}{ Total } \\
\hline \hline B2 sluice chute entrance & open & closed & open & closed & open & closed \\
W/in 10 ft B2 sluice chute & 59 & $\mathrm{n} / \mathrm{a}$ & 33 & $\mathrm{n} / \mathrm{a}$ & 92 & $\mathrm{n} / \mathrm{a}$ \\
Into B2 sluice chute & 42 & 0 & 25 & 0 & 67 & 0 \\
Guided & 17 & 25 & 10 & 20 & 27 & 45 \\
Unguided & 22 & 25 & 35 & 46 & 57 & 71 \\
Total into B2 and B2 sluice chute & 81 & 50 & 70 & 66 & 151 & 116 \\
Discovery efficiency & 0.73 & $\mathrm{n} / \mathrm{a}$ & 0.47 & $\mathrm{n} / \mathrm{a}$ & 0.61 & $\mathrm{n} / \mathrm{a}$ \\
Entrance efficiency & 0.71 & $\mathrm{n} / \mathrm{a}$ & 0.76 & $\mathrm{n} / \mathrm{a}$ & 0.73 & $\mathrm{n} / \mathrm{a}$ \\
Forebay collection efficiency & 0.52 & $\mathrm{n} / \mathrm{a}$ & 0.36 & $\mathrm{n} / \mathrm{a}$ & 0.44 & $\mathrm{n} / \mathrm{a}$ \\
CBE & 0.73 & 0.50 & 0.50 & 0.30 & 0.62 & 0.39 \\
\hline
\end{tabular}

Overall, B2 sluice chute efficiency for radio-tagged fish relative to passage at the entire B2 powerhouse was impressive: 52\% for steelhead and 36\% for yearling Chinook salmon (Table 3.12). Given the relatively small proportion of flow entering the B2 sluice chute $(\sim 2 \%)$, effectiveness (B2 sluice chute efficiency/percent B2CC flow) of the B2 sluice chute was about 26 for steelhead and 18 for yearling Chinook salmon. Effectiveness this high had not been observed at any other surface bypass in the region (see Dauble et al. 1999 for a review).

Comparing combined bypass efficiency $[\mathrm{CBE}=(\mathrm{B} 2$ sluice chute + guided $) /$ total at Units 11-13] with the B2 sluice chute open and closed showed the positive effect of the B2 sluice chute. CBE was higher for steelhead with the B2 sluice chute open than with it closed (73\% open vs. 50\% closed; Table 3.12). The same trend held for yearling Chinook salmon ( $50 \%$ open vs. $30 \%$ closed; Table 3.12 ). Clearly, the operating the B2 sluice chute resulted in more fish passing B2 through non-turbine routes than with it closed (23\% more for steelhead and 20\% more for yearling Chinook salmon; Table 3.12). The B2 sluice chute did not "rob" fish that would otherwise have been guided by the intake screens because CBE was so much higher with the B2 sluice chute open than closed. In fact, the data indicated that the B2 sluice chute passed many fish that would otherwise have gone through B2 turbines.

Also in 1998, Ploskey et al. (2001a) used hydroacoustics to monitor fish passage into the sluice chute and Intakes 11B, 12B, and 13B. The trend in $\mathrm{CBE}$ for the sluice chute and Units 11-3 for the run-at-large was consistent with that observed for radio tagged fish; CBE was significantly higher with the sluice chute open than closed (Table 3.13). Sluice chute efficiency relative to Units $11-13$ was $83 \%$ in spring and $81 \%$ in summer. Sluice chute effectiveness was 5.8 in spring and 4.6 in summer. When extrapolated to the entire powerhouse, effectiveness was about 12-16. These values are less than those estimated using radio telemetry data, but are still high relative to other regional surface bypasses. 
Synthesis of Biological Research on Juvenile Salmonid Passage and Survival at Bonneville Dam through 2005

Table 3.13. Combined Bypass Efficiency for the Sluice Chute and Screens at Units 11-13 when the Sluice Chute was Open and Closed in Spring and Summer 1998. Based on hydroacoustic data from Ploskey et al. (2001a, p. 35).

\begin{tabular}{|lcc|}
\hline Sluice Chute & Spring & Summer \\
\hline Open & 0.90 & 0.90 \\
Closed & 0.55 & 0.30 \\
\hline
\end{tabular}

Overall, results from the 1998 radio telemetry and hydroacoustic studies indicated strong potential for the B2 sluice chute to successfully collect juvenile salmonids because of their distribution in the forebay relative to the dominant flow patterns. Juvenile salmonids were concentrated in relatively shallow water ( $\sim 5 \mathrm{ft}$ deep) on approach over the forebay shelf. Many remained surface-oriented and were guided along the face of the dam toward the B2 sluice chute in the large eddy in the southwest corner of the forebay. This eddy flow, in conjunction with the $45 \mathrm{deg}$ orientation of the B2 sluice chute entrance relative to the face of the dam, seemed to cause high discovery efficiencies ( $\sim 61 \%)$. Presumably gradual acceleration into the B2 sluice chute entrance until juvenile salmonids were entrained in the high velocity B2 sluice chute flows probably caused the high entrance efficiencies $(\sim 73 \%)$. Juvenile salmonids that did not enter initially could have multiple discovery and entry opportunities because of the large forebay eddy. Thus, forebay collection efficiency was high ( $44 \%$ ) given the small amount of B2 sluice chute flow ( $\sim 3 \%$ of total B2). Conveyance and outfall issues, however, remained to be resolved. From the results of the 1998 studies, however, the fisheries managers recommended development of the B2 sluice chute as a permanent surface flow outlet. This SFO would be called the B2 corner collector.

\subsubsection{High Flow Outfall Studies at B2}

Guidelines for high flow outfalls were critical to development of the B2 corner collector outfall, as well as the surface flow outlets elsewhere. The NMFS outfall criterion for mean jet entry velocity is $<25$ fps. However, outfall discharges for SFOs at mainstem dams (without dewatering) have jet entry velocities much greater than $25 \mathrm{fps}$. Thus, there was a need to estimate fish injury and survival rates under various outfall conditions to establish high flow outfall guidelines.

Research applicable to high flow outfalls was conducted by Normandeau et al. (1996). They used balloon tags at the sluiceways at B1 and B2 to study injury and mortality rates for hatchery yearling Chinook salmon $(n=100$ each). Control fish were not included in these preliminary investigations conducted in October 1995. B1 sluice discharge was about 200-300 cfs, while B2 sluice discharge was about $650 \mathrm{cfs}$. At the B1 sluice outfall, 7 of 100 fish were not recaptured, and 4 of the 7 were probably preyed upon based radio-tracking information. The authors noted that predation did not seem to be a problem during their October study at the B2 sluice outfall. Injury rates were low at both sluices (1 of 93 recaptured fish and 1 of 90 at $\mathrm{B} 1$ and $\mathrm{B} 2$, respectively).

In 1999, a formal project within the Anadromous Fish Evaluation Program was established to develop high flow outfall guidelines. ENSR and INCA (2000) calculated energy dissipation, strain, deceleration and other rates, strain rates to support test design for the high flow outfall research in a laboratory flume. Johnson et al. (1999) offered preliminary guidelines, but concluded that more research was necessary before they could be finalized. In 2001, Normandeau et al. (2001) performed balloon tag studies at the 
B2 sluice chute outfall that showed low $(<1 \%)$ injury rates. The high flow outfall research culminated in the following guidelines:

Locate where

- Receiving water velocities are greater than $4 \mathrm{fps}$, unless site-specific velocities with an operating high flow outfall are determined to be acceptable.

- Receiving water characteristics, especially depth in combination with magnitude and trajectory of outfall discharge, are sufficient to prevent mechanical fish injury if they contact the bottom.

- Eddies or back-rollers in the pre-outfall receiving water are minimal.

- Predators are not concentrated near the outfall plume.

- Adult migration (fishway entrances, shorelines, or known adult migration paths) will not be deleteriously affected by the high flow outfall discharge and plume.

- Project operations do not produce changes in hydraulic conditions that result in violations of other guidelines.

Design so that

- Mean entry velocity for high flow outfalls can be up to $50 \mathrm{fps}$, and may be higher depending on site-specific conditions.

- Eddies or back-rollers in the outfall pool and plume are minimized.

- The high flow outfall does not cause the cumulative total dissolved gas concentration released by the project to exceed accepted criteria.

- Adult fish that happen to encounter the outfall discharge are not prevented from continuing to move upstream, and those that may leap at the discharge should not strike any solid objects.

Johnson et al. (2003) published field studies and laboratory experiments to determine the relationship between direct injury and mortality rates of juvenile salmon (Oncorhyncus spp.) and jet entry velocities characteristic of high flow ( $>28.3 \mathrm{~m}^{3} / \mathrm{s}$ ) outfalls at hydroelectric facilities. During field tests, the range of calculated mean entry velocities was $9.3-13.7 \mathrm{~m} / \mathrm{s}$ for low $\left(28.3 \mathrm{~m}^{3} / \mathrm{s}\right)$ and high $\left(68.0-70.2 \mathrm{~m}^{3} / \mathrm{s}\right)$ outfall discharge rates and two receiving water elevations. Mortality and injury rates of balloon-tagged hatchery spring Chinook salmon juveniles in the field tests were less than 1\%. At a high-velocity flume in a laboratory, small $(87-100 \mathrm{~mm}$ fork length) and large $(135-150 \mathrm{~mm})$ hatchery fall Chinook salmon were exposed to velocities of $0.0-24.4 \mathrm{~m} / \mathrm{s}$ in a fast-fish-to-slow-water scenario (Figure 3.34). Jet entry velocities up to $15.2 \mathrm{~m} / \mathrm{s}$ provided benign passage conditions for the sizes and physiological states of juvenile salmonids tested under the particular environmental conditions present during this study. The authors concluded that direct injury and mortality results indicated that a jet entry velocity up to $15.2 \mathrm{~m} / \mathrm{s}$ should safely pass juvenile salmon at high-flow outfalls. The authors concluded it will be necessary, 
however, to conduct site-specific, post-construction verification studies of fish injury and mortality at new high-flow outfalls.

\section{a. Small Fall Chinook Salmon}

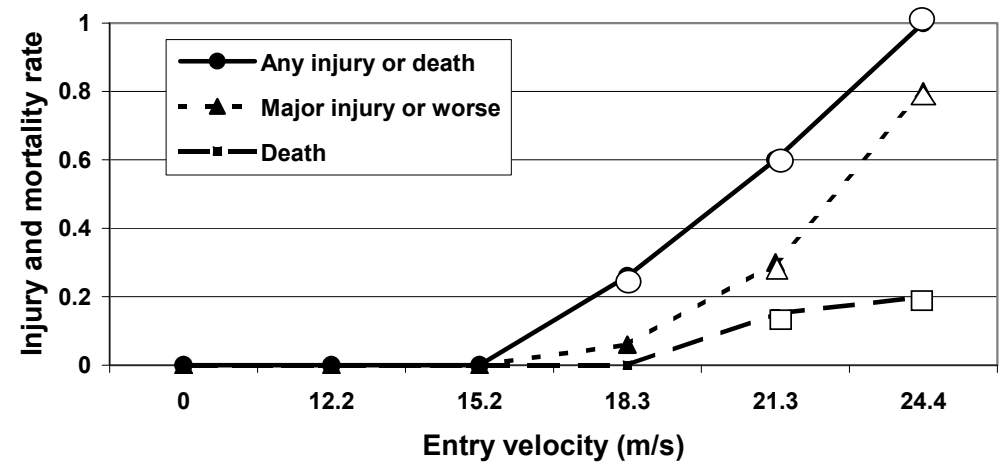

b. Large Fall Chinook Salmon

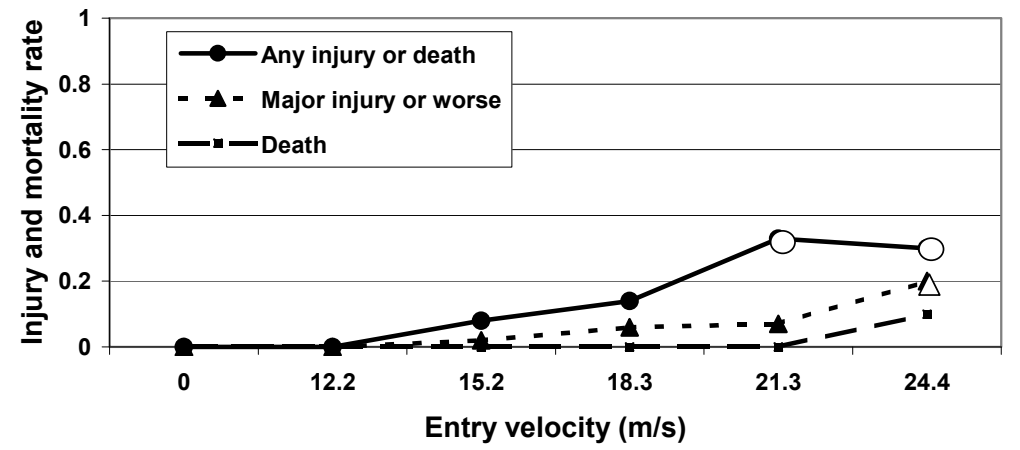

Figure 3.34. Injury and Mortality Rates from Experiments Conducted in a High-velocity Jet in a Laboratory Flume.

\subsubsection{B2CC Design}

The design effort for the B2 corner collector involved an outfall site and type selection study (INCA et al. 2001), as well as entrance gate, ogee, and conveyance channel design (USACE 2003). The overall system is depicted in Figure 3.35.

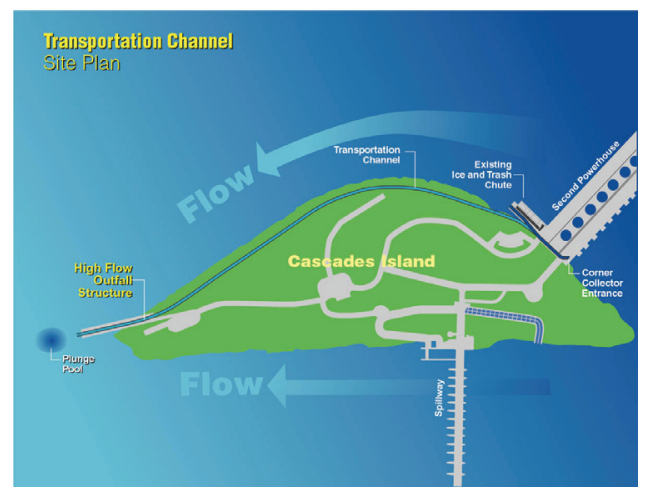

Figure 3.35. Plan View of the B2 Corner Collector Showing the Entrance (Far Right), Transportation Channel, and Outfall (Far Left). The figure was provided by CENWP. 
The original entrance gate was replaced by a new gate and hoists. The usable entrance depth was increased from El. 62 to El. $52 \mathrm{ft}$. This increased discharge from about 2,200 to 5,200 cfs. Downstream of the entrance gate weir, an ogee was installed to smooth the passage route for juvenile salmonids and the conveyance channel was re-routed toward the new outfall location. The outfall was designed to accommodate a tailwater elevation range of El. 7-35 ft.

Design tools included physical-scale models (General 1:100, B2 Forebay 1:40, Outfall 1:30) and computational fluid dynamics (CFD) modeling. Figure 3.36 (photo courtesy of ENSR) shows a dye plume in the 1:30 scale physical model of the B2 corner collector outfall. Note the plunging flow and well-defined plume.

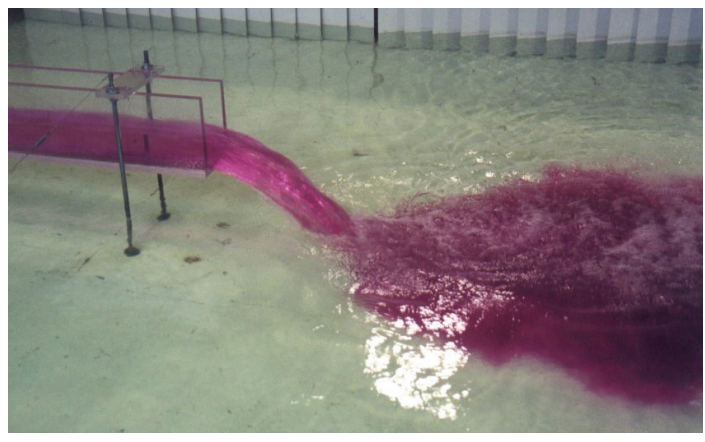

Figure 3.36. B2CC Outfall in 1:30 Model

The outfall type selection study (INCA et al. 2001) winnowed 13 original alternatives (Figure 3.37) down to one. This process involved setting criteria (e.g., cost, complexity, plume proximity to shorelines), rating the alternatives by multiple reviewers, and averaging the scores.

The final selection for the type of outfall, the mid-level cantilever, is shown in Figure 3.38. The conveyance structure is built at grade along the north shore of Cascades Island. The outfall is at a monolith at the downstream tip of the island. The invert is at El. $16 \mathrm{ft}$. It has a plunge pool $445 \mathrm{ft} \times 165$ $\mathrm{ft}$ that was excavated to $50 \mathrm{ft}$ below the existing bottom.

Site selection for the B2CC outfall started with nine alternatives (Figure 3.39). Egress conditions as shown in the 1:100 general model of Bonneville Dam were examined for each alternative. The final site selected was site "F" at the tip of cascades Island (Figure 3.39). INCA et al. (2001) documented the site selection process for the $\mathrm{B} 2 \mathrm{CC}$ outfall.

\subsubsection{Post-Construction Evaluation of the B2 Corner Collector: 2004-2005}

Route-specific survival estimates for the B2CC were nearly 100\%. In 2004 and 2005, Counihan et al. (2006a and 2006b) reported very high survival for yearling Chinook salmon (0.990-1.028 in 2004 and 1.02 in 2005), steelhead (1.02 to 1.03 in 2004 and 1.01 in 2005), and subyearling Chinook salmon (mean $=0.97$ and range $=0.95$ to 1.01 in 2004 and 1.01 in 2005).

These results are reported in greater detail with other project-wide and route-specific survival data in Sections 3.2.4 and 3.2.5. They are presented here to show that the new B2CC surface flow outlet is safe for juvenile salmonids and has the highest survival of all passage routes at Bonneville Dam. 


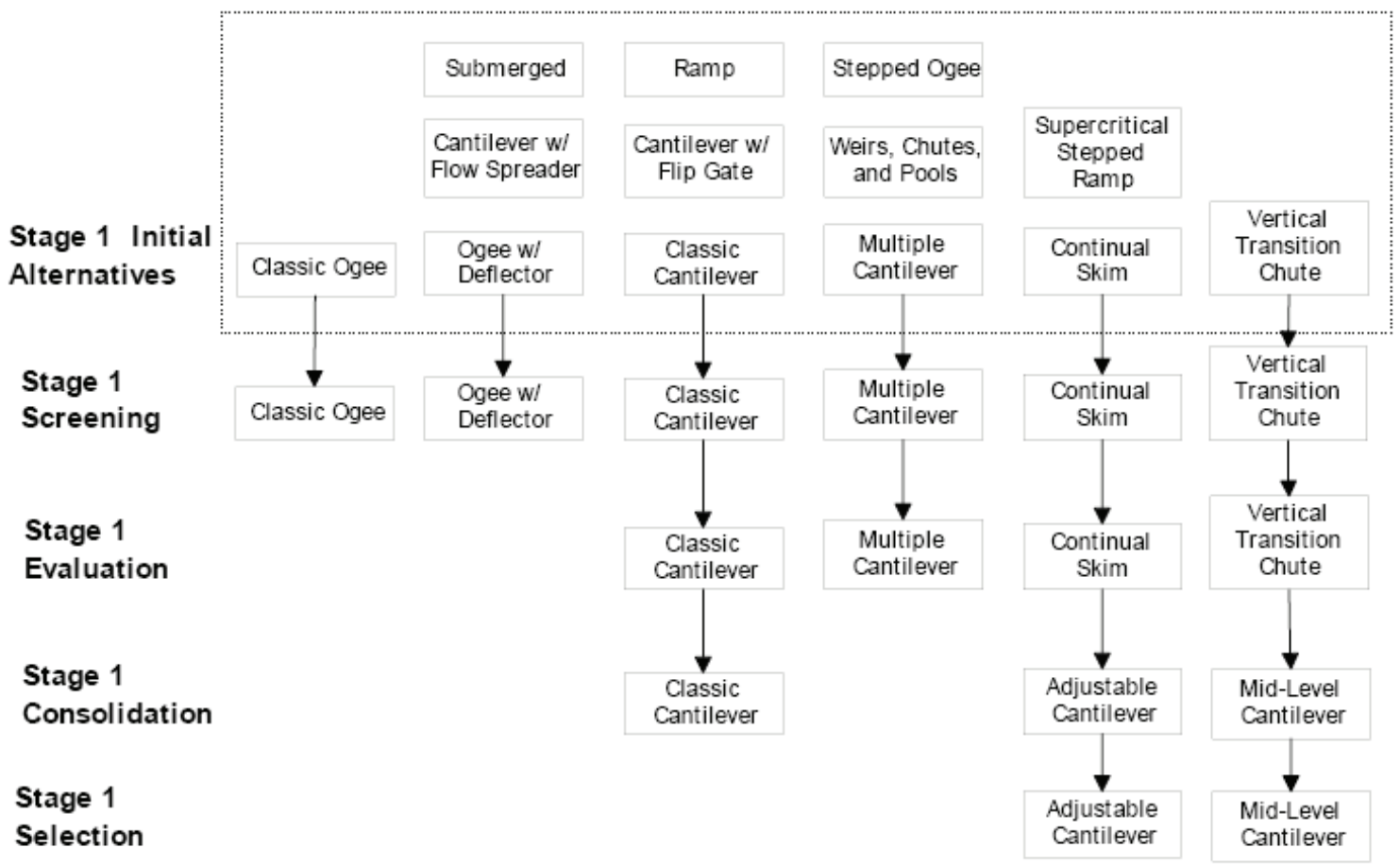

Figure 3.37. Process to Select the Outfall Type. Stage 1 was when the 13 original alternatives were narrowed down to two. The final selection was made in a subsequent stage.

Side View

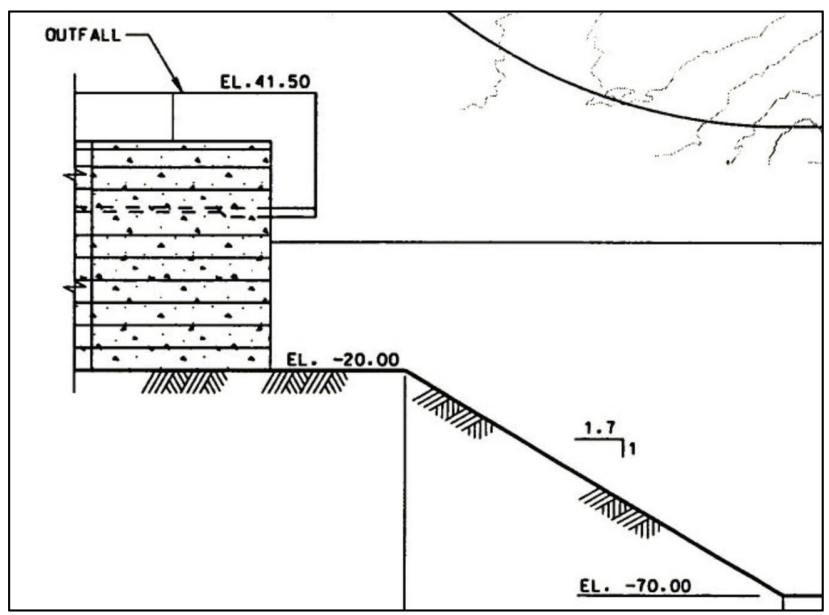

End View

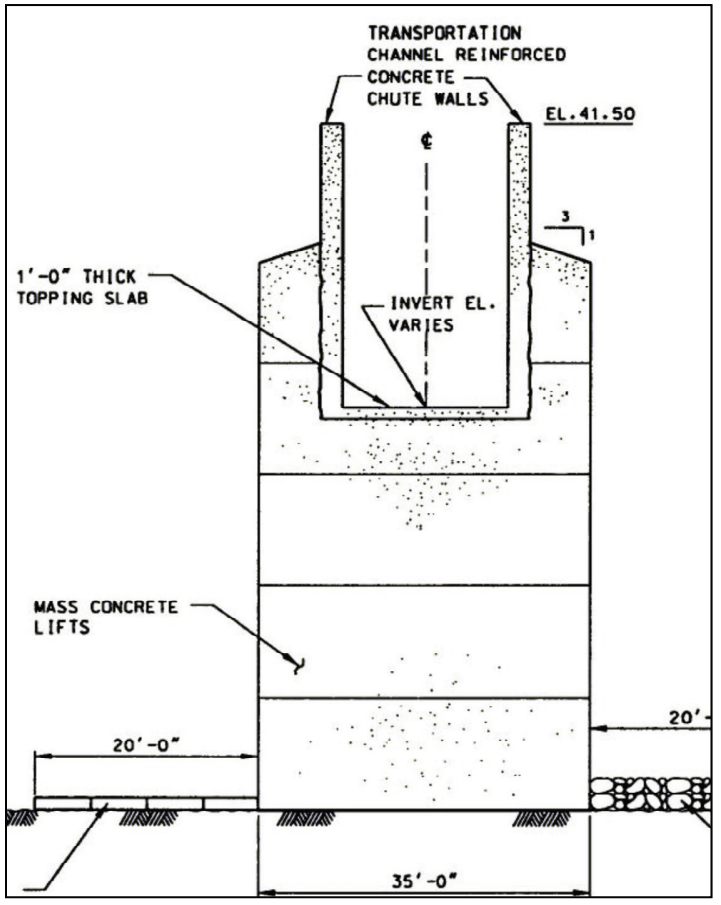

Figure 3.38. Schematic of the B2 Corner Collector Outfall: Mid-level Cantilever. 

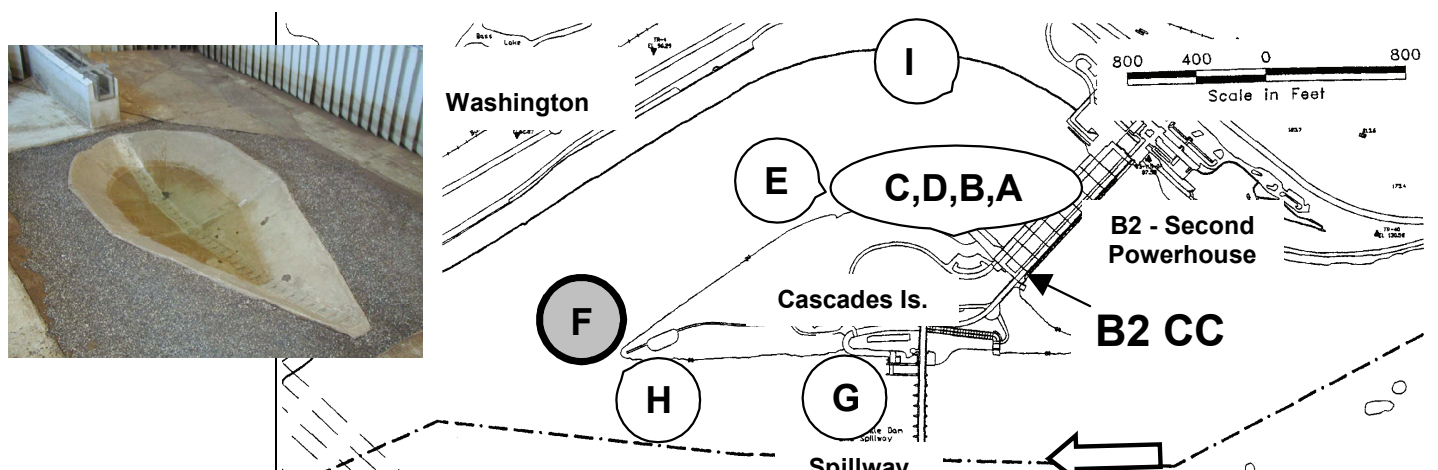

B2 CC

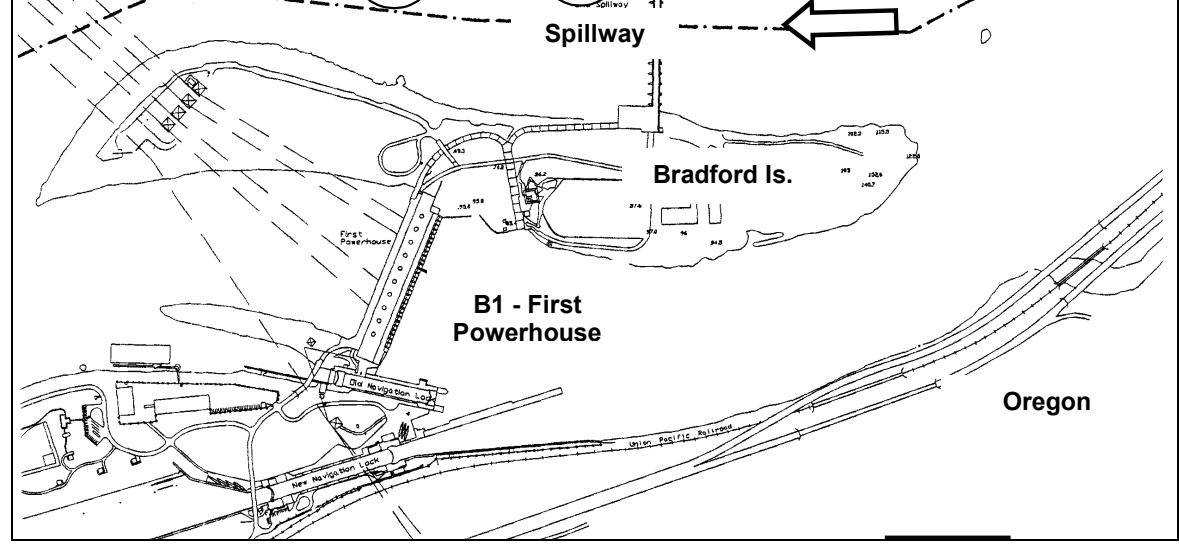

Figure 3.39. Map of Bonneville Dam Showing the Various Alternatives Studied during the B2CC Outfall Site Selection Process. Site F was chosen. The inset shows the 1:30 scale physical model of the outfall and its plunge pool.

Collection efficiency and effectiveness relative to B2 was highest for steelhead trout (66\%-74\%) and reasonably similar for the run-at-large (31\%-32\% in spring and $40 \%-44 \%$ in summer as estimated by hydroacoustic sampling to the estimate for Chinook salmon by radio telemetry $(30 \%-37 \%$ in spring and $37-40 \%$ in summer) (Tables 3.2 through 3.5). For spring 2004 and 2005, fish-collection effectiveness relative to B2 averaged 7.3 for the run-at-large in spring, 6.5 for yearling Chinook salmon, and 13.7 for steelhead. In summer of those years, B2CC effectiveness relative to B2 was 7.3 according to the hydroacoustic estimate and 6.5 for subyearling Chinook salmon, according to the radio telemetry estimate (Tables 3.2 through 3.5).

\subsubsection{B2 Corner Collector Conclusions}

The B2 Corner Collector is a permanent, long-term surface flow outlet at the B2 powerhouse. It has a state-of-the-art conveyance channel and outfall that passes juvenile salmonids with utmost safety into environs downstream of the dam. The $\mathrm{B} 2 \mathrm{CC}$ takes advantage of the location of the old sluice chute relative to the forebay eddy to pass surface-oriented emigrants. The intention is for the $\mathrm{B} 2 \mathrm{CC}$ not to be a stand-alone route, but rather to complement the intake screen system to protect fish at B2. The efficiency and effectiveness was much higher for steelhead than it was for Chinook salmon for unknown reasons. Ways to improve the efficiency for juvenile Chinook salmon should be researched. 


\subsection{Fish Guidance Efficiency of Screens}

\subsubsection{Introduction}

Intake screens intercept and guide into a juvenile bypass system a portion of the smolts entering turbines. The proportion of smolts entering the intake that is diverted is referred to as fish guidance efficiency (FGE). Two general types of screens are in place or have been tested at Bonneville Dam, submersible traveling screens (STS) and extended length submerged bar screens (ESBS). As of the writing of this report, no screens are in place at B1. They were removed prior to the 2004 migration given concerns over low survival associated with the bypass system.

Smolt FGE has been estimated using a variety of methods including simultaneous netting of intakes and gatewells, hydroacoustic sampling with fixed transducers, radio telemetry detections, and detection of PIT-tagged fish. At Bonneville Dam, estimates have been obtained using the first three approaches.

Estimates of FGE are highly variable and can be affected by numerous factors. These include the sampling method, screen type (STS or ESBS), time of day, operating conditions, species, and fish behavior/physiological changes during the migratory period (Ferguson et al. 2005). For these reasons, it is difficult to determine what the "real" or "effective" FGE is at a dam for a particular species, although often such estimates are requested by fishery managers. For example, passage models often require absolute measures of FGE as input parameters. More often, FGE is monitored at a dam to assess the change in diversion screen performance under different operating conditions and structural configurations. In this type of application, relative changes in FGE rather than absolute values are instructive and appropriate.

\subsubsection{Fyke Net Studies}

\subsubsection{Bonneville First Powerhouse (B1)}

The diversion screen evaluation and development program at B1 began in 1981. Krcma et al. (1982) and DeHart (1987) estimated that FGE exceeded 70\% during the early spring test period. Later tests that year were compromised by a heavy debris load. DeHart (1987) reported that descaling attributable to the STS was negligible for all species examined except for sockeye. Approximately $7 \%$ of the guided sockeye were descaled, whereas only $3 \%$ of a non-screened control group was descaled. These encouraging results led to the installation of STS in all ten turbine units by the time of the 1983 migration.

Fish guidance efficiency was revisited again in 1988 at B1 following the construction of the new navigation lock and other actions in the forebay. Evaluations targeted subyearling Chinook salmon during late spring and summer periods. During the first week of June, the weighted mean FGE equaled 40.7\% (Gessel et al. 1989), far below the 71.5\% reported by Krcma et al. (1982) for the same sampling period. Even more disappointing was the very low mean FGE of 11.4\% FGE documented during the summer sampling period (Table 3.14).

Evaluations in 1989 confirmed the poor results observed in 1988. The FGE for yearling Chinook salmon averaged $41.7 \%$ (Table 3.14). Subyearling Chinook salmon FGE during the summer was even lower than measured the previous year, at $4.4 \%$. These continuing discouraging results prompted investigators to recommend detailed hydraulic studies and a systematic program to address guidance issues at B1. 
Table 3.14. Estimates of FGE for Bonneville Dam Powerhouse 1. For fyke-net based estimates, we primarily report values for the control or reference screen configuration. These represent the general screen type in the majority of turbine units. This provides an FGE index that could be applied to the overall powerhouse. For other tools the specified screen configuration in some cases was not the standard reference configuration.

\begin{tabular}{|c|c|c|c|c|c|c|}
\hline \multirow[b]{2}{*}{ Year } & \multirow{2}{*}{$\begin{array}{c}\text { Species } \\
\text { or } \\
\text { Season }\end{array}$} & \multicolumn{2}{|c|}{ FGE (Percent) } & \multirow[b]{2}{*}{ Range Screen Configuration } & \multirow[b]{2}{*}{$\begin{array}{c}\text { Evaluation } \\
\text { Method }\end{array}$} & \multirow[b]{2}{*}{ Source } \\
\hline & & Mean & Range & & & \\
\hline 1981 & Y. Chin. & 76.4 & --- & STS; Standard Elev.; 47 degree angle (pooled); (30 Apr. to 13 May) Unit 4 & Fyke net & Krcma et al. (1982) \\
\hline 1989 & Y. Chin. & 41.7 & (34.7 to 49.6 ) & STS; Standard Elev. (8 May to 14 May); Unit 3B & Fyke net & Gessel et al. (1990) \\
\hline 1991 & Y. Chin. & 45.8 & (36.9 to 65.3 ) & STS; Standard Elev. (22 to 27 April); Unit 3B & Fyke net & Monk et al. (1992) \\
\hline 1991 & Y. Chin. & 31.7 & (19.3 to 49.5$)$ & STS; Standard Elev. (22 to 27 April); Unit 8B & Fyke net & Monk et al. (1992) \\
\hline 1991 & Y. Chin. & 28.9 & (21.2 to 38.9$)$ & STS; Standard Elev. (29 April to 4 May); Unit 5B & Fyke net & Monk et al. (1992) \\
\hline 1991 & Y. Chin. & 38.7 & (34.7 to 45.0$)$ & STS; Standard Elev. (29 April to 4 May); Unit 8B & Fyke net & Monk et al. (1992) \\
\hline 1991 & Y. Chin. & 46.5 & (36.4 to 56.6$)$ & STS; Standard Elev. (20 to 24 May); Unit 3B & Fyke net & Monk et al. (1992) \\
\hline 1991 & Y. Chin. & 45.4 & (33.6 to 54.9$)$ & STS; Standard Elev. (20 to 24 May); Unit 8B & Fyke net & Monk et al. (1992) \\
\hline 1992 & Y. Chin. & 46.0 & & STS; Standard Elev. (25 April to 20 May); Unit 3B & Fyke net & Monk et al. (1993) \\
\hline 1992 & Y. Chin. & 38.0 & & STS; Standard Elev. (25 April to 1 June); Unit 3B & Fyke net & Monk et al. (1993) \\
\hline 1998 & Y. Chin. & 72.0 & (53 to 87$)$ & ESBS; Unit 8B; 24 April to 21 May; No STS tests conducted this year & Fyke net & Monk et al. (1999b) \\
\hline 2000 & Y. Chin. & 66.0 & (52 to 76$)$ & ESBS; Unit 8B; 24 April to 24 May; No STS tests conducted this year & Fyke net & Monk and Sandford (2001) \\
\hline 2000 & Y. Chin. & 50.0 & --- & Spring Evaluation; All operable units; $\mathrm{n}=153 / 305$ & Radio-Telemetry & Evans et al. (2001b) \\
\hline 2001 & Y. Chin. & 45.0 & --- & Spring Evaluation; All operable units; $\mathrm{n}=5 / 11$ & Radio-Telemetry & Evans et al. (2001d) \\
\hline 2002 & Y. Chin. & 50.0 & $(32 \text { to } 58)^{1}$ & Spring Evaluation; All operable units; $n=47 / 94$ & Radio-Telemetry & Evans et al. (2003a; 2006a) \\
\hline 1981 & Sub. Chin. & 71.5 & --- & STS; Standard Elev.; 47 degree angle (pooled); ( 30 Apr. to 13 May) Unit 4 & Fyke net & Krcma et al. (1982) \\
\hline 1988 & Sub. Chin. & 40.7 & (32.9 to 60.5$)$ & STS; Standard Elev. (30 May to 6 June); Unit 3B & Fyke net & Gessel et al. (1989) \\
\hline 1988 & Sub. Chin. & 11.4 & (5.5 to 28.1$)$ & STS; Standard Elev. (6 July to 27 July); Unit 3B & Fyke net & Gessel et al. (1989) \\
\hline 1989 & Sub. Chin. & 36.8 & (31.0 to 50.0$)$ & STS; Standard Elev. (27 May to 30 May); Unit 3B & Fyke net & Gessel et al. (1990) \\
\hline 1989 & Sub. Chin. & 4.4 & --- & STS; Standard Elev. (12 July to 24 July); Unit 3B & Fyke net & Gessel et al. (1990) \\
\hline 1991 & Sub. Chin. & 32.9 & --- & STS; Standard Elev. (22 April to 24 May); Units 3B, 5B and 8B Combined & Fyke net & Monk et al. (1992) \\
\hline 1992 & Sub. Chin. & 22.0 & --- & STS; Standard Elev. (17 May to 1 June); Unit 3B & Fyke net & Monk et al. (1993) \\
\hline 1998 & Sub. Chin. & 67.0 & --- & ESBS; Unit 8B; 24 April to 21 May; No STS tests conducted this year & Fyke net & Monk et al. (1999b) \\
\hline 1998 & Sub. Chin. & 27.0 & --- & ESBS; Unit 8B; 29 June to 17 July; No STS tests conducted this year & Fyke net & Monk et al. (1999b) \\
\hline 2000 & Sub. Chin. & 46.0 & ( 25 to 62$)$ & ESBS; Unit 8B; 12 June to 7 July; No STS tests conducted this year & Fyke net & Monk and Sandford (2001) \\
\hline 2000 & Sub. Chin. & 29.0 & --- & Summer Evaluation; All operable units; $\mathrm{n}=20 / 70$ & Radio-Telemetry & Evans et al. (2001a) \\
\hline 2001 & Sub. Chin. & 57.0 & --- & Summer Evaluation; All operable units; $n=4 / 7$ & Radio-Telemetry & Evans et al. (2001c) \\
\hline 2002 & Sub. Chin. & 43.0 & (38 to 57$)$ & Summer Evaluation; All operable units; $n=78 / 181$ & Radio-Telemetry & Evans et al. (2006b) \\
\hline 1981 & Steelhead & 77.0 & --- & STS; Standard Elev.; 47 degree angle (pooled); (30 Apr. to 13 May) Unit 4 & Fyke net & Krcma et al. (1982) \\
\hline 1989 & Steelhead & 55.8 & --- & STS; Standard Elev. ( 9 to 14 May; and 27 to 30 May); Unit 3B & Fyke net & Gessel et al. (1990) \\
\hline 1991 & Steelhead & 59.1 & --- & STS; Standard Elev. (22 April to 24 May); Units 3B, 5B and 8B Combined & Fyke net & Monk et al. (1992) \\
\hline 1992 & Steelhead & 54.0 & --- & STS; Standard Elev. (29 April to 1 June); Unit 3B & Fyke net & Monk et al. (1993) \\
\hline 1998 & Steelhead & 85.0 & --- & ESBS; Unit 8B; 24 April to 21 May; No STS tests conducted this year & Fyke net & Monk et al. (1999b) \\
\hline 2000 & Steelhead & 76.0 & --- & ESBS; Unit 8B; 24 April to 24 May; No STS tests conducted this year & Fyke net & Monk and Sandford (2001) \\
\hline 2000 & Steelhead & 59.0 & --- & Spring Evaluation; All operable units; $\mathrm{n}=131 / 223$ & Radio-Telemetry & Evans et al. (2001b) \\
\hline 2002 & Steelhead & 75.0 & $(67 \text { to } 100)^{1}$ & Spring Evaluation; All operable units; $\mathrm{n}=9 / 12$ & Radio-Telemetry & Evans et al. (2003a; 2006a) \\
\hline 1981 & Coho & 81.3 & --- & STS; Standard Elev.; 47 degree angle (pooled); (30 Apr. to 13 May) Unit 4 & Fyke net & Krcma et al. (1982) \\
\hline 1988 & Coho & 56.8 & --- & STS; Standard Elev. (1 June); Unit 3B & Fyke net & Gessel et al. (1989) \\
\hline 1989 & Coho & 63.0 & --- & STS; Standard Elev. (9 to 14 May; and 27 to 30 May); Unit 3B & Fyke net & Gessel et al. (1990) \\
\hline 1991 & Coho & 58.2 & --- & STS; Standard Elev. (22 April to 24 May); Units 3B, 5B and 8B Combined & Fyke net & Monk et al. (1992) \\
\hline 1992 & Coho & 52.0 & --- & STS; Standard Elev. (29 April to 1 June); Unit 3B & Fyke net & Monk et al. (1993) \\
\hline 1998 & Coho & 80.0 & -- & ESBS; Unit 8B; 24 April to 21 May; No STS tests conducted this year & Fyke net & Monk et al. (1999b) \\
\hline 2000 & Coho & 76.0 & --- & ESBS; Unit 8B; 24 April to 24 May; No STS tests conducted this year & Fyke net & Monk and Sandford (2001) \\
\hline 1981 & Sockeye & 81.7 & --- & STS; Standard Elev.; 47 degree angle (pooled); (30 Apr. to 13 May) Unit 4 & Fyke net & Krcma et al. (1982) \\
\hline 1991 & Sockeye & 27.4 & -- & STS; Standard Elev. (22 April to 24 May); Units 3B, 5B and 8B Combined & Fyke net & Monk et al. (1992) \\
\hline 1992 & Sockeye & 18.0 & --- & STS; Standard Elev. (25 April to 1 June); Unit 3B & Fyke net & Monk et al. (1993) \\
\hline 1998 & Sockeye & 51.0 & --- & ESBS; Unit 8B; 24 April to 21 May; No STS tests conducted this year & Fyke net & Monk et al. (1999b) \\
\hline 1996 & Spring & 49.0 & --- & (26 Apr to 24 May); Unit 3; outfitted with an STS & Hydroacoustics & Ploskey et al. (1998) \\
\hline 1996 & Spring & 29.0 & -- & (26 Apr to 24 May); Unit 5; outfitted with an STS & Hydroacoustics & Ploskey et al. (1998) \\
\hline 1998 & Spring & 79.0 & --- & Unit $1 \mathrm{~B}$; outfitted with an STS & Hydroacoustics & Ploskey et al. (2001) \\
\hline 1998 & Spring & 46.0 & --- & Unit 2B; outfitted with an STS & Hydroacoustics & Ploskey et al. (2001) \\
\hline 2000 & Spring & 48.0 & --- & STS; Units 7, 9 and 10 & Hydroacoustics & Ploskey et al. (2002a) \\
\hline 2001 & Spring & 47.0 & $(0.22$ to 0.57$)$ & (1 May to 9 June); Units 1-10 (Unit 8 w/ESBS, no U3) & Hydroacoustics & Ploskey et al. (2002b) \\
\hline 2002 & Spring & --- & (0.21 to 0.79$)$ & (20 April to 2 June); Units 1-10 (Unit 8 w/ESBS, no U5) & Hydroacoustics & Ploskey et al. (2003) \\
\hline 1996 & Summer & 57.0 & --- & Summer Evaluation (14 June to 12 July); Unit 3; outfitted with an STS & Hydroacoustics & Ploskey et al. (1998) \\
\hline 1996 & Summer & 49.0 & --- & Summer Evaluation (14 June to 12 July); Unit 5; outfitted with an STS & Hydroacoustics & Ploskey et al. (1998) \\
\hline 1998 & Summer & 62.0 & --- & Summer Evaluation; Unit 1B; outfitted with an STS & Hydroacoustics & Ploskey et al. (2001) \\
\hline 1998 & Summer & 21.0 & -- & Summer Evaluation; Unit 2B; outfitted with an STS & Hydroacoustics & Ploskey et al. (2001) \\
\hline 2000 & Summer & 36.0 & --- & Summer Evaluation; STS; Units 7, 9 and 11 & Hydroacoustics & Ploskey et al. (2002a) \\
\hline 2001 & Summer & 47.0 & ( 0.29 to 0.53$)$ & Summer Evaluation ( 1 to 15 July); Units 1-10 (Unit 8 w/ESBS, no U3) & Hydroacoustics & Ploskey et al. (2002b) \\
\hline 2002 & Summer & --- & $(0.20$ to 0.79$)$ & (3 June to 15 July); Units 1-10 (Unit 8 w/ESBS, no U5) & Hydroacoustics & Ploskey et al. (2003) \\
\hline
\end{tabular}


By 1998, the focus shifted to evaluating ESBS and different operating gate configurations. FGE improved markedly during the spring with an ESBS in place. Summer estimates of FGE were also considerably higher than previously documented with the STS as shown in Table 3.15 (from Monk et al. 1999b). The FGE gains in the spring were substantial with the ESBS, but summer improvements were disappointing to many managers. Later in this report we note that hydroacoustic indices for summer migrants also indicate low FGE. By the spring of 2004, guidance screens had been removed from Powerhouse 1. Thus, no FGE estimates exist after 2003.

Table 3.15. Mean FGE Estimates for the ESBS (1998) and the STS $(1988,1989$, and 1991) by Species from Monk et al. (1999b). Standard errors shown in parentheses.

\begin{tabular}{|lcc|}
\hline \multicolumn{1}{|c}{ Species } & ESBS (1998) & STS (1988, 1989 and 1991) \\
\hline \hline Yearling Chinook & $72(1.9)$ & $36(2.4)$ \\
Steelhead & $85(1.5)$ & $58(3.5)$ \\
Coho & $80(2.3)$ & $53(4.9)$ \\
Sockeye & $51(5.0)$ & $25(3.1)$ \\
Subyearling Chinook & -- & --- \\
Spring sampling & $67(4.7)$ & $33(4.0)$ \\
Summer sampling & $23-48(1.1-2.7)$ & $4-11(1.0-2.0)$ \\
\hline \hline
\end{tabular}

\subsubsection{Bonneville Second Powerhouse (B2)}

In 1982, with the completion of B2, the downstream migrant bypass system was activated. In 1983, initial FGE evaluations were conducted. During that era fish passage managers had established a generic FGE goal of $70 \%$ for all species. Krcma et al. (1984), using the fyke net method, reported values that generally ranged from $20 \%-40 \%$, far below the stated standard. For the next two decades, numerous operations and configurations were tested as a means to improve FGE with minimal injury to fish.

The conditions tested often consisted of combinations of assorted actions including raised operating gates, lowered STS, blocked trashracks, lights, reconfigured trashracks, flow turning vanes, turbine intake extensions, etc. Gessel et al. (1991) summarized results obtained from 1983-1989. Performance was improved for spring migrants with FGE attaining levels near 70\%. The actions that resulted in the highest FGE included lowering the STS by 22 inches, streamlining the trashracks, and installing TIEs. However, FGE for summer migratory ocean-type Chinook salmon remained substandard at below $30 \%$ (Table 3.16).

Based on those early preliminary findings, TIEs were installed across the face of the powerhouse, but fish guidance performance was disappointing. Monk et al. (1999a) noted that FGE tests conducted in 1993 and 1994 with STS in place revealed that guidance of spring migrants had dropped to about 50\%. This was considerably lower than the $70 \%$ observed in the late 1980 s and well below the new regional standard of $80 \%$ FGE. Furthermore, results were highly variable and thus there was difficulty identifying the combination of conditions and structures that resulted in poor FGE. 
Table 3.16. Estimates of FGE at the Bonneville Dam Powerhouse 2. For fyke-net-based estimates, we primarily report values for the control or reference screen configuration. These represent the general screen-type in the majority of turbine units at the powerhouse. This provides an FGE index that could be applied to the overall powerhouse. For other tools, the specified screen configuration in some cases was not the standard reference configuration.

\begin{tabular}{|c|c|c|c|c|c|c|}
\hline \multirow{2}{*}{ Year } & \multirow{2}{*}{$\begin{array}{c}\text { Species } \\
\text { or } \\
\text { Season }\end{array}$} & \multicolumn{2}{|c|}{ FGE Percent } & \multirow[b]{2}{*}{ Screen Configuration } & \multirow{2}{*}{$\begin{array}{c}\text { Evaluation } \\
\text { Method }\end{array}$} & \multirow[b]{2}{*}{ Source } \\
\hline & & Mean & Range & & & \\
\hline 1983 & Y. Chin. & 19.3 & (6.3 to 50.6$)$ & STS; Standard Depth; Angles of 47 and 60 Degrees (Pooled) & Fyke net & Krcma et al. (1984) \\
\hline 1984 & Y. Chin. & 32.0 & --- & STS; Standard Depth; Angle of 60 Degrees; with trash rack deflector; Unit 12; 2-3 June & Fyke net & Gessel et al. (1985) \\
\hline 1985 & Y. Chin. & 33.4 & --- & STS; Standard Depth; Angle of 65 Degrees; streamlined trash rack; Unit 12B; 3-7 May & Fyke net & Gessel et al. (1986) \\
\hline 1986 & Y. Chin. & 44.3 & --- & STS; 27" lowered Depth; Angle of 55 Degrees; streamlined trash rack; Unit 12B; 21-29 & Fyke net & Gessel et al. (1987) \\
\hline 1986 & Y. Chin. & 35.2 & --- & STS; 27" lowered Depth; Angle of 55 Degrees; standard trash rack; Unit 12A; 23-29 & Fyke net & Gessel et al. (1987) \\
\hline 1986 & Y. Chin. & 60.5 & --- & STS; 27" lowered Depth; Angle of 55 Degrees; streamlined trash rack; Unit 12B; 19-24 & Fyke net & Gessel et al. (1987) \\
\hline 2000 & Y. Chin. & 39.0 & --- & Spring Evaluation; All operable units; $\mathrm{n}=156 / 398$ & Radio-Telemetry & Evans et al. (2001b) \\
\hline 2001 & Y. Chin. & 46.0 & --- & Spring Evaluation; All operable units; $n=417 / 915$ & Radio-Telemetry & Evans et al. (2001d) \\
\hline 2002 & Y. Chin. & 37.0 & $(30 \text { to } 45)^{1}$ & Spring Evaluation; All operable units; $n=251 / 674$ & Radio-Telemetry & Evans et al. (2003a; 2006a) \\
\hline 2004 & Y. Chin. & 33.0 & (31 to 37 ) & Spring Evaluation; All operable units; $n=730 / 2,229$ & Radio-Telemetry & Reagan et al. (2006) \\
\hline 2005 & Y. Chin. & 36.0 & (29 to 42$)$ & Spring Evaluation; All operable units; $n=786 / 2,160$ & Radio-Telemetry & Adams et al. (2006) \\
\hline 1983 & Sub. Chin. & 24.3 & (7.4 to 55.3 ) & STS; Standard Depth; Angles of 47 and 60 Degrees (Pooled); Day and Night (Pooled) & Fyke net & Krcma et al. (1984) \\
\hline 1984 & Sub. Chin. & 22.0 & --- & STS; Standard Depth; Angle of 60 Degrees; with trash rack deflector; Unit 12; 2-3 June & Fyke net & Gessel et al. (1985) \\
\hline 1984 & Sub. Chin. & 27.0 & --- & STS; Standard Depth; Angle of 60 Degrees; no trash rack deflector; Unit $12 ; 17-22$ July & Fyke net & Gessel et al. (1985) \\
\hline 1985 & Sub. Chin. & 9.9 & --- & STS; Standard Depth; Angle of 65 Degrees; standard trash rack; Unit 12A; $16-19$ July & Fyke net & Gessel et al. (1986) \\
\hline 1985 & Sub. Chin. & 13.6 & --- & STS; Standard Depth; Angle of 65 Degrees; streamlined trash rack; Unit 12B; 20-23 July & Fyke net & Gessel et al. (1986) \\
\hline 1987 & Sub. Chin. & --- & ( 2 to 34$)$ & STS's in unit 12 ; summer run of subyearling chinook; 14 to 31 July & Fyke net & Gessel et al. (1988) \\
\hline 2000 & Sub. Chin. & 25.0 & --- & Summer Evaluation; All operable units; $n=1 / 4$ & Radio-Telemetry & Evans et al. (2001a) \\
\hline 2001 & Sub. Chin. & 35.0 & --- & Summer Evaluation; All operable units; $\mathrm{n}=169 / 479$ & Radio-Telemetry & Evans et al. (2001c) \\
\hline 2002 & Sub. Chin. & 47.0 & (36 to 59$)$ & Summer Evaluation; All operable units; $\mathrm{n}=317 / 681$ & Radio-Telemetry & Evans et al. (2006b) \\
\hline 2004 & Sub. Chin. & 22.0 & (20 to 24$)$ & Summer Evaluation; All operable units; $\mathrm{n}=714 / 312$ & Radio-Telemetry & Evans et al. (2006c) \\
\hline 2005 & Sub. Chin. & 24.0 & (15 to 42$)$ & Summer Evaluation; All operable units; $\mathrm{n}=367 / 1,572$ & Radio-Telemetry & Adams et al. (2006) \\
\hline 1983 & Steelhead & 34.7 & (15.3 to 50.0$)$ & STS; Standard Depth; Angles of 47 and 60 Degrees (Pooled) & Fyke net & Krcma et al. (1984) \\
\hline 2000 & Steelhead & 55.0 & --- & Spring Evaluation; All operable units; $\mathrm{n}=90 / 163$ & Radio-Telemetry & Evans et al. (2001b) \\
\hline 2002 & Steelhead & 59.0 & $(50 \text { to } 63)^{1}$ & Spring Evaluation; All operable units; $n=135 / 229$ & Radio-Telemetry & Evans et al. (2003a; 2006a) \\
\hline 2004 & Steelhead & 40.0 & (40 to 44$)$ & Spring Evaluation; All operable units; $n=273 / 685$ & Radio-Telemetry & Reagan et al. (2006) \\
\hline 2005 & Steelhead & 36.0 & (34 to 40$)$ & Spring Evaluation; All operable units; $\mathrm{n}=258 / 711$ & Radio-Telemetry & Adams et al. (2006) \\
\hline 1983 & Coho & 24.7 & (25.6 to 35.0$)$ & STS; Standard Depth; Angles of 47 and 60 Degrees (Pooled) & Fyke net & Krcma et al. (1984) \\
\hline 1983 & Sockeye & 14.0 & (0.0 to 28.6$)$ & STS; Standard Depth; Angles of 47 and 60 Degrees (Pooled) & Fyke net & Krcma et al. (1984) \\
\hline 1987 & Spring & 32.0 & --- & STS; 30 " lowered Depth; Angle of 55 Degrees; streamlined trash rack; Unit 12B; 21 Apr. & Hydroacoustics & Magne (1987a,c) \\
\hline 1987 & Spring & --- & $(25$ to 75$)$ & STS's in unit 12; mix of Y. chinook and coho; 21 Apr. to 3 June & Fyke net & Gessel et al. (1988) \\
\hline 1996 & Spring & 37.0 & $(16.0$ to 66.0$)$ & Spring Evaluation; Units 11A, 12A, 13C, 14B, 15B, 16C, 17B, and 18A & Hydroacoustics & Ploskey et al. (1998) \\
\hline 1997 & Spring & 4.2 & (0.0 to 7.44$)$ & Spring Evaluation; Unit 11A; STS with TIE; sluice gate closed & Hydroacoustics & BioSonics (1998) \\
\hline 1997 & Spring & 2.4 & $(0.0$ to 8.34$)$ & Spring Evaluation; Unit 11A; STS with TIE; sluice gate operated at 61' & Hydroacoustics & BioSonics (1998) \\
\hline 1997 & Spring & 5.0 & (2.75 to 8.24$)$ & Spring Evaluation; Unit 11A; STS with TIE; sluice gate closed & Hydroacoustics & BioSonics (1998) \\
\hline 1997 & Spring & 2.5 & (1.08 to 4.78$)$ & Spring Evaluation; Unit 11A; STS with TIE; sluice gate operated at $68^{\prime}$ & Hydroacoustics & BioSonics (1998) \\
\hline 1998 & Spring & 55.0 & --- & Spring Evaluation; Units 11-13; No TIE's in Units 11-14; Sluice Gate not operated & Hydroacoustics & Ploskey et al. (2001a) \\
\hline 2000 & Spring & 52.0 & --- & Spring Evaluation; Units 11-18; Sluice Gate Operational & Hydroacoustics & Ploskey et al. (2002a) \\
\hline 2001 & Spring & 56.0 & $(0.35$ to 0.72$)$ & Spring Evaluation (1 May to 9 June); Units 11-18 (Unit 15 modified); Sluice Gate & Hydroacoustics & Ploskey et al. (2002b) \\
\hline 2002 & Spring & 53.0 & --- & (20 April to 2 June); Units $11-18$ (Units 15 and 17 modified) & Hydroacoustics & Ploskey et al. (2006) \\
\hline 2004 & Spring & 48.0 & \pm 3.33 & Spring Evaluation with Corner Collector operating & Hydroacoustics & Ploskey et al. (2005) \\
\hline 2005 & Spring & 45.0 & \pm 4.33 & Spring Evaluation with Corner Collector operating & Hydroacoustics & Ploskey et al. (2006c) \\
\hline 1996 & Summer & 26.0 & $(10.0$ to 42.0$)$ & Summer Evaluation; Units $11 \mathrm{~A}, 12 \mathrm{~A}, 13 \mathrm{C}, 14 \mathrm{~B}, 15 \mathrm{~B}, 16 \mathrm{C}, 17 \mathrm{~B}$, and $18 \mathrm{~A}$ & Hydroacoustics & Ploskey et al. (1998) \\
\hline 1997 & Summer & 2.8 & $(1.02$ to & Summer Evaluation; Unit 11A; STS with TIE; sluice gate closed & Hydroacoustics & BioSonics (1998) \\
\hline 1997 & Summer & 2.2 & ( 0.38 to 8.55$)$ & Summer Evaluation; Unit 11A; STS with TIE; sluice gate operated at $68^{\prime}$ & Hydroacoustics & BioSonics (1998) \\
\hline 1998 & Summer & 30.0 & --- & Summer Evaluation; Units 11-13; No TIE's in Units 11-14; Sluice Gate not operated & Hydroacoustics & Ploskey et al. (2001a) \\
\hline 2000 & Summer & 38.0 & --- & Summer Evaluation; Units 11, 13, 14, 15, 16, 17, 18; Sluice Gate Operational & Hydroacoustics & Ploskey et al. (2002a) \\
\hline 2001 & Summer & 44.0 & (0.11 to 0.54$)$ & Summer Evaluation (1 July to 15 July); Units $11-18$ (Unit 15 modified); Sluice Gate & Hydroacoustics & Ploskey et al. (2002b) \\
\hline 2002 & Summer & --- & (0.25 to 0.65$)$ & (3 June to 15 July); Units $11-18$ (Units 15 and 17 modified) & Hydroacoustics & Ploskey et al. (2003) \\
\hline 2004 & Summer & 36.0 & \pm 2.93 & Summer Evaluation with Corner Collector operating & Hydroacoustics & Ploskey et al. (2005) \\
\hline 2005 & Summer & 37.0 & \pm 4.43 & Summer Evaluation with Corner Collector operating & Hydroacoustics & Ploskey et al. (2006c) \\
\hline 1988 & All & --- & --- & --- & Fyke net & Gessel et al. (1989) \\
\hline 1989 & All & --- & --- & --- & Fyke net & Gessel et al. (1990) \\
\hline 1993 & All & --- & --- & --- & Fyke net & Monk et al. (1994) \\
\hline 1994 & All & --- & --- & --- & Fyke net & Monk et al. (1995) \\
\hline 2001 & All & --- & --- & --- & Fyke net & Monk et al. (2002) \\
\hline \multicolumn{7}{|c|}{${ }^{1}$ Range over varying spill operations, taken from Table 9 of Evans et al. (2006b) } \\
\hline & & & ing the & $n$ Table 9 of Evans et al. (2006b) & & \\
\hline & & & & & & \\
\hline
\end{tabular}


In their review of information gathered through 1998, NOAA Fisheries investigators identified factors that could be contributing to the poor FGE at B2 (Monk et al. 1999a). The two most important ones were as follows:

- A hydraulic bottleneck exists above the STS screens that may be restricting the flow of water and fish into the gatewell and bypass.

- Unique hydraulic conditions in the forebay cause large-scale current patterns along the face of the dam that affect the vertical distribution of smolts upon entering turbine intakes.

Using that information as a foundation, the fishery agencies directed the USACE to initiate a thorough FGE improvement study for B2 that included ample hydraulic modeling and a full assessment of biological benefits and risks. To accomplish this, the USACE contracted with INCA Engineers et al. (1999) who assembled a team of hydraulic, structural, and civil engineers and fish passage biologists to conduct the study. Based on results and recommendations from that study and those previously reported by Monk et al. (1999a), several cost-effective and promising actions were implemented and evaluated in 2001. These included

- removal of a section of concrete beam to accommodate a larger VBS and improve hydraulic conditions

- installing a turning vane above the STS to improve hydraulic conditions

- Installing a gap closure at the upper downstream edge of the STS to direct more flow and fish upward into the gatewell.

Monk et al. (2002) evaluated the combined biological effect of these conditions and structural modifications. FGE increased dramatically over that last documented in 1994 with the standard STS configuration, i.e., all species exhibited a net improvement in FGE. In the modified unit, FGE during spring testing averaged $71 \%, 82 \%, 88 \%$, and $62 \%$ for yearling Chinook salmon, steelhead, coho, and subyearling Chinook salmon, respectively. During the summer, FGE for subyearling Chinook salmon was the highest observed before at either powerhouse, at 57\%. Furthermore, screen-related injury and descaling rates were among the lowest observed since the Second Powerhouse has been operated.

\subsubsection{Characterizing FGE at B1 and B2: Fyke-Net Data}

Fishery managers and analysts require estimates of FGE to apply in certain evaluations, such as those involving fish passage models. FGE estimates are just one of many input parameters that are used to populate a passage model. Selecting a representative value for the species of interest can be challenging as witnessed by the variability in measured values and ever-changing screen systems. The difficulty is magnified if retrospective analyses are pursued, which requires establishing what effective FGE was at some point in history. Often such details are ignored or cannot be reasonably determined. In most cases a generic value that is considered representative is applied across dam configuration eras. This can result in rather coarse assessments.

The most recent generic FGE values for B1 and B2 were reported by Ferguson et al. (2005) (see Table 3.17). 
Table 3.17. Generic FGE Values for B1 and B2 Calculated by NOAA Staff for the 1999 Dam Configuration Compared with Those Used Last in the PATH Modeling Forum.

\begin{tabular}{|lcccc||}
\hline & \multicolumn{2}{c}{ PATH } & NOAA - 1999 Configuration \\
\hline \hline Species & B1 & B2 & B1 & B2 \\
Yearling Chinook & 41 & 43 & 38 & 44 \\
Subyearling Chinook & --- & --- & 16 & 18 \\
Steelhead & --- & --- & 41 & 48 \\
\hline
\end{tabular}

These values were distilled from the complex of fyke net-based FGE estimates in the historical database. Staff used their judgment in selecting values that they believed were most representative of the general dam configuration pre-BiOp. Some of those estimates were then adjusted based on side-by-side PIT tag and fyke net data obtained at Snake River dams to yield the values above. Later in this report we will compare these FGE indices with those obtained using other tools.

\subsubsection{Hydroacoustics}

Hydroacoustic sampling methods were used to estimate FGE at Bonneville Dam in the late 1980s. Magne (1984 and 1987a,b,c), and Magne et al. (1986 and 1989), and Stansell et al. (1990) used hydroacoustics to monitor smolt passage through select units and found positive correlations with FGE estimates based on fyke net sampling. Thorne and Kuehl 1989 evaluated the efficacy of using hydroacoustic techniques for estimating FGE at B1 in 1988. In the late 1990s, as research efforts focused increasingly on evaluating diversion screen performance, more complex and extensive use of hydroacoustics for estimating FGE became common place.

In 1996, Ploskey et al. (1998) observed that FGE at B2 varied among seasons, time of day, and turbine units monitored. FGE was higher during spring than summer and higher during day than night sampling periods. They also reported that the 1996 hydroacoustic estimates were of similar magnitude to previously reported estimates from fyke net sampling. The mean difference in ten estimates was $10.7 \%$, with a $95 \%$ CI of $5 \%$.

In 1997, some incongruous estimates of FGE were reported by BioSonics (1998). Across a variety of test configurations in Unit 11a, spring FGE ranged from only $2.4 \%$ to $5.0 \%$ (Table 3.16 ). Estimates obtained during the summer were even lower, ranging from $2.2 \%$ to $2.8 \%$. Operation of the sluice chute adjacent to the unit had no appreciable affect on FGE. It was very low regardless of whether the chute was operating. The estimates reported by BioSonics are about an order of magnitude lower than those documented in any other FGE evaluation at this site, regardless of the tool employed. We conclude these estimates are an anomaly and are not useful for representing FGE dynamics at B2.

In 1998, sampling was done at select units at B1 (Ploskey et al. 2001a). As observed with other techniques, FGE was lower during the summer than in the spring (Table 3.14). But the persistent sampling also revealed that there was a continual declining trend in FGE throughout the summer sampling period. This was consistent with patterns observed with both hydroacoustics and net sampling (Figure 3.40). That same year at B2, they observed that FGE also decreased throughout the summer. 


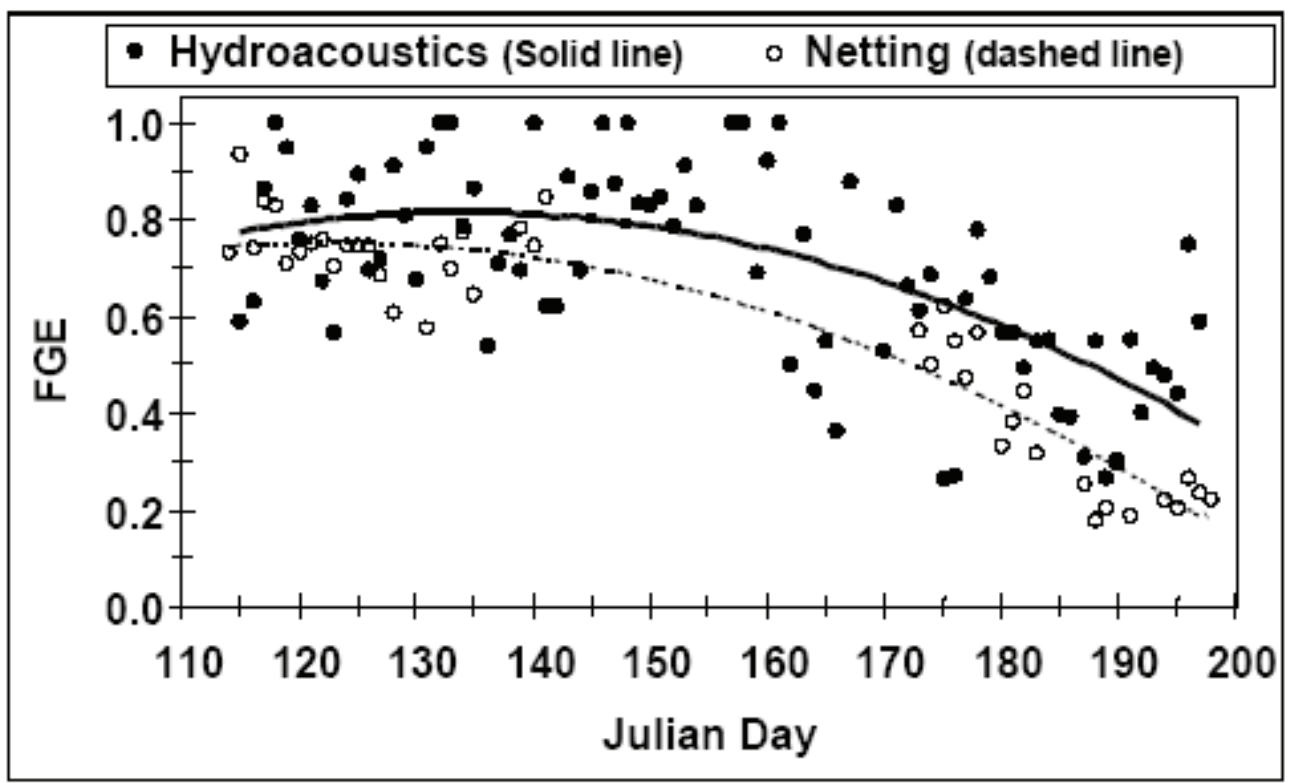

Figure 3.40. FGE of an Extended-length Bar Screen at Intake 8b Estimated by Fixed Aspect Hydroacoustics and Netting. Netting data were collected and provided by the NMFS. From Ploskey et al. 2001a, Figure 25; data from 1998.

In 2000, an ESBS was installed in Unit 8 at B1 and FGE was monitored (Ploskey et al. 2002a). They found that the ESBS FGE was greater than STS FGE. Also, they reported a strong correlation $\left(\mathrm{r}^{2}=0.65\right)$ between hydroacoustic and fyke net-based FGE estimates obtained by NOAA investigators (Figure 3.28). Their extended monitoring revealed a dramatic temporal trend of decreasing FGE from spring through summer, regardless of screen type (Figure 3.28). As a point of contrast, we note later in this report that the PSC efficiency remained high throughout the entire spring and summer sampling periods. Over the sampling period, the average FGE was $46 \%$ during the spring and $36 \%$ in summer.

In 2001, following recommendations by ENSR and NMFS (Monk et al. 1999a), the USACE modified the VBS and intake structure at Unit 15 (B2). A broad multi-pronged evaluation of B1 and B2 was undertaken using hydroacoustics, net sampling, and radio-telemetry. With respect to FGE, the objective was to determine the effect of modifications to Unit 15 (Ploskey et al. 2002c). Also, other observations reinforced findings from previous years. They noted that spring FGE was greater than summer FGE, based on both hydroacoustic and fyke net sampling.

Hydroacoustic estimates of FGE were consistent with and similar to net-based estimates (Figure 3.41). FGE varied widely across turbine units (Figure 3.42). Importantly, FGE in the modified Unit 15 was consistently higher than unmodified units fitted with STS (Figure 3.43). Ploskey et al. (2002c) also reported that season-wide FGE estimates based on hydroacoustics and radio-telemetry varied by as much as 10\% as illustrated in Table 3.18. The difference in estimates is not surprising, given the methods in which investigators using each tool document, monitor, and calculate FGE is fundamentally different. 


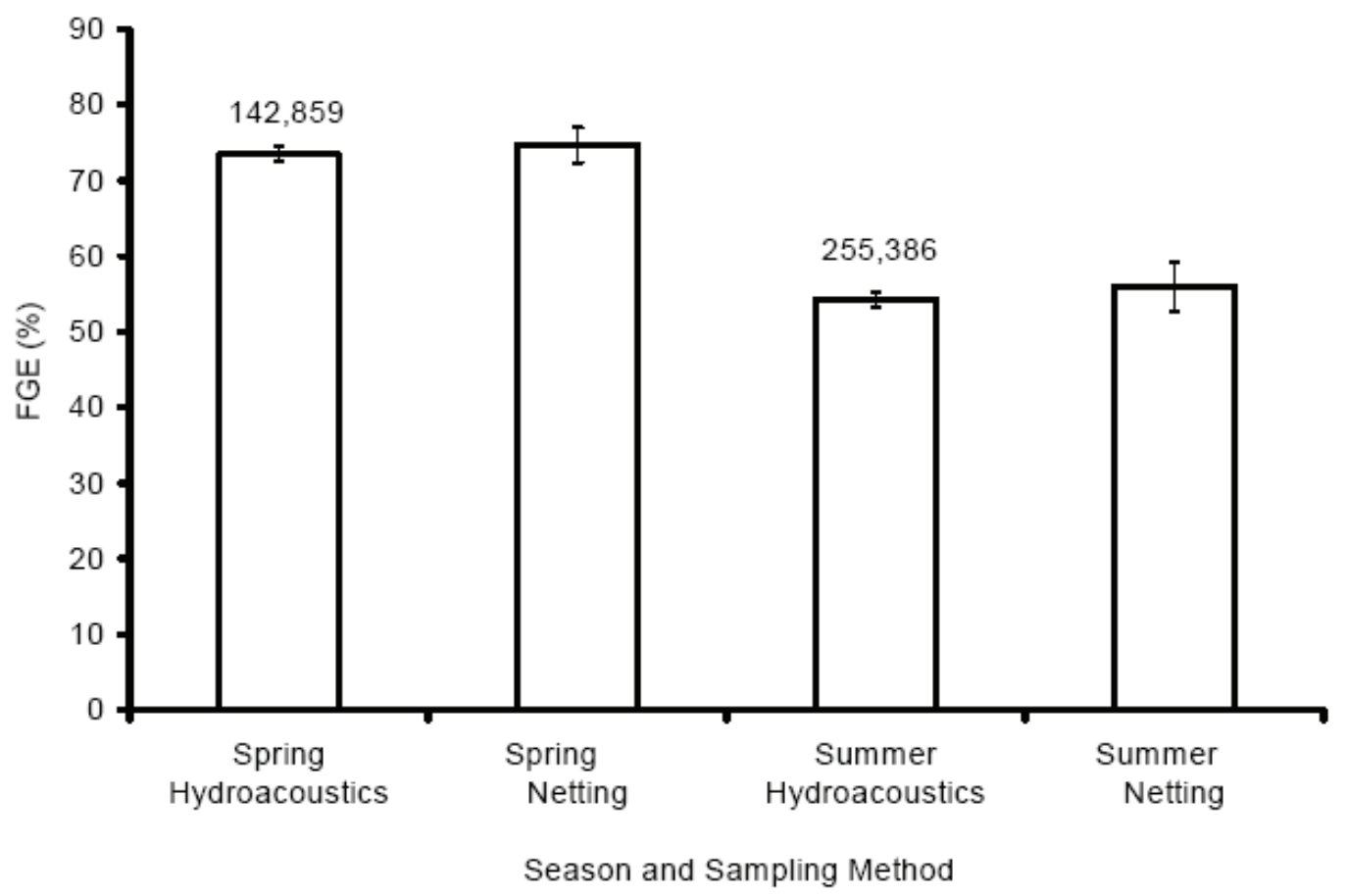

Figure 3.41. Plot of FGE Estimates Made from all Nighttime Hours of Hydroacoustic Sampling (20000500) Compared to Estimates based on Netting from about 2000 to 2100 or $2200 \mathrm{~h}$. Vertical bars are $95 \%$ confidence limits. The expanded numbers of fish upon which FGE estimates were based are shown above the bars for hydroacoustic sampling each season. 2001 data, figure reproduced from Ploskey et al. (2002c, Figure S.2).

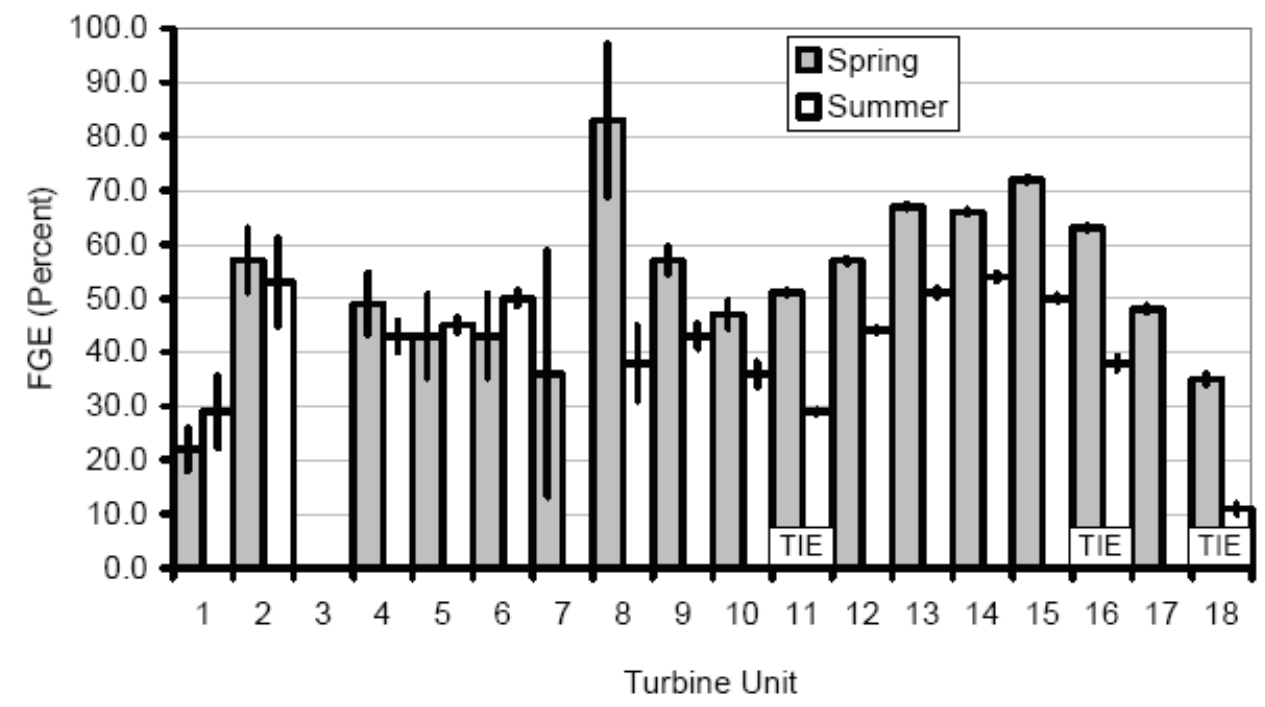

Figure 3.42. Estimates of FGE and 95\% Confidence Limits for Turbine Units at Bonneville Dam in Spring and Summer. Figure reproduced from 2001 data (Ploskey et al. 2002c, Figure 3.43). 


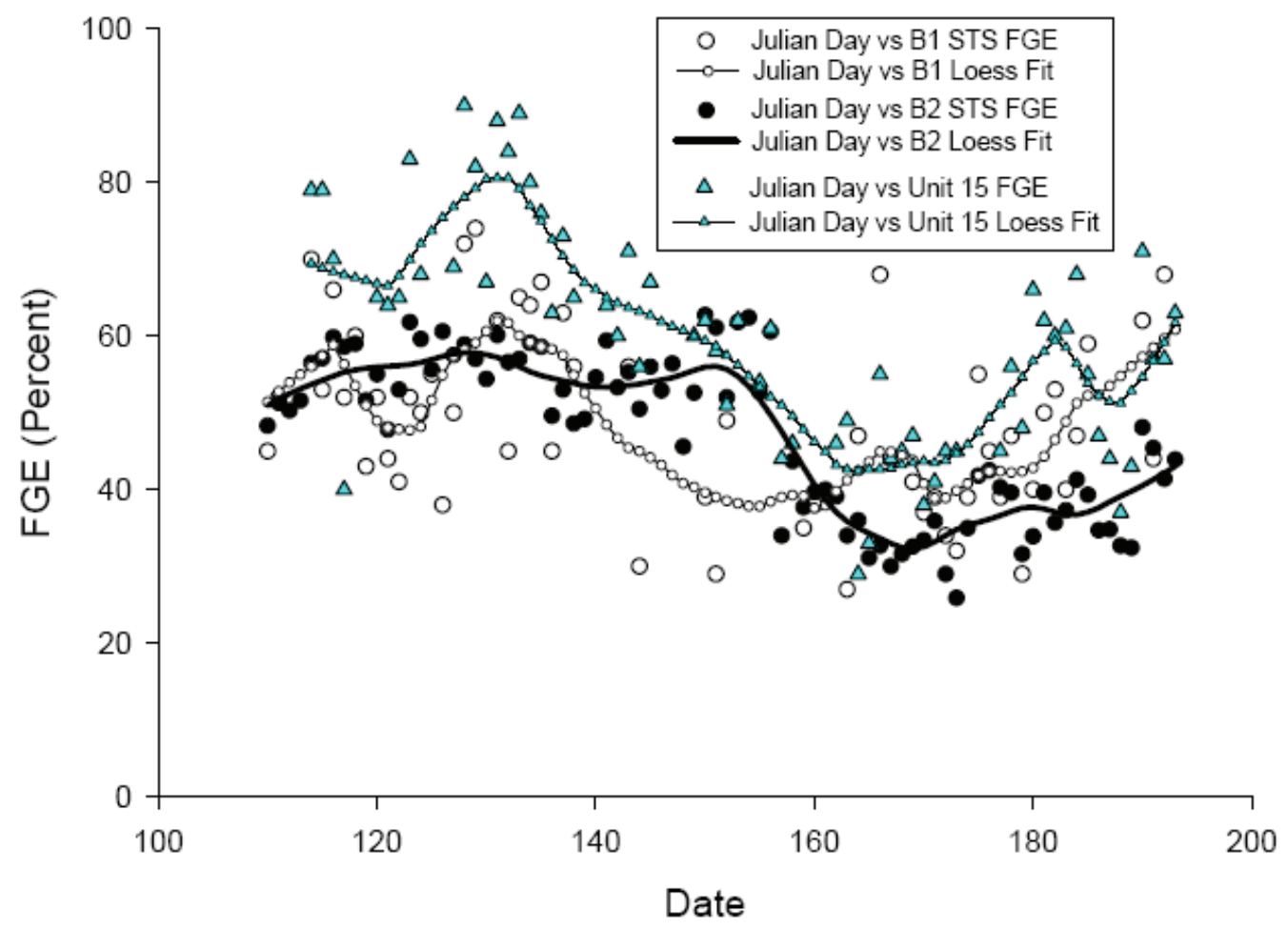

Figure 3.43. Comparison of FGE among Types of Units with STS at Powerhouse 1, Powerhouse 2, and at Modified Unit 15 by Date. 2001 data, figure reproduced from Ploskey et al. (2002c, Figure 3.42).

Table 3.18. Hydroacoustic and Radiotelemetry Estimates of FGE at B1 and B2 in 2001

\begin{tabular}{|ccc|}
\hline Period/Powerhouse & Hydroacoustics & Radio-Telemetry \\
\hline \hline & Spring & \\
B1 & $47 \%$ & $45 \%$ \\
B2 & $56 \%$ & $46 \%$ \\
& Summer & \\
B1 & $47 \%$ & $57 \%$ \\
B2 & $44 \%$ & $35 \%$ \\
\hline
\end{tabular}

In 2002, Ploskey et al. (2003) noted that FGE was highest in units at B2 that had been modified (units 15 and 17), and at Unit 8 at B1, which was equipped with an ESBS (Figure 3.44). A seasonal decrease in FGE was still apparent at some units, even the modified Unit 17 (Figure 3.45). Furthermore, the presence or absence of TIEs did not appear to influence FGE as much as the location of the unit across B2 (Figure $3.45)$. 
By the start of the 2004 out-migration, guidance screens had been removed from the First Powerhouse, and the corner collector was in full operation at B2. The effect of the corner collector on FGE at B2 was of interest. Ploskey et al. (2005 and 2006c) provided FGE estimates that suggested that FGE had dropped slightly from levels observed in previous years, at least during the spring (Table 3.2). The summer estimates suggest a similar effect compared to 2001 and 2002 but not relative to 2000 (Table 3.3). This could have been the result of the $\mathrm{B} 2 \mathrm{CC}$ shallow fish that otherwise may have been guided by screens, as hypothesized by Adams et al. (2006).

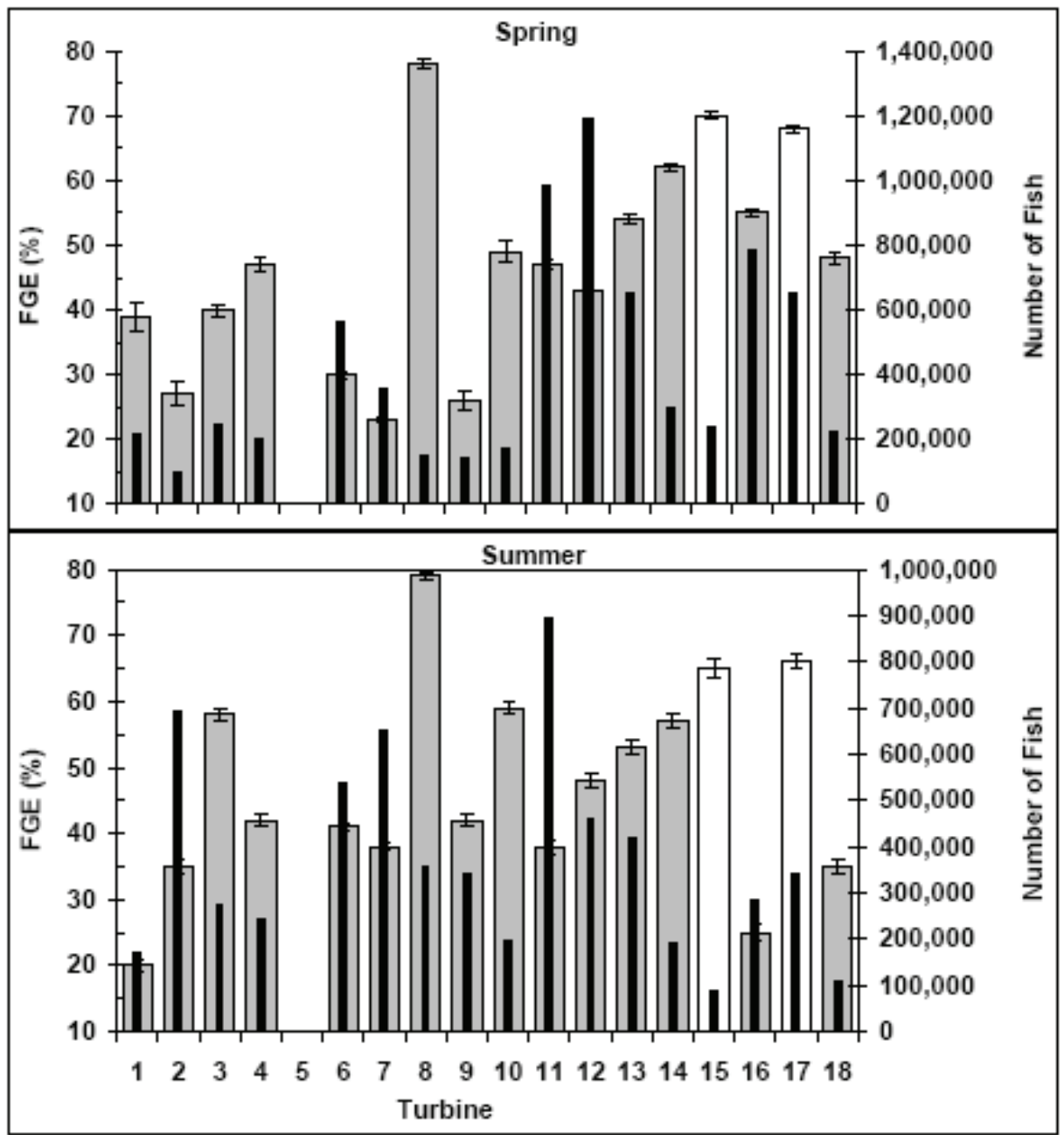

Figure 3.44. Comparison of FGE (Wide Bars) and Fish Passage (Narrow Black Bars) among Turbines at Bonneville Dam in Spring and Summer 2002. Turbines 1-10 are located at B1 and turbines $11-18$ are at B2. All turbine intakes have submerged traveling screens except for intakes at Unit 8 (lined bar), which had extended submerged bar screens. The gatewells at units 15 and 17 (white bars) were modified to increase flow up the slot relative to gatewells at other units $(11-14,16$, and 18) Error bars are 95\% confidence limits. 2002 data, reproduced from Ploskey et al. (2003, Figure S.12). 


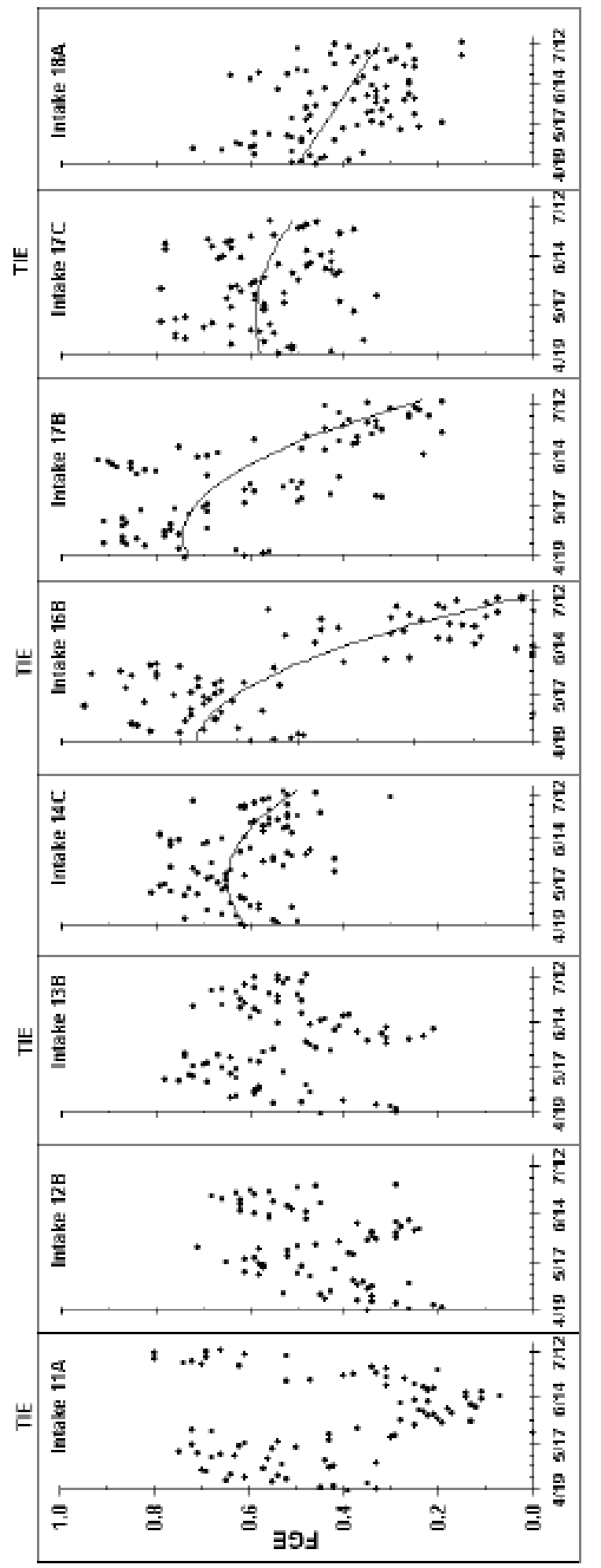

Figure 3.45. Plots of Seasonal Trends of Intake-Specific FGE for B2 in 2002 with Labels Indicating the Intakes that were Behind, as Opposed to, Between TIES. Intake 15B only ran during the spring and therefore was not plotted. 2002 data, reproduced from Ploskey et al. (2003, Figure 3.1.6). 


\subsubsection{Radio Telemetry Estimates}

\subsubsection{Bonneville Powerhouse 1}

Beginning in 2000, radio-telemetry was used to estimate FGE as well as passage. In 2000, Evans et al. (2001a and 2001b) reported FGE estimates for three species (Table 3.14). FGE reflected the fraction of fish arriving at the powerhouse that were guided by the collective screens into the JBS. That year, the average FGE was 50\% for yearling Chinook salmon, 59\% for steelhead, and 29\% for subyearling Chinook salmon during the summer.

In 2001, only estimates for yearling and subyearling Chinook salmon were reported (Evans et al. 2001c and 2001d). FGE averaged 45\% and 57\% for each species, respectively (Table 3.14). The value for subyearling Chinook salmon was surprisingly high; since estimates generated using other tools have consistently indicated much lower values. Furthermore, that summer estimate is nearly twice the level observed the previous year using telemetry. This estimate may well be unrealistic and may be an artifact of the low sample size of only seven fish detected at the powerhouse, with only four of those being identified as guided.

In 2002, overall FGE for yearling Chinook salmon was estimated at 50\%, and $75 \%$ for steelhead (Figure 3.14; Evans et al. 2003a). The sample size for steelhead was notably low with 9 of 12 fish at the powerhouse being guided.

Although measures of precision were not reported by the authors, it was apparent that sample sizes varied considerably across years. Once Bonneville Powerhouse 2 became the priority powerhouse, sample sizes at Bonneville 1 dropped dramatically.

\subsubsection{Bonneville Powerhouse 2}

In 2000, FGE estimates at Bonneville 2 were generally similar to those reported at Bonneville 1, except for yearling Chinook salmon which was 11 percentage points lower at Bonneville 2 (Table 3.16). The FGE over the period radio-tagged fish were passing the dam was 39\%, 55\%, and $25 \%$ for yearling Chinook salmon, steelhead, and subyearling Chinook salmon, respectively. In 2001, FGE was 46\% for yearling Chinook salmon and 35\% for subyearling Chinook salmon. In 2002, FGE for yearling Chinook salmon and steelhead were lower than observed at Bonneville 1 the same year, averaging $37 \%$ and 59\%, respectively. Adams et al. (2006) hypothesized that lower FGE at B2 in 2004 and 2005 was due to the corner collector passing the majority of the shallow fish, fish that may otherwise have been guided.

In general, the radio-tag estimates of FGE appear to be sound species-specific indices, as long as a satisfactory number of fish arrive at the powerhouse and enter the screened bypass system. With Bonneville 2 as the priority unit and increased spill levels realized in recent years, it will be increasingly difficult to obtain ample recoveries at Bonneville 1 to provide robust FGE estimates at that powerhouse.

\subsubsection{Comparison Among Tools}

Attempts to compare absolute values of FGE that were obtained using different tools are not particularly instructive. Methods not only differ in sampling capability, but also differ with respect to the population they monitor or index. Thus, it is not surprising that different tools yield different estimates. To illustrate such differences, we present hydroacoustic and radio-telemetry estimates obtained in two recent years (Table 3.19). 
Table 3.19. Season-Wide FGE Estimates for each Entire Powerhouse as Determined Using Radio Telemetry and Hydroacoustics. Standard Errors are indicated as such, other precision estimates are at $95 \%$ confidence limits.

\begin{tabular}{|lll|}
\hline \multicolumn{1}{|c}{ Estimate } & B2 - 2004 & B2 - 2005 \\
\hline \hline Radio-telemetry - Yearling Chinook & $33 \%($ S.E. $=1.0)$ & $36 \%($ S.E. $=1.0)$ \\
Radio-telemetry - Steelhead & $40 \%($ S.E. $=1.9)$ & $36 \%($ S.E. $=1.8)$ \\
Hydroacoustics - Spring & $48 \%( \pm 3.3)$ & $45 \%( \pm 4.3)$ \\
Radio-telemetry - Subyearling Chinook & $22 \%($ S.E. $=0.7)$ & $24 \%($ S.E. $=1.1)$ \\
Hydroacoustics - Summer & $36 \%( \pm 2.9)$ & $37 \%( \pm 4.4)$ \\
\hline \hline
\end{tabular}

We focus on B2 FGE, because these data are most relevant given contemporary operations (B2 priority and corner collector operations). Consistently, hydroacoustic estimates are greater than those obtained with radio-telemetry (Table 3.19). This pattern was evident during spring and summer sampling periods in both 2004 and 2005.

Both sets of estimates apply to each entire powerhouse over the range of operating conditions prevailing in those years. The difference in the values yielded by different tools is obvious, but bears repeating. Each telemetry-based estimate is specific to that species, whereas hydroacoustic estimates reflect the population at large. In the spring, the population is comprised of more species than merely yearling Chinook salmon and steelhead. Coho are also abundant in the spring at Bonneville Dam. The proportions of the different species will affect the FGE estimate using hydroacoustics. In the summer, the presence of shad also contributes to the FGE estimate at times, so that summer estimates do not always pertain exclusively to salmonids. Also, there are late-migrating steelhead and yearling Chinook salmon that can contribute to the summer hydroacoustic estimate.

The fyke net-based estimates common in early years, are based on measurements taken in primarily a single unit that differed across years and sampling was brief, spanning only a few hours in any one season. These limited estimates were, in turn, extrapolated across all turbines. We regard this approach to be a rather coarse index of the effective FGE for any powerhouse and question its utility in characterizing the overall performance of screened bypass systems.

For years when there was full hydroacoustic coverage of the turbine units across a powerhouse, the season-wide estimates have the capacity to generally represent overall FGE at either powerhouse, albeit lacking species-specific indicators. In such years, the sampling technique is spatially and temporally extensive and able to capture the pronounced variability inherent in these dynamics.

In many cases the radio-telemetry estimates reflect FGE performance across the entire powerhouse and across seasonal operating conditions for individual species, providing perhaps the most useful overall species-specific index of FGE. However, sample sizes must be high enough to provide reliable estimates.

\subsubsection{Synthesis and Conclusions}

In viewing the collective FGE information obtained with fyke nets, hydroacoustics, and radiotelemetry, we submit the following synthesis and conclusions. 
Establishing reliable, representative estimates of powerhouse FGE for use in retrospective passage modeling analyses for either B1 or B2 will be difficult. We could not readily identify any preferred set of estimates. Results vary by turbine unit, configuration, operations, and monitoring tool. There is no correct or best estimate of FGE available for application across all years. Furthermore, across and within years, so many conditions have been explored and tested that no typical or standard FGE can easily be distilled from the information. Managers seeking such estimates will have to make value judgments regarding the suitability of year-specific estimates for use in retrospective model analyses. NOAA, the Action Agencies, and state and tribal biologists engaged in such an effort as part of the 2006 remand process for the BiOp. Managers must determine what the further monitoring objectives are for Bonneville Dam and select the appropriate tool and method to satisfy them.

The fyke net method for estimating FGE seems best suited for evaluating different screen configurations in side-by-side comparisons. Since such evaluations involve only monitoring one or two units, this technique is not well suited for generating FGE estimates that represent performance across the entire powerhouse.

Hydroacoustic monitoring seems well suited for providing season-wide estimates of FGE if temporal and spatial coverage of the powerhouse is adequate. It is also the only practical method for documenting temporal changes in FGE over the migration period. An obvious shortcoming is the lack of speciesspecific information, but depending on the management objectives, this may not be a handicap.

The radio-telemetry method provides sound estimates of the effective FGE across the entire powerhouse during the period tagged fish are passing the project. This may be the most representative estimate of FGE that could be adopted and applied in model analyses. Even so, only a few estimates from recent years are available.

\subsection{Fine-Scale Passage Distribution}

\subsubsection{Introduction}

The distribution of downstream fish passage at Bonneville Dam reported over the last two decades has been derived from two sampling techniques: fixed-aspect hydroacoustics and radio telemetry. Each technique has important advantages and limitations. For example, fixed-aspect hydroacoustics detects enough fish at individual turbines, sluiceways, and spill bays to provide passage distribution data for the run at large but is limited by the inability to distinguish species of fish. Radio telemetry studies provide species-specific information for a few tagged species or age groups, but usually cannot provide robust passage distributions among individual turbines, spill bays, and sluiceways, although data usually are sufficient to describe passage distribution by type of route (e.g., B1 turbines, B1 sluiceway, spillway or type of spill bay with 7- or 14-ft elevation spill deflectors, B2 turbines, B2 JBS, and B2CC). This section of the report describes fish passage distributions using both techniques.

The use of hydroacoustics for assessing fish passage at Bonneville Dam began in 1985 with Nagy and Magne (1986) where fish distributions and fish guidance efficiency were first reported for two turbine units at B2. Turbine passage estimates for that initial hydroacoustic study, as well as for follow-on efforts in 1986 and 1987 (Magne et al. 1986; Magne 1987c) were likely inaccurate due to transducer deployment location. These early turbine passage studies using hydroacoustics at Bonneville Dam were based on 
assessing fish distributions with transducers deployed on the upstream face of the trashracks and aimed upward into the forebay. Targets ensonified by beams upstream of the trashracks may not have been committed to passage and thus should not be considered accurate measures of passage distributions. For this reason, we decided not to include passage estimates from these early studies in this synthesis report. By 1997, transducer deployment evolved to placement on the downstream side of the trashracks, where detected fish are assumed to be committed to passage (Magne et al. 1989). Early hydroacoustic passage investigations typically focused on just two or three turbine units, whereas recent efforts have included coverage at all routes of passage through Bonneville Dam (e.g., Ploskey et al. 2003).

Fish passage distribution studies at Bonneville Dam using radio telemetry techniques date back to Holmberg et al. (1996). That effort resulted in the first estimates of species-specific fish passage by primary structure (B1, B2, or spillway). Since 1996, each successive year through the present, radio telemetry has been used to assess horizontal and diel fish passage distributions at Bonneville Dam.

\subsubsection{Horizontal Distributions}

\subsubsection{Powerhouse 1}

\subsection{Hydroacoustics}

Ploskey et al. (1998) reported horizontal distribution of fish targets across all intakes (A, B and C) of units 3 and 5 in spring of 1996, indicating fewer fish were passed via intakes 5B and 5C relative to the other four intakes (Figure 3.46). Reasons for the differences are unknown. Hydroacoustic estimates for fish passage into Sluiceway Outlet 5C were not correlated with estimates from an up-looking video camera, but the camera clearly detected more fish near the piers than near the middle of the outlet.

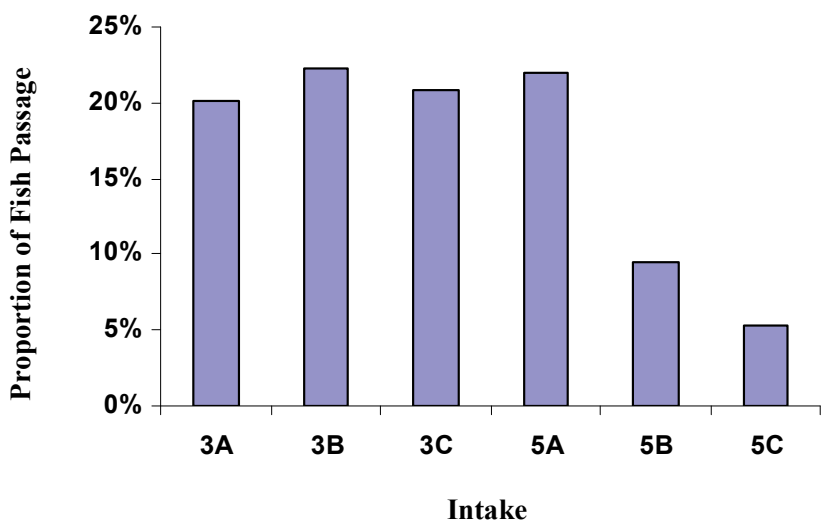

Figure 3.46. Relative Fish Passage at each Intake in Units 3 and 5 in 1996. Plot created from Ploskey et al. 1998.

In 1998, Ploskey et al. (2001b) evaluated a Prototype Surface Collector (PSC) designed to simulate entrance hydraulics associated with 5-ft and 20 -ft slot widths at Powerhouse 1 in front of Intakes $3 \mathrm{~B}$ and 5B. Hydroacoustic estimates of lateral fish distribution across the PSC intakes with the 20-ft slot indicated greater proportions of fish at the south and north portions of the intake compared to the middle of the intake during both spring and summer (Figure 3.47). This may have been indicative of fish tracking along the face of the PSC to discover an opening. Guided fish were those that passed into the 
collector slot and were detected inside the turbine above the floor elevation. Unguided fish were those detected below the collector.

Horizontal distribution of fish passage within and among intakes of Unit 5 in 1999 was not uniform based on data from the two pairs of transducers sampling in each intake (Figure 3.48; Ploskey et al. 2001b). A Wilcox sign rank test of the significance of the data indicated the most prevalent skew in distribution occurred at Intake $5 \mathrm{C}$ with unguided fish passage, where the south side showed significantly greater passage than the north side across slot treatment and season (Table 3.20). It also showed that guided fish passage was significantly greater through the north side of intakes $\mathrm{A}$ and $\mathrm{C}$ in spring and in all intakes in summer (Ploskey et al. 2001b).

Horizontal distribution of total fish passage at B1 turbines in 2000 indicates Units 4 and 9 had the highest fish passage during both the spring and summer (Figure 3.49; Ploskey et al. 2002a). Units 7, 8, and 10 passed the fewest fish for B1 in both seasons.

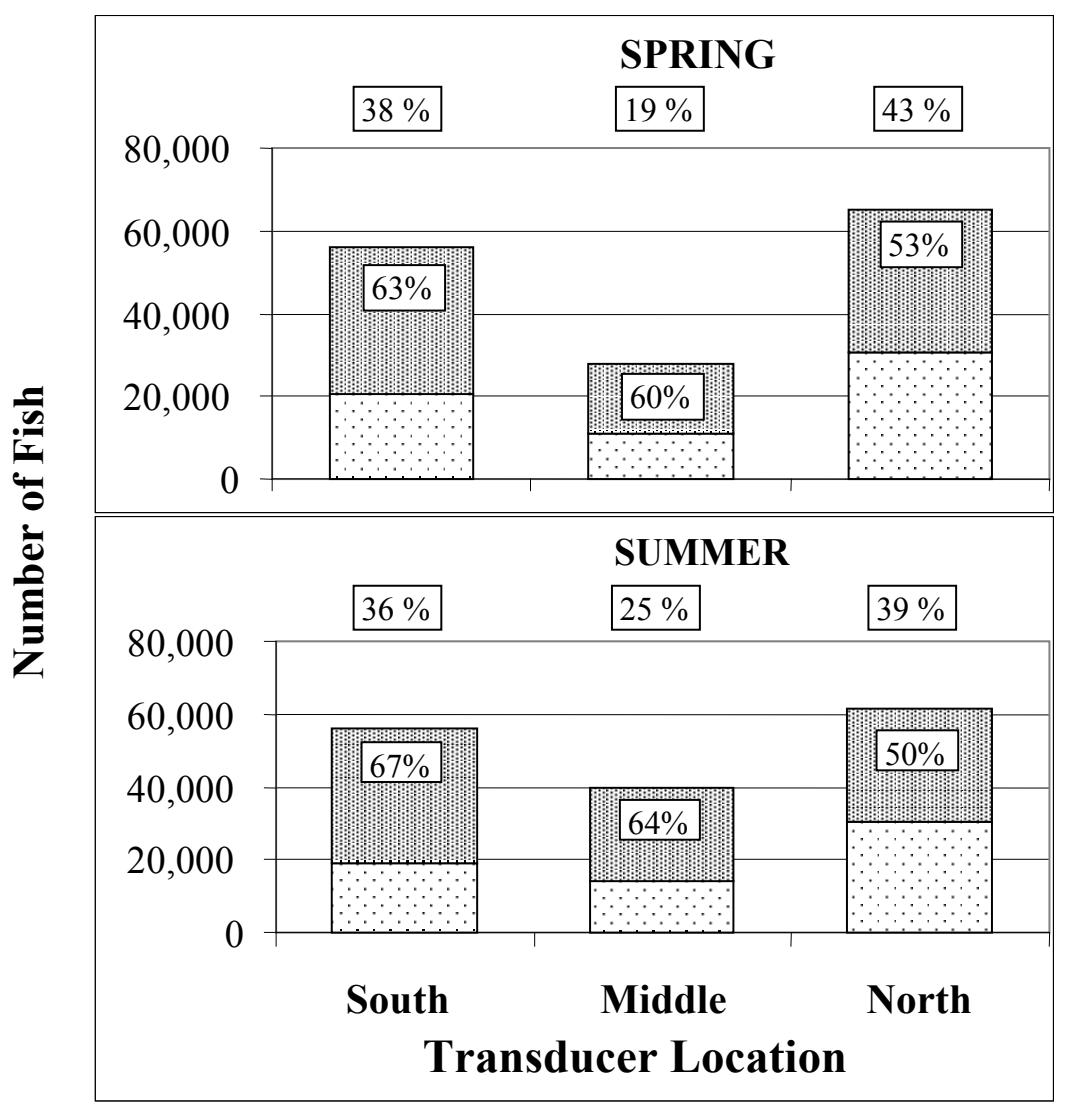

Figure 3.47. Lateral and Vertical Distribution of Fish Passing through 20-ft-wide Slots in the Prototype Surface Collector (PSC) at Intakes $3 b$ and 5b in 1998. Percentages at the top of each graph indicate the lateral distribution of fish across the slot entrance. Shaded portion of bars and labels in the bars show the percent of PSC-collected fish that were counted in the upper half of the slot entrance to the PSC. Plot from Ploskey et al. 2001a. 


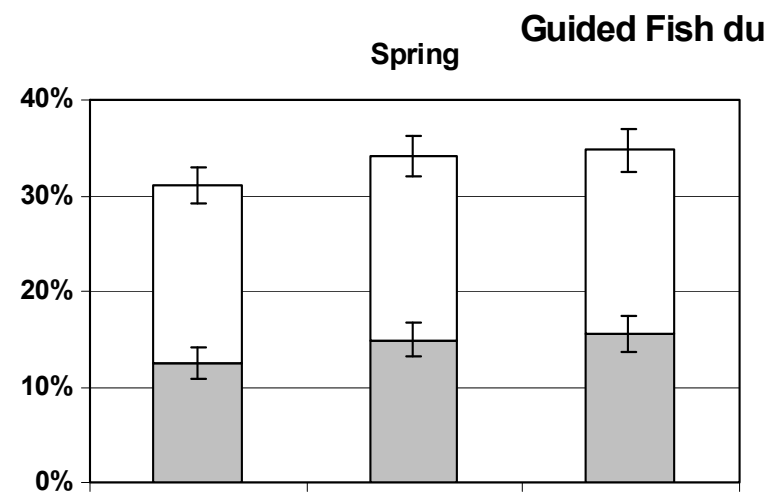

A
B
C
Summer

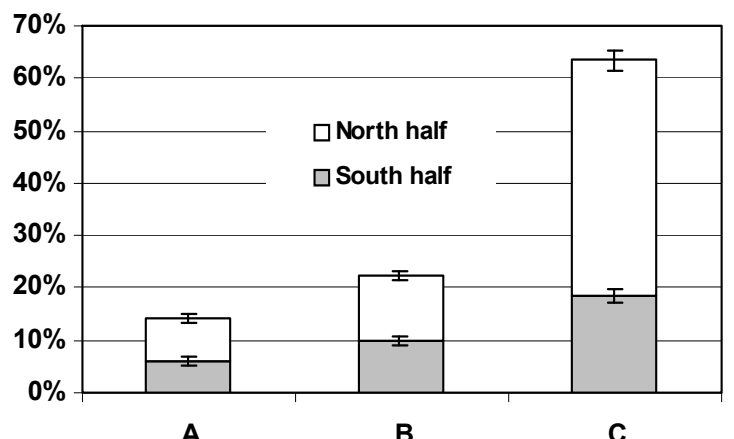

A
B
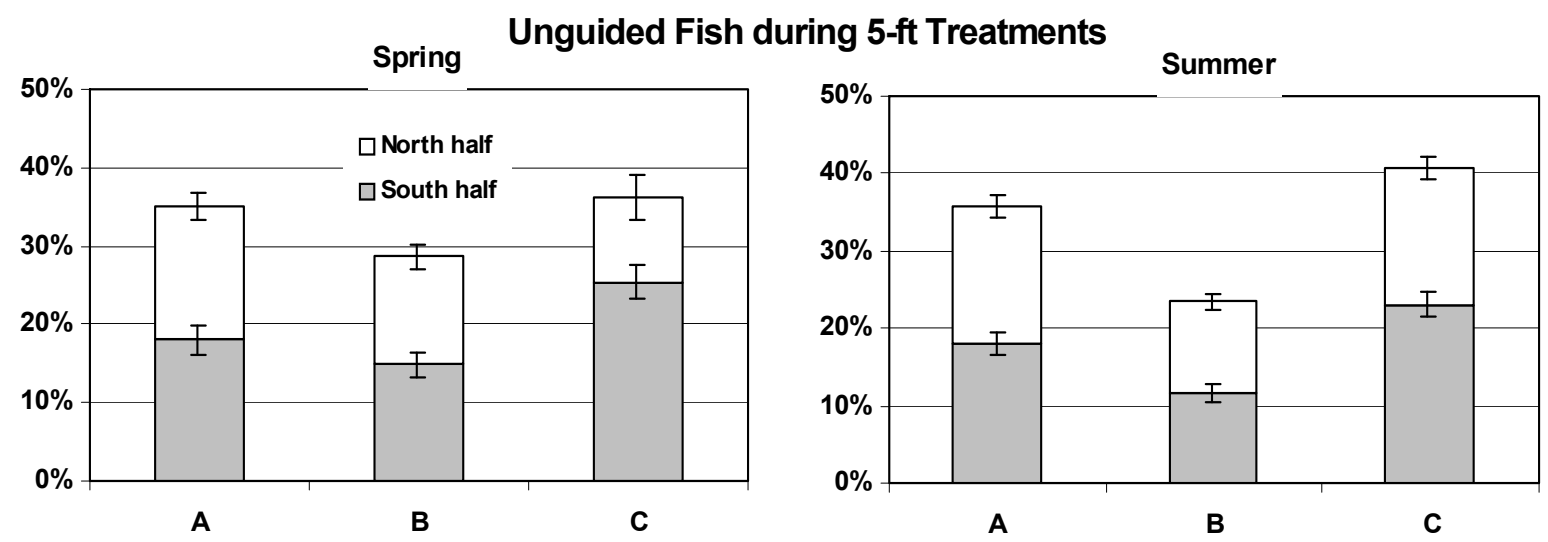

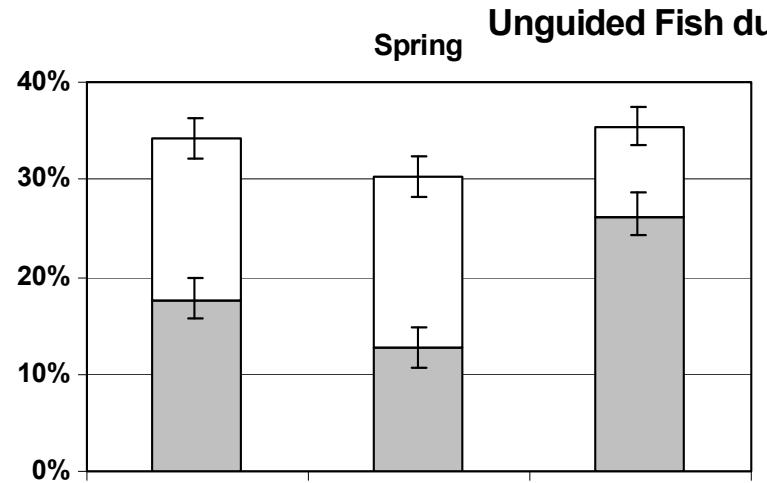

A
B
C

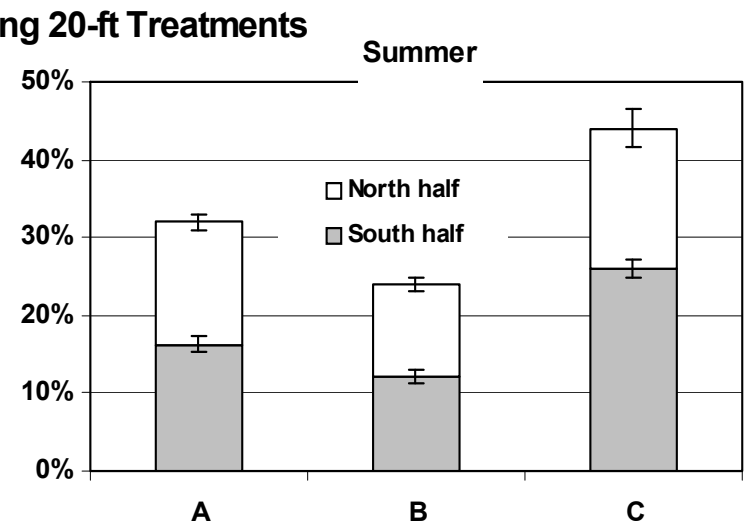

Unit 5 Intake

Figure 3.48. Percent of Fish Passage among and within Intakes of Unit 5 in Spring and Summer 1999. Guided fish during 5-ft treatments are shown in the upper plots, unguided fish are shown during 5 -ft (middle plots) and 20-ft treatments (lower plots). Proportions of fish within intakes are illustrated with light (north half) and dark (south half) portions of bars. Error bars reflect $95 \%$ confidence limits. Figure from Ploskey et al. 2001b. 
Table 3.20. Results from Wilcoxon Sign Rank Test. Tests compare guided and unguided fish passage estimates between locations within intakes of Unit 5 by slot treatment and season for 1999 . Locations within intakes are labeled as $\mathrm{n}$ (north) and $\mathrm{s}$ (south). Significant differences are indicated by showing the nature of the relationship between intake locations. Numbers in parentheses indicate probability values $(\operatorname{Pr}=|\mathrm{S}|)$. The sample size $(\mathrm{N})$ reflects the number of test days per season. Table from Ploskey et al. 2001b.

\begin{tabular}{|c|c|c|c|c|c|c|c|c|c|c|}
\hline \multirow[b]{2}{*}{ Season } & \multirow[b]{2}{*}{ Slot } & \multicolumn{3}{|c|}{ INTAKE A } & \multicolumn{3}{|c|}{ INTAKE B } & \multicolumn{3}{|c|}{ INTAKE C } \\
\hline & & $\mathrm{N}$ & Guided & Unguided & $\mathrm{N}$ & Guided & Unguided & $\mathrm{N}$ & Guided & Unguided \\
\hline spring & 5 & 18 & $n>s(0.002)$ & no diff & 16 & no diff & no diff & 18 & $n>s(0.014)$ & $s>n(0.0001)$ \\
\hline spring & 20 & 18 & $\mathrm{n} / \mathrm{a}$ & no diff & 16 & $\mathrm{n} / \mathrm{a}$ & $n>s(0.001)$ & 18 & $\mathrm{n} / \mathrm{a}$ & $s>n(0.0001)$ \\
\hline summer & 5 & 20 & $n>s(0.005)$ & no diff & 20 & $n>s(0.004)$ & no diff & 20 & $n>s(0.0001)$ & $s>n(0.0001)$ \\
\hline summer & 20 & 20 & $\mathrm{n} / \mathrm{a}$ & no diff & 20 & $\mathrm{n} / \mathrm{a}$ & no diff & 20 & $\mathrm{n} / \mathrm{a}$ & $s>n(0.0002)$ \\
\hline
\end{tabular}

Spring Fish Passage by Turbine Unit and Spillway Section

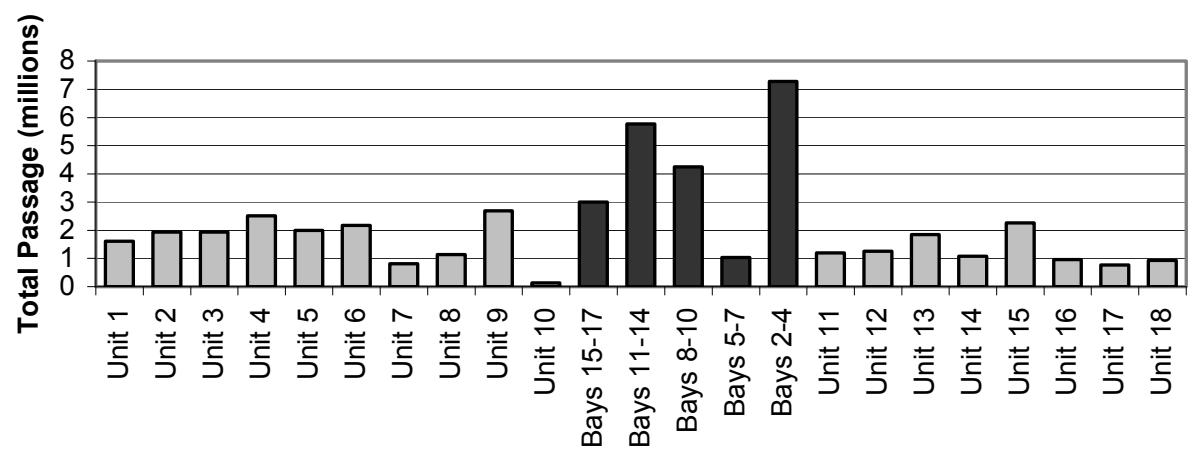

Turbine Unit (Gray) or Spillway Section (Black)

Summer Fish Passage by Turbine Unit and Spillway Section

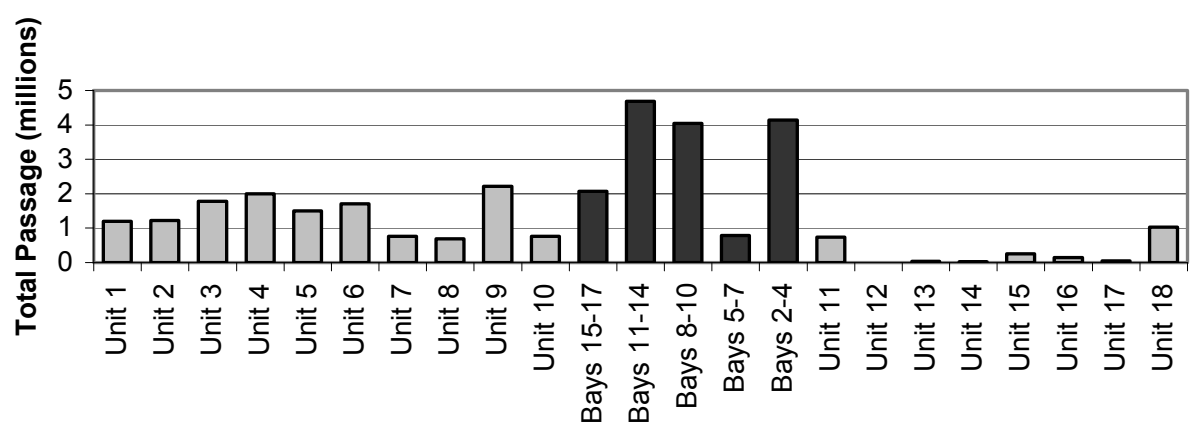

Turbine Unit (Gray) or Spillway Section (Black)

Figure 3.49. Horizontal Distribution of Total Fish Passage at B1 and B2 Turbines and the Spillway in Spring and Summer 2000. Figure from Ploskey et al. 2002a.

Year 2001 was considered a drought, and as such B1 represented only about $7 \%$ of total discharge through the project for both spring and summer since B2 was given priority for generation. Ploskey et al. 
(2002c) sampled B1 turbine units and reported that, during the short duration the B1 units were operable, Units 9 and 10 passed the greatest number of fish in both spring and summer (Figure 3.50).

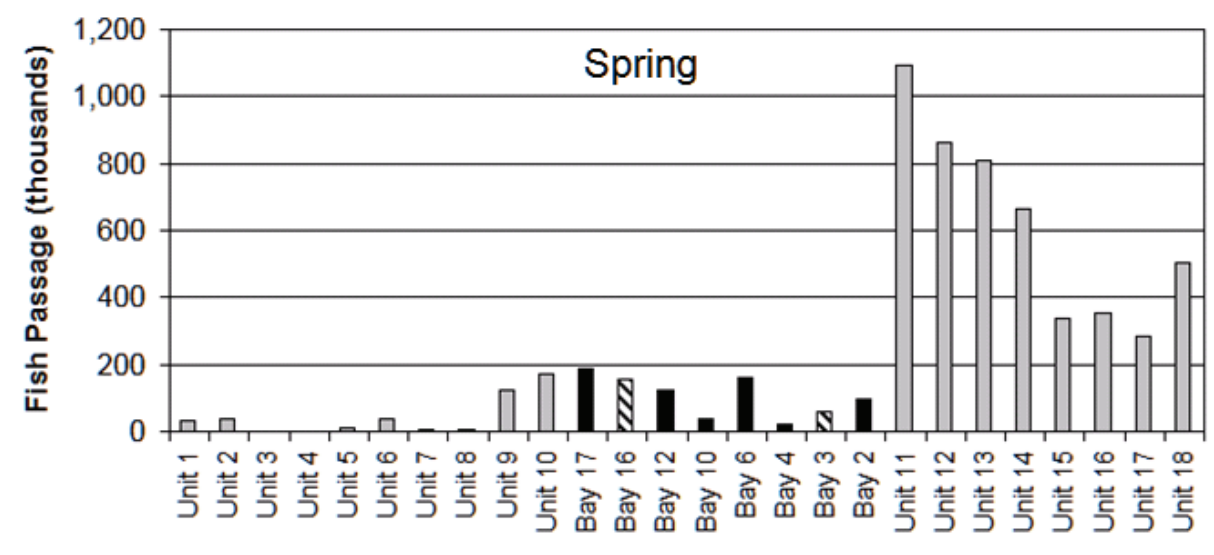

Turbine Unit or Spill Bay

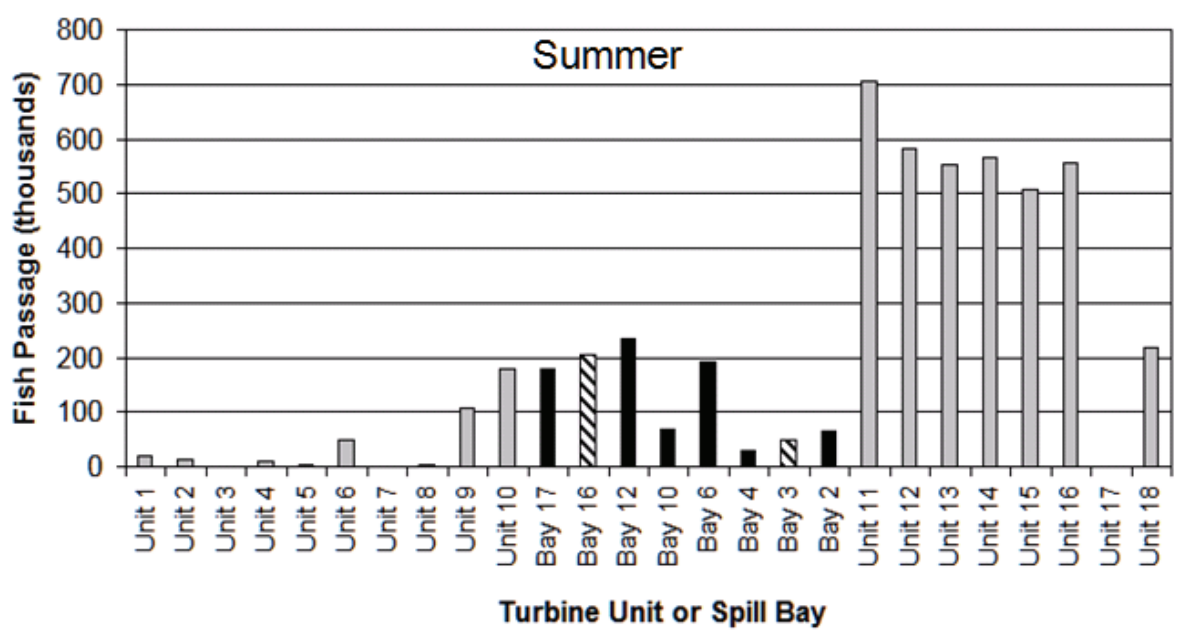

Figure 3.50. Horizontal Distribution of Fish Passage through Turbines (Gray Bars) and Spill Bays (Black or Striped Bars) in Spring (Top) and Summer (Bottom) 2001. Spill bays 1 and 18 were opened only four inches and other bays that were closed all season are not displayed. Estimates for spill bays 3 and 16 were interpolated from the nearest operating spill bays. Turbine unit 17 did not operate in summer. Figure from Ploskey et al. 2002c.

Horizontal distribution of fish passage at B1 in spring of 2002 revealed a general trend of higher passage through the central units (particularly units 6 and 7) and lower passage at units 2, 8, and 9 (Figure 3.51; Ploskey et al. 2003). The sluiceway at Intake 7B dominated passage, passing an estimated $33 \%$ of all fish at B1. In summer, units 2, 6, and 7 passed the most fish while units 1 and 10 passed the fewest. As in the spring, the sluiceway at B1 passed more fish than any individual turbine (about $30 \%$ of total passage at B1). Patterns of distribution of fish per water volume differed from patterns for total passage; in spring the highest densities passed through Unit 9 and the lowest passed through Unit 4 (Figure 3.52). Summertime passage densities peaked through units 1 and 6, with lowest densities through Unit 10. The sluiceway passed inordinately greater densities of fish relative to individual turbines in both spring and summer. 

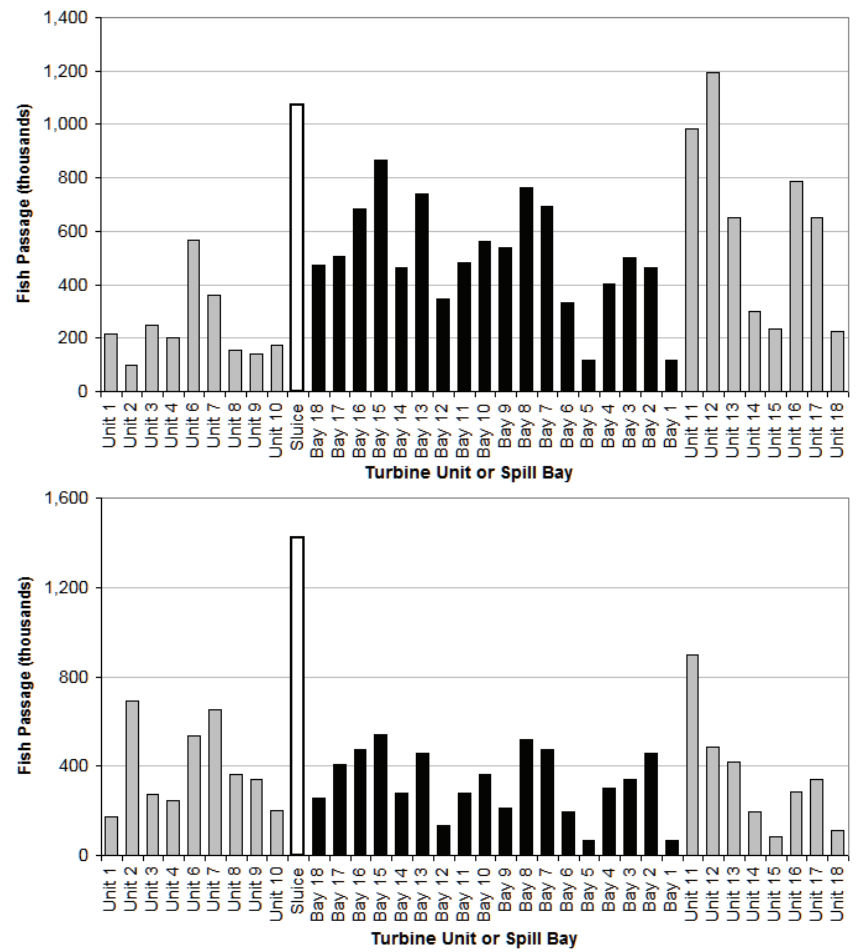

Figure 3.51. Horizontal Distribution of Fish Passage through Bonneville Dam in Spring (Top) and Summer (Bottom) 2002. Passage through turbines at B1 and B2 is shown with gray bars, through the B1 sluiceway by the white bar, and through the spill bays by black bars. Unit 5 was not operable in 2002. Figure from Ploskey et al. 2003.
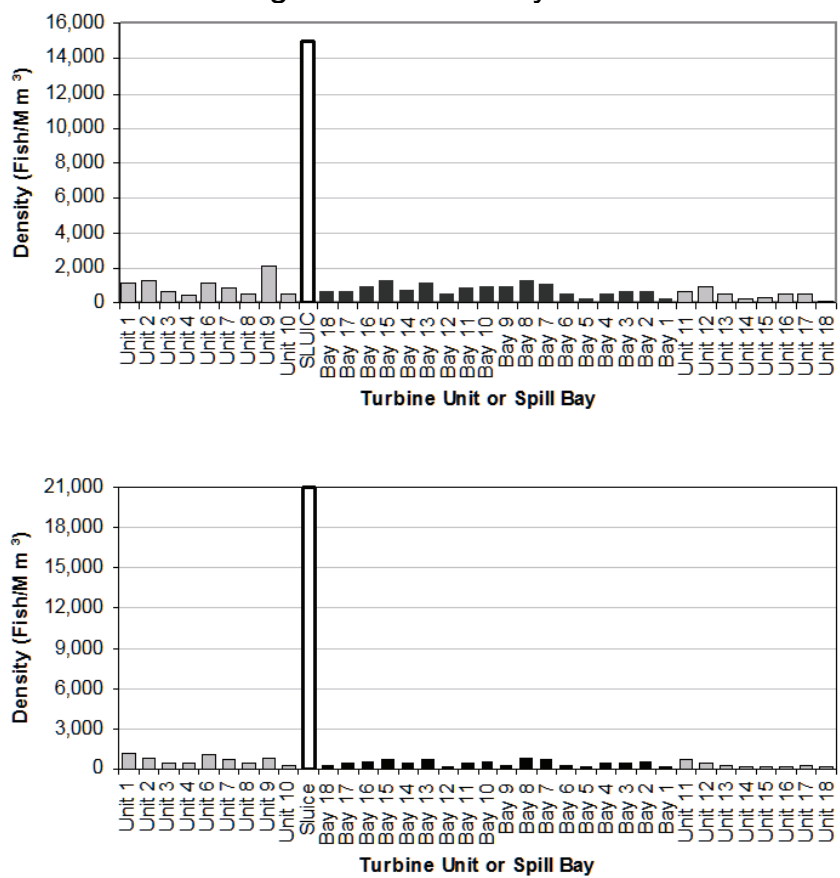

Figure 3.52. Horizontal Distribution of Fish Density through Bonneville Dam in Spring (Top) and Summer (Bottom). Fish density through turbines at B1 and B2 is shown with gray bars, through the B1 sluiceway by the white bar, and through the spill bays by black bars. Unit 5 was not operable in 2002. Figure from Ploskey et al. 2003. 
In 2002, Ploskey et al. (2003) sampled fish passage into the sluiceway entrance at Intake 7A using both hydroacoustics and video techniques. The horizontal distribution of passage into the sluiceway was higher in the middle than near the sides and was slightly skewed toward the south in both spring and summer (Figure 3.53). The horizontal distributions estimated by both methods were similar, although the hydroacoustic sampling provided much finer resolution than did the four optical cameras.
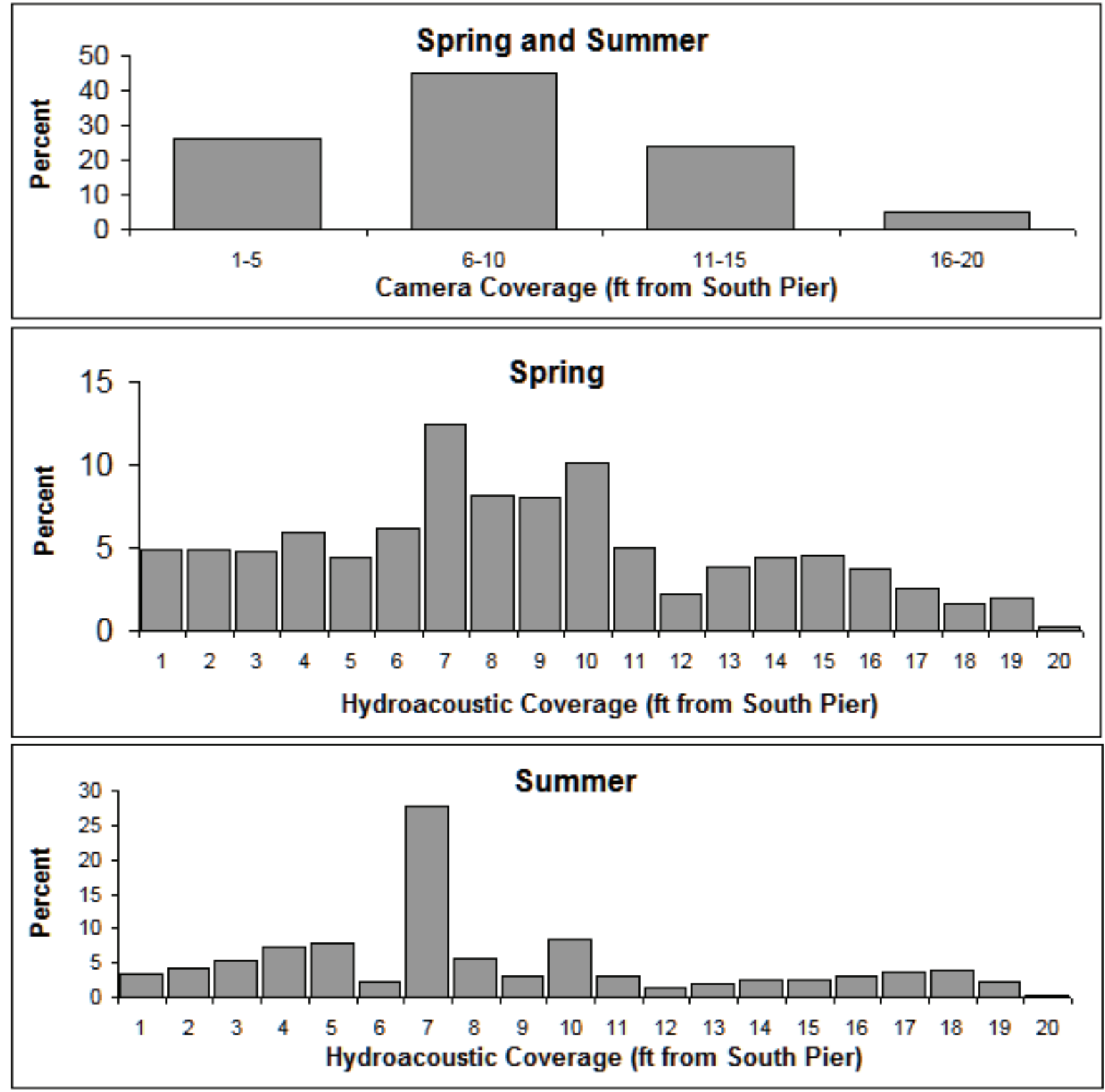

Figure 3.53. Plots of Horizontal Distribution of Fish Passage into Sluiceway Entrance 7A in Spring and Summer 2002 based on Video (Top) and Hydroacoustic Sampling (Middle and Bottom). Figure from Ploskey et al. 2003.

In spring 2004, the distribution of passage across the spillway did not follow the distribution of corresponding discharge, contrasting with the passage/discharge distributions observed at B1 (Figure 3.54). Spill bays that passed large volumes of water did not pass large numbers of fish. More fish passed through Spill Bay 16 than any other bay in the spring. In the summer, almost 16 million juvenile salmonids passed the Bonneville Dam (Figure 3.54). The horizontal distributions of passage for B1, the 
spillway, and B2 were estimated at $16 \%, 33 \%$, and $51 \%$, respectively, following the proportion of associated discharge through those structures. At B1, passage at the three sluiceways accounted for 38\% of the total fish passed there, a 5\% increase over what was observed in spring.
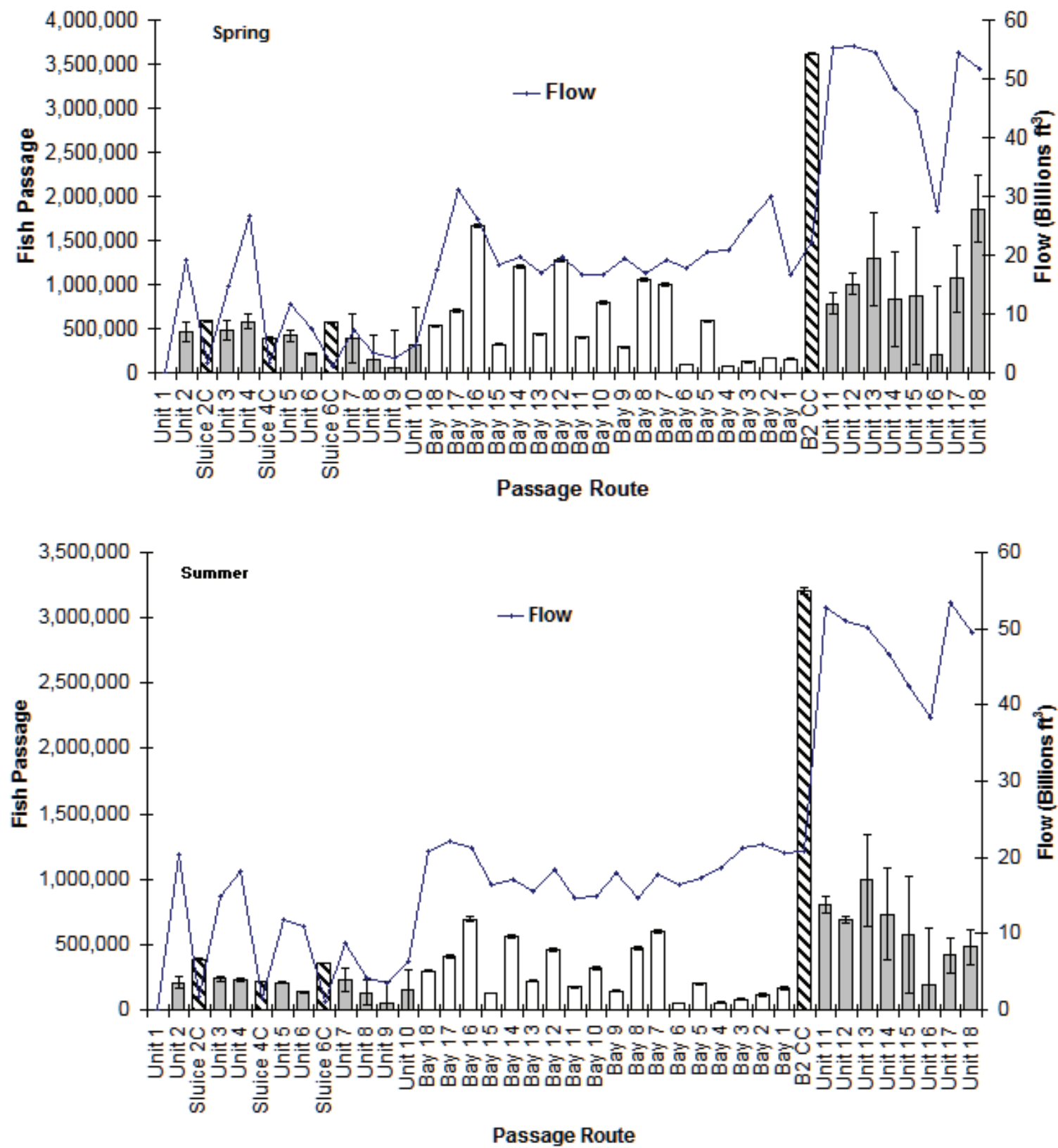

Figure 3.54. Estimated Fish Passage and Flow through All Sampled Routes at Bonneville Dam in Spring and Summer 2004. Turbine units are shown in light gray, spill bays in white, and surface passage routes (B1 sluiceways and B2 CC) in crosshatched black and white. Turbine Unit 1 did not operate in spring and summer 2004. Error bars represent $95 \%$ confidence limits on hydroacoustic estimates. The lines represent total spring and summer discharge by passage route (from Ploskey et al. 2005).

The horizontal distribution of fish densities in spring and summer 2004 suggests that each of the surface passage routes passed higher densities of fish than any one turbine unit or spill bay (Figure 3.55). 


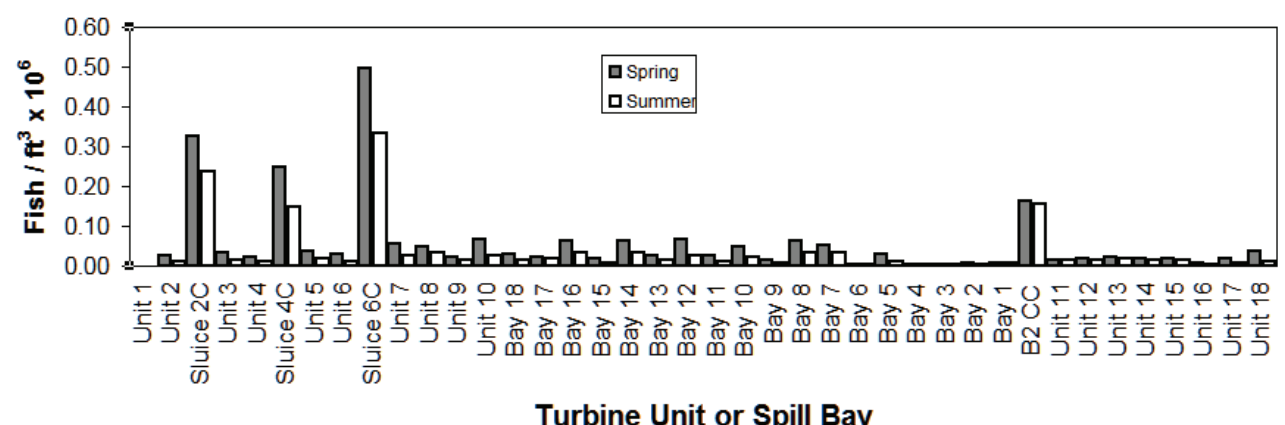

Figure 3.55. Fish Passage Density by Route in Spring and Summer 2004.

In 2005, the proportion of flow and fish passage at B1 was lower in summer than it was in spring since more flow was routed from B1 to the spillway in summer (Figure 3.56).
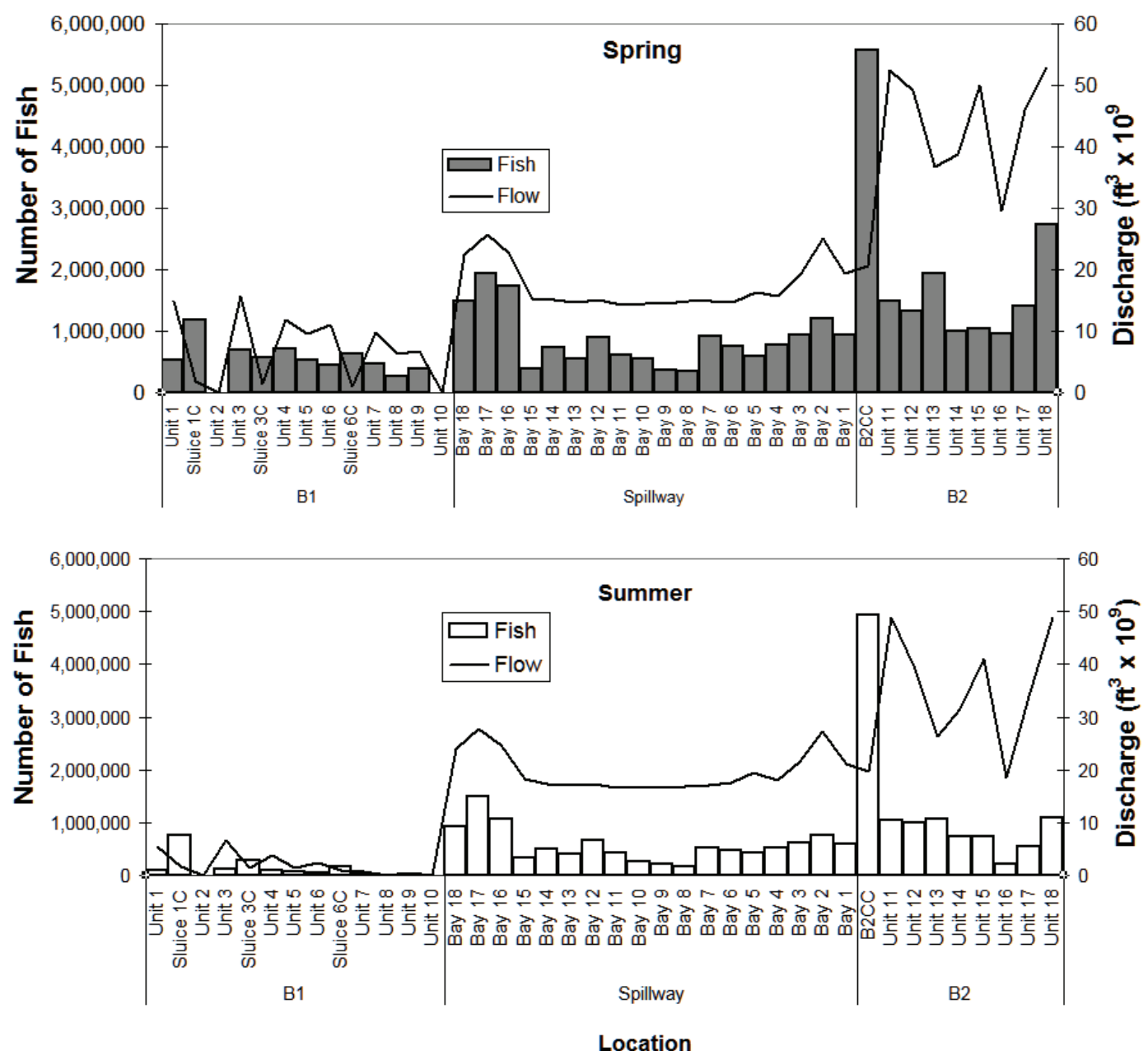

Figure 3.56. Estimated Fish Passage and Flow through all Sampled Routes at Bonneville Dam in Spring and Summer 2005. The lines represent total spring and summer discharge by passage route (from Ploskey et al. 2006c).

In 2005, the highest fish densities were observed at the surface flow outlets in both spring and summer compared to the other outlets (Figure 3.57). Passage densities were lower in summer than in spring 2005. 


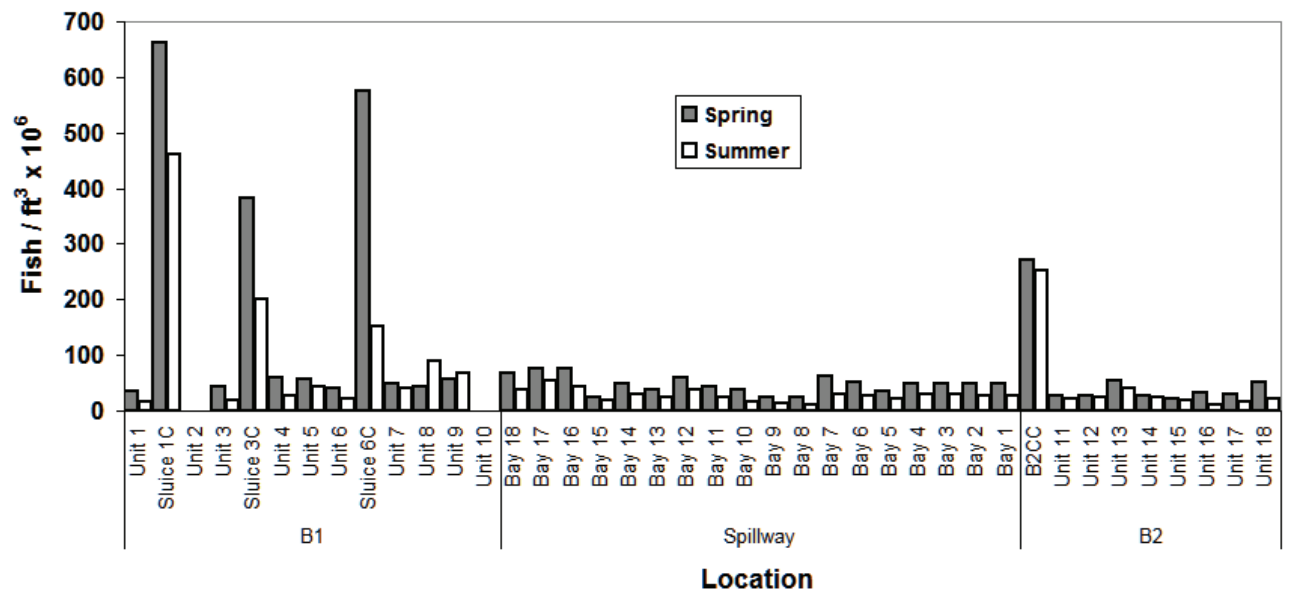

Figure 3.57. Fish Passage Density by Route in Spring and Summer 2005

\subsection{Radio Telemetry}

Holmberg et al. (1996) reported there was no apparent pattern of distribution of fish passage at B1 in 1996. About two-thirds of the yearling Chinook salmon last detected at B1 passed on the north side of the powerhouse and about $60 \%$ of the subyearling Chinook salmon also passed on the north side. No radio-tagged fish passed through the sluiceway in 1996.

In 1997, of the hatchery and wild steelhead and yearling and subyearling Chinook salmon last detected at B1, the majority passed through turbine units at the north half of the powerhouse relative to the south side (Hensleigh et al. 1999). Of the fish that passed B1 in spring of 1997, 16\% (12 of 73) of hatchery steelhead, $17 \%$ (1 of 6) wild steelhead, and 16\% (6 of 37) of yearling Chinook salmon passed through the sluiceway. Sluiceway passage for subyearling Chinook salmon was unknown due to gear limitations.

Hansel et al. (1999) reported that, of the 174 hatchery steelhead passing B1 in 1998, 64\% passed north of the wing wall, $16 \%$ passed either under or through the PSC, 18\% passed south of the PSC, and about $2 \%$ passed through the navigation lock. Of the 144 yearling Chinook salmon passing B1, 56\% passed north of the wing wall, 16\% passed either under or through the PSC, 26\% passed south of the PSC and about $1 \%$ passed through the navigation lock. Of 108 subyearling Chinook salmon passing B1 in $1998,70 \%$ passed north of the wing wall, 13\% passed either under or through the PSC, 16\% passed south of the PSC, and about $2 \%$ passed through the navigation lock.

Plumb et al. (2001) portioned the passage distribution at B1 in 1999 by north of the wing wall, through or under the PSC (Units 3-6), and south of the PSC. The majority of both hatchery steelhead (68\% of 265 fish) and yearling Chinook salmon (53\% of 200 fish) passed B1 through the north portion of the powerhouse. Plumb et al. (2001) observed that $14 \%$ of steelhead and $25 \%$ of yearling Chinook salmon passed via the PSC and $19 \%$ of steelhead and $22 \%$ of yearling Chinook salmon passed via the south side of the powerhouse.

In 2000, of the hatchery steelhead passing B1, 44\% (of 399 fish) passed via the sluiceway, 33\% were guided into the juvenile bypass system, and 23\% passed through the turbine units (Evans et al. 2001a). Almost equal numbers of yearling Chinook salmon were guided (36\% of 431 fish) and unguided (35\%) at 
B1 and 29\% passed through the sluiceway. Based on total turbine passage (guided and unguided fish), Unit 2 passed the greatest numbers of steelhead whereas Unit 5 passed the greatest number of yearling Chinook salmon. Fifty-five percent of hatchery steelhead and 56\% of yearling Chinook salmon entered the southern half of the PSC (units 1-3). Of 214 subyearling Chinook salmon passing B1, 68\% passed though the sluiceway, 9\% were guided into the bypass, and 23\% passed through turbine routes (Evans et al. 2001b). Unit 5 passed the greatest number of total turbine-passed subyearling Chinook salmon. Slightly more than half (54\%) of subyearling Chinook salmon passed through the northern half of the PSC (units 4-6).

In the drought year of $2001, \mathrm{~B} 1$ received about $7 \%$ of the total discharge through the Bonneville Project. Of the 47 yearling Chinook salmon that passed B1 through known passage routes, $76 \%$ passed through the sluiceway, $13 \%$ passed unguided through the turbines, and $11 \%$ were guided into the juvenile bypass system (Evans et al. 2001c). Of 30 subyearling Chinook salmon, 70\% passed the sluiceway, 13\% were guided into the bypass, $10 \%$ passed unguided through the turbines, and $7 \%$ passed through the adult ladder on Bradford Island (Evans et al. 2001d).

In 2002, of the 156 yearling Chinook salmon observed to pass through known routes at B1, 35\% passed the sluiceway, 30\% were guided into the bypass channel, 30\% passed through turbine units, $4 \%$ passed the navigation lock, and 1\% passed the project via the adult ladder (Evans 2003a). The majority of hatchery steelhead passed B1 through the sluiceway (65\%), followed by guidance into the bypass (26\%), and turbine passage (9\%). Subyearling passage through B1 by location was dominated by the sluiceway (48\%), followed by turbines (28\%), the bypass (21\%), and the navigation lock (1\%; Evans et al. 2003b). Based on total turbine passage, subyearling Chinook salmon numbers peaked through Unit 10 and were lowest through Unit 3.

In spring 2004, B2 passed the largest percentage of fish (59\% of yearling Chinook salmon and 66\% of steelhead). The spillway passed $33 \%$ of yearling Chinook salmon and $25.5 \%$ of steelhead. Finally, B1 passed $8 \%$ of yearling Chinook salmon and $8.5 \%$ of steelhead. Of the fish passing through the first powerhouse, $53 \%$ of yearling Chinook salmon and $55 \%$ of steelhead passed into the sluiceway, with $46 \%$ of yearling Chinook salmon and $42 \%$ of steelhead passing unguided through the turbines. At the second powerhouse, $43 \%$ of yearling Chinook salmon passed unguided through the turbines, $36 \%$ passed through the B2CC, and 21\% were guided to the downstream migrant bypass system (DSM). Seventy-four percent of steelhead were captured by the B2CC, 16\% were passed unguided through the turbines, and 10\% were guided into the DSM (Reagan et al. 2006, updated from 2005 report).

In summer 2004, as in the spring, the B2 passed the most subyearling Chinook salmon (60\%), followed by the spillway (35\%), and then B1 (5\%). Of the B1 fish, 48\% passed through the turbines unguided, $47 \%$ passed through the sluiceway, and $5 \%$ passed through the navigation lock. The majority of the fish passing B2 (49\%) passed through the turbines unguided, while 39\% passed through the B2CC, and 14\% were guided to the DSM (Evans et al. 2006c, updated from 2005 report).

In spring 2005, the passage distribution was similar to 2004 with the majority of yearling Chinook salmon (56\%) and steelhead (53\%) passing through the B2, followed by the spillway (38\% of yearling Chinook salmon and $39 \%$ of steelhead), and finally B1 passing $6 \%$ of yearling Chinook salmon and $8 \%$ of steelhead. Thirty-three percent of yearling Chinook salmon and $29 \%$ of steelhead passed into the 
sluiceway, and $65 \%$ of Chinook salmon and $70 \%$ of steelhead passed through the turbines unguided. Fish passing B2 were apportioned as follows: with $45 \%$ yearling Chinook salmon passing unguided through the turbines, $29 \%$ through the B2CC, and $26 \%$ guided into the DSM. A higher proportion of the steelhead (66\%) were passed through the corner collector, $22 \%$ were unguided through the turbines, and $12 \%$ were guided to the DSM (Adams et al. 2006).

In summer 2005, the spillway passed the majority of subyearling Chinook salmon (51\%), with the B2 accounting for $48 \%$, and B1 only passing $1 \%$ of the subyearlings. Of all the tracked subyearlings passing through B1, 31\% went through the turbines unguided, 59\% passed through the sluiceway, and 10\% entered the navigation lock. At B2, 46\% passed through the turbines unguided, $40 \%$ were captured by the B2CC, and 14\% were guided into the JBS (Adams et al. 2006).

\subsubsection{Spillway}

\subsection{Hydroacoustics}

Trends in the hydroacoustic distribution of fish passed at the spillway can be summarized by a threeyear mean from data acquired in 2002, 2004, and 2005 when every bay was sampled (Figure 3.58). Another reason for using data for these years was that a new spill pattern was first implemented in 2002. The figure shows that trends were similar in spring and summer. There was slightly higher percent passage at units 16 and 17 than at most other bays, and this skew resulted in $40 \%-43 \%$ of fish passage through bays with 7 -ft-elevation deflectors, when $33 \%$ would be expected based upon the percent of bays with 7-ft-elevation deflectors (bays 1-3 and 16-18). Survival data suggest that fish passing through bays with older 14 -ft-elevation deflectors (57\%-60\% of passage through bays $4-15)$ may have lower survival than fish passing through bays with the new 7-ft-elevation deflectors (Counihan et al. 2003, 2006a).

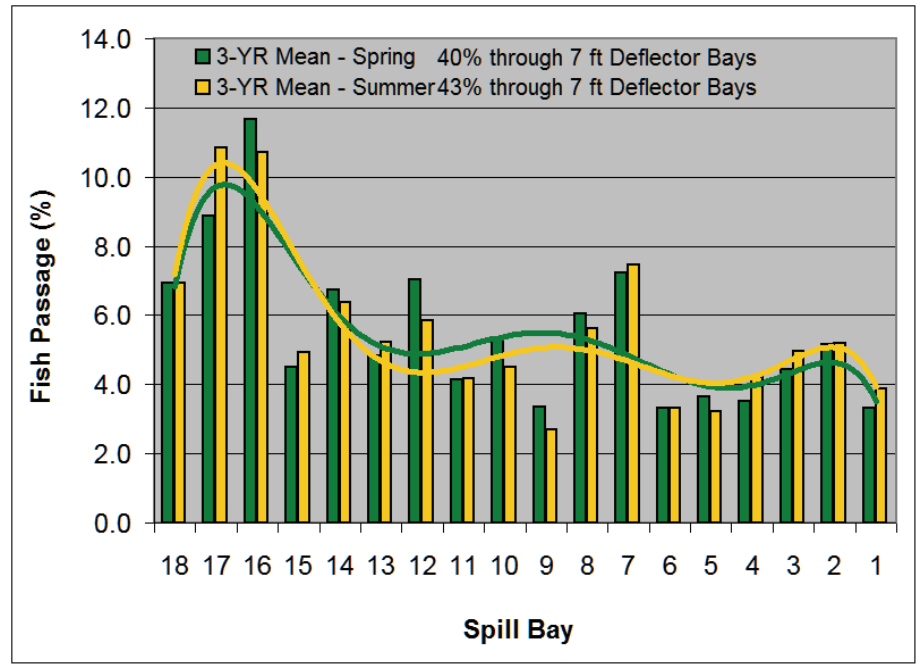

Figure 3.58. Fish Passage Distribution based on a Three-year Mean of Spring and Summer Estimates from 2002 through 2005 under New Spill Patterns

Ploskey et al. (2002a) provided the first horizontal distribution of passage estimates at the Bonneville spillway in 2000 using hydroacoustics and sampling of strata of 3-4 adjacent bays. In the spring, passage was distributed very unevenly with bays 2-4 passing the most fish followed by bays 11-14 and 8-10; the fewest fish passed bays 5-7 (Figure 3.49). In summer, the distribution of passage was slightly less varied 
with bays 11-14 passing the most fish followed by bays 2-4 and 8-10. As in spring, bays 5-7 passed the fewest fish (Figure 3.49). When fish passage densities (fish passing per unit volume) were examined, bays 11-14 passed the highest densities of fish in the spring and bays 15-17 passed the lowest densities in summer (Ploskey et al. 2002a).

In the drought year of 2001 , only $16 \%$ of total discharge passed the spillway in the spring and $20 \%$ in the summer (Ploskey et al. 2002c). Based on sampled and interpolated estimates in 2001, spill bays 6, 12, 16, and 17 passed the most fish in the spring and in summer (Figure 3.50; Ploskey et al. 2002c).

Distribution of fish passage at the spillway in spring of 2002 indicated high variability across spill bays, with the southern half of the spill bays (bays 10-18) passing 13\% more fish than the northern eight bays (Figure 3.51; Ploskey et al. 2003). Similar to the spring results, summer spill passage was unevenly distributed across spill bays, with the southern half passing 14\% more fish than the northern half (Figure 3.51). Discharge was fairly evenly distributed across all bays in both seasons, so distribution patterns of fish passed per water volume (Figures 3.52) did not differ from total fish passage distributions.

In 2004, the distribution of passage across the spillway in spring did not follow the distribution of discharge there, contrasting with the passage/discharge distributions observed for B1 (Figure 3.54). Spill bays 2,3, and 17 passed the greatest volumes of water relative to other spill bays but did not pass large numbers of fish. In fact, Bay 3 passed very few fish relative to the other spill bays. Spill bays 6-15 all passed similar volumes of water but disparate numbers of fish. More fish passed through Bay 16 than any other bay. The estimated distribution of passage across the spillway in the summer was similar to the spring distribution, with the highest passage occurring at Bay 16 and lowest passage numbers occurring at spill bays 4 and 6 . As in spring, the horizontal distribution of passage in summer did not follow the distribution of discharge.

In 2005, during both sampling seasons, the percentage of the total fish that passed the spillway was similar to the percentage of discharge through the spillway (Figure 3.59). Within the spillway structure, however, fish passage was less related to discharge. In spring and summer, the south end of the spillway (bays 16-18) passed the highest number of fish (Figure 3.56). Fewer fish passed B1 in summer because flows had been diverted to the spillway resulting in lower flows at B1.

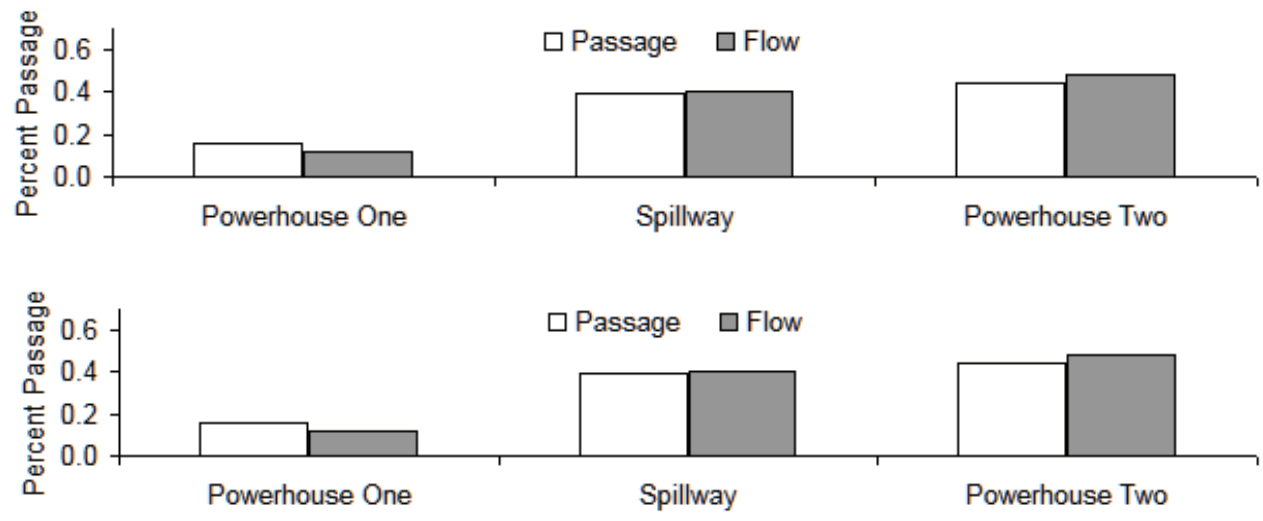

Figure 3.59. Percentage of Fish Passage and Discharge at Each Major Passage Structure in Spring (top) and Summer (bottom) 2005 


\subsection{Radio Telemetry}

Numbers of radio-tagged fish detected at the spillway each season between 1996 and 1999 were only sufficient to provide a broad description of passage trends by north and south halves of the structure, and estimates in later studies were reported only as a proportion of total project passage (Table 3.21). At best, skews in spillway passage distributions could be described as weak in most years. In 1996, discharge was higher on the north and south ends of the spillway and tagged-fish passage was higher there than it was in the middle of the spillway (Holmberg et al. 1996). About 53\% of 165 yearling Chinook salmon were last detected at the south half of the spillway, and $56 \%$ of 53 subyearling Chinook salmon were detected on the north half (Holmberg et al. 1996). In 1997, 403 of 596 hatchery steelhead (68\%) and 153 of 240 yearling Chinook salmon (64\%) passed through the south spillway, whereas subyearling Chinook passage was split evenly between the north and south halves of the spillway (Hensleigh et al. 1999). Spillway passage distributions were slightly skewed toward the north in spring of 1998 when $56 \%$ of 211 steelhead and $52 \%$ of 201 yearling Chinook salmon passed through the nine northern bays (Hansel et al. 1999), but the skew was a little stronger toward the north in summer, when $64 \%$ of 224 subyearling Chinook salmon passed bays 1-9. The distribution of spillway passage was slightly skewed toward the north in 1999 , when the majority of both steelhead (67\% of 250 fish) and yearling Chinook salmon (68\% of 284 fish) passed through the north half of the spillway (Plumb et al. 2001).

Table 3.21. Proportion of Total Passage (in percent) through the Three Primary Passage Routes at Bonneville Dam (Evans et al. 2001a, b, and c; 2003a and b, Evans et al. 2006a, b, and c; Reagan et al. 2006; Adams et al. 2006).

\begin{tabular}{|c|c|c|c|c|c|c|c|}
\hline \multirow[b]{2}{*}{ Year } & \multirow[b]{2}{*}{ Sampling Season } & \multicolumn{2}{|c|}{ B1 } & \multicolumn{2}{|c|}{ Spillway } & \multicolumn{2}{|c|}{ B2 } \\
\hline & & Chinook & Steelhead & Chinook & Steelhead & Chinook & Steelhead \\
\hline \multirow{2}{*}{2000} & Spring & & 49 & 44 & 34 & & 17 \\
\hline & Summer & 30 & & 69.5 & & 0.5 & \\
\hline \multirow{2}{*}{2001} & Spring & 4 & & 16 & & 80 & \\
\hline & Summer & 6 & & 2 & & 92 & \\
\hline \multirow{2}{*}{2002} & Spring & 8 & 6 & 57 & 55 & 35 & 39 \\
\hline & Summer & 14 & & 59 & & 27 & \\
\hline \multirow{2}{*}{2004} & Spring & 8 & 8.5 & 33 & 25.5 & 59 & 66 \\
\hline & Summer & 5 & & 35 & & 60 & \\
\hline \multirow{2}{*}{2005} & Spring & 6 & 8 & 38 & 39 & 56 & 53 \\
\hline & Summer & 1 & & 51 & & 48 & \\
\hline
\end{tabular}




\subsubsection{Powerhouse 2}

\subsection{Hydroacoustics}

Stansell et al. (1990) reported the first estimates for horizontal fish passage across a structure at Bonneville Dam based on hydroacoustics employed in 1989. All intakes of units 11 and 18 and the sluice chute were sampled in spring and summer. During the day in spring, Unit 18 passed a much higher proportion of fish than did Unit 11 or the sluice chute (Table 3.22). At night in the spring, Unit 18 passed more fish than the other two routes but not to the same degree as in the daytime. During the summer at night Unit 11 passed the most fish and the sluice chute the least of the three routes.

Among intakes in Unit 11, the distribution of passed fish was not uniform, with the greatest proportions at Intake A during the day in spring, Intake B at night in the spring, and Intake $\mathrm{C}$ at night in the summer (relative to the other intakes in the respective season and time period; Table 3.23). Among intakes in Unit 18, the distribution of passed fish was also non-uniform with Intake $\mathrm{C}$ passing the majority of fish in the spring, both during the day and at night, and Intake B passing much higher proportions than the other intakes during the night in the summer. Lateral passage into the sluice chute was skewed toward the middle third, with about half of all fish passing through the center during the day in spring and during the night both in spring and summer.

Table 3.22. Proportion of Fish Passed (\%) by Season, Time Period and Passage Route in 1989. The daytime period is defined as 0900 to 1600 whereas night is defined as 1600 to 2300 . Table created based on Appendices A1, A2, and C1 in Stansell et al. 1990.

\begin{tabular}{|ccccc|}
\hline Season & Time Per. & Unit 11 & Unit 18 & Sluice \\
\hline \hline Spring & Day & 17 & 62 & 21 \\
& Night & 37 & 39 & 24 \\
Summer & Night & 52 & 33 & 15 \\
\hline
\end{tabular}

Table 3.23. Proportion of Fish Passed (\%) by Season, Time Period and Passage Route in 1989, for each Intake. The daytime period is defined as 0900 to 1600 whereas night is defined as 1600 to 2300. The ' $A$ ', ' $B$ ', and ' $C$ ' designations refer to the individual intakes within each turbine unit. Under the Sluice heading, ' $N$ ' = north, ' $M$ ' = middle, and ' $S$ ' = south. Table created based on Appendices A1, A2, and C1 in Stansell et al. 1990.

\begin{tabular}{|c|c|c|c|c|c|c|c|c|c|c|}
\hline \multirow[b]{2}{*}{ Season } & \multirow[b]{2}{*}{$\begin{array}{l}\text { Time } \\
\text { Per. }\end{array}$} & \multicolumn{3}{|c|}{ Unit 11} & \multicolumn{3}{|c|}{ Unit 18} & \multicolumn{3}{|c|}{ Sluice } \\
\hline & & A & B & C & A & B & C & $\mathbf{N}$ & $\mathbf{M}$ & S \\
\hline \multirow[t]{2}{*}{ Spring } & Day & 38 & 30 & 32 & 25 & 33 & 41 & 23 & 58 & 19 \\
\hline & Night & 33 & 37 & 30 & 22 & 36 & 42 & 26 & 48 & 26 \\
\hline Summer & Night & 20 & 37 & 43 & 19 & 61 & 20 & 17 & 56 & 27 \\
\hline
\end{tabular}

In 1996, Ploskey et al. (1998) sampled one intake (A, B, or C) at each turbine unit (11-18) at B2 and observed the highest proportions of passage at Unit 11 in the spring both during the day and at night 
(Figure 3.60). During the day and night in spring, units 12 and 15 passed the smallest proportion fish. In the summer during the day, the majority of fish passed through units 12-14, with the fewest passing through Unit 15. At night in the summer, units 12 and 18 passed the most fish and again Unit 15 passed the least.

In 2000, Ploskey et al. (2002a) reported the horizontal distribution across all turbine units at B2. In the spring, total passage estimates indicated most fish passed units 13 and 15, while the fewest fish passed Unit 17 (Figure 3.49). In summer, units 11 and 18 passed the most fish (Figure 3.49) due to the fact that unit 12 was inoperable and units 13-17 were operated sparingly. Based on fish density in the spring, the horizontal distribution pattern was similar to that of total passage at B2.

Ploskey et al. (2002a) characterized the distribution of passage at B2 in 2001 as noticeably skewed toward the south half of the powerhouse in the spring (Figure 3.50) and a more even distribution in summer with peak passage at Unit 11 and the fewest fish passing at Unit 18 (Figure 3.50). Patterns of fish per flow volume differed from that of total passage, with the density highest and more evenly distributed across units 11-15 and the fewest fish passing Unit 18 in the spring (Figure 3.61). Based on fish density, most fish passed through units 13-15 in the summer.

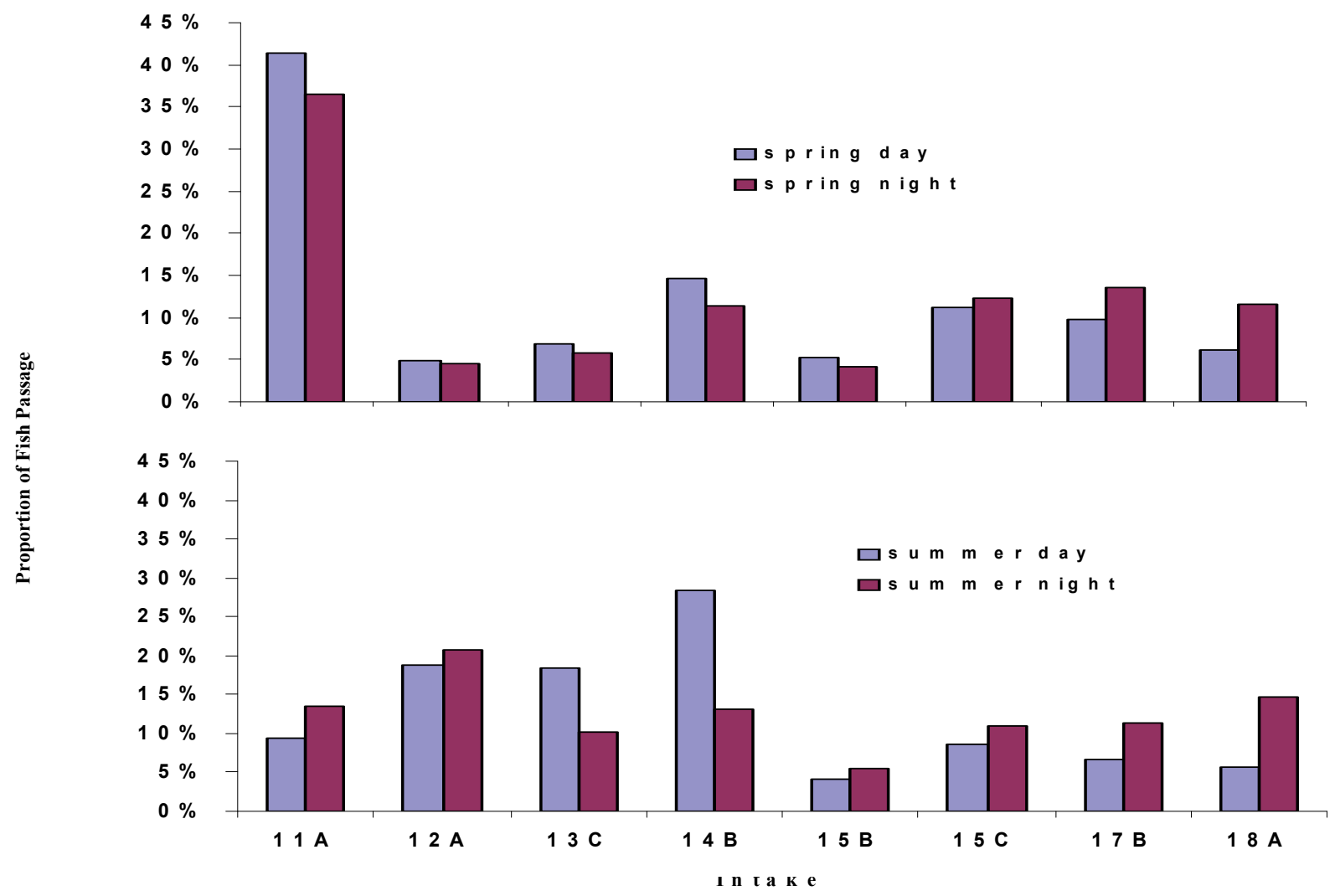

Figure 3.60. Proportional Fish Passage Across All Sampled Units at B2 in 1996 by Season and Time of Day. Plot created from Ploskey et al. 1998. 

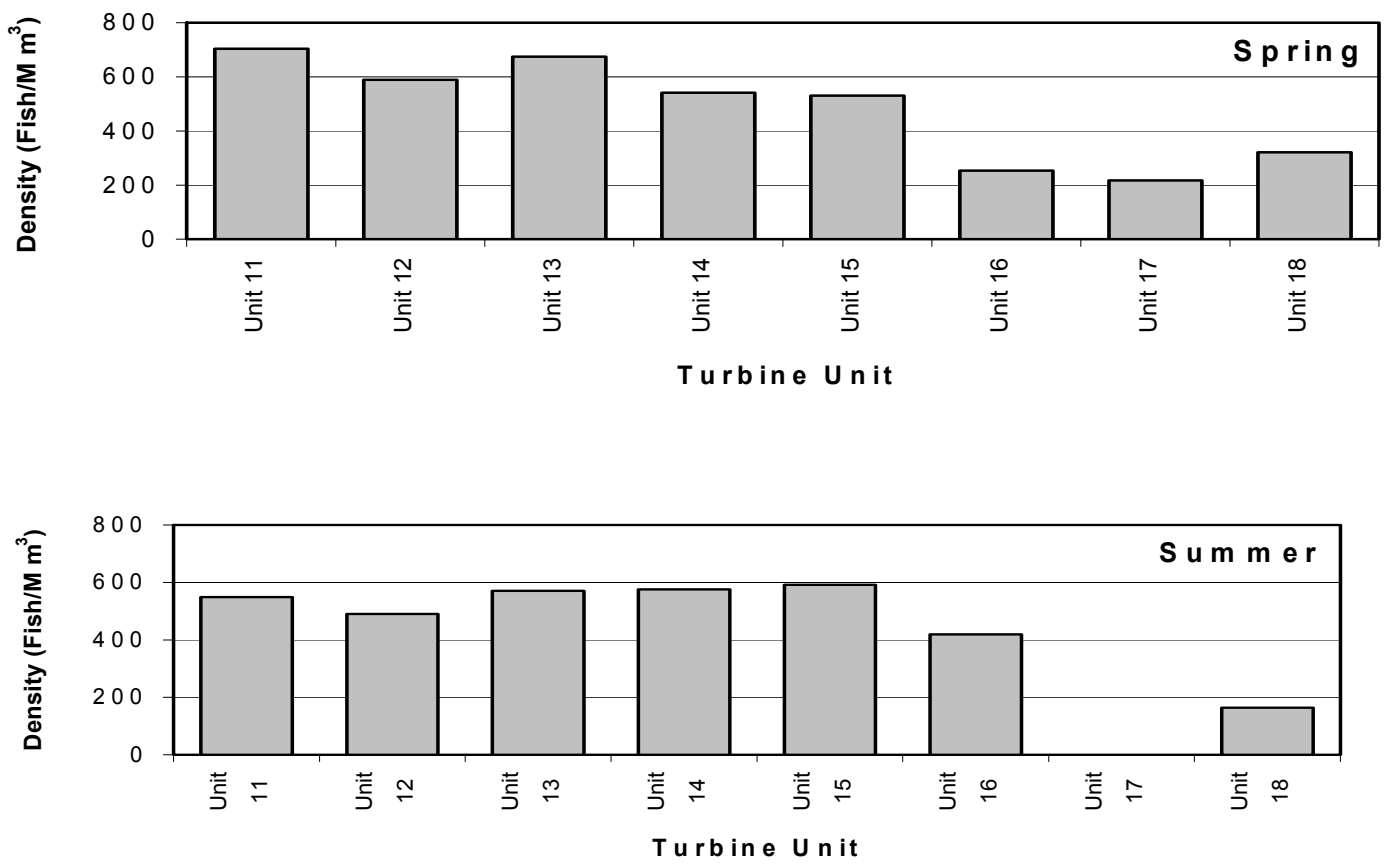

Figure 3.61. Horizontal distribution of Fish Passage Density, in Fish per Million Cubic Meters of Water, by Turbine Unit in Spring and Summer 2001. Unit 17 was inoperable during the summer season. Figure from Ploskey et al. 2002c.

In 2002, the distribution of fish passage at B2 in the spring was uneven with most fish passing through units 11 and 12, and the fewest fish passing units 15 and 18 (Figure 3.51; Ploskey et al. 2003). Summertime distributions again revealed a skew toward the south end of B2, with units 11 and 12 passing the greatest numbers of fish, and as in the spring, units 15 and 18 passing the fewest fish. The distribution patterns of fish density passage were similar to those of total passage for both spring and summer (Figure $3.52)$.

Estimated horizontal distributions of fish passage during the Spring Creek release during March 2004 indicated that the majority of both flow and fish passed through B2 for all three operational conditions tested (1) five days of 31,400 cfs spill with no B2CC operations; 2) four days of B2CC operation with no spill; 3) approximately seven days of no spill and no B2CC operation].

In spring 2004, the B2CC surpassed all other routes in terms of numbers of fish passed (Figure 3.54). At B2, the B2CC passed $31 \%$ of all fish in about $5 \%$ of all discharge through that powerhouse.

Horizontal distribution of passage among turbine units at B2 generally followed flow with Unit 16 passing the least amount of water and the fewest fish relative to the other units. Units 11-13 and 17 all discharged higher volumes of water than did the other units, but Unit 18 passed the most fish.

In summer 2004, the horizontal distributions of passage for B1, the spillway, and B2 were 16\%, 33\%, and $51 \%$, respectively. This generally matches the proportions of discharge through those structures. The $\mathrm{B} 2 \mathrm{CC}$ had higher estimated passage than did any other individual route in summer (Figure 3.54), as was the case in spring. The B2CC passed $40 \%$ of all fish through that structure, an increase of $9 \%$ over that in 
spring with just $5 \%$ of the water passing B2. The horizontal distribution of passage among turbine units at B2 generally followed flow with Unit 16 passing the least amount of water and the fewest fish relative to the other units. Unit 13 passed the greatest number of fish, but Unit 17 passed the most water.

The horizontal distribution of fish passage into the $\mathrm{B} 2 \mathrm{CC}$ also had a definite pattern with peak passage near the center of the $\mathrm{B} 2 \mathrm{CC}$ entrance in both spring and summer and a second peak toward the south side of the collector in summer (Figure 3.62). The peak on the south side of the entrance in summer disappeared when data collected after July 4, which were contaminated by American shad detections, were excluded (Figure 3.63).

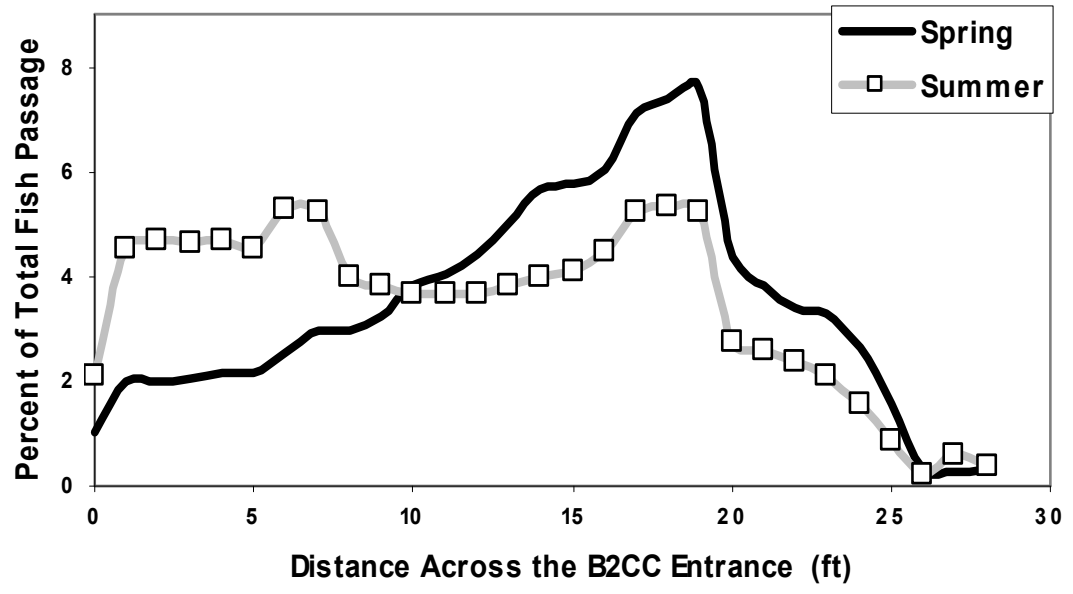

Figure 3.62. Horizontal Distribution of Fish Passing through the B2CC in Spring and Summer, 2004. The entrance narrows to a width of $15 \mathrm{ft}$, which would correspond to the 10 to $25 \mathrm{ft}$ distance on the $\mathrm{x}$ axis. Zero to $10 \mathrm{ft}$ is toward the south of the 15-ft wide opening, and 25 to $30 \mathrm{ft}$ is toward the north.

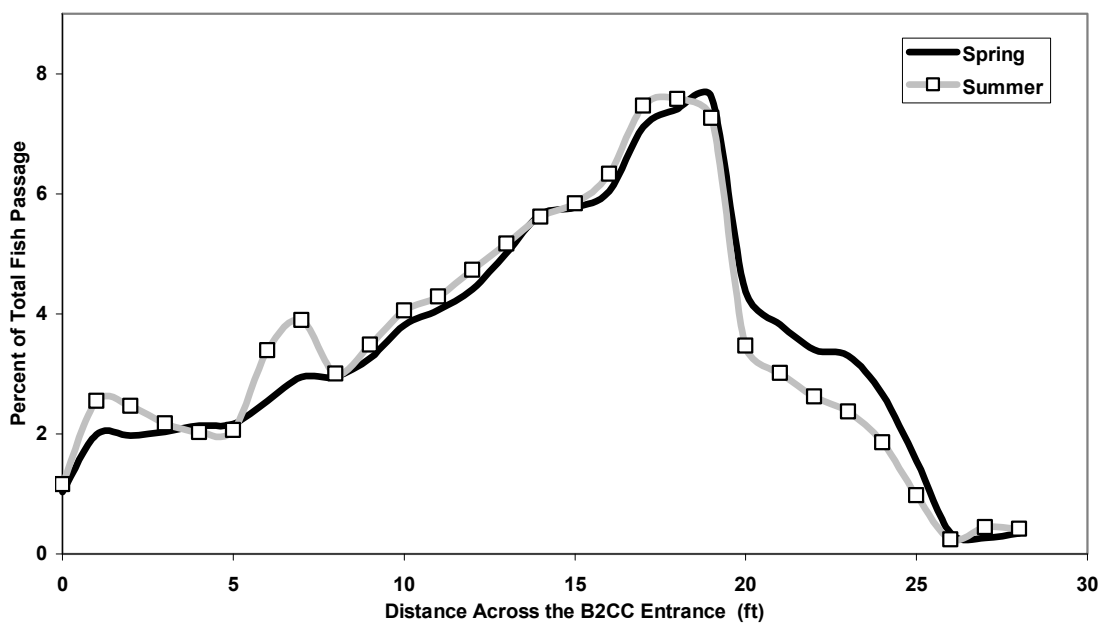

Figure 3.63. Horizontal Distribution of Fish Passing through the B2CC in Spring and Summer through July 3,2004 . The entrance narrows to a width of $15 \mathrm{ft}$, which would correspond to the 10to 25 - $\mathrm{ft}$ distance on the $\mathrm{x}$ axis. Zero to $10 \mathrm{ft}$ is toward the south of the 15 -ft-wide opening, and 25 to $30 \mathrm{ft}$ is toward the north. 
The horizontal distribution for each season (Figure 3.63) was produced primarily by a predominance of fish in the upper $5 \mathrm{ft}$ of the water column, but the pattern of horizontal distribution certainly was not consistent among 4-ft depth strata (Figure 3.64). Trends in spring and summer were similar within depth bins, except for some anomalous peaks toward the south end of the entrance at depths of 9 to $20 \mathrm{ft}$ in summer, which could be removed by dropping data collected after July 4. Over $95 \%$ of the fish passed in the upper $4 \mathrm{ft}$ of the water column, which explains why the trend in the top plot of Figure 3.64 is very similar to the trend in the composite horizontal distribution (Figure 3.63).
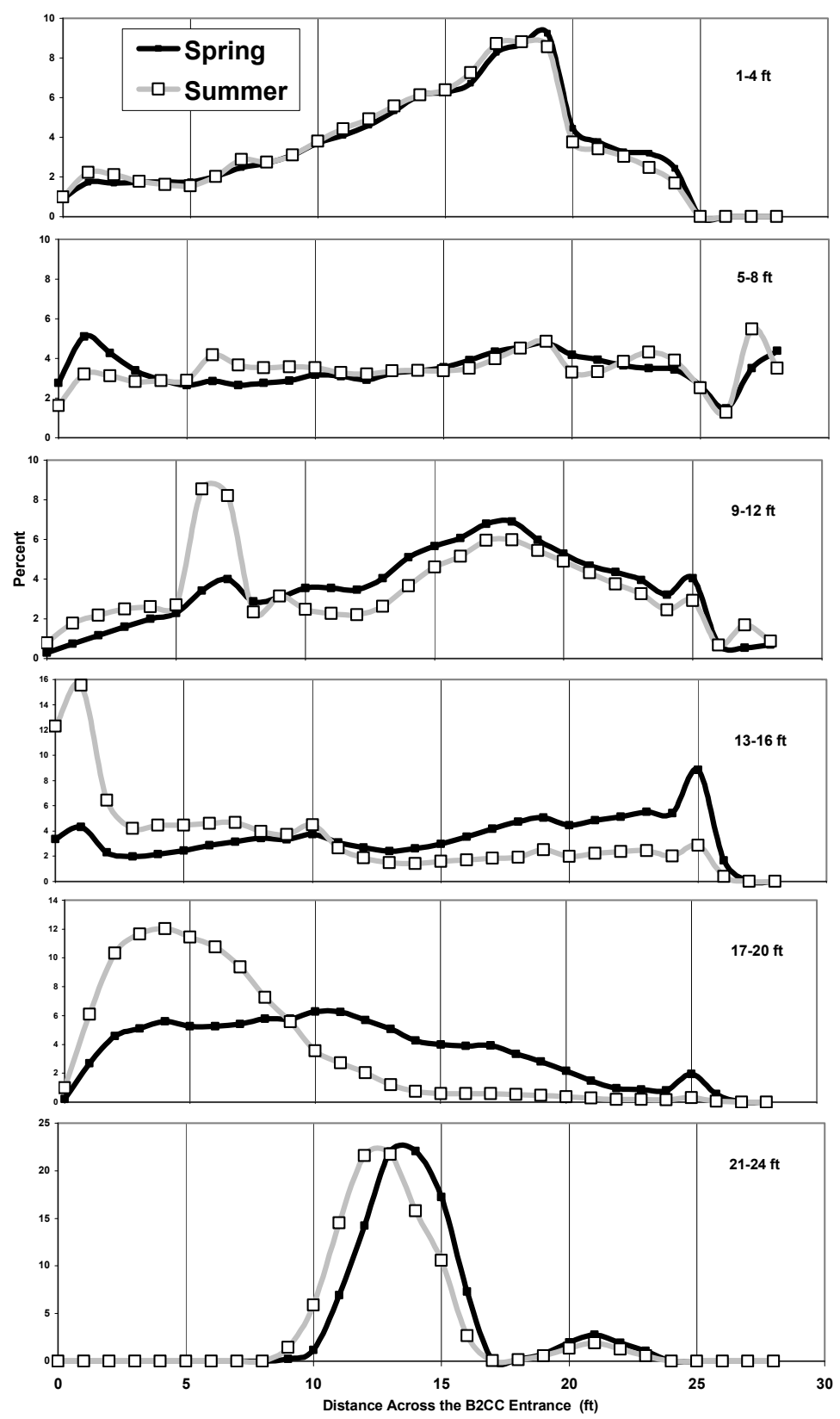

Figure 3.64. Horizontal and Vertical Distribution of Smolt-Sized Fish Upstream of the B2CC Entrance in Spring and Summer 2004. The entrance narrows to a width of $15 \mathrm{ft}$, which would correspond to the 10 to $25 \mathrm{ft}$ distance on the $x$ axis. Zero to $10 \mathrm{ft}$ is toward the south of the 15 -ft-wide opening, and 25 to $30 \mathrm{ft}$ is toward the north. 
In spring and summer 2005, most fish passed at the B2CC and at B2 units 11-13 and density for the most part paralleled route-specific discharge. The horizontal distribution of fish passage at the B2CC was highest in the center of the entrance during spring and slightly skewed toward the south during the summer (Figure 3.65).

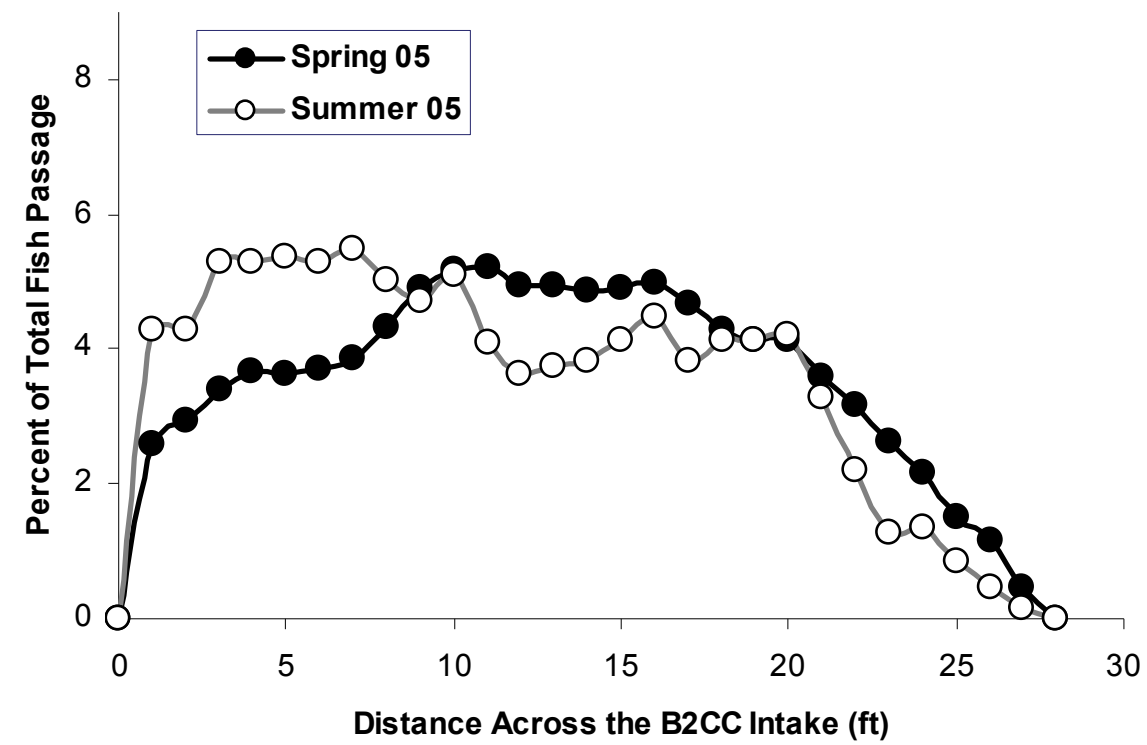

Figure 3.65. Horizontal Distribution of Fish Passage at the B2CC.

\subsection{Radio Telemetry}

Holmberg et al. (1996) reported that despite uniform flow distribution at B2 in 1996, most yearling Chinook salmon passed through the south end units 11-13. Unlike with yearling fish, slightly more than half the subyearling Chinook salmon passed through turbine units at the north end of B2. Sluice chute passage was not observed for either yearling or subyearling fish.

In 1997, the south half of B2 passed the majority of subyearling Chinook salmon (64 of 101) while the north half passed the majority of wild steelhead (2 of 2) and yearling Chinook salmon (8 of 15); equal numbers of hatchery steelhead (4) passed each half (Hensleigh et al. 1999). Based on opened/closed sluice chute test conditions, 37 subyearling Chinook salmon passed B2 during the former condition and 64 passed B2 during the latter condition. The distribution of last detections during sluice chute open conditions was significantly different when the sluice chute was closed $(P=0.002)$ indicating a shift towards the south end of B2 when the sluice was open. The sample size was too small for spring migrants to examine differences during sluice chute conditions (Hensleigh et al. 1999).

Passage at B2 in 1998 indicated the south half of the powerhouse passed the majority of all migrants ( $60 \%$ of 141 steelhead, $57 \%$ of 138 yearling Chinook salmon, and $51 \%$ of subyearling Chinook salmon; Hansel et al. 1999). When the sluice chute was open, Hansel et al. (1999) reported 59\% of 85 juvenile steelhead, $45 \%$ of 69 yearling Chinook salmon, and 37\% of 54 subyearling Chinook salmon passed through the chute. As in 1998, the south half of B2 passed the majority of all migrants (66\% of 152 steelhead and 57\% of 204 yearling Chinook salmon) in 1999 (Plumb et al. 2001). 
Evans et al. (2001a) reported for year 2000 slightly more steelhead (55\%) passed guided through B2 than were unguided, contrasting with yearling Chinook salmon which passed a majority (60\%) unguided through the powerhouse. Based on total turbine passage, Unit 11 passed the majority of both spring migrants. One percent of yearling Chinook salmon and no steelhead were observed to pass through the sluice chute, which was operated minimally in the spring of 2000. Of the four subyearling Chinook salmon passing B2 in 2000, three passed unguided through turbines and one was guided into the bypass system (Evans et al. 2001b).

In 2001, of the 915 yearling Chinook salmon that passed through known routes at B2, 54\% passed unguided through the turbines and 46\% were guided into the juvenile bypass (Evans et al. 2001c). Overall total turbine passage (guided and unguided) for yearling Chinook salmon across all spill conditions peaked at Unit 13. Examining total turbine passage under 37\% and 2\% spill conditions reveals a peak in passage through Unit 13 during the higher spill level and a peak at Unit 14 during the lower spill level. Of the 479 subyearling Chinook salmon passing B2, 65\% passed unguided through the turbine units and the remaining 35\% were guided into the bypass (Evans et al. 2001d). Total turbine passage peaked at Unit 16 for subyearling Chinook salmon.

Evans et al. (2003a) reported yearling Chinook salmon passage at B2 to be comprised of $63 \%$ unguided through turbines and $37 \%$ guided into the bypass system in 2002 . Hatchery steelhead passage contrasted with yearling Chinook salmon, with 59\% guided into the bypass and $41 \%$ passing through turbine units. Total turbine passage peaked for yearling Chinook salmon at Unit 11 and for steelhead at Unit 13. Unit 18 passed the fewest fish of both species in 2002. Of the 682 subyearling Chinook salmon passing B2 through known routes, 53\% passed into turbine units while $47 \%$ were guided into the bypass channel (Evans et al. 2003b). Total turbine passage for subyearling Chinook salmon peaked through Unit 14 and Unit 18 passed the fewest numbers of the summer migrants.

Of the yearling Chinook salmon that passed at B2 in spring 2004, 43\% passed unguided through the turbines, $36 \%$ passed through the B2CC, and $21 \%$ were guided into the DSM (Reagan 2006). A larger percentage of the steelhead at B2 (74\%) passed through the corner collector, while $16 \%$ passed unguided through the turbines, and 10\% were guided into the DSM. In summer 2004, 49\% passed unguided through the turbines, $37 \%$ passed through the corner collector, and 14\% were guided into the DSM.

In spring 2005, the $45 \%$ of yearling Chinook salmon that passed at B2 were unguided through the turbines, $29 \%$ passed through the corner collector, and 26\% were guided into the DSM. For steelhead passing at B2, 66\% passed through the corner collector, $22 \%$ passed unguided through the turbines, and $12 \%$ were guided into the DSM. The greatest discharge occurred at B2; thus, more than half of both species entered the forebay of B2. In summer 2005, 46\% of the subyearling Chinook salmon passed unguided through the turbines, $40 \%$ passed through the $\mathrm{B} 2 \mathrm{CC}$, and $14 \%$ were guided into the DSM. As in previous years, the proportion of discharge allocated among B1, B2, and the spillway appeared to dictate which dam area fish entered and passed.

\subsubsection{Comparison of Hydroacoustics and Radio Telemetry Estimates}

Prior to 2000, estimates of passage at B1 were not collected or reported in a manner conducive for comparison across techniques. Passage estimates at B1 from hydroacoustic and radio telemetry studies in 2000 yielded contrasting results. Based on hydroacoustic methods, Ploskey et al. (2002a) reported that 
Units 4 and 9 passed the greatest number of fish in spring and summer 2000. Based on radio telemetry for spring migrants, Unit 2 passed the greatest number of hatchery steelhead, and yearling Chinook salmon passage peaked through Unit 5 (Evans et al. 2001a). Summer 2000 subyearling Chinook salmon passage also peaked through Unit 5 (Evans et al. 2001b). Horizontal distribution estimates at B1 for 2001 could not be compared across methods since so few radio-tagged fish passed the structure that turbine unit-specific passage was not reported (Evans et al. 2001c).

The B1 sluiceway dominated passage for both seasons based on both hydroacoustic and radio telemetry techniques in 2002. Ploskey et al. (2003) reported that, within B1, the sluiceway passed 33\% and $30 \%$ of all fish for spring and summer, respectively. Radio-telemetry results on B1-passed fish showed that $35 \%$ of yearling Chinook salmon and $65 \%$ of hatchery steelhead of moved through the sluiceway in the spring of 2002 (Evans et al. 2003a), as did 47\% of subyearling Chinook salmon in summer of the same year (Evans et al. 2003b). Too few spring migrants passed B1 to effectively assess passage through individual turbine units (Evans et al. (2003a) but for subyearling Chinook salmon in the summer, Unit 10 passed the greatest numbers while Unit 3 passed the fewest number (Evans et al. 2003b). Estimates for hydroacoustics did not concur, instead showing summer passage peaking through units 2 and 7, with the fewest fish passing units 1 and 10 (Ploskey et al. 2003).

For research years 2002 through 2005, Ploskey et al. (2003, 2005, and 2006c) provided hydroacoustic estimates of passage through individual bays at the Bonneville Dam spillway. During that same time period, estimates of passage for radio-tagged migrants through the spillway were limited to proportions of total passage through Bonneville Dam. Passage across spill bays was not reported; therefore, a comparison of the horizontal distribution of fish passage among methods could not be accomplished.

Estimates of the horizontal distribution of fish passage at B2 were generally similar across methods in 1996. Ploskey et al. (1998) observed peak passage through Unit 11 in the spring using hydroacoustics, which matched up with Holmberg et al. (1996) who reported most yearling Chinook salmon passed through the south end units 11-13. Summertime passage based on hydroacoustics indicated units 12-14 passed the most fish during the day and units 12 and 18 passed the most fish during the night (Ploskey et al. 1998). To some extent, radio telemetry estimates concurred with those from hydroacoustics as Holmberg et al. (1996) reported slightly more than half of the subyearling migrants passed B2 at the north end. However, radio telemetry passage estimates were not reported separately by day and night time periods.

Different passage trends at B2 in 2000 were observed between the two monitoring techniques as Ploskey et al. (2002a) reported peak passage in the spring through units 13 and 15 with hydroacoustics. Radio telemetry indicated hatchery steelhead and yearling Chinook salmon passed in the greatest numbers through Unit 11 in spring (Evans et al. 2001a). Unit 17 passed the fewest spring migrants based on hydroacoustics (Ploskey et al. 2002a), while Evans et al. (2001a) reported Unit 15 as passing the fewest steelhead and Chinook salmon. The sample size was too small to report unit-specific turbine passage for radio-tagged subyearling Chinook salmon.

Hydroacoustic estimates for springtime passage in 2001 indicated a skew toward the south half of B2, with a peak in passage at Unit 11 (Ploskey et al. 2002c). Radio telemetry estimates showed peak passage at Unit 13 for yearling Chinook salmon in 2001 (Evans et al. 2001c). The two methods did show 
agreement, however, on unit 18 passing the smallest proportion of spring migrants. Summertime passage estimates at B2 collected with hydroacoustics indicated peak passage density through Units 13-16 (Ploskey et al. 2002c) while radio-tagged subyearling Chinook salmon passed the in greatest numbers through Unit 16 (Evans et al. 2001d). As in spring, Unit 18 passed the fewest fish in summer according to both monitoring techniques.

Springtime lateral passage trends at B2 in 2002 were to some degree similar across methods (Figure 3.66). Ploskey et al. (2003) estimated peak passage with hydroacoustics through units 11 and 12 , concurring with Evans et al. (2003a) who reported peak passage through Unit 11 for radio-tagged yearling Chinook salmon. Radio-tagged hatchery steelhead, however, passed in greatest numbers through Unit 13. As in 2001, Unit 18 passed the fewest spring migrants based on both hydroacoustics and radio telemetry. In the summer of 2002, the Ploskey et al. (2003) hydroacoustic study reported peak passage occurred through units 11 and 12, with the fewest fish passing through units 15 and 18. In contrast, the Evans et al. (2003b) radio telemetry study indicated subyearling Chinook salmon passed in greatest numbers through Unit 14, with Unit 18 again passing the fewest numbers of summer migrants.
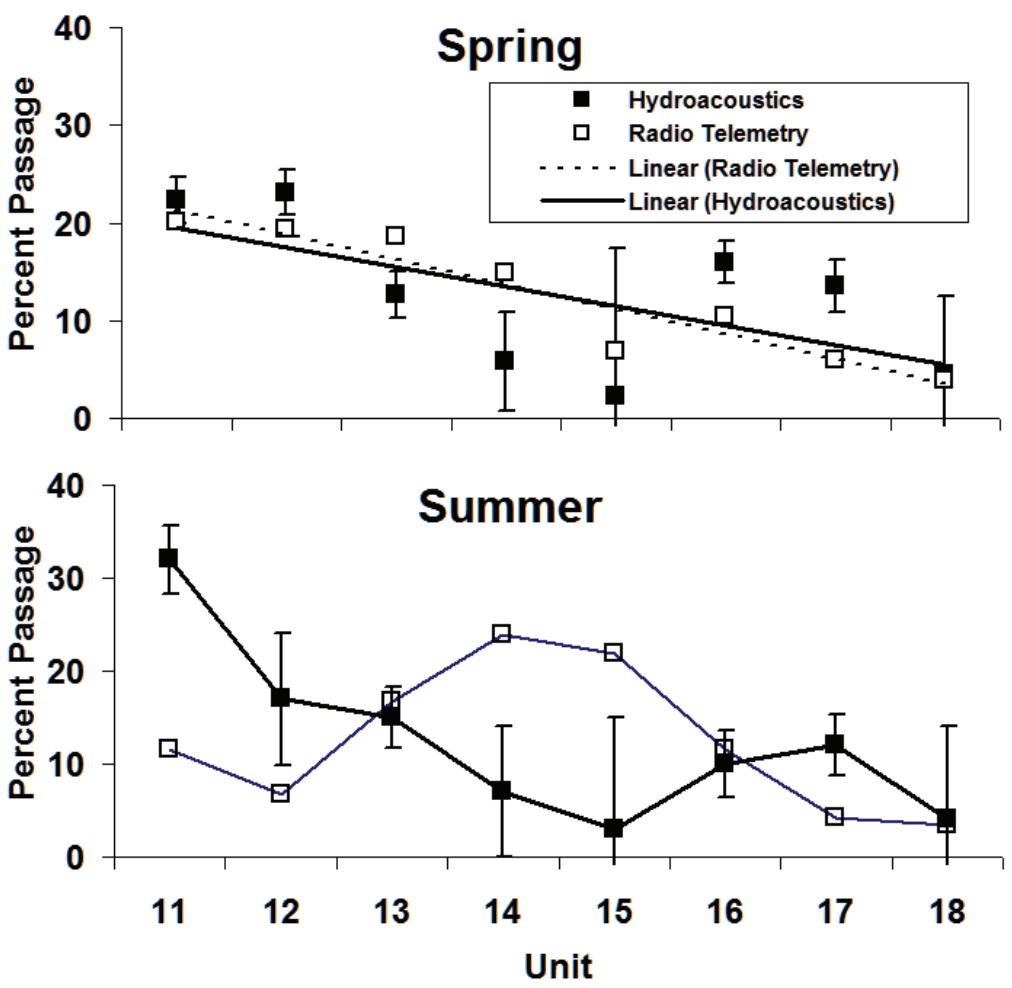

Figure 3.66. Plots of the Percent of Total Passage Estimated by Hydroacoustics and Radio Telemetry at B2 in Spring and Summer 2002. Estimates were based on the percent of passage during the same days. Vertical bars on hydroacoustic estimates are $95 \%$ confidence limits. Figure from Ploskey et al. 2003.

In 2004 and 2005, the distribution of passage at B2 included passage at the B2CC, and hydroacoustic and radio telemetry estimates of passage were correlated (Figure 3.67), with similarities in distribution patterns readily evident (Figure 3.68). The correlation in distribution pattern was diminished by divergent estimates for Unit 17 in spring and Unit 18 in both seasons. The correlations between estimates by the 
two methods were stronger in summer than they were in spring, perhaps because subyearling Chinook salmon made up most of the run-at-large and all of the tagged fish population in summer.

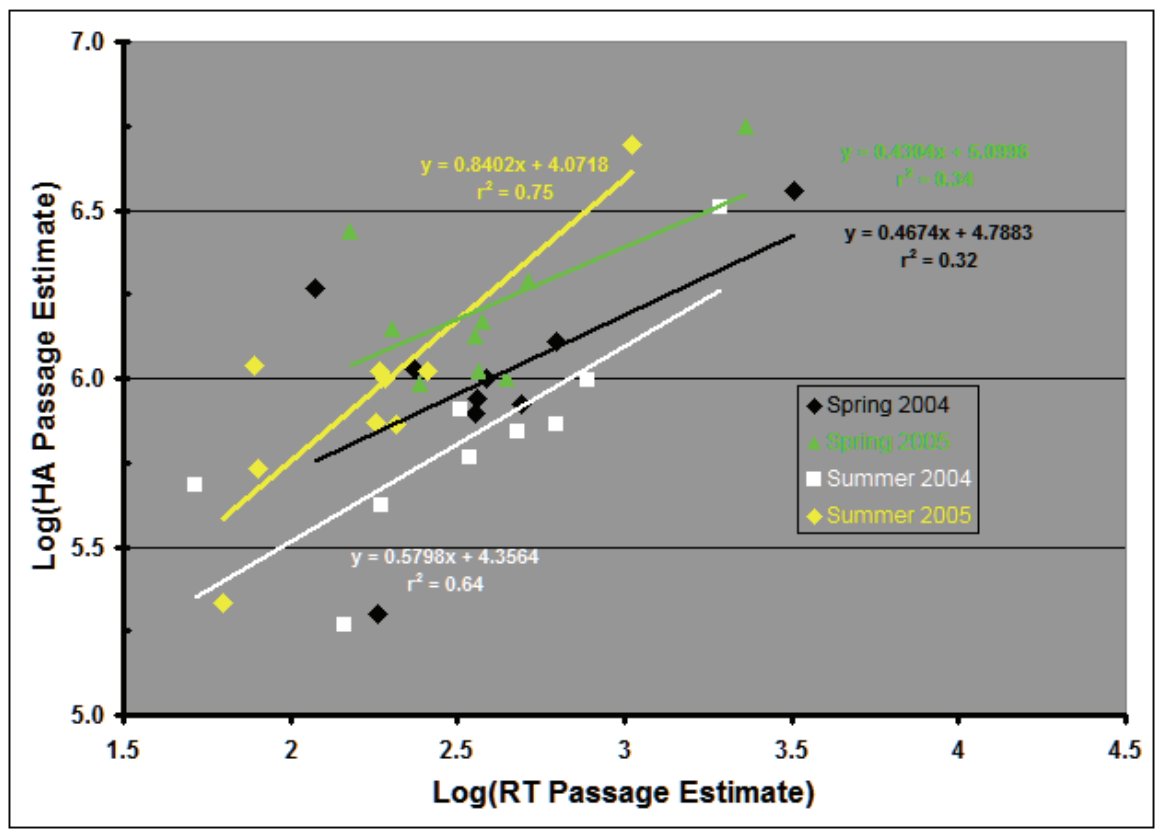

Figure 3.67. Correlations between Hydroacoustic and Radio Telemetry Estimates of Percent Passage by Route at B2 in 2004 and 2005.

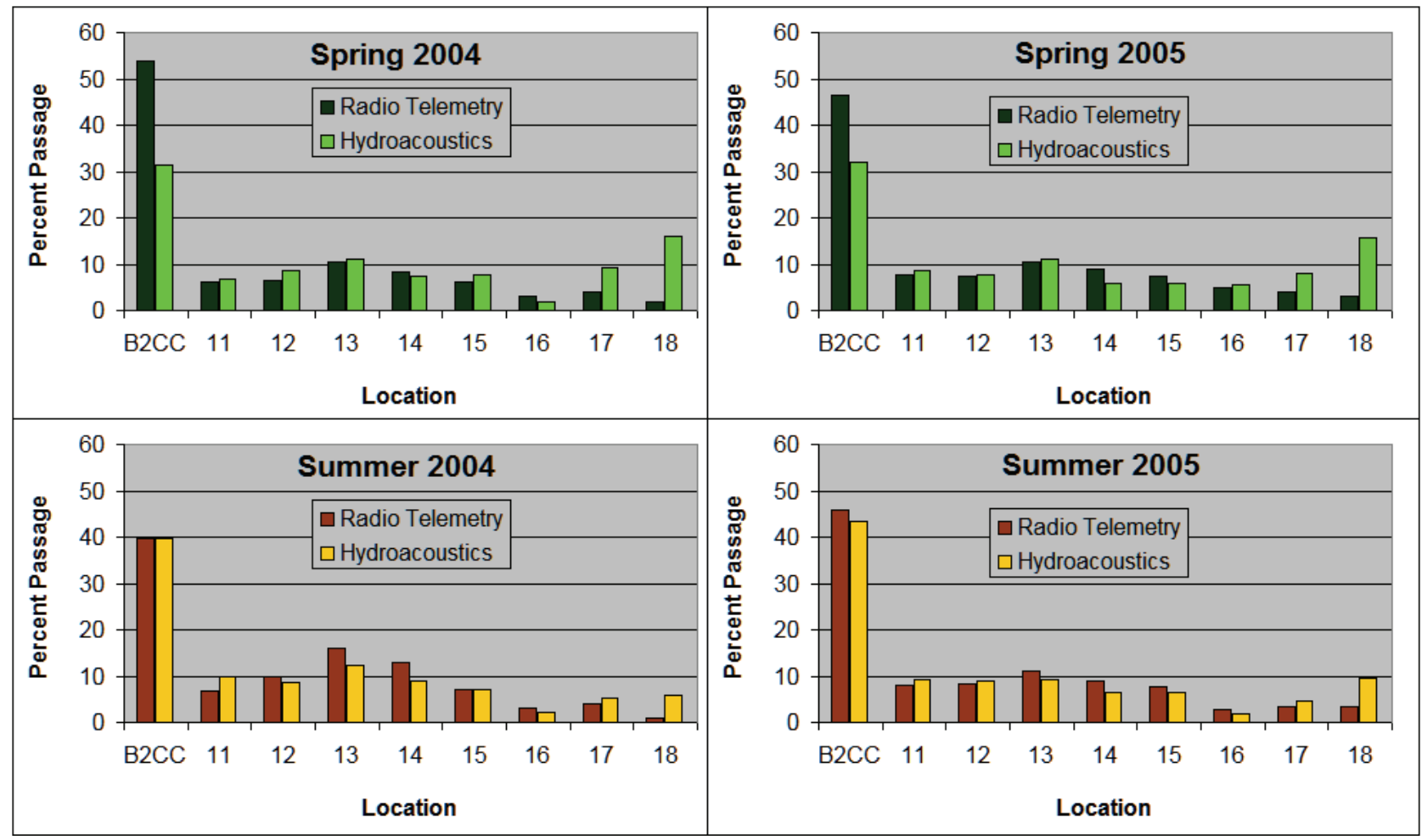

Figure 3.68. Distribution in Percent Passage Among B2 Routes in Spring and Summer of 2004 and 2005, as Estimated by Radio-Telemetry and Hydroacoustic Methods. 


\subsubsection{Vertical Distributions}

\subsubsection{Turbines}

Ploskey et al. (2001b) used hydroacoustics to sample Unit 5 in 1999 and reported that during 5-ft slot treatments in-turbine vertical distributions of fish were similar in spring and summer (Figure 3.69). There were slight differences in guided and unguided fish distributions between seasons, with guided fish slightly deeper in spring than in summer, contrary to unguided fish where peak concentrations were slightly deeper in summer than in spring.

In 2001, Ploskey et al. (2002c) used hydroacoustics to examine the vertical distribution of smolt-sized fish inside Intake 10B at B1. The distribution in the spring was skewed toward higher elevations with a slight proportional increase near the floor of the turbine intake (Figure 3.70). The summer distribution was skewed toward both higher elevations and the intake floor (Figure 3.71).
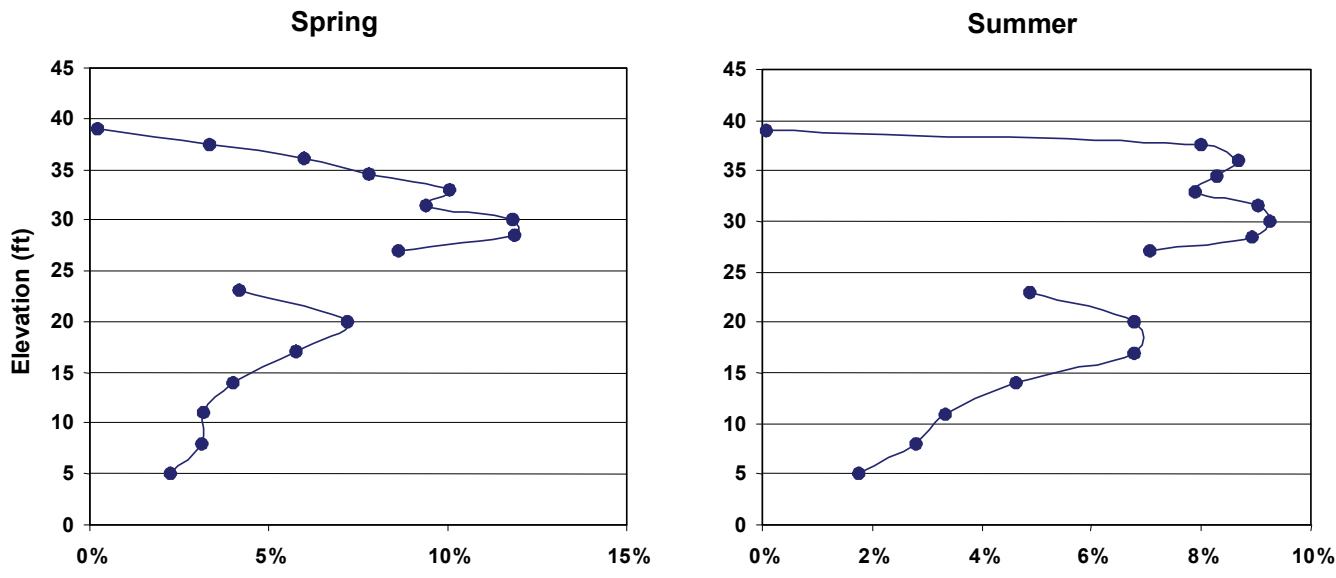

Proportion of Fish

Figure 3.69. Vertical Distributions of In-Turbine Fish Passage Estimates during 5-ft Slot Treatments for Spring and Summer 1999. Plots illustrate distributions of guided (upper portions of distributions) and unguided (lower portions) fish. The gaps between the upper and lower portions reflect the elevations that were not sampled. Figure from Ploskey et al. 2001b.

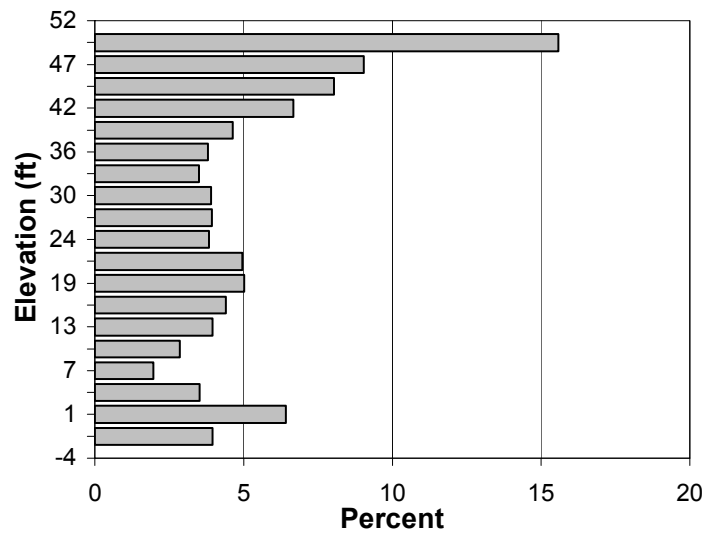

Figure 3.70. Vertical Distribution of Smolt-Sized Fish Detected Inside Intake 10B in Spring 2001. Figure from Ploskey et al. 2002c. 
With radio telemetry, Evans et al. (2001a) determined the depth of entrance into the PSC using the last detection received by underwater antennas along the face of the PSC before the first detection inside the PSC. In 2000, 73\% of 211 hatchery steelhead were observed to enter the PSC at shallow depths (0 to $6.5 \mathrm{~m})$. In contrast, $55 \%$ of yearling Chinook salmon entered the PSC at deep depths (6.5 and $13 \mathrm{~m})$. At night the majority of both species entered the PSC at deep depths while during the day $84 \%$ of steelhead and $48 \%$ of yearling Chinook salmon entered at shallow depths. Of the 204 subyearling Chinook salmon detected at the PSC entrance, 52\% approached at deep depths (Evans et al. 2001b). Subyearling Chinook salmon differed in their approach depth by time of day: 59\% of daytime approaches occurred at deep depths while at night $69 \%$ of approaches occurred at shallow depths.

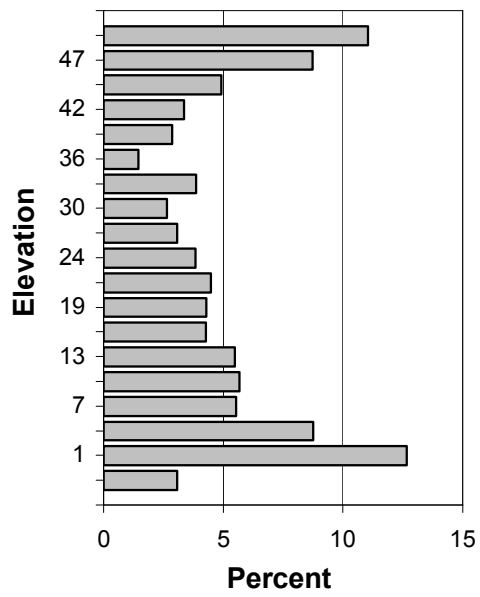

Figure 3.71. Vertical Distribution of Smolt-Sized Fish Detected Inside Intake 10B in Summer 2001. Figure from Ploskey et al. 2002c.

For research year 2001, the gatewell and vertical barrier screen at Intake 15B were modified to increase flow into the gatewell. Ploskey et al. (2002c) reported the vertical distribution of fish inside Intake $15 \mathrm{~B}$ to be similar in pattern across seasons but spring fish were distributed more frequently at higher elevations and less frequently at lower elevations than summer fish (Figure 3.72).

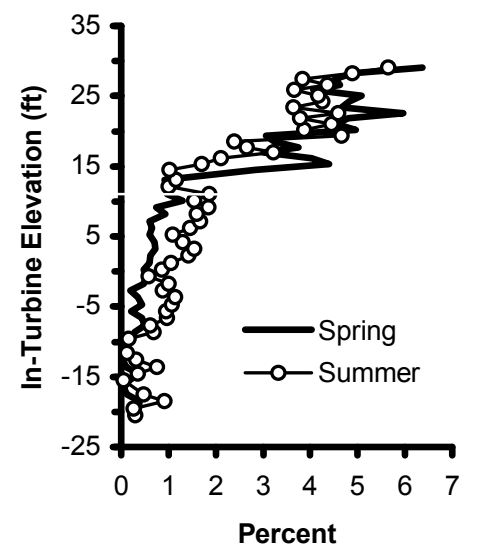

Figure 3.72. Vertical Distribution of Smolt-Sized Targets Inside Modified Intake 15B for Spring and Summer 2001. Figure from Ploskey et al. 2002c. 
The estimated vertical distribution patterns of fish within turbine intakes at B1 in 2004 were multimodal during both spring and summer, with modes occurring at a shallow elevation of about $60 \mathrm{ft}$. mean sea level, just above midwater (about EL $37 \mathrm{ft}$ ), and near the bottom of the turbine entrance (at about El. 6 $\mathrm{ft}$ ) (Figure 3.73). In the spring, we estimated that the greatest proportions of fish were detected near the lowest elevations, whereas in summer fish were distributed at highest frequencies near the highest elevations.

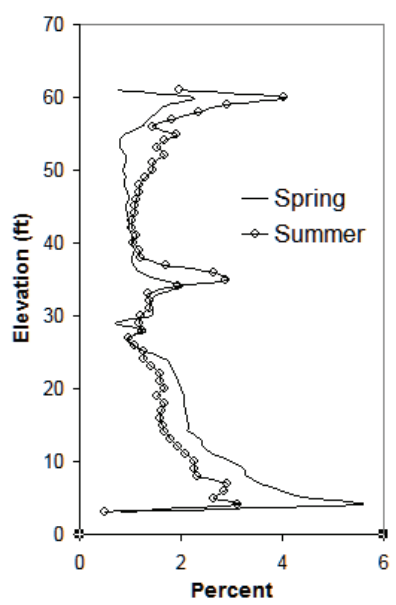

Figure 3.73. Estimates of Vertical Distributions of Fish within Turbine Intakes at Bonneville Dam First Powerhouse in Spring and Summer 2004

Vertical distribution patterns of fish passing the spillway were similar in spring and summer, characterized by a general increase in percentages with increasing depth. However, a slight decrease in percent passage with increasing depth is evident in spring and summer between elevations 37 and $39 \mathrm{ft}$. Both distributions peaked at about $36 \mathrm{ft}$ elevation, with the peak slightly higher in spring than in summer.

The estimated vertical distributions of fish within turbine intakes at B1 also were multi-modal in 2005, with peaks in fish-passage percentages near the top of the intakes (about elevation $60 \mathrm{ft}$.), at about the middle of the intakes (elevation $36 \mathrm{ft}$.), and near the bottom of the intakes (Figure 3.74). The largest peak was near the bottom of the intake in each season. A similar pattern was observed in 2004, with a prominent peak near the bottom of the intakes that rivaled the peak near the ceiling in spring and exceeded the ceiling peak in summer.

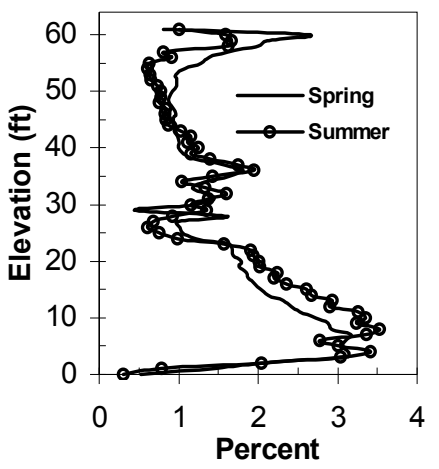

Figure 3.74. Vertical Distributions of Fish within Turbine Intakes at B1 in 2005. 
Hydroacoustic sampling at B1 in 2004 and 2005 differed from that in earlier years so an effort was made in 2005 to standardize vertical distribution data with what was collected before 2004. For example, the average B1 vertical distribution was adjusted in 2005 by moving fish detected above Elevation $47 \mathrm{ft}$ and near the trash racks deeper into the intake which corresponded to the uppermost strata sampled in 2002 and earlier years (EL 41-47 ft). This standardization of maximum elevations to those sampled in 2001 and 2002 restored the predominance of fish passage in the upper water column for the 2005 data (Figure 3.75), although a substantial percent of fish passed deep through B1 turbines. Data from 2002 (Figure 3.76) also show sizeable percentages of fish passing deep, as do data from 2001 (Ploskey et al. 2002c).

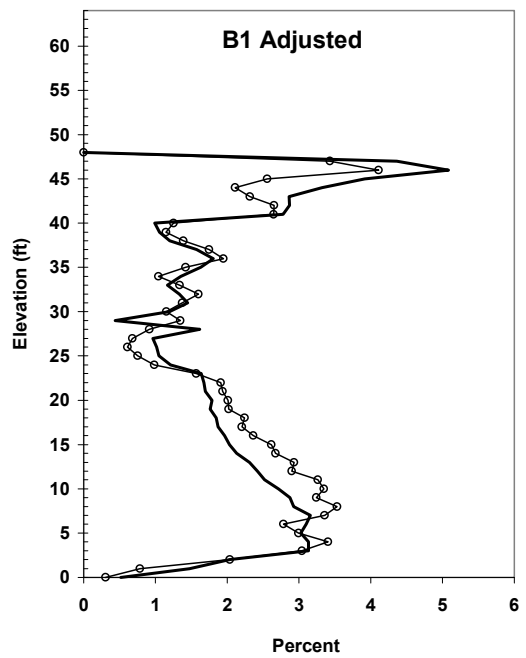

Figure 3.75. Average Vertical Distributions of Fish Passage within B1 Turbine Intakes in Spring and Summer 2005, after Standardizing Sampling Elevation. Percentages above elevation $31 \mathrm{ft}$ were estimated from samples of up-looking hydroacoustic beams and those at or below elevation 31 were estimated from down-looking hydroacoustic beams. Figure from Ploskey et al. 2006c.

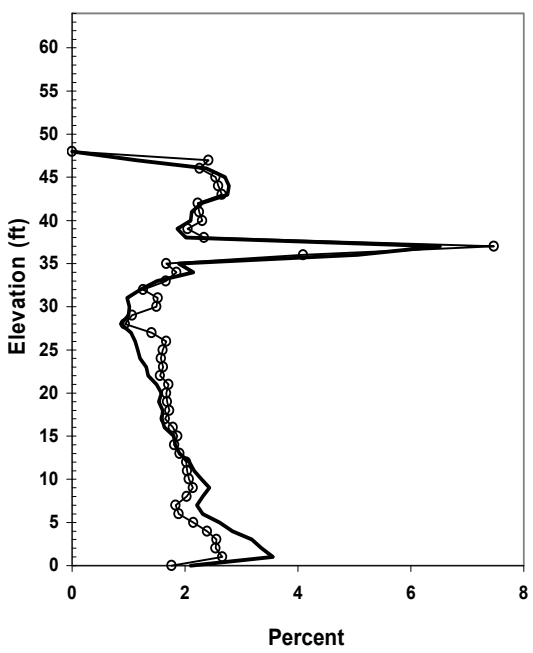

Figure 3.76. Average Vertical Distributions of Fish Passage within B1 Turbine Intakes in Spring and Summer 2002. Percentages above elevation $31 \mathrm{ft}$ were estimated from samples of uplooking hydroacoustic beams and those at or below elevation 31 were estimated from down-looking hydroacoustic beams. Figure from Ploskey et al. 2003. 
The percent of fish passage varied just 1-2\% among 1-ft-depth strata in B2 turbines and exhibited only a slight decline with decreasing elevation in spring and summer 2005. In spring, the percent passage within 1-ft strata between the bottom and ceiling of the intakes ranged from $1.0 \%$ to $3.5 \%$ (Figure 3.77). Except for a single peak of 5.4\% at Elevation $21 \mathrm{ft}$ in summer, the same relatively narrow range in percent passage also was observed for all strata in summer (Figure 3.77).
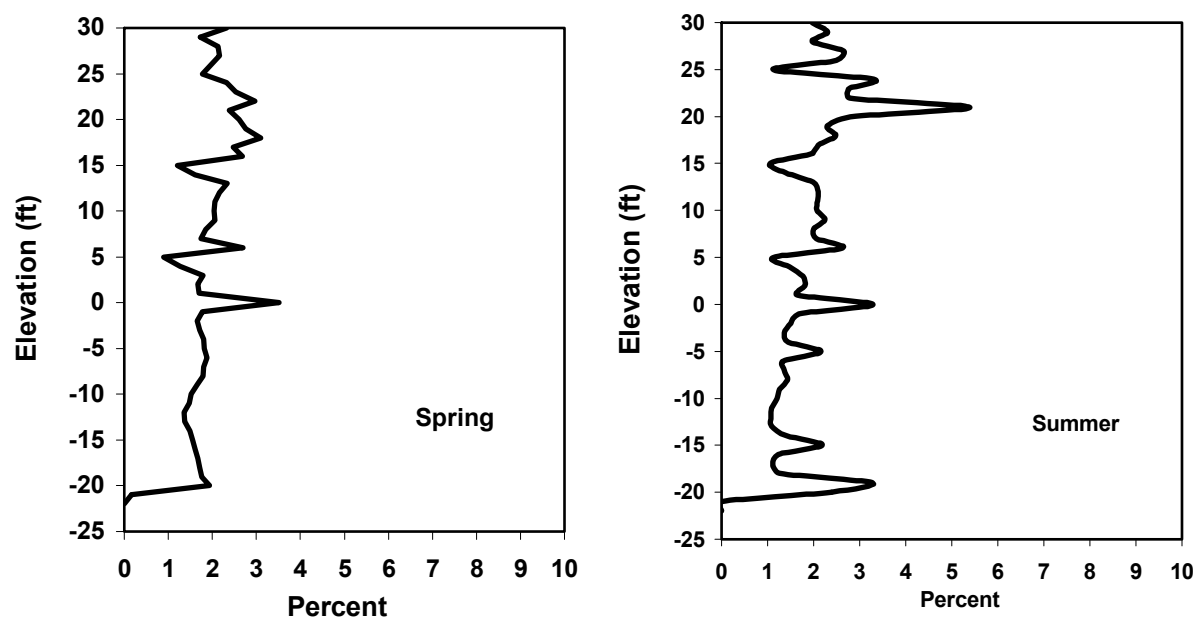

Figure 3.77. Vertical Distributions of Fish within B2 Turbine Intakes in Spring and Summer 2005

\subsubsection{Spillway}

The vertical distributions of fish passing the spillway in spring and summer were similar in 2004 and 2005 (Figure 3.78) and a peak occurred within $3 \mathrm{ft}$ of the ogee at elevation $24 \mathrm{ft} \mathrm{MSL} \mathrm{(Ploskey} \mathrm{et} \mathrm{al.}$ 2005). Spilling through more gates with smaller openings may have implications for survival as recent data suggest that passage near an ogee may increase the risk of injury or death (Thomas Carlson, PNNL, Personal Communication).
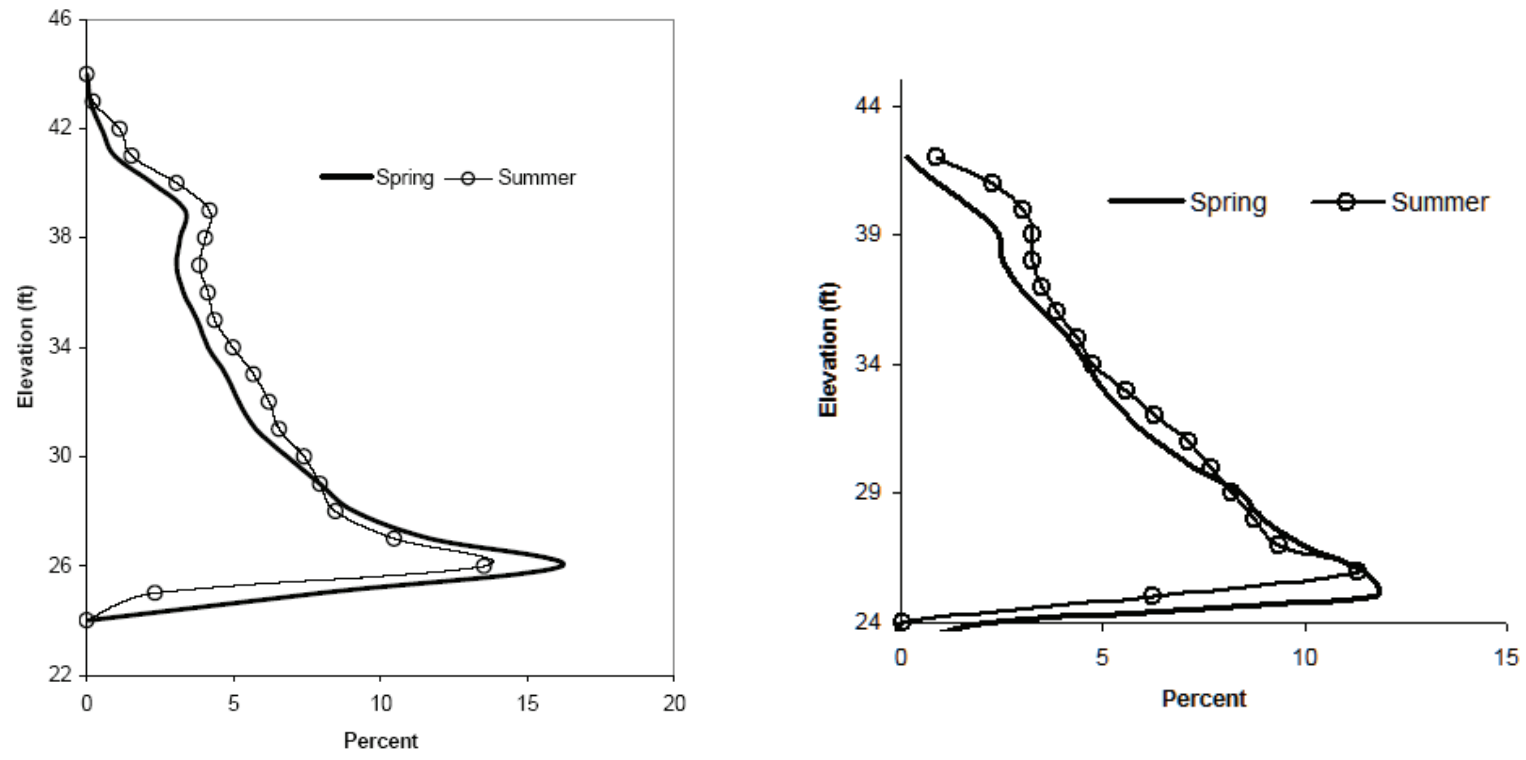

Figure 3.78. Vertical distributions of Fish Passage at Spillway in 2004 (Left) and 2005 (Right) 


\subsubsection{Deep Surface Flow Outlets - PSC and B2CC}

A full evaluation of the Prototype Surface Collector (PSC) was undertaken in 2000 with results presented in Section 3.3 of this report as provided by Ploskey et al. (2002a and b), Evans et al. (2001a and b), and Johnson and Carlson (2001). The vertical distribution of fish in front of the PSC at Powerhouse 1 was conducive for successful surface collection with a deep slot configuration. Sample volumes 1 to $3 \mathrm{~m}$ upstream of the PSC detected $92 \%$ to $99 \%$ of fish in spring and from $85 \%$ to $96 \%$ in summer above the elevation of the PSC floor.

The coverage of split-beams across the entrance of the $\mathrm{B} 2 \mathrm{CC}$ can be visualized by examining a composite plot of all fish detections within the beams in spring and summer (Figure 3.79).

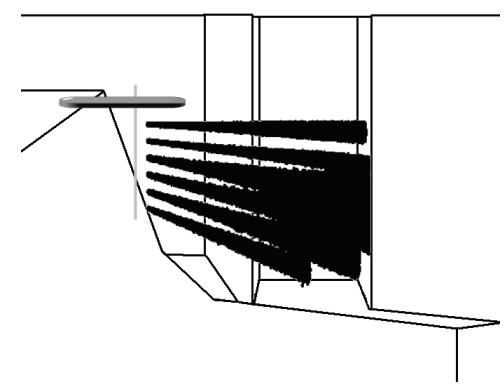

Figure 3.79. Plot of All Fish as Dots Where They were Detected within Acoustic Sample Volumes of Split-Beam Transducers to Illustrate Sampling Coverage at the B2CC Entrance in Spring and Summer, 2004. At low forebay elevations, the bottom two beams were truncated by the sill.

Fish passage at the $\mathrm{B} 2 \mathrm{CC}$ was highly skewed toward the surface in both spring and summer (Figure 3.80). The percent of fish passing within $4 \mathrm{ft}$ of the water surface was $63 \%$ in spring and $46 \%$ in summer. In summer, there was a noticeable peak in passage between the 15- and 20-ft depths, representing about $25 \%$ of the fish passing through the B2CC (Figure 3.80). The vertical distribution trend was similar during the day and night in both seasons, except for the peak in summer at 15 to $20 \mathrm{ft}$, which was only a daytime occurrence. When summer data collected after July 4 (when shad were running) are removed, the vertical distribution for summer is very similar to that observed in spring (Figure 3.81).

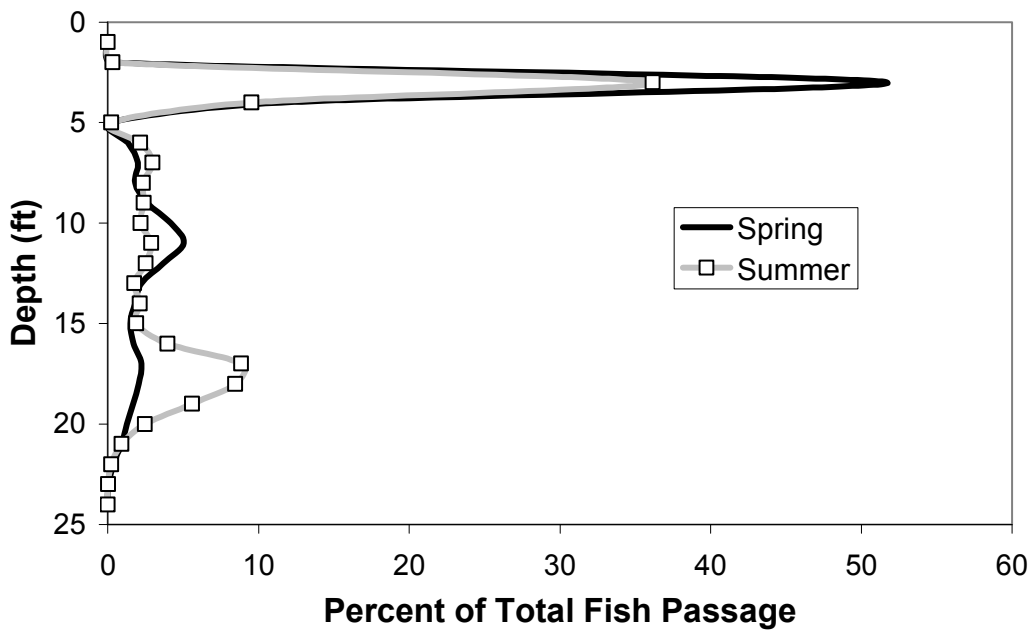

Figure 3.80. Vertical Distribution of Fish Passing through the B2CC in Spring and Summer 2004 


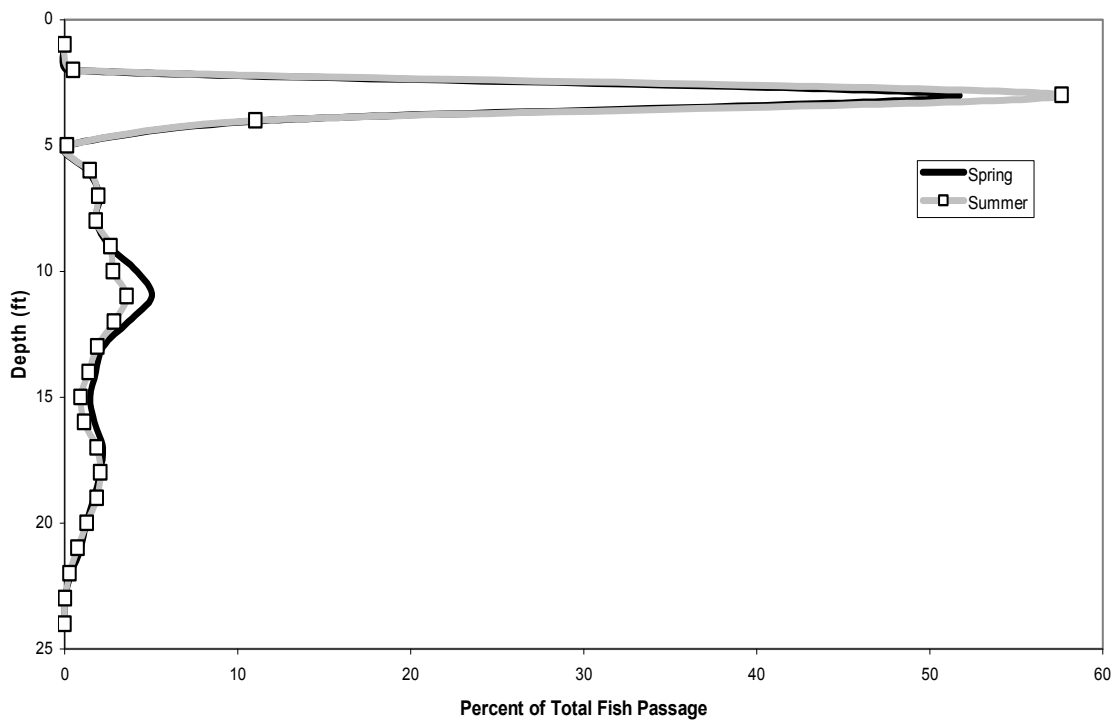

Figure 3.81. Vertical Distribution of Fish Passing through the B2CC in Spring and Summer through July 4, 2004, Only

In 2005, fish entering the B2CC were surface oriented in both seasons but were somewhat lower in the water column in summer than they were in spring (Figure 3.82). About 70\% were detected in the top half of the opening (about $11 \mathrm{ft}$ of depth) in spring, while only $60 \%$ were in the top half of the opening in summer.

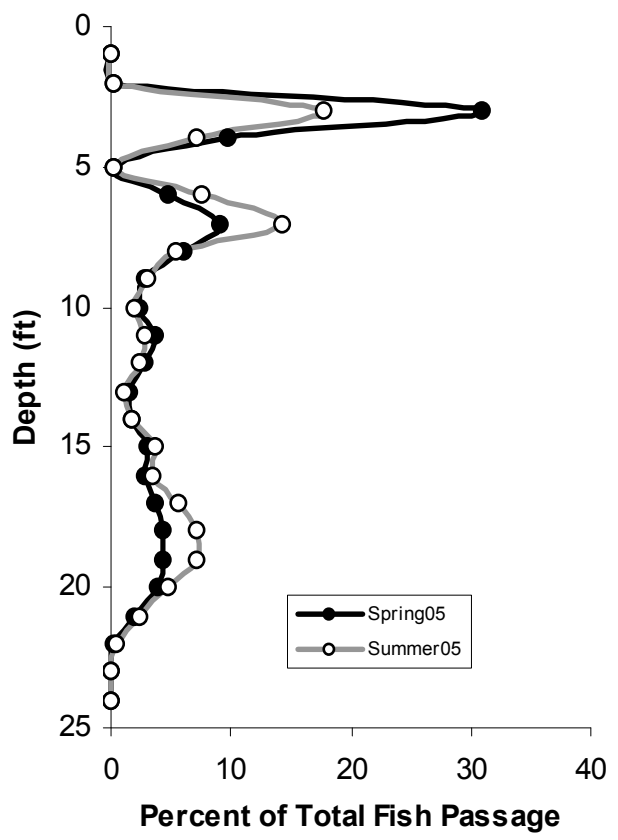

Figure 3.82. Vertical Distributions of Fish at the B2CC Entrance in 2005. 


\subsubsection{Diel Distributions}

It is easiest to talk about diel distribution by type of passage route (turbines, spillway, and surface passage outlets) because trends are more apparent and consistent than they are by structure (B1, B2, and the spillway). However, it is very important to differentiate between diel patterns that are driven by diel shifts in project operations and discharge and natural patterns that occur when operations are relatively constant.

\subsubsection{Turbines}

When turbines run 24 hours per day, fish passage usually is crepuscular with peaks occurring after sunset and about dawn, and passage usually is higher at night than it is during the daytime. Some examples will help make this point. Willis and Uremovich (1981) found that $60 \%$ of juvenile salmonids passed Powerhouse 1 at night, in spite of the fact that $82 \%$ of the sluiceway-passage component occurred during the daytime. Mean hourly hydroacoustic estimates of smolt passage into turbine units 3 and 5 in 1996 generally were higher during night hours than during day hours for both the spring and summer (Figure 3.83). Another example from B1 is Unit 8 in 1998 (Figure 3.84). Abrupt peaks in passage around sunset are evident for fish guided by the extended submerged traveling screen in both spring and summer and for unguided fish in summer. Note that the onset of increased passage occurs 1-2 hours later in summer than it did in spring. These trends are not unlike what can be observed for juvenile bypass system (JBS) data except that there is a delay of several hours in the observed peaks for JBS data since fish may delay in gatewell slots (e.g., see Ploskey et al. 2000). When turbines dominate project operations, as they did in 2001, similar diel patterns can be observed for total project passage (Figure 3.85 ), but in general a single turbine running the same discharge 24 hours per day provides the best look at a typical diel pattern (e.g., B2 Turbine 18 in spring 2005 - Figure 3.86). At B2, turbines 11 and 18 had generation priority, and were most likely to run 24 hours per day.

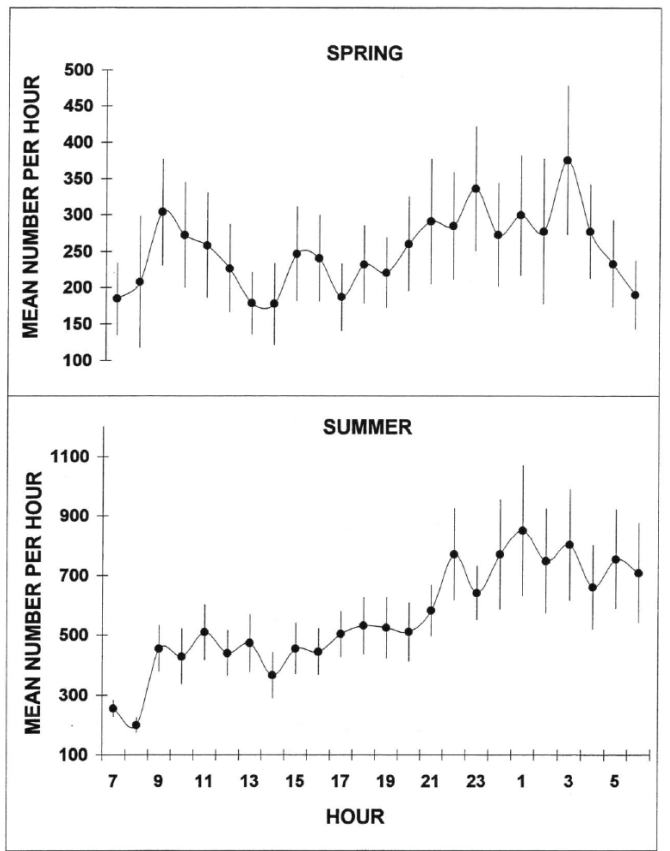

Figure 3.83. Diel Trend in Mean Hourly Passage in 1996 at Two B1 Turbines 


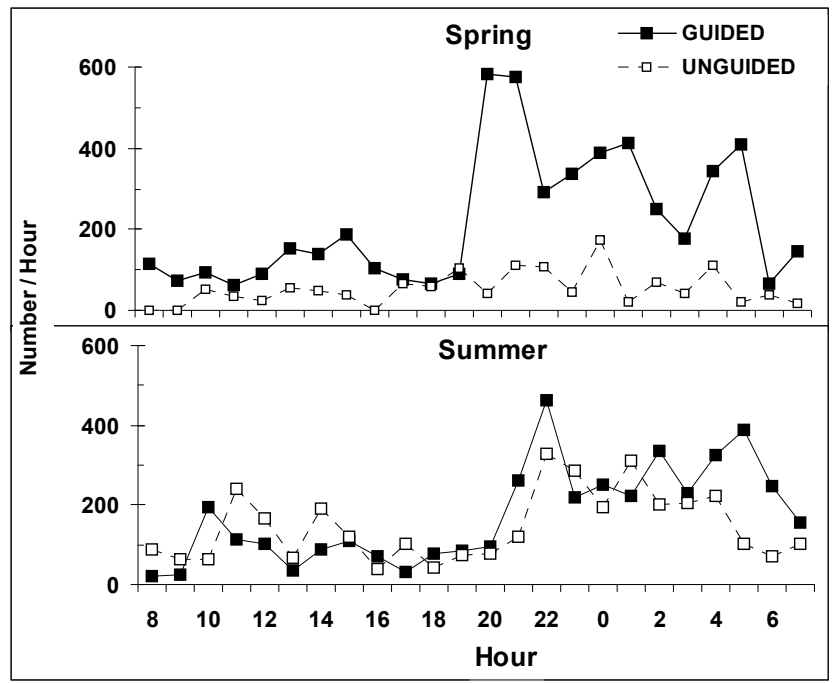

Figure 3.84. Diel Trends in Fish Passage Above (Guided) and Below (Unguided) an ESBS at Intake 8B in Spring and Summer 1998. Figure from Ploskey et al. 2001a.
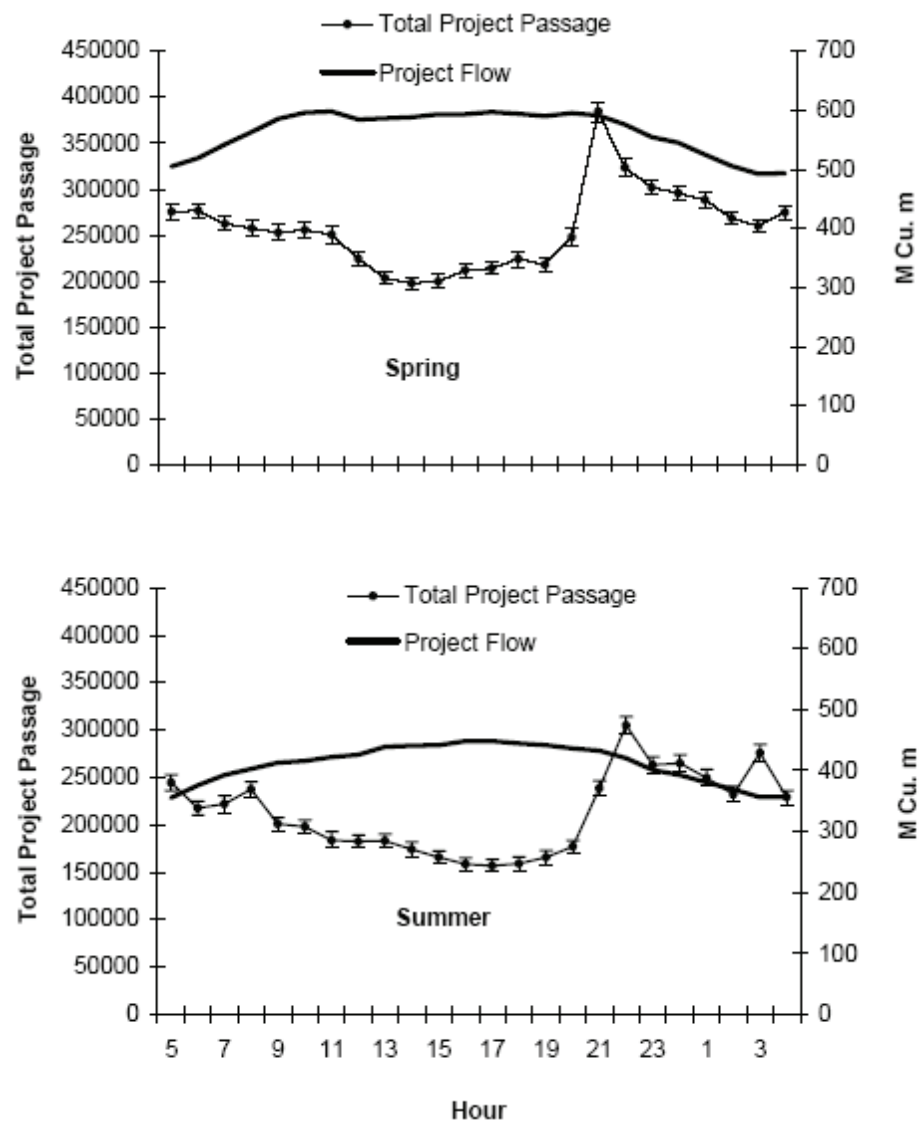

Figure 3.85. Diel Trends in Total Project Passage in 2001, when Spill Passage was Low Relative to Turbine Passage. Figure from Ploskey et al. 2002c. 


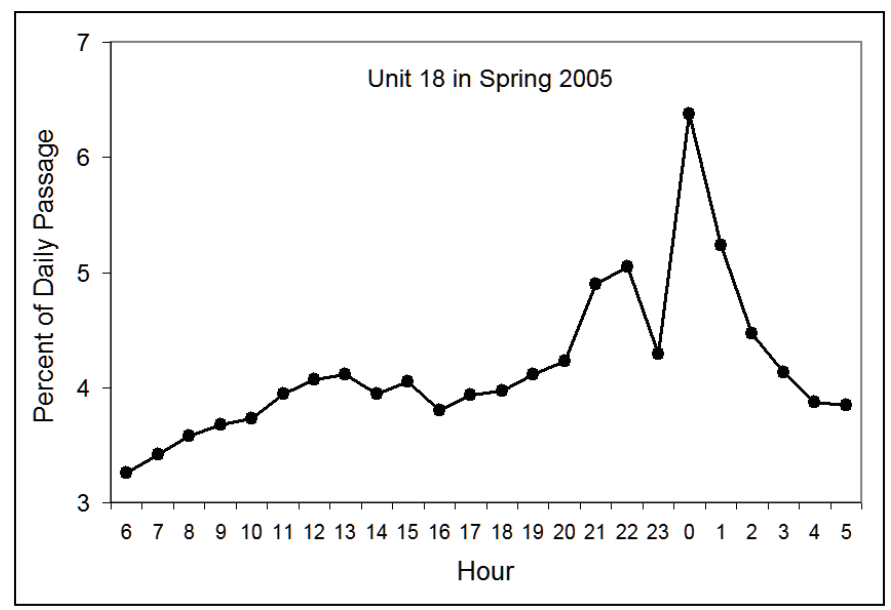

Figure 3.86. Average Diel Trend in Fish Passage through Turbine 18 in Spring 2005.

Turbine discharge and fish passage at B1 in spring and summer 2005 provide a good example of an atypical diel pattern driven by turbine operations (Figure 3.87; Ploskey et al. 2006c). In this example, turbine discharge controls passage, whereas in earlier examples for B1 turbines, the units ran 24 hours per day. Similar atypical examples were observed at B1 in 2004 (Ploskey et al. 2005). These diel patterns are of interest because they show the degree to which diel patterns can be altered by operations. Another atypical example of a diel trend for turbine passage was observed in B2 turbine passage in summer 2005, when most turbines between Unit 11 and 18 were shut down to provide water for increased spill at night (Figure 3.88). In both Figure 3.87 and 3.88, we would expect to see higher turbine passage at night than during the day if discharge had been constant, which it was not.
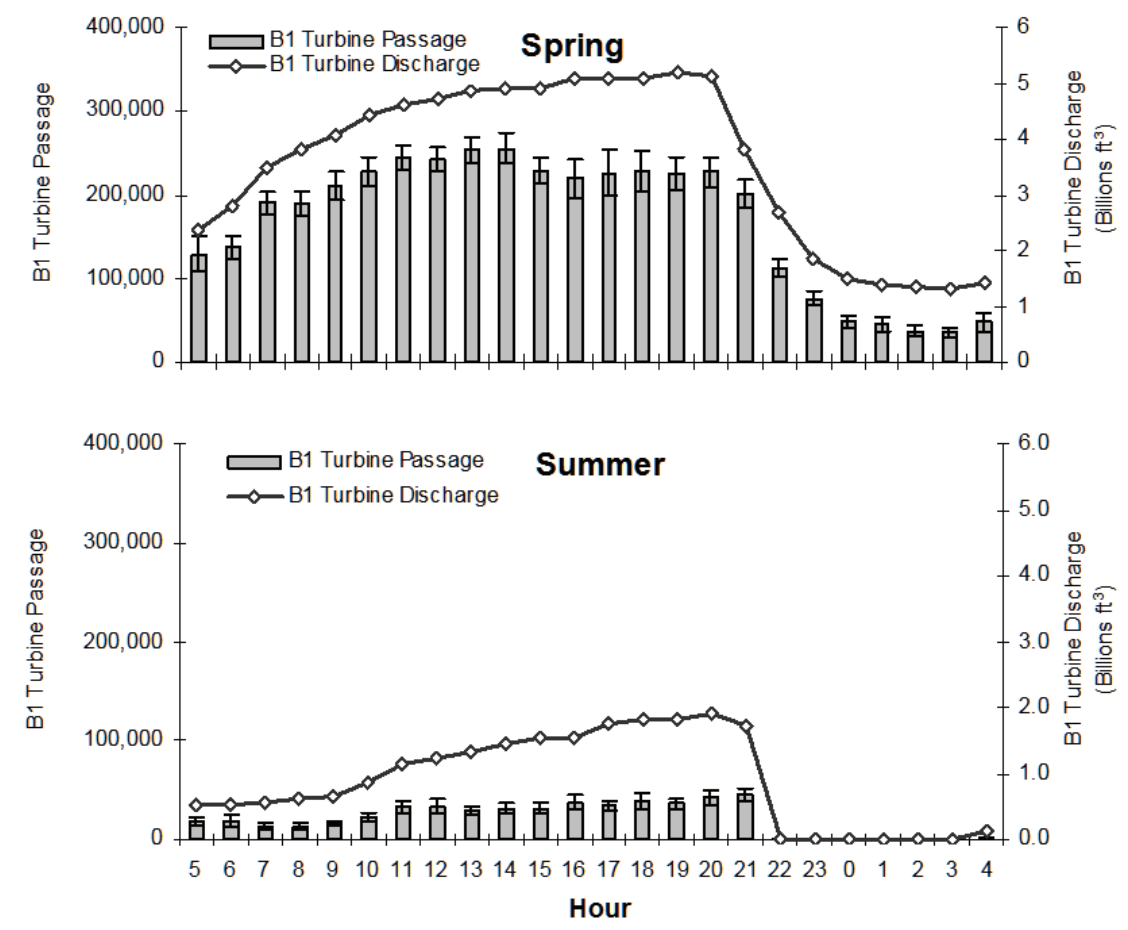

Figure 3.87. Diel Trends in Fish Passage Above (Guided) and Below (Unguided) an ESBS at Intake 8B in Spring and Summer 1998. Plots were taken from Ploskey et al. 2006c. 


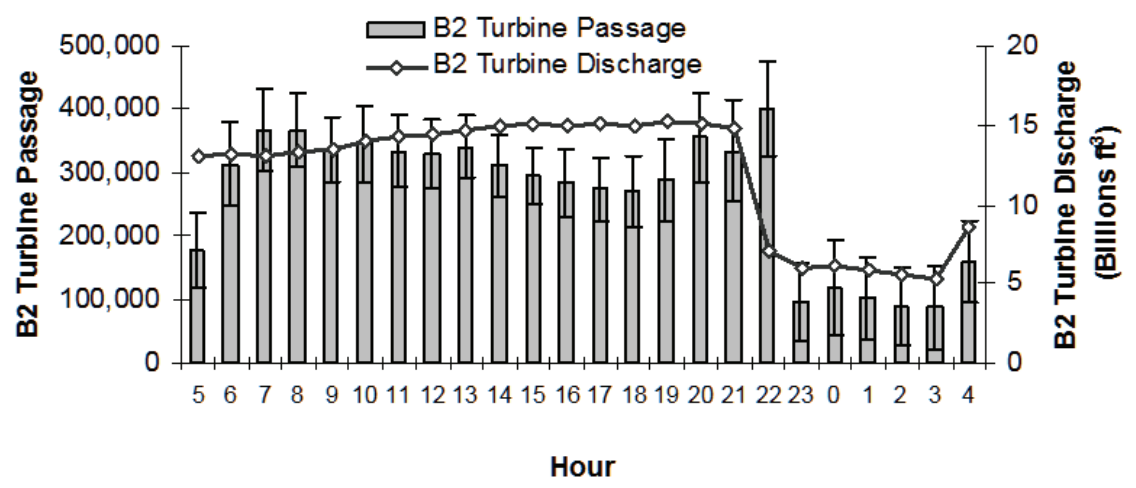

Figure 3.88. Diel Trends in Fish Passage in B2 Turbine Passage in Summer 2005. Plot was taken from Ploskey et al. 2006c.

\subsubsection{Spillway}

\subsection{Hydroacoustics}

Determining a natural diel pattern of passage at the Bonneville Dam spillway has been difficult because discharge usually is much higher at night than it is during the day, and spill passage efficiency is directly correlated with percent spill (Figures 3.2, 3.3, and 3.4). Typically, spill passage and spill efficiency increase significantly at night because discharge increases (e.g., Figure 3.89, 3.90, 3.91, 3.92).

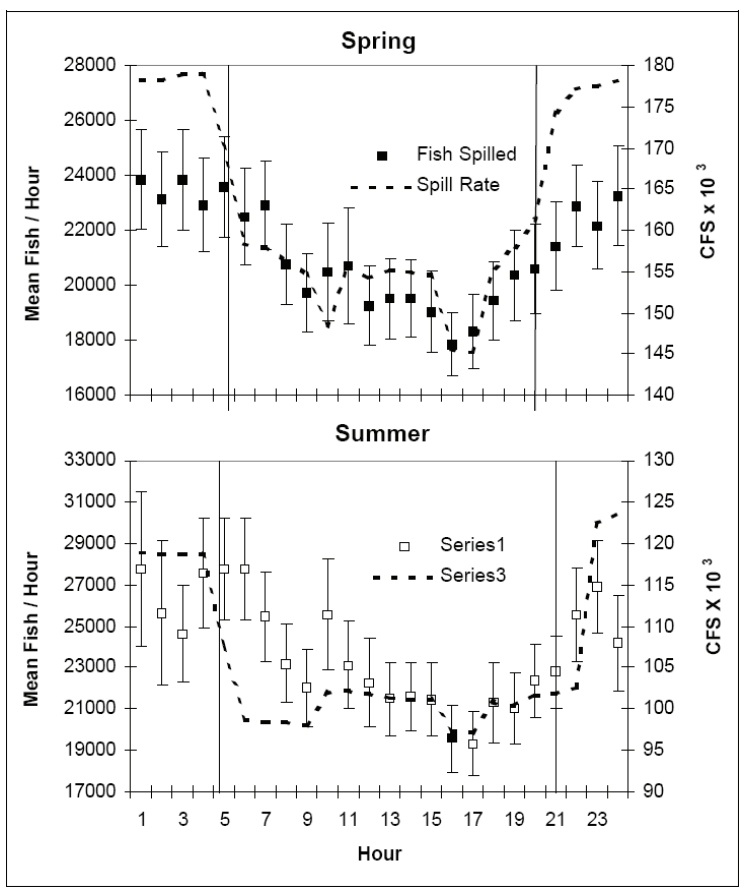

Figure 3.89. Hourly Patterns in the Mean Number of Fish Spilled per Hour in Spring and Summer 2000. Error bars represent $80 \%$ confidence limits about the mean. Vertical lines indicate average times of sunrise and sunset. Figure from Ploskey et al. 2002a. 


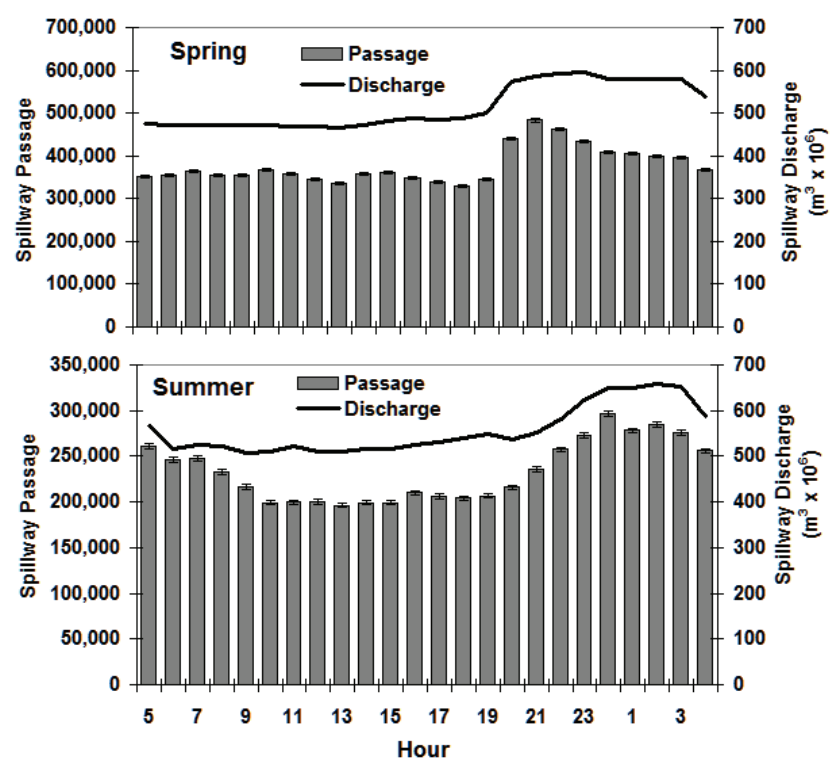

Figure 3.90. Estimates of Diel Trends in Spilled Fish and Spillway Discharge in Spring and Summer 2002. Note the scale of vertical passage (left) axis in spring extends to twice what it does in summer. Error bars represent $95 \%$ confidence intervals on fish passage estimates. Figure from Ploskey et al. 2003.
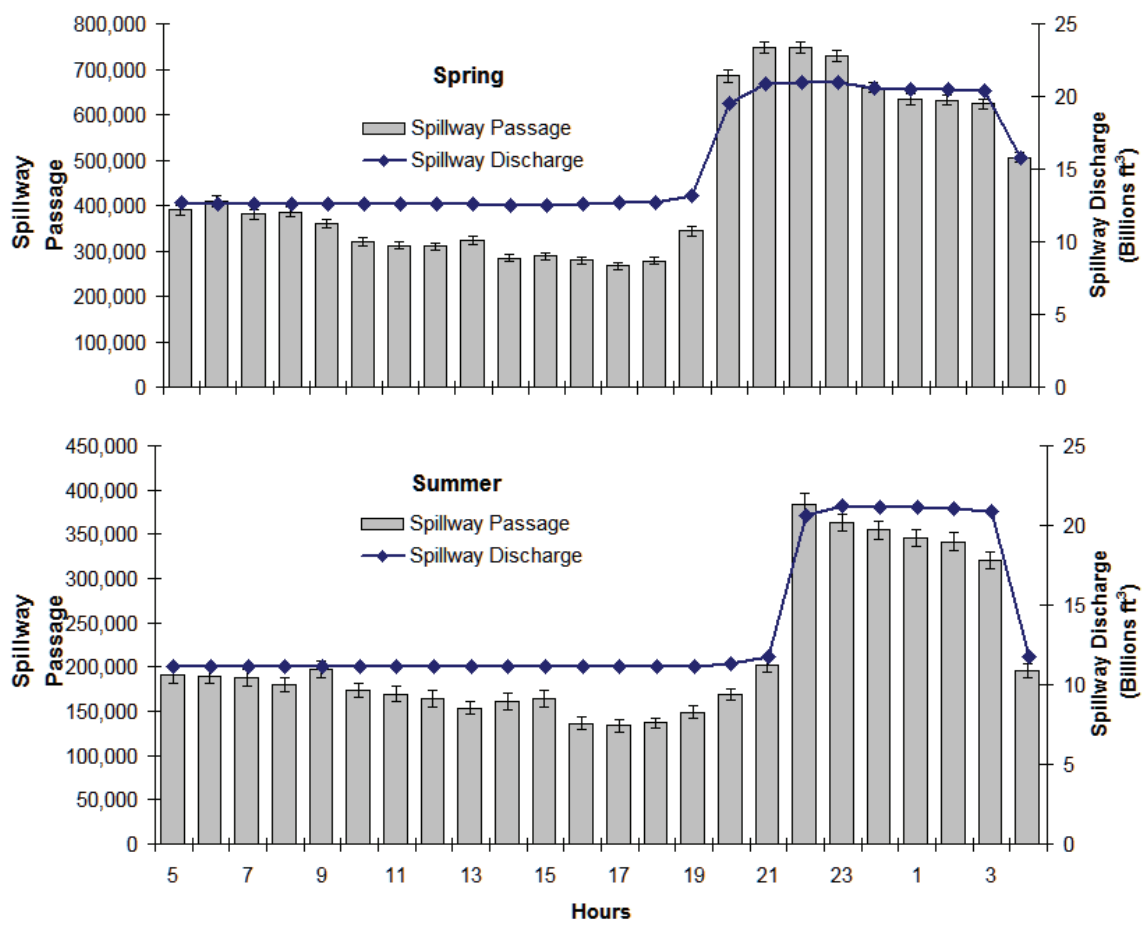

Figure 3.91. Estimated Hourly Spillway Passage and Discharge at Bonneville Dam in Spring and Summer of 2004. Error bars represent $95 \%$ confidence limits on fish passage estimates. From Ploskey et al. 2005.

There have only been a few times when spill was held constant and a natural diel pattern, independent of discharge, could be observed. In the drought year of 2001, when spill was nearly constant 24 hours per day, Ploskey et al. (2002c) described diel trends with a decline during daylight hours and an increase at 
2100 hours in spring and 2200 hours in summer (Figure 3.93). In 2004, there were six days in summer when spill was deliberately held constant for 24 hours, and these conditions again afforded researchers the opportunity to examine diel patterns of spill passage independent of discharge (Figure 3.94). The patterns in Figures 3.93 and 3.94 clearly indicate that the diel patterns observed in Figures 3.89 through 3.92 are not entirely due to increased discharge at night.

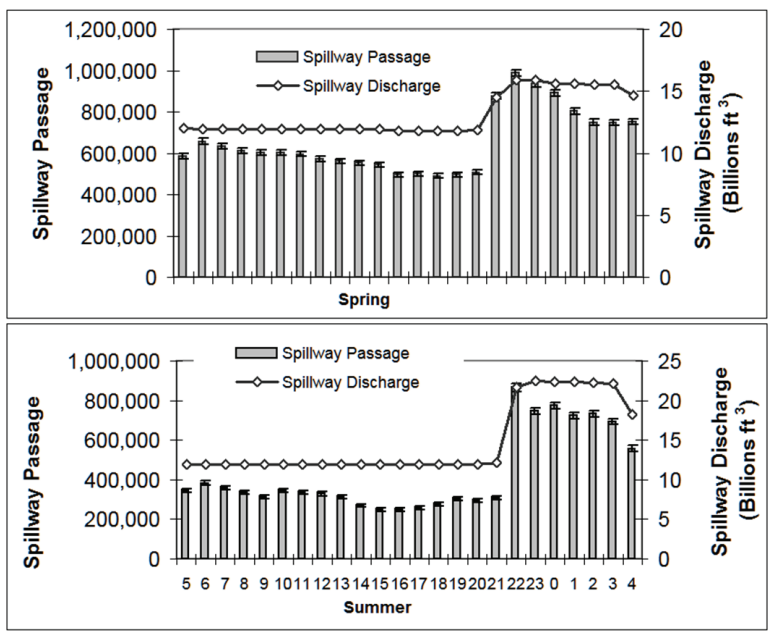

Figure 3.92. Estimated Hourly Spillway Passage and Discharge at Bonneville Dam in Spring and Summer of 2005. Error bars represent $95 \%$ confidence limits on fish passage estimates. From Ploskey et al. 2006c.
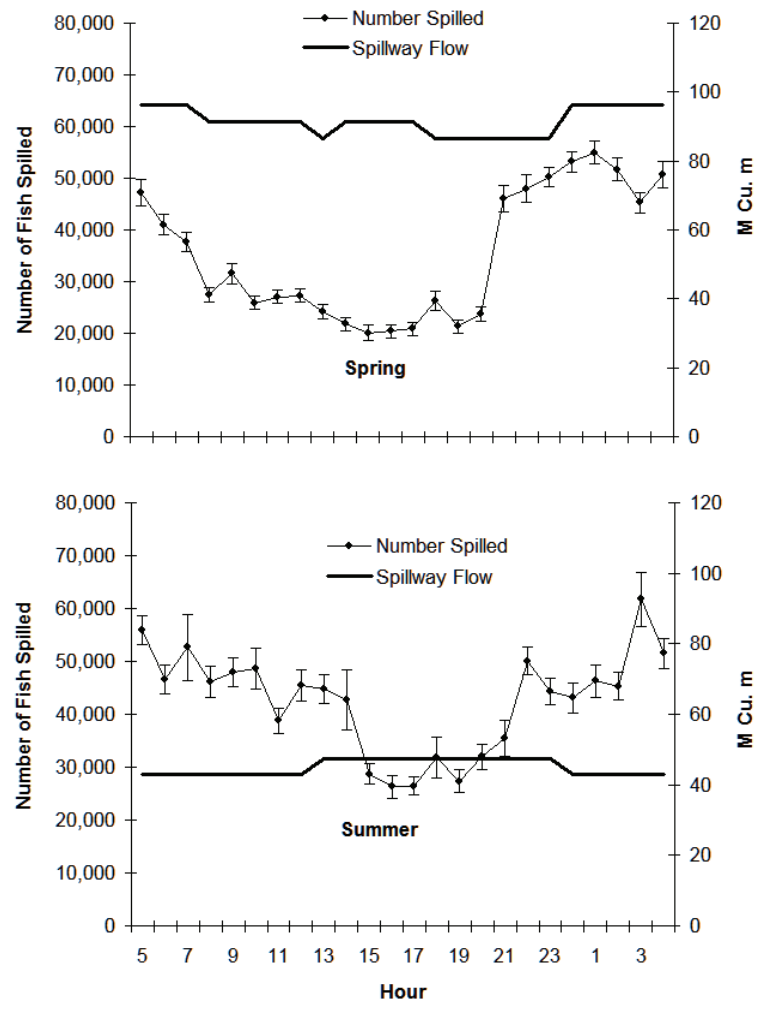

Figure 3.93. Estimates of Diel Trends in Spillway Fish Passage and Spillway Discharge in Spring And Summer 2001 Under Nearly Constant Spill. Error bars represent 95\% confidence intervals. Figure from Ploskey et al. 2002c. 


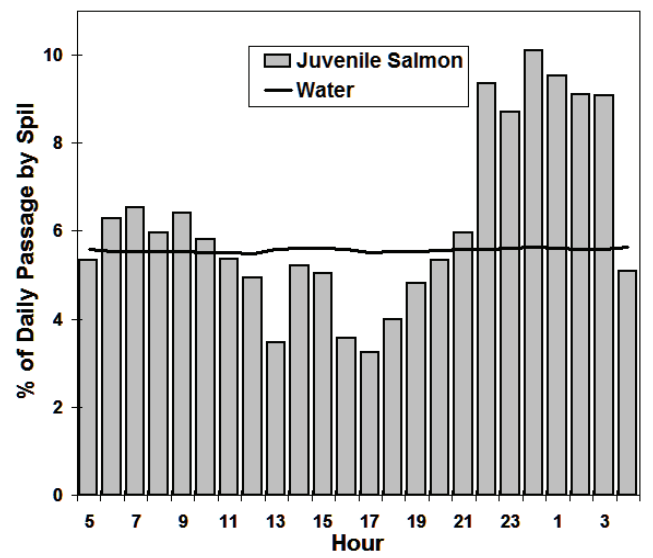

Figure 3.94. Estimated Hourly Spillway Passage and Discharge at Bonneville Dam during Six Days in Summer 2004. From Ploskey et al. 2005.

\subsection{Radio Telemetry}

With the exception of yearling Chinook salmon in 2000, all species passed the spillway at a higher hourly rate at night than during the day in studies conducted from 2000 through 2002. All but one radiotelemetry result in 2004 and 2005 indicated that spillway passage rates were higher at night than they were during the day (Table 3.24). Prior to 2001, diel passage trends based on radio-tagged fish were only reported on a project-wide basis; therefore, structure-specific diel patterns are not available for those years (Holmberg et al. 1996; Hensleigh et al. 1999; Hansel et al. 1999; Plumb et al. 2001). Spillway passage of yearling Chinook salmon in 2001 indicated a diel pattern characterized by a primary mode of passage peaking at $0700 \mathrm{hr}$ and a secondary mode peaking at $1600 \mathrm{hr}$ (Evans et al. 2001c). Only 11 subyearling Chinook salmon passed the spillway in 2001, resulting in an uninformative diel picture of passage (Evans et al. 2001d). Other than day/night differences in passage through the spillway in 2000 and 2002, hourly passage patterns were not reported for the different structures at Bonneville Dam for those years.

Table 3.24. Radio Telemetry Rates of Spillway Passage during the Day and at Night

\begin{tabular}{||cccccc||}
\hline \multirow{2}{*}{ Year } & Tagged Fish & Spill Treatment & Night & Day & Reference \\
\hline \hline 2004 & Yearling Chinook & & 2.8 & 1.7 & Reagan et al. \\
2005 & Yearling Chinook & & 2.9 & 1.7 & Adams et al. \\
2004 & Steelhead & & 0.5 & Reagan et al. \\
2005 & Steelhead & & 3.4 & 0.7 & Adams et al. \\
2004 & Subyearling Chinook & Overall & 3.5 & 3.1 & Evans et al. \\
2004 & Subyearling Chinook & Biop Spill & 5.7 & 2.9 & Evans et al. \\
2004 & Subyearling Chinook & 37 kcfs spill & 1.6 & 2.1 & Evans et al. \\
2005 & Subyearling Chinook & Overall & 3.1 & 2.7 & Adams et al. \\
\hline \hline
\end{tabular}




\subsubsection{Surface Flow Outlets}

Most research indicates that a majority of fish pass surface-flow outlets during daylight hours, unlike passage through turbines and the spillway, as described above. The only exceptions that we found were based upon early video camera and hydroacoustic estimates for the B1 sluiceway (Ploskey et al. 1998) and for PSC slots in 1998 (Ploskey et al. 2001a) and for the 5-ft-wide PSC slot in 1999 (Ploskey et al. 2001b). These data were collected before detectability effects of turbulence and light on video samples and of water velocity on fish movement were considered or addressed. Most hydroacoustic estimates for the B1 sluiceway before 2002 were based on samples upstream of the sill and included very few entrained fish. Therefore, those estimates were not reliable because uncommitted fish could be detected more than once. We suspect that is why some hydroacoustic estimates for fish detected upstream of PSC slots in 1998 appeared to be higher at night than they were during the day (Ploskey et al. 2001b). Recent DIDSON video clips (Ploskey et al. 2006c) show that smolts hold in loose schools upstream of the B1 sluiceway at night and are more hesitant to enter the B1 sluiceway at night than they are during the day. If the same hesitation to enter upstream of the 5-ft-wide-PSC slot at night would lead to multiple counting that would be less likely to occur during the day.

\subsection{B1 Sluiceway}

Willis and Uremovich (1981) fished a fyke net in the B1 sluiceway outlet at Unit 1 and found that $82 \%$ of all yearling salmonids passed during the day between 1700 and 1900 hours. They presented diel plots for yearling Chinook salmon, coho, steelhead, and sockeye, and each plot indicated predominant passage during daylight hours. The very first reliable hydroacoustic estimates of passage into the B1 sluiceway were reported in 2004 (Figure 3.95) and 2005 (Figure 3.96), and both show higher passage during the day than at night.
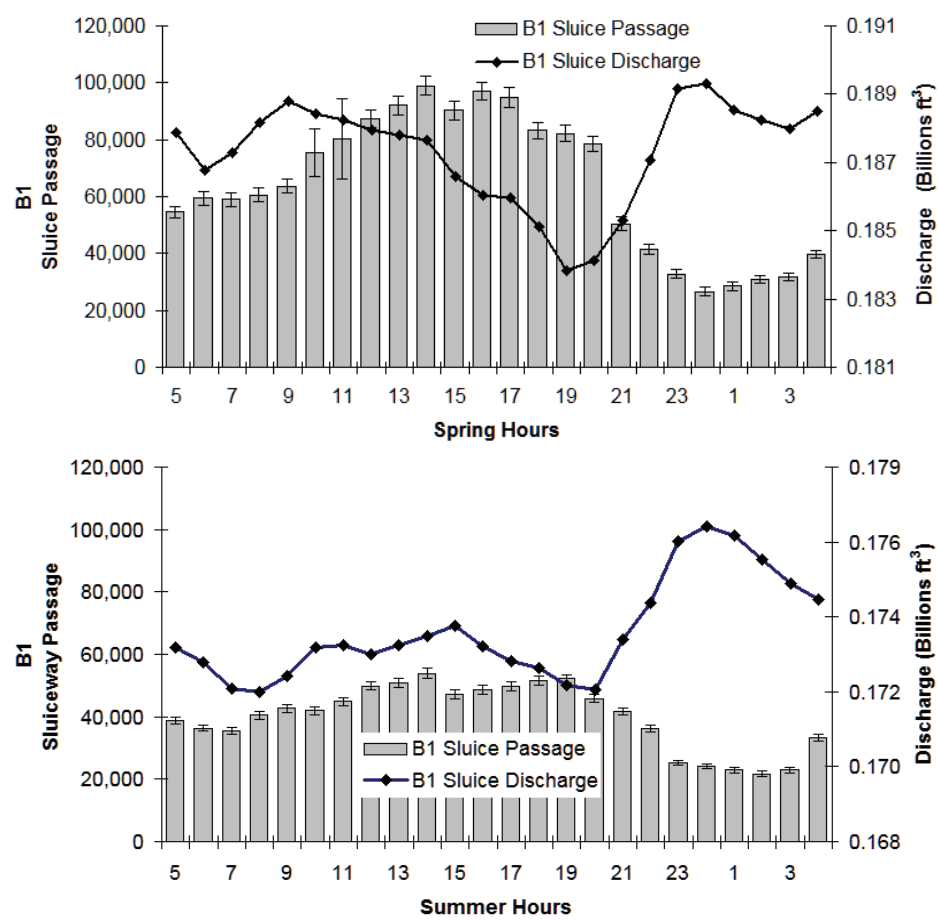

Figure 3.95. Diel Trends in B1 Sluiceway Passage in Spring (Top) and Summer (Bottom) 2004. Plots were adapted from Ploskey et al. 2005. 

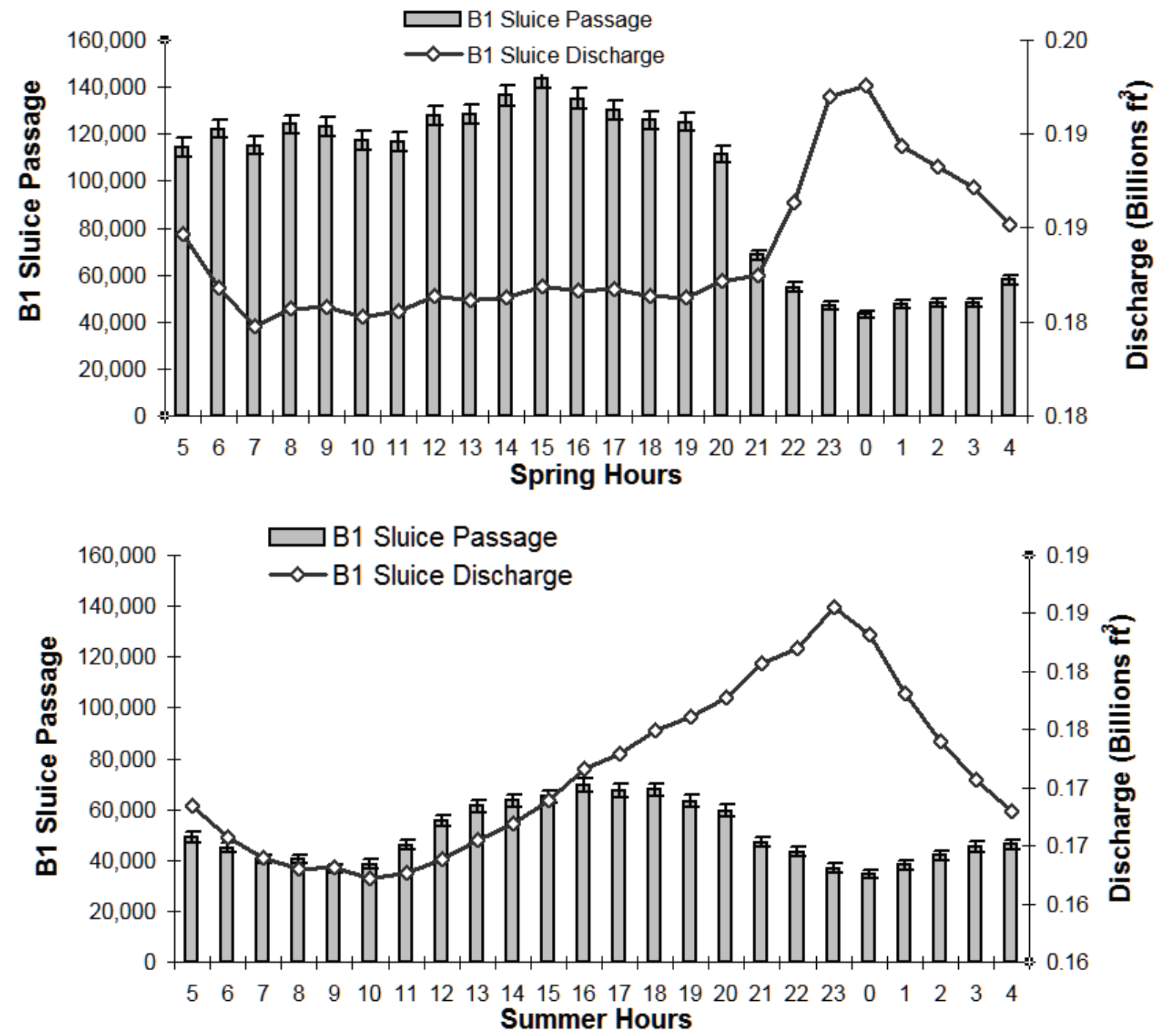

Figure 3.96. Diel Trends in B1 Sluiceway Passage in Spring (Top) and Summer (Bottom) 2005. Plots were adapted from Ploskey et al. 2006c.

\subsection{Prototype Surface Collector}

Hydroacoustic data from 1998 and 2000 indicated that detections of fish upstream of the 20-ft-wide PSC slots were much higher during the day than they were at night (Figure 3.97 and 3.98), although this was not true for detections upstream of the 5 - $\mathrm{ft}$ wide slot, for unknown reasons. These data undoubtedly were subject to bias because fish were not entrained when detected. However, Evans et al. (2001a) also reported that most steelhead and yearling Chinook salmon entered the 20-ft-wide entrance slot during the day (Figure 3.99). Sixty-nine percent of steelhead entered the PSC during daylight hours, and passage of steelhead into the PSC peaked during the crepuscular period. Likewise, $83 \%$ of Chinook salmon entered the PSC during daylight hours. Passage of yearling Chinook salmon into the PSC peaked during midday. Evans et al. (2001b) reported that $85 \%$ of subyearling Chinook salmon entered the PSC during the day. 
Guided Fish - 20-ft Slot
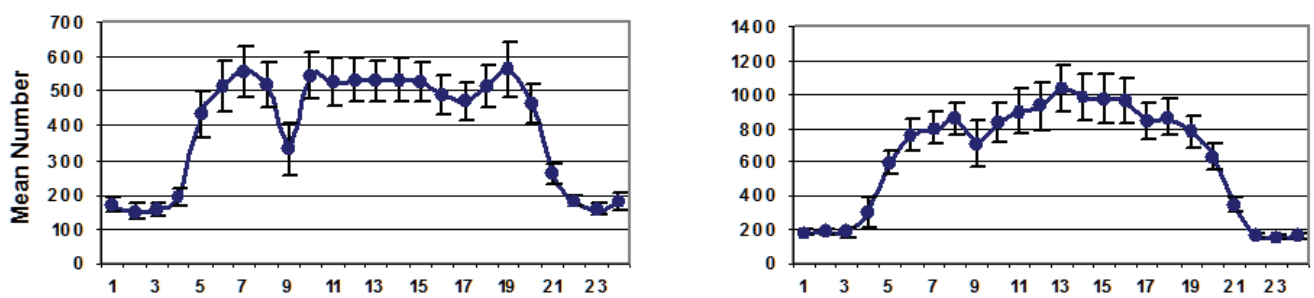

Guided Fish - 5-ft Slot
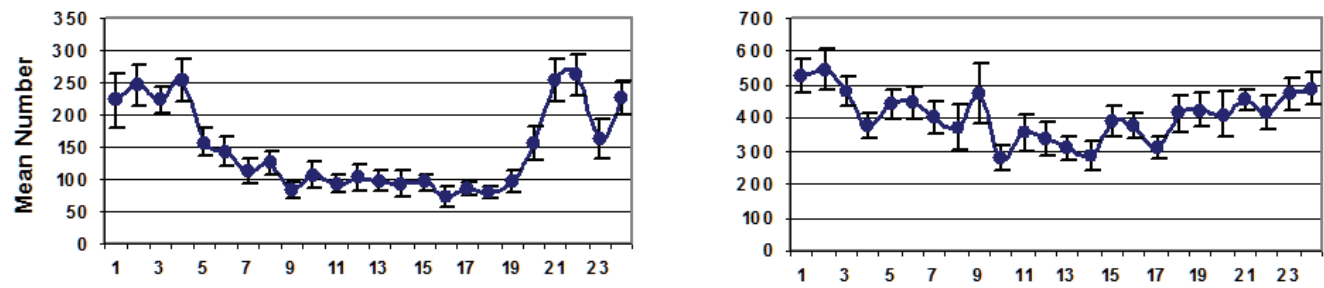

Figure 3.97. Estimated Mean Hourly Passage into the 20-ft and 5-ft Wide Slots in the PSC in 1998 (from 'Ploskey et al. 2001a).
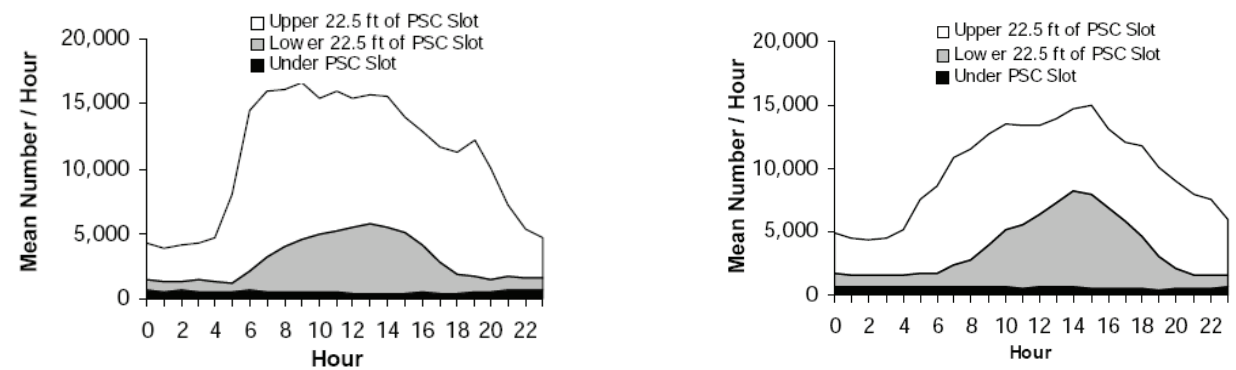

Figure 3.98. Estimated Mean Hourly Passage into the 20-ft Wide Slot in the PSC in 2000 (from Ploskey et al. 2002b).

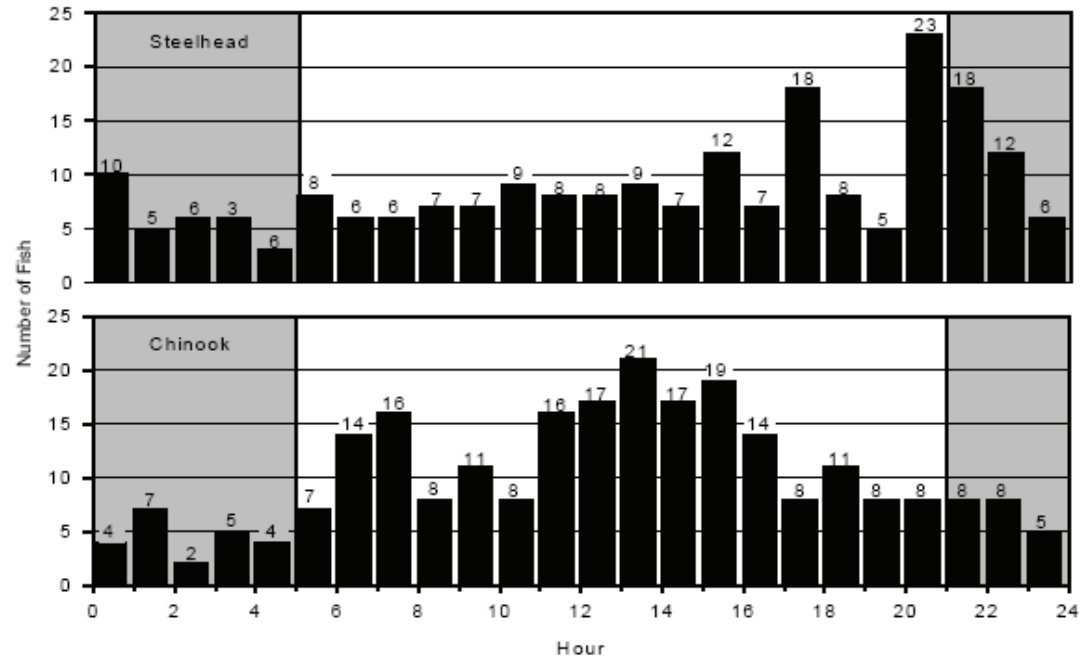

Figure 3.99. Number of Steelhead and Yearling Chinook Salmon that Entered the PSC by Hour of Day during Spring 2000. From Evans et al. 2001a. 


\subsection{B2 Sluice Chute / B2CC}

Like other surface passage routes at Bonneville Dam, the B2 sluiceway outlet (B2 sluice chute before 2004 and B2CC thereafter) has a daytime dominated diel pattern of fish passage. The first reported diel passage data for Bonneville Dam was that of Magne et al. (1986), who noted that sluice chute passage in 1986 during the period June 11-14 was highest during daylight hours as compared to hours of darkness. However, Magne et al. (1986) stated that this trend might have been influenced by operations since B2 was only operated from 0700-2000 hr during the period of sampling. In 1997, fish passing the sluice chute exhibited a peak in passage during the day between 0800 and 1100 hours in the spring with a secondary mode between 1800 and 2100 hours (BioSonics 1998). During summer 1997, passage was characterized by a morning primary peak between 0600 and 0900 hours, and the fewest fish passed between 2100 and 2200 hours (BioSonics 1998). Diel patterns of sluice chute passage in 1998 were characterized by higher counts during the day and considerably fewer fish passing at night during spring and summer (Figure 3.100). In 2004 and 2005, the diel patterns of the B2CC continued to have higher passage during the day than at night (Figure 3.101; Ploskey et al. 2005, 2006c).

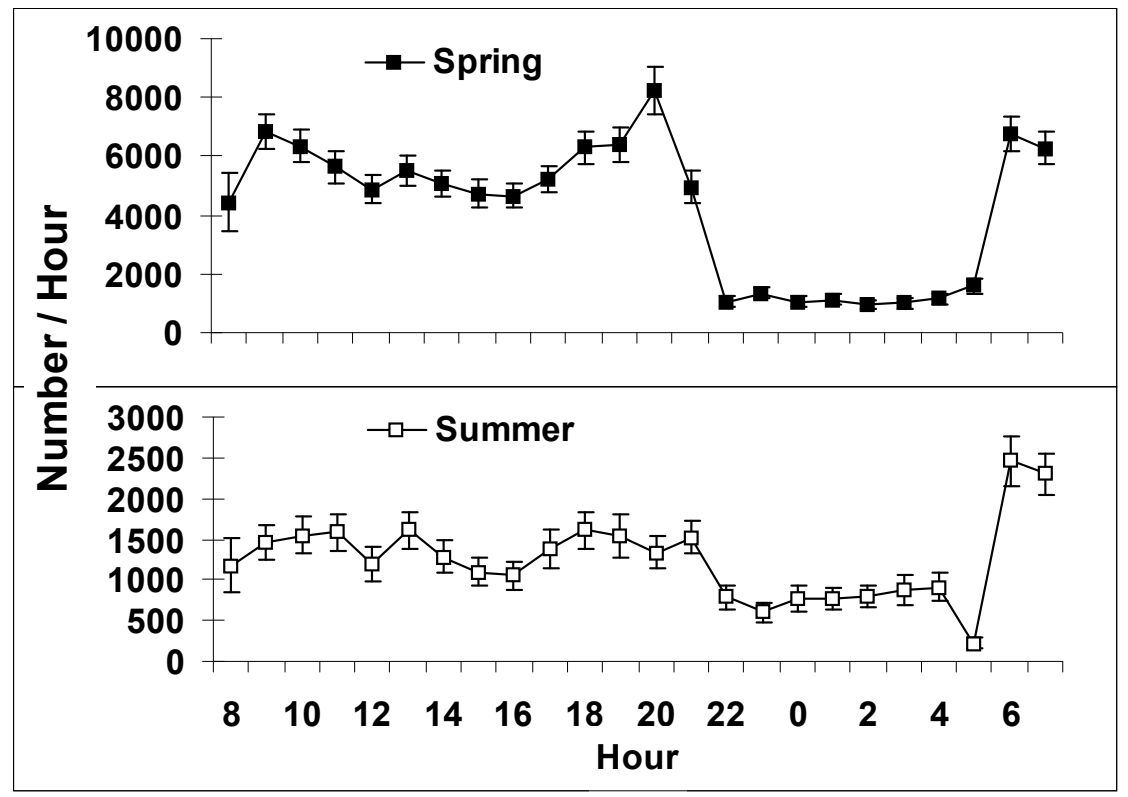

Figure 3.100. Diel Trends in Hourly Passage of Fish through the Sluice Chute at B2 in Spring and Summer 1998. Note the vertical scale for spring is three times greater than for summer. Error bars denote $95 \%$ confidence intervals on estimates. Figure from Ploskey et al. 2001a.

\subsubsection{Synthesis and Conclusions}

After reviewing the body of work conducted over the last 20 years assessing the distribution of fish passage at Bonneville Dam, we offer the following synthesis and conclusions.

\subsubsection{Horizontal Distributions}

The proportion of fish passage through B1, the spillway, and B2 was nearly proportional to discharge at each location. This observation was consistent throughout five years of full-project-passage assessment based upon both radio telemetry and hydroacoustic techniques. 
Distributions of fish associated with passage through various routes within B1, the spillway, and B2 depend on discharge in that fish cannot pass through routes that are closed. This is why patterns of fish passage through B1 turbines varied a lot after the powerhouse priority was shifted to B2 in 2001 and thereafter. Different units were running in different years depending upon unit priority and outages for retrofitting or maintenance. The general correspondence between fish passage and discharge can be seen in parts of Figures 3.54 and 3.56, although exceptions are there as well (e.g., bays 1-4 in Figure 3.54).

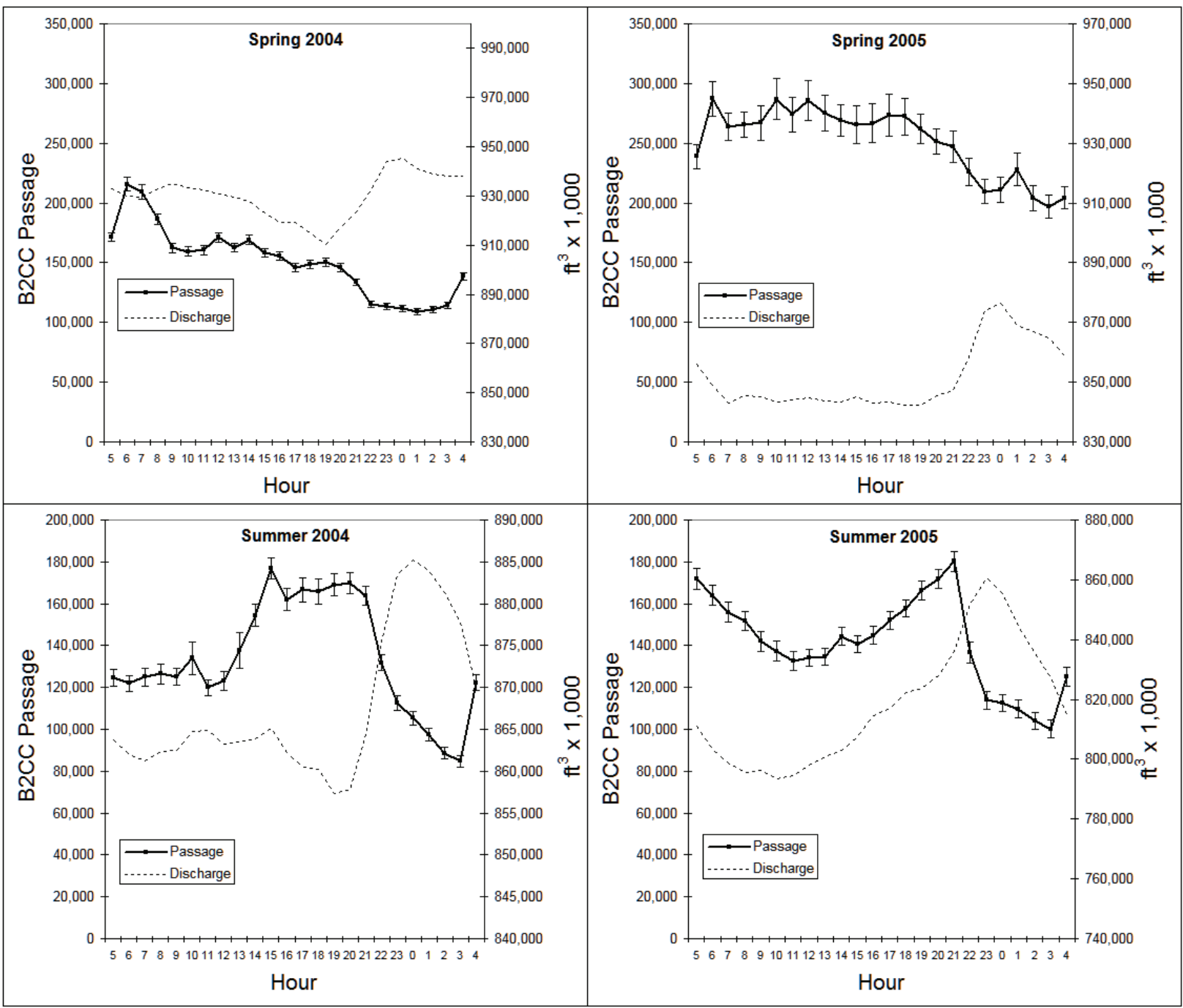

Figure 3.101. Diel Trends in Hourly Passage of Fish through the B2CC in Spring and Summer of 2004 and 2005 . Error bars denote $95 \%$ confidence intervals on estimates. Figure adapted from data in Ploskey et al. 2005, 2006c.

Horizontal distributions should always be plotted with route-specific discharge and interpreted in that context, something that was not always done in reports before 2004. The addition of discharge to distribution plots allows readers to get a sense of whether or not distributions were driven by project operations. Without plotting or considering the route-specific distribution of discharge, one might conclude that the fish passage distribution across B1 from 1996 to 2002 were simply not uniform or consistent. Distributions of passage varied across years and seasons, with units north of the wing wall 
passing the majority of fish in some years (e.g., in 1996, Holmberg et al. 1996, and 2001, Ploskey et al. $2002 \mathrm{c}$, and units south of the wing wall passing the most fish in other years, e.g., in 2000, Evans et al. (2001a, b).

However, the general relation between discharge and passage breaks down for surface flow outlets, because juvenile salmonids apparently preferentially select these surface routes over other, deeper routes. This selection leads to high measures of effectiveness (high efficiency with low water proportions). This is very evident in plots of the fish density of passage by route (Figures 3.52, 3.55, and 3.57). Surface passage routes have much higher efficiency at low flow proportions than do either the spillway or turbines (Figure 3.13).

Like the sluiceway at $\mathrm{B} 1$, the $\mathrm{B} 2 \mathrm{CC}$ is a highly effective route of passage, clearly passing many more fish than any turbine unit and exponentially more on the basis of fish per unit of discharge. Lateral passage into the $\mathrm{B} 2 \mathrm{CC}$ is not uniform. A majority of fish pass in the middle relative to the north and south sides, at least near the water's surface, where most fish are distributed. Intake piers from units 11 through 13 shed vortices and create turbulence that has an unknown effect on B2CC performance. Spare trash racks with plywood blocks on the upstream surfaces could be dropped into trash-rack slots in units 11 and 12 on top of existing trash racks to reduce shedding of turbulent flow. The blocked racks would act as cheap fillers for the space between piers and could be put in and removed to create treatments that could be evaluated. The turbulence shed from piers tends to push flow away from the powerhouse face, and this could increase passage of fish into the north eddy instead of into the B2CC.

Non-uniformity of passage across openings to surface flow outlets was typical. Distributions of fish passing over chain gates at B1 sluiceway outlets sometimes favored the middle and sometimes edges near piers according to video camera counts and later according to hydroacoustic counts after hydroacoustic sampling became reliable (after 2001). Acoustic camera (DIDSON) images of fish entering these outlets reveal a dynamic seemingly unpredictable process mediated by time of day, vortices to the turbine below the opening, and other hydraulic characteristics, as well as the original direction of approach by fish (Ploskey et al. 2006c). The same was true for the lateral distribution of fish entering the PSC and the $\mathrm{B} 2 \mathrm{CC}$, where lateral distribution sometimes varied with depth.

The distribution of fish passage among bays with different spill deflector types may be more important than north or south skews in spillway passage distributions, both of which have been reported. Survival data suggest that fish passing through bays with older 14-ft-elevation deflectors may have lower survival than fish passing through bays with the new 7-ft-elevation deflectors (Counihan et al. 2003, 2006a). If passage among bays were uniform, we would expect $67 \%$ of fish to pass through bays with the older, apparently less fish-friendly deflectors. However, 2004 and 2005 operations apparently reduced the percentage passing through bays $4-15$ by $6-9 \%$ from what would be expected. Hydroacoustic data indicated that $57 \%-60 \%$ of fish passage was through bays $4-15$ instead of $67 \%$. Since discharge patterns appear to be partially responsible for trends in spillway passage distributions (see Figure 3.54 and 3.56), some tweaking of discharge to reduce the percent passing through bays with old spill deflectors may be warranted. Spill patterns were changed in 2002, and new patterns spill slightly more on the ends than in the middle of the spillway, and this apparently slightly favors passing fish through bays with 7-ft elevation deflectors. 
Numbers of radio tagged fish detected at the spillway each season between 1996 and 1999 were only sufficient to provide a broad description of passage trends by north and south halves of the structure, and estimates in later studies were reported only as a proportion of total project passage. At best, skews in spillway passage distributions could be described as weak in most years, with just over $50 \%$ to $65 \%$ of fish favoring one half of the spillway or the other.

Almost all hydroacoustic and radio telemetry studies reflect a strong skew toward the south end of the powerhouse. With very few exceptions across season, year, or methodology, units 11-14 (especially units 11 and 12) passed the majority of fish as compared to units 15-18 on the north half of B2. As with lateral fish passage across intakes at B1, distributions across turbine intakes at B2 were not uniform. Leaving TIEs out from unit 11 through 14 undoubtedly facilitates a strong southerly flow of water along the powerhouse face toward the $\mathrm{B} 2 \mathrm{CC}$, and this is highly desirable for increasing fish passage at the $\mathrm{B} 2 \mathrm{CC}$. The TIEs retained on every other intake from Intake 15A through $18 \mathrm{~B}$ help break up the flow toward the north eddy and likely increase passage and FGE at intakes between TIEs.

Turbine-intake extensions have created some predictable patterns in passage among intakes at B2, although horizontal distributions across intakes of the same turbine typically were not uniform or predictable based on hydroacoustic sampling at B1. Discharge through Bonneville Dam turbines typically is highest at the south (A) intake, intermediate at the middle (B) intake, and lowest at the north (C) intake, but passage seldom follows the discharge pattern. Hydroacoustic data have sometimes shown about $10 \%$ higher passage through intakes between TIEs than intakes behind TIEs at B2 (e.g., Ploskey et al. 2002c; Ploskey et al. 2003). In 2002, the B and C slots of B2 units and those intakes between TIEs at B2 had significantly higher FGE than did A slots or intakes behind TIEs, respectively. This probably is because two adjacent TIEs create vortices between them, and vortices funnel fish down the face of the dam where they enter high in the intake and are easily guided. In 2002, the B slot of Unit 17 had a higher FGE than did the C slot, and this likely was because the B slot was between two TIEs. Monk et al. (1999b) noted that FGE for yearling Chinook salmon increased 20\% for intakes between TIEs.

\subsubsection{Vertical Distributions}

A number of investigators have assessed the vertical distribution of fish upstream of passage structures, but those data do not accurately reflect distributions of fish committed to passage. About 100 $\mathrm{ft}$ upstream of trash racks at B2, fish were distributed very high in the water column, and those distributions seemed contrary with low in-turbine estimates of FGE (Ploskey et al. 2002a) but were fairly consistent with vertical distribution estimates for the B2CC (Ploskey et al. 2005, 2006c). Fish upstream of the PSC and immediately upstream of B2 trash racks were less highly skewed toward the water's surface (Ploskey et al. 2002a and 2002c).

The vertical distribution at surface flow outlets first depends upon the depth of the outlet. The B1 sluiceway is very shallow and yet highly efficient, consistently passing over $33 \%$ of B1 fish passage, when B1 is not the priority powerhouse. When the 40-45 ft deep PSC took fish at all depths although slightly more entered in the upper half than the lower half, and the PSC also was highly efficient and effective. Given that the vertical distribution of fish in B1 turbines is not skewed toward the top of the intake and fish occur a many depths, the depth of the PSC was not wasted. At the PSC, entrance depths varied by species and time of day according to radio telemetry. The vertical distribution of passage at the 
B2CC is highly skewed toward the surface of the water, even though about $24 \mathrm{ft}$ of depth is available for passage.

At the spillway, the vertical distribution of passage peaks within a few feet above the elevation of the ogee crest, and this could be undesirable in terms of survival. Fish passing deep and close to the ogee sometimes experience higher incidence of injury and mortality than fish passing from higher in the water column (Thomas Carlson, Personal Communication).

In-turbine distributions at both B1 and B2 are not highly skewed toward higher elevations as they often are at upstream hydropower projects. There also is evidence of a skew toward both higher and lower elevations at B1 intakes, especially in summer (e.g., Ploskey et al. 2002c). In-turbine vertical distribution data are generally consistent with FGE estimates that are $50 \%$ or less.

\subsubsection{Diel Distributions}

It is easiest to talk about diel distribution by type of passage route (turbines, spillway, and surface passage outlets) because trends are more apparent and consistent than they are by structure (B1, B2, and the spillway). However, it is very important to differentiate between diel patterns that are driven by diel shifts in project operations and discharge and natural patterns that occur when operations are relatively constant.

The diel patterns of passage through turbines and the spillway suggest that some fish may be holding in forebay areas during the day and passing at night, although short radio telemetry residence times suggest that holding cannot be prolonged (a few hours at most). Nevertheless, the crepuscular peaks in passage in bypass systems, fyke net samples, and hydroacoustic samples would only result if some delay occurred. The loss of visual position cues may be responsible for increased fish passage into turbines just after sunset because smolt passage at turbine units is not a function of increased flow at that time.

\subsection{Turbines}

When turbines run 24 hours per day, fish passage usually is crepuscular with peaks occurring after sunset and about dawn, and passage usually is higher at night than it is during the daytime. These trends are not unlike what can be observed for JBS data except that there is a delay of several hours in the observed peaks for JBS data since fish may delay in gatewell slots. When turbines dominate project operations, as they did in 2001, similar diel patterns can be observed for total project passage, but in general a single turbine running the same discharge 24 hours per day provides the best look at a typical diel pattern.

Atypical diel patterns of passage at turbines result from turbines not running consistently over a diel cycle, so it is important to show discharge on diel plots, if turbine operations are unknown. Turbine discharge and fish passage at B1 in spring and summer 2005 provide a good example of an atypical diel pattern driven by turbine operations (Figure 3.87; Ploskey et al. 2006c). These diel patterns are of interest because they show the degree to which diel patterns can be altered by operations. Another atypical example of a diel trend for turbine passage was observed in B2 turbine passage in summer 2005, when most turbines between units 11 and 18 were shut down to provide water for increased spill at night. 


\subsection{Spillway}

In a couple of cases when discharge was held constant throughout 24-hour periods (e.g., during the drought of 2001 and for six days in summer 2004), hourly passage estimates clearly indicate that nighttime-dominated diel patterns are not entirely due to increased discharge at night. In the drought year of 2001, when spill was nearly constant 24 hours per day, Ploskey et al. (2002c) described diel trends with a decline during daylight hours, an increase at 2100 hours in spring and 2200 hours in summer (Figure 3.93). Except for those periods of constant discharge for 24 hours, separating a natural diel pattern of passage at the Bonneville Dam spillway has been difficult because discharge usually is much higher at night and spill efficiency is directly correlated with discharge. With the exception of yearling Chinook salmon in 2000, all other studies of radio-tagged fish showed higher hourly rates of spillway passage at night than during the day.

\subsection{Surface Flow Outlets}

Most research indicates that a majority of fish pass surface flow outlets during daylight hours, unlike passage through turbines and the spillway described above. Netting data by Willis and Uremovich (1981), hydroacoustic data collected after 2001, and DIDSON video clips all indicate that B1 sluiceway passage is higher at night than it was during the day. Results for the 20 -ft-wide slot at the PSC showed higher passage at night than during the day based upon hydroacoustic sampling (Ploskey et al. 2001b, 2002a and b) and radio telemetry sampling (Evans et al. 2001a; Evans et al. 2001b). The B2 sluiceway outlet (B2 sluice chute before 2004 and B2CC thereafter) had a daytime-dominated diel pattern of fish passage (Magne et al. 1886; BioSonics 1998; Ploskey et al. 2001a; Ploskey et al. 2005, 2006c).

The predominance of fish passage through surface routes during the day indicates that smolts are readily entering those outlets, but DIDSON video indicates that smolts often are holding upstream of outlets at night. Day and night DIDSON recordings of smolt behavior upstream of the B1 sluiceway in 2005 (Ploskey et al. 2006c) certainly support the nighttime holding hypothesis for that location. Not only were smolts holding in large, loose schools at night, they were subjected to intensive predation, whereas during the daytime, tight schools of smolts readily entered B1 Sluiceway Outlet 3C and predation events were relatively rare. Similar recordings showing increased holding and predation at night in the south eddy upstream of the B2CC were recorded in 2004. 


\subsection{Survival}

\subsection{Dam and Project Survival}

Shortly after the Bonneville Dam first powerhouse (B1) and spillway were built, efforts were initiated to estimate the passage effects on downstream migrating salmon. Holmes (1952) analyzed data collected during a series of experiments conducted between 1939 and 1945. In two of those years, treatment fish were released about five miles upstream from the dam, from either the Washington or Oregon shores in different years. Control groups were released in either the powerhouse tailrace or spillway tailrace in different years. Survival from release sites to the tailrace of the dam was estimated from adult recoveries of fin-clipped fish at hatcheries and fisheries (Table 4.1). Mortality passing the dam was estimated at $11 \%$ to $15 \%$ ( $85 \%-89 \%$ survival), depending on the analytical method Holmes (1952) applied, and was also likely influenced by the mix of release and control sites used in the different study years.

Not until 1999 was there another attempt to empirically estimate smolt survival passing the dam as a unit. Using radio-tagged yearling Chinook salmon, Counihan et al. (2002a) estimated survival from the face of the dam to the control release site below the new B2 JBS outfall at 96\%. However, they cautioned that their estimate may be biased high. They noted that independent tests revealed some known dead fish bearing active tags that were intentionally released in the tailrace were subsequently detected at the detection arrays downstream. Detection of those fish indicated that one of the primary assumptions of the survival model had been violated.

In 2001, Counihan et al. (2002b) again used miniaturized radio tags to estimate smolt survival from Hood River, Oregon, to the tailrace of Bonneville Dam below the JBS outfall. Mean survival was estimated as $0.937($ S.E. $=0.014)$ and $0.902($ S.E. $=0.036)$ for yearling and subyearling Chinook salmon, respectively. These estimates reflect total effects incurred during passage. Overall, subyearling Chinook salmon survived at lower rates than yearlings. This is consistent with observations from other dams. As a cautionary note, these estimates reflect survival through only a portion of the entire hydroelectric project, since fish were released at Hood River and not the tailrace of The Dalles Dam. Also, the point estimates reported in this document (July 10, 2002; Final Draft) likely over-estimate the actual survival. As in the previous year, they observed that 1 of 30 known dead tagged fish of each species were detected at the downstream detection sites (i.e., false positive detections were verified).

In 2002 (Counihan et al. 2003) found that survival of yearling Chinook salmon passing the dam was the highest observed to date. Estimated survival from the face of the dam to the location of the JBS outfall was 0.977 (S.E. $=0.019)$. Unlike previous years, no known dead tagged fish were observed at downstream transects. Also, this was the first year they used a double detection array at the dam to yield a Lincoln Index for use in estimation models.

In 2004 and 2005, species coverage was broader (Table 4.1). Estimates of dam survival were generally high during these years, ranging from $93.8 \%$ to $-99.1 \%$ across all species. Whether these 
should be treated as absolute estimates is uncertain. But given difficulties observed with false positives in previous years, it would be more conservative to use them as relative estimates.

Table 4.1. Smolt Survival Passing Bonneville Dam, or Partial-Project Survival (Part of the Pool and Dam). In some cases, partial-project estimates were calculated and noted in the table. These all reflect total effects.

\begin{tabular}{|c|c|c|c|c|}
\hline Year & Species & $\begin{array}{c}\% \text { Survival } \\
\text { (SE) }\end{array}$ & Coverage & Investigators \\
\hline $\begin{array}{r}1939- \\
1945\end{array}$ & Fall Chinook & $85-89$ & $\begin{array}{c}5 \text { miles upstream to } \\
\text { tailrace }^{1}\end{array}$ & Holmes (1952) \\
\hline 2000 & $\begin{array}{l}\text { Yearling } \\
\text { Chinook }\end{array}$ & 96.0 & $\begin{array}{c}\text { Face of dam to below JBS } \\
\text { outfall }\end{array}$ & Counihan et al. (2002a) \\
\hline 2001 & $\begin{array}{l}\text { Yearling } \\
\text { Chinook }\end{array}$ & $93.7(1.4)$ & $\begin{array}{c}\text { Hood River, OR to JBS } \\
\text { outfall }\end{array}$ & Counihan et al. (2002b) \\
\hline 2001 & $\begin{array}{l}\text { Subyearling } \\
\text { Chinook }\end{array}$ & $90.2(3.6)$ & $\begin{array}{c}\text { Hood River, OR to JBS } \\
\text { outfall }\end{array}$ & Counihan et al. (2002b) \\
\hline 2002 & $\begin{array}{l}\text { Yearling } \\
\text { Chinook }\end{array}$ & $97.7(1.9)$ & $\begin{array}{c}\text { Face of dam to JBS } \\
\text { outfall }\end{array}$ & Counihan et al. (2003) \\
\hline 2004 & $\begin{array}{l}\text { Yearling. } \\
\text { Chinook }\end{array}$ & $95.1(0.8)$ & " " & Counihan et al. (2006a) \\
\hline \multirow{4}{*}{2005} & Steelhead & $99.1(0.8)$ & " $"$ & " $"$ \\
\hline & $\begin{array}{l}\text { Yearling } \\
\text { Chinook }\end{array}$ & $96.6(0.7)$ & $"$ " & Counihan et al. (2006b) \\
\hline & Steelhead & $96.3(0.7)$ & " $"$ & " $"$ \\
\hline & Sub. Chinook & $93.8(0.7)$ & $"$ " & " $"$ \\
\hline
\end{tabular}

The telemetry-based survival estimates from the modern era (2000-2005) are all higher than survival estimates reported during the 1940s. This may not be surprising since numerous passage improvements in the form of bypasses and plant operations have been tested and adopted over the decades.

Additionally, the estimates of Holmes (1952) include any delayed passage effects that might have existed and not been expressed until later in life. Even so, at least some of the dam survival estimates reported for the modern era may overstate passage survival to some extent because, in some years, dead fish bearing active tags were detected at downstream detection arrays. If radio-telemetry or any active tag methodology is to be accepted as producing an accurate measure of absolute survival, then new downstream detection sites should be established that avert this problem. Alternatively, perhaps a correction factor for false positives can be incorporated into the analytical method. In any event, dam or project survival estimates recently reported for this site may be biased slightly high.

The differences in survival estimates among years could be in part attributable to dam operations. In the drought year of 2001, the percent of water spilled (16\%) was far below levels that occurred in other years like 2000 (32\%) and 2002 (47\%). Later in this document we explore how spill operations can influence survival at Bonneville Dam. 


\subsection{Powerhouse and Turbine Survival}

Survival estimates through a powerhouse are not the same as individual turbine-specific survival estimates. Powerhouse survival reflects effects incurred by a population of fish naturally dispersed and passing through all operating units, not just a single test unit. Thus the estimate is more comprehensive.

Counihan et al. (2002b) reported survival estimates for powerhouse-passed fish in 2001. Using radiotagged yearling Chinook salmon released at Hood River, Oregon, they estimated the overall combined survival of yearling Chinook salmon passing through any turbine unit at Bonneville Dam. Controls were released below the JBS outfall. They reported relative survival as 0.929 (S.E. $=0.02$ ) for all turbinepassed fish. This value was nearly the same as the survival they calculated for non-turbine-passed fish (0.937; S. E. $=0.02)$, which included those collectively using the spillway and bypass systems.

In 2002, Counihan et al. (2003) reported similar types of survival estimates, but not identical to the overall powerhouse-passed category. They estimated survival through B1 and B2 powerhouses separately for radio-tagged yearling Chinook salmon. Total effects relative to control groups released below the JBS outfall were estimated as 0.902 for fish passing B1 and 0.993 at B2. The high survival through B2 and fish passing the entire dam (0.977) may seem unrealistically high to some parties. If dead treatment fish drifted to the recovery sites, this could explain the situation. But the investigators did not report this as being a problem in 2002.

In 2004 and 2005 there was no standard operation in place at Bonneville Dam. Instead, a variety of spill operations were tested to assess effects on route-specific survival, including through the powerhouses. Survival through various routes was affected by prevailing spill test conditions. Thus we do not report a season-wide estimate, since it presents limited insight and may be confusing.

In addition to powerhouse-wide estimates, turbine unit-specific survival estimates are commonly obtained at dams, including Bonneville. These studies usually involve releasing treatment fish through specific turbine units via a hose, paired with control group releases somewhere in the tailrace. Holmes (1952) first estimated survival at Bonneville Dam using this technique. Studies were conducted in June and early July using fin-clipped hatchery fall Chinook salmon. Based on adult recoveries, he estimated that the average survival through a turbine was $88.5 \%$ (11.5\% loss as he reported). This estimate reflects the total effects incurred from the turbine intake to the control site(s) located several hundred meters downstream from either the spillway or powerhouse. However, hose releases may have been compromised since the head on the hose differed for treatment and control releases. Control fish releases had a higher head, which could have inflicted higher mortality based on independent tests, resulting in an overestimate of treatment survival, since the controls may have incurred an additional release-related effect. This point was not prominently noted in the reported results. Also, precision associated with the estimates was relatively poor and therefore statistical tests could not demonstrate a significant difference from an accompanying spill bay survival estimate of $97 \%$.

The next series of investigations that assessed the effects of turbine passage on smolt survival (as part of a much broader research effort) commenced in 1987 and continued in most years through 1992. 
However, the scope of those studies was broad and involved a variety of treatments and reference (control) releases that varied through the years (Dawley et al. 1988 and 1989; Ledgerwood et al. 1990, 1991 and 1994). The NOAA Fisheries conducted these studies using hatchery fall Chinook salmon bearing both freeze-brands and coded wire tags (CWT). Short-term survival was estimated using branded fish recovered with seines near Jones Beach. Long-term survival was to be based on recoveries of CWT at hatcheries and within the fishery. But adult return rates were so low that meaningful comparisons among treatment and reference groups were impractical (Gilbreath et al. 1993).

Typically, survival estimates were not expressed as absolute values referenced to any specific control release. Rather, relative differences in survival among the particular suite of releases became the index of performance. This method was adopted, since over the years it became apparent that the location of the control release affected the magnitude of treatment effects being characterized. Treatments included turbine, bypass, and spillway passage effects, which were determined by releasing marked fish directly into those routes using hoses. Control or reference groups were released at a variety of locations over the years, including the Washington shore near Hamilton Island, offshore in the same area, and in the vicinity of the B2 bypass outfall. This shifting of controls was driven by the previous year's results, which were often surprising and thus posed new management concerns and ultimately new objectives for the ensuing study.

Dawley et al. (1993b) and Ferguson (1993) attempted to draw all of these assorted estimates together by adopting "differences in relative survival among passage routes" as a common currency to view information across years. Dawley's findings on relative survival for B2 in 1987, 1988, 1989, and 1990 and for B1 in 1992 are shown in Table 4.2 (Table 1 from Dawley et al. 1993b).

Important findings from Dawley et al. (1993b) and Ferguson (1993) include the following:

1. At the Bonneville Powerhouse 2 during that era, turbine-passed fall Chinook salmon survived at higher rates than fish using the bypass system.

2. Fish passing through turbines near the ceiling survived at lower rates than deeper fish, but not significantly so.

3. These studies were conducted during the summer, when smolt mortality associated with predatory fish was high. This mortality factor was considered the most likely agent causing the low bypass survival. Predatory fish appeared to be focusing on the concentrated smolt source at the bypass outfall.

4. Survival through the B2 bypass was lower than that observed for any other passage route including the spillway. 
Table 4.2. Differences in Relative Survival between Fish Passing through the Bypass Systems and other Passage Routes at Bonneville Dam based upon Juvenile Recovery Data from Estuarine Sampling (Reproduced from Dawley et al. 1993b).

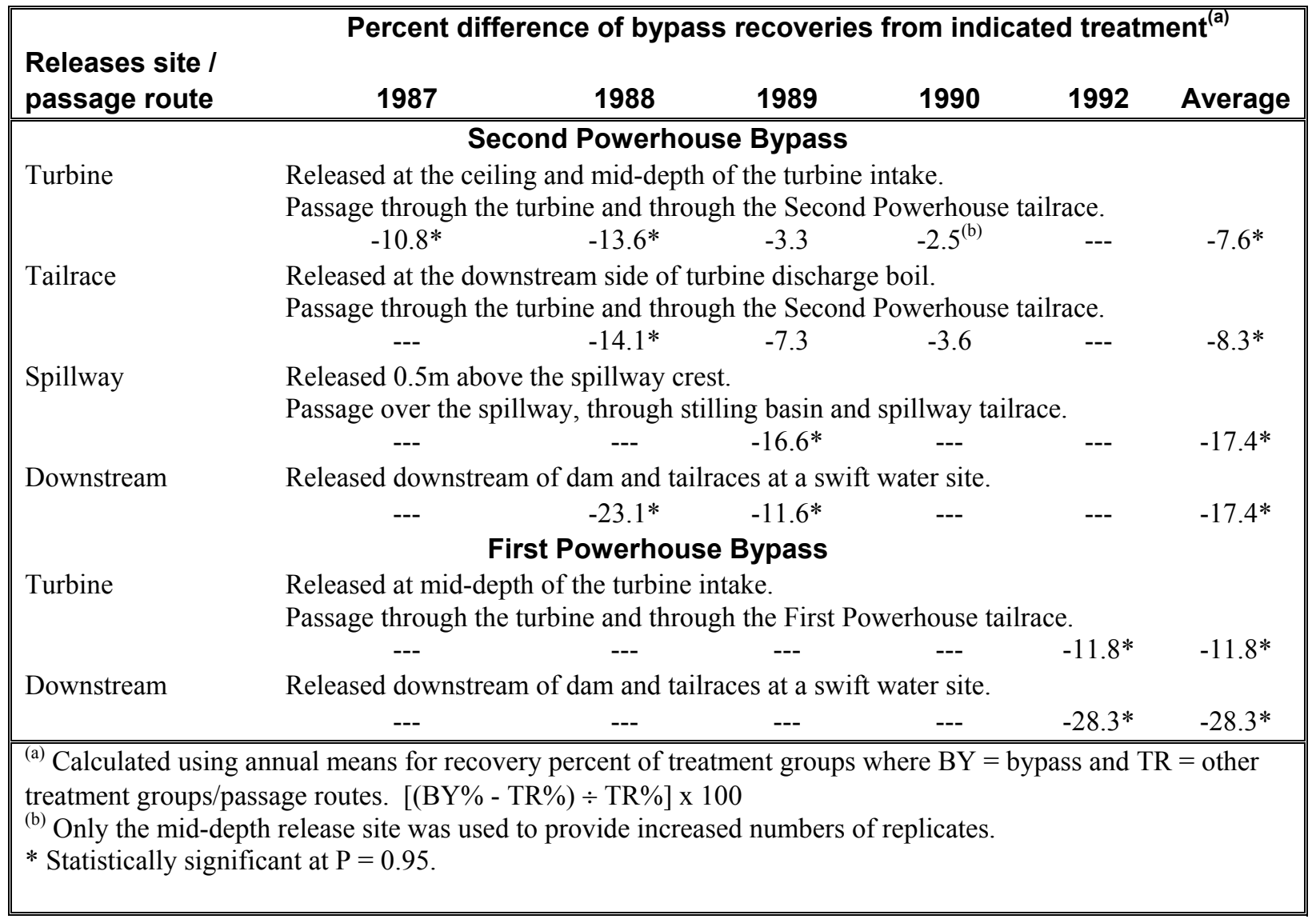

This series of studies illustrates how difficult it can be to assign an absolute value to smolt survival associated with turbine passage or passage through any route at this dam site. Clearly, such estimates are sensitive to the location of control releases. This will complicate matters for managers or modelers who strive to accurately index turbine or powerhouse survival for applications in model analyses.

\subsection{Minimum Gap Runner Turbine Survival}

From November 1999 through January 2000, Normandeau et al. (2000) estimated direct survival through minimum gap runner (MGR) turbines using balloon-tagged Chinook salmon (mean = $166 \mathrm{~mm}$ ). Comparisons with existing turbine units indicated that the MGR yielded equivalent, or perhaps slightly better, survival. Test fish were released at different locations into the turbines (blade tip, mid-blade, and hub) over a range of four power generation levels. Overall, survival was highest for fish released near the hub, then mid-blade, and lowest at the blade tip regardless of turbine type. No significant correlation was found between survival and turbine operating efficiency in either type turbine. 
Table 4.3 shows the average survival across the three blade locations relative to controls released at the exit of the draft tube, which we calculated from data presented in the executive summary of Normandeau et al. (2000).

Table 4.3. Mean Percent Direct Survival in 1999 for Balloon-Tagged Chinook Salmon Passed through a MGR and a Standard Turbine, Calculated from Normandeau et al. (2000). Power level 1 was the lowest and level 4 was the highest level tested.

\begin{tabular}{||cccccc|}
\hline \multirow{2}{*}{ Turbine Type } & Unit & $\mathbf{1}$ & $\mathbf{2}$ & $\mathbf{3}$ & $\mathbf{4}$ \\
\hline \hline Standard-Existing & 5 & 96.0 & 96.4 & 96.5 & 96.0 \\
MGR & 6 & 96.7 & 95.7 & 97.0 & 96.2 \\
\hline
\end{tabular}

The direct survival values in Table 4.3 based on balloon tag data differ substantially from those reported by Counihan et al. (2003). According to Counihan, mean survival through the MGR turbine varied with the release location of the control group. It was either 101\% (control below JBS) or 106\% (control at turbine front-roll; Table 4.4). Even if capped at 100\%, these estimates of total effects do not comport with direct effects reflected in the Normandeau 2000 study. The estimates appear to be biased high and are not representative of actual effects. Some problem with the survival experiment protocol assumptions likely occurred. On the one hand, the passive drift of dead treatment fish to the detection transects would explain the incongruous estimates (although that problem was not reported as being observed with independent releases of tagged, dead fish). Alternatively, control fish may have, for some unexplained or unrecognized reason, incurred greater mortality than turbine-passed fish. This would result in a higher relative survival for the MGR fish. Whatever the cause, the absolute values obviously overstate true survival.

In 2004, Counihan et al. (2006a) again reported survival through MGR units. Survival estimates relative to two control release locations produced unexpected results. The highest survival estimates were obtained using controls released below the JBS, whereas those released in the frontroll produced the lowest survival (Table 4.4). The opposite is expected to occur. When controls are released further downstream, additional tailrace effects should be reflected in the survival estimate.

Skalski et al. (2002) re-analyzed Bonneville Powerhouse 1 balloon-tag data originally reported by Normandeau et al. (2000). Their objective was to describe the relationship between survival and turbine operating (efficiency) levels. They compared survival through a turbine unit (unit 5) at three release locations (blade tip, mid-blade, and near the hub), and four discharge levels. Estimated survival ranged from a low of $90.9 \%$ to $100.9 \%$. The highest survival was associated with hub releases, but no correlation with turbine discharge (or operating efficiency) was evident. Fish released near the blade tip exhibited the lowest survival, with no relationship to discharge (operating efficiency). These results indicate that survival for smolts passing through the powerhouse is sensitive to their spatial distribution within the turbine. 
Table 4.4. Comparison of Turbine Passage Survival Estimates from Several Studies, Reflecting either Direct or Total Effects

\begin{tabular}{|c|c|c|c|c|}
\hline Investigators & $\begin{array}{l}\text { Treatment } \\
\text { Zone }\end{array}$ & $\begin{array}{c}\text { Mean } \\
\text { Survival (S.E.) }\end{array}$ & Species & Comment \\
\hline \multicolumn{5}{|c|}{$\begin{array}{ll}\text { Indirect Effects } \\
\end{array}$} \\
\hline $\begin{array}{l}\text { Counihan et al. } \\
\qquad(2002 b)\end{array}$ & $\begin{array}{l}\text { Collectively all } \\
\text { turbines }\end{array}$ & $0.929(0.02)$ & Y. Chinook & $\begin{array}{c}\text { Non-turbine passed }= \\
0.937 \text { (S.E. }=0.02)\end{array}$ \\
\hline Holmes (1952) & Individual turbines & 0.885 & S. Chinook & \\
\hline Counihan et al. (2003) & Powerhouse 1 & $0.902(0.036)$ & Y. Chinook & \\
\hline Counihan et al. (2003) & Powerhouse 2 & $0.993(0.036)$ & Y. Chinook & \\
\hline \multicolumn{5}{|c|}{ Direct Effects } \\
\hline $\begin{array}{c}\text { Normandeau et al. } \\
\qquad(2000)\end{array}$ & MGR (Unit 6) & $0.957-0.970^{\mathrm{a}}$ & & \\
\hline $\begin{array}{l}\text { Normandeau et al. } \\
\qquad(2000)\end{array}$ & Standard turbines & $0.960-0.965^{\mathrm{a}}$ & & \multirow{4}{*}{$\begin{array}{l}\text { Front roll controls } \\
\text { yielded lowest value } \\
\end{array}$} \\
\hline Counihan et al. (2003) & MGR & $1.01-1.06$ & Y. Chinook & \\
\hline Counihan et al. (2006a) & MGR & $0.956-0.996$ & Y. Chinook & \\
\hline Counihan et al. (2006a) & MGR & $0.952-0.974$ & Steelhead & \\
\hline
\end{tabular}

It is difficult to ascertain whether minimum gap runners provide any substantive improvement in survival, given the suite of estimates currently available. However, in general, the MGR units appear to cause effects similar to the standard units based on the direct comparison reported by Normandeau et al. (2000).

\subsection{Spill Survival}

Through 2002, survival for the entire spillway at Bonneville Dam has only been estimated in one investigation. Counihan et al. (2003) estimated that $97.7 \%($ S.E. $=0.14)$ of the radio-tagged yearling Chinook salmon survived passing the spillway. This value may be biased high for reasons discussed previously.

Survival through individual spill bays has been estimated by several investigators over the decades. Holmes (1952) was the first to conduct such a study. Using the same hose release protocol described previously, he estimated the survival of fall Chinook salmon to average $97 \%$ (3\% loss in his terms). The same cautionary point made for the turbine survival estimates applies here. This value may overestimate actual survival through the spillway, since the author identified differential hose effects between a number of treatment and control releases. 


\subsubsection{Spillway Deflectors}

With the development of spillway flow deflectors for gas abatement in the early 1970s, there was a need to assess the effects of these devices on smolt survival. Freeze-branded hatchery fall Chinook salmon were released into spill gates at the dam in July and August 1974 and subsequently recovered with beach seines at Jones Beach (Johnsen and Dawley 1974). We used their recovery data and calculated survival at $95.8 \%$ for the standard spill bays and $86.8 \%$ for the deflector-equipped spill bays, relative to controls released $1.6 \mathrm{~km}$ below the dam. This was the first indication that the presence of deflectors may decrease survival through the spillway.

Spillway deflectors became the focus of attention during the 1990s as the use of spill as a passage strategy intensified. In 1995, Normandeau et al. (1996) used balloon-tagged hatchery fall Chinook salmon to assess the effects of spillway deflectors at Bonneville Dam. One treatment group was released through a standard spill bay (Spill bay 2) and another group was released through a spill bay fitted with a deflector (Spill bay 4). Control fish were released into the tailrace. Survival through each spill bay was equivalent and was estimated at 1.0. In contrast to the findings of Johnsen and Dawley (1974), no mortality could be attributed to the presence of deflectors, at least under the conditions prevailing in 1995. Furthermore, injury rates through both spill configurations were modest at $1.3 \%$.

The USACE continued to investigate the performance of spillway deflectors across a broader range of operating conditions. At Bonneville Dam, one strategy that was explored was the lowering of deflectors to ensure adequate submergence during low tailwater conditions. An assessment of a modified spillway deflector yielded confusing results in 2002. The intended treatments were one spill bay with a standard deflector (Bay 14) and another with the deflector lowered by seven feet (Bay 16). However, the amount of water discharged through each spill bay was different over the course of the investigation. Spill bay 16 consistently passed higher volumes of water, often ranging from 1,000 to 2,000 cfs more than Spill bay 14. Furthermore, two different spill regimes were examined ( $75 \mathrm{kcfs}$ and a gas cap) during both the spring and summer tests. Results from Normandeau et al. (2003) were summarized as reported here (Table 4.5).

Significant differences in spill bay survival were not discernable at the precision levels attained. That may be moot since effects from deflector position may have been masked by the different flow volumes discharged through each spill bay. Apart from the main study objective of testing deflector types, a comparison of survival at the two spill regimes (high and low tailwater) indicated that during the summer, when the tailwater was low and temperatures were warm, estimated survival at the gas cap was near $100 \%$ and appeared considerably higher than the $88.6 \%$ survival observed at the $75 \mathrm{kcfs}$ spill level. No clear, solid explanation was offered other than the implication that some gross spill volume effect may have occurred that was specific to the location of those particular spill bays.

In 2004, this matter was further examined using radio-tagged smolts (Counihan et al. 2006a). Three species, two spill conditions, and two deflector elevations were investigated. Results were mixed (Table 4.6). At the existing deflector elevation, survival was poor for all species at the nominal $75 \mathrm{kcfs}$ spill 
level. Even the $7 \mathrm{ft}$ deflector yielded suboptimal survival at $75 \mathrm{kcfs}$. Thus, the $75 \mathrm{kcfs}$ condition does not appear to be the preferred operation in any season. With respect to spill level, the nominal gas cap yielded the highest estimates during the spring. But in the summer, the $75 \mathrm{kcfs}$ spill condition produced higher survival. We use the term "nominal" here because the actual spill levels prevailing during the study were subsequently found to be in error and were recalculated by the USACE. Counihan et al. (2006a) reports that the spill discharge was generally $20 \mathrm{kcfs}$ less than what had been reported

Table 4.5. Survival Estimates for Balloon-Tagged Chinook Salmon at Two Deflector Elevations and Spill Levels (Data from Normandeau et al. 2003)

\begin{tabular}{|c|c|c|c|c|}
\hline \multirow[t]{2}{*}{ Tailwater Condition } & \multicolumn{2}{|c|}{$\begin{array}{c}\text { Spill bay } 14 \\
\text { Existing Deflector } \\
\text { Lower Discharge }\end{array}$} & \multicolumn{2}{|c|}{$\begin{array}{c}\text { Spill bay } 16 \\
\text { 7' Lowered Deflector } \\
\text { Higher Discharge }\end{array}$} \\
\hline & $75 \mathrm{kcfs}$ & Gas Cap & $75 \mathrm{kcfs}$ & Gas Cap \\
\hline $\begin{array}{l}\text { High Tailwater } \\
\text { (Spring - Cool) }\end{array}$ & 97.9 & 98.6 & 95.9 & 99.0 \\
\hline $\begin{array}{c}\text { Low Tailwater } \\
\text { (Summer - Warm) }\end{array}$ & 90.5 & 1.0 & 88.6 & 1.0 \\
\hline
\end{tabular}

However, there are further considerations that complicate our ability to draw clear conclusions regarding the overall benefits of spill as a passage option. At face value, these spillbay survival estimates do not appear to comport with overall dam survival estimates reported by Counihan et al. (2006a) for 2004 (Table 4.1). Dam survival was high for both yearling Chinook salmon (95.1\%) and steelhead (99.1\%), higher than these estimates of spill survival would be expected to provide. However, one needs to consider survival and fish proportions passing through all routes to resolve this seeming incongruity. One explanation is that survival through other heavily used routes is appreciably higher than occurs at the spillway. That issue is explored in a subsequent section of this report.

Table 4.6. Survival Estimates (\%) through Spillbays at Different Spill Regimes (Data from Counihan et al. 2006a). The $75 \mathrm{kcfs}$ condition was actually about $20 \mathrm{kcfs}$ lower than originally reported.

\begin{tabular}{|ccccc|}
\hline Species / Age & \multicolumn{2}{c|}{ Existing Deflector elevation } & \multicolumn{2}{c|}{$\mathbf{7}^{\prime}$ - Lowered Deflector } \\
\hline \hline & $\mathbf{7 5}$ kcfs & Gas Cap & $\mathbf{7 5}$ kcfs & Gas Cap \\
Y. Chinook & 77.3 & 94.6 & 93.7 & 94.3 \\
Steelhead & 85.0 & 101.2 & 92.7 & 97.9 \\
S. Chinook & 80.3 & 74.1 & 92.0 & 89.9 \\
\hline
\end{tabular}




\subsubsection{Bypass System Survival}

\subsubsection{Powerhouse 2; Original Bypass System}

The first indication that the original Powerhouse 2 bypass system may be a source of pronounced smolt mortality came in 1987. Dawley et al. (1988) conducted the first of a series of annual investigations at the dam. Over the years 1987-1990 and 1992, it became evident that fall Chinook salmon survival was worse for fish passing through the bypass than for any other route including the turbines (Table 4.2). Years of study suggested that most of the bypass mortality was associated with fish predation concentrated near the outfall. These findings led to the construction of a new bypass conduit and outfall at B2.

In 1991 and 1992, NOAA investigators focused on experimentally isolating direct effects associated with the bypass system from indirect predator-related effects near the bypass outfall. To estimate direct effects, they attached a trap net to the outfall. Treatment fish were released at the upper end of the bypass system and matched with controls released directly in the net. Dawley et al. (1998) generally concluded that mortality and injury were minimal while fish passed through the bypass structure. This observation reinforced previous presumptions that the primary agent of bypass mortality was predator feeding in the vicinity of the outfall. However, Dawley et al. noted that short-term stress and fatigue associated with passage through the bypass may have increased smolt vulnerability to predation and indirectly contributed to total bypass-related mortality.

\subsubsection{Powerhouse 2; New JBS}

In 2000, Counihan et al. (2002a) estimated survival of radio-tagged yearling Chinook salmon passing through the new juvenile bypass system (JBS) at Bonneville Second Powerhouse. Treatment fish released into the upper end of the JBS were paired with controls released below the outfall. Survival was estimated as 0.98 (S.E. $=0.025)$, reflecting total survival through that zone.

In 2001, the same investigators repeated the evaluation of the JBS, using the same approach as in 2000 (Counihan et al. 2002b). They estimated survival as 0.962 (S.E. $=0.023$ ) for yearling Chinook salmon and 0.90 (S.E. $=0.053$ ) for subyearling Chinook salmon. In both years, survival through the JBS was high for yearling Chinook salmon.

\subsubsection{Powerhouse 1; DSM}

Dawley et al. (1993a) measured descaling and survival based upon trap-net catches of tagged juvenile salmonids in 1993, and found higher mortality for fish traveling greatest distances. For yearling Chinook salmon, mortality was about $0.9 \%$ for fish released at the down-well, $7.7 \%$ for fish released half-way down the channel, and $1.2 \%$ for fish released at the south end. Mortality for subyearlings $(2.2 \%)$ did not differ from that of control fish released downstream. In 2002, Counihan et al. (2003) evaluated smolt survival through the downstream migrant bypass system (DSM) at the Bonneville First Powerhouse. Survival through the DSM at B1 was estimated by releasing radio-tagged fish into the bypass (treatment) 
and pairing those with releases below the JBS outfall at the powerhouse (control). Survival was low at 0.91 , with a $95 \%$ CI of 0.081 .

\subsubsection{Outfall Survival}

In planning the Bonneville Powerhouse 2 corner collector outfall, it was necessary to determine if there were deleterious effects associated with the impact between the outfall discharge jet and the receiving water in the tailrace. Direct survival was estimated for two outfall discharges $(1,000$ and 2,500 cfs) and two tailwater elevations (19.7 and 10.3 feet). Entry velocities ranged from 31 to 48 fps.

Effects of any treatment were negligible. At 48 -h, survival was $99.6 \%$ to $100.0 \%$ across all four tailwater and discharge combinations. Injury rates were low at $0.7 \%$ for all treatment fish released during the study. The authors concluded that at the Bonneville Powerhouse 2 outfall when the impact velocity was less than or equal to $48 \mathrm{fps}$, mortality was negligible.

\subsubsection{Route-Specific Survival - Recent Evaluations}

The advent of new survival models has afforded the ability to estimate smolt survival through all routes at Bonneville Dam simultaneously. This permits direct comparisons among routes under common operating conditions. This approach was used in 2004 and 2005 (Counihan et al. 2006a; Counihan et al. 2006b). Using this method it is easier to determine which routes are actually the safest and thus the preferred routes. In those years survival estimates were calculated for a variety of spill operations. Survival estimates varied broadly, depending on species, passage route, and spill condition. Spill conditions examined included 75kcfs+gas cap night, $75 \mathrm{kcfs}$-day, and gas cap-night (in 2004 a $50 \mathrm{kcfs}$ condition was also evaluated during the summer). With respect to the five primary passage routes, the main points we observed were

- Survival was always highest through the B2 corner collector - all species.

- The JBS at B2 typically ranked second or tied for first - all species.

- Ranking among the other three routes varied substantially, with no consistent pattern evident.

These rankings were determined by inspecting summary tables and figures appearing in the reports (Counihan et al. 2006a, 2006b). Depending on the species and prevailing condition, spillway survival was often low, ranking 4 th or 5 th of the five routes available. This may suggest that spill is not particularly beneficial for enhancing passage survival for the population at large. However, spilling water also enhances egress conditions in the tailrace and likely contributes to the high survival realized at the corner collector. We did not encounter any assessments that focused on determining what volume discharged through particular spillbays is required to produce adequate egress conditions.

The investigators used route-specific survival estimates to calculate dam passage survival under the different spill conditions. We view this as a more instructive performance index, because it reflects not only survival through routes but the proportion of the tagged population passing each route, as well as any indirect benefits associated with tailrace egress conditions. A consistent pattern is evident; during the 
gas cap-night condition, survival is highest for all species in both years. The only qualification is that, in 2004, the survival of subyearling Chinook salmon was uniform across the spill conditions.

Table 4.7. Dam Survival Estimates (\%) as Derived from Route-Specific Estimates at Bonneville Dam in 2004 and 2005. Data were taken from tables appearing in the executive summary from Counihan et al. (2006a, 2006b).

\begin{tabular}{|llccc||}
\hline Year & \multicolumn{1}{c}{ Species } & 75kcfs-day & $\begin{array}{c}\text { Spill Condition } \\
\text { Gas cap-night }\end{array}$ & 75kcfs+gascap \\
\hline \hline 2004 & Y. Chinook & 92.5 & 97.9 & 95.1 \\
& Steelhead & 98.2 & 100 & 99.1 \\
& S. Chinook & 88.2 & 88.8 & 89.1 \\
& Y. Chinook & 95.5 & 97.8 & 96.6 \\
& Steelhead & 95.7 & 97.0 & 96.3 \\
& S. Chinook & 91.6 & 98.5 & 93.8 \\
\hline \hline
\end{tabular}

\subsection{Synthesis and Conclusions}

Comparisons of survival estimates from assorted investigations can be confusing at times. Nearly every treatment estimate reported herein is probably best viewed as a relative estimate of survival. The control release sites establish the reference point, and the recovery of control fish constitutes the tag recovery proportions for the condition specific to that time and space.

Not all studies have released controls in the same locations. Even within a multi-year study conducted by the same investigation team, the location of control release sites can vary. Similarly, the location where and the means by which treatment groups are released has varied across studies. These attributes can, in turn, affect the survival estimates. Managers must select those estimates that best reflect the zone of interest and the set of conditions that are of primary concern and then focus on survival estimates that best bracket those parameters. We have attempted to provide that information in this report to guide those management decisions.

Survival through minimum gap runner turbines tested at Bonneville appears equivalent to that realized for smolts passing through standard units. Thus, the MGR provides no discernable improvement in turbine passage survival. Balloon tag survival estimates are clear on this point, although the potential for some delayed effects associated with injury could be manifested as increased survival well downstream from the dam. Radio tag-based survival estimates did not shed light on this potential effect. Survival through a standard unit was not available for direct comparison with the MGR estimate.

The absolute values of a number of survival estimates that were obtained using radio telemetry are suspicious, since they approach or exceed $100 \%$. Indications are that they were likely biased high. This was because in several instances a key assumption was violated. Independent tests revealed that some known dead fish bearing active tags released in the tailrace were subsequently detected at downstream detection transects. This raises the possibility that some smolts killed during dam passage could have drifted to the detection sites and been logged as live fish. The extent to which this actually occurred 
cannot be accurately determined. Perhaps relocating the downstream detection sites could avert this problem in the future.

Despite the uncertainty regarding bias associated with the absolute values of some telemetry estimates, the technique can still be used to generate acceptable estimates of relative survival. Thus use of this tool for determining optimal passage routes or operations appears sound if based on relative estimates. Conversely, it may require caution on the part of managers to rely on these telemetry-based survival estimates as input for passage modeling at Bonneville, because they may be mischaracterizing the true magnitude of passage effects.

Other mark-recapture approaches may not experience the difficulties unique to telemetry, but they are not without limitations. The absolute values of survival estimates obtained using freeze brands varied widely depending on the location at which the controls were released. As a consequence, those investigators expressed results as relative differences in recovery proportions to avoid the complication (Dawley et al. 1993b).

Absolute values generated using balloon tags appear sound and are readily interpretable. But of course they only reflect direct effects. Managers that are intent on analyzing the full passage effects through the FCRPS desire estimates that reflect total passage effects. For such purposes, managers will be forced to select judiciously from the estimates reported to date and select those that best reflect the zones and class of effects they wish to incorporate in their analyses. We cannot identify a best universal set of estimates that are suitable for all applications.

Radio tags provide a sound means to evaluate the effects of recent operations, using dam survival estimates derived from route-specific estimates. Furthermore we see this as an instructive performance index. In 2004 and 2005, survival during the gas-cap-night condition consistently was highest for all tagged species, except for subyearling Chinook salmon survival, which was uniform across all spill conditions. If future conditions need to be evaluated, a fruitful analytical approach is at hand. Again, we suggest the reader consider these as relative survival estimates, not absolute survival probabilities.

In our opinion, the affects of deflector elevation on spillway survival is becoming clearer, as evidenced by recent estimates compiled in Table 4.6. Based on radio tag data, the lower deflector yielded higher (or equivalent) survival than the $14 \mathrm{ft}$ deflector, regardless of the spill level, species, or season. The only exception may be for steelhead under gas cap spill levels. It appears that the lowered deflector is the preferred configuration, although another year of testing may be prdent.

The safest passage routes at Bonneville Dam are the B2 corner collector and the B2 JBS. Operations that maximize passage through these routes are advantageous to the population. This appears to hold for all species tested thus far. The ranking of survival among the three other routes reveals no clear and consistent pattern. 
Synthesis of Biological Research on Juvenile Salmonid Passage and Survival at Bonneville Dam through 2005

4.14 


\subsection{Optimizing Juvenile Fish Passage Strategies at Bonneville Dam}

\subsection{Historical Perspective}

Stated goals for juvenile salmonid passage at Bonneville Dam have changed over the years. Before B2 was completed in late 1982, spill was not a requirement for passing juvenile salmonids at Bonneville Dam. Spill was adequate even in low-flow years as it occurred whenever river discharge exceeded the hydraulic capacity of B1 (136,000 cfs through all turbines). From 1983 through about 1992, restrictions on B2 turbine operations during fish-passage seasons usually resulted in spill, much as it did in earlier years. Turbines at B2 were only operated as needed to limit spill to 75,000 cfs during the day or for fishery research testing at single units. From 1992 through 1994, the Portland District adopted a goal of 70\% FPE for yearlings and 50\% FPE for subyearlings from the Northwest Power Planning Council's Fish and Wildlife Program. This goal was also stated in the 1994 Biological Opinion by the National Marine Fisheries Service. The 1995 Biological Opinion called for spill at all projects to achieve $80 \%$ project FPE, but recognized that a daytime spill cap of 75,000 cfs to reduce adult fallback and low FGE at inturbine screens probably would prevent spill from achieving that goal at Bonneville Dam.

The Washington Department of Fish and Wildlife (WDFW), Oregon Department of Fish and Wildlife (ODFW), Idaho Department of Fish and Game (IDFG), and Columbia River Inter-Tribal Fish Commission (CRITFC) (1995) supported spill at Bonneville Dam because in their analysis the risk to juvenile salmonids passing a spillway was lower than for those passing through turbines as long as spillgenerated total dissolved gas levels did not exceed $120 \%$ to $125 \%$ of supersaturation. As a result of this report, NOAA Fisheries recommended using spill at mainstem projects to reach a goal of $80 \% \mathrm{FPE}$ in the 1995 Opinion and its supplements through 1998. The 2000 Biological Opinion called for action agencies to continue to provide spill for fish passage. References to FPE were noticeably absent from the 2004 Biological Opinion, mention of survival criteria was very common, and the assumption that spill provides the best survival was retained, as indicated by the following excerpt:

In developing the reference operation, as further described in Appendix D, NOAA Fisheries adjusted the operational parameters for the FCRPS to maximize fish survival based on the best science available and guided by NOAA Fisheries' juvenile fish passage strategy, which was originally developed in the 2000 FCRPS Biological Opinion (Section 9.6.1.4.1) and has been subsequently updated for this Opinion (Section 5.2.1.1.1.2). For example, the preferred passage method for most juvenile salmonids in the strategy is spillway passage, since spilling water over the spillways up to the current state water quality gas standard level is the option that provides dam passage with the least mortality, and therefore the reference operation calls for the use of additional spill for fish passage.

\subsection{The Safest Passage Routes}

Now that we have more years of survival data for Bonneville Dam, it may be time to reassess the underlying assumption of relative risk by ranking of routes by season and survival based upon data from active tagging studies. Information provided in Chapter 4 indicates that the spillway is not the safest passage route at the Bonneville Project. According to Table 4.8, it ranked second behind the $\mathrm{B} 2 \mathrm{CC}$ out of six possible passage routes for steelhead and fourth behind the B2CC, B2 JBS, and B1 turbines for yearling Chinook salmon. For summer, the spillway ranked fourth behind the B2CC, B1 sluiceway, and B2 JBS in 2004 when spillway survival was 74.4\%-87.6\% (Table 4.9). The spillway ranked fifth in 2005 when survival was $91.1 \%$ and this rate did not differ from that of B2 turbines $(89.5 \%)$, which were ranked 
sixth. The B2 Corner Collector consistently provides the highest survival for all migration periods, species, and treatments. Ranking among other routes is more variable, and survival probabilities are so similar that real differences likely do not exist in most cases. Certainly the proportion of smolts using the various routes factors greatly into any assessment. We recommend that the managers embark on some simple passage modeling exercises to formulate effective and safe passage strategies at the Bonneville Project.

\subsection{Considerations for Performance Goals}

Currently, in the remand process for the Biological Opinion, dam survival performance standards are being proposed. One of those standards is the dam survival metric of 95\% per dam, averaged across a series of dams in the system. Presumably, any mix of passage routes that yields the desired dam survival standard should be satisfactory. However, establishing an absolute standard presumes one can monitor and estimate survival at each dam in absolute, not relative, terms. This may be difficult to accomplish at Bonneville where survival through some routes is obviously inaccurate $(>100 \%)$. Biased route survival estimates can bias the dam survival estimates to some degree, depending on the analytical model. This matter deserves consideration by those agencies charged with prescribing passage strategies and associated monitoring.

An alternative goal at Bonneville could be to formulate passage strategies that maximize survival for the species of interest. Simple modeling exercises using observed variability in passage proportions and relative survivals could be conducted to explore scenarios. Data presented herein provide grist to conduct such exploratory analyses. Side-by-side comparisons between steelhead and yearling Chinook salmon are warranted, since the ranking of survival among routes varies for those co-mingled migrants.

\subsection{Possible Measures to Improve Survival}

We offer measures for managers to consider for improve juvenile passage survival for each major route at Bonneville Dam.

\subsubsection{Bonneville Powerhouse 1}

There have been four main passage routes at B1: intake screen juvenile bypass system, turbines, and surface flow outlets (including the sluiceway), and the prototype surface collector. It is reasonable to assume that intake screen technology is likely not a viable solution at B1 in the near or long term, given the regional agreement to remove the devices in recent years. Turbine passage survival, although based on telemetry-based estimates, has been reasonable for spring migrating fish (Table 4.8) but very poor for summer migrating fall Chinook salmon (Table 4.9). This leaves surface flow outlets as the primary means for a non-turbine passage route at B1. The existing sluiceway is known to pass fish and, while improvements are being made, more could be done. The PSC had fish collection efficiencies greater than $80 \%$ extrapolated to the entire powerhouse (Sweeney et al. 2007). Surface flow outlet approaches or enhancements are worth considering.

The B1 sluiceway will be refurbished by 2008 with auto-adjusting chain gates and a new collection channel. Managers should also consider improvements to provide safer passage conditions for fish at the conveyance structure at the terminus of the channel and the outfall. The drop at the end of the channel could be replaced with an ogee. The conveyance channel could lead to a new, custom-designed high-flow outfall. BioAnalysts et al. (2000), in a preliminary site selection study for a high-flow SFO outfall for B1, identified several possible locations that might be applicable to a new B1 sluiceway outfall. 
A partial powerhouse retrofit SFO with vertical slot entrances was identified by Harza et al. (2001) during the post-PSC period. This concept might be reconsidered given that improvements to the sluiceway might include a new conveyance structure and outfall. The B1 powerhouse could have a vertical slot retrofit SFO in front of Units 1-6 and a sluiceway SFO at Units 7-10. This would provide a combination SFO that may benefit more species and age classes than either SFO alone.

In the original SFO alternatives report for B1, Harza and ENSR (1996) identified numerous SFO concepts, including one called Alternative A. Alternative A was a full powerhouse retrofit SFO with ten vertical slot entrances, each corresponding to a turbine unit, and a high-flow conveyance channel and outfall. It was estimated that the Alternative A structure would costs tens of millions of dollars. However, if one considers operation of Bonneville Dam without spill, Alternative A might become costeffective.

\subsubsection{Spillway}

Spill to pass juvenile salmonids at Bonneville is often, but not always, a viable strategy; it depends on the season. If spill survival is as high as that of the $\mathrm{B} 2 \mathrm{CC}$ and other surface passage routes, which it is in spring, then spill should be used to the extent necessary to supplement safe passage by the best surface flow outlets (B2CC) and perhaps the B1 sluiceway, after improvement to the channel, control gates, and possibly the outfall in the future. The SFOs are five or six times more effective than the spillway for passing juveniles because they have very high efficiency at low percentage discharge (see Section 3.2). In summer, the spillway should be used only after passage has been maximized through all other routes that have better survival. Survival of fish passing the spillway has been observed to decline as summer progresses, but survival of fish passing the B2CC is consistently high according to a 2006 survival study (Ploskey et al. 2007). Clearly, seasonal trends in survival must be considered in any optimization strategy for the spillway at Bonneville Dam.

Strategies for maximizing spillway survival include the existing configuration, low elevation deflectors, and high elevation deflectors. Although not significant at a 5\% level, trends in data from Counihan et al. (2006a) support an alternative hypothesis that survival is lower at bays with 14-ft elevation deflectors (Bays 4-15) than at end bays with 7-ft elevation deflectors (Bays 1-3 and 16-18). If these differences are real, then it might be worth considering lowering deflectors at Bays 4-15, or even replacing fixed deflectors with moveable ones that function optimally at all tailwater elevations. Results from Normandeau et al. (2003) and Counihan et al. (2006a) also suggest that low spill volume through individual bays and low tailwater pool elevations may reduce survival.

Surface spill SFOs, such as a removable spillway weir (RSW), are popular, but do they make sense for the Bonneville Dam spillway given the Project's configuration? There is only one reason, in our opinion, that might justify installing an RSW at the spillway -- an RSW would increase surface flow, which might thereby attract fish from adjacent, poorer-survival passage routes at the spillway. For example, RSWs in Bays 2 and 16 might attract fish that otherwise may pass at interior Bays 4 through 15. Those bays have standard (high-elevation) deflectors that potentially provide lower survival than end bays with low-elevation deflectors, as described above. The cost-effectiveness of installing two RSWs would have to be compared with other options for altering spill deflectors, as described in the previous paragraph. Given the islands separating the spillway from the powerhouses at BON, it is unrealistic to think that an RSW might increase spill-passage efficiency or effectiveness as it might at other dams where fish could be attracted from a powerhouse. An RSW has the potential to reduce forebay residence times for some species, but they are already short at the Bonneville spillway, averaging 0.21 hours for yearling 
Chinook salmon, 0.34 hours for steelhead, and 0.77 hours for subyearling Chinook salmon. Multiple RSWs with associated training spill would likely be required, potentially reducing any cost benefits.

\subsubsection{Bonneville Powerhouse 2}

A forebay guidance structure might be useful to divert fish from the northern half of the forebay to the $\mathrm{B} 2 \mathrm{CC}$ entrance. A guidance wall concept to divert fish to the spillway was the subject of a previous preliminary engineering design ( $\mathrm{CH} 2 \mathrm{M}$ Hill et al. 1998). The authors concluded that the $\mathrm{B} 2$ wall concept had sufficient merit to warrant continued investigation, but new models and acquisition of additional biological and physical information would be required. They recommended a process to acquire the necessary information.

Managers might consider a second corner collector for the northern corner of the B2 powerhouse forebay. Harza and ENSR (1996b) mentioned this idea over ten years ago. Flow might be dewatered and plumbed into the low-flow JBS conveyance pipe if there is available capacity.

A smooth face to the plane of the powerhouse at the pier noses and above the turbine intakes would reduce turbulence along the face of the dam and might improve entrance conditions at the $\mathrm{B} 2 \mathrm{CC}$. While said conditions are relatively good, incremental improvement may increase B2CC forebay collection efficiency, particularly for juvenile Chinook salmon, which lag far behind steelhead. 


\subsection{Literature Cited}

Adams, N. S., R. E. Reagan, S. D. Evans, M. J. Farley, L. S. Wright, and D. W. Rondorf. 2006. Movement, Distribution, and Passage Behavior of Radio-Tagged Juvenile Chinook Salmon and Steelhead at Bonneville Dam, 2005. Draft Annual Report by the U.S. Geological Survey, Columbia River Research Laboratory, Cook, Washington for the U.S. Army Engineer District, Portland, Oregon.

Anglea, S.M., K.D. Ham, G.E. Johnson, M.A. Simmons, C.S. Simmons, E. Kudera, and J. Skalski. 2003. Hydroacoustic Evaluation of the Removable Spillway Weir at Lower Granite Dam in 2002. Final Report PNNL-3219, to the U.S. Army Corps of Engineers District, Portland, OR, by Pacific Northwest National Laboratory, Richland, WA.

BioAnalysts, ENSR, and INCA. 2000. Bonneville First Powerhouse High Flow Outfall Site Selection Study. Final submittal to the U.S. Army Corps of Engineers, Portland, Oregon.

Biosonics, Inc. 1998. Hydroacoustic Evaluation and Studies at Bonneville Dam, Spring/Summer 1997. Final report to the U.S. Army Corps of Engineers, Portland District, by Biosonics, Inc., Seattle, Washington.

Bisson, P. A., C. C. Coutant, D. Goodman, J. Lichatowich, W. Liss, L. McDonald, P. R. Mundy, B. Riddell, R. Whitney, and R. Williams. 1999. Review of the U.S. Army Corps of Engineers' capital construction program. Part II. A. Development and testing of surface bypass. Independent Scientific Advisory Board ISAB Report 99-4 to the Northwest Power Planning Council and NMFS. February 16, 1999, Portland, OR.

CH2M-Hill/Montgomery Watson, BioAnalysts, Inc., and Pacific Northwest National Laboratory. 1998. Bonneville Dam Second Powerhouse Physical Guidance Device. Letter report submitted to Portland District, U.S. Army Corps of Engineers.

Committee on Fishery Operations. 1979. A Summary of the Special Operations and Activities of Committee on Fishery Operations during the 1978 Spring and Summer Migrations. Columbia River Water Management Group.

Committee on Fishery Operations. 1980. 1979 Annual Report. Columbia River Water Management Group. Available online: http://www.nwd-wc.usace.army.mil/crwmg/crwmg_reports.htm

Committee on Fishery Operations. 1981. 1980 Annual Report. Columbia River Water Management Group. Available online: http://www.nwd-wc.usace.army.mil/crwmg/crwmg_reports.htm

Committee on Fishery Operations. 1982. 1981 Annual Report. Columbia River Water Management Group. Available online: http://www.nwd-wc.usace.army.mil/crwmg/crwmg_reports.htm

Committee on Fishery Operations. 1983. 1982 Annual Report. Columbia River Water Management Group. Available online: http://www.nwd-wc.usace.army.mil/crwmg/crwmg_reports.htm

Committee on Fishery Operations. 1985. 1983 Annual Report. Columbia River Water Management Group. Available online: http://www.nwd-wc.usace.army.mil/crwmg/crwmg_reports.htm 
Counihan, T. D., J. H. Petersen, N. S. Adams, R. S. Shively, and H. C. Hansel. 2002a. Feasibility of Extracting Survival Information from Radio-Telemetry Studies at the John Day Dam, 1999. Annual Report by the U.S. Geological Survey, Columbia River Research Laboratory, Cook, Washington for the U.S. Army Engineer District, Portland, Oregon.

Counihan, T. D., K. J. Felton, G. Holmberg, and J. H. Peterson. 2002b. Survival Estimates of Migrant Juvenile Salmonids in the Columbia River through Bonneville Dam Using Radio-Telemetry. Annual Report by the U.S. Geological Survey, Columbia River Research Laboratory, Cook, Washington for the U.S. Army Engineer District, Portland, Oregon.

Counihan, T. D., G. S. Holmberg, and J. H. Petersen. 2003. Survival Estimates of Migrant Juvenile Salmonids through Bonneville Dam using Radio-Telemetry, 2002. Annual Report by the U.S. Geological Survey, Columbia River Research Laboratory, Cook, Washington for the U.S. Army Engineer District, Portland, Oregon.

Counihan, T.D., J. Hardiman, C. Walker, A. Puls, and G. Holmberg. 2006a. Survival Estimates of Migrant Juvenile Salmonids through Bonneville Dam Using Radio Telemetry, 2004. Annual Report by the U.S. Geological Survey, Columbia River Research Laboratory, Cook, Washington for the U.S. Army Engineer District, Portland, Oregon.

Counihan, T.D., J. Hardiman, C. Walker, A. Puls, and G. Holmberg. 2006b. Survival Estimates of Migrant Juvenile Salmonids through Bonneville Dam using Radio Telemetry, 2005. Annual Report by the U.S. Geological Survey, Columbia River Research Laboratory, Cook, Washington for the U.S. Army Engineer District, Portland, Oregon.

Dauble, D., S. Anglea, and G. Johnson. 1999. Surface Flow Bypass Development in the Columbia and Snake Rivers and Implications Related to Research at Lower Granite Dam. Final report prepared by Pacific Northwest National Laboratory for the Walla Walla District, U.S. Army Corps of Engineers. July 21, 1999.

Dawley, E. M., L. G. Gilbreath, and R. D. Ledgerwood. 1988. Evaluation of Juvenile Salmonid Survival through the Second Powerhouse Turbines and Downstream Migrant Bypass System at Bonneville Dam, 1987. Annual Report of Research for the U.S. Army Corps of Engineer District, Portland, Oregon by the National Oceanic and Atmospheric Administration, Northwest and Alaska Fisheries Science Center, Seattle, Washington.

Dawley, E. M., L. G. Gilbreath, R. D. Ledgerwood, P. J. Bentley, B. P. Sanford, and H. H. Schiewe. 1989. Survival of Subyearling Chinook Salmon which Have Passed through the Turbines, Bypass System, and Tailrace Basin of Bonneville Dam Second Powerhouse, 1988. Annual Report of Research for the U.S. Army Corps of Engineer District, Portland, Oregon by the National Oceanic and Atmospheric Administration, Northwest and Alaska Fisheries Science Center, Seattle, Washington.

Dawley, E. M., R. D. Ledgerwood, L. G. Gilbreath, B. P. Sandford, P. J. Bentley, M. H. Schiewe, and S. J. Grabowski. 1992. Passage and Survival of Juvenile Chinook Salmon Migrating from the Snake River Basin. Proceedings of a technical workshop held February 26-28, 1992, University of Idaho. Moscow, Idaho. 
Dawley, E. M., L. G. Gilbreath, R. D. Ledgerwood, P. J. Bentley, and S. J. Grabowski. 1993a. Direct Measure of Stress, Descaling, Injury and Mortality for Juvenile Salmonids Passing through the Bypass System of the Bonneville Dam First Powerhouse. Annual Report of Research for the U.S. Army Corps of Engineer District, Portland, Oregon by the National Oceanic and Atmospheric Administration, Northwest Fisheries Science Center, Seattle, Washington.

Dawley, E. M., R. D. Ledgerwood, L. G. Galbreath , P. J. Bently, and S. J. Grabowski. 1993b. Do bypass systems protect salmonids at dams? Pages 161-168 in Proceedings of the Symposium on Fish Passage Policy and Technology, 1-2 September 1993, Portland, OR. Am. Fish Soc., Bioengineering Section, Bethesda, MD.

Dawley, E. M., L .G. Gilbreath, R. D. Ledgerwood, P. J. Bentley, and B. P. Sandford. 1998. Effects of Bypass System Passage at Bonneville Dam Second Powerhouse on Downstream Migrant Salmon and Steelhead; Direct Capture Assessment, 1990-1992. Annual Report of Research for the U.S. Army Corps of Engineer District, Portland, Oregon by the National Oceanic and Atmospheric Administration, Northwest Fisheries Science Center, Seattle, Washington.

DeHart, D. A. 1987. "Downstream Migrant Juvenile Salmonid Protection Systems for Low to Medium Head Hydroelectric Dams." Doctoral dissertation submitted to the University of Washington, Seattle, Washington.

ENSR Corporation, Harza Northwest, Inc., Inca Engineers, Inc., and Cornforth Consultants, Inc. 1998. Bonneville First Powerhouse Juvenile Fish Surface Bypass High Flow Dewatering Facility and Outfall Alternatives Study. Final report submitted to Portland District, U.S. Army Corps of Engineers. October 1998.

ENSR Corporation, Harza Northwest, Inc., Inca Engineers, Inc., and Cornforth Consultants, Inc. 1999. Bonneville First Powerhouse Juvenile Fish Surface Bypass High Flow Dewatering Facility and Outfall Alternatives Study. Final report for the U.S. Army Engineer District, Portland, OR.

ENSR Corporation and Inca Engineers, Inc. 2000. Bonneville Second Powerhouse Corner Collector Outfall, 1:30 Scale Physical Hydraulic Model. 30\% submittal model study report for the U.S. Army Engineer District, Portland, OR.

Evans, S. D., J. M. Plumb, A. C. Braatz, K. S. Gates, N. S. Adams, and D. W. Rondorf. 2001a. Passage Behavior of Radio-Tagged Yearling Chinook Salmon and Steelhead at Bonneville Dam Associated with the Surface Bypass Program, 2000. Annual Report by the U.S. Geological Survey, Columbia River Research Laboratory, Cook, Washington for the U.S. Army Engineer District, Portland, Oregon.

Evans, S. D., N. S. Adams, and D. W. Rondorf. 2001b. Passage Behavior of Radio-Tagged Subyearling Chinook Salmon at Bonneville Dam Associated with the Surface Bypass Program, 2000. Annual Report by the U.S. Geological Survey, Columbia River Research Laboratory, Cook, Washington for the U.S. Army Engineer District, Portland, Oregon.

Evans, S. D, C. D. Smith, N. S. Adams, and D. W. Rondorf. 2001c. Passage Behavior of Radio-Tagged Yearling Chinook Salmon at Bonneville Dam, 2001. Annual Report by the U.S. Geological Survey, Columbia River Research Laboratory, Cook, Washington for the U.S. Army Engineer District, Portland, Oregon. 
Evans, S. D, C. D. Smith, N. S. Adams, and D. W. Rondorf. 2001d. Passage Behavior of Radio-Tagged Subyearling Chinook Salmon at Bonneville Dam, 2001. Annual Report by the U.S. Geological Survey, Columbia River Research Laboratory, Cook, Washington for the U.S. Army Engineer District, Portland, Oregon.

Evans, S. D., L. S. Wright, C. D. Smith, R. E. Wardell, N. S. Adams, and D. W. Rondorf. 2003a. Passage Behavior of Radio-Tagged Yearling Chinook and Steelhead at Bonneville Dam, 2002. Annual Report by the U.S. Geological Survey, Columbia River Research Laboratory, Cook, Washington for the U.S. Army Engineer District, Portland, Oregon.

Evans, S. D., L. S. Wright, R. E. Wardell, N. S. Adams, and D. W. Rondorf. 2003b. Passage Behavior of Radio-Tagged Subyearling Chinook at Bonneville Dam, 2002. Annual Report by the U.S. Geological Survey, Columbia River Research Laboratory, Cook, Washington for the U.S. Army Engineer District, Portland, Oregon.

Evans, S., L. Wright, C. Smith, R. Wardell, N. Adams, and D. Rondorf. 2006a. Passage Behavior of Radio-Tagged Yearling Chinook Salmon and Steelhead at Bonneville Dam, 2002: Revised for Corrected Spill. Annual Report by the U.S. Geological Survey, Columbia River Research Laboratory, Cook, Washington for the U.S. Army Engineer District, Portland, Oregon.

Evans, S., L. Wright, R. Wardell, N. Adams, and D. Rondorf. 2006b. Passage Behavior of RadioTagged Subyearling Chinook Salmon at Bonneville Dam, 2002: Revised for Corrected Spill. Annual Report by the U.S. Geological Survey, Columbia River Research Laboratory, Cook, Washington for the U.S. Army Engineer District, Portland, Oregon.

Evans, S., L. Wright, R. Reagan, N. Adams, and D. Rondorf. 2006c . Passage Behavior of RadioTagged Subyearling Chinook Salmon at Bonneville Dam, 2004: Revised for Corrected Spill. Annual Report by the U.S. Geological Survey, Columbia River Research Laboratory, Cook, Washington for the U.S. Army Engineer District, Portland, Oregon.

Faber, D.M., M.A. Weiland, R.A. Moursund, and T.J. Carlson. 2001. Evaluation of the Fish Passage Effectiveness of the Bonneville I Prototype Surface Collector using Three-Dimensional Ultrasonic Fish Tracking, PNNL-13526, Prepared for U.S. Army Corps of Engineer District, Portland, Oregon by Pacific Northwest National Laboratory, Richland, Washington.

Ferguson, J. 1993. "Relative Survival of Juvenile Chinook Salmon through Bonneville Dam on the Columbia River," pp 58-65. In Proceedings of the Workshop on Fish Passage at Hydroelectric Developments, March 26-28, 1991, St. John's, Newfoundland. Canadian Technical Report of Fisheries and Aquatic Sciences, No. 1905, Department of Fisheries and Oceans, St. John's Newfoundland.

Ferguson, J. W., G. M. Matthews, R. L. McComas, R. F. Absolon, D. A. Brege, M. H. Gessel, and L. G. Gilbreath. 2005. Passage of Adult and Juvenile Salmon Through Federal Columbia River Power System Dams. NOAA Technical Memorandum, Fish Ecology Division, Northwest Fisheries Science Center, Seattle, WA, USA.

Gessel, M. H., R. F. Krcma, W. D. Muir, C. S. McCutcheon, L. G. Gilbreath and B. H. Monk. 1985. Evaluation of the Juvenile Collection and Bypass Systems at Bonneville Dam - 1984. Annual Report of Research for the U.S. Army Corps of Engineer District, Portland, Oregon by the National Oceanic and Atmospheric Administration, Northwest and Alaska Fisheries Science Center, Seattle, Washington. 
Gessel, M. H., L. G. Gilbreath, W. D. Muir, B. H. Monk and R. F. Krcma. 1987. Evaluation of the Juvenile Salmonid Collection and Bypass Systems at Bonneville Dam - 1986. Annual Report of Research for the U.S. Army Corps of Engineer District, Portland, Oregon by the National Oceanic and Atmospheric Administration, Northwest and Alaska Fisheries Science Center, Seattle, Washington.

Gessel, M. H., B. H. Monk and J. G. Williams. 1988. Evaluation of the Juvenile Fish Collection and Bypass Systems at Bonneville Dam -1987. Annual Report of Research for the U.S. Army Corps of Engineer District, Portland, Oregon by the National Oceanic and Atmospheric Administration, Northwest and Alaska Fisheries Science Center, Seattle, Washington.

Gessel, M. H., B. H. Monk, D. A. Brege and J. G. Williams. 1989. Fish Guidance Efficiency Studies at Bonneville Dam First and Second Powerhouses - 1988. Annual Report of Research for the U.S. Army Corps of Engineer District, Portland, Oregon by the National Oceanic and Atmospheric Administration, Northwest and Alaska Fisheries Science Center, Seattle, Washington.

Gessel, M. H., D. A. Brege, B. H. Monk and J. G. Williams. 1990. Continued Studies to Evaluate the Juvenile Bypass Systems at Bonneville Dam - 1989. Annual Report of Research for the U.S. Army Corps of Engineer District, Portland, Oregon by the National Oceanic and Atmospheric Administration, Northwest Fisheries Science Center, Seattle, Washington.

Gessel, M. H., J. G. Williams, D. A. Brege, R. F. Krcma and D. R. Chambers. 1991. Juvenile Salmonid Guidance at the Bonneville Dam Second Powerhouse, Columbia River, 1983-1989. North American Journal of Fisheries Management 11:400-412.

Giorgi, A. E. and J. R. Stevenson. 1995. A Review of Biological Investigations Describing Smolt Passage Behavior at Portland District Corps of Engineer Projects: Implications in Surface Collection Systems. Prepared by Don Chapman Consultants, Inc. for the U.S. Army Engineer, Portland District, Portland, Oregon.

Gilbreath, L. G., E. M. Dawley, R. D. Ledgerwood, P. J. Bently, and S. J. Grabowski. 1993. Relative Survival of Subyearling Chinook Salmon that have Passed Bonneville Dam Via the Spillway or Second Powerhouse Turbines or Bypass System: Adult Recoveries through 1991. Annual Report of Research for the U.S. Army Corps of Engineer District, Portland, Oregon by the National Oceanic and Atmospheric Administration, Northwest Fisheries Science Center, Seattle, Washington.

Hansel, H. C., R. S. Shively, J. E. Hensleigh, B. D. Liedtke, R. E. Wardell, R. H. Wertheimer, and T. P. Poe. 1999. Movement, Distribution, and Behavior of Radio-Tagged Juvenile Chinook Salmon and Steelhead in the Forebay of Bonneville Dam, 1998. Annual Report by the U.S. Geological Survey, Columbia River Research Laboratory, Cook, Washington for the U.S. Army Engineer District, Portland, Oregon.

Harza Northwest, Inc. and ENSR Corporation. 1996a. Surface Bypass Alternative Study at Bonneville First Powerhouse. Volume 1. Final report submitted to Portland District, U.S. Army Corps of Engineers.

Harza Northwest, Inc. and ENSR Corporation. 1996b. Surface Bypass Alternative Study at Bonneville Second Powerhouse. Volume 2. Final report submitted to Portland District, U.S. Army Corps of Engineers. 
Hensleigh, J. E., R. S. Shively, H. C. Hansel, B. D. Liedtke, K. M. Lisa, P. J. MacDonald, and T. P. Poe. 1998. Movement, Distribution, and Behavior of Radio-Tagged Yearling Chinook Salmon and Juvenile Steelhead in the Forebay of Bonneville Dam, 1998. Annual Report by the U.S. Geological Survey, Columbia River Research Laboratory, Cook, Washington for the U.S. Army Engineer District, Portland, Oregon.

Hensleigh, J. E., R. S. Shively, H. C. Hansel, J. M. Hardiman, G. S. Holmberg, B. D. Liedtke, T. L. Martinelli, R. E. Wardell, R. H. Wertheimer, and T. P. Poe. 1999. Movement, Distribution, and Behavior of Radio-Tagged Juvenile Chinook Salmon and Steelhead in John Day, The Dalles, and Bonneville Dam Forebays, 1997. Annual Report by the U.S. Geological Survey, Columbia River Research Laboratory, Cook, Washington for the U.S. Army Engineer District, Portland, Oregon.

Holmberg, G. S., R. S. Shively, H. C. Hansel, T. L. Martinelli, M. B. Sheer, J. M. Hardiman, B. D. Liedtke, L. S. Blythe, and T. P. Poe. 1996. Movement, Distribution, and Behavior of RadioTagged Juvenile Chinook Salmon in John Day, The Dalles, and Bonneville Dam Forebays, 1996. Annual Report by the U.S. Geological Survey, Columbia River Research Laboratory, Cook, Washington for the U.S. Army Engineer District, Portland, Oregon.

Holmes, H. B. 1952. Loss of Fingerlings in Passing Bonneville Dam as Determined by Marking Experiments. unpublished manuscript, U.S. Fish and Wildlife Service, Portland, Oregon.

INCA Engineers, Inc., FishPro, Inc., Northwest Hydraulic Consultants, Inc., R.W. Beck, AGRA Earth and Environmental, Inc., BioAnalysts, Inc., and Battelle Pacific Northwest Laboratories. 1997. Bonneville Second Powerhouse Prototype Corner Collector. Letter report submitted to Portland District, U.S. Army Corps of Engineers. November 21, 1997.

INCA Engineers, Inc., BioAnalysts, Inc., Chinook Engineering, ENSR, and R2 Resource Consultants. 1999. Bonneville $2^{\text {nd }}$ Powerhouse Fish Guidance Efficiency Improvement Study. Report prepared for the U.S. Army Corps of Engineers, Portland District. Portland, Oregon.

INCA Engineers, ENSR, and BioAnalysts, Inc. 2001. Bonneville Second Powerhouse Corner Collector Site Selection Study. Technical Report under Contract No. DACW57-D-0003, Task Order No. 0013.

Johnsen, R. C., and E. M. Dawley. 1974. The Effect of Spillway Flow Deflectors At Bonneville Dam on Total Gas Supersaturation and Survival of Juvenile Salmon. Report to U.S. Army Corps of Engineers, Contract DACW-57-74-F-0122, 19 p. (Available from the Northwest Fisheries Science Center, 2725 Montlake Blvd. E., Seattle, WA 98112-2097.)

Johnson, G. E., A. E. Giorgi, and M. W. Erho. 1997. Critical Assessment of Surface Flow Bypass Development in the Lower Columbia and Snake Rivers, completion report. Prepared for the U.S. Army Corps of Engineers, Walla Walla and Portland Districts, Portland, Oregon, by BioAnalysts, Inc., Vancouver, Washington.

Johnson, G., A. Giorgi, C. Sweeney, M. Rashid, and J. Plump. 1999. High Flow Outfalls for Juvenile Fish Bypasses: Preliminary Guidelines and Plans for Research and Implementation. Final Report submitted to U.S. Army Corps of Engineers by INCA Engineers, Portland District, Bellevue, Washington. 
Johnson, G. E. and A. E. Giorgi. 1999. Development of Surface Flow Bypasses at Bonneville Dam: A Synthesis of Data From 1995 to 1998 and a Draft M\&E Plan for 2000. Annual Report to U.S. Army Corps of Engineers, Portland District, Portland, Oregon, by BioAnalysts, Inc., Vancouver, Washington.

Johnson, G. E., B. D. Ebberts, D. D. Dauble, A. E. Giorgi, P. G. Heisey, R. P. Mueller, and D. A. Neitzel. 2003. Effects of Jet Entry at High-Flow Outfalls on Juvenile Pacific Salmon. N. Am. J. of Fish. Manage. 23: 441-449.

Johnson, G. E. and T. J. Carlson. 2001. Monitoring and Evaluation of the Prototype Surface Collector at Bonneville First Powerhouse: Synthesis of Results. PNNL-13516, Prepared for the U.S. Army Corps of Engineers by Pacific Northwest National Laboratory, Richland, Washington.

Johnson, G. E. and D. D. Dauble. 2006. Surface Flow Outlets to Protect Juvenile Salmonids Passing through Hydropower Dams. Reviews in Fisheries Science 14: 213-244.

Johnson, R. L., R. A. Moursund, and M. A. Simmons. 1999. Fish behavior in front of the prototype surface collector at Bonneville Dam in 1998. Final report by the Pacific Northwest National Laboratory, Richland, WA for the Portland District, U.S. Army Corps of Engineers. February 22, 1999.

Johnson, R. L., M. A. Simmons, C. S. Simmons, K. D. Hand, and J. Thomas. 2000. Hydroacoustic Evaluation of Fish Behavior in Front of the Prototype Surface Collector at Bonneville Dam, 1999. Final report by the Pacific Northwest National Laboratory, Richland, WA, for the Portland District, U.S. Army Corps of Engineers.

Johnson, R. L., M. A. Simmons, C. S. Simmons, C. A. McKinstry, S. L. Thornsten, K. D. Hand, M. A. Chamness. 2001. Hydroacoustic Evaluation of Fish Behavior at Bonneville Dam First Powerhouse: 2000 Prototype Surface Flow Bypass. Final report by the Pacific Northwest National Laboratory, Richland, WA for the Portland District, U.S. Army Corps of Engineers.

Krcma, R. F., D. DeHart, M. Gessel, C. Long and C. W. Sims. 1982. Evaluation of Submersible Traveling Screens, Passage of Juvenile Salmonids through the Ice-Trash Sluiceway, and Cycling of Gatewell-Orifice Operations at the Bonneville First Powerhouse, 1981. Annual Report of Research for the U.S. Army Corps of Engineer District, Portland, Oregon by the National Oceanic and Atmospheric Administration, Northwest and Alaska Fisheries Science Center, Seattle, Washington.

Krcma, R. F., M. H. Gessel, W. D. Muir, C. S. McCutcheon, L. G. Gilbreath, and B. H. Monk. 1984. Evaluation of the Juvenile Collection and Bypass System at Bonneville Dam - 1983. Annual Report of Research for the U.S. Army Corps of Engineer District, Portland, Oregon by the National Oceanic and Atmospheric Administration, Northwest and Alaska Fisheries Science Center, Seattle, Washington.

Ledgerwood, R. D., E. M. Dawley, L. G. Gilbreath, P. J. Bently, B. P. Sanford, and M. H. Schiewe. 1990. Relative Survival of Subyearling Chinook Salmon which have Passed Bonneville Dam via the Spillway or the Second Powerhouse Turbines or Bypass System in 1989, with Comparisons to 1987 and 1988. Annual Report of Research for the U.S. Army Corps of Engineer District, Portland, Oregon by the National Oceanic and Atmospheric Administration, Northwest Fisheries Science Center, Seattle, Washington. 
Ledgerwood, R. D., E. M. Dawley, L. G. Gilbreath, P. T. Bently, B. P. Sanford, and M. H. Schiewe. 1991. Relative Survival of Subyearling Chinook Salmon that have Passed through the Turbines and Bypass System of Bonneville Dam Second Powerhouse, 1990. Annual Report of Research for the U.S. Army Corps of Engineer District, Portland, Oregon by the National Oceanic and Atmospheric Administration, Northwest Fisheries Science Center, Seattle, Washington.

Ledgerwood, R. D., E. M. Dawley, L. G. Gilbreath, L. T. Parker, B. P. Sanford, and S. J. Grabowski. 1994. Relative Survival of Subyearling Chinook Salmon after Passage through the Bypass System at the First Powerhouse or a Turbine at the First or Second Powerhouse and the Tailrace Basins at Bonneville Dam, 1992. Annual Report of Research for the U.S. Army Corps of Engineer District, Portland, Oregon by the National Oceanic and Atmospheric Administration, Northwest Fisheries Science Center, Seattle, Washington.

Lee, R. and D. Schwartz. 2003. Fish Guidance Efficiency Improvements 1995-2002 Prototype Design and Evaluations: Bonneville First Powerhouse. U.S. Army Corps of Engineers - Portland District, Portland, Oregon.

Magne, R. A. 1987a. Bonneville II Hydroacoustic Monitoring Memorandum for the Record, \#1, 27 May 1987. Report of the U.S. Army Corps of Engineers Fisheries Field Unit, Bonneville Lock and Dam, for the U.S. Army Corp of Engineers, Portland District, Portland, Oregon.

Magne, R. A. 1987b. Hydroacoustic Monitoring at the Bonneville Dam Project in 1988 (a proposal plus 1987 data). Report of the U.S. Army Corps of Engineers Fisheries Field Unit, Bonneville Lock and Dam, for the U.S. Army Corp of Engineers, Portland District, Portland, Oregon.

Magne, R. A. 1987c. Hydroacoustic Monitoring of Downstream Migrant Juvenile Salmonids at Bonneville Dam, 1987. U.S. Army Corps of Engineers, Portland District, Portland, Oregon. Report of the US Army Corps of Engineers Fisheries Field Unit, Bonneville Lock and Dam, for the U.S. Army Corp of Engineers, Portland District, Portland, Oregon.

Magne, R. A., D. J. Rawding and W. T. Nagy. 1986. Hydroacoustic Monitoring at the Bonneville Dam Second Powerhouse during 1986 Fish Guidance Efficiency Tests. Report of the U.S. Army Corps of Engineers Fisheries Field Unit, Bonneville Lock and Dam, for the U.S. Army Corp of Engineers, Portland District, Portland, Oregon.

Magne, R. A., R. Stansell, and W. T. Nagy. 1989. A Summary of Hydroacoustic Monitoring at the Bonneville Dam Second Powerhouse in 1988. Report of the US Army Corps of Engineers Fisheries Field Unit, Bonneville Lock and Dam, for the U.S. Army Corp of Engineers, Portland District, Portland, Oregon.

Michimoto, R. T. and L. Korn. 1969. A Study to Determine the Value of Using the Ice-Trash Sluiceway for Passing Downstream-Migrant Salmonids at Bonneville Dam. Prepared for the U.S. Army Corps of Engineers, North Pacific Division, Portland, Oregon, by the Fish Commission of Oregon, Research Division.

Michimoto, R. T. 1971. Bonneville and The Dalles Dams Ice-Trash Sluiceway Studies, 1971. Report \#20, Prepared for the U.S. Army Corps of Engineers, North Pacific Division, Portland, Oregon, by the Fish Commission of Oregon, Research Division. 
Monk, B. H., B. P. Sandford, and D. B. Dey. 1994. Evaluation of Fish Guidance Efficiency of Submersible Traveling Screens and other Modifications at Bonneville Dam, Second Powerhouse 1993. Annual Report of Research for the U.S. Army Corps of Engineer District, Portland, Oregon by the National Oceanic and Atmospheric Administration, Northwest Fisheries Science Center, Seattle, Washington.

Monk, B. H., M. H. Gessel and J. W. Ferguson. 1999a. An Evaluation of the Biological Database for Improving Fish Guidance Efficiency at Bonneville Dam Second Powerhouse. Annual Report of Research for the U.S. Army Corps of Engineer District, Portland, Oregon by the National Oceanic and Atmospheric Administration, Northwest Fisheries Science Center, Seattle, Washington.

Monk, B. H., B. P. Sandford, and D.B. Dey. 1999b. Evaluation of Extended-Length Submersible Bar Screens at Bonneville Dam First Powerhouse, 1998. Annual Report of Research for the U.S. Army Corps of Engineer District, Portland, Oregon by the National Oceanic and Atmospheric Administration, Northwest Fisheries Science Center, Seattle, Washington.

Monk, B. H. and B. P. Sandford. 2001. Evaluation of Extended-Length Submersible Bar Screens at Bonneville Dam First Powerhouse, 2000. Annual Report of Research for the U.S. Army Corps of Engineer District, Portland, Oregon by the National Oceanic and Atmospheric Administration, Northwest Fisheries Science Center, Seattle, Washington.

Monk, B. H., R. F. Absolon, B. P. Sandford and J. W. Ferguson. 2002. Evaluation of Intake Modification at Bonneville Dam Second Powerhouse, 2001. Annual Report of Research for the U.S. Army Corps of Engineer District, Portland, Oregon by the National Oceanic and Atmospheric Administration, Northwest Fisheries Science Center, Seattle, Washington.

Monk, B.H., B.P. Sandford, D.A. Brege, and J.W. Ferguson. 2004. Evaluation of Turbine Intake Modifications at the Bonneville Dam Second Powerhouse, 2002. Annual Report of Research for the U.S. Army Corps of Engineer District, Portland, Oregon by the National Oceanic and Atmospheric Administration, Northwest Fisheries Science Center, Seattle, Washington.

Moursund, R.A. K.D. Ham, P.S. Titzler. 2003. Hydroacoustic Evaluation of Downstream Fish Passage at John Day Dam in 2002. Final Report PNWD-3236, Pacific Northwest National Laboratory, Richland, WA, for the U.S. Army Corps of Engineers District, Portland, OR.

Muir, W. D., A. E. Giorgi, W. S. Zaugg and B. R. Beckman. 1989. An Assessment of the Relationship Between Smolt Development and Fish Guidance Efficiency at Bonneville Dam. Annual Report of Research for the U.S. Army Corps of Engineer District, Portland, Oregon by the National Oceanic and Atmospheric Administration, Northwest and Alaska Fisheries Science Center, Seattle, Washington.

Nagy, W. T. and R. A. Magne. 1986. Hydroacoustic Study of Juvenile Fish Passage at the Bonneville Dam Second Powerhouse in 1985. Report of the US Army Corps of Engineers Fisheries Field Unit, Bonneville Lock and Dam, for the U.S. Army Corp of Engineers, Portland District, Portland, Oregon.

National Marine Fisheries Service (NOAA Fisheries). 1995. Biological Opinion on 1994-1998 Operation of the Federal Columbia River Power System and Juvenile Transportation Program. National Marine Fisheries Service, Seattle, Washington. 
National Marine Fisheries Service (NOAA Fisheries). 1998. Biological Opinion on Operation of the Federal Columbia River Power System and Juvenile Transportation Program. May 14, 1998.

National Marine Fisheries Service (NOAA Fisheries). 2000. Biological Opinion: Reinitiation of Consultation on Operation of the Federal Columbia River Power System, Including the Juvenile Fish Transportation Program, and 19 Bureau of Reclamation Projects in the Columbia Basin. National Marine Fisheries Service, Northwest Region, Seattle, Washington.

National Marine Fisheries Service (NOAA Fisheries). 2004. Biological Opinion on Operation of the Federal Columbia River Power System and Juvenile Transportation Program. December 2004.

Normandeau Associates Inc., J. R. Skalski, and Mid Columbia Consulting Inc. 1996. Potential Effects of Spillway Flow Deflectors on Fish Condition and Survival at the Bonneville Dam, Columbia River, Prepared for the U.S. Army Corps of Engineers - Portland District by Normandeau Associated Inc., Drumore, Pennsylvania.

Normandeau Associates Inc., J.R. Skalski, and Mid Columbia Consulting, Inc. 2000. Direct Survival and Condition of Juvenile Chinook Salmon Passed through an Existing and New Minimum Gap Runner Turbines at Bonneville Dam First Powerhouse, Columbia River. Prepared for US Army Corps of Engineers, Portland District, by Normandeau Associates, Inc. Drumore, Pennsylvania.

Normandeau Associates Inc., J. R. Skalski, and Mid-Columbia Consulting Inc. 2001. Passage survival investigation of juvenile chinook salmon through Bonneville Powerhouse II bypass sluice at two tailwater conditions Columbia River, Washington. Final report.

Normandeau Associates Inc., Mid Columbia Consulting Inc., and J. R. Skalski. 2003. Juvenile Salmonid Survival and Condition in Passage through Modified Spillbays at Bonneville Dam, Columbia River. Prepared for U.S. Army Corps of Engineers, Portland District, Portland, Oregon, by Normandeau Associated Inc., Drumore, Pennsylvania.

Ott Water Engineers, Inc. 1985. Review and Study of the Bonneville Second Powerhouse Fish Guidance Efficiency Program. Prepared for U.S. Army Corps of Engineers, Portland District, Portland, Oregon, by Ott Water Engineers, Inc.

Ploskey, G. R., L. R. Lawrence, P. N. Johnson, W. T. Nagy and M. G. Burczynski. 1998. Hydroacoustic Evaluations of Juvenile Salmonid Passage at Bonneville Dam including Surface-Collection Simulations. Technical Report EL-98-4 prepared for the U.S. Army Corps of Engineers Portland District by the U.S. Army Corps of Engineers Waterways Experiment Station, Vicksburg, Mississippi.

Ploskey, G. R., W. T. Nagy, L. R. Lawrence, D. S. Patterson, C. R. Schilt, P. N. Johnson and J. R. Skalski. 2001a. Hydroacoustic Evaluation of Juvenile Salmonid Passage through Experimental Routes at Bonneville Dam in 1998. ERDC/EL TR-01-2, prepared for the U.S. Army Corps of Engineers - Portland District by the U.S. Army Corps of Engineers Engineer Research and Development Center, Environmental Laboratory, Vicksburg, Mississippi.

Ploskey, G. R., L. R. Lawrence, P. N. Johnson, C. R. Schilt, W. T. Nagy, D. S. Patterson, J. Skalski. 2001b. Hydroacoustic Evaluation of the Bonneville Dam Prototype Surface Collector in 1999. Final Report ERDC/EL TR-01-1, prepared for the U.S. Army Corps of Engineers - Portland District by the U.S. Army Corps of Engineers Engineer Research and Development Center, Environmental Laboratory, Vicksburg, Mississippi. 
Synthesis of Biological Research on Juvenile Salmonid Passage and Survival at Bonneville Dam through 2005

Ploskey, G.R., W.T. Nagy, L.R. Lawrence, M.E. Hanks, C.R. Schilt, P.N. Johnson, G.E. Johnson, D.S. Patterson, and J.R. Skalski. 2001c. Hydroacoustic Evaluation of Juvenile Salmon Passage at The Dalles Dam: 1999. ERDC/EL TR-01-11, U.S. Army Engineer Research and Development Center, Vicksburg, Mississippi.

Ploskey, G. R., C. R. Schilt, M. E. Hanks, J. R. Skalski, W. T. Nagy, P. N. Johnson, D. S. Patterson, J. Kim and L. R. Lawrence. 2002a. Hydroacoustic Evaluation of Fish Passage through Bonneville Dam in 2000. ERDC/EL TR-02-8, Prepared for the U.S. Army Corps of Engineers - Portland District, by the U.S. Army Engineer Research and Development Center, Environmental Laboratory, Vicksburg, Mississippi.

Ploskey, G. R., C. R. Schilt, M. E. Hanks, J. R. Skalski, W. T. Nagy, P. N. Johnson, D. S. Patterson, J. Kim and L. R. Lawrence. 2002b. Hydroacoustic Evaluation of a Prototype Surface Collector and In-Turbine Screens at Bonneville Dam Powerhouse 1 in 2000. ERDC/EL TR-02-15, Prepared for the U.S. Army Corps of Engineers - Portland District, by the U.S. Army Engineer Research and Development Center, Environmental Laboratory, Vicksburg, Mississippi.

Ploskey, G. R., C. R. Schilt, M. E. Hanks, P. N. Johnson, J. Kim, J. R. Skalski, D. S. Patterson, W. T. Nagy and L. R. Lawrence. 2002c. Hydroacoustic Evaluation of Fish Passage Efficiency at Bonneville Dam in 2001. PNNL-14047, Prepared for the U.S. Army Corps of Engineers, Portland District, by Pacific Northwest National Laboratory, Richland, Washington.

Ploskey, G. R., C. R. Schilt, J. Kim, C. W. Escher and J. R. Skalski. 2003. Hydroacoustic Evaluation of Fish Passage through Bonneville Dam in 2002. PNNL-14356, Prepared for the U.S. Army Corps of Engineers - Portland District, by Pacific Northwest National Laboratory, Richland, Washington.

Ploskey, G.R., M.A. Weiland, C. R. Schilt. 2004. Evaluation of Fish Losses through Screen Gaps at Modified and Unmodified Intakes of Bonneville Dam Second Powerhouse in 2003, PNNL-14539, Prepared for the U.S. Army Corps of Engineers, Portland District, Portland, Oregon, by Pacific Northwest National Laboratory, Richland, Washington.

Ploskey G. R., M. A. Weiland, C. R. Schilt, P. N. Johnson, M. E. Hanks, D. S. Patterson, J. R. Skalski, and J. Hedgepeth. 2005. Hydroacoustic Evaluation of Fish Passage through Bonneville Dam in 2004. PNNL-15249, Pacific Northwest National Laboratory, Richland, WA, for the U.S. Army Corps of Engineers, Portland District, Portland, Oregon.

Ploskey, G. R., G. E. Johnson, M. A. Weiland, F. Khan, R. P. Mueller, J. A. Serkowski, C. L. Rakowski, J. B. Hedgepeth, J. R. Skalski, B. D. Ebberts, and B. A. Klatte. 2006a. "Acoustic camera evaluation of juvenile salmonid approach and fate at surface flow outlets of two hydropower dams." HydroVision 2006 Conference held in Portland, Oregon. HCI Publications, Kansas City Missouri, USA.

Ploskey, G. R., J. Kim, M. A. Weiland, J. S. Hughes, and E. S. Fischer. 2006b. Reanalysis of Hydroacoustic Fish-Passage Data from Bonneville Dam after Spill-Discharge Corrections. Draft Report by the Pacific Northwest National Laboratory, Richland, WA, for the U.S. Army Corps of Engineers, Portland District, Portland, Oregon. 
Ploskey, G. R., M. A. Weiland, S. A. Zimmerman, J. S. Hughes, K. Bouchard, E. S. Fischer, C. R. Schilt, M. E. Hanks, J. Kim, J. R. Skalski, J. Hedgepeth, and W. T. Nagy. 2006c. Hydroacoustic Evaluation of Fish Passage through Bonneville Dam in 2005. PNNL-15944, Pacific Northwest National Laboratory, Richland, WA, for the U.S. Army Corps of Engineers, Portland District, Portland, Oregon.

Plumb, J. M., M. S. Novick, B. D. Liedtke, and N. S. Adams. 2001. Passage Behavior of Radio-Tagged Yearling Chinook Salmon and Steelhead at Bonneville Dam Associated with the Surface Bypass Program, 1999. Annual Report by the U.S. Geological Survey, Columbia River Research Laboratory, Cook, Washington for the U.S. Army Engineer District, Portland, Oregon.

Portland District, Corps of Engineers. 2002. Bonneville Decision Document: Juvenile Fish Passage Recommendation. U.S. Army Corps of Engineers - Portland District, Portland, Oregon.

Rakowski C. L., J. A. Serkowski, M. C. Richmond, and K. P. Recknagle. 2001. Development and Application of a 3D CFD Model for the Bonneville Project Powerhouse 1 and Powerhouse 2 . PNNL-13593, Pacific Northwest National Laboratory, Richland, WA.

Rakowski C.L., M.C. Richmond, J.A. Serkowski, and G.E. Johnson. 2005. Forebay Computational Fluid Dynamics Modeling for The Dalles Dam to Support Behavior Guidance System Siting Studies. PNNL-15689, Pacific Northwest National Laboratory, Richland, WA.

Reagan, R., S. Evans, L. Wright, M. Farley, N. Adams, and D. Rondorf. 2006. Passage Behavior of Radio-Tagged Yearling Chinook Salmon and Steelhead at Bonneville Dam, 2004: revised for corrected spill. Annual Report by the U.S. Geological Survey, Columbia River Research Laboratory, Cook, Washington for the U.S. Army Engineer District, Portland, Oregon.

Reservoir Control Center. 1985a. Columbia River Fishery Operations 1984 Annual report. U.S. Army Corps of Engineers, North Pacific Division, Portland, Oregon.

Reservoir Control Center. 1985b. Juvenile Fish Passage Plan for 1985 for Corps of Engineers Projects. U.S. Army Corps of Engineers, North Pacific Division, Portland, Oregon.

Reservoir Control Center. 1986. Operating Standards and Maintenance Plan for 1986. U.S. Army Corps of Engineers, North Pacific Division, Portland, Oregon.

Reservoir Control Center. 1987. Juvenile Fish Passage Plan for 1987 for Corps of Engineers Projects. U.S. Army Corps of Engineers, North Pacific Division, Portland, Oregon.

Reservoir Control Center. 1988. Juvenile Fish Passage Plan for 1988 for Corps of Engineers Projects. U.S. Army Corps of Engineers, North Pacific Division, Portland, Oregon.

Reservoir Control Center. 1989. Juvenile Fish Passage Plan for 1989 for Corps of Engineers Projects. U.S. Army Corps of Engineers, North Pacific Division, Portland, Oregon.

Reservoir Control Center. 1990. Fish Passage Plan for 1990 Corps of Engineers Projects. U.S. Army Corps of Engineers, North Pacific Division, Portland, Oregon.

Reservoir Control Center. 1991. Fish Passage Plan for 1991 Corps of Engineers Projects. U.S. Army Corps of Engineers, North Pacific Division, Portland, Oregon. 
Reservoir Control Center. 1992. Fish Passage Plan for 1992 Corps of Engineers Projects. U.S. Army Corps of Engineers, North Pacific Division, Portland, Oregon.

Reservoir Control Center. 1993. Fish Passage Plan for 1993 Corps of Engineers Projects. U.S. Army Corps of Engineers, North Pacific Division, Portland, Oregon.

Reservoir Control Center. 1994. Fish Passage Plan for 1994 Corps of Engineers Projects. U.S. Army Corps of Engineers, North Pacific Division, Portland, Oregon.

Reservoir Control Center. 1995. Fish Passage Plan for 1995 Corps of Engineers Projects. U.S. Army Corps of Engineers, North Pacific Division, Portland, Oregon.

Reservoir Control Center. 1996. Fish Passage Plan for 1996 Corps of Engineers Projects. U.S. Army Corps of Engineers, North Pacific Division, Portland, Oregon.

Reservoir Control Center. 1997. Fish Passage Plan for 1997 Corps of Engineers Projects. U.S. Army Corps of Engineers, North Pacific Division, Portland, Oregon.

Reservoir Control Center. 1998. Fish Passage Plan for 1998 Corps of Engineers Projects. U.S. Army Corps of Engineers, North Pacific Division, Portland, Oregon.

Reservoir Control Center. 1999. Fish Passage Plan for 1999 Corps of Engineers Projects. U.S. Army Corps of Engineers, North Pacific Division, Portland, Oregon.

Reservoir Control Center. 2000. Fish Passage Plan for 2000 Corps of Engineers Projects. U.S. Army Corps of Engineers, North Pacific Division, Portland, Oregon.

Reservoir Control Center. 2001. Fish Passage Plan for 2001 Corps of Engineers Projects. U.S. Army Corps of Engineers, North Pacific Division, Portland, Oregon.

Reservoir Control Center. 2002. Fish Passage Plan for 2002 Corps of Engineers Projects. U.S. Army Corps of Engineers, North Pacific Division, Portland, Oregon.

Reservoir Control Center. 2003. Fish Passage Plan for 2003 Corps of Engineers Projects. U.S. Army Corps of Engineers, North Pacific Division, Portland, Oregon.

Reservoir Control Center. 2004. Fish Passage Plan for 2004 Corps of Engineers Projects. U.S. Army Corps of Engineers, North Pacific Division, Portland, Oregon.

Reservoir Control Center. 2005. Fish Passage Plan for 2005 Corps of Engineers Projects. U.S. Army Corps of Engineers, North Pacific Division, Portland, Oregon.

Schneider, M. L., J. Carroll, C. C. Schneider, and K. Barko. 2003. Total Dissolved Gas Exchange at Bonneville Dam, 2002 Spill Season. Technical Report by the U.S. Army Engineer Research and Development Center for the U.S. Army Engineer District, Portland, USA. 
Skalski, J. R., D. Mathur, and P. G. Heisey 2002. "Effects of Turbine Operating Efficiency on Smolt Passage Survival.” North American Journal of Fisheries Management 22:1193-1200.

Stansell, R. J., R. A. Magne, W. T. Nagy and L. M. Beck. 1990. Hydroacoustic Monitoring of Downstream Migrant Juvenile Salmonids at Bonneville Dam, 1989. Report of the US Army Corps of Engineers Fisheries Field Unit, Bonneville Lock and Dam, for the U.S. Army Corp of Engineers, Portland District, Portland, Oregon.

Sweeney, C., G. Johnson, and A. Giorgi. 2006. Surface Bypass Program Comprehensive Review Report. $30 \%$ draft submitted to the U.S. Army Engineer District, Portland, Oregon.

Thorne, R. E. and E. S. Kuehl. 1989. Evaluation of Hydroacoustics Techniques for Assessment of Juvenile Fish Passage at Bonneville Powerhouse I. Final Report Prepared for U.S. Army Corps of Engineers, Portland District, by BioSonics, Inc., Seattle, Washington.

Thorne, R.E. and G.E. Johnson. 1993. "A review of hydroacoustic studies for estimation of salmonid downriver migration past hydroelectric facilities on the Columbia and Snake Rivers in the 1980s." Reviews in Fisheries Science. 1 (1) 27-56.

Uremovich, B. L., S. P. Cramer, C. F. Willis, and C. O. Junge. 1980. Passage of Juvenile Salmonids through the Ice-Trash Sluiceway and Squawfish Predation at Bonneville Dam, 1980. Prepared for the U.S. Army Corps of Engineers - Portland District by the Oregon Department of Fish and Wildlife.

USACE (U.S. Army Corps of Engineers). 2001. Design Documentation Report-Bonneville Second Powerhouse High Flow Outfall Bypass System. U.S. Army Corps of Engineers, Portland District, Portland, Oregon.

USACE. 1995. Lower Snake and Columbia Rivers Surface Bypass and Collection Systems Prototype Development Program. Portland and Walla Walla Districts, U.S. Corps of Engineers. August 1995.

WDFW, ODFW, IDFG, and CRITFC. 1995. Spill and 1995 risk management. Joint Report by the Washington Department of Fish and Wildlife, Oregon Department of Fish and Wildlife, Idaho Fish and Game, and the Columbia River Inter-Tribal Fish Commission.

Willis, C. F. and B. L. Uremovich. 1981. Evaluation of the Ice and Trash Sluiceway at Bonneville Dam as a Bypass System for Juvenile Salmonids, 1981. Prepared for the U.S. Army Corps of Engineers Portland District, by the Oregon Department of Fish and Wildlife. 
Appendix A

References on C.D. have Hyperlinks to Portable Document Files (PDFs) containing Copies of Original Papers 



\section{Appendix A}

\section{References with Hyperlinks to Portable Document Files (PDFs) containing Copies of Original Papers}

This chapter includes citations with hyperlinks to PDF versions of original papers on juvenile salmon passage and survival studies conducted at Bonneville Dam from 1939 through 2005. It also includes citations and hyperlinks to Fish Passage Plans from 1978 through 2005. For convenience, citations were arranged alphabetically by the last name of the first author and year, regardless of coauthors. If more than one paper was written in a single year by the same first author, we assigned letters alphabetically to correspond to callouts in the text of the report.

Adams, N. S., R. E. Reagan, S. D. Evans, M. J. Farley, L. S. Wright, and D. W. Rondorf. 2006. Movement, Distribution, and Passage Behavior of Radio-Tagged Juvenile Chinook Salmon and Steelhead at Bonneville Dam, 2005. Draft Annual Report by the U. S. Geological Survey, Columbia River Research Laboratory, Cook, Washington for the U. S. Army Engineer District, Portland, Oregon.

\section{$\underline{\mathrm{BS} 176}$}

Bell, M. C. 1971. Ecological Impact of Pool and Tailwater Regulations at Bonneville Dam (fish and wildlife). Submitted to Corps of Engineers, Portland, Oregon.

\section{$\underline{B S 112}$}

Bickford, S. H. and J. R. Skalski. 2000. "Reanalysis and interpretation of 25 years of Snake-Columbia River juvenile salmonid survival studies." North American Journal of Fisheries Management. 20:53-68.

$\underline{\text { BS022 }}$ PDF reproduced with permission of www.fisheries.org.

BioAnalysts, ENSR, and INCA. 2001. Bonneville 2nd Powerhouse Corner Collector Site Selection Study. Report Prepared for U.S. Army Corps of Engineers, Portland District, Portland, Oregon.

\section{$\underline{\mathrm{BS} 007}$}

BioSonics Inc. 1998. Hydroacoustic Evaluation and Studies at Bonneville Dam, Spring/Summer 1997 Volume 1 and 2. Contract Report to the U.S. Army Corps of Engineers, Portland District, Portland, Oregon.

\section{$\underline{\mathrm{BS} 024}$}


Committee on Fishery Operations. 1979. A Summary of the Special Operations and Activities of Committee on Fishery Operations during the 1978 Spring and Summer Migrations. Columbia River Water Management Group.

\section{$\underline{\mathrm{BS} 143}$}

Committee on Fishery Operations. 1980. 1979 Annual Report. Columbia River Water Management Group.

\section{$\underline{B S 144}$}

Committee on Fishery Operations. 1981. 1980 Annual Report. Columbia River Water Management Group.

\section{$\underline{\mathrm{BS} 145}$}

Committee on Fishery Operations. 1982. 1981 Annual Report. Columbia River Water Management Group.

\section{$\underline{\mathrm{BS} 146}$}

Committee on Fishery Operations. 1983. 1982 Annual Report. Columbia River Water Management Group.

\section{$\underline{B S 147}$}

Committee on Fishery Operations. 1985. 1983 Annual Report. Columbia River Water Management Group.

\section{BS148}

Counihan, T. D., K. J. Felton, G. Holmberg, and J. H. Peterson. 2002. Survival Estimates of Migrant Juvenile Salmonids in the Columbia River through Bonneville Dam Using Radio-Telemetry, 2001. Final Report of Research by the U. S. Geological Survey, Columbia River Research Laboratory for the U.S. Army Corps of Engineers, Portland District, Portland, Oregon.

\section{$\underline{\text { BS139 }}$}

Counihan, T.D., G.S. Holmberg, and J.H. Petersen. 2003. Survival Estimates of Migrant Juvenile Salmonids through Bonneville Dam using Radio-Telemetry, 2002. Final Report of Research by the U. S. Geological Survey, Columbia River Research Laboratory for the U.S. Army Corps of Engineers, Portland District, Portland, Oregon.

\section{$\underline{B S 136}$}


Counihan, T. D., J. Hardiman, C. Walker, A. Puls, and G. Holmberg. 2006a. Survival Estimates of Migrant Juvenile Salmonids through Bonneville Dam Using Radio Telemetry, 2004. Final Report of Research by the U. S. Geological Survey, Columbia River Research Laboratory for the U.S. Army Corps of Engineers, Portland District, Portland, Oregon.

\section{$\underline{\mathrm{BS} 172}$}

Counihan, T. D., J. Hardiman, C. Walker, A. Puls, and G. Holmberg. 2006b. Survival Estimates of Migrant Juvenile Salmonids through Bonneville Dam Using Radio Telemetry, 2005. Final Report of Research by the U. S. Geological Survey, Columbia River Research Laboratory for the U.S. Army Corps of Engineers, Portland District, Portland, Oregon.

\section{$\underline{B S 173}$}

Dawley, E. M., L. G. Gilbreath, and R. D. Ledgerwood. 1988. Evaluation of Juvenile Salmonid Survival through the Second Powerhouse Turbines and Downstream Migrant Bypass System at Bonneville Dam, 1987. Annual Report of Research for the U.S. Army Corps of Engineer District, Portland, Oregon by the National Oceanic and Atmospheric Administration, Northwest and Alaska Fisheries Science Center, Seattle, Washington.

\section{$\underline{B S 090}$}

Dawley, E. M., L. G. Gilbreath, R. D. Ledgerwood, P. J. Bently, B. P. Sanford, and H. H. Schiewe. 1989. Survival of Subyearling Chinook Salmon which Have Passed through the Turbines, Bypass System, and Tailrace Basin of Bonneville Dam Second Powerhouse, 1988. Annual Report of Research for the U.S. Army Corps of Engineer District, Portland, Oregon by the National Oceanic and Atmospheric Administration, Northwest Fisheries Science Center, Seattle, Washington.

\section{$\underline{B S 088}$}

Dawley, E. M., R. D. Ledgerwood, L. G. Gilbreath , and P. J. Bentley. 1991. Survival of Juvenile Salmon Studied at Bonneville Dam. National Oceanic and Atmospheric Administration, Northwest Fisheries Science Center Quarterly Report. July-August-September 1991:1-5.

\section{BS133}

Dawley, E. M., R. D. Ledgerwood, L. G. Gilbreath, B. P. Sandford, P. J. Bentley, M. H. Schiewe, and S. J. Grabowski. 1992. "Survival of Juvenile Salmon Passing through Bonneville Dam and Tailrace," Pages 145-156 in Passage and Survival of Juvenile Chinook Salmon Migrating from the Snake River Basin. Proceedings of a technical workshop held February 26-28, 1992, University of Idaho.

\section{$\underline{\text { BS129 }}$}


Dawley, E. M., L. G. Gilbreath, R. D. Ledgerwood, P. J. Bentley, and S. J. Grabowski. 1993a. Direct Measure of Stress, Descaling, Injury and Mortality for Juvenile Salmonids Passing through the Bypass System of the Bonneville Dam First Powerhouse. Annual Report of Research for the U.S. Army Corps of Engineer District, Portland, Oregon by the National Oceanic and Atmospheric Administration, Northwest Fisheries Science Center, Seattle, Washington.

\section{$\underline{\mathrm{BS} 130}$}

Dawley, E. M., R. D. Ledgerwood, L. G. Galbreath, P. J. Bently, and S. J. Grabowski. 1993b. “Do bypass systems protect salmonids at dams?" Pages 161-168 in Proceedings of the Symposium on Fish Passage Policy and Technology, 1-2 September 1993, Portland, OR. Am. Fish Soc., Bioengineering Section, Bethesda, MD.

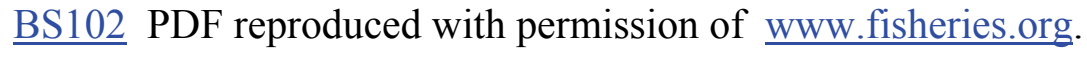

Dawley, E. M., L .G. Gilbreath, R. D. Ledgerwood, P. J. Bentley, and B. P. Sandford. 1998. Effects of Bypass System Passage at Bonneville Dam Second Powerhouse on Downstream Migrant Salmon and Steelhead; Direct Capture Assessment, 1990-1992. Annual Report of Research for the U.S. Army Corps of Engineer District, Portland, Oregon by the National Oceanic and Atmospheric Administration, Northwest Fisheries Science Center, Seattle, Washington.

\section{BS114}

Evans, S. D., J. M. Plumb, A. C. Braatz, K. S. Gates, N. S. Adams, and D. W. Rondorf. 2001a. Passage Behavior of Radio-Tagged Yearling Chinook Salmon and Steelhead at Bonneville Dam Associated with the Surface Bypass Program, 2000. Annual Report by the U. S. Geological Survey, Columbia River Research Laboratory, Cook, Washington for the U. S. Army Engineer District, Portland, Oregon.

\section{$\underline{B S 014}$}

Evans, S. D., N. S. Adams, and D. W. Rondorf. 2001b. Passage Behavior of Radio-Tagged Subyearling Chinook Salmon at Bonneville Dam Associated with the Surface Bypass Program, 2000. Annual Report by the U. S. Geological Survey, Columbia River Research Laboratory, Cook, Washington for the U. S. Army Engineer District, Portland, Oregon.

\section{$\underline{\mathrm{BS} 013}$}

Evans, S. D., C. D. Smith, N. S. Adams, and D. W. Rondorf. 2001c. Passage Behavior of Radio-Tagged Yearling Chinook Salmon at Bonneville Dam, 2001. Annual Report by the U. S. Geological Survey, Columbia River Research Laboratory, Cook, Washington for the U. S. Army Engineer District, Portland, Oregon. 
Evans, S. D., C. D. Smith, N. S. Adams, and D. W. Rondorf. 2001d. Passage Behavior of Radio-Tagged Subyearling Chinook Salmon at Bonneville Dam, 2001. Annual Report by the U. S. Geological Survey, Columbia River Research Laboratory, Cook, Washington for the U. S. Army Engineer District, Portland, Oregon.

\section{BS005}

Evans, S. D., L. S. Wright, C. D. Smith, R. E. Wardell, N. S. Adams, and D. W. Rondorf. 2003a. Passage Behavior of Radio-Tagged Yearling Chinook Salmon and Steelhead at Bonneville Dam, 2002. Annual Report by the U. S. Geological Survey, Columbia River Research Laboratory, Cook, Washington for the U. S. Army Engineer District, Portland, Oregon.

\section{$\underline{\mathrm{BS} 037}$}

Evans, S. D., L. S. Wright, R. E. Wardell, N. S. Adams, and D. W. Rondorf. 2003b. Passage Behavior of Radio-Tagged Subyearling Chinook Salmon at Bonneville Dam, 2002: Revised for Corrected Spill. Annual Report by the U. S. Geological Survey, Columbia River Research Laboratory, Cook, Washington for the U. S. Army Engineer District, Portland, Oregon.

\section{$\underline{\text { BS137 }}$}

Evans, S. D., L. S. Wright, C. D. Smith, R. E. Wardell, N. S. Adams, and D. W. Rondorf. 2006 a. Passage Behavior of Radio-Tagged Yearling Chinook Salmon and Steelhead at Bonneville Dam, 2002: Revised for Corrected Spill. Annual Report by the U. S. Geological Survey, Columbia River Research Laboratory, Cook, Washington for the U. S. Army Engineer District, Portland, Oregon.

\section{$\underline{\text { BS177 }}$}

Evans, S. D., L. S. Wright, R. E. Wardell, N. S. Adams, and D. W. Rondorf. 2006b. Passage Behavior of Radio-Tagged Subyearling Chinook Salmon at Bonneville Dam, 2002: Revised for Corrected Spill. Annual Report by the U. S. Geological Survey, Columbia River Research Laboratory, Cook, Washington for the U. S. Army Engineer District, Portland, Oregon.

\section{$\underline{\mathrm{BS} 178}$}

Evans, S. D., L. S. Wright, R. E. Reagan, N. S. Adams, and D. W. Rondorf. 2006c. Passage Behavior of Radio-Tagged Subyearling Chinook Salmon at Bonneville Dam, 2004: Revised for Corrected Spill. Annual Report by the U. S. Geological Survey, Columbia River Research Laboratory, Cook, Washington for the U. S. Army Engineer District, Portland, Oregon.

\section{$\underline{\mathrm{BS} 180}$}

Faber, D.M., M.A. Weiland, R.A. Moursund, and T.J. Carlson. 2001. Evaluation of the Fish Passage Effectiveness of the Bonneville I Prototype Surface Collector using Three-Dimensional Ultrasonic Fish Tracking, PNNL-13526 Prepared for U.S. Army Corps of Engineer District, Portland, Oregon by Pacific Northwest National Laboratory, Richland, Washington.

\section{$\underline{B S 141}$}


Ferguson, J. 1993. "Relative Survival of Juvenile Chinook Salmon through Bonneville Dam on the Columbia River." Pages 58-65 in Proceedings of the Workshop on Fish Passage at Hydroelectric Developments, March 26-28, 1991, St. John's, Newfoundland. Canadian Technical Report of Fisheries and Aquatic Sciences, No. 1905, Department of Fisheries and Oceans, St. John's Newfoundland.

BS087 PDF reproduced with permission of the NRC Research Press. http://pubs.nrccnrc.gc.ca/cgi-bin/rp/rp2 desc_e?cjfas

Ferguson, J. W., G. M. Matthews, R. L. McComas, R. F. Absolon, D. A. Brege, M. H. Gessel, and L. G. Gilbreath. 2005. Passage of Adult and Juvenile Salmon Through Federal Columbia River Power System Dams. NOAA Technical Memorandum, Fish Ecology Division, Northwest Fisheries Science Center, Seattle, WA, USA.

\section{$\underline{\mathrm{BS} 183}$}

Fisheries Engineering Research Program. 1957. Effect of Structures at Main Columbia River and

Certain Other Dams on Downstream Migration of Fingerling Salmon. North Pacific Division, U. S. Army Corps of Engineers, Portland, Oregon.

\section{$\underline{\mathrm{BS} 107}$}

Gauley, J. E., R. E. Anas, and L. C. Schlotterbeck. 1958. Downstream Movement of Salmonids at Bonneville Dam. U. S. Fish and Wildlife Service, Special Scientific Report \#236, Washington, DC.

\section{$\underline{B S 122}$}

Gessel, M. H., R. F. Krcma, W. D. Muir, C. S. McCutcheon, L. G. Gilbreath, and B. H. Monk. 1985. Evaluation of the Juvenile Collection and Bypass Systems at Bonneville Dam - 1984. Annual Report of Research for the U.S. Army Corps of Engineer District, Portland, Oregon by the National Oceanic and Atmospheric Administration, Northwest and Alaska Fisheries Science Center, Seattle, Washington.

\section{$\underline{\mathrm{BS} 032}$}

Gessel, M. H., L. G. Gilbreath, W. D. Muir, and R. F. Krcma. 1986a. Evaluation of the Juvenile Collection and Bypass Systems at Bonneville Dam - 1985. Annual Report of Research for the U.S. Army Corps of Engineer District, Portland, Oregon by the National Oceanic and Atmospheric Administration, Northwest and Alaska Fisheries Science Center, Seattle, Washington.

\section{$\underline{B S 031}$}


Gessel, M. H., L. G. Gilbreath, W. D. Muir, and R. F. Krcma. 1986b. Continuing studies to Improve and Evaluate the Fingerling Collection and Bypass System at Bonneville Dam. Annual Report of Research for the U.S. Army Corps of Engineer District, Portland, Oregon by the National Oceanic and Atmospheric Administration, Northwest and Alaska Fisheries Science Center, Seattle, Washington.

\section{$\underline{B S 131}$}

Gessel, M. H., L. G. Gilbreath, W. D. Muir, B. H. Monk, and R. F. Krcma. 1987. Evaluation of the Juvenile Salmonid Collection and Bypass Systems at Bonneville Dam - 1986. Annual Report of Research for the U.S. Army Corps of Engineer District, Portland, Oregon by the National Oceanic and Atmospheric Administration, Northwest and Alaska Fisheries Science Center, Seattle, Washington.

\section{BS029}

Gessel, M. H., B. H. Monk, and J. G. Williams. 1988. Evaluation of the Juvenile Fish Collection and Bypass Systems at Bonneville Dam - 1987. Annual Report of Research for the U.S. Army Corps of Engineer District, Portland, Oregon by the National Oceanic and Atmospheric Administration, Northwest and Alaska Fisheries Science Center, Seattle, Washington.

\section{$\underline{\mathrm{BS} 028}$}

Gessel, M. H., B. H. Monk, D. A. Brege, and J. G. Williams. 1989. Fish Guidance Efficiency Studies at Bonneville Dam First and Second Powerhouse - 1988. Annual Report of Research for the U.S. Army Corps of Engineer District, Portland, Oregon by the National Oceanic and Atmospheric Administration, Northwest and Alaska Fisheries Science Center, Seattle, Washington.

\section{$\underline{\mathrm{BS} 089}$}

Gessel, M. H., D. A. Brege, B. H. Monk, and J. G. Williams. 1990. Continued Studies to Evaluate the Juvenile Bypass Systems at Bonneville Dam, 1989. Annual Report of Research for the U.S. Army Corps of Engineer District, Portland, Oregon by the National Oceanic and Atmospheric Administration, Northwest Fisheries Science Center, Seattle, Washington.

\section{$\underline{\mathrm{BS} 086}$}

Gessel, M. H., J. G. Williams, D. A. Brege, R. F. Krcma, and D. R. Chambers. 1991. "Juvenile Salmonid Guidance at the Bonneville Dam Second Powerhouse, Columbia River, 1983-1989.” North American Journal of Fisheries Management. 11:400-412.

\section{$\underline{\mathrm{BS} 025}$}

Gessel. M. H., B. P. Sandford, B. H. Monk, and D. A. Brege. 1994. "Population estimates of northern squawfish, Ptychocheilus oregonensis, at Bonneville Dam First Powerhouse, Columbia River." NOAA technical memorandum NMFS-NWFSC-18, Northwest Fisheries Science Center, Seattle, Washington.

\section{$\underline{B S 118}$}


Gilbreath, L. G., E. M. Dawley, R. D. Ledgerwood, P. J. Bently, and S. J. Grabowski. 1993. Relative Survival of Subyearling Chinook Salmon that Have Passed Bonneville Dam via the Spillway or Second Powerhouse Turbines or Bypass System: Adult Recoveries through 1991. Annual Report of Research for the U.S. Army Corps of Engineer District, Portland, Oregon by the National Oceanic and Atmospheric Administration, Northwest Fisheries Science Center, Seattle, Washington.

\section{$\underline{B S 081}$}

Giorgi, A. E. and J. R. Stevenson. 1995. A Review of Biological Investigations Describing Smolt Passage Behavior at Portland District Corps of Engineer Projects: Implications in Surface Collection Systems. Contract Report prepared by Don Chapman Consultants, Inc. for the U.S. Army Engineer, Portland District, Portland, Oregon.

\section{BS075}

Hanks, M. E. and G. R. Ploskey. 2000. Experimental Hydroacoustic Deployments to Improve Estimates of Fish Guidance Efficiency. Technical Report ERDC/EL TR-00-8 prepared by the USACE Engineer Research and Development Center, Vicksburg, MS for the USACE Portland District, Portland, OR.

\section{$\underline{\mathrm{BS} 020}$}

Hansel, H. C., R. S. Shively, J. E. Hensleigh, B. D. Liedtke, R. E. Wardell, R. H. Wertheimer, and T. P. Poe. 1999. Movement, Distribution, and Behavior of Radio-Tagged Juvenile Chinook Salmon and Steelhead in the Forebay of Bonneville Dam, 1998. Annual Report by the U. S. Geological Survey, Columbia River Research Laboratory, Cook, Washington for the U. S. Army Engineer District, Portland, Oregon.

\section{$\underline{\mathrm{BS} 038}$}

Hawkes, L. A., R. C. Johnsen, W. W. Smith, R. D. Martinson, W. A. Hevlin, and R. F. Absolon. 1991. Monitoring of Downstream Salmon and Steelhead At Federal Hydroelectric Facilities. Annual Report 1990 by the U.S. Department Commerce, National Oceanic and Atmospheric Administration, National Marine Fisheries Service, ETSD, to the U.S. Department of Energy, Bonneville Power Administration, Portland, Oregon.

\section{$\underline{\mathrm{BS} 023}$}

Hensleigh, J. E., R. S. Shively, H. C. Hansel, J. M. Hardiman, G. S. Holmberg, B. D. Liedtke, T. L. Martinelli, R. E. Wardell, R. H. Wertheimer, and T. P. Poe. 1999. Movement, Distribution and Behavior of Radio-Tagged Juvenile Chinook Salmon and Steelhead in John Day, The Dalles and Bonneville Dam Forebays, 1997. Annual Report by the U. S. Geological Survey, Columbia River Research Laboratory, Cook, Washington for the U. S. Army Engineer District, Portland, Oregon. 
Holmberg, G. S., R. S. Shively, H. C. Hansel, T. L. Martinelli, M. B. Sheer, J. M. Hardiman, B. D. Liedtke, L. S. Blythe, and T. P. Poe. 1996. Movement, Distribution, and Behavior of RadioTagged Juvenile Chinook Salmon in John Day, The Dalles, and Bonneville Dam Forebays, 1996. Annual Report by the U. S. Geological Survey, Columbia River Research Laboratory, Cook, Washington for the U. S. Army Engineer District, Portland, Oregon.

\section{$\underline{\mathrm{BS} 036}$}

Holmberg, G. S., R. E. Wardell, M. G. Mesa, N. S. Adams, and D. W. Rondorf. 2001a. Evaluation of the Bonneville Dam Second Powerhouse new Juvenile Bypass System, 1999. Annual Report by U. S. Geological Survey, Columbia River Research Laboratory, Cook, Washington for the U. S. Army Engineer District, Portland, Oregon.

\section{BS016}

Holmberg, G. S., R. E. Wardell, M. G. Mesa, N. S. Adams, and D. W. Rondorf. 2001b. Evaluation of the Bonneville Dam Second Powerhouse Juvenile Bypass System, 2000. Annual Report by the U. S. Geological Survey, Columbia River Research Laboratory, Cook, Washington for the U. S. Army Engineer District, Portland, Oregon.

\section{$\underline{\mathrm{BS} 008}$}

Holmes, H. B. 1952. Loss of Fingerlings in Passing Bonneville Dam as Determined by Marking Experiments. U.S. Fish and Wildlife Service, Portland, Oregon.

\section{$\underline{\mathrm{BS} 103}$}

Jensen, A. L. 1987. Bonneville Dam Second Powerhouse Fish Guidance Research. Velocity Mapping Studies. Annual Report of Research for the U.S. Army Corps of Engineer District, Portland, Oregon by the National Oceanic and Atmospheric Administration, Northwest and Alaska Fisheries Science Center, Seattle, Washington.

\section{$\underline{\mathrm{BS} 092}$}

Johnsen, R. C. and E. M. Dawley. 1974. The Effect Of Spillway Flow Deflectors at Bonneville Dam on Total Gas Supersaturation and Survival of Juvenile Salmon. Annual Report of Research for the U.S. Army Corps of Engineer District, Portland, Oregon by the National Oceanic and Atmospheric Administration, Northwest and Alaska Fisheries Science Center, Seattle, Washington.

\section{$\underline{\mathrm{BS} 171}$}

Johnson, G. E., A. E. Giorgi, and M. W. Erho. 1997. Critical Assessment of Surface Flow Bypass Development in the Lower Columbia and Snake Rivers, completion report. U. S. Army Corps of Engineers, Walla Walla and Portland Districts, Portland, OR.

\section{BS128}


Johnson, G. E. and A. E. Giorgi. 1999. Development of Surface Flow Bypasses at Bonneville Dam: A Synthesis of Data from 1995 to 1998 and a Draft M\&E Plan for 2000. Annual Report, U.S. Army Corps of Engineers, Portland District, Portland, Oregon.

\section{$\underline{B S 015}$}

Johnson, G. E. and T. J. Carlson. 2001. Monitoring and evaluation of the Prototype Surface Collector at Bonneville First Powerhouse: Synthesis of Results. Final report, PNNL-13516.

\section{$\underline{B S 125}$}

Johnson, R. L. 1970. Tests of Fingerling Passage at Bonneville Dam. Summary. Report No. 18. U.S. Army Corps of Engineers, North Pacific Division, Fisheries-Engineering Research Program, August 1970.

\section{BS098}

Johnson, R. L., R. A. Moursund, and M. A. Simmons. 1999. Fish behavior in Front of the Prototype Surface Collector at Bonneville Dam in 1998. Final Report Prepared for U.S. Army Corps of Engineers, Portland District, Portland, Oregon.

\section{$\underline{\mathrm{BS} 030}$}

Johnson, R. L., M. A. Simmons, C. S. Simmons, K. D. Hand, and J. Thomas. 2000. Hydroacoustic Evaluation of Fish Behavior in Front of the Prototype Surface Collector at Bonneville Dam, 1999. Final Report Submitted to U.S. Army Corps of Engineers, Portland District, Portland, Oregon.

\section{$\underline{\mathrm{BS} 027}$}

Johnson, R. L., M. A. Simmons, C. S. Simmons, C. A. McKinstry, S. L. Thorsten, K. D. Hand, and M. A. Chamness. 2001. Hydroacoustic Evaluation of Fish Behavior at Bonneville Dam First Powerhouse: 2000 Prototype Surface Flow Bypass. Final report by the Pacific Northwest National Laboratory to the U. S. Army Corps of Engineers, Portland District, Portland, Oregon.

\section{$\underline{\mathrm{BS} 124}$}

Jones, S. T., G. M. Starke, and R. J. Stansell. 1996. Predation by Birds and Effectiveness of Predation Control Measures at Bonneville, The Dalles and John Day Dams in 1995. CENPP-CO-SRF, USACE.

\section{$\underline{B S 108}$}

Jones, S. T., G. M. Starke, and R. J. Stansell. 1997. Predation by Gulls and Effectiveness of Predation Control Measures at Bonneville, The Dalles and John Day Dams in 1996. CENWP-CO-SRF, USACE.

\section{$\underline{\mathrm{BS} 105}$}


Jones, S. T., G. M. Starke, and R. J. Stansell. 1999. Predation by Gulls and Effectiveness of Predation Control Measures at Bonneville, The Dalles and John Day Dams. CENWP-OP-SRF, USACE.

$\underline{\text { BS106 }}$

Krcma, R. F., C. W. Long, and C. S. Thompson. 1978. Research on the Development af a Fingerling Protection System for Low Head Dams - 1977. Annual Report of Research for the U.S. Army Corps of Engineer District, Portland, Oregon by the National Oceanic and Atmospheric Administration, Northwest and Alaska Fisheries Science Center, Seattle, Washington.

\section{$\underline{B S 095}$}

Krcma, R. F., D. DeHart, M. Gessel, C. Long, and C. W. Sims. 1982. Evaluation of Submersible Traveling Screens, Passage of Juvenile Salmonids through the Ice-Trash Sluiceway, and Cycling of Gatewell-Orifice Operations at the Bonneville First Powerhouse, 1981. Annual Report of Research for the U.S. Army Corps of Engineer District, Portland, Oregon by the National Oceanic and Atmospheric Administration, Northwest and Alaska Fisheries Science Center, Seattle, Washington.

\section{$\underline{\text { BS039 }}$}

Krcma, R. F., M. H. Gessel, W. D. Muir, C. S. McCutcheon, L. G. Gilbreath, and B. H. Monk. 1984. Evaluation of the Juvenile Collection and Bypass System at Bonneville Dam - 1983. Annual Report of Research for the U.S. Army Corps of Engineer District, Portland, Oregon by the National Oceanic and Atmospheric Administration, Northwest and Alaska Fisheries Science Center, Seattle, Washington.

\section{$\underline{\mathrm{BS} 033}$}

Ledgerwood, R. D., E. M. Dawley, L. G. Gilbreath, P. J. Bently, B. P. Sanford, and M. H. Schiewe. 1990. Relative Survival Of Subyearling Chinook Salmon Which Have Passed Bonneville Dam Via the Spillway or the Second Powerhouse Turbines or Bypass System in 1989, with Comparisons to 1987 and 1988. Annual Report of Research for the U.S. Army Corps of Engineer District, Portland, Oregon by the National Oceanic and Atmospheric Administration, Northwest Fisheries Science Center, Seattle, Washington.

\section{$\underline{\mathrm{BS} 085}$}

Ledgerwood, R. D., E. M. Dawley, L. G. Gilbreath, P. T. Bently, B. P. Sanford, and M. H. Schiewe. 1991. Relative Survival of Subyearling Chinook Salmon that Have Passed through the Turbines and Bypass System of Bonneville Dam Second Powerhouse, 1990. Annual Report of Research for the U.S. Army Corps of Engineer District, Portland, Oregon by the National Oceanic and Atmospheric Administration, Northwest Fisheries Science Center, Seattle, Washington. 
Ledgerwood, R. D., E. M. Dawley, L. G. Gilbreath, L. T. Parker, B. P. Sanford, and S. J. Grabowski. 1994. Relative Survival of Subyearling Chinook Salmon after Passage through the Bypass System at the First Powerhouse or a Turbine at the First or Second Powerhouse and the Tailrace Basins at Bonneville Dam, 1992. Annual Report of Research for the U.S. Army Corps of Engineer District, Portland, Oregon by the National Oceanic and Atmospheric Administration, Northwest Fisheries Science Center, Seattle, Washington.

\section{$\underline{\text { BS079 }}$}

Long, C. W. 1976. Final Report on Vertical Distribution of Fingerling Salmonids in Turbine Intakes of the Bonneville First Powerhouse. Annual Report of Research for the U.S. Army Corps of Engineer District, Portland, Oregon by the National Oceanic and Atmospheric Administration, Northwest and Alaska Fisheries Science Center, Seattle, Washington.

\section{BS097}

Long, C. W. and R. F. Krcma. 1977. Development of a System for Protecting Juvenile Salmonids at the Second Powerhouse at Bonneville Dam - Progress 1976. Annual Report of Research for the U.S. Army Corps of Engineer District, Portland, Oregon by the National Oceanic and Atmospheric Administration, Northwest and Alaska Fisheries Science Center, Seattle, Washington.

\section{$\underline{\text { BS096 }}$}

Magne, R. A. 1984. Hydroacoustic Survey of the Bonneville Second Powerhouse Forebay to Determine the Spatial Distribution of Outmigrant Juvenile Salmonids. U.S. Army Corps of Engineers, Portland District, NPPOP-RM-FFU, Fisheries Office, Bonneville Lock and Dam, Cascade Locks, Oregon.

\section{$\underline{\mathrm{BS} 110}$}

Magne, R. A. 1987a. Bonneville II Hydroacoustic Monitoring Memorandum for the Record \#1, 27 May 1987.

\section{$\underline{\text { BS094 }}$}

Magne, R. A. 1987b. Hydroacoustic Monitoring at the Bonneville Dam Project in 1988, Proposal plus 87 data. U.S. Army Corps of Engineers, Portland District, Bonneville Lock and Dam, Cascade Locks, Oregon.

\section{$\underline{\mathrm{BS} 043}$}

Magne, R. A. 1987c. Hydroacoustic Monitoring of Downstream Migrant Juvenile Salmonids at Bonneville Dam, 1987. U.S. Army Corp of Engineers, Portland District, Operations Division, Fisheries Field Unit, Bonneville Lock and Dam, Cascade Locks, Oregon.

\section{$\underline{B S 109}$}


Magne, R. A., D. J. Rawding, and W. T. Nagy. 1986. Hydroacoustic Monitoring at the Bonneville Dam Second Powerhouse during 1986 Fish Guiding Efficiency Tests. Fishery Field Unit, U.S. Army Corps of Engineers, Portland District, Portland, Oregon.

\section{$\underline{\mathrm{BS} 042}$}

Magne, R. A., R. J. Stansell, and W. T. Nagy. 1989. A Summary of Hydroacoustic Monitoring at the Bonneville Dam Second Powerhouse in 1988. Fishery Field Unit, U.S. Army Corps of Engineers, Portland District, Portland, Oregon.

\section{$\underline{\mathrm{BS} 044}$}

Martinson, R. D., R. J. Graves, R. B. Mills, and J. W. Kamps. 1997. Monitoring of Downstream Salmon and Steelhead at Federal Hydroelectric Facilities - 1996. Prepared for U.S. Department of Energy, Bonneville Power Administration, Environment, Fish and Wildlife, Portland, Oregon, Project Number 84-014, Contract Numbers DE-AI79-85BP20733.

\section{$\underline{B S 116}$}

McConnell, R. J. and W. D. Muir. 1982. Preliminary Evaluation of the Bonneville Juvenile Bypass System - Second Powerhouse. Annual Report of Research for the U.S. Army Corps of Engineer District, Portland, Oregon by the National Oceanic and Atmospheric Administration, Northwest and Alaska Fisheries Science Center, Seattle, Washington.

\section{$\underline{\mathrm{BS} 104}$}

Michimoto, R. T. and L. Korn. 1969. A Study to Determine the Value of Using the Ice-Trash Sluiceway for Passing Downstream-Migrant Salmonids at Bonneville Dam. Final report by Research Division, Fish Commission of Oregon, September 1969. Prepared for U.S. Army Corps of Engineers, Portland District, Contract DACW-57-69-C-0099.

\section{$\underline{\text { BS099 }}$}

Michimoto, R. T. 1971. Bonneville and The Dalles Dams Ice-Trash Sluiceway Studies, 1971. U. S. Army Corps of Engineers, North Pacific Division, Fisheries-Engineering Research Program, Portland, Oregon, Report \#20.

\section{$\underline{\text { BS091 }}$}

Monk, B. H., G. E. Varney, and S. J. Grabowski. 1992. Continuing Studies to Evaluate and Improve Submersible Traveling Screens for Fish Guidance at Bonneville Dam First Powerhouse, 1991. Annual Report of Research for the U.S. Army Corps of Engineer District, Portland, Oregon by the National Oceanic and Atmospheric Administration, Northwest Fisheries Science Center, Seattle, Washington.

\section{BS082}


Monk, B. H., J. A. Ross, B. P. Sanford, and D. B. Dey. 1993. Continuing Studies to Measure and Improve Fish Guidance Efficiency of Submersible Traveling Screens at Bonneville Dam First Powerhouse, 1992. Annual Report of Research for the U.S. Army Corps of Engineer District, Portland, Oregon by the National Oceanic and Atmospheric Administration, Northwest Fisheries Science Center, Seattle, Washington.

\section{$\underline{\mathrm{BS} 080}$}

Monk, B. H., B. P. Sandford, and D. B. Dey. 1994. Evaluation of the Fish Guidance Efficiency of Submersible Traveling Screens and Other Modifications at Bonneville Dam Second Powerhouse, 1993. Annual Report of Research for the U.S. Army Corps of Engineer District, Portland, Oregon by the National Oceanic and Atmospheric Administration, Northwest Fisheries Science Center, Seattle, Washington.

\section{BS055}

Monk, B. H., B. P. Sandford, and D. B. Dey. 1995. Evaluation of the Fish Guidance Efficiency of Submersible Traveling Screens and other Modifications at Bonneville Dam Second Powerhouse, 1994. Annual Report of Research for the U.S. Army Corps of Engineer District, Portland, Oregon by the National Oceanic and Atmospheric Administration, Northwest Fisheries Science Center, Seattle, Washington.

\section{$\underline{B S 056}$}

Monk, B. H., B. P. Sandford, and D. B. Dey. 1999a. Evaluation of Extended-Length Submersible Bar Screens at Bonneville Dam First Powerhouse, 1998. Report of Research for the U.S. Army Corps of Engineer District, Portland, Oregon by the National Oceanic and Atmospheric Administration, Northwest Fisheries Science Center, Seattle, Washington.

\section{$\underline{B S 018}$}

Monk, B. H., M. H. Gessel, and J. W. Ferguson. 1999b. An Evaluation of the Biological Database for Improving Fish Guidance Efficiency at Bonneville Dam Second Powerhouse. Annual Report of Research for the U.S. Army Corps of Engineer District, Portland, Oregon by the National Oceanic and Atmospheric Administration, Northwest Fisheries Science Center, Seattle, Washington.

\section{$\underline{\mathrm{BS} 054}$}

Monk, B. H. and B. P. Sandford. 2001. Evaluation of Extended-Length Submersible Bar Screens at Bonneville Dam First Powerhouse, 2000. Annual Report of Research for the U.S. Army Corps of Engineer District, Portland, Oregon by the National Oceanic and Atmospheric Administration, Northwest Fisheries Science Center, Seattle, Washington.

\section{$\underline{\mathrm{BS} 009}$}

Monk, B. H., R. Absolon, B. P. Sandford, and J. W. Ferguson. 2002. Evaluation of Intake Modifications at Bonneville Dam Second Powerhouse, 2001. Annual Report of Research for the U.S. Army Corps of Engineer District, Portland, Oregon by the National Oceanic and Atmospheric 
Administration, Northwest Fisheries Science Center, Seattle, Washington.

$\underline{\mathrm{BS} 003}$

Monk, B. H., B. P. Sandford, D. A. Brege, and J. W. Ferguson. 2004. Evaluation of Turbine Intake Modifications at the Bonneville Dam Second Powerhouse, 2002. Annual Report of Research for the U.S. Army Corps of Engineer District, Portland, Oregon by the National Oceanic and Atmospheric Administration, Northwest Fisheries Science Center, Seattle, Washington.

\section{$\underline{\mathrm{BS} 142}$}

Muir, W. D., A. E. Giorgi, W. S. Zaugg, and B. R. Beckman. 1989. An Assessment of the Relationship Between Smolt Development and Fish Guidance Efficiency at Bonneville Dam. Annual Report of Research for the U.S. Army Corps of Engineer District, Portland, Oregon by the National Oceanic and Atmospheric Administration, Northwest Fisheries Science Center, Seattle, Washington.

\section{$\underline{\mathrm{BS} 045}$}

Muir, W. D., S. G. Smith, J. G. Williams, E. E. Hockersmith, and J. R. Skalski. 2001. Survival Estimates for Migrant Yearling Chinook Salmon and Steelhead Tagged with Passive Integrated Transponders in the Lower Snake and lower Columbia Rivers, 1993-1998. North American Journal of Fisheries Management. 21:269-282.

$\underline{\text { BS067 PDF reproduced with permission of } \underline{w w w . f i s h e r i e s . o r g . ~}}$

Muir, W. D., S. G. Smith, R. W. Zabel, D. M. Marsh, and J. G. Williams. 2003. Survival Estimates for the Passage of Spring-Migrating Juvenile Salmonids through Snake and Columbia River Dams and Reservoirs, 2002. Annual Report of Research for the U.S. Army Corps of Engineer District, Portland, Oregon by the National Oceanic and Atmospheric Administration, Northwest Fisheries Science Center, Seattle, Washington.

\section{$\underline{\mathrm{BS} 074}$}

Nagy, W. T. and R. A. Magne. 1986. Hydroacoustic Study of Juvenile Fish Passage at the Bonneville Second Powerhouse in 1985. U.S. Army Corps of Engineers, Portland, NPPOP-P-NR-FFU, Fisheries Office, Bonneville Lock and Dam, Cascade Locks, Oregon, 17 April 1986.

\section{$\underline{\mathrm{BS} 093}$}

Nagy, W. T. 1997. Final Report on the Search to Find a Non-Lethal Method for Measuring Fish Guiding Efficiency within Turbine Intakes. U.S. Army Corps of Engineers, Portland District, Fish Field Unit, Bonneville Lock and Dam, Cascade Locks, Oregon, June 1997.

\section{$\underline{\mathrm{BS} 078}$}


Normandeau Associates Inc., J. R. Skalski, and Mid Columbia Consulting Inc. 1996. Potential Effects of Spillway Flow Deflectors on Fish Condition and Survival at the Bonneville Dam, Columbia River. Drumore, Pennsylvania.

\section{$\underline{\mathrm{BS} 126}$}

Normandeau Associates Inc., J. R. Skalski, and Mid-Columbia Consulting Inc. 2000. Direct Survival and Condition of Juvenile Chinook Salmon Passed through an Existing and New Minimum Gap Runner Turbines at Bonneville Dam First Powerhouse, Columbia River. Prepared for Department of the Army, Portland District, Corps of Engineers, Portland, Oregon.

\section{$\underline{\mathrm{BS} 077}$}

Normandeau Associates Inc., J. R. Skalski, and Mid-Columbia Consulting Inc. 2001. Passage Survival Investigation of Juvenile Chinook Salmon through Bonneville Powerhouse Ii Bypass Sluice at Two Tailwater Conditions Columbia River, Washington. Final report.

\section{BS123}

Normandeau Associates Inc., Mid Columbia Consulting Inc., and J. R. Skalski. 2003. Juvenile Salmonid Survival and Condition in Passage through Modified Spillbays at Bonneville Dam, Columbia River. Prepared for U.S. Army Corps of Engineers, Portland District, Portland, Oregon.

\section{$\underline{\mathrm{BS} 002}$}

Northwest Fisheries Science Center. 2000. Salmonid Travel Time and Survival Related to Flow in the Columbia River Basin. White Paper of the National Oceanic and Atmospheric Administration, Northwest Fisheries Science Center, Seattle, Washington.

\section{$\underline{\mathrm{BS} 069}$}

Petersen, J. H., D. M. Gadomski, and T. P. Poe. 1994. "Differential predation by northern squawfish (Ptychocheilus oregonensis) on live and dead juvenile salmonids in the Bonneville Dam tailrace (Columbia River).” Can. J. Fish. Aquat. Sci. 51:1197-1204.

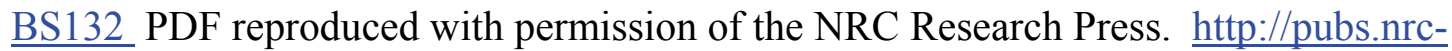
cnrc.gc.ca/cgi-bin/rp/rp2 desc_e?cjfas

Ploskey, G. R., L. R. Lawrence, P. N. Johnson, W. T. Nagy, and M. G. Burczinski. 1998. Hydroacoustic Evaluation of Juvenile Salmonid Passage at Bonneville Dam Including Surface Collection Simulations. Technical Report EL-98-4, Prepared for the U.S. Army Corps of Engineers, Portland District, Portland, Oregon, by US Army Corps of Engineers Waterways Experiment Station, Vicksburg, Mississippi.

\section{$\underline{\mathrm{BS} 040}$}


Ploskey, G. R., P. N. Johnson, and T. J. Carlson. 2000. Evaluation of a low-frequency, sound-pressure system for guiding juvenile salmon away from turbines at Bonneville Dam, Columbia River. North American Journal of Fisheries Management. 20:951-967.

$\underline{\mathrm{BS} 021}$ PDF reproduced with permission of $\underline{w w w . f i s h e r i e s . o r g}$.

Ploskey, G. R., W. T. Nagy, L. R. Lawrence, D. S. Patterson, C. R. Schilt, P. N. Johnson, and J. R. Skalski. 2001a. Hydroacoustic Evaluation of Juvenile Salmonid Passage through Experimental Routes at Bonneville Dam in 1998. ERDC/EL TR-01-2, U.S. Army Engineer Research and Development Center, Vicksburg, Mississippi.

\section{$\underline{\mathrm{BS} 019}$}

Ploskey, G. R., P. N. Johnson, W. T. Nagy, C. R. Schilt, L. R. Lawrence, D. S. Patterson, and J. R. Skalski. 2001b. Hydroacoustic Evaluation of the Bonneville Dam Prototype Surface Collector in 1999. ERDC/EL TR-01-1, U.S. Army Engineer Research and Development Center, Vicksburg, Mississippi.

\section{$\underline{\mathrm{BS} 048}$}

Ploskey, G. R., C. R. Schilt, M. E. Hanks, J. R. Skalski, W. T. Nagy, P. N. Johnson, D. S. Patterson, J. Kim, and L. R. Lawrence. 2002a. Hydroacoustic Evaluation of Fish Passage through Bonneville Dam in 2000. ERDC/EL TR-02-8, U.S. Army Engineer Research and Development Center, Vicksburg, Mississippi.

$\underline{\mathrm{BS} 011}$

Ploskey, G. R., C. R. Schilt, M. E. Hanks, J. R. Skalski, W. T. Nagy, P. N. Johnson, D. S. Patterson, J. Kim, and L. R. Lawrence. 2002b. Hydroacoustic Evaluation of a Prototype Surface Collector and In-Turbine Screens at Bonneville Dam Powerhouse 1 in 2000. ERDC/EL TR-02-15, U.S. Army Engineer Research and Development Center, Vicksburg, Mississippi.

\section{$\underline{\mathrm{BS} 012}$}

Ploskey, G. R., C. R. Schilt, M. E. Hanks, P. N. Johnson, J. Kim, J. S. Skalski, D. S. Patterson, W. T. Nagy, and L. R. Lawrence. 2002c. Hydroacoustic Evaluation of Fish-Passage Efficiency at Bonneville Dam in 2001. Prepared for U.S. Army Corps of Engineers Under a Related Services Agreement With the U.S. Department of Energy, PNNL-14047.

\section{$\underline{\mathrm{BS} 004}$}

Ploskey, G. R., C. R. Schilt, J. Kim, C. W. Escher, and J. R. Skalski. 2003. Hydroacoustic Evaluation of Fish Passage through Bonneville Dam in 2002. Annual Report, U.S. Army Corps of Engineers, Under a Related Services Agreement with the U.S. Department of Energy, PNNL-14356.

\section{BS001}


Ploskey, G. R., M. A. Weiland, and C. R. Schilt. 2004. Evaluation of Fish Losses Through Screen Gaps at Modified and Unmodified Intakes of Bonneville Dam Second Powerhouse in 2003. Prepared for U.S. Army Corps of Engineers Portland District, Portland, Oregon Under a Related Services Agreement With the U.S. Department of Energy, Contract DE-AC06-76RLO1830, PNNL-14047.

\section{BS140}

Ploskey G. R., M. A. Weiland, C. R. Schilt, P. N. Johnson, M. E. Hanks, D. S. Patterson, J. R. Skalski, and J. Hedgepeth. 2005. Hydroacoustic Evaluation of Fish Passage through Bonneville Dam in 2004. PNNL-15249, Pacific Northwest National Laboratory, Richland, WA, for the U. S. Army Corps of Engineers, Portland District, Portland, Oregon.

\section{BS174}

Ploskey, G. R., G. E. Johnson, M. A. Weiland, F. Khan, R. P. Mueller, J. A. Serkowski, C. L. Rakowski, J. B. Hedgepeth, J. R. Skalski, B. D. Ebberts, and B. A. Klatte. 2006a. "Acoustic camera evaluation of juvenile salmonid approach and fate at surface flow outlets of two hydropower dams." HydroVision 2006 Conference held in Portland, Oregon. HCI Publications, Kansas City Missouri, USA. http://www.hcipub.com/

$\underline{\text { BS181 PDF reproduced with permission of HCI Publications. http://www.hcipub.com/ }}$

Ploskey, G. R., J. Kim, M. A. Weiland, J. S. Hughes, and E. S. Fischer. 2006b. Reanalysis of Hydroacoustic Fish-Passage Data from Bonneville Dam after Spill-Discharge Corrections. Draft Report by the Pacific Northwest National Laboratory, Richland, WA, for the U. S. Army Corps of Engineers, Portland District, Portland, Oregon.

\section{$\underline{\mathrm{BS} 182}$}

Ploskey, G. R., M. A. Weiland, S. A. Zimmerman, J. S. Hughes, K. Bouchard, E. S. Fischer, C. R. Schilt, M. E. Hanks, J. Kim, J. R. Skalski, J. Hedgepeth, and W. T. Nagy. 2006c. Hydroacoustic Evaluation of Fish Passage through Bonneville Dam in 2005. PNNL-15944, Pacific Northwest National Laboratory, Richland, WA, for the U. S. Army Corps of Engineers, Portland District, Portland, Oregon.

\section{$\underline{\mathrm{BS} 175}$}

Plumb, J. M., M. S. Novick, B. D. Liedtke, and N. S. Adams. 2001. Passage Behavior of Radio-Tagged Yearling Chinook Salmon and Steelhead at Bonneville Dam Associated with the Surface Bypass Program, 1999. Annual Report by the U. S. Geological Survey, Columbia River Research Laboratory, Cook, Washington for the U. S. Army Engineer District, Portland, Oregon.

\section{$\underline{\mathrm{BS} 017}$}

Portland District, USACE. 2002. Bonneville Decision Document: Juvenile Fish Passage

Recommendation. U. S. Army Engineer District, Portland, Oregon.

\section{$\underline{\text { BS134 }}$}


Reagan, R. E., S. D. Evans, L. S. Wright, M. J. Farley, N. S. Adams, and D. W. Rondorf. 2006. Passage Behavior of Radio-Tagged Yearling Chinook Salmon and Steelhead at Bonneville Dam, 2004: Revised for Corrected Spill. Annual Report by the U. S. Geological Survey, Columbia River Research Laboratory, Cook, Washington for the U. S. Army Engineer District, Portland, Oregon.

\section{$\underline{\mathrm{BS} 179}$}

Reservoir Control Center. 1985a. Columbia River Fishery Operations 1984 Annual report. U.S. Army Corps of Engineers, North Pacific Division, Portland, Oregon.

\section{$\underline{B S 149}$}

Reservoir Control Center. 1985b. Juvenile Fish Passage Plan for 1985 for Corps of Engineers Projects. U.S. Army Corps of Engineers, North Pacific Division, Portland, Oregon.

\section{$\underline{B S 150}$}

Reservoir Control Center. 1986. Operating Standards and Maintenance Plan for 1986. U.S. Army Corps of Engineers, North Pacific Division, Portland, Oregon.

\section{$\underline{B S 151}$}

Reservoir Control Center. 1987. Juvenile Fish Passage Plan for 1987 for Corps of Engineers Projects. U.S. Army Corps of Engineers, North Pacific Division, Portland, Oregon.

\section{$\underline{\mathrm{BS} 152}$}

Reservoir Control Center. 1988. Juvenile Fish Passage Plan for 1988 for Corps of Engineers Projects. U.S. Army Corps of Engineers, North Pacific Division, Portland, Oregon.

\section{$\underline{B S 153}$}

Reservoir Control Center. 1989. Juvenile Fish Passage Plan for 1989 for Corps of Engineers Projects. U.S. Army Corps of Engineers, North Pacific Division, Portland, Oregon.

\section{$\underline{B S 154}$}

Reservoir Control Center. 1990. Fish Passage Plan for 1990 Corps of Engineers Projects. U.S. Army Corps of Engineers, North Pacific Division, Portland, Oregon.

\section{$\underline{B S 155}$}

Reservoir Control Center. 1991. Fish Passage Plan for 1991 Corps of Engineers Projects. U.S. Army Corps of Engineers, North Pacific Division, Portland, Oregon.

\section{$\underline{B S 156}$}


Reservoir Control Center. 1992. Fish Passage Plan for 1992 Corps of Engineers Projects. U.S. Army Corps of Engineers, North Pacific Division, Portland, Oregon.

\section{$\underline{B S 157}$}

Reservoir Control Center. 1993. Fish Passage Plan for 1993 Corps of Engineers Projects. U.S. Army Corps of Engineers, North Pacific Division, Portland, Oregon.

\section{$\underline{B S 158}$}

Reservoir Control Center. 1994. Fish Passage Plan for 1994 Corps of Engineers Projects. U.S. Army Corps of Engineers, North Pacific Division, Portland, Oregon.

\section{$\underline{B S 159}$}

Reservoir Control Center. 1995. Fish Passage Plan for 1995 Corps of Engineers Projects. U.S. Army Corps of Engineers, North Pacific Division, Portland, Oregon.

\section{$\underline{\mathrm{BS} 160}$}

Reservoir Control Center. 1996. Fish Passage Plan for 1996 Corps of Engineers Projects. U.S. Army Corps of Engineers, North Pacific Division, Portland, Oregon.

\section{$\underline{\mathrm{BS} 161}$}

Reservoir Control Center. 1997. Fish Passage Plan for 1997 Corps of Engineers Projects. U.S. Army Corps of Engineers, North Pacific Division, Portland, Oregon.

\section{BS162}

Reservoir Control Center. 1998. Fish Passage Plan for 1998 Corps of Engineers Projects. U.S. Army Corps of Engineers, North Pacific Division, Portland, Oregon.

\section{$\underline{B S 163}$}

Reservoir Control Center. 1999. Fish Passage Plan for 1999 Corps of Engineers Projects. U.S. Army Corps of Engineers, North Pacific Division, Portland, Oregon.

\section{$\underline{\mathrm{BS} 164}$}

Reservoir Control Center. 2000. Fish Passage Plan for 2000 Corps of Engineers Projects. U.S. Army Corps of Engineers, North Pacific Division, Portland, Oregon.

\section{$\underline{\mathrm{BS} 165}$}


Reservoir Control Center. 2001. Fish Passage Plan for 2001 Corps of Engineers Projects. U.S. Army Corps of Engineers, North Pacific Division, Portland, Oregon.

\section{BS166}

Reservoir Control Center. 2002. Fish Passage Plan for 2002 Corps of Engineers Projects. U.S. Army Corps of Engineers, North Pacific Division, Portland, Oregon.

\section{BS167}

Reservoir Control Center. 2003. Fish Passage Plan for 2003 Corps of Engineers Projects. U.S. Army Corps of Engineers, North Pacific Division, Portland, Oregon.

\section{$\underline{\mathrm{BS} 168}$}

Reservoir Control Center. 2004. Fish Passage Plan for 2004 Corps of Engineers Projects. U.S. Army Corps of Engineers, North Pacific Division, Portland, Oregon.

\section{$\underline{B S 169}$}

Reservoir Control Center. 2005. Fish Passage Plan for 2005 Corps of Engineers Projects. U.S. Army Corps of Engineers, North Pacific Division, Portland, Oregon.

\section{$\underline{\mathrm{BS} 138}$}

Shrank, B. P., E. M. Dawley, and B. Ryan. 1997. Evaluation of the Effects of Dissolved Gas Supersaturation on Fish and Invertebrates in Priest Rapids Reservoir and Downstream from Bonneville and Ice Harbor Dams, 1995. Annual Report of Research for the U.S. Army Corps of Engineer District, Portland, Oregon by the National Oceanic and Atmospheric Administration, Northwest Fisheries Science Center, Seattle, Washington.

\section{BS119}

Simmons, M. A., C. S. Simmons, S. L. Thorsten, M. A. Chamness, R. L. Johnson, C. A. McKinstry, and K. D. Hand. 2001 . Splitbeam Evaluation of Near-Field Fish Behavior at Bonneville Dam First Powerhouse, Unit 8. U.S. Army Corps of Engineers, Pacific Northwest National Laboratory, Richland, Washington.

\section{$\underline{B S 115}$}

Skalski, J. R., D. Mathur, and P. G. Heisey. 2002. Effects of turbine operating efficiency on smolt passage survival. North American Journal of Fisheries Management 22: 1193-1200.

$\underline{B S 170}$ PDF reproduced with permission of www.fisheries.org. 
Smith, S. G., W. D. Muir, S. Achord, E. E. Hockersmith, B. P. Sandford, J. G. Williams, and J. R. Skalski. 2000a. Survival Estimates for the Passage of Juvenile Salmonids through Snake \& Columbia River Dams \& Reservoirs, 1998. Annual Report Prepared for the U.S. Department of Energy, Bonneville Power Administration, Portland, Oregon by the National Oceanic and Atmospheric Administration, Northwest Fisheries Science Center, Seattle, Washington.

\section{BS064}

Smith, S. G., W. D. Muir, G. A. Axel, R. W. Zabel, J. G. Williams, and J. R. Skalski. 2000b. Survival Estimates for the Passage of Juvenile Salmonids through Snake and Columbia River Dams and Reservoirs, 1999. Annual Report of Research for the U.S. Army Corps of Engineer District, Portland, Oregon by the National Oceanic and Atmospheric Administration, Northwest Fisheries Science Center, Seattle, Washington.

\section{BS073}

Snelling, J. C. and S. A. Mattson. 1996. Movement and Behavior of Juvenile Salmonids at Three Lower Columbia River Dams. Report by the Cooperative Research Unit, Corvallis, Oregon for the U. S. Geological Survey and the U. S. Army Engineer District, Portland, Oregon.

\section{$\underline{B S 127}$}

Stansell, R. J., R. A. Magne, W. T. Nagy, and L. M. Beck. 1990. Hydroacoustic Monitoring of Downstream Migrant Juvenile Salmonids at Bonneville Dam, 1989. Fishery Field Unit, U.S. Army Engineer, Portland District, Portland, Oregon.

\section{$\underline{\mathrm{BS} 050}$}

Thorne, R. E. and E. S. Kuehl. 1989. Evaluation of Hydroacoustics Techniques for Assessment of Juvenile Fish Passage at Bonneville Powerhouse I. Final Report by BioSonics, Inc., Seattle, Washington for the U.S. Army Engineer, Portland District, Portland, Oregon.

\section{$\underline{\mathrm{BS} 047}$}

Thorne, R. E. and G. E. Johnson. 1993. A review of hydroacoustic studies for estimation of salmonid downriver migration past hydroelectric facilities on the Columbia and Snake Rivers in the 1980s. Reviews in Fisheries Science. 1 (1):27-56.

Permission was not granted by the publisher (Taylor and Francis Group) for us to provide a PDF of this copyrighted article.

Toner, M. A. and E. M. Dawley. 1995. Evaluation of the Effects of Dissolved Gas Supersaturation on Fish and Invertebrates Downstream from Bonneville Dam, 1993. Annual Report of Research for the U.S. Army Corps of Engineer Division, Portland, Oregon by the National Oceanic and Atmospheric Administration, Northwest Fisheries Science Center, Seattle, Washington.

\section{BS121}


Toner, M. A., B. Ryan, and E. M. Dawley. 1995. Evaluation of the Effects of Dissolved Gas Supersaturation on Fish and Invertebrates Downstream from Bonneville, Ice Harbor and Priest Rapids Dams, 1994. Annual Report of Research for the U.S. Army Corps of Engineer Division, Portland, Oregon by the National Oceanic and Atmospheric Administration, Northwest Fisheries Science Center, Seattle, Washington.

\section{$\underline{\mathrm{BS} 120}$}

Uremovich, B. L., S. P. Cramer, C. F. Willis, and C. O. Junge. 1980. Passage of Juvenile Salmonids Through The Ice-Trash Sluiceway And Squawfish Predation at Bonneville Dam, 1980. Oregon Department of Fish and Wildlife Annual Progress Report Prepared for the U.S. Army Engineer, Portland District, Portland, Oregon.

\section{BS051}

Ward, D. L., J. H. Petersen, and J. J. Loch. 1995. Index of predation on juvenile salmonids by northern squawfish in the lower and middle Columbia River and in the lower Snake River. Trans. Am. Fish. Soc. 124:321-334.

$\underline{\text { BS135 }}$ PDF reproduced with permission of www.fisheries.org.

Willis, C. F. and B. L. Uremovich. 1981. Evaluation of the Ice and Trash Sluiceway at Bonneville Dam as a Bypass System for Juvenile Salmonids, 1981. Oregon Department of Fish and Wildlife Annual Progress Report Prepared for the U.S. Army Engineer, Portland District, Portland, Oregon.

\section{$\underline{\mathrm{BS} 062}$}

Zabel, R. W., S. G. Smith, W. D. Muir, D. M. Marsh, J. G. Williams, and J. R. Skalski. 2001. Survival Estimates for the Passage of Spring-Migrating Juvenile Salmonids Through Snake And Columbia River Dams and Reservoirs, 2000. Annual Report to the U.S. Department of Energy, Bonneville Power Administration, Portland, Oregon by the National Oceanic and Atmospheric Administration, Northwest Fisheries Science Center, Seattle, Washington.

\section{$\underline{\mathrm{BS} 072}$}

Zimmerman, M. P. and D. L. Ward. 1999. Index of Predation on Juvenile Salmonids by Northern Pikeminnow in the Lower Columbia River Basin, 1994-1996. Transactions of the American Fisheries Society. 128:995-1007.

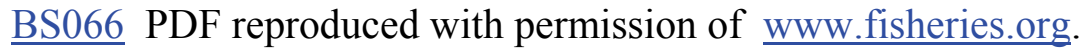


Appendix B

\section{Annotated Bibliography}

References on C.D. have Hyperlinks to Portable Document Files (PDFs) containing Copies of Original Papers 



\section{Appendix B}

\section{Annotated Bibliography}

This annotated bibliography includes citations with hyperlinks to portable document files on this digital video disk (DVD) and brief abstracts describing original juvenile salmonid passage and survival studies at Bonneville Dam from 1939 through 2005. The intent of the abstract is to elaborate slightly on the title so that readers less familiar with the research can determine whether they want to open the portable document file (PDF). For convenience, citations with more than two authors are arranged by first author, year, and an assigned alphabetic letter within years, because that is how they were called out in the synthesis report (e.g., Evans et al. 2006b).

Adams, N. S., R. E. Reagan, S. D. Evans, M. J. Farley, L. S. Wright, and D. W. Rondorf. 2006. Movement, Distribution, and Passage Behavior of Radio-Tagged Juvenile Chinook Salmon and Steelhead at Bonneville Dam, 2005. Draft Annual Report by the U. S. Geological Survey, Columbia River Research Laboratory, Cook, Washington for the U. S. Army Engineer District, Portland, Oregon.

In 2005, the authors used radio telemetry to examine the movements and behavior of yearling and subyearling Chinook salmon Oncorhynchus tshawytscha and steelhead O. mykiss in the forebay of Bonneville Dam. There are actually two reports under this cover and they have different authors. The first (Page 1) is on yearling Chinook salmon and steelhead, and the second (Page 54) is on subyearling Chinook salmon, and the two reports have different authors. The objectives of this research were to: 1) determine the behavior, distribution, and approach patterns of fish in the forebay areas of Bonneville Dam, 2) determine the timing and route of dam passage of fish, 3) estimate fish passage efficiency for the entire Bonneville Dam complex, fish guidance efficiency for powerhouses I and II, and efficiency and effectiveness for the spillway and corner collector, and 4) provide data to estimate survival of radio tagged fish released above Bonneville Dam. This report includes the study of yearling Chinook salmon and steelhead trout during spring, 2005, and the study of subyearling Chinook salmon during summer, 2005. BS176

Bell, M. C. 1971. Ecological impact of pool and tailwater regulations at Bonneville Dam (fish and wildlife). U. S. Army Corps of Engineers, Portland, Oregon.

This paper assessed the impact of extreme operational conditions on fish and wildlife resources in the lower Columbia River. The author summarized effects of extreme operations on the following: 1) embayments; 2) spawning grounds for shad, smelt, and sturgeon; 3) Waukeena Pond; 4) hatcheries located in the Bonneville Pool area; 5) Hood River spawning grounds; 6) nitrogen exposure; 7) fishway facilities constructed in tributary streams entering Bonneville Pool; 8) temperature; 9) passage of adult salmon at Bonneville; 10) waterfowl and wildlife; 11) rate of movement of downstream migrants in the Bonneville Pool areas; and 12) potential stranding areas. BS112

\section{Bickford, S.H. and J.R. Skalski. 2000. Re-Analysis and Interpretation of 25 Years of Snake- Columbia River Juvenile Salmonid Survival Studies. North American Journal of Fisheries Management. 20:53-68.}

This is a meta-analysis study that examines trends and variability in estimates of the survival of juvenile salmonids between 1971 and 1995 in the Snake-Columbia Basin, where tagging studies to 
estimate salmonid smolt survival have been done for decades. There is a short review of the history of the Federal Hydropower System and of survival studies in the Columbia-Snake system. Experimental (paired release, balloon tag, PIT tag, etc.) and analytical methods are discussed. Fifty-three smolt survival investigations from 1971 to 1996 were reexamined to identify general patterns for survival of smolts through turbines, spill bays, and river reaches. Of these, 33 met the authors' criteria (which are presented in an appendix) for meta-analysis. The assumptions of the studies were reevaluated whenever possible and those results are presented in an appendix. Although the project, its operations, fish species, size, condition, head, and other factors may confound comparisons among studies, generally consistent results were found among projects, species, and head levels. BS022 PDF reproduced with permission of www.fisheries.org.

\section{BioAnalysts, ENSR, and INCA. 2001. Bonneville 2nd Powerhouse Corner Collector site selection study. Report Prepared for U.S. Army Corps of Engineers, Portland District, Portland, Oregon.}

This study identified, evaluated, and recommended a location and a preliminary design for a high flow outfall as part of a corner collector surface flow bypass system, formed by modifying the existing ice and trash sluiceway at B2. The B2 Corner Collector (B2CC) project would enlarge and deepen the old sluiceway entrance, create a conveyance channel to the west (down stream) end of Cascades Island, and create a high-flow outfall there in the spillway tailrace. At a normal forebay elevation of $74.5 \mathrm{ft}$, the $\mathrm{B} 2 \mathrm{CC}$ would discharge just over five kcfs.

This is a very complete project analysis including rationale, computational and physical modeling reports, site selection for both ends of the B2CC, tailrace egress, a decision-making analysis, costs, a high-flow outfall survival study, and a review of studies of juvenile salmonid passage survival with special attention to northern pikeminnow predation. $\underline{\mathrm{BS} 007}$

\section{BioSonics Inc. 1998. Hydroacoustic evaluation and studies at Bonneville Dam, spring/summer 1997 volume 1 and 2. Contract Report to the U.S. Army Corps of Engineers, Portland District, Portland, Oregon.}

In 1997 BioSonics, Inc. conducted this hydroacoustic study of fish distribution upstream of and passage through the southern end of B2. The study had two main tasks. The first, using data obtained from fixed-aspect hydroacoustics, they estimated fish passage through and effects on Unit 11 passage of the sluice at the south end of the powerhouse. The second, using mobile hydroacoustic data, they described the spatial and temporal aspects of fish distribution in the Bonneville Dam powerhouse forebays in general and upstream of the south end of B2 as a function of sluice operation. There was also an effort to evaluate the efficacy of three different transducer mounts for sampling spillway passage.

The fixed-aspect study was carried on using single beam hydroacoustics, a 6-degree and a 12-degree transducer, each aimed upward from below the upstream side of the sluice entrance to sample sluiceway passage and an opposed pair of single-beam 6-degree transducers sampling above and below the tip of the Intake 11A STS to sample fish passage above and below the STS there. Sluiceway operation was set according to a randomized block experimental design. The sluice was operated in three ways: closed, open down to Elevation (EL) $61 \mathrm{ft}$ above mean sea level (MSL) producing a discharge of about $3.3 \mathrm{kcfs}$, and open down to EL $68 \mathrm{MSL}$, which passed about $1.1 \mathrm{kcfs}$. Response variables were estimates of fish passage through the sluiceway and Intake 11A and fish guidance efficiency at Intake 11A. The 1997 passage season was a very high water season.

Sluiceway operation at both elevations was found to have "a substantial impact" on fish passage through Intake 11A in spring with total Unit 11 passage being "much lower" with the sluice open, the 
difference being "significant" for guided passage. Estimates of sluiceway passage were "much lower" with the weir at EL 61 than at EL 68, which the authors attribute to low fish detectability with the higher velocities and turbulence inherent in the lower elevation. At the shallower EL 68 weir level the sluiceway passed an estimated 3,000 fish per day in both spring and summer. In summer sluiceway operation made little difference in fish passage estimates at Intake 11A. BS024

\section{Counihan, T. D., K. J. Felton, G. Holmberg, and J. H. Peterson. 2002. Survival Estimates of Migrant Juvenile Salmonids in the Columbia River through Bonneville Dam Using Radio- Telemetry, 2001. Final Report of Research by the U. S. Geological Survey, Columbia River Research Laboratory, Cook, Washington for the U.S. Army Corps of Engineers, Portland District, Portland, Oregon.}

The objectives of this work were to provide estimates of relative survival of yearling and sub-yearling Chinook salmon passing via all routes at Bonneville Dam in 2001 and to provide relative survival estimates of fish passing through the juvenile bypass system at Powerhouse 2. Based on a paired release strategy above and below the dam, relative survival probabilities ranged from 0.85 to 1.05 for yearling Chinook salmon and 0.73 to 1.08 for sub-yearling Chinook. Survival through the JBS ranged from 0.78 to 1.1 for yearling and from 0.62 to 1.28 for sub-yearling Chinook. Relative survival ranged from 0.83 to 1.07 for turbine-passed yearling Chinook salmon and from 0.82 to 1.03 for non-turbine passed yearling Chinook salmon. No significant differences between the survival of yearling Chinook salmon passing all routes at Bonneville Dam during spill and no-spill operations were detected. Significant differences were detected when separating yearling passage through turbine and non-turbine routes during spill and nospill conditions: survival of turbine-passed fish was greater during periods of no spill and survival of nonturbine-passed fish was greater during periods of spill. $\underline{\text { BS139 }}$

\section{Counihan, T.D., G.S. Holmberg, and J.H. Petersen. 2003. Survival Estimates of Migrant Juvenile Salmonids through Bonneville Dam using Radio-Telemetry, 2002. Final Report of Research by the U. S. Geological Survey, Columbia River Research Laboratory for the U.S. Army Corps of Engineers, Portland District, Portland, Oregon.}

This study evaluated the survival of radio-tagged yearling Chinook salmon through a Minimum Gap Runner (MGR) turbine unit and the downstream migration (DSM) channel at Bonneville Dam's first powerhouse and route specific survival. Using releases of radio-tagged yearling Chinook salmon released as part of the survival study at The Dalles Dam and releases made below the outfall of the $2^{\text {nd }}$ powerhouse JBS, the authors were able to evaluate survival through the spillway (including by spill deflector type) and the two powerhouses, including turbines, the JBS, and the B2 Corner Collector. Survival estimates ranged from 0.90 to 1.33 for fish released through the John Day Dam JBS and 0.90 to 1.13 for fish released into the MGR at powerhouse 1. Survival estimates for fish released in the DSM ranged from 0.60 to 1.05 . Survival of fish was estimated to be 0.98 through the spillway, 0.90 through powerhouse 1 , 0.99 through powerhouse 2 . Overall survival through the dam was estimated to be 0.98 . BS136

\section{Counihan, T. D., J. Hardiman, C. Walker, A. Puls, and G. Holmberg. 2006a. Survival estimates of migrant juvenile salmonids through Bonneville Dam using radio telemetry, 2004. Final Report of Research by the U. S. Geological Survey, Columbia River Research Laboratory, Cook, Washington for the U.S. Army Corps of Engineers, Portland District, Portland, Oregon.}

During 2004, the USGS evaluated the survival of radio-tagged yearling and subyearling Chinook salmon and steelhead trout through the ice and trash sluiceway and the minimum gap runner (MGR) turbine unit at Bonneville Dam's powerhouse 1. In addition, releases of radio-tagged yearling Chinook salmon, 
steelhead trout, and subyearling Chinook salmon at The Dalles Dam and below the outfall of the $2^{\text {nd }}$ powerhouse JBS were used to estimate survival through the spillway and the two powerhouses. Spillway survival was by spill condition and the type of spill-bay deflector, and estimates were also made for the turbines, juvenile bypass systems, and sluiceways, including the B2 Corner Collector. BS172

\section{Counihan, T. D., J. Hardiman, C. Walker, A. Puls, and G. Holmberg. 2006b. Survival estimates of migrant juvenile salmonids through Bonneville Dam using radio telemetry, 2005. Final Report of Research by the U. S. Geological Survey, Columbia River Research Laboratory, Cook, Washington for the U.S. Army Corps of Engineers, Portland District, Portland, Oregon.}

During 2005, the USGS evaluated the survival of radio-tagged yearling and subyearling Chinook salmon and steelhead trout through the Bonneville Dam spillway, powerhouses 1 and 2, the B2 Corner Collector, the juvenile bypass system (JBS) at powerhouse 2, and through all routes collectively using the routespecific survival model. Radio-tagged fish were released at The Dalles Dam and in the tailrace of Bonneville Dam and were interrogated at Bonneville Dam and three radio-telemetry arrays below Bonneville Dam. The USGS also evaluated the survival of radio-tagged yearling and subyearling Chinook salmon and steelhead trout using paired releases through the ice and trash sluiceway at Bonneville Dam's powerhouse 1. Site-specific releases were made directly into the ice and trash sluiceway and in the tailrace of Bonneville Dam below the outfall of Powerhouse 2 JBS. BS173

\section{Dawley, E. M., L. G. Gilbreath, and R. D. Ledgerwood. 1988. Evaluation of juvenile salmonid survival through the second powerhouse turbines and downstream migrant bypass system at Bonneville Dam, 1987. Annual Report of Research for the U.S. Army Corps of Engineer District, Portland, Oregon by the National Oceanic and Atmospheric Administration, Northwest and Alaska Fisheries Science Center, Seattle, Washington.}

Fish guidance efficiency (FGE) testing at the Bonneville Dam Second Powerhouse since 1983 has shown poor guidance of downstream migrant salmonids from turbine intakes equipped with submersible traveling screens (STS) (Krcma et al. 1984; Gessel et al. 1987). Pending resolution of FGE problems, operation of the Second Powerhouse during juvenile migration periods has been curtailed at night and restricted in daytime. During these periods, downstream migrants pass Bonneville Dam via the First Powerhouse turbines and bypass system and over the spillway between the two powerhouses. While it is generally agreed that operation in this manner will maximize survival of migrants passing Bonneville Dam, the rationale for this procedure is based on studies of passage mortality at Bonneville Dam First Powerhouse (Holmes 1952) and at other hydroelectric projects with different operating conditions (Schoeneman 1961). Since survival studies have not been conducted at the Bonneville Dam Second Powerhouse, information specific to this location is needed.

In 1987, the National Marine Fisheries Service (NMFS), in cooperation with the U.S. Army Corps of Engineers (COE), began a multi-year study to evaluate survival of subyearling fall Chinook salmon passing through the Bonneville Dam Second Powerhouse turbines and bypass system and through the spillway. Research conducted in 1987 had the following objectives: (1) Determine short-term comparative survival of juvenile salmon released at upper and lower locations in a Second Powerhouse turbine intake; in the Second Powerhouse bypass system; and below Bonneville Dam at Hamilton Island, Columbia River kilometer (Rkm) 232. Estimates are to be obtained from brand recoveries in the estuary at Jones Beach (Rkm75). (2) Determine the long-term survival (to adults) of marked subyearling Chinook salmon released at the locations listed in (1) above. Estimates are to be obtained from tag and grand recoveries in various fisheries, at the Bonneville Dam fish trap, and at hatcheries. BS090 
Dawley, E. M., L. G. Gilbreath, R. D. Ledgerwood, P. J. Bently, B. P. Sanford, and H. H. Schiewe. 1989. Survival of subyearling Chinook salmon which have passed through the turbines, bypass system, and tailrace basin of Bonneville Dam Second Powerhouse, 1988. Annual Report of Research for the U.S. Army Corps of Engineer District, Portland, Oregon by the National Oceanic and Atmospheric Administration, Northwest Fisheries Science Center, Seattle, Washington.

Research at the Columbia River's Bonneville Dam Second Powerhouse has shown that subyearling Chinook salmon (Oncorhynchus tshawytscha) migrating in summer, mostly fall Chinook salmon, are not effectively guided into the bypass system from turbines equipped with submersible traveling screens (STS; Gessel et al. 1988). Consequently, most pass downstream through the turbines. To minimize turbine passage losses pending resolution of this guidance problem, operation of the Second Powerhouse has been curtailed at night; daytime operation has been restricted to periods necessary to limit spill to less than $2,124 \mathrm{~m}^{8} / \mathrm{sec}\left(75,000 \mathrm{ft}^{8} / \mathrm{sec}\right)$ or to meet firm energy demands if energy is unavailable elsewhere in the power system. As a result downstream migrants usually pass Bonneville Dam via the turbines and bypass system of the First Powerhouse and, when flow conditions allow, over the spillway between the two powerhouses.

The rationale for this operating procedure was based on studies of passage mortality at the Bonneville Dam First Powerhouse (Holmes 1952) and at other hydroelectric projects (Schoeneman et al. 1961) with different physical features and turbine operating characteristics (elevation of blade in relation to tailwater, dimension of blades, and hydraulic head). Hence, the adequacy of this procedure as the best means of protecting downstream migrant salmonids at the Second Powerhouse had not been rigorously documented. Moreover, the Kaplan turbines installed at the Second Powerhouse are of a more efficient design (less cavitation) than those previously studied at Bonneville First Powerhouse, and passage mortality is thought to be inversely related to turbine efficiency (Bell et al. 1981). Highly sensitive survival studies have not been conducted at Bonneville Dam since construction of spillway flow deflectors or the Second Powerhouse; therefore, information specific to this project was needed for management of fish passage in relation to power production.

Accordingly, in 1987, the National Marine Fisheries Service (NMFS), in cooperation with the U.S. Army Corps of Engineers (COE), began a multi-year study to evaluate relative survival of subyearling fall Chinook salmon that have passed through the Bonneville Second Powerhouse turbines and bypass and through the spillway. Estimates of long- and short-term survival of marked Chinook salmon using various passage routes were compared to similar estimates for control groups released in the tailrace and in the river $2.5 \mathrm{~km}$ downstream. Long-term relative survival was based on returns of tagged and branded adult fish to ocean fisheries, Columbia River fisheries, the Bonneville Dam Second Powerhouse fish trap, and Columbia River hatcheries. Short-term relative survival was based on recoveries of branded fish 157 $\mathrm{km}$ downstream from the dam at the head of the estuary at Jones Beach, river kilometer $(\mathrm{Rkm}) 75$. Secondary objectives of the estuarine sampling were to evaluate the success of the release strategies, condition of test fish (descaling, injuries, size, and gill $\mathrm{Na}^{+}-\mathrm{K}^{+} \mathrm{ATPase}$ ), and migration behavior.

During the second year of this study, in 1988, as in 1987, the spillway releases were cancelled due to insufficient river flow in this drought year. In 1988, fish planned for release in the spillway were instead released into the front roll of the turbine discharge. Also in 1988, the downstream control release site was changed from the shoreline location used in 1987 to a mid-river site. The bypass and turbine release sites were the same as used in 1987 (Dawley et al. 1988). BS088

Dawley, E. M., R. D. Ledgerwood, L. G. Gilbreath , and P. J. Bentley. 1991. Survival of juvenile salmon studied at Bonneville Dam. National Oceanic and Atmospheric Administration, Northwest Fisheries Science Center Quarterly Report. July-August-September 1991:1-5. 
This is a Northwest Fisheries Science Center Coastal Zone and Estuarine Studies Division quarterly report that summarizes different approaches towards improving survival of downstream migrants. The paper emphasizes the juvenile fish transportation program and bypass system technology. The authors contend the most striking finding of the "Bonneville Survival Study" is that differences in estuarine recoveries of juvenile salmon from turbine and bypass groups suggested little survival benefit associated with the bypass system. Data to date clearly suggest that bypass passage has not substantially improved survival over turbine passage for summer-migrating juvenile Chinook salmon at Bonneville Dam. BS133

\section{Dawley, E. M., R. D. Ledgerwood, L. G. Gilbreath, B. P. Sandford, P. J. Bentley, M. H. Schiewe, and S. J. Grabowski. 1992. Survival of Juvenile Salmon Passing through Bonneville Dam and Tailrace. Pages 145-156 in Passage and Survival of Juvenile Chinook Salmon Migrating from the Snake River Basin. Proceedings of a technical workshop held February 26-28, 1992, University of Idaho.}

Authors used a trap net to assess survival of juvenile salmonids passing through Bonneville Dam from 1987-1990. Trends observed in the juvenile recovery data suggest that bypass passage has not substantially improved survival as compared to turbine passage for summer-migrating juvenile Chinook salmon at Bonneville Dam. Authors concluded that 1) bypass passage appears to cause significant stress, loss of scales, and some direct mortality; 2) survival of fish leaving the bypass system appears to be diminished by northern squawfish predation; 3) conditions that appear to increase survival of downstream-released fish over bypass-released fish include high water velocity, long distance to predator habitat, current direction parallel to shoreline, low level of stress for migrants at river entry, lack of predator attraction from continuous availability of juvenile salmon, and nighttime release of fish to limit avian predation, and 4) conditions thought to decrease survival of outmigrants at Bonneville Dam second powerhouse bypass system may be important at other dams, and should be investigated. BS129

Dawley, E. M., L. G. Gilbreath, R. D. Ledgerwood, P. J. Bentley, and S. J. Grabowski. 1993a. Direct Measure of Stress, Descaling, Injury and Mortality for Juvenile Salmonids Passing through the Bypass System of the Bonneville Dam First Powerhouse. Report for the U.S. Army Corps of Engineers - North Pacific Division, by the National Oceanic Atmospheric Administration National Marine Fisheries Service, Northwest and Alaska Fisheries Center, Coastal Zone and Estuarine Studies Division, Seattle, Washington.

Juvenile salmon fish condition was assessed using a triangular-shaped net deployed to trap fish as they moved from the bypass system discharge conduit in winter of 1992-93. Turbine operations were reduced to provide calm water for net deployment. Trap net recovery estimates ranged from $52 \%$ to $99 \%$. High recovery percentages of fish killed immediately prior to release suggested that test fish, which suffered injuries and were moribund or incapacitated upon entry to the net, were recovered at a higher rate than unaffected fish. These results suggested that the observed effects represent a liberal estimate of impacts of bypass passage. Yearling and subyearling Chinook salmon were the primary test fish used in the assessment. Descaling and mortality observed after passage were insignificant for hatchery-reared spring Chinook salmon. Effects observed among the test fish generally increased with distance traveled through the bypass collection channel and discharge conduit. Releases directly into the net showed little or no effects, with descaling and mortality $0.3 \%$ or less for yearlings and about $1 \%$ for subyearlings. Scale loss and mortality percentages for yearling Chinook salmon averaged $4.5 \%$ and $0.9 \%$, respectively, for fish released into the downwell; $12.4 \%$ and $7.7 \%$, respectively, for those released about half way down the collection channel; and 3.1\% and $1.2 \%$, respectively, for those released at the south end of the channel. Scale loss and mortality for subyearling Chinook salmon averaged 9.5 and $1.0 \%$, respectively, for fish released into the downwell; and $7.8 \%$ and $1.2 \%$, respectively, for fish released into the middle of 
the channel. Fish passing through the tailrace release hose experienced similar scale loss and mortality. BS130

Dawley, E. M., R. D. Ledgerwood, L. G. Galbreath, P. J. Bently, and S. J. Grabowski. 1993b. "Do bypass systems protect salmonids at dams?" in Proceeding of the Fish Passage Policy and Technology Symposium, pp 161-168. September 1993, Portland, Oregon. American Fisheries Society.

Bypass systems at dams on the Columbia and Snake Rivers divert large numbers of juvenile salmonids away from turbine intakes and downstream into tailrace areas. However, few rigorous assessments of comparative survival have been made between bypassed fish and those passing through turbines. A study was initiated at Bonneville Dam in 1987 to provide definitive information regarding passage survival. Results to date show bypassed fish had lower survival than fish passing the dam through turbines or spillways. Fish exiting the bypass system had elevated plasma concentrations of cortisol (an index of stress), but physical injuries were not apparent. One likely cause for decreased survival of bypassed fish was predation by northern squawfish on fish exiting the bypass outlet. Study results indicate that bypass operational procedures, as well as location and physical conditions at the bypass outlet, favor high predation. Factors contributing to high predation include 1) river-water velocity of less than $1.2 \mathrm{~m} / \mathrm{s}$ at the bypass exit; 2) proximity of the bypass exit to predator sanctuary areas; 3 ) location of the bypass exit at a curved reach of river where flow was directed toward shorelines; 4) poor dispersal of released fish, resulting in increased juvenile salmon density in the migration route; 5) disorientation of juvenile salmonids upon exiting the bypass outlet; and 6) continuous release at one site. (This is the original abstract). BS102 PDF reproduced with permission of www.fisheries.org.

Dawley, E. M., L .G. Gilbreath, R. D. Ledgerwood, P. J. Bentley, and B. P. Sandford. 1998. Effects of Bypass System Passage at Bonneville Dam Second Powerhouse on Downstream Migrant Salmon and Steelhead; Direct Capture Assessment, 1990-1992. Final Report for the U.S. Army Corps of Engineers, by the National Oceanic Atmospheric Administration National Marine Fisheries Service, Northwest and Alaska Fisheries Center, Coastal Zone and Estuarine Studies Division, Seattle, Washington.

The general objective of this work was to isolate water flow conditions and sections of the second powerhouse bypass system that may cause physical trauma to juvenile salmonids during passage. The authors concluded that injury and mortality of test fish was not occurring during passage through the bypass system at the $2^{\text {nd }}$ powerhouse. However, they did state that passage through the bypass system likely caused stress and fatigue in juvenile migrants and could contribute to diminished predator avoidance. They also noted that northern pikeminnow predation is particularly intense at the outlet of the bypass system. The authors offered the following conclusions: 1) the point source release from the bypass discharge conduit allows for increased predation; 2) migration through the low-velocity tailrace basin results in increased predation; and 3) the location of the bypass outlet on the north side of the tailrace in conjunction with the southward bend in the river tends to direct outmigrants shoreward toward rip-rap areas that are prime habitat for northern pikeminnow. BS114

Evans, S. D., J. M. Plumb, A. C. Braatz, K. S. Gates, N. S. Adams, and D. W. Rondorf. 2001a. Passage behavior of radio-tagged yearling chinook salmon and steelhead at Bonneville Dam associated with the surface bypass program, 2000. Annual Report by the U. S. Geological Survey, Columbia River Research Laboratory, Cook, Washington for the U. S. Army Engineer District, Portland, Oregon. 
In 2000, the B1 prototype surface collector (PSC) was extended to include turbines 1-6. Each vertical-slot entrance was $20 \mathrm{ft}$ wide. This spring study used radio telemetry to examine the movements of Chinook salmon (this time yearlings) as they approached and passed the dam. The objectives were to 1) determine the behavior, distribution, and approach patterns of yearling salmonids in the forebay areas of Bonneville Dam; 2) determine the time and route of dam passage; 3 ) determine movement patterns and behavior in the vicinity of the PSC; and 4) assess the efficiency and effectiveness of the PSC. B1 had generation priority.

Nearly half (49\%) of steelhead passed at B1 and 34\% passed the spillway. Of the steelhead that passed at B1, 44\% passed into the sluiceway, 33\% were guided into the downstream migration channel by screens, and $23 \%$ passed through the turbines $(\mathrm{B} 1 \mathrm{FPE}=77 \%)$. Forty-four percent of Chinook salmon passed through the spillway. Of the Chinook salmon that passed at B1, 29\% passed into the sluiceway, $36 \%$ were guided into the bypass, and 35\% were unguided and passed directly through the turbines. Of the fish that passed at B2, 55\% of steelhead and 39\% of Chinook salmon were guided into the bypass by the STS and $45 \%$ of steelhead and $60 \%$ of Chinook salmon passed through the turbines. Passage rates were highest for both species during the day at the spillway and B1 whereas passage rates were highest for both species during the night at B2.

The PSC was quite efficient at collecting fish. The collection efficiency (number entering the PSC/the total number passing units 1-6) was $83 \%$ for steelhead and $78 \%$ for Chinook salmon ( $80 \%$ combined). The PSC was also relatively effective compared to water passing into the turbines and the spillway. When compared to spillway effectiveness (1.0 for steelhead and 1.3 for Chinook salmon), PSC effectiveness was about twice as high. BS014

\section{Evans, S. D., N. S. Adams, and D. W. Rondorf. 2001b. Passage behavior of radio-tagged subyearling Chinook salmon at Bonneville Dam associated with the surface bypass program, 2000. Annual Report by the U. S. Geological Survey, Columbia River Research Laboratory, Cook, Washington for the U. S. Army Engineer District, Portland, Oregon.}

This summer study used radio telemetry to examine the movements and behavior of sub-yearling Chinook salmon in the forebay of Bonneville Dam during the 2000 passage season when the prototype surface collector (PSC) was in place over the 18 intakes of units 1-6. The objectives were to 1) determine the behavior, distribution, and approach patterns of sub-yearling Chinook salmon in the forebay areas of Bonneville Dam; 2) determine the time and route of dam passage of yearling Chinook salmon; 3) determine movement patterns and behavior of yearling Chinook salmon in the vicinity of the PSC; and 4) assess the efficiency and effectiveness of the PSC. B1 had generation priority.

Median travel rate from release to Bonneville Dam was $2.3 \mathrm{~km} / \mathrm{h}$ for fish released from both The Dalles Dam and Hood River Bridge, resulting in travel times of $34.6 \mathrm{~h}$ and $18.2 \mathrm{~h}$, respectively. Median forebay residence time was shortest at the spillway $(7.2 \mathrm{~min}$ ) compared to $1.8 \mathrm{~h}$ and $2.1 \mathrm{~h}$ at B1 and B2, respectively. The spillway passed the most fish $(69.5 \%)$, followed by B1 $(30 \%)$ and B2 $(0.5 \%)$. Of the fish that passed at B1, 68\% passed into the sluiceway, 23\% passed directly through the turbines, and $9 \%$ were guided into the bypass via the turbine intake screens. At the spillway and B2, a higher proportion of fish passed during night compared to day. In contrast, at B1 a lower proportion of fish passed during night compared to day.

Of the fish that entered the B1 forebay, $72 \%$ were detected within $20 \mathrm{ft}$ of the PSC and were therefore considered to have discovered the PSC. Of those fish, $67 \%$ entered the PSC. However, of the fish that entered the PSC, only 41\% (59 of 143) entered via the entrance they were first detected at without moving to one or more other entrances. In relation to units 1-6, the PSC was quite efficient at collecting fish. Of the fish that passed at units 1-6 (guided, unguided, and sluiceway), $81 \%$ entered the PSC. The PSC was also relatively effective compared to water passing into the turbines and the spillway. 
An effectiveness of 2.5 indicated that the percentage of fish that entered the PSC out of total passage at units 1-6 was 2.5 times the percentage of water that entered the PSC. When compared to spillway effectiveness (1.2), PSC effectiveness was over twice as high. Since fish that entered the PSC could pass through other routes, the PSC was not considered an actual passage route for purposes of calculating passage metrics such as FPE. However, if the PSC had been an actual passage route, FPE would have increased from $91 \%$ to $94 \%$. BS013

\section{Evans, S. D., C. D. Smith, N. S. Adams, and D. W. Rondorf. 2001c. Passage behavior of radio- tagged yearling chinook salmon at Bonneville Dam, 2001. Annual Report by the U.S. Geological Survey, Columbia River Research Laboratory, Cook, Washington for the U. S. Army Engineer District, Portland, Oregon.}

This is the spring 2001 radio telemetry study at Bonneville Dam. From 1 May to 2 June, 1,211 yearling Chinook salmon were tagged and release near Hood River, OR, about 20 mi upstream. This was a severe drought year and mean river discharge at Bonneville Dam during the study period was only $134.9 \mathrm{kcfs}$, with $72 \%$ of flow through B2, $22 \%$ at the spillway, and $6 \%$ at B1. From May 1-15 and during three 5-h blocks on May 24-25, $1.2 \mathrm{kcfs}$ of spill was discharged through each of spill bays 1 and 18 and represented $1.7 \%$ of total discharge (hereafter referred to as $2 \%$ spill). From May 16 to June 9, a mean 50 kcfs was discharged through 10 spill bays and represented $37 \%$ of total discharge (hereafter referred to as $37 \%$ spill).

Of the 1,211 tagged fish released at Hood River, 1,117 (97\%) were detected at Bonneville Dam. Median travel rate to the dam was $1.8 \mathrm{~km} / \mathrm{h}$, resulting in a median travel time of $22.1 \mathrm{~h}$. Median forebay residence time was shortest at B2 $(0.2 \mathrm{~h})$ compared to $2.7 \mathrm{~h}$ at B1 and $0.3 \mathrm{~h}$ at the spillway. Passage routes were determined for $98 \%$ of fish detected at Bonneville Dam. B2 passed the most fish (80\%), followed by the spillway (16\%) and B1 (4\%). Of the fish that passed at B1, 76\% passed into the sluiceway, $13 \%$ passed through the turbines (unguided), and $11 \%$ were diverted into the turbine bypass system by turbine intake screens (guided). Since the B2 sluiceway did not operate in 2001, all fish that passed at B2 entered the turbine intakes; $54 \%$ were unguided and $46 \%$ were guided. At all dam areas, a higher proportion of fish passed during night compared to day.

Estimated fish passage efficiency (Project FPE) in spring 2001 was 56\%. During hours of 37\% spill, estimated FPE was $64 \%$, and during hours of $2 \%$ spill, FPE was $47 \%$. At B1, FPE was $87 \%$ overall, $100 \%$ during $37 \%$ spill, and $86 \%$ during $2 \%$ spill. At B2, FPE was $46 \%$ overall, $49 \%$ during $37 \%$ spill, and $43 \%$ during $2 \%$ spill. Spillway efficiency was $16 \%$ overall, $30 \%$ during $37 \%$ spill, and $1 \%$ during $2 \%$ spill. Spillway effectiveness was 0.70 overall, 0.86 during $37 \%$ spill, and 0.53 during $2 \%$ spill.

The proportion of discharge allocated at B1, B2, and the spillway affected which dam area fish entered and passed, as well as the time spent in the forebay before passing. All passage metrics except FGE at B2 were lower in 2001 than 2000, largely due to low river flows in 2001. All passage metrics were higher during periods of $37 \%$ spill than during periods of $2 \%$ spill. The results indicate that, during a low flow year, the current intake screen guidance systems at B1 and B2 do not divert sufficient numbers of yearling Chinook salmon to meet the project FPE goal of 80\%. BS006

\section{Evans, S. D., C. D. Smith, N. S. Adams, and D. W. Rondorf. 2001d. Passage behavior of radio- tagged subyearling Chinook salmon at Bonneville Dam, 2001. Annual Report by the U.S. Geological Survey, Columbia River Research Laboratory, Cook, Washington for the U. S. Army Engineer District, Portland, Oregon.}

This was the summer 2001 radio-telemetry study at Bonneville Dam. It involved 647 subyearling Chinook salmon smolts that were tagged and released at Hood River (about 20 miles upstream from 
Bonneville dam) from July 1 through July 19 of 2001. This was a very low-water year and the mean Bonneville Dam discharge during the study was only $81 \mathrm{kcfs}$, most (94\%) of which went through B2, while only $3.4 \%$ at passed B1 and $2.4 \%$ was spilled. Fish passage very roughly correlated with discharge. Of the $90 \%$ (582) of the tagged fish for which passage rates were determined, $92 \%$ passed at B2, $6 \%$ passed at B1, and only $2 \%$ passed the spillway. Median travel time from Hood River to the dam was just over one day $(26.8 \mathrm{~h})$.

Median forebay residence time was shortest at B2 $(0.7 \mathrm{~h})$ compared to $2.4 \mathrm{~h}$ at B1 and $1.5 \mathrm{~h}$ at the spillway. Of the 49 fish that passed B1, 34 (70\%) went through the sluiceway, six (13\%) were guided by screens, five (10\%) passed through turbines, and three (7\%) went through the Bradford Island fishway. Since B2's sluice was not operated in 2001, all fish that passed at B2 entered the turbine intakes; $65 \%$ were unguided and 35\% were guided. At all dam areas, a higher proportion of fish passed during night compared to day.

Project FPE was $40 \%$ overall, $89 \%$ at B1 and 35\% at B2. FGE was higher at B1 (57\%) than B2 $(35 \%)$. However, the sample size was small at B1 ( $n=7$ fish). Spillway efficiency was $2 \%$. Spillway effectiveness was 0.8 .

The proportion of discharge allocated at B1, B2, and the spillway affected which dam area fish entered and passed, as well as the time spent in the forebay before passing. All passage metrics except FGE (at B1 and B2) were lower in 2001 than in 2000, largely due to low river flows in 2001. Although

low discharge lowered passage metrics in general, at B1, it was likely responsible for fewer fish becoming entrained in turbine flow, thereby increasing the number of fish available to the surface-oriented sluiceway. Our results indicate that, during a low flow year, the current intake screen guidance systems at B1 and B2 do not divert sufficient numbers of yearling Chinook salmon to meet the project FPE goal of $80 \%$. BS005

\section{Evans, S. D., L. S. Wright, C. D. Smith, R. E. Wardell, N. S. Adams, and D. W. Rondorf. 2003a. Passage behavior of radio-tagged yearling Chinook salmon and steelhead at Bonneville Dam, 2002. Annual Report by the U. S. Geological Survey, Columbia River Research Laboratory, Cook, Washington for the U. S. Army Engineer District, Portland, Oregon.}

In 2002, the USGS used radio telemetry to examine the movements and behavior of yearling Chinook salmon Oncorhynchus tshawytscha and steelhead Oncorhynchus mykiss, in the forebay of Bonneville Dam. The objectives of this research were to 1) determine the behavior, distribution, and approach patterns of fish in the forebay areas of Bonneville Dam; 2) determine the timing and route of dam passage of fish; 3) estimate fish passage efficiency for the entire Bonneville Dam complex, fish guidance efficiency for powerhouses I and II, and spillway efficiency and effectiveness; and 4) provide data to estimate survival of radio-tagged fish released above Bonneville Dam.

As in previous years, the proportion of discharge allocated at B1, B2, and the spillway affected which dam area fish entered and passed, as well as the time fish spent in the forebay before passing. Overall, greater than half of both species passed through the spillway and of the three spill treatments, TDG Day spill was the most efficient, passing $63 \%$ of Chinook salmon and $70 \%$ of steelhead relative to all other passage routes. Passage metrics for yearling Chinook salmon were higher in 2002 than in 2001. All passage metrics, except FPEB1 and FGEB2 (and therefore FPEB2), were very similar to passage metrics in 2000. Spillway efficiency and FPE were lower in 2001, largely because of low river flows. Very little water was available for spill in 2001 and that resulted in minimal spill and very low spill efficiency and, therefore, low FPE. Fish passage efficiency at B1 in 2001 was $18-22 \%$ greater than in 2002 and 2000, respectively. Fish passage efficiency at B1 was higher in 2001 because a large proportion of smolts entered the sluiceway. The authors believe the cause of high sluiceway passage in 2001 was 
due to very low turbine operation at B1, which entrained less fish and made them available to the surfaceoriented sluiceway. No steelhead were tagged in 2001 so no comparisons could be drawn for this species and year. However, a comparison of passage metrics for steelhead between 2002 and 2000 shows that, unlike for Chinook salmon, most efficiencies were greater in 2002. In general, this may be attributable to the natural tendency of steelhead to migrate shallower in the water column than Chinook salmon, enabling steelhead to utilize shallower, non-turbine passage routes to a greater extent than Chinook salmon. Our results indicate that, although the current intake screen guidance systems at B1 and B2 have relatively poor guidance efficiency, the project FPE goal of $80 \%$ can be attained if sufficient numbers of fish are passed via a combination of non-turbine routes (spill, sluice, and turbine guidance systems). $\underline{\mathrm{BS} 037}$

\section{Evans, S. D., L. S. Wright, R. E. Wardell, N. S. Adams, and D. W. Rondorf. 2003b. Passage behavior of radio-tagged subyearling Chinook salmon at Bonneville Dam, 2002: Revised for Corrected Spill. Annual Report by the U. S. Geological Survey, Columbia River Research Laboratory, Cook, Washington for the U. S. Army Engineer District, Portland, Oregon.}

The objectives to this 2002 study were to: 1 ) determine the behavior, distribution, and approach patterns of fish in the forebay areas of Bonneville Dam, 2) determine the timing and route of dam passage, 3) estimate fish passage efficiency for the entire Bonneville Dam, fish guidance efficiency for powerhouses I and II, and spillway efficiency and effectiveness, and 4) provide data to estimate survival of radio-tagged fish released above Bonneville Dam. Median travel rates to the dam were $2.1 \mathrm{~km} / \mathrm{h}$ and $2.5 \mathrm{~km} / \mathrm{h}$ for fish released from Rock Creek and from both John Day and The Dalles dams, respectively. Travel times from the release site to the dam were $64.4 \mathrm{~h}$ (Rock Creek), $45.6 \mathrm{~h}$ (John Day), and $29.1 \mathrm{~h}$ (The Dalles). Of 3,357 fish released, 78\% were detected at Bonneville. Most fish passed the spillway followed by B2 and B1. Of the fish passing B1, the majority passed into the sluiceway, followed by turbine passage, screen guidance, and the navigation lock. Slightly more than half the fish passing B2 were unguided into the turbine units, with the remainder guided by screens. Overall, a higher proportion of fish passed the project during the day than at night. Fish passage efficiency was $82 \%$ overall, $72 \%$ at B1, and $47 \%$ at B2. Fish guidance efficiency was higher at B2 than at B1. Spillway efficiency and effectiveness were 58\% and 1.2, respectively. Sluiceway efficiency at B1 was 48\% and sluiceway effectiveness was 27.9. BS137

\section{Evans, S. D., L. S. Wright, C. D. Smith, R. E. Wardell, N. S. Adams, and D. W. Rondorf. $2006 a$. Passage behavior of radio-tagged yearling Chinook salmon and steelhead at Bonneville Dam, 2002: Revised for Corrected Spill. Annual Report by the U. S. Geological Survey, Columbia River Research Laboratory, Cook, Washington for the U. S. Army Engineer District, Portland, Oregon.}

In 2002, the authors used radio telemetry to examine the movements and behavior of yearling Chinook salmon Oncorhynchus tshawytscha and steelhead Oncorhynchus mykiss, in the forebay of Bonneville Dam. The objectives of this research were to: 1) determine the behavior, distribution, and approach patterns of fish in the forebay areas of Bonneville Dam, 2) determine the timing and route of dam passage of fish, 3) estimate fish passage efficiency for the entire Bonneville Dam complex, fish guidance efficiency for powerhouses I and II, and spillway efficiency and effectiveness, and 4) provide data to estimate survival of radio tagged fish released above Bonneville Dam. BS177

Evans, S. D., L. S. Wright, R. E. Wardell, N. S. Adams, and D. W. Rondorf. 2006b. Passage behavior of radio-tagged subyearling Chinook salmon at Bonneville Dam, 2002: Revised for Corrected Spill. Annual Report by the U. S. Geological Survey, Columbia River Research Laboratory, Cook, Washington for the U. S. Army Engineer District, Portland, Oregon. 
In 2002, the authors used radio telemetry to examine the movements and behavior of subyearling Chinook salmon, Oncorhynchus tshawytscha, in the forebay of Bonneville Dam. The objectives of this research were to: 1) determine the behavior, distribution, and approach patterns of fish in the forebay areas of Bonneville Dam, 2) determine the timing and route of dam passage of fish, 3) estimate fish passage efficiency for the entire Bonneville Dam complex, fish guidance efficiency for powerhouses I and II, and spillway efficiency and effectiveness, and 4) provide data to estimate survival of radio tagged fish released above Bonneville Dam. This report covers the study of subyearling Chinook salmon during the summer of 2002. Study activities on yearling Chinook salmon and steelhead conducted in spring 2002 were reported by Evans et al. (2002). BS178

\section{Evans, S. D., L. S. Wright, R. E. Reagan, N. S. Adams, and D. W. Rondorf. 2006c. Passage behavior of radio-tagged subyearling Chinook salmon at Bonneville Dam, 2004: Revised for Corrected Spill. Annual Report by the U. S. Geological Survey, Columbia River Research Laboratory, Cook, Washington for the U. S. Army Engineer District, Portland, Oregon.}

The behavior, passage efficiency, and survival of subyearling Chinook salmon were investigated in 2004 at Bonneville Dam using radio telemetry. Over 11,000 tagged fish were release for the investigation and $75 \%$ of those fish were detected at Bonneville Dam. Median travel times were 55.9 hours and 38.5 hours from the release sites at John Day Dam and The Dalles Dam, respectively. Bonneville Powerhouse 2 (B2) passed $60 \%$ of the fish detected while the spillway passed $35 \%$ of fish detected and Powerhouse 1 (B1) passed $5 \%$ of fish detected. Fish passage efficiency was $68 \%$ for the project. Passage efficiency was also calculated for each passage route available to fish. Surface passage routes were more efficient at than other areas of the dam when spill discharge was higher. Passage metrics were generally lower in 2004 than 2002, but the $68 \%$ passage efficiency for the project was achievable because of the effectiveness of the B2 corner collector (5.9) which passed 14 times less water than the spillway with an effectiveness of 0.9 . BS180

\section{Faber, D.M., M.A. Weiland, R.A. Moursund, and T.J. Carlson. 2001. Evaluation of the Fish Passage Effectiveness of the Bonneville I Prototype Surface Collector using Three- Dimensional Ultrasonic Fish Tracking, PNNL-13526 Prepared for U.S. Army Corps of Engineer District, Portland, Oregon by Pacific Northwest National Laboratory, Richland, Washington.}

This report describes tests conducted at Bonneville Dam on the Columbia River in the spring of 2000. The studies used three-dimensional (3D) acoustic telemetry and computational fluid dynamics (CFD) hydraulic modeling techniques to evaluate the response of outmigrating juvenile steelhead (Oncorhynchus mykiss) and yearling Chinook salmon (O.tshawytscha) to the Prototype Surface Collector (PSC) installed at Powerhouse I of Bonneville Dam in 1998 to test the concept of using a deep-slot surface bypass collector to divert downstream migrating salmon from turbines. The study was conducted by Pacific Northwest National Laboratory (PNNL), the Waterways Experiment Station of the U.S. Army Corp of Engineers (COE), Asci Corporation, and the U.S. Geological Survey (USGS), and was sponsored by COE's Portland District. The goal of the study was to observe the three-dimensional behavior of tagged fish (fish bearing ultrasonic micro-transmitters) within 100 meters $(\mathrm{m})$ of the surface flow bypass structure to test hypotheses about the response of migrants to flow stimuli generated by the presence of the surface flow bypass prototype and its operation. Research was done in parallel with radio telemetry studies conducted by USGS and hydroacoustic studies conducted by WES \& Asci to evaluate the prototype surface collector. $\underline{B S 141}$ 
Ferguson, J. 1993. Relative Survival of Juvenile Chinook Salmon through Bonneville Dam on the Columbia River. Pages 58-65 in Proceedings of the Workshop on Fish Passage at Hydroelectric Developments, March 26-28, 1991, St. John's, Newfoundland. Canadian Technical Report of Fisheries and Aquatic Sciences, No. 1905, Department of Fisheries and Oceans, St. John's Newfoundland.

Juvenile Chinook salmon that passed through the Bonneville second powerhouse juvenile bypass system, during the summer, had significantly lower survival rates than upper and lower turbine, spillway, and downstream control groups. Predation by northern squawfish (Ptychocheilus oregonensis) was suspected to have been the cause of high mortalities among bypassed fish. No significant difference existed between survival rates of upper and lower turbine groups. Estimates of long-term survival using adult returns are incomplete at this time. (This is the original abstract). BS087 PDF reproduced with permission of the NRC Research Press. http://pubs.nrc-cnrc.gc.ca/cgi-bin/rp/rp2 desc_e?cjfas

Ferguson, J. W., G. M. Matthews, R. L. McComas, R. F. Absolon, D. A. Brege, M. H. Gessel, and L. G. Gilbreath. 2005. Passage of Adult and Juvenile Salmon Through Federal Columbia River Power System Dams. NOAA Technical Memorandum, Fish Ecology Division, Northwest Fisheries Science Center, Seattle, WA, USA.

This technical memorandum focuses primarily on passage data associated with the dams as they have been configured recently, and not on effects on salmon that might accrue from major changes such as dam removal. The effects of the FCRPS on evolutionarily significant units of salmon listed under the Endangered Species Act and potential benefits to these populations from actions undertaken in the hydropower system are being addressed elsewhere, such as through deliberations of the Technical Recovery Teams, which establish biologically based recovery goals, and Biological Opinions. The authors present a synthesis of the most recent and current information and summary conclusions on the following topics: 1) juvenile salmonid passage through spillways, 2) juvenile passage through mechanical screen bypass systems, 3) juvenile passage through turbines, 4) juvenile passage through sluiceways and surface bypass systems, 5) juvenile diel passage and timing past dams, and 6) adult salmonid passage past dams and through the eight-dam reach. BS183 PDF reproduced with permission of the NRC Research Press. http://pubs.nrc-cnrc.gc.ca/cgi-bin/rp/rp2 desc e?cjfas

Fisheries Engineering Research Program. 1957. Effect of Structures at Main Columbia River and Certain Other Dams on Downstream Migration of Fingerling Salmon. U.S. Army Engineer Division, North Pacific.

This work was initiated to determine under prototype conditions the rate of survival or mortality of fingerling salmon passing through the turbines, spillways, and stilling basins of main-stem Columbia River dams. Some of the work was conducted at dams in other watersheds to test methods and techniques and to compare results. The primary objective was to obtain information needed in the design and operation of different features at dams. The following are some of the conclusions offered: 1) there was little or no significant mortality in passing pressure accommodated and non-pressurized fingerling salmon through the Bonneville and McNary turbines; 2) spillway mortality data from Bonneville and McNary are not conclusive; 3 ) more controlled testing is necessary to learn the effect of the gossamer bags on survival of fish under prototype conditions; 4) spillway split gate experiments at McNary gave indication of little or no significant mortality; 5) air and mechanical agitation tests conducted under laboratory conditions caused mortality to fingerling salmon in gossamer bags but did not injure free-swimming fingerlings; 6 ) no significant mortality resulted during the performance of laboratory tests wherein large numbers of fingerling salmon were caused to pass through a venturi where pressure ranged as low as 0.5 pounds psi; 
and 7) impact at $45.6 \mathrm{fps}$ velocity in an 8-inch jet of water against a solid steel plate set both at 45-degree and 90 -degree angles caused no significant mortality to fingerling salmon. BS107

\section{Gauley, J. E., R. E. Anas, and L. C. Schlotterbeck. 1958. Downstream Movement of Salmonids at Bonneville Dam. Special Scientific Report \#236, U. S. Fish and Wildlife Service, Washington, DC.}

This study assessed movement of outmigrant salmonids based on trap catches in fishways at Bonneville Dam. Results indicated most outmigrants were caught during hours of darkness during the years 1946, 1949, 1950, and 1953. In 1952, the majority were day migrants. Hourly fishing in 1952 and 1953 indicated that maximum movement of Chinook salmon and steelhead trout tends to occur at dawn and dusk. The authors conclude that the percentage of Chinook salmon that migrate at night appears to be more highly correlated with turbidity than with days elapsed from start of sampling. BS122

Gessel, M. H., R. F. Krema, W. D. Muir, C. S. McCutcheon, L. G. Gilbreath, and B. H. Monk. 1985. Evaluation of the juvenile collection and bypass systems at Bonneville Dam - 1984. Annual Report of Research for the U.S. Army Corps of Engineer District, Portland, Oregon by the National Oceanic and Atmospheric Administration, Northwest and Alaska Fisheries Science Center, Seattle, Washington.

Initial studies to evaluate the efficiency of the fingerling collection and bypass system at the Bonneville Dam Second Powerhouse began in 1983. These studies showed a very low fish guiding efficiency (FGE) of less than 30\% for the submersible traveling screens (STS) (Krcma et al. 1984). Vertical distribution tests, conducted during the same period, indicated two problem areas in developing acceptable ( $>70 \%)$ FGE. First, a large percentage of the smolts were passing through the intakes at a depth below the STS. Second, significant avoidance or rejection of guidance was occurring because FGE was approximately half of the potential indicated by vertical distribution studies. An extensive model study program was initiated to investigate ways of improving the distribution of fish entering the turbine intakes and reducing or eliminating the avoidance/rejection problem, thereby improving the guiding capabilities of the STS. A series of methods for improving FGE was developed.

During the 1984 smolt migration, the National Marine Fisheries Service (NMFS) under contract to the U.S. Army Corps of Engineers (COE) evaluated various methods that were intended to improve the fingerling collection and bypass efficiency at the Bonneville Dam Second Powerhouse. Studies were also conducted to evaluate the operation of the newly completed fingerling bypass and indexing facility at the First Powerhouse and to identify problem areas and make recommendations if necessary for improved operation.

The 1984 research had the following primary objectives: (1) Evaluate the various modifications/additions developed during model studies to improve FGE at the Second Powerhouse. (2) Continue monitoring the downstream migrant system (DSM) and smolt indexing facilities at the Second Powerhouse. (3) Evaluate the operation of the smolt indexing system facilities at the First Powerhouse. (4) Determine fish quality and stress through the juvenile bypass and indexing system at the First Powerhouse. (5) Measure orifice passage efficiency (OPE) of the fingerling bypass orifices at both powerhouses. $\underline{\mathrm{BS} 032}$

Gessel, M. H., L. G. Gilbreath, W. D. Muir, and R. F. Krcma. 1986a. Evaluation of the juvenile collection and bypass systems at Bonneville Dam - 1985. Annual Report of Research for the U.S. Army Corps of Engineer District, Portland, Oregon by the National Oceanic and Atmospheric Administration, Northwest and Alaska Fisheries Science Center, Seattle, Washington. 
The National Marine Fisheries Service (NMFS) under contract to the U.S. Army Corps of Engineers (COE) began studies in 1983 to evaluate the fingerling collection and bypass system at the Bonneville Dam Second Powerhouse. These studies have concentrated primarily on improving the fish guiding efficiency (FGE) of the submersible traveling screens (STS). Studies in 1983 showed very low FGEs of less than 30\% for the STS (Krcma et al. 1984). Vertical distribution tests conducted during the same period indicated two problem areas: (1) a large percentage of the juvenile salmonids were passing through the turbine intake below the STS and (2) avoidance and/or deflection was also occurring because FGE was approximately half of the theoretical potential FGE (based on vertical distribution tests). An extensive model study was initiated to determine potential methods of increasing FGE.

Studies during the 1984 field season implemented several of the recommended modifications/additions to the STS and trashracks (Gessel et al. 1985). FGE, however, remained at an unacceptable level, plus fish condition deteriorated as indicated by increased descaling and mortality. Vertical distribution tests reinforced the indication of an avoidance/deflection problem since potential FGEs greater than 70\% were indicated, but FGEs of only 30\%-50\% were attained. Several possible reasons were suspected for the avoidance/deflection problem: (1) a flow restriction causing a "zone of resistance" that fish detect and avoid, (2) increasing velocity below the STS that attracts smolts, (3) a flow deflection that diverts a percentage of the intercepted fish below the STS, and (4) a combination of all three.

During the 1985 smolt migration, NMFS evaluated various methods intended to improve the fingerling collection and bypass system efficiency at the Bonneville Dam Second Powerhouse. Studies were also conducted to evaluate the fingerling bypass and sampling facilities at the First Powerhouse. Research for 1985 had the following primary objectives: (1) Evaluate modifications to improve FGE at the Second Powerhouse. (2) Continue monitoring the Second Powerhouse downstream migrant system (DSM) sampling facilities. (3) Evaluate the First Powerhouse juvenile bypass and sampling system. (4) Determine fish quality and stress through the First Powerhouse juvenile bypass and indexing system. (5) Continue orifice passage efficiency (OPE) studies at the First Powerhouse. (6) Determine diel passage of juvenile migrants at the First Powerhouse. (7) Continue temporal smolt passage studies at Bonneville Dam. This report provides pertinent findings of the research conducted in 1985. BS031

Gessel, M. H., L. G. Gilbreath, W. D. Muir, and R. F. Krcma. 1986b. Continuing studies to improve and evaluate the fingerling collection and bypass system at Bonneville Dam. Annual Report of Research for the U.S. Army Corps of Engineer District, Portland, Oregon by the National Oceanic and Atmospheric Administration, Northwest and Alaska Fisheries Science Center, Seattle, Washington.

The objectives of this work were to 1) continue FGE and vertical distribution test to evaluate a variety of modifications or additions to improve the effectiveness of the submerged traveling screens, and 2) operate the first and second powerhouse collection facilities to obtain data related to FGE research and to continue to evaluate the collection and indexing site at the first powerhouse. BS131

Gessel, M. H., L. G. Gilbreath, W. D. Muir, B. H. Monk, and R. F. Krcma. 1987. Evaluation of the juvenile salmonid collection and bypass systems at Bonneville Dam - 1986. Annual Report of Research for the U.S. Army Corps of Engineer District, Portland, Oregon by the National Oceanic and Atmospheric Administration, Northwest and Alaska Fisheries Science Center, Seattle, Washington.

This NMFS netting report is the immediate predecessor to Gessel et al. 1988 and reports on some of the work contributing to Gessel et al. 1991 involving modifications to improve FGE at B2. It also discusses an evaluation of both powerhouse downstream migrant (DSM) systems. 
Turbine Intake Modifications - Prior to 1985 FGE at selected test B2 intakes, assayed by netting, had been incrementally raised from about $25 \%$ to about $40 \%$. This effort used netting to evaluate FGE and vertical distribution with and without
a. lowering the STS 27 in.
b. raising the hydraulic "operating gate"
c. streamlining the top three trash racks on the top half of the intake
d. a "false" gap
e. internal deflectors
f. intake ceiling extensions (later called "turbine intake extensions" or "TIES").

FGE tests were conducted in intakes $12 \mathrm{~A}$ and $12 \mathrm{~B}$ and vertical distribution tests were conducted in Intake 13A for the spring (yearling) migration and in Intake 13B for the summer (subyearling) migration. Test unit loading was generally about $18 \mathrm{kcfs}$ in spring and $17 \mathrm{kcfs}$ in summer, but powerhouse loading was variable.

The authors concluded the following:

1. FGE of almost $70 \%$ was attained on the experimental intake in spring (yearling fish) with the intake modifications and TIES.

2. Streamlined trash racks improved guidance.

3. Modifications, including trash racks and TIES, did not raise sub-adult FGE over that of the previous year.

4. Descaling at $\mathrm{B} 2$ was worse than in the previous year.

Other matters, including the B2 dry separator and sampling methods, were discussed. BS029

\section{Gessel, M. H., B. H. Monk, and J. G. Williams. 1988. Evaluation of the juvenile fish collection and bypass systems at Bonneville Dam - 1987. Annual Report of Research for the U.S. Army Corps of Engineer District, Portland, Oregon by the National Oceanic and Atmospheric Administration, Northwest and Alaska Fisheries Science Center, Seattle, Washington.}

This report evaluates improvements to the Bonneville Dam B2 submerged traveling screens (STSs) and their intakes, the downstream migrant (DSM) collection and handling facilities, and the temporal distribution of smolt passage as well as assaying fish condition ("quality"). Some of the work reported (the part about turbine intake modifications) here is also discussed in the North American Journal of Fisheries Management paper Gessel et al 1991.

Turbine Intake Modifications - The 1987 season involved testing variations on the best passage configuration from the previous year. There were three main lines of investigation. The first compared FGE with lowered STSs, streamlined trash racks, and intake ceiling extensions on six adjacent intakes (11C-13B) to FGEs with lowered STSs and streamlined trash racks on those same intakes but with the intake ceiling extensions removed from every other intake. Two powerhouse operational regimes were tested; four units running vs. six or seven units running. The second line of investigation on Intake 12B tested the efficacy of an array of $40250-\mathrm{W}$ mercury vapor lights, deployed on the ceiling intake, ceiling extension, and trash rack to attract fish to shallower depth for better screen guidance. The third intake alteration tested was a small external (upstream side) deflector on the trash rack. Removal of the top three trash racks was also tested with an "internal deflector" closing the gap left by the top trash rack and the STS. That test was done because the distance from the trash rack to the screen at B2 is less than half the 6-m distance at $\mathrm{B} 1$ and other projects.

These investigations produced the following results: 
Synthesis of Biological Research on Juvenile Salmonid Passage and Survival at Bonneville Dam through 2005

1) At full operations (six or seven units), spring Chinook salmon FGE of greater than $70 \%$ was attained at Intake 12A (no ceiling extension) and 60\% was attained at Intake 12B (with ceiling extension). In summer, Chinook salmon FGE averaged only $16 \%$ and none of the modifications seemed to improve that.

2) Mercury vapor lights showed some promise for raising FGE.

3) The small external deflector did not raise FGE.

4) Removing the top three trash racks did not raise FGE.

Smolt Collection Systems - This part of the report addresses the B1 and B2 Downstream Migrant (DSM) facilities, which were operated to determine fish "quality" (condition) relative to the FGE studies as well as to generally evaluate the systems. The systems were found to be operable "as is" but recommendations were made to improve the ease and quality of fish and water handling, especially in full operations, with fluctuating pool levels, and debris loading. Descaling and mortality were found to be very low except for yearling Chinook salmon and especially for sockeye salmon.

Utility of DSM Systems to Sample the Run at Large - In general the authors conclude that sampling of the two DSM systems as is currently conducted is inadequate to estimate the multi-species run at large. Even with more extensive sampling, the facts that different species and runs guide at different rates and that both turbine and spillway passage would remain unsampled means that the DSM system will not be satisfactory indices of the run at large. $\underline{\mathrm{BS} 028}$

Gessel, M. H., B. H. Monk, D. A. Brege, and J. G. Williams. 1989. Fish guidance efficiency studies at Bonneville Dam First and Second Powerhouse - 1988. Annual Report of Research for the U.S. Army Corps of Engineer District, Portland, Oregon by the National Oceanic and Atmospheric Administration, Northwest and Alaska Fisheries Science Center, Seattle, Washington.

At Bonneville Dam First Powerhouse, fish guidance efficiency (FGE) testing with submersible traveling screens (STS) was initially conducted during the early and late portions of the 1981 spring outmigration. Guidance in excess of $70 \%$ was observed for all species (Krcma et al. 1982). These results were considered adequate; however, since these tests, further FGE studies at other projects have indicated that FGEs varied considerably from year to year as well as within each field season. Additionally, average FGE measurements on summer migrating subyearling Chinook salmon have been less than 50\% at McNary Dam (Brege et al. 1988) and John Day Dam (Krcma et al. 1986). Thus, measurements of subyearling Chinook salmon FGE during the summer migration were made to provide baseline information prior to completion of the new navigational lock at Bonneville First Powerhouse.

Evaluation of the juvenile bypass and collection system at Bonneville Dam Second Powerhouse began in 1983. The initial FGE estimate of traveling screens was less than $30 \%$ for yearling Chinook lowered STS increased FGE to $>40 \%$. In 1986, the addition of turbine intake extensions (TIE) improved FGE to over $70 \%$ for some tests. In 1987, results from guidance tests indicated that underwater mercury vapor lights could alter the movement of juvenile migrants into and within a turbine intake. Studies in 1988 continued light tests, and initial tests were conducted on the feasibility of using bar screens instead of STSs to improve FGEs.

During the 1988 juvenile salmonid outmigration, the National Marine Fisheries Service (NMFS) in conjunction with the U.S. Army Corps of Engineers (COE) conducted studies at both Bonneville powerhouses with the following objectives: (1) Continue the FGE and vertical distribution testing program Bonneville Second Powerhouse to evaluate the following modifications/additions for improving FGE and STS effectiveness: (a) Turbine intake extensions (b) Higher porosity guiding device (bar screen) (c) Internal trashrack deflector (d) Illuminated trashracks and intake ceiling. (2) Conduct standard 
FGE and vertical distribution measurements at Bonneville First Powerhouse to provide data comparable to 1981 research and baseline data for late summer subyearling Chinook salmon migrants.

In addition to these investigations, a complementary physiological study was conducted to determine if relationships existed between the physiological status of the migrant population and the prevailing FGE estimates. Results from that study will be reported in a separate document. BS089

\section{Gessel, M. H., D. A. Brege, B. H. Monk, and J. G. Williams. 1990. Continued studies to evaluate the juvenile bypass systems at Bonneville Dam, 1989. Annual Report of Research for the U.S. Army Corps of Engineer District, Portland, Oregon by the National Oceanic and Atmospheric Administration, Northwest Fisheries Science Center, Seattle, Washington.}

Research at Bonneville Dam Second Powerhouse (Bonneville II) began in 1983 with the evaluation of the fingerling collection and bypass system. In these studies, fish guiding efficiency (FGE) was between $20 \%$ and $25 \%$ for yearling Chinook salmon, far less than the $70 \%$ or greater at Bonneville Dam First Powerhouse (Bonneville I), and much below the $70 \%$ guidance standard considered by the Columbia Basin Fish and Wildlife Authority as the minimum level needed for adequate fish passage. Research in 1985 indicated that streamlined trashracks and lowered submersible traveling screens (STSs) could increase FGE to $>40 \%$ for yearling Chinook salmon. Research in 1986 and 1987 resulted in some FGE estimates $>70 \%$ when using turbine intake extensions (TIEs) combined with earlier modifications. Tests in 1988 with submerged bar screens (SBSs) resulted in increased FGE; however, descaling of juvenile salmonids during testing was unacceptable. Also in 1988, mercury vapor lights attached to the intake ceiling and STS frame increased FGE, but results were inconsistent.

Initial studies of FGE with prototype STSs at Bonneville I were conducted during the early and late portions of the 1981 juvenile salmonid spring outmigration. Guidance estimates $>70 \%$ were observed for all species tested (Krcma et al. 1982). Based on these results and information obtained at similar projects, a full complement of STSs was installed at the powerhouse in 1984. Subsequent research on summer migration subyearling Chinook salmon at John Day Dam (Krcma et al. 1986; Brege et al. 1987) and McNary Dam (Brege et al. 1988) indicated guidance ranged from $25 \%$ to $45 \%$, varying both during the season and from year to year. Because of these poor results, FGE was measured for the first time during the 1988 summer outmigration at Bonneville I to determine baseline guidance levels prior to installation of a floating guide wall for the new Bonneville Dam navigation lock. Fish guidance was $<12 \%$ (Gessel et al. 1989), which was much lower than the $70 \%$ average for subyearling Chinook salmon measured during May 1981 (Krcma et al. 1982).

During the 1989 juvenile salmonid outmigration, the National Marine Fisheries Service (NMFS) conducted studies at both Bonneville Dam powerhouses with the following objectives: (1) Continue FGE and vertical distribution testing at Bonneville II to evaluate the following modifications or additions for improving FGE and STS effectiveness in conjunction with TIEs: (a) raised operating gate (b) bar screens (c) perforated plate with bar screens to reduce descaling, and(d) illuminated guiding device. (2) Continue FGE and vertical distribution testing at Bonneville I to more accurately assess FGE and STS effectiveness over the spring and summer juvenile salmonid outmigration prior to construction of the navigation lock guide wall. $\underline{\mathrm{BS} 086}$

\section{Gessel, M. H., J. G. Williams, D. A. Brege, R. F. Krcma, and D. R. Chambers. 1991. Juvenile salmonid guidance at the Bonneville Dam Second Powerhouse, Columbia River, 1983-1989. North American Journal of Fisheries Management. 11:400-412.}

This North American Journal of Fisheries Management paper begins with a short history of the development of turbine intake screening systems in the Columbia-Snake River System, which began at 
Synthesis of Biological Research on Juvenile Salmonid Passage and Survival at Bonneville Dam through 2005

Ice Harbor Dam in 1970, but concentrates on NMFS netting and gatewell dipping studies at B2 from 1983 to 1989. Initial expectations of fish guidance efficiency (FGE, the proportion of fish that passed a turbine intake or unit that passes above a screen) of over $70 \%$ for all species were not realized. Rather, FGEs of less than $25 \%$ were recorded for subyearling Chinook salmon and coho salmon and about $33 \%$ for steelhead were estimated.

Modeling and empirical studies, some of which are described, led in 1984 to modification of trash racks (changing the pitch on shallower ones and blocking deeper ones), effectively extending the screen to the trash racks with wedge wire, closing gaps at the sides of the STS, and other structural modifications as well as reducing turbine loading and installing attracting lights over intakes. This increased FGE slightly (to about 30\%) but also increased descaling and mortality and the louvered and blocked trash racks were removed for summer.

In 1985, one STS was incrementally lowered to increase the gap between the top of the STS and the intake ceiling, and streamlined trash racks were installed upstream of the test intake. Lowering the screen $1.2 \mathrm{~m}$, along with the streamlined trash racks, produced a Chinook salmon FGE of 33\% and lowering it just $0.7 \mathrm{~m}$ resulted in FGE of 40\%. In all cases the gap net catch was below 1\% although the actual gap and flow through it had been substantially increased. Mean steelhead FGE remained below 39\% and subyearling Chinook salmon FGE ranged from 28\% down to 20\%. In 1985 modeling studies suggested that the installation of turbine intake extensions (TIEs) might reduce the eddies and provide more uniform vertical flows into the intakes. In 1985 FGEs remained lower than about $40 \%$ for both Chinook salmon and steelhead.

In 1986 TIES were found to improve guidance under restricted operations but a substantial cross current still formed under full powerhouse loading and that reduced guidance efficiencies. Summer guidance was especially low (18-24\%). Modeling indicated that TIEs placed on every other (alternating) intake might further disrupt the current and improve guidance. In 1987 the two possible schemes of alternating intakes were tested and found not to differ substantially, but guidance was improved in both spring and summer and was not dependent on powerhouse operations. Tests with mercury vapor lights as attractants were promising. In 1988 experiments were conducted with a high-porosity bar screen that did not improve guidance for most of the season and substantially increased descaling. The mercury vapor lights did not improve guidance in 1988. In 1989 the bar screen porosity was reduced from 45\% to 33\% and this reduced descaling to the level of the STSs while contributing to higher guidance in spring (to $78 \%$ in mid May).

The authors discuss their methods and application of those methods for other water projects. They acknowledge that the sensory and behavioral mechanisms that influence guidance and passage are ill understood, that the short passage season severely limits testing and replication, and that project operations are important determinants. Results are also very species-specific and life stage-specific. They concluded that higher-porosity bar screen, although it sometimes improved guidance, was too apt to foul and injure fish. The final configurations, with lowered STS, streamlined trash racks, and TIEs on alternate intakes would result in the highest possible guidance and survival. $\underline{\mathrm{BS} 025}$

\section{Gessel. M. H., B. P. Sandford, B. H. Monk, and D. A. Brege. 1994. Population estimates of northern squawfish, Ptychocheilus oregonensis, at Bonneville Dam First Powerhouse, Columbia River. NOAA technical memorandum NMFS-NWFSC-18, Northwest Fisheries Science Center, Seattle, Washington.}

Northern squawfish are well-known predators of juvenile salmonids in the Pacific Northwest rivers and may substantially deplete the number of subyearling Chinook salmon passing Bonneville Dam. To assess predation impacts and evaluate management decisions, population estimates of northern squawfish are needed. Angling was used to derive a population estimate of northern squawfish in the Bonneville 
Dam first powerhouse forebay pool during summer 1989. A crew of three to six fished from the forebay deck of the powerhouse with light sport-tackle and artificial lures. Between 5 and 19 July, a total of 2,464 adult northern squawfish were captured and 2,399 tagged. Tagged fish were recovered as early as the day after tagging; a total of 35 were recovered. The catch per unit effort for the marking period averaged approximately 19 northern squawfish per hour. Nine additional tagged fish were recovered from 226 squawfish captured on 4 August. Three different statistical methods were applied to the catch data to provide population estimates of northern squawfish ranging from 54,480 to 61,828 . (This is the original abstract). $\underline{\text { BS118 }}$

Gilbreath, L. G., E. M. Dawley, R. D. Ledgerwood, P. J. Bently, and S. J. Grabowski. 1993. Relative Survival of Subyearling Chinook Salmon that have Passed Bonneville Dam Via the Spillway or Second Powerhouse Turbines or Bypass System: Adult Recoveries through 1991. Prepared for U.S. Army Corps of Engineers by the National Oceanic Atmospheric Administration National Marine Fisheries Service, Northwest and Alaska Fisheries Center, Coastal Zone and Estuarine Studies Division, Seattle, Washington.

Objectives were 1) compare relative survival among marked treatment groups of subyearling Chinook salmon released simultaneously through a turbine and the bypass system at Bonneville Dam powerhouse 2 and 2) from coded-wire tag recovery data for immature and adult Chinook salmon, estimate long-term relative survival of treatment groups.

Juvenile fall Chinook salmon with distinguishable marks were released simultaneously through a turbine and the bypass system at Bonneville Dam second powerhouse during the summers of 1987-1990 and recovered with seines near the upper boundary of the Columbia River estuary at Jones Beach to estimate short-term comparative passage survival relative to passage routes through the dam. Additional releases were made into the tailrace. Recovery of bypass released fish was significantly lower than recovery of fish released into the turbine at powerhouse 2 over the four years of the study and recovery of both turbine- and bypass-released fish was lower than fish released into the tailrace.

Data from the adult portion of this study was incomplete at the time of this report since a majority of the tagged juveniles were not returning to spawn as adults yet. The data set for 1987 was nearly complete and suggested no significant difference in survival between turbine- and bypass-released fish. BS081

\section{Giorgi, A. E. and J. R. Stevenson. 1995. A Review of Biological Investigations Describing Smolt Passage Behavior at Portland District Corps of Engineer Projects: Implications in Surface Collection Systems. Prepared by Don Chapman Consultants, Inc., Boise, Idaho, for the U.S. Army Corps of Engineers, Portland District, Portland, Oregon.}

The objective was to provide a review of the available information on smolt passage studies at Bonneville, The Dalles, and John Day dams and to discuss the relevance of research findings to the design of surface collector and bypass devices.

This report summarizes the available information on smolt passage studies at Bonneville, The Dalles, and John Day dams for research efforts using radio telemetry, hydroacoustics, netting, and smolt monitoring. Studies of diel passage patterns, vertical distribution, horizontal distribution, forebay approach patterns, and specific passage strategies are reviewed and summarized. Recommendations were made using the available data for design and placement of surface collector and bypass devices. $\underline{B S 075}$ 
Hanks, M. E. and G. R. Ploskey. 2000. Experimental hydroacoustic deployments to improve estimates of fish guidance efficiency. Technical Report ERDC/EL TR-00-8 prepared by the USACE Engineer Research and Development Center, Vicksburg, MS for the USACE Portland District, Portland, Oregon.

This study tested transducer locations and orientations in order to improve the hydroacoustic detectability of fish and to identify important sampling considerations to increase the accuracy, reliability, and comparability of hydroacoustic estimates of fish passage and FGE. The work involved two splitbeam and six single-beam transducers in several configurations in Intake 8B of BI to assess the effects of transducer location and orientation on FGE estimates.

Through the sampling season the single beam transducers were deployed in four different ways while the two split-beam transducer deployments remained constant for comparison with the other four.

Split-beam Deployment Standard for Comparison, One Up Looker for Guided, One Down Looker for Unguided - One split beam transducer, mounted near the bottom of Trash Rack 5 and aimed 53 degrees above the horizontal, sampled guided (above the STS screen) passage. The other, mounted near the top of Trash Rack 1 and aimed 77 degrees below the horizontal, sampled unguided (below the STS tip) passage. Both were set about a half meter from the Oregon (south) side of the screen and were aimed about 11 degrees towards Washington (north) of vertical so that the beams sampled a large proportion of the intake's width, albeit at different elevations. The transducers were slow multiplexed at 2-sec intervals with a ping rate of 15 pings per second for 5 out of every $20 \mathrm{~min}$.

The single-beam transducers were deployed in four different sampling configurations throughout the sampling season and the passage and FGE estimates of each were compared with the unchanged splitbeam deployment. Intake $8 \mathrm{~B}$ was divided into thirds and each was sampled with a pair of single-beam transducers arrayed in different ways. The deployments were:

Detectability modeling for all deployment resulted in effective beam angles very similar to the nominal values. The "Discussion and Recommendations" section includes rationales for different deployments and sampling (ping rate vs. volume reverberation, target time in-beam, beam diameter and range, fish aspect, etc.). There is considerable discussion of the sampling requirements needed to capture the lateral variability of passage within an intake. Transducer rotators and beam steering are discussed as possible strategies for getting intake-wide variability in a relatively short time, such as within a passage season. $\underline{\mathrm{BS} 020}$

Hansel, H. C., R. S. Shively, J. E. Hensleigh, B. D. Liedtke, R. E. Wardell, R. H. Wertheimer, and T. P. Poe. 1999. Movement, distribution, and behavior of radio-tagged juvenile chinook salmon and steelhead in the forebay of Bonneville Dam, 1998. Annual Report by the U.S. Geological Survey, Columbia River Research Laboratory, Cook, Washington for the U. S. Army Engineer District, Portland, Oregon.

In 1994 the U.S. Army Corps of Engineers (COE) initiated a program to develop and evaluate surface-oriented juvenile salmonid bypass systems at hydroelectric dams on the Columbia and Snake rivers. The goal of the program was to develop juvenile bypass systems that would significantly improve the passage efficiency and survival of juvenile salmonids as they migrate downstream.

From 1995 to 1997 the COE has contracted the Biological Resources Division (BRD) of the U.S. Geological Survey to evaluate the efficiency of prototype surface collector and bypass systems by examining the behavior of juvenile steelhead and yearling and subyearling Chinook salmon using radio telemetry in the forebays of John Day Dam (JDA), The Dalles Dam (TDA), and Bonneville Dam (BON). 
In 1998, BRD again used radio telemetry to examine the movements and behavior of radio-tagged juvenile steelhead and yearling and subyearling Chinook salmon in the forebay of BON. The objectives of this research were to determine 1) the general behavior, distribution, and approach patterns of juvenile salmonids in the near-dam forebay areas of BON; 2) the time and route of dam passage; and 3) the behavior of fish associated with tests of surface bypass concepts and prototype surface bypass structures. $\underline{\mathrm{BS} 038}$

Hawkes, L. A., R. C. Johnsen, W. W. Smith, R. D. Martinson, W. A. Hevlin, and R. F. Absolon. 1991. Monitoring of downstream salmon and steelhead at federal hydroelectric facilities. Annual Report 1990 by the U.S. Department Commerce, National Oceanic and Atmospheric Administration, National Marine Fisheries Service, ETSD, to the U.S. Department of Energy, Bonneville Power Administration, Portland, Oregon.

This old NMFS smolt monitoring study involved sampling smolts passing three dams, John Day, The Dalles, and Bonneville in 1990. Smolts were collected by three different methods (a "funnel airlift pump system" at John Day Dam, gatewell dipping at The Dalles Dam until July 4 when a system similar to that at John Day Dam was installed, and smolt traps in the bypasses of both Bonneville Dam powerhouses.

Sampled animals were anaesthetized and examined for species and condition with subsamples measured for length. The John Day passage season involved several shutdowns of the sampled unit (Unit 5) including an 11-day period (May 29 - June 9) when the parts of the powerhouse were shut down due to a fire. The fire at John Day Dam also affected juvenile passage at the other two dams because of pool maintenance and because two smolt transport barges had to discharge cargo in the upper John Day Dam pool. For these reasons and others (the differences in sampling schedules, locations, and methods from dam to dam and from year to year, operational effects, etc.), comparisons with data from other years is problematic.

Injury and descaling data are presented, along with river discharge, spillway discharge, and unit discharge where appropriate. Sockeye salmon were found to be especially fragile to descaling and handling stress. $\underline{\mathrm{BS} 023}$

Hensleigh, J. E., R. S. Shively, H. C. Hansel, J. M. Hardiman, G. S. Holmberg, B. D. Liedtke, T. L. Martinelli, R. E. Wardell, R. H. Wertheimer, and T. P. Poe. 1999. Movement, distribution and behavior of radio-tagged juvenile chinook salmon and steelhead in John Day, The Dalles and Bonneville Dam forebays, 1997. Annual Report by the U. S. Geological Survey, Columbia River Research Laboratory, Cook, Washington for the U. S. Army Engineer District, Portland, Oregon.

In 1994 the U.S. Army Corps of Engineers (COE) initiated a program to develop and evaluate surface-oriented juvenile salmonid bypass systems at hydroelectric dams on the Columbia and Snake rivers. The goal of the program was to develop juvenile bypass systems that would significantly improve the passage efficiency and survival of juvenile salmonids as they migrate downstream.

n 1995 and 1996 the COE contracted the Biological Resources Division (BRD) of the U.S. Geological Survey (formerly National Biological Service) to evaluate the efficiency of prototype surface collector and bypass systems by examining the behavior of yearling and subyearling Chinook salmon using radio telemetry in the forebays of John Day Dam (JDA), The Dalles Dam (TDA), and Bonneville Dam (BON).

In 1997, BRD again used radio telemetry to examine the movements and behavior of radio-tagged yearling Chinook salmon, subyearling Chinook salmon, and juvenile steelhead in the forebays of JDA, 
TDA, and BON. The objectives of this research were to determine: (1) the general behavior, distribution, and approach patterns of juvenile salmonids upriver and in the forebay areas of JDA, TDA, and BON; (2) the behavior of fish once inside the near-dam forebay area; (3) the time and route of dam passage; and (4) the changes in behavior of fish associated with tests of surface bypass concepts and prototype surface bypass structures. $\underline{\mathrm{BS} 035}$

\section{Holmberg, G. S., R. S. Shively, H. C. Hansel, T. L. Martinelli, M. B. Sheer, J. M. Hardiman, B. D. Liedtke, L. S. Blythe, and T. P. Poe. 1996. Movement, distribution, and behavior of radio- tagged juvenile chinook salmon in John Day, The Dalles, and Bonneville Dam forebays, 1996. Annual Report by the U. S. Geological Survey, Columbia River Research Laboratory, Cook, Washington for the U. S. Army Engineer District, Portland, Oregon.}

In 1994 the U.S. Army Corps of Engineers (Portland District) initiated a program to develop and evaluate surface-oriented juvenile salmonid bypass systems at lower Columbia River hydroelectric dams with the goal of significantly improving the passage efficiency and survival of juvenile salmonids. The following studies were conducted as part of the biological evaluation of surface bypass concepts and prototypes.

In 1995 the National Biological Service (now the USGS, Biological Resources Division) and the Oregon Cooperative Fishery Research Unit examined the movements and behavior of radio-tagged juvenile yearling and subyearling Chinook salmon in the forebays of John Day and The Dalles dams. Information collected on fish behavior included approach to the dams, residence time and fish location in the forebay, and time and route of passage.

In 1996, the Geological Resources Division continued similar research efforts at John Day and The Dalles dams and initiated research efforts at Bonneville Dam. The main objectives of the study were to describe (1) the general behavior, distribution, and approach patterns of juvenile salmonids upriver and into the forebay areas of the dams; (2) the behavior of fish once inside the near-dam forebay areas in relation to dam operating conditions; and (3) the time and route of dam passage. BS036

\section{Holmberg, G. S., R. E. Wardell, M. G. Mesa, N. S. Adams, and D. W. Rondorf. 2001a. Evaluation of the Bonneville Dam Second Powerhouse new juvenile bypass system, 1999. Annual Report by U. S. Geological Survey, Columbia River Research Laboratory, Cook, Washington for the U. S. Army Engineer District, Portland, Oregon.}

This study evaluates the $2.7 \mathrm{~km}$ conveyance pipe and outfall that take screened smolts from B2 past known foraging habitat for northern pikeminnow. The main objectives of the study were to determine

1. the physiological effects on smolts of traveling through the conveyance pipe,

2. the effects of passage through the conveyance pipe on tailrace egress, and

3. the influence of tailrace water velocities on fish movements.

Physiological effects were assayed by comparing blood cortisol and lactate levels from PIT-tagged hatchery Chinook salmon (162 sub-yearling and 168 yearling) and 336 steelhead smolts as well as run-ofriver smolts sampled before and after passage through the system. Plasma cortisol and lactate concentrations increased between entrance to the conveyance pipe and after passage, especially in the hatchery fish, which also had tagging stress. When fish were allowed to recover in tanks, lactate levels increased then returned to pre-passage levels within $6 \mathrm{~h}$. Cortisol showed more protracted increases followed by a decrease, but did not return to pre-entrance levels. There were no differences in cortisol and lactate concentrations between night and day. Some PIT-tagged steelhead delayed in the pipe, possibly due to factors including hatchery steelhead not being disposed to migrate and initial operations 
of the facility. As water temperatures increased and operations of the facility were adjusted, delay decreased.

Radio-tagged smolts were released upriver from the dam and directly into the JBS. Fish movements were monitored from the forebay through the JBS to the outfall area, and to an exit site $8 \mathrm{~km}$ downriver of the dam. The influence of tailrace hydraulic conditions was evaluated by comparing the movements of radio-tagged fish to a passive drift buoy, or drogue, equipped with a global positioning system (GPS), and by measuring water velocities using an acoustic Doppler current profiler.

Travel time and movement data were obtained for 454 yearling Chinook, 361 steelhead, and 100 sub-yearling Chinook salmon released from upriver studies and 134 yearling Chinook salmon, 135 steelhead, and 148 sub-yearling Chinook salmon placed into the upstream end of the bypass. Overall, fish moved quickly through the conveyance pipe with no evidence of direct mortality. Travel time between the forebay and the outfall area was longer than travel time through non-JBS passage routes. This was a result of the longer distance of the pipe compared to the spillway and BI tailrace areas. Yearling Chinook salmon took $79 \mathrm{~min}$ and steelhead took $74 \mathrm{~min}$ to travel between the forebay and the outfall area through the JBS. The majority of this time was spent in the conveyance pipe. Yearling Chinook salmon and steelhead that passed the dam through the spillway and BI took between 24 and 30 min to travel from the forebay to the outfall area. Median travel time between the outfall and the downriver exit site was $36 \mathrm{~min}$ for yearling Chinook, $33 \mathrm{~min}$ for steelhead, and $34 \mathrm{~min}$ for sub-yearling Chinook. Travel time through the tailrace was similar for fish that passed through the JBS and non-JBS routes. Less than 5\% of the fish monitored took more than 90 min to travel between the outfall area and the exit site. BS016

\section{Holmberg, G. S., R. E. Wardell, M. G. Mesa, N. S. Adams, and D. W. Rondorf. 2001b. Evaluation of the Bonneville Dam Second Powerhouse juvenile bypass system, 2000. Annual Report by the U. S. Geological Survey, Columbia River Research Laboratory, Cook, Washington for the U. S. Army Engineer District, Portland, Oregon.}

In 1999 the new B2 juvenile bypass and $2.7 \mathrm{~km}$ conveyance pipe were completed. This study evaluated the effects of travel through the modified bypass system in 2000 . The main objectives of the study were to determine: 1) the physiological effects of passing down the pipe on smolts, 2) the effects of passage through the conveyance pipe on tailrace egress behavior, and 3) the influence of tailrace water velocities on fish movements.

The physiological evaluation assayed blood plasma cortisol and lactate concentrations in down migrating smolts before entering and after passage through the conveyance pipe. Based on these assays the stress response from passage through the conveyance pipe was minimal.

Radio telemetry was used to evaluate dam passage and tailrace egress. Median travel time from the forebay to the outfall area through the JBS was longer than median travel time through non-JBS routes. Delay of Chinook salmon may have been caused by fish holding in the collection channel upstream of the conveyance pipe. For steelhead, the majority of this time was spent in the conveyance pipe. Yearling Chinook salmon and steelhead that passed the dam through the spillway and BI had a median travel time of approximately 30 minutes between the forebay and the outfall. Overall, fish moved quickly through the conveyance pipe. There was no evidence of direct mortality caused by the pipe.

Median travel time and behavior through the tailrace area below the outfall was similar for upriver fish that passed through JBS and through other routes. No significant differences were detected in median travel times to the downriver exit stations for either yearling or sub-yearling Chinook salmon released into the JBS compared to stressed and unstressed fish released near the outfall. However, stressed steelhead took longer to reach the downriver exit stations compared to steelhead released into the JBS and unstressed steelhead released near the outfall. Less than $4 \%$ of the fish the authors released into the JBS and obtained travel times for took more than $90 \mathrm{~min}$ to travel between the outfall area and the 
first exit station $8 \mathrm{~km}$ downriver. Mobile tracking contacted $28(18 \%)$ of the fish the authors released into the upstream end of the conveyance pipe. Of these, none were believed to be consumed by predators. One delayed before moving downriver, and none used the side channel behind Ives Island. The authors also contacted 86 fish that were released upriver. Of these, $2 \%$ were believed to be consumed by predators, $7 \%$ delayed before moving downriver, and 3\% used the side channel behind Ives Island. Of the yearling Chinook salmon that were detected by fixed site antennas behind Ives Island, $14 \%$ had passed through the JBS, and $15 \%$ of the steelhead detected there had passed through the JBS. BS008

\section{Holmes, H. B. 1952. Loss of fingerlings in passing Bonneville Dam as determined by marking experiments. U.S. Fish and Wildlife Service, Portland, Oregon.}

This work involved a series of marking experiments designed to assess the magnitude of loss of fingerlings passing Bonneville Dam. A total of 1.5 million fingerlings were marked and 4,197 adult marked fish were recovered. The major findings of the study were as follows: 1) individual experiments should be looked upon as independent measures of differing conditions as to loss in passing the dam;2) losses of fingerlings in a hose used for liberating the fingerlings may have added bias to the results; 3 ) by assigning varying weights to the individual observations, average losses of $11 \%$ to $15 \%$ were obtained; and 4) results indicated a somewhat greater loss of fingerlings as a result of passage through the turbines as compared with passage through the spillway. BS103

\section{Jensen, A. L. 1987. Bonneville Dam Second Powerhouse Fish Guidance Research: Velocity Mapping Studies. Prepared for the U.S. Army Corps of Engineers, by the National Oceanic and Atmospheric Administration, National Marine Fisheries Service, Coastal Zone and Estuarine Studies Division, Northwest and Alaska Fisheries Center, Seattle, Washington.}

Studies to evaluate the efficiency of the fingerling collection and bypass system at the Bonneville Dam 2nd Powerhouse indicated that hydraulic conditions in and around the turbine intakes might be a factor in the low fish guiding efficiencies (FGE) measured (Krcma et al. 1984; Gessel et al. 1985, 1986). The study reported here was undertaken to obtain measurements of the velocities occurring near the trashracks and within the intakes of Turbines 12 and 15 at the Bonneville 2nd Powerhouse. Earlier studies showed good FGE at the Bonneville 1st Powerhouse and the McNary Powerhouse, so similar measurements were made at these sites for comparison. BS092

\section{Johnsen, R. C. and E. M. Dawley. 1974. The effect of spillway flow deflectors at Bonneville Dam on total gas supersaturation and survival of juvenile salmon. Final Report by the National Marine Fisheries Service for the U. S. Army Engineer District, Portland, Oregon.}

In the late 1960's supersaturation of dissolved gases caused by spillway discharges was noted in the waters of the Lower Columbia River. Prototype flow deflectors were installed at Bonneville Dam in 1971 and tested to determine if dissolved gas levels would be reduced. These tests indicated a substantial reduction in the amount of supersaturation produced when compared to standard spillbays. In 1974 three additional deflectors were added at Bonneville to ascertain effects of multiple flow deflectors of dissolved gas content and anadromous fish passage through and around the spill discharge.

Five flow volumes were tested at four different elevations and water samples were collected to determine amount of gas supersaturation. Gas concentrations of water passing over the spillway deflectors were 6 to $12 \%$ less than those in water passing through the control bays. At saturation levels over $120 \%$ this is a significant difference. However, when 431,453 juvenile fall Chinook salmon were released in three treatments (control, modified spillway, standard spillway), no significant differences in 
survival were found. Therefore, the spillway deflectors are not considered to be detrimental to juvenile fall Chinook salmon passing through the spillway. BS171

\section{Johnson, G. E., A. E. Giorgi, and M. W. Erho. 1997. Critical Assessment of Surface Flow Bypass Development in the Lower Columbia and Snake Rivers, Completion Report. Prepared for the U.S. Army Corps of Engineers, Walla Walla and Portland Districts, Portland, Oregon, by BioAnalysts, Inc., Vancouver, Washington.}

The overall objectives of this study was to critically assess surface flow bypass (SFB) development in the Columbia Basin, especially as it pertains to mainstem Columbia and Snake River dams operated by the Corps of Engineers. This report describes the basic premises of SFB development in the Columbia and Snake Rivers and evaluates SFB development strategies relative to the basic SFB premises. It discusses research and evaluation efforts and lessons learned at SFB prototype development sites, assesses the direction and plans for future SFB development at Corps dams, and identifies major information deficiencies. The report ends with recommendations and conclusions on the Corps' SFB program. (This is the original abstract). $\underline{\mathrm{BS} 128}$

Johnson, G. E. and A. E. Giorgi. 1999. Development of surface flow bypasses at Bonneville Dam: A synthesis of data from 1995 to 1998 and a draft M\&E plan for 2000. Annual Report, prepared for the U.S. Army Corps of Engineers, Portland District, Portland, Oregon, by BioAnalysts, Inc. Vancouver, Washington.

This study was undertaken as part of the Portland District's surface bypass program at Bonneville Dam. It begins with a thorough history of surface bypass work in the Basin. It includes reviews of both hydrology and fish passage studies going back over 30 years at Bonneville Dam and follows the development of surface passage at both B1 (the "prototype surface collector") and B2 (the prototype corner collector). It discusses hydrology, bathymetry, project operations, juvenile migration timing and pathways, forebay delay, smolt injury and survival, tailrace passage, and predation. Tests of modifications to Bonneville Dam that are discussed include trash rack blockages at B1, the effects of turbine intake extensions (TIES) at B2, and operations of sluiceways at both powerhouses, the several steps of developing the B1 prototype, and the high-flow outfall study. Near the end there is a large table with unresolved questions about surface collection at Bonneville Dam and how they might be resolved, as well as flow charts with suggested strategies and time lines for implementation. This is a very well organized and useful analysis of the development of surface collection for Bonneville Dam prior to 2000. $\underline{\mathrm{BS} 015}$

Johnson, G. E. and T. J. Carlson. 2001. Monitoring and Evaluation of the Prototype Surface Collector at Bonneville First Powerhouse: Synthesis of Results. PNNL-13516, Prepared for the U.S. Army Corps of Engineers by Pacific Northwest National Laboratory, Richland, Washington.

The purpose of this report was to consolidate results from surface bypass studies at Bonneville Powerhouse 1 in 2000. Specific objectives were to 1) review results from the 2000 PSC studies; 2) relate 2000 results to previous findings (1998 and 1999); and 3) make conclusions about PSC performance (its potential to collect fish) on a species-specific basis and for the run at large. Primary conclusions were 1) monitoring and evaluation of the PSC in 2000 allowed for a thorough evaluation of its performance; 2) the surface bypass concept was found to be an efficient way to collect smolts and minimize turbine passage; 3) PSC collection efficiency estimates from independent methods comported reasonably well; 4) the best available data for collection efficiency are from the 2000 evaluation; 5) collection efficiency was similar between spring and summer (did not decrease in summer but stayed largely unchanged while the 
run composition changed); 6) Collection efficiency for the B1 PSC was higher than that for the SBC at Lower Granite Dam and was comparable to that for the Wells Dam surface bypass; 7) extending the PSC to units 1 and 2 was worthwhile because the surface bypass entrances at units 1 and 3 passed a substantial proportion of total PSC fish passage; 8) the PSC was twice as effective as spill at passing fish at Bonneville Dam in 2000; and 9) there are uncertainties with development of a permanent surface bypass at B1, but is likely they can be satisfactorily resolved with additional research and development. BS125

\section{Johnson, R. L. 1970. Tests of fingerling passage at Bonneville Dam. Summary. Report No. 18. U.S. Army Corps of Engineers, North Pacific Division, Fisheries-Engineering Research Program, August 1970.}

The purpose of this work was to compare the effectiveness of the ice and trash sluice with the power units for passing fingerling fish downstream from the powerhouse into the downstream flow of the tailrace. Buoyant grapefruits were used as fish surrogates. Variable river discharges were tested to observe the effect of differing tailwater depth. The first test group results indicated that about two-thirds of the grapefruit went directly downstream with low tailwater conditions. A maximum of $72 \%$ of the fruit went downstream with high sluice discharge while normal and low sluice discharge passed $60 \%$ and $68 \%$, respectively. The second group of tests with higher river discharge resulted in 19\%, 22\%, and 33\% of downstream passage of grapefruit associated with the low, normal, and high sluice discharges, respectively. BS098

Johnson, R. L., R. A. Moursund, and M. A. Simmons. 1999. Fish Behavior in Front of the Prototype Surface Collector at Bonneville Dam in 1998. Final Report, prepared for U.S. Army Corps of Engineers, Portland District, Portland, Oregon, by Pacific Northwest National Laboratory, Richland, Washington.

This document is the third in a series of reports that describe the results of the fixed-location hydroacoustic evaluation of the prototype surface collector (PSC) at Bonneville Dam in the spring and summer of 1998. The smolt behavior evaluation was planned and executed in conjunction with the fish passage evaluation of the first powerhouse by the U.S. Army Engineer Waterways Experiment Station (CEWES). The overall aim of the behavioral component was to evaluate the fine-scale fish behavior in front of the PSC. This was accomplished by remotely and non-intrusively sensing precise travel routes, mean swimming directions, and velocities, and reconciling observed fish movements with flow vectors to obtain the swimming effort vector. Specific objectives for this first year of PSC evaluation were to examine the potential fish behavioral differences based on slot configuration and to build a basis of understanding about the approach dynamics of smolts related to the PSC structure. The first objective focused on determining the optimal slot width, velocity, and flow for attracting smolts in the near-field zone $(0$ to $3 \mathrm{~m})$. The second, and perhaps most crucial, objective focused on understanding fish behavior from the face of the PSC through the intermediate zone $(3$ to $15 \mathrm{~m})$ to provide design insight for functional installation and operation of a permanent structure. $\underline{\mathrm{BS} 030}$

Johnson, R. L., M. A. Simmons, C. S. Simmons, K. D. Hand, and J. Thomas. 2000. Evaluation of Fish Behavior in Front of the Prototype Surface Collector at Bonneville Dam, 1999. (Hydroacoustic) Final Report Prepared for the U.S. Army Corps of Engineers, Portland District, by Pacific Northwest National Laboratory, Richland, Washington.

In the spring and summer of 1999 Battelle (led by R. L. Johnson) conducted split-beam hydroacoustics and multibeam sonar studies of fish trajectories just upstream of the Unit 3 slot entrance of the B1 Prototype Surface Collector (PSC). The B1 PSC was a temporary structure with variable width entrances designed to test surface bypass concepts. It was configured to test two different entrance slot 
widths, $5 \mathrm{ft}$ and $20 \mathrm{ft}$. The SimRad multibeam system was used to evaluate fish trajectories through a composite beam aimed from a barge tethered about $18 \mathrm{~m}$ upstream of the face of the PSC's Unit 5 entrance slot and six PAS split-beam transducers, arranged above and below the slot in three opposed pairs, one up-looking and one down-looking. The barge-mounted multibeam system captured fish approach trajectories and the smaller (six degree) split-beam systems sampled very near-field trajectories. The multibeam system sampled 9,372 fish tracks and the split-beam system sampled 34,599 fish tracks.

The narrower (5-ft) slot configuration was associated with a notable downward movement as fish came within the $60-\mathrm{ft}$ range of the multibeam system. Nearer the collector, they scattered both upward and downward. Fish approaching the wider $(20-\mathrm{ft})$ configuration remained at a relatively constant depth during their approach until very near the structure where they moved downward several meters. Lateral, southerly movement was not apparent for the 5 -ft configuration until fish were within about 15 feet of the opening. For the 20 - $\mathrm{ft}$ configuration there was more movement of fish to the south approximately $25 \mathrm{ft}$ from the face of the collector. $\mathrm{BS} 027$

\section{Johnson, R.L. C.S. Simmons, S.L. Thornsten, M.A. Chamness, M.A. Simmons, C.A. McKinstry and K.D. Hand. 2001. Hydroacoustic Evaluation of Fish Behavior at Bonneville Dam First Powerhouse: 2000 Prototype Surface Flow Bypass. Final report prepared for U.S. Army Corps of Engineers, Portland District, Portland, Oregon, by Battelle, Pacific Northwest Division, Richland, Washington.}

The purpose of this study was to evaluate fish behavior in front of the PSC at turbine Unit 3 of the first powerhouse at Bonneville Dam. The objectives were to describe fish behavior within $18 \mathrm{~m}$ of the collector with respect to direction of movement and water flow, and to compare the behavior of fish in front of the opening with those along the side of the opening. Fish were sampled using multibeam and split-beam sonar systems. Major findings were 1) the percentage of milling fish was the highest within 5 $\mathrm{m}$ of the collector. Based on a comparison of displacement versus swimming speed, milling fish expend more energy than directed fish; 2) half the fish detected along the sides of the collector were milling; 3 ) more fish were present in front of the collector during the day; and 4) in spring, the fish were distributed higher in the water column than in summer. Based on these results the authors recommend that, for future fish bypass design efforts, the mechanisms that cause milling in front of an unobstructed collector opening be modeled. Improved mitigation technologies may become apparent by understanding these delay mechanisms. BS124

\section{Jones, S. T., G. M. Starke, and R. J. Stansell. 1996. Predation by birds and effectiveness of predation control measures at Bonneville, The Dalles and John Day Dams in 1995. CENPP- CO-SRF, US Army Corps of Engineers, Cascade Locks, Oregon.}

This study assessed avian predation at Bonneville, The Dalles and John Day dams in 1995. The authors estimated a minimum of 52,773 juvenile fish were taken by gulls at Bonneville Dam and 64,787 were juveniles taken by gulls at The Dalles Dam in 1995. Observations of avian predation at John Day Dam were too infrequent to estimate the total number of taken fish. At Bonneville, predation primarily occurred in the tailwaters of both powerhouses and the spillway. At The Dalles, predation was almost exclusive to the spillway tailrace. At John Day, most predation occurred at the powerhouse forebay and at the JBS outfall. Predation was heaviest in April and June at Bonneville, April through July at The Dalles, and in April and early June at John Day. At Bonneville, predation success for gulls ranged from $35 \%$ to $43 \%$ by location, for ospreys from 69 to $80 \%$ and for great blue herons $73 \%$ to $100 \%$. Gull predation success ranged from $20 \%$ to $42 \%$ at The Dalles and $25 \%$ to $56 \%$ at John Day Dam. Predation abatement lines appeared effective at times and ineffective at other times. On many occasions birds showed no response to propane canons used at The Dalles Dam. BS108 
Jones, S. T., G. M. Starke, and R. J. Stansell. 1997. Predation by gulls and effectiveness of predation control measures at Bonneville, The Dalles and John Day Dams in 1996. CENWP-CO-SRF, USACE, US Army Corps of Engineers, Cascade Locks, Oregon.

Estimates of feeding gull numbers, of juvenile fish consumed by gulls, and of gull predation control methods were examined at Bonneville, The Dalles, and John Day dams in 1996. Feeding activity occurred primarily in the spillway tailwaters at Bonneville, in the area of The Dalles Bridge at The Dalles Project, and near the JBS outfall at John Day. Gull predation success rates were $43 \%$ at Bonneville, and 52\% at John Day. On the basis of average daily numbers of gulls present, the new line array at The Dalles Dam appeared to deter over $95 \%$ of gulls from feeding. The line arrays at Bonneville were not installed until gull numbers had dropped for the season, and the hydrocannon installation was not complete or functional during the 1996 evaluation. BS105

Jones, S. T., G. M. Starke, and R. J. Stansell. 1999. Predation by gulls and effectiveness of predation control measures at Bonneville, The Dalles and John Day Dams. CENWP-OPSRF, US Army Corps of Engineers, Cascade Locks, Oregon.

This study assessed the effectiveness of avian deterrent methods and determined gull numbers, feeding locations, and seasonal distributions and estimated minimum numbers of juvenile fish consumed by gulls at Bonneville, The Dalles, and John Day dams. Stainless steel avian line arrays were observed to be $100 \%$ effective in preventing gulls from feeding within the area of their coverage. The hydrocannon installed on the John Day Dam JBS outfall was also observed to be effective at deterring gulls. Significant feeding locations were the middle and lower spillway channel at Bonneville, just upstream of The Dalles Bridge at The Dalles Project, and the JBS outfall and the area adjacent to the lower navigation lock wall at John Day dam. At all three projects, the greatest number of feeding gulls were present during the month of May. Estimated minimum numbers of juvenile fish taken by gulls were 35,966 at Bonneville and 94,176 at John Day. No estimate was calculated for The Dalles because shoreline viewing distances to feeding gulls were too great. $\underline{\text { BS106 }}$

Krcma, R. F., C. W. Long, and C. S. Thompson. 1978. Research on the development of a fingerling protection system for low head dams - 1977. Annual Report of Research for the U.S. Army Corps of Engineer District, Portland, Oregon by the National Oceanic and Atmospheric Administration, Northwest and Alaska Fisheries Science Center, Seattle, Washington.

The research goals for this work were to 1) evaluate the prototype bar screen and 2) complete studies on the design and operating criteria for submerged orifices. Primary research findings were 1) significant descaling of fingerlings occurred when fish were detained in gatewells equipped with vertical barrier screens, especially of the design for the Bonneville $2^{\text {nd }}$ powerhouse; 2 ) to provide fish timely egress from the gatewells, an orifice system with at least a 75\% FPE is needed; 3 ) one 12-inch-diameter lighted orifice in a darkened gatewell provides acceptable ( $>75 \%)$ FPE through the entire range of submergence ( 3 to 10 feet); fish showed no preference for either the north or the south orifice; and 4) a significant percentage of the total debris entering gatewells can be expected to pass out through 12-inch-diameter orifices. BS095

Krcma, R. F., D. DeHart, M. Gessel, C. Long, and C. W. Sims. 1982. Evaluation of submersible traveling screens, passage of juvenile salmonids through the ice-trash sluiceway, and cycling of gatewell-orifice operations at the Bonneville First Powerhouse, 1981. Annual Report of Research for the U.S. Army Corps of Engineer District, Portland, Oregon by the National Oceanic and Atmospheric Administration, Northwest and Alaska Fisheries Science Center, Seattle, Washington. 
The U.S. Army Corps of Engineers (COE) is proceeding with the design and implementation of the fingerling bypass for the Bonneville First Powerhouse. The final configuration could either be a conventional submersible traveling screen (STS) system (similar to McNary and Lower Granite Dam), a bypass for fish directly from the forebay through the existing ice and trash sluiceway to the tailrace, or some combination of the above. To obtain the necessary data for determining the final configuration, the COE funded a cooperative study with the National Marine Fisheries Service (NMFS) and the Oregon Department of Fish and Wildlife (ODFW).

The study had the following primary objectives: (1) evaluate the effectiveness of the STS for guiding juvenile salmonids, (2) evaluate the feasibility of cycling the operation of the submerged orifices providing egress for juvenile salmonids from the gatewells, and (3) evaluate the use of the ice and trash sluiceway as a means of bypassing juveniles directly from the forebay to the tailrace. A secondary objective was to evaluate a balance flow vertical barrier screen (BFVBS) in a model and test a prototype screen if time permitted.

NMFS was responsible for the STS and orifice cycling studies and also monitored fish entering intake gatewells as part of the evaluation of the effectiveness of the ice and trash sluice. ODFW was responsible for the operation and evaluation of the ice and trash sluice for bypassing fingerling salmonids directly from the forebay to the tailrace. This report covers the NMFS portion of the research. A separate report covering the ODFW segment of the research was prepared by ODFW and is attached as Appendix B. $\underline{\mathrm{BS} 039}$

Krcma, R. F., M. H. Gessel, W. D. Muir, C. S. McCutcheon, L. G. Gilbreath, and B. H. Monk. 1984. Evaluation of the juvenile collection and bypass system at Bonneville Dam - 1983. Annual Report of Research for the U.S. Army Corps of Engineer District, Portland, Oregon by the National Oceanic and Atmospheric Administration, Northwest and Alaska Fisheries Science Center, Seattle, Washington.

The fingerling collection and bypass system for the Bonneville Second Powerhouse was completed in 1982 and was in full-scale operation during the 1983 smolt migration. The National Marine Fisheries Service (NMFS), under contract to the U.S. Army Corps of Engineers (COE), conducted a research program during the 1983 smolt migration to evaluate this bypass system, attempt to identify problem areas, and make recommendations if necessary. In addition, a study was conducted to determine the potential of a screen cycling operation for submersible traveling screens (STS) at both the $1^{\text {st }}$ and $2^{\text {nd }}$ Powerhouses.

The primary objectives of the research at Bonneville Dam during the 1983 smolt migration were as follows: (1) Evaluate the efficiency of the STS and the gatewell orifice bypass system ( $2^{\text {nd }}$ Powerhouse). (2) Monitor fish quality and stress through the collection and bypass systems (both powerhouses).

(3) Evaluate the smolt collection system and its potential for indexing smolt migration ( $2^{\text {nd }}$ Powerhouse).

(4) Evaluate the potential of screen cycling (both powerhouses). (5) Determine the feasibility of using the downwell release site in the observation room at the $2^{\text {nd }}$ Powerhouse as a release site for transported fingerlings. This report provides the final analysis of the results by objectives of the 1983 research program. $\underline{\mathrm{BS} 033}$

Ledgerwood, R. D., E. M. Dawley, L. G. Gilbreath , P. J. Bently, B. P. Sanford, and M. H. Schiewe. 1990. Relative survival of subyearling chinook salmon which have passed Bonneville Dam via the spillway or the Second Powerhouse turbines or bypass system in 1989, with comparisons to 1987 and 1988. Annual Report of Research for the U.S. Army Corps of Engineer District, Portland, Oregon by the National Oceanic and Atmospheric Administration, Northwest Fisheries Science Center, Seattle, Washington. 
Objectives were to 1) compare relative survival among marked treatment groups of subyearling Chinook salmon released simultaneously through a turbine and the bypass system at Bonneville Dam Powerhouse 2,2) compare relative survival of subyearling Chinook salmon released into the bypass system to fish released at the bypass outfall to estimate bypass mortality, and 3) estimate long-term relative survival of treatment groups from coded-wire tag recovery data for immature and adult Chinook salmon.

Juvenile fall Chinook salmon with distinguishable marks were released simultaneously through a turbine, into the bypass system, and at the bypass outfall at Bonneville Dam second powerhouse from 30 June to 3 August and recovered with seines near the upper boundary of the Columbia River estuary at Jones Beach to estimate short-term comparative passage survival relative to passage route through the dam. There were no significant differences in relative survival of subyearling Chinook salmon released into the bypass system, the turbines, or at the bypass outfall. The authors speculate that difference in survival in previous years may have been due to predation by northern squawfish at the bypass outlet and that the increase in tailwater elevation due to increased turbine operation may have reduced predatory effectiveness at the bypass outlet.

Adult recovery data for the 1987 released fish showed a poor return rate. Of the groups released in 1987 only fish release at the Hamilton Island shoreline showed significantly different survival. Lower survival was also documented for these fish as subyearlings in 1987. The authors suspect this lower survival was due to predation in the near shore area. $\underline{\mathrm{BS} 085}$

Ledgerwood, R. D., E. M. Dawley, L. G. Gilbreath , P. T. Bently, B. P. Sanford, and M. H. Schiewe. 1991. Relative survival of subyearling chinook salmon that have passed through the turbines and bypass system of Bonneville Dam Second Powerhouse, 1990. Annual Report of Research for the U.S. Army Corps of Engineer District, Portland, Oregon by the National Oceanic and Atmospheric Administration, Northwest Fisheries Science Center, Seattle, Washington.

In 1990, based on 10 releases, there were no significant differences in relative survival of subyearling Chinook salmon released into the bypass system, the turbines, or at the bypass egress at Bonneville Dam Second Powerhouse. The failure of the turbine release hose severely compromised the study by reducing from 21 to 10 the number of data blocks available for analysis of turbine to bypass passage survival differences.

The following conclusions were based on 4 years of estuarine recoveries of juvenile salmonids released at Bonneville Dam. It cannot be over-emphasized that these conclusions are valid only for the species and size of fish tested (subyearling chinook salmon) and the dam passage conditions and river environment during testing. Other fish species or other sizes of chinook salmon passing through the dam at other times of the year may have substantially different survival levels. Moreover, these conclusions are preliminary pending assessment of treatment group differences among adults recovered over the next 5 years.

1) In 1990, based on 10 releases and much reduced statistical power, there were no significant differences in relative survival of subyearling chinook salmon released into the bypass system, the turbines, or at the bypass egress at Bonneville Dam Second Powerhouse.

2) The failure of the turbine release hose compromised the study by reducing from 21 to 10 the number of data blocks available for analysis of turbine to bypass passage survival differences.

3) Estuarine sampling of juveniles provided recovery data to make statistical comparisons among treatment groups that are as sensitive as comparisons from expected adult recovery data; the lack of differences in catch distributions through time among treatment groups suggests uniform sampling of all treatment groups. 
Synthesis of Biological Research on Juvenile Salmonid Passage and Survival at Bonneville Dam through 2005

4) Analyses of differences in recoveries of bypass- and egress-released fish using 21 release blocks suggest that in past years of study (1988 and 1989) the front-roll release was not a good control for the bypass system. The authors speculate that predation by northern squawfish in the locality of the bypass outlet structure may have caused the diminished survival.

5) The authors speculate that increased turbine operation (from four to eight units) may have diminished abundance and predatory effectiveness of northern squawfish near the bypass outlet. The reduced statistical power compromised this assessment.

6) Tailwater elevation may be an important factor in explaining differences in turbine versus bypass passage survival; generally, the relative survival of bypass fish increased with increased tailwater surface elevation.

7) Few descaled fish (less than $1 \%$ of the total) were captured at Jones Beach, and, except for the lower turbine groups released through a torn hose early in the study, there was no apparent relationship with the treatments tested.

8) The conditions tested did not necessarily represent environmental conditions in the tailrace after long-term operation of the Second Powerhouse, but provided observations useful for evaluating the reasons for and the seriousness of decreased survival associated with bypass passage.

9) Adult recovery data for the 1987 releases are essentially complete, but detection power was low $(15.5 \%)$ due to poor return rate. Except for the lower survival of Hamilton Island (shoreline) release groups, all differences were insignificant $(\mathrm{P}=0.05) . \underline{\mathrm{BS} 083}$

Ledgerwood, R. D., E. M. Dawley, L. G. Gilbreath, L. T. Parker, B. P. Sanford, and S. J. Grabowski. 1994. Relative survival of subyearling Chinook salmon after passage through the bypass system at the First Powerhouse or a turbine at the First or Second Powerhouse and the tailrace basins at Bonneville Dam, 1992. Annual Report of Research for the U.S. Army Corps of Engineer District, Portland, Oregon by the National Oceanic and Atmospheric Administration, Northwest Fisheries Science Center, Seattle, Washington.

The objective was to compare relative survival among marked groups of subyearling Chinook salmon released into the bypass system of Bonneville Dam first powerhouse, the turbines at the first and second powerhouses, and at a site in swift water about $2.5 \mathrm{~km}$ downstream from the dam.

Fish were marked with coded wire tags and cold branded. These fish were released in groups into the bypass channels at the first powerhouse, the turbine at the first powerhouse, the turbine at the second powerhouse, and at a mid-channel $2.5 \mathrm{~km}$ downstream of the dam. Tagged fish were recovered near the upper boundary of the Columbia River estuary at Jones Beach to estimate short-term survival. Results showed lower survival rates for fish released into the bypass system at the first powerhouse compared to fish released into the turbines at the first powerhouse. Fish passing through the second powerhouse turbines and tailrace had lower survival than fish passing through the first powerhouse turbines and tailrace. $\underline{\mathrm{BS} 079}$

Long, C. W. 1976. Final report on vertical distribution of fingerling salmonids in turbine intakes of the Bonneville First Powerhouse. Annual Report of Research for the U.S. Army Corps of Engineer District, Portland, Oregon by the National Oceanic and Atmospheric Administration, Northwest and Alaska Fisheries Science Center, Seattle, Washington.

This study estimated the vertical distribution of out-migrant steelhead trout, coho, sockeye, and both spring and fall Chinook salmon in turbine intakes 3B and 5B of Bonneville first powerhouse during the spring of 1975. Fyke nets were used to capture fish in the gatewells. Results indicated that for steelhead, coho, and spring Chinook, the percentage caught in the top two nets did not differ between units 3 and 5 at full turbine load. However, significantly fewer sockeye and fall Chinook were caught in the top two 
nets when the load on Unit 3 was reduced to two-thirds capacity. Data indicated that all species are more highly concentrated in the upper $29 \%$ of the intake flows at Bonneville as compared to The Dalles or McNary Dam (data from The Dalles and McNary were collected in a previous study in 1960 and 1961). BS097

Long, C. W. and R. F. Krcma. 1977. Development of a system for protecting juvenile salmonids at the Second Powerhouse at Bonneville Dam - progress 1976. Annual Report of Research for the U.S. Army Corps of Engineer District, Portland, Oregon by the National Oceanic and Atmospheric Administration, Northwest and Alaska Fisheries Science Center, Seattle, Washington.

This work addressed the problem of increasing the FPE of submerged orifices by developing better orifice design and operating criteria. The premise was that if passage efficiencies of $90 \%$ or more could be achieved in spite of increased flows and turbulence within the gatewells, delay of fish within the gatewells would be reduced. The tests were conducted in gatewell 9B at Bonneville Dam first powerhouse. Initial tests showed that 8 -inch orifices were inadequate and that 18 -inch orifices were overadequate. Two 12-inch orifices were found to be superior to two 10-inch orifices. Based on diel passage of smolts through the collection system, it was determined that maintenance work on the system would have the least impact on fish passage if done between 1200 and $1600 \mathrm{hrs}$. Descaling of smolts was not a serious problem as long as a high FPE was maintained. BS096

\section{Magne, R. A. 1984. Hydroacoustic Survey of the Bonneville Second Powerhouse Forebay to Determine the Spatial Distribution of Outmigrant Juvenile Salmonids. U.S. Army Corps of Engineers, Portland District, NPPOP-RM-FFU, Fisheries Office, Bonneville Lock and Dam, Cascade Locks, Oregon.}

The primary objectives of this study were to define lateral and vertical distributions of downstream migrant salmonids in three areas upstream of the second powerhouse. The secondary objectives were to assess vertical distributions of fish at individual turbine intakes and to identify behavior of smolts inside the turbine intake above the traveling screens. The major findings were as follows: 1) horizontal distribution of smolts in the near forebay at night was not evenly distributed but was more in line with expected flows into the active turbines at the north and south extremes of the dam;2) vertical distribution of smolts passing into turbine units 11 and 12 during full and reduced loading showed the smolts to be interceptable by the screen; and 3) $85 \%$ of the fish distribution was within 10 meters of the surface, indicating that smolts following modeled flow lines would be directed below the traveling screens. $\underline{\mathrm{BS} 110}$

Magne, R. A. 1987a. Bonneville II Hydroacoustic Monitoring Memorandum for the Record, \#1, 27 May 1987.

The purpose of this work was to describe temporal and spatial distributions of fish passage through the main turbine units, fish turbine and sluiceway, and to estimate FGE for turbine passage. Limited results in this memorandum indicated individual daily estimates of FGE between NMFS netting efforts and hydroacoustic techniques were poorly correlated. Large numbers of fish passed through the sluice, and passage was observed to occur during both day and night time periods. Temporal peaks in passage were observed at the sluiceway between 0600 and $1000 \mathrm{hrs}$ and between 1600 and $2000 \mathrm{hrs}$, with the fewest fish passing between 0000 and $0600 \mathrm{hrs}$. No obvious behavioral differences were noted associated with fish at intake slots with and without intake extensions. BS094 


\section{Magne, R. A. 1987b. Hydroacoustic Monitoring at the Bonneville Dam Project in 1988, Proposal plus 1987 data. U.S. Army Corps of Engineers, Portland District, Bonneville Lock and Dam, Cascade Locks, Oregon.}

Operation of the second powerhouse at Bonneville Dam has been severely restricted because of the ineffectiveness of the juvenile bypass collection system. The expected guidance of at least $70 \%$ of the juvenile downstream migrants into this system has not been realized. Revenue losses have been substantial and will continue with restrictions that are in place now. Structural improvements to the turbine intakes (lowered STS, streamlined trash racks, and roof extensions) have improved fish guiding efficiency (FGE) for yearlings; however, it is unknown if similar improvements can be expected.

Proposals to operate the second powerhouse based solely on hydroacoustic estimates of passage there have not been acceptable. Instead there has been considerable interest in a distribution of passage study for the entire Bonneville project (powerhouse 1, powerhouse 2 and the spillway). Hydroacoustic monitoring, radio telemetry tracking, and mark recapture techniques are all being considered for this work. All have deficiencies regarding providing the necessary information on distribution of passage at the project.

Preliminary analysis of spring hydroacoustic monitoring data at the second powerhouse in 1987 showed that the ice and trash sluiceway at the south end of the powerhouse passed a large proportion of the downstream migrants between $0600 \mathrm{~h}$ and $2000 \mathrm{~h}$. The Corps proposes operation of some or all of the turbines at powerhouse 2 and that an independent, mutually acceptable, technique could verify those results, then operation of the powerhouse would be warranted. Operation of the second powerhouse to determine the proportion of subyearling downstream migrants passing through the bypass facilities and main turbines would also be investigated. Objectives of the program would be as follows: (1) Determine bypass effectiveness (the proportion of downstream migrants that pass through the bypass system and sluiceway out of total second powerhouse passage) during both the spring and summer outmigrations. (2) Determine the accuracy of hydroacoustic estimates of passage into main turbine unit intakes and the sluiceway. (3) Determine the extent of residualism in the forebay and tailrace area after shut down of the powerhouse in the evening. (4) Determine ways to effectively make hydroacoustic estimates at the first powerhouse main turbine unit intakes, sluiceway intakes and spillway. (5) Determine the percent mortality of downstream migrants caused by passage through the ice and trash sluiceway at the second powerhouse. BS043

\section{Magne, R. A. 1987c. Hydroacoustic Monitoring of Downstream Migrant Juvenile Salmonids at Bonneville Dam, 1987. U.S. Army Corp of Engineers, Portland District, Operations Division, Fisheries Field Unit, Bonneville Lock and Dam, Cascade Locks, Oregon.}

The sluiceway at Bonneville Dam second powerhouse was evaluated for effectiveness in passing juvenile salmonids under various powerhouse loading conditions. Also evaluated were transducers located inside a turbine intake, and the difference in fish abundance or behavior in slots between turbine intake extensions and slots with turbine intake extensions.

Fish passage at the sluiceway averaged $81 \%$ of the total passing the $2^{\text {nd }}$ powerhouse during the hours of 0600 and 2000 . Between 2000 and $2100 \mathrm{~h}$ fish passage averaged about $30 \%$ through the sluiceway with two, three, four, or five turbine units operating. In general the more turbines operating, the fewer fish passed the sluiceway. Tight groups of fish were observed passing the sluiceway, which could result in underestimated counts. The technique of hydroacoustic monitoring at the $2^{\text {nd }}$ powerhouse sluiceway should be evaluated for accuracy.

The sonar estimate of FGE using transducers oriented inside the turbine intake at Unit 12 was 36\% while the NMFS estimate was $45 \%$. Daily comparisons showed poor correlation, possibly due to small 
sample sizes. Seasonal estimates were more favorable. Transducers installed inside turbine intakes seemed to perform well.

No obvious difference was noted in fish behavior or counts between slots with a turbine intake extension and slots without a turbine intake extension. (This is the original abstract). BS109

\section{Magne, R. A., D. J. Rawding, and W. T. Nagy. 1986. Hydroacoustic Monitoring at the Bonneville Dam Second Powerhouse during 1986 Fish Guiding Efficiency Tests. Fishery Field Unit, U.S. Army Corps of Engineers, Portland District, Portland, Oregon.}

The Portland District Fisheries Field Unit conducted a second year of hydroacoustic studies at the Bonneville Dam Second Powerhouse in 1986. This study took place in conjunction with efforts by the National Marine Fisheries Service (NMFS) to evaluate the effect of modifications to turbine intakes to improve fish guiding efficiency (FGE) at that site. The work was initiated by the Corps to improve the unacceptably low FGE of submersible traveling screens (STSs) documented by the NMFS after the powerhouse came on line in 1982 (Krcma et al. 1984; Gessel et al. 1985; Gessel et al. 1986a, b). Sonar monitoring of juvenile salmonids (Oncorhynchus app., Salmo gairdneri) passing into turbines at the second powerhouse was intended to provide insight into the effect of the roof extensions on the distribution of fish just upstream of the trash racks. Differences in the depth distributions of passage at turbines with and without the extensions and differences in these distributions between 1985 and 1986 were expected to provide clues to the reasons for the results obtained and to furnish guidance for further development of structural modifications to improve survival of salmonids passing the project.

Improved FGE was obtained for yearling Chinook salmon (Oncorhynchus tshawytscha) with various modifications tested by the NMFS during this year's outmigration; the roof extensions did not provide any improvement in FGE over 1985 (no roof extensions) for subyearlings according to a preliminary report by Gessel et al. (1986b).

This report addresses the hydroacoustic findings on fish behavior at the second powerhouse observed during the 1986 spring and summer outmigrations of juvenile salmonids and refers back to 1985 results to identify differences in vertical distributions between the two years. The objectives of the study at the second powerhouse during the FGE test were to (1) Determine the vertical distribution of juvenile salmonids entering each monitored turbine intake and the relationship these distributions have with FGE test results. (2) Determine the horizontal distribution of juvenile salmonids entering monitored turbine intakes across the powerhouse. (3) Determine estimates of passage into the ice and trash sluiceway. $\underline{\mathrm{BS} 042}$

\section{Magne, R. A., R. J. Stansell, and W. T. Nagy. 1989. A Summary of Hydroacoustic Monitoring at the Bonneville Dam Second Powerhouse in 1988. Fishery Field Unit, U.S. Army Corps of Engineers, Portland District, Portland, Oregon.}

Efforts to improve guidance of migrating, juvenile salmonids into the bypass systems at the Bonneville Dam Second Powerhouse continued in 1988. The Corps has been directly involved in the hydroacoustic assessment of fish behavior and in estimating the numbers of fish passing into the turbine intakes and ice and trash sluiceway. In the course of the monitoring in 1987, it became evident, both visually and hydroacoustically, that large numbers of juveniles were passing into the sluiceway. For this reason, a determination of the proportion of passage into the sluiceway compared to passage into the turbine intakes became an object of particular interest. Objectives for the 1988 work were as follows: (1) Determine the relationship between acoustic estimates of passage into a turbine and estimates of passage into that turbine based on fish guidance efficiency (FGE) tests conducted concurrently by the National Marine Fisheries Service (NMFS). (2) Determine target strengths of juveniles inside a turbine intake and 
at the sluiceway using dual-beam techniques. (3) Determine if a low-light, silicon-intensified target (SIT) video camera can provide reliable estimates of juvenile passage and behavior at the second powerhouse sluiceway intake. BS044

\section{Martinson, R. D., R. J. Graves, R. B. Mills, and J. W. Kamps. 1997. Monitoring of Downstream Salmon and Steelhead at Federal Hydroelectric Facilities - 1996. Prepared for Bonneville Power Administration, Environment, Fish and Wildlife, Portland, Oregon, by NOAA Environmental and Technical Services Division Northwest Region, Portland, Oregon.}

This paper summarizes the NMFS Smolt Monitoring Project for 1996 and discusses the smolt monitoring facilities at John Day and Bonneville Dams. Data generated from monitoring the smolt passage facilities include 1) species-specific hourly and daily sample totals; 2) brands and fin clips; 3) descaling and mortality; 4) species-specific length and condition data; 5) river, powerhouse, turbine, and spill flow data; and 6) PIT tag detection and recapture conditions. A total of 70,559 fish were handled at John Day and 58,128 fish at Bonneville in 1996. BS116

McConnell, R. J. and W. D. Muir. 1982. Preliminary evaluation of the Bonneville juvenile bypass system - Second Powerhouse. Annual Report of Research for the U.S. Army Corps of Engineer District, Portland, Oregon by the National Oceanic and Atmospheric Administration, Northwest and Alaska Fisheries Science Center, Seattle, Washington.

The objective of this study was to identify potential problems with the DSM prior to a comprehensive evaluation scheduled for the spring of 1983. Marked fish were released into gatewells and into a portion of the DSM. No statistical difference was observed in recoveries of DSM- and tailracereleased fish, indicating that fish who entered the downwell in the DSM gallery and were transported downstream from the $2^{\text {nd }}$ powerhouse survived as well as those released directly into the tailrace. The $10 \%$ sampler was exceptionally accurate as it recovered $9.9 \%$ of 2,230 marked fish released into a gatewell. Subyearling fall Chinook salmon smolts were captured most frequently and had the least descaling, whereas sockeye smolts were captured less frequently but suffered a higher rate of descaling. BS104

Michimoto, R. T. and L. Korn. 1969. A Study to Determine the Value of Using the Ice-Trash Sluiceway for Passing Downstream-Migrant Salmonids at Bonneville Dam. Final report Prepared for the U. S. Army Corps of Engineers, North Pacific Division, FisheriesEngineering Research Program, Portland, Oregon, by the Fish Commission of Oregon, Research Division, Portland, Oregon.

The purpose of this work was to determine the value of using the sluiceway at Bonneville Dam to pass out-migrant fish. The specific objectives of the project were to 1) estimate the number of downstream migrants entering the sluiceway at Bonneville Dam during part-time use; 2) of the fish migrating through the powerhouse side of the forebay at Bonneville Dam determine the proportion entering the sluiceway; and 3) determine if fish survive best when passing through the sluiceway or turbines at Bonneville Dam. The authors estimated that 41,992 steelhead, 101,750 coho and 75,555 Chinook salmon passed the sluiceway during the six weekends of sampling. Small proportions of the first two release groups and $15 \%$ of the third release group entered the sluiceway. Sluiceway mortality testing results were inconclusive. $\underline{\mathrm{BS} 099}$ 
Michimoto, R. T. 1971. Bonneville and The Dalles Dams Ice-Trash Sluiceway Studies, 1971. Report \#20, Prepared for the U. S. Army Corps of Engineers, North Pacific Division, FisheriesEngineering Research Program, Portland, Oregon, by the Fish Commission of Oregon, Research Division, Portland, Oregon.

In the spring of 1969, the Fish Commission of Oregon, with funds supplied by the U.S. Army Corps of Engineers, studied the feasibility of using the ice-trash sluiceway at Bonneville Dam to pass downstream-migrant salmonids. The study was an attempt to pass migrants via the sluiceway rather than through the turbines where, as established in previous studies, significant mortalities occur (Schoeneman, Pressey, and Junge, 1961). The authors found that fish entered the sluiceway mainly during the day and that they suffered negligible mortality.

At the conclusion of the study, the authors recommended full-time operation of the Bonneville icetrash sluiceway during the spring of each year to pass downstream migrants. The authors also recommended that the Fisheries-Engineering Technical Advisory Committee consider the value of operating sluiceways at other main-stem dams for passing juvenile fish.

The U.S. Army Corps of Engineers agreed to operate the ice-trash sluiceways at Bonneville and The Dalles dams for fish passage beginning in the spring of 1971 and financed a study by the Fish Commission of Oregon to evaluate the operation of the sluiceways. At Bonneville Dam the authors compared the entry of fish into the sluiceway using overflow and submerged-orifice entrances, and determined if submerged mercury-vapor lights increased collection of fish at night. At The Dalles Dam the authors determined if there were operational problems associated with using the sluiceway to pass downstream migrants. $\underline{\text { BS091 }}$

Monk, B. H., G. E. Varney, and S. J. Grabowski. 1992. Continuing studies to evaluate and improve submersible traveling screens for fish guidance at Bonneville Dam First Powerhouse, 1991. Annual Report of Research for the U.S. Army Corps of Engineer District, Portland, Oregon by the National Oceanic and Atmospheric Administration, Northwest Fisheries Science Center, Seattle, Washington.

Objectives were to 1) determine if FGE is similar in various turbine intakes across the face of the powerhouse and 2) evaluate the effects of a raised operating gate on FGE.

Fish guidance efficiency was calculated from gatewell dip-net catches (guided fish estimate) and gap and fyke nets attached to the STS (unguided fish estimate). There was not a significant difference in FGE in paired tests between units 3 and 8. Unit 5 had significantly lower FGE than unit 8 during paired tests. The authors suggest that this difference may be due to the small sample size. FGE was significantly increased by raising the operating gate.

$\underline{\mathrm{BS} 082}$

Monk, B. H., J. A. Ross, B. P. Sanford, and D. B. Dey. 1993. Continuing studies to measure and improve fish guidance efficiency of submersible traveling screens at Bonneville Dam First Powerhouse, 1992. Annual Report of Research for the U.S. Army Corps of Engineer District, Portland, Oregon by the National Oceanic and Atmospheric Administration, Northwest Fisheries Science Center, Seattle, Washington. 
Objectives were to compare fish guidance efficiency 1) using a standard elevation submerged traveling screen with a stored operating gate, 2) using a standard elevation submerged traveling screen with a raised operating gate, and 3) using a lowered submerged traveling screen with a raised operating gate.

Fish guidance efficiency was calculated from gatewell dip-net catches (guided fish estimate) and gap and fyke nets attached to the STS (unguided fish estimate). Results showed that lowering the STS did not improve FGE. Raising the operating gate did not significantly improve FGE for yearling Chinook salmon. However, FGE was significantly increased for subyearling Chinook salmon, coho salmon, and steelhead.

\section{BS080}

Monk, B. H., B. P. Sandford, and D. B. Dey. 1994. Evaluation of the fish guidance efficiency of submersible traveling screens and other modifications at Bonneville Dam Second Powerhouse, 1993. Annual Report of Research for the U.S. Army Corps of Engineer District, Portland, Oregon by the National Oceanic and Atmospheric Administration, Northwest Fisheries Science Center, Seattle, Washington.

Bonneville Dam Second Powerhouse was completed in 1982 and National Marine Fisheries Service (NMFS) researchers began evaluating fish guidance efficiency (FGE) at this facility in 1983. Initial measurements of FGE with standard-length submersible traveling screens (STSs) were less than 24\% for yearling Chinook (Oncorhynchus tshawytsca) and coho salmon (O. kisutch), and approximately 33\% for steelhead (O. mykiss). These results were lower than the expected design level of greater than $70 \%$ for all species (Krcma et al. 1984). As a result, the NMFS study objective changed from evaluating FGE to determining means to improve FGE.

Research at Bonneville Dam Second Powerhouse from 1983 to 1989 indicated that modifications to increase flows above the STS and smooth flows into and within the turbine intake could substantially increase juvenile salmonid guidance during the spring outmigration (Gessel et al. 1991). At that time, lowering the STS by $0.8 \mathrm{~m}$ using streamlined trashracks, and installing alternating TIEs appeared to be the best way to accomplish this. Therefore, even though most FGE testing was done at the south end of the powerhouse (Unit 12), the authors recommended lowering all STSs at Bonneville Dam Second Powerhouse $0.8 \mathrm{~m}$, and installing streamlined trashracks and alternating TIEs across the entire width of the powerhouse. Tests in 1987 showed that, with these modifications in place, FGE in Unit 12 was higher with seven turbine units in operation than with four turbine units in operation (Gessel et al. 1988). However, tests were not conducted in other units across the powerhouse.

Our research objective during the 1993 spring and summer outmigrations was to evaluate the effects of these modifications (alternating TIEs, lowered STSs, and streamlined trashracks) on FGE in south, middle, and north turbine units, under full and partial powerhouse operation.

\section{$\underline{\mathrm{BS} 055}$}

Monk, B. H., B. P. Sandford, and D. B. Dey. 1995. Evaluation of the fish guidance efficiency of submersible traveling screens and other modifications at Bonneville Dam Second Powerhouse, 1994. Annual Report of Research for the U.S. Army Corps of Engineer District, Portland, Oregon by the National Oceanic and Atmospheric Administration, Northwest Fisheries Science Center, Seattle, Washington. 
The Bonneville Dam Second Powerhouse was completed in 1982 and the National Marine Fisheries Service (NMFS) began evaluating fish guidance efficiency (FGE) at this facility in 1983. Initial measurements of FGE with standard-length submersible traveling screens (STSs) were less than 25\% for yearling Chinook (Oncorhynchus tshawytsca) and coho salmon (O. kisutch), and approximately 33\% for steelhead (O. mykiss). These guidance levels were considerably lower than the expected design level of greater than $70 \%$ for all species (Krcma et al. 1984).

From 1984 to 1989, the U.S. Army Corps of Engineers and NMFS tested various design modifications to improve FGE at Bonneville Dam Second Powerhouse. The results of this research indicated that modifications to increase flows above the STS and smooth flows into and within the turbine intake could substantially increase FGE for yearling Chinook salmon during the spring outmigration (Gessel et al. 1991). This was accomplished by lowering the STSs $0.8 \mathrm{~m}$ (30 in) and installing streamlined trashracks and turbine intake extensions (TIEs). From 1987 to 1989, FGE tests were conducted with these modifications installed in Units 11, 12, and 13. Mean FGE in Unit 12 (for 4- to 5day test series) ranged from $51 \%$ to $74 \%$. Although this FGE testing was done at the south end of the powerhouse, with only partial powerhouse operation, NMFS recommended the installation of these modifications across the entire powerhouse.

In 1993, studies were conducted during the spring and summer juvenile salmonid outmigrations to evaluate FGE after the full installation of TIEs (in alternate slots), lowered STSs, and streamlined trashracks at the second powerhouse.

Because of the need to establish and confirm accurate FGE values at this dam, a short series of FGE tests were conducted during the 1994 spring outmigration to evaluate how representative or anomalous the 1993 FGE results were. These tests were also conducted in Turbine Units 12, 15, and 17, but only in the non-TIE slots (1993 tests had been conducted in adjacent TIE and non-TIE slots). Since the 1993 results did not indicate large differences between 4- and 6-unit operation, 4-unit tests were not conducted in 1994 and comparisons were made between 6- and 8-unit operation only. BS056

Monk, B. H., B. P. Sandford, and D. B. Dey. 1999a. Evaluation of extended-length submersible bar screens at Bonneville Dam First Powerhouse, 1998. Report of Research for the U.S. Army Corps of Engineer District, Portland, Oregon by the National Oceanic and Atmospheric Administration, Northwest Fisheries Science Center, Seattle, Washington.

In 1998, NMFS conducted in-turbine netting and gatewell dipping to estimate fish guidance efficiency (FGE), 24-hour orifice passage efficiency (OPE), and levels of descaling and injury for three extended-length submersible bar screens (ESBSs) installed in Unit 8 at B1. To further improve FGE by increasing flows into the gatewell, operating gates were raised in the $\mathrm{A}$ and $\mathrm{C}$ slot of Turbine Unit 8, and the gate was removed in the B slot to accommodate a fyke-net frame for FGE testing.

Research objectives were as follows:

1) Evaluate the FGE of a prototype ESBS during spring and summer juvenile salmonid out migration.

2) Evaluate 24-hr orifice passage efficiency (OPE) of juvenile fish bypass orifices with the ESBSs during spring and summer out migration.

3) Evaluate the effects of the ESBSs and associated guidance devices (including the vertical barrier screen) on juvenile salmonids and lamprey. BS018

Monk, B. H., M. H. Gessel, and J. W. Ferguson. 1999b. An evaluation of the biological database for improving fish guidance efficiency at Bonneville Dam Second Powerhouse. Annual Report of Research for the U.S. Army Corps of Engineer District, Portland, Oregon by the 
Synthesis of Biological Research on Juvenile Salmonid Passage and Survival at Bonneville Dam through 2005

\section{National Oceanic and Atmospheric Administration, Northwest Fisheries Science Center, Seattle, Washington.}

Biological and hydraulic data collected between 1983 and 1998 are reviewed and discussed. The biological data were collected using a variety of methods, including direct capture fyke netting and gatewell dipping, hydroacoustics, and radio telemetry. Hydraulic data were collected by both field measurements and model techniques. Results of the experimental period from 1983 to 1989, and the post-construction evaluation period from 1993 to 1998, are described.

\section{BS054}

\section{Monk, B. H. and B. P. Sandford. 2001. Evaluation of extended-length submersible bar screens at Bonneville Dam First Powerhouse, 2000. Annual Report of Research for the U.S. Army Corps of Engineer District, Portland, Oregon by the National Oceanic and Atmospheric Administration, Northwest Fisheries Science Center, Seattle, Washington.}

In hopes of increasing FGE over that achieved by conventional, 20-ft long submersible traveling screens (STSs), 40-ft-long extended-length bar screens (ESBSs) were installed in Unit 8 at B1 and tested in 1998. These screens have been successful at increasing FGE at middle Columbia and Snake River dams. To further improve FGE by increasing flows into the gatewell, operating gates were also raised in the $\mathrm{A}$ and $\mathrm{C}$ slots and the gate was removed in the B slot to accommodate a fyke-net frame used for FGE testing.

In 2000, FGE netting tests with ESBSs and raised operating gates were repeated. As in 1998, orifice passage efficiency (OPE) tests with the ESBSs installed were also conducted. OPE is the percentage of guided fish that leave the gatewell via the orifice in a proscribed time (17 hours in 2000). Fish sampled from both the FGE and OPE tests were also examined for descaling and injury. For statistical comparisons, OPE and descaling-injury rates were also acquired at Unit 9, in which STSs were installed with the operating gate in the stored position. Average FGE for the spring migration in 2000 ranged from $4 \%$ to $9 \%$ lower for all species than in 1998 . However, average FGE for the two years combined was $70 \%$ or greater for yearling Chinook, coho, and steelhead during the spring migration. For all three species, this indicated a potential increase in FGE of $23 \%$ to $34 \%$ with the extended screens.

In June and early July, FGE for yearling Chinook salmon averaged 47\% in both 1998 and 2000. In the later part of July 1998, average FGE for yearling Chinook salmon decreased to 23\% (tests were not conducted in 2000 because insufficient numbers of fish were available for meaningful analysis). Compared to tests also conducted in the later part of July 1988 and 1989 with STSs, this indicated a potential increase in FGE for yearling Chinook salmon with ESBSs of approximately $13 \%$ during the later part of the summer migration.

Combined average OPE for 1998 and 2000 was over $75 \%$ for yearling Chinook salmon and over 90\% for sub-yearling Chinook salmon (in both the STS and ESBS units). In 2000, passage times for both yearling and sub-yearling Chinook salmon from the gatewell to the passive integrated transponder (PIT)tag detector at the downstream monitoring facility was approximately 3 hours for the STS and 4 hours for the ESBS. These differences in OPE and passage time were not significant, indicating that fish passage from the gatewell to the bypass channel was not changed by the ESBS.

Instances of significantly higher descaling were measured once for yearling Chinook salmon in the ESBSs in 1998 and once in 2000 but these differences ranged from only $1.5 \%$ to $2 \%$. For all other species in both years, there was no difference in descaling rates between the two screens. Hemorrhaged eyes and torn or bent opercula were the only other injuries found in 1998 or 2000 with either screen. In both years, 
the injury rate was $1 \%$ or less for all species during both spring and summer testing, with no significant differences between the two screens. BS009

\section{Monk, B. H., R. Absolon, B. P. Sandford, and J. W. Ferguson. 2002. Evaluation of intake modifications at Bonneville Dam Second Powerhouse, 2001. Annual Report of Research for the U.S. Army Corps of Engineer District, Portland, Oregon by the National Oceanic and Atmospheric Administration, Northwest Fisheries Science Center, Seattle, Washington.}

In an effort to improve fish guidance at Bonneville Second Powerhouse, the Portland District made structural changes to smooth and increase flow up the gatewells of some turbine intakes. Those changes, made in the spring of 2001 to intakes B and C of Unit 15 were as follows:

1) Extending the vertical barrier screen (VBS) downward by removing part of the concrete beam below it,

2) Installing a turning vane below the submerged traveling screen (STS) picking beam to direct more flow upward and into the gatewell, and

3) Installing a "gap closure device" to narrow the gap between the top of the STS and the intake ceiling through which some flow, and possibly some fish, may pass back to the turbine.

In Intake 15A the concrete beam was reduced, the VBS was extended downward, and a turning vane was installed but there was no gap closure device.

Spring testing produced FGE estimates of $71 \%$ for yearling Chinook salmon and over $80 \%$ for steelhead and coho, the highest estimated values ever for B2 (15\%-33\% higher than equivalent estimates made in 1994). In summer the estimated FGE for yearling Chinook salmon averaged $57 \%$, or $17 \%$ higher than previously estimated.

Concurrent OPE estimates found that $94 \%$ of yearling Chinook salmon in spring and $99 \%$ of yearling Chinook salmon in summer left the gatewell within 17 hours. For each species there were no significant differences in either OPE or passage times between Gatewells 15B and 16B (an unmodified turbine intake). Descaling rates were low ( $2 \%-3 \%$ in spring and $<2 \%$ in summer) for both the modified (Intake 15B) and unmodified (Intake 16B) intakes as well as for modified Intake 15A, which had no gap closure device. The authors deem these results encouraging and recommend similar modifications for the entire powerhouse. The passage time to the Smolt Monitoring Facility for the PIT-tagged OPE test fish averaged 1.6 hours for yearling and 0.8 hour for subyearling Chinook.

Results from salmonid parr and juvenile lamprey were also tabulated. $\underline{\mathrm{BS} 003}$

Monk, B. H., B. P. Sandford, D. A. Brege, and J. W. Ferguson. 2004. Evaluation of turbine intake modifications at the Bonneville Dam Second Powerhouse, 2002. Annual Report of Research for the U.S. Army Corps of Engineer District, Portland, Oregon by the National Oceanic and Atmospheric Administration, Northwest Fisheries Science Center, Seattle, Washington.

In 2000, the U.S. Army Corps of Engineers conducted hydraulic model studies to evaluate flow in the second powerhouse intakes at Bonneville Dam. As a result of these evaluations, three modifications were proposed to increase upward flow toward the intake gatewells:

1. Increase the size of the vertical barrier screen (VBS) by removing a portion of the concrete beam below it.

2. Install a turning vane below the picking beam on the submersible traveling screen (STS). 
3. Install a gap-closure device on the intake ceiling downstream from the top edge of the STS.

In addition, to meet new design criteria for salmonid fry established by NOAA Fisheries, screen mesh openings on the new VBS were decreased to reduce impingement of fry.

In 2001, with all three of these modifications installed in the B and $\mathrm{C}$ gatewells of unit 15, the authors measured fish guidance efficiency (FGE), orifice passage efficiency (OPE), and fish condition. Mean FGE was $71 \%$ for yearling Chinook salmon and over $80 \%$ for steelhead and coho, the highest values measured at the second powerhouse since testing began in the early 1980s. Improvements in FGE were similar for subyearling Chinook salmon. OPE was high for yearling Chinook salmon in the spring (94\%) and for subyearling Chinook salmon in the summer (99\%). All fish in the 2001 OPE tests were PIT-tagged, so passage times from release in the gatewell to the detectors at the downstream smoltmonitoring facility could be measured. Median passage time for the 10 replicate tests averaged 1.6 and $0.8 \mathrm{~h}$ for yearling and subyearling Chinook salmon, respectively. For each species, there was no significant difference between unit 15 and an unmodified unit for either OPE or passage time. During FGE and OPE tests, descaling and injury rates were low for all species, with no significant differences between the modified and unmodified units.

Because of these promising results, the same three intake modifications were installed in turbine unit 17 to determine if the results obtained in the middle of the powerhouse (unit 15) could also be achieved along the northern shoreline, where eddies and cross currents in the forebay were thought to reduce FGE. For all species tested during spring 2002, FGE was higher in gatewell 17B, with no turbine intake extension (TIE), than in either gatewell with a TIE (17A and 17C). Differences were significant $(P=0.05)$ for yearling Chinook salmon among all three gatewells. Respective mean FGEs for yearling Chinook, steelhead, and coho were $66 \%, 54 \%$, and $71 \%$ in gatewell $17 \mathrm{~B}$ (with no TIE), and $47 \%, 49 \%$, and $51 \%$ in gatewell 17A (with TIE). Although values were not as high as those obtained in unit 15 in 2001, they were higher than those observed in unit 17 in 1994.

Mean FGE during spring 2002 was higher than in 1994 for all yearling species and for both test gatewells. For gatewell 17B, the differences between 2002 and 1994 were 14\%, 20\%, and 21\% for yearling Chinook salmon, coho salmon, and steelhead, respectively. For 17A the differences between 2002 and 1994 were $8 \%, 1 \%$, and $17 \%$ for yearling Chinook salmon, coho salmon, and steelhead, respectively. The higher FGEs observed for all species in 2002 in the gatewell with no TIE (17B) were similar to results observed for the entire second powerhouse in 1993 and 1994. During summer testing, mean FGE for subyearling Chinook salmon was 57\% in gatewell 17B (identical to that found in 2001 in gatewell unit 5B) and 47\% in 17A. Summer FGE studies were not conducted in 1994.

During spring 2002, OPE was not as high for yearling Chinook salmon (87\%) as it was the previous year $(94 \%)$. Structural problems with the redesigned VBSs interrupted testing and thus reduced the number of replicates. During FGE and OPE tests, descaling and injury rates were low for all species, with no significant differences between the modified and unmodified unit. Release and recovery of frysized coho salmon in the bypass pipe and to gatewell slot 15B during the last two weeks of March indicated minimal impingement or injury. BS142

Muir, W. D., A. E. Giorgi, W. S. Zaugg, and B. R. Beckman. 1989. An assessment of the relationship between smolt development and fish guidance efficiency at Bonneville Dam. Annual Report of Research for the U.S. Army Corps of Engineer District, Portland, Oregon by the National Oceanic and Atmospheric Administration, Northwest Fisheries Science Center, Seattle, Washington.

Research conducted by the National Marine Fisheries Service (NMFS) in cooperation with the U.S. Army Corps of Engineers (COE) has demonstrated that fish guidance efficiency (FGE) not only changes from year to year and among dams, but can also change during the course of any year's outmigration and 
even within a day. Data acquired at Lower Granite and Little Goose Dams from 1985 to 1987 suggest that intraseasonal changes in FGE are associated with the changing physiological status of the smolt population. NMFS researchers have presented evidence, which indicates that yearling Chinook salmon, Oncorhynchus tshawytscha, that are fully smolted within the population are more susceptible to guidance by traveling screens (Giorgi et al. 1988; Muir et al. 1988). The authors hypothesize that over the course of the outmigration the proportion of fully smolted fish in the population increases, which in turn explains intraseasonal increases in FGE observed at Lower Granite Dam. The purpose of this study is to determine if seasonal changes in the physiological status of the migrant population are evident at Bonneville Dam, and assess whether those changes are related to concurrent FGE estimates. BS045

\section{Muir, W. D., S. G. Smith, J. G. Williams, E. E. Hockersmith, and J. R. Skalski. 2001. Survival estimates for migrant yearling chinook salmon and steelhead tagged with passive integrated transponders in the lower Snake and lower Columbia Rivers, 1993-1998. North American Journal of Fisheries Management. 21:269-282.}

Precise, up-to-date survival estimates for salmonids that migrate through reservoirs, hydroelectric dams, and free-flowing sections of the Snake and Columbia rivers are essential to develop effective strategies for recovering depressed stocks. To provide this information, survival was estimated for yearling Chinook salmon Oncorhynchus tshawytscha and steelhead O. mykiss that were tagged with passive integrated transponder (PIT) tags and released to migrate through Snake River dams and reservoirs during the study years 1993 through 1998. A multiple-recapture model for single release groups was used to estimate survival from detections of PIT-tagged fish at dams. The stretch of river over which survival was estimated varied between years, depending on the release site, the number of dams with the capability to detect and re-release PIT-tagged fish back to the river, the total number of fish marked, and the efficiency of detecting PIT-tagged fish at each dam.

Precision of survival estimates varied with the number of fish PIT-tagged and released and the amount of spill at dams with PIT-tag detectors. When spill levels were high, detection probabilities were lower, as was precision. Mortality at bypass outfall sites was not significant at any Snake River dam investigated. Estimated annual average per-project (combined reservoir and dam passage) survival ranged from $86 \%$ to $94 \%$ for yearling Chinook salmon and from $88 \%$ to $92 \%$ for steelhead. Survival estimates were higher for both species in years when spill was used specifically to pass fish through nonturbine routes. Over the same stretches of river in years with similar flow conditions from 1970 through 1975 , per-project survival estimates typically averaged $57 \%-71 \%$ for yearling Chinook salmon and 77\%-90\% for steelhead. From 1993 to 1998, survival estimates for fish released from Snake River basin hatcheries to the Lower Granite Dam tailrace indicated that substantial smolt mortality occurred before fish entered the hydropower system. For each hatchery, estimated survival varied each year, and estimates from different hatcheries to Lower Granite Dam varied inversely with the distance fish traveled. (This is the original abstract). BS067 PDF reproduced with permission of www.fisheries.org.

Muir, W. D., S. G. Smith, R. W. Zabel, D. M. Marsh, and J. G. Williams. 2003. Survival estimates for the passage of spring-migrating juvenile salmonids through Snake and Columbia River dams and reservoirs, 2002. Annual Report of Research for the U.S. Army Corps of Engineer District, Portland, Oregon by the National Oceanic and Atmospheric Administration, Northwest Fisheries Science Center, Seattle, Washington.

Objectives were 1) estimate reach and project survival and travel time in the Snake and Columbia Rivers throughout the migration period of yearling Chinook salmon and steelhead; 2) evaluate relationships between survival estimates and migration conditions; and 3) evaluate the survival-estimation models under prevailing conditions. 
This report provides reach survival and travel time estimates for PIT-tagged yearling Chinook salmon (hatchery and wild), hatchery sockeye salmon, hatchery coho salmon, and steelhead (hatchery and wild) in the Snake and Columbia Rivers in 2002. PIT-tagged smolts were detected at interrogation facilities at Lower Granite, Little Goose, Lower Monumental, McNary, John Day, and Bonneville Dams and in the PIT-tag detector trawl operated in the Columbia River estuary. Survival estimates were calculated using a statistical model for tag-recapture data from single release groups (the "Single-Release Model").

Estimated survival from the tailrace of Lower Granite Dam to the tailrace of Little Goose Dam averaged 0.949 for yearling Chinook salmon and 0.882 for steelhead. Respective average survival estimates for yearling chinook salmon and steelhead were 0.980 and 0.882 from Little Goose Dam tailrace to Lower Monumental Dam tailrace; 0.837 and 0.652 from Lower Monumental Dam tailrace to McNary Dam tailrace (including passage through Ice Harbor Dam); 0.907 and 0.844 from McNary Dam tailrace to John Day Dam tailrace; and 0.840 and 0.612 from John Day Dam tailrace to Bonneville Dam tailrace (including passage through The Dalles Dam). Combining average estimates from the Snake River smolt trap to Lower Granite Dam, from Lower Granite Dam to McNary Dam, and from McNary Dam to Bonneville Dam, estimated annual average survival through the entire hydropower system from the head of Lower Granite reservoir to the tailrace of Bonneville Dam (eight projects) was 0.551 ( $\mathrm{SE}=$ $0.057)$ for Snake River yearling chinook salmon and 0.234 $(\mathrm{SE}=0.045)$ for Snake River steelhead. For yearling spring chinook salmon released in the Upper Columbia River, estimated survival from point of release to McNary Dam tailrace was 0.573 (SE 0.005) for fish released from Leavenworth Hatchery, $0.533(\mathrm{SE}=0.009)$ for fish released from Entiat Hatchery, and $0.505(\mathrm{SE}=0.021)$ for those from Winthrop Hatchery. The results are reported primarily in tables and figures with minimal explanation of methodology. Methodology and statistical models used in the analyses were the same as in previous study years, and details are provided in previous annual reports cited in the text. $\underline{\mathrm{BS} 074}$

\section{Nagy, W. T. and R. A. Magne. 1986. Hydroacoustic Study of Juvenile Fish Passage at the Bonneville Second Powerhouse in 1985. U.S. Army Corps of Engineers, Portland, NPPOP- P-NR-FFU, Fisheries Office, Bonneville Lock and Dam, Cascade Locks, Oregon, 17 April 1986.}

The objectives of this work were to 1) determine the vertical distribution of juvenile salmonids entering Unit 12 during testing of modified trash racks and guidance structures within the intake; 2) determine if juvenile salmonids within the intake above the STS are rejecting guidance into the gatewell; and 3) determine if there is lateral movement of juvenile salmonids near the intakes of units 11 and 12 . Results indicated that generally fish further away from the trash racks were more evenly distributed than fish immediately upstream of the trash racks. Detected fish exhibited no obvious signs of rejecting guidance by the submerged traveling screen. The majority of fish detected in front of Unit 12 showed movement in a southward direction. BS093

\section{Nagy, W. T. 1997. Final Report on the Search to Find a Non-Lethal Method for Measuring Fish Guiding Efficiency within Turbine Intakes. U.S. Army Corps of Engineers, Portland District, Fish Field Unit, Bonneville Lock and Dam, Cascade Locks, Oregon.}

The objective was, through a literature review, to develop a non-lethal technique that is as nonobtrusive as possible for determining fish guiding efficiency within turbine intakes.

From the literature review, four types of remote sensing technologies were applicable: 1) light imaging including range-gated video, synchronous-scan video, separation of light, and camera and polarization techniques, 2) sound imaging, including acoustic camera, acoustic holography, and highresolution sonar, 3) acoustic screen methods, including electronic within-pulse scanning, quasi-ideal 
beam, two-element split-beam sonar, and moving target indication sonar and 4) scanned laser radar. Advantages and disadvantages of each technology are provided in the report. BS078

\section{Normandeau Associates Inc., J. R. Skalski, and Mid Columbia Consulting Inc. 1996. Potential Effects of Spillway Flow Deflectors on Fish Condition and Survival at the Bonneville Dam, Columbia River. Prepared for US Army Corps of Engineers, Portland District, by Normandeau Associates, Inc. Drumore, Pennsylvania.}

This study assessed fish condition and survival of hatchery-reared Chinook salmon that passed over the Bonneville spillway with and without flow deflectors, as well as those passing through the sluiceways at both powerhouses. The authors observed that a small proportion of fish suffered injuries $(1.3 \%)$, were descaled $(0.5 \%)$, or lost equilibrium $(0.5 \%)$ associated with spillway passage. Primary injuries were hemorrhaging, bruises, and bulging eyes, and the cause of the injuries was attributed to contacts with hard surfaces of the spill bay and tainter gate. The small size of injured fish precluded determining whether injury types were significantly different for the "with" and "without flow" deflector conditions. Injury rate was $1.1 \%$ at both sluiceways. BS126

Normandeau Associates Inc., J.R. Skalski, and Mid Columbia Consulting, Inc. 2000. Direct Survival and Condition of Juvenile Chinook Salmon Passed through an Existing and New Minimum Gap Runner Turbines at Bonneville Dam First Powerhouse, Columbia River. Prepared for US Army Corps of Engineers, Portland District, by Normandeau Associates, Inc. Drumore, Pennsylvania.

Objectives were to 1) test the hypothesis of whether the passage survival through a newly installed minimum gap runner turbine (unit 6) equals or exceeds that of the existing Kaplan turbine (unit 5); 2) determine whether peak turbine operating efficiency is correlated with turbine passage survival; 3 ) determine the effectiveness of gap minimization; and 4) identify injury mechanisms and in-turbine areas where fish injuries occur.

Hatchery Chinook salmon with balloon tags and radio transmitters were released into a standard Kaplan turbine and a MGR turbine through a specially designed induction system to evaluate passage survival of the two turbine types. The study design was a two-by-three-by-four factorial (two turbines $\mathrm{x}$ three release locations $x$ four power levels). Induction pipes released fish at the stay vanes at three vertical release points so fish would pass near the blade tip, mid-blade, or hub region. The turbines were operated at four power levels from the lower $1 \%$ operating limit to the upper $1 \%$ operating limit. Overall results showed fish passage survival through the MGR was equal to or better than through an existing turbine.

\section{$\underline{\mathrm{BS} 077}$}

Normandeau Associates Inc., J. R. Skalski, and Mid-Columbia Consulting Inc. 2001. Passage Survival Investigation of Juvenile Chinook Salmon through Bonneville Powerhouse II Bypass Sluice at Two Tailwater Conditions Columbia River, Washington. Final report. Prepared for US Army Corps of Engineers, Portland District, by Normandeau Associates, Inc. Drumore, Pennsylvania.

The specific objective of this study was to estimate absolute survival and condition of yearling Chinook salmon at two different outfall flows (1 and $2.5 \mathrm{kcfs}$ ) and two tailrace levels (high and low). This study was conducted to assess only the direct effects of juvenile fish passing at a surrogate high flow outfall sluice chute at B2. Incidence of injury, scale loss, or loss of equilibrium was low at both discharge 
rates during both the high and low tailwater tests. Less than $1 \%$ of recaptured treatment fish displayed any visible injuries. The authors concluded that, based on their results, the periphery region of the B2 outfall sluice chute, with estimated entry velocities of 31 to $48 \mathrm{ft} / \mathrm{sec}$, inflicts minimal mortality and injury to entrained juvenile salmon. The field tests indicated that a high outfall with entry velocities $<48 \mathrm{ft} / \mathrm{sec}$ should provide safe fish passage, provided other factors such as sufficient tailrace depth, no predator haven, and minimal outfall jet recirculation are also present. $\underline{\mathrm{BS} 123}$

\section{Normandeau Associates Inc., Mid Columbia Consulting Inc., and J. R. Skalski. 2003. Juvenile Salmonid Survival and Condition in Passage through Modified Spillbays at Bonneville Dam, Columbia River. Prepared for US Army Corps of Engineers, Portland District, by Normandeau Associates, Inc. Drumore, Pennsylvania.}

This is a tag-recapture study in which hatchery Chinook salmon were balloon and radio tagged and passed through two Bonneville Dam spill bays. Recovered fish were assessed for injury and death and then held 48 hours for final tabulation. Spill Bay 14 had a flow deflector at the standard depth of $14 \mathrm{ft}$ above mean sea level (MSL) whereas Spill Bay 14 was lower, at seven $\mathrm{ft}$ above MSL to reduce total dissolved gas levels induced by spillway discharge and the present study investigated the possible effects of the lowered flow deflector on injury and survival rates. Fish releases through both spill bays were done in spring at relatively high and cool tailwater conditions (18.4-25.4 MSL, 12.3-14.2 $\left.{ }^{\circ} \mathrm{C}\right)$; in summer tailwater conditions were relatively low and warm (11.0-13.6 MSL, 19.5-20.5 ${ }^{\circ} \mathrm{C}$ ). Two spillway discharge rates were tested, $75 \mathrm{kcfs}$ and the dissolved gas cap, although Spill Bay 16 was up to $2 \mathrm{kcfs}$ higher at a given setting than was that from Spill Bay 14. Control fish were released downstream of Spill Bay 17. In all there were eight experimental treatments:

Bay 14 (14 ft MSL flow deflector) $75 \mathrm{kcfs}$ spillway discharge, spring (high tailwater)

Bay 16 (7 ft MSL flow deflector) $75 \mathrm{kcfs}$ spillway discharge, spring (high tailwater)

Bay 14 (14 ft MSL flow deflector) Gas Cap spillway discharge, spring (high tailwater)

Bay 16 (7 ft MSL flow deflector) Gas Cap spillway discharge, spring (high tailwater)

Bay 14 (14 ft MSL flow deflector) $75 \mathrm{kcfs}$ spillway discharge, summer (low tailwater)

Bay 16 (7 ft MSL flow deflector) $75 \mathrm{kcfs}$ spillway discharge, summer (low tailwater)

Bay 14 (14 ft MSL flow deflector) Gas Cap spillway discharge, summer (low tailwater)

Bay 16 (7 ft MSL flow deflector) Gas Cap spillway discharge, summer (low tailwater).

Two primary response variables were reported, probability of surviving and proportion of clean ("without evident injury, scale loss, or loss of equilibrium") fish. Probabilities of survival were very similar between the two spill bays under similar discharge and tailwater conditions and the authors found the effect of the flow deflector on probability of surviving "difficult to isolate." Statistical hypothesis tests to evaluate differences between the two flow deflector configurations tests are not presented. "Clean Fish" probabilities also were similar among treatments and statistical tests are presented. The authors point out that the $95 \%$ confidence intervals computed for each treatment type overlap except for the 75 kcfs treatments in summer (low tailwater) at both spill bays where the probabilities were lower. Both probability of surviving and probability of being "clean" were always higher in the gas cap spillway discharge than at the $75 \mathrm{kcfs}$ spillway discharge although again statistical tests to evaluate the significance of those differences are not presented. $\underline{\mathrm{BS} 002}$

Northwest Fisheries Science Center. 2000. Salmonid travel time and survival related to flow in the Columbia River Basin. White Paper of the National Oceanic and Atmospheric Administration, Northwest Fisheries Science Center, Seattle, Washington.

The purpose of this white paper is to provide a synthesis of scientific information regarding the effects of river flow through the hydropower system, as it is presently configured and operated, on 
anadromous salmonids. Other white papers are available that address the effects of predation and dam passage on salmonids. A fourth white paper provides a synthesis of scientific information on the effects of transporting juvenile salmonids around dams to mitigate for losses of juvenile migrants that would otherwise migrate downstream through the dams on the lower Snake and Columbia rivers.

The white papers do not address the possible effects on salmonids that might accrue from major changes to the present configuration of the hydropower system (e.g., draw down or dam removal); nor do they speculate about potential indirect effects (e.g., delayed mortality) that might occur as a result of hydropower system passage. Empirical data on these subjects are scarce. Other forums, such as the Plan for Analyzing and Testing Hypotheses (PATH) and the Cumulative Risk Initiative (CRI), are addressing these issues. Nonetheless, it is recognized that many of the impacts of dams on migrant fish, as identified in the white papers, would decrease with removal of dams. Most analyses conducted to date indicate that removal of dams would lead to higher direct survival of migrant fish. Such findings are not inconsistent with anything presented in this white paper.

Following regional review beginning in October 1999, this white paper has been modified to reflect comments and information provided by numerous reviewers and resource agencies including Idaho Water Users Association, Inc., IDACORP, Inc., Oregon Department of Fish and Wildlife, U.S. Fish and Wildlife Service, Idaho Department of Fish and Game, Columbia Basin Fish and Wildlife Authority, Washington Department of Fish and Wildlife, Columbia River Inter-Tribal Fish Commission Center, and Fish Passage Center. BS069 White papers like this one are available on the Northwest Fisheries Science Center home page (www.nwfsc.noaa.gov/pubs/nwfscpubs.html).

\section{Petersen, J. H., D. M. Gadomski, and T. P. Poe. 1994. "Differential predation by northern squawfish (Ptychocheilus oregonensis) on live and dead juvenile salmonids in the Bonneville Dam tailrace (Columbia River)." Can. J. Fish. Aquat. Sci. 51:1197-1204.}

Juvenile salmonids (Oncorhynchus spp.) that have been killed or injured during dam passage may be highly vulnerable or preferred prey of predators that aggregate below dams. Salmonid loss due to predation will be overestimated using gut content analysis if some prey were dead or moribund when consumed. To examine this issue, field experiments were conducted in the Bonneville Dam tailrace to compare rates of capture of live and dead juvenile salmonids by northern squawfish. Known numbers of coded-wire tagged live and dead Chinook salmon were released into the tailrace on six nights. Northern squawfish were collected after each release and their gut contents were examined for tags. When $50 \%$ of salmon released were dead, northern squawfish consumed $62 \%$ dead salmon. When $10 \%$ of salmon released were dead, comparable with dam passage mortality, $22 \%$ of the tags found in northern squawfish digestive tracts were from dead salmon. These results indicate that predator feeding behavior and prey condition are important considerations when estimating the impact of predation on a prey population. (This is the original abstract). BS132 PDF reproduced with permission of the NRC Research Press. http://pubs.nrc-cnrc.gc.ca/cgi-bin/rp/rp2 desc e?cjfas

\section{Ploskey, G. R., L. R. Lawrence, P. N. Johnson, W. T. Nagy, and M. G. Burczinski. 1998. Hydroacoustic evaluation of juvenile salmonid passage at Bonneville Dam including surface collection simulations. Technical Report EL-98-4, Prepared for the U.S. Army Corps of Engineers, Portland District, Portland, Oregon, by US Army Corps of Engineers Waterways Experiment Station, Vicksburg, Mississippi.}

This Technical Report describes results of studies conducted by the U.S. Army Engineer District, Portland (CENPP) and the U.S. Army Engineer Waterways Experiment Station (CEWES) to resolve critical uncertainties in the implementation of smolt-collector technologies and estimation of fish passage efficiency (FPE) for the Bonneville Project. Available biological information is inadequate to design and 
locate surface collector prototypes at Bonneville Dam (Giorgi and Stevenson 1995). Information on the vertical and lateral distributions of smolts in forebay areas of both powerhouses and the spillway was limited, no mobile surveys had been conducted, and no manipulative testing had been done to determine likely responses of smolts to surface openings.

The goals of this study were to (1) provide the biological information necessary to facilitate the design and placement of a surface-collector prototype and (2) make progress toward the estimation of FPE for the entire Bonneville Project. Objectives were as follows: (1) use mobile hydroacoustics to measure the vertical and horizontal distribution of salmon smolts in forebay areas of both powerhouses and to characterize the day and night variation in distributions in spring and summer; (2) estimate smolt passage into two turbines and into the center sluice gate above each turbine, as well as the FPE ratio for pared sluiceway/turbine openings under two test conditions (blocked versus unblocked trash racks and open versus closed sluice gates) in spring and summer at Powerhouse 1; (3) evaluate smolt swimming direction in the area immediately upstream of two test units at Powerhouse 1, particularly at the zone of separation between flows entering turbines and flows entering sluice gates; (4) estimate guided and unguided smolt passage into eight turbine intakes of Powerhouse 2 and identify effects of an open or closed sluice chute on the fish guidance efficiency (FGE) of adjacent turbine units. BS040

\section{Ploskey, G. R., P. N. Johnson, and T. J. Carlson. 2000. Evaluation of a low-frequency, sound- pressure system for guiding juvenile salmon away from turbines at Bonneville Dam, Columbia River." North American Journal of Fisheries Management. 20:951-967.}

This paper presents two different but related studies, the first conducted at Bonneville Dam and the second in net pens in Ballard, WA. In June of 1995 the effectiveness of a 122-m-long array of 25 lowfrequency transducers for guiding juvenile salmon away from turbine units 9 and 10 at B1 was tested using fixed-aspect hydroacoustics to assay. Test sounds were dominated by $300-$ and $400-\mathrm{Hz}$ frequencies and transmitted as 2-s crescendos with repeated amplitude ramps from 0 to about $160 \mathrm{~dB}$ referenced to 1 $\mu \mathrm{Pa}$ at $1 \mathrm{~m}$ every $2 \mathrm{~s}$. No significant differences in the mean number of fish passing north or south across the upstream end of the transducer array, where the angle of incidence of flow was only about 5 degrees, were found during sound-on and sound-off treatments. The power of these one-tailed t-tests $(\alpha=0.05)$ for detecting $50 \%$ differences in means was $82 \%$ for fish passing north across the array and $99 \%$ for fish passing to the south. Sampling in front of four turbine intakes using fixed-aspect hydroacoustics found no significant differences in the mean number of smolts upstream of intakes during 4-h sound-on and soundoff treatments. The statistical power of the 4 -h tests was at least $98 \%$ for detecting differences in means as small as $20 \%$ at $\alpha=0.05$ in a two-tailed analysis of variance and a one-tailed t-test.

In 1997, net-pen tests were done to corroborate and interpret the negative results from the 1995 field experiment. Captive schools of sub-yearling Chinook salmon and coho and yearling sockeye salmon were exposed to the same $300-400 \mathrm{~Hz}$ signal as was used in the Bonneville Dam study but in a net pen in Ballard (Seattle) WA. Fish were videotaped using underwater visible light cameras. No startle reactions were observed and the frequency of avoidance of the signal was less than or equal to the frequency of coincidental avoidance during control trials without sound. After exposure to the 300- and $400-\mathrm{Hz}$ signal, one school of sub-yearling Chinook salmon exhibited non-directional startle responses to $150-$ or $180-\mathrm{Hz}$ sound, indicating that those fish could respond. The authors concluded that the $300-$ and $400-\mathrm{Hz}$ signal did not influence the behavior or distribution of juvenile salmon in either study. BS021 PDF reproduced with permission of www.fisheries.org. 
Ploskey, G. R., W. T. Nagy, L. R. Lawrence, D. S. Patterson, C. R. Schilt, P. N. Johnson, and J. R. Skalski. 2001a. Hydroacoustic Evaluation of Juvenile Salmonid Passage through Experimental Routes at Bonneville Dam in 1998. ERDC/EL TR-01-2, Prepared for the U.S. Army Corps of Engineers, Portland District, Portland, Oregon, by US Army Engineer Research and Development Center, Vicksburg, Mississippi.

This study dealt with surface collection both at the PSC on B1 and the sluice chute that would become the $\mathrm{B} 2$ corner collector. It used fixed-aspect hydroacoustics to evaluate passage and the efficiency and effectiveness of several experimental passage routes. Routes at B1 included the PSC on units 3-6 (units 4 and 6 were off line), units adjacent to the PSC with STSs, and Intake 8B with an ESBS. The widths of the 40-ft-deep PSC entrance slots were alternated between 5 and $20 \mathrm{ft}$ wide to provide stratified random treatments lasting two days each at intakes $3 \mathrm{~B}$ and $5 \mathrm{~B}$ in spring and summer to determine if slot width altered fish-passage indices at the PSC. At B2, routes included the sluice chute, units 11-13 adjacent to the sluice, and the JBS. B2 tests consisted of 24-hr opened and closed sluice treatments on fish passage. The overall goal was to inform the implementation of surface collection for juvenile salmon passage at Bonneville Dam. $\underline{\text { BS019 }}$

Ploskey, G. R., P. N. Johnson, W. T. Nagy, C. R. Schilt, L. R. Lawrence, D. S. Patterson, and J. R. Skalski. 2001b. Hydroacoustic Evaluation of the Bonneville Dam Prototype Surface Collector in 1999. ERDC/EL TR-01-1, Prepared for the U.S. Army Corps of Engineers, Portland District, Portland, Oregon, by US Army Engineer Research and Development Center, Vicksburg, Mississippi.

This study, which was conducted in spring and summer 1999, evaluated the efficiency and effectiveness of one unit of a prototype surface collector (PSC) for collected juvenile salmon at Powerhouse 1, Bonneville Dam. The 50-ft-deep slots in Intake 5b were configured to have 5- or 20-ftwide openings that were changed according to a blocked experimental design for evaluating effects on fish passage, efficiency, and effectiveness. The PSC, located in front of units 3 through 6 , extends $20 \mathrm{ft}$ upstream into the forebay and $50 \mathrm{ft}$ below the surface at maximum pool elevation. It was not intended to be a fish bypass structure but a test facility. As it exists, fish entering the PSC pass through the structure and into the turbine, as opposed to being deposited into a bypass channel in a full-scale collector.

The original goals for 1999 research were as follows: (1) Test hydroacoustic-sampling methods proposed for the year-2000 evaluation of the prototype surface collector (PSC) and identify any potential problems or biases. (2) Evaluate a split-beam deployment upstream of a PSC slot and determine whether it provides estimates of fish passage that can be correlated to estimates from in-turbine transducers. (3) Estimate the efficiency and effectiveness of two adjacent PSC units and determine whether 1998 results hold for adjacent units creating greater downward flow than a single operating unit. Goal number three could not be realized in 1999 since Unit 6 remained inoperable throughout the sampling seasons. Nevertheless, the authors did evaluate the performance of a single PSC unit relative to its performance in the previous year. $\underline{\mathrm{BS} 048}$

Ploskey, G. R., C. R. Schilt, M. E. Hanks, J. R. Skalski, W. T. Nagy, P. N. Johnson, D. S. Patterson, J. Kim, and L. R. Lawrence. 2002a. Hydroacoustic Evaluation of Fish Passage through Bonneville Dam in 2000. ERDC/EL TR-02-8, U.S. Army Engineer Research and Development Center, Vicksburg, Mississippi.

This report summarizes the first of three consecutive years of full-project hydroacoustic passage estimation (project and powerhouse FPEs, turbine FGEs, spill efficiency and effectiveness, temporal and spatial trends) at Bonneville Dam. It differed from the subsequent two years in two important respects. 
There was generation priority at B1 and a prototype surface collector (PSC) was in place over the eighteen intakes of units 1-6.

Eight of the 18 spill bays were sampled, as were one of each turbine intakes at units 7-10 (B1) and 11-18 (B2). At the B1 PSC, sampling was done by opposed pairs of split beams at the 20 -ft-wide entrance slots in front of units 1,2, 4, 5, and 6. The entrance slot in front of Unit 3 was sampled with a barge-mounted multibeam system (see BS124) and the volume just upstream of the Unit 8 trash racks was sampled by two fixed and one traversing split beam transducers (see BS 115). BS011

\section{Ploskey, G. R., C. R. Schilt, M. E. Hanks, J. R. Skalski, W. T. Nagy, P. N. Johnson, D. S. Patterson, J. Kim, and L. R. Lawrence. 2002b. Hydroacoustic Evaluation of a Prototype Surface Collector and In-Turbine Screens at Bonneville Dam Powerhouse 1 in 2000. ERDC/EL TR- 02-15, U.S. Army Engineer Research and Development Center, Vicksburg, Mississippi.}

The year 2000 was the first of three consecutive years of full-project hydroacoustic passage estimation. It was unique among the three in that it involved the testing of a full-scale (over all 18 intakes of units 1-6) deep-slot prototype surface collector (PSC) and because B1 had generation priority. In the same year as the full-project hydroacoustic sampling effort (Ploskey et al. 2002), U.S. Geological Survey radio-telemetry studies of yearling Chinook salmon and yearling Chinook salmon and steelhead passage (Evans et al. 2001), National Marine Fisheries Service conducted in-turbine netting at Unit 8 (Simmons et al. 2001) and the Pacific Northwest National Laboratory evaluated approach behavior and fish distributions at Unit 8 using fixed and traversing split beam sonar and at the PSC entrance in front of Unit 3 using multi-beam and split beam sonar (Johnson et al. 2001). A joint effort by PNNL and USGS investigated behavior of acoustic tagged yearling Chinook salmon as they approached the project.

Based upon results from 1998 and 1999, the PSC slot configuration for 2000 had 20-ft-wide slot widths for all six PSC units. The primary effects evaluated in 2000 were weekly changes throughout spring and summer in a variety of fish passage measures, including numbers passing into and under the PSC, and efficiency, effectiveness, diel patterns, and horizontal and vertical patterns of distribution. Beyond the PSC there was interest in testing the guidance efficiency of extended-length submersible bar screens (ESBSs) at Unit 8. $\underline{\text { BS012 }}$

\section{Ploskey, G. R., C. R. Schilt, M. E. Hanks, P. N. Johnson, J. Kim, J. S. Skalski, D. S. Patterson, W. T. Nagy, and L. R. Lawrence. 2002c. Hydroacoustic evaluation of fish-passage efficiency at Bonneville Dam in 2001. PNNL-14047, Prepared for U.S. Army Corps of Engineers by Pacific Northwest National Laboratory, Richland, Washington.}

This is the second of three consecutive years of full-project fixed-aspect hydroacoustic studies at Bonneville Dam. The 2001 passage season occurred during a severe drought and with unusually high demand for electricity; therefore, spillway discharge was curtailed such that the project spilled roughly half of what had been spilled in the previous year.

Project FPE was estimated at $63 \%$ in spring and 53\% in summer. In the previous year it was estimated at $79 \%$ in both seasons and the large difference was attributed to the much lower spill discharge in 2001 as well as the loss of the guidance contribution of the prototype surface collector that covered the upper portions if the 18 intakes of units 1-6 at B1 in 2000. In 2001 the FPE estimates at the two powerhouses was also low (49\% in spring and $40 \%$ in summer for B1, $57 \%$ in spring and $42 \%$ in summer for B2). Project FPE was $15 \%$ and $35 \%$ higher during $50 \mathrm{kcfs}$ spill periods in spring and summer, respectively, than it was during non-spill periods.

Overall (in both spill and no spill periods) spill efficiency estimates in spring (14\%) and summer (20\%) 2001 were significantly lower than were estimates made in 2000, undoubtedly because of reduced 
volume and duration of spill during the drought in 2001. For periods of spill, spill efficiency was $33 \%$ in spring and 58\% in summer. Overall spill effectiveness was 0.84 in spring and 1.83 in summer. For periods of spill, spill effectiveness was 0.93 in spring and 1.6 in summer. Spill effectiveness also was about 38\% lower in spring 2001 than it was the previous spring. In 2000, spill was continuous at about $75,000 \mathrm{cfs}$ during the day and 120,000 cfs at night, but lack of water in 2001 limited spill to about 50,000 cfs for about 21 of 45 days in spring and 10 of 40 days in summer.

There were positive relations between the number of hours of spill per day and FPE and spillefficiency metrics, with significantly higher fish passage through the spillway at night than during the day, even though the amount of spill was the same during each period. In a typical water year, nighttime spill discharge is often set to the gas cap whereas daytime spill is lower to reduce adult fallback. In 2001 the spill discharge was about $50 \mathrm{kcfs}$ day and night and this study found much higher estimated spillway passage at night, suggesting that fish behavior as well as discharge is involved. Both spill efficiency and Project FPE increased linearly with the number of spill hours per day in spring. At spill durations of 0 to $10 \mathrm{~h}$ /day, average FPE was about 54\% whereas at spill durations of 11 to $24 \mathrm{~h}$ /day average FPE was about $71 \%$. The authors recommend that, under low-water conditions, spillway operation be at least for $11 \mathrm{hr} /$ day and that nighttime spill predominate when full-time spill is impossible. BS004

\section{Ploskey, G. R., C. R. Schilt, J. Kim, C. W. Escher, and J. R. Skalski. 2003. Hydroacoustic Evaluation of Fish Passage through Bonneville Dam in 2002. PNNL-14356, Prepared for the U.S. Army Corps of Engineers by Pacific Northwest National Laboratory, Richland, Washington.}

This report summarizes the results of two different studies. The first study was the third consecutive year of Bonneville Dam full-project juvenile passage estimates based on fixed-aspect hydroacoustics. Sampling was done in the intakes of all operating turbines and spill bays, and in the two operating sluiceway entrances at B1. Estimated passage metrics included turbine guidance efficiency (FGE), FPE (79\% in spring and 74\% in summer), spill efficiency (52\% in spring and $42 \%$ in summer), spill effectiveness (108\% in spring and $96 \%$ in summer), sluiceway efficiency (6\% in spring and $11 \%$ in summer), and sluiceway effectiveness (21.9\% in spring and $47.9 \%$ in summer). Powerhouse FPEs were $58 \%$ in spring and $61 \%$ in summer for B1 and 53\% in spring and $46 \%$ in summer for the Second Powerhouse (B2). Sluiceway efficiency and effectiveness relative just to B1 (efficiency 33\% in spring and $29 \%$ in summer; effectiveness $13.5 \%$ in spring and $26.9 \%$ in summer) were also calculated. Seasonal and diel trends are reported. Comparisons of major passage metrics for the three study years (2000-2002) and recommendations for future project operations, especially powerhouse and turbine unit priorities and the effects of spill discharge on other passage metrics, were made.

The second study reported was an evaluation of the effects on fish guidance of structural modifications that had been made to the intakes of two B2 turbine units as compared to that at the other six at B2. Hydroacoustic sampling found estimated FGE at the modified intakes of units 15 and 17 to be significantly higher than those at the unmodified intakes. Besides the fixed-aspect hydroacoustic sampling in the turbine intakes, a Dual-frequency IDentification SONAR (DIDSON) unit was deployed for two days in each passage season to estimate the proportions of fish that were lost back to the turbine by passing through the gap. Gap loss was estimated to be as high as $14.7 \%$ of the total passage (guided + unguided) through unmodified intake $18 \mathrm{~A}$ and as low as $2.7 \%$ at modified intake $17 \mathrm{~B}$ in spring. In summer, estimated gap loss was similar (between 12\% and 13\%) at unmodified intake 13B and modified intake 17C. The DIDSON was also deployed from the downstream side of a trash rack on one spring night to determine its efficacy for estimating fish passage around the sides of an STS. The deployment that was tested was deemed unable to image a large enough fraction of the side gap to permit gap-passage estimation. BS001 
Ploskey, G.R., M.A. Weiland, C. R. Schilt. 2004. Evaluation of Fish Losses through Screen Gaps at Modified and Unmodified Intakes of Bonneville Dam Second Powerhouse in 2003, PNNL14539 Prepared for the U.S. Army Corps of Engineers, Portland District, Portland, Oregon, by PNNL Richland WA.

In a 2003 study by Pacific Northwest National Laboratory (PNNL) for the U.S. Army Corps of Energy, the authors sampled nine gatewell slots at Bonneville Dam Second Powerhouse (B2) with a Dual-frequency Identification Sonar (DIDSON) acoustic imaging device to estimate the gap loss of juvenile salmonids. Gap loss is the number of fish guided by screens but lost to turbine passage through the gaps between the tops of submerged traveling screens (STSs) and the intake ceilings. Six of the intakes (Units 15 and 17) had been modified to improve fish guidance efficiency (FGE, the proportion of fish passing above intake screens) while the three unmodified intakes at Unit 13 served as controls. All three units had similar configurations of turbine intake extensions (TIES). Intake modifications included removal of concrete between the gatewell and bulkhead slots to increase the area of the vertical barrier screen and installation of a turning vane and gap-closure device to direct more flow up into the gatewell slot.

This study was to determine if those modifications, which did increase FGE, had the added benefit of reducing gap loss. In the unmodified intakes of Unit 13, the authors also sampled with infrared optical cameras to evaluate the proportions of fish and non-fish objects passing through the STS gaps and found that fish composed just $28.6 \%$ of all objects in spring and $12.9 \%$ in summer. Experiments in a laboratory tank confirmed that the DIDSON detects echoes from the surfaces of waterlogged sticks, macrophytes, and other debris as well as from fish. The authors developed filters based on target size, motion, range at first appearance, and the number of frames in which a target was seen to discriminate between fish and non-fish images. Filtered data produced estimates within $6 \%$ of those obtained by multiplying unfiltered DIDSON counts by the fish fraction estimated from optical-camera data. BS140

Ploskey G. R., M. A. Weiland, C. R. Schilt, P. N. Johnson, M. E. Hanks, D. S. Patterson, J. R. Skalski, and J. Hedgepeth. 2005. Hydroacoustic Evaluation of Fish Passage through Bonneville Dam in 2004. PNNL-15249, Pacific Northwest National Laboratory, Richland, WA, for the U. S. Army Corps of Engineers, Portland District, Portland, Oregon.

The Portland District of the U.S. Army Corps of Engineers requested that the Pacific Northwest National Laboratory (PNNL) conduct fish-passage studies at Bonneville Dam in 2004. These studies support the Portland District's goal of maximizing fish-passage efficiency (FPE) and obtaining 95\% survival for juvenile salmon passing Bonneville Dam. Major passage routes include 10 turbines and a sluiceway at Powerhouse 1 (B1), an 18-bay spillway, and eight turbines and a sluiceway at Powerhouse 2 (B2).

In this report, the authors present results of four studies related to juvenile salmonid passage at Bonneville Dam. The studies were conducted between April 15 and July 15, 2004, encompassing most of the spring and summer migrations. Studies included evaluations of 1) project fish passage efficiency and other major passage metrics, 2) B2 fish guidance efficiency and gap loss, 3) smolt approach and fate at the B2 Corner Collector (B2CC), and 4) B2 vertical barrier screen head differential. BS174

Ploskey, G. R., G. E. Johnson, M. A. Weiland, F. Khan, R. P. Mueller, J. A. Serkowski, C. L. Rakowski, J. B. Hedgepeth, J. R. Skalski, B. D. Ebberts, and B. A. Klatte. 2006a. Acoustic camera evaluation of juvenile salmonid approach and fate at surface flow outlets of two hydropower dams. HydroVision 2006 Conference held in Portland, Oregon. HCI Publications, Kansas City Missouri, USA. 
The objective of this study was to estimate and compare fate probabilities for juvenile salmon approaching two surface flow outlets (SFOs) to identify effective design characteristics. The SFOs differed principally in forebay location, depth, discharge, and water velocity over a sharp-crested weir. Both outlets were about $20 \mathrm{ft}$ wide. The 22-ft deep Bonneville Powerhouse 2 Corner Collector (B2CC) was located in the southwest corner of the forebay and passed $5,000 \mathrm{ft}^{3} / \mathrm{s}$ of water at normal-pool elevation. In contrast, The Dalles Dam ice and trash sluiceway outlet above Main Unit 1-3 (TDITC) was not located in a forebay corner, was only 8-ft deep, and discharged about $933 \mathrm{ft} / \mathrm{s}$ at normal-pool elevation. The linear velocity of water over the weir was about $15 \mathrm{ft} / \mathrm{s}$ at the B2CC and $5 \mathrm{ft} / \mathrm{s}$ at the TDITC. The authors used a Dual-Frequency Identification Sonar (DIDSON) to record movements of fish within about $65 \mathrm{ft}$ of the B2CC and within $35 \mathrm{ft}$ of the TDITC. Fish were actively tracked fish by manually adjusting pan and tilt rotator angles to keep targets in view. The probability of fish entering each SFO was estimated by a Markov chain analysis, which did not require complete fish tracks. There are two important components to designing SFOs, the location within the forebay to take advantage of forebay circulation and specific entrance characteristics such as discharge and depth which affect the size and shape of the entrainment zone and high entrance probability zone. Providing SFOs with an entrainment zone extending upstream of structure could reduce entrance rejection, decrease forebay residence time and risk of predation, and increase passage of schools of smolts. BS181 PDF reproduced with permission of HCI Publications. http://www.hcipub.com/

Ploskey, G. R., J. Kim, M. A. Weiland, J. S. Hughes, and E. S. Fischer. 2006b. Reanalysis of hydroacoustic fish-passage data from Bonneville Dam after spill-discharge corrections. Draft Report by the Pacific Northwest National Laboratory, Richland, WA, for the U. S. Army Corps of Engineers, Portland District, Portland, Oregon.

This report presents a reanalysis of four years (2000, 2001, 2002, and 2004) of fish passage estimates at Bonneville Dam after spill discharge was reevaluated for those years. Data was collected using fixed-aspect hydroacoustics. Results from the 2005 fixed-aspect hydroacoustics study at Bonneville dam are also included. Metrics include passage efficiencies for all passage routes at Bonneville Dam: spill, Powerhouse 1 (B1) turbines, Powerhouse 2 (B2) turbines, B1 sluiceway, B2 corner collector (B2CC), and non-turbine routes. Comparisons between passage routes (i.e. spill vs. sluiceway) are also reevaluated in this report. This reanalysis showed an increase in spill effectiveness that was significantly higher than previous estimates. Increased spill effectiveness still shows a trend that the $\mathrm{B} 2 \mathrm{CC}$ and the $\mathrm{B} 1$ sluiceway are much more efficient at passing fish at low water discharge. Recommendations, based on the data collected and the resulting trends, are to maximize surface-collection and reduce dependency on spill as a method of fish passage. BS182

Ploskey, G. R., M. A. Weiland, S. A. Zimmerman, J. S. Hughes, K. Bouchard, E. S. Fischer, C. R. Schilt, M. E. Hanks, J. Kim, J. R. Skalski, J. Hedgepeth, and W. T. Nagy. 2006c. Hydroacoustic Evaluation of Fish Passage through Bonneville Dam in 2005. PNNL-15944, Pacific Northwest National Laboratory, Richland, WA, for the U. S. Army Corps of Engineers, Portland District, Portland, Oregon.

The Portland District of the U.S. Army Corps of Engineers requested that the Pacific Northwest National Laboratory (PNNL) conduct fish-passage studies at Bonneville Dam in 2005. In this report, the authors present results of two juvenile salmonid passage studies conducted at Bonneville Dam during the spring and summer migrations between April 16 and July 15, 2005: 1) a hydroacoustic evaluation of project fish passage efficiency and other major passage metrics, and (2) a DIDSON evaluation of smolt approach and fate at the B1 Sluiceway Outlet 3C from the B1 forebay. BS175 
Plumb, J. M., M. S. Novick, B. D. Liedtke, and N. S. Adams. 2001. Passage behavior of radiotagged yearling chinook salmon and steelhead at Bonneville Dam associated with the surface bypass program, 1999. Annual Report by the U. S. Geological Survey, Columbia River Research Laboratory, Cook, Washington for the U. S. Army Engineer District, Portland, Oregon.

In 1999, the USGS used radio telemetry to examine the movements and behavior of juvenile hatchery steelhead and yearling spring Chinook salmon in the forebay of Bonneville Dam. In 1999 the PSC covered units 3-5 but only Unit 5 was operating. The deep-slot entrance was alternated between $5 \mathrm{ft}$ and $20 \mathrm{ft}$ wide.

The objectives were to determine

1. the general behavior, distribution, and approach patterns of juvenile salmonids upriver and in the forebay areas of Bonneville Dam

2. the time and route of dam passage

3. fish behavior associated with tests of surface bypass concepts and prototype surface bypass structures;

4. and to compare these results to those observed during 1998.

\section{$\underline{\mathrm{BS} 017}$}

Portland District Corps of Engineers. 2002. Bonneville decision document: juvenile fish passage recommendation. System Configuration Team, U.S. Army Engineer District, Portland, Oregon.

This is a decision document to address various proposed structural alternatives for fishery improvements at Bonneville Dam. Throughout the development of the document, a model called SIMPAS developed by NMFS was used to evaluate the various combinations of alternatives and the assumptions made by the authors where risk and uncertainty of the survival data had to be assigned and used as input to the model. The following recommendations will be forwarded to the System Configuration Team for yearly regional prioritization and implementation funding: 1) B2 will be the priority powerhouse; 2) implement the B2 Corner Collector as soon as possible; 3) continue to evaluate methods to improve B2 FGE and implement if results are favorable; 4) defer decision on B1 until critical information is available (B1 sluiceway efficiency and survival, B1 DSM Spring survival and adult fallback with high spill); and 5) defer the performance standard for B1 as laid out in the December 2000 BIOP due to deferral of the B1 decision. $\underline{B S 134}$

Reagan, R. E., S. D. Evans, L. S. Wright, M. J. Farley, N. S. Adams, and D. W. Rondorf. 2006. Passage Behavior of Radio-Tagged Yearling Chinook Salmon and Steelhead at Bonneville Dam, 2004: Revised for Corrected Spill. Final Report of Research by the U. S. Geological Survey, Columbia River Research Lab for the U. S. Army Corps of Engineers District, Portland, Oregon.

The behavior, passage efficiency, and survival of yearling Chinook salmon and steelhead were investigated in 2004 at Bonneville Dam using radio telemetry. Over 11,000 tagged fish were release for the investigation and approximately $90 \%$ of those fish were detected at Bonneville Dam. Median travel times were from 29.6 to 41.5 hours from the release sites at John Day Dam and The Dalles Dam. Bonneville Powerhouse 2 (B2) passed 59\% of the Chinook salmon detected and $66 \%$ of the steelhead detected while the spillway passed $33 \%$ of yearling Chinook salmon detected and $25.5 \%$ of steelhead detected and Powerhouse 1 (B1) passed the remainder of fish detected. Fish passage efficiency was $71 \%$ 
for yearling Chinook salmon and $86 \%$ steelhead for the project. Passage efficiency was also calculated for each passage route available to fish. Surface passage routes were more efficient at than other areas of the dam when spill discharge was higher. Passage metrics were generally lower in 2004 than 2002, but the passage efficiencies for the project was achievable because of the effectiveness of the B2 corner collector (8.4 for yearling Chinook salmon and 19.1 for steelhead) which passed 17 times less water than the spillway which had an effectiveness of 0.9 for yearling Chinook salmon and 0.7 for steelhead. BS179

\section{Shrank, B. P., E. M. Dawley, and B. Ryan. 1997. Evaluation of the Effects of Dissolved Gas Supersaturation on Fish and Invertebrates in Priest Rapids Reservoir and Downstream from Bonneville and Ice Harbor Dams, 1995. Coastal Zone and Estuarine Studies Division, Seattle, Washington.}

The objective of this study was to assess some of the impacts of ambient levels of gas-supersaturated water on aquatic organisms residing in the Columbia and Snake Rivers. Visual examinations were made of fish and invertebrates using 2.5- to 5-power magnification lenses to assess external signs of GBD (subcutaneous emphysema on fins, head, eyes, and body surface). The authors examined 84 salmonid fishes, 7,272 non-salmonid fishes, and 1,303 invertebrates for signs of GBD. Few signs of GBD among invertebrates were observed. Signs of GBD in fish were prevalent downstream from Ice Harbor Dam but were rare in the other river reaches sampled. Dissolved gas supersaturation (DGS) was extremely high downstream from Ice Harbor between 8 May and 20 June as a result of turbine outages at the dam. When DGS reached $138 \%$ and $130 \%$ of saturation, signs of GBD were observed in $20 \%$ of resident fish, with nearly half of these fish displaying severe signs. Upstream from Priest Rapids Dam, substantive signs of GBD were observed in only one sampling period. Downstream from Bonneville Dam, signs of GBD were observed in five species of fish, but the highest prevalence of GBD signs did not exceed 3\% at any time. $\underline{\mathrm{BS} 119}$

\section{Simmons, M. A., C. S. Simmons, S. L. Thorsten, M. A. Chamness, R. L. Johnson, C. A. McKinstry, and K. D. Hand. 2001. Splitbeam Evaluation of Near-Field Fish Behavior at Bonneville Dam First Powerhouse, Unit 8. Prepared for the U.S. Army Corps of Engineers, by Pacific Northwest National Laboratory, Richland, Washington.}

The purpose of this study was to evaluate fish behavior in front of Unit 8 of the first powerhouse at Bonneville Dam and to determine if this behavior could be attributed to the presence of a modified extended-length submersible bar screen (ESBS) installed in 2000. Juvenile migrant behavior was characterized using split-beam hydroacoustics at the B slot of Unit 8. Based on their results, the authors concluded that 1) because the fish population immediately upstream of the trash racks was high in the water column, the majority of fish would not have been entrained under the tip of the ESBS from the sample region; 2) there was a substantial degree of milling upstream of the trash racks; 3) only one region was identified that potentially could contribute to fish entrainment, but that occurred at night, when relatively few fish were detected (at that time fish were still relatively high in the water column away from the tip of the ESBS); and 4) the majority of tracked fish were located in the center region of the slot opening with lower numbers to the north and south. Based on these conclusions, the authors recommended that 1) for future fish bypass design efforts, the mechanisms that cause milling in front of an unobstructed turbine intake be modeled; and 2) further research be conducted to establish the validity of their finding that the majority of tracked fish were located in the center region of the slot opening with lower numbers to the north and south sides. BS115

Skalski, J. R., D. Mathur, and P. G. Heisey. 2002. Effects of Turbine Operating Efficiency on Smolt Passage Survival. North American Journal of Fisheries Management 22:1193-1200. 
The authors conducted a retrospective analysis of data on the relationship between operating efficiency of Kaplan turbines and direct passage survival of salmonid smolts. A review of a key report instrumental in establishing 61\% turbine efficiency rule for operating Snake and Columbia river hydroelectric stations found a weak association $\left(\mathrm{r}^{2}=0.112\right)$ but also found misspecification of the turbine efficiency data. At four Snake and Columbia river dams, manipulative studies were performed to investigate the relationship between turbine performance and smolt passage survival, as estimated with balloon-tag releases and recoveries. At all sites, peak passage survival did not coincide with the observed turbine operating efficiency peak. The difference between maximum survival and survival at peak turbine efficiency was as much as $3.2 \%$. However, at three sites, maximum survival was within the $61 \%$ peak efficiency operating rule. A meta-analysis that used balloon-tag survival results from 11 different hydropower projects also found no association between relative turbine efficiency at a site and smolt passage survival $\left(\mathrm{r}^{2}=0.0311, \mathrm{P}=0.2640\right)$. For the benefit of smolt survival during passage, the authors recommend managing turbine operations to achieve maximum passage survival rather than focusing solely on peak operating efficiency of Kaplan turbines. BS170 PDF reproduced with permission of www.fisheries.org.

Smith, S. G., W. D. Muir, S. Achord, E. E. Hockersmith, B. P. Sandford, J. G. Williams, and J. R. Skalski. 2000a. Survival Estimates for the Passage of Juvenile Salmonids through Snake \& Columbia River Dams \& Reservoirs, 1998. Annual Report Prepared for by the Fish Ecology Division, Northwest Fisheries Science Center, National Marine Fisheries Service, Seattle, Washington.

In 1998, the National Marine Fisheries Service and the University of Washington completed the sixth year of a study to estimate survival of juvenile salmonids passing through dams and reservoirs on the Snake and Columbia Rivers. Actively migrating steelhead smolts (Oncorhynchus mykiss) were collected at Lower Granite Dam, tagged with passive integrated transponder (PIT) tags, and released to continue their downstream migration. Steelhead (hatchery and wild) were PIT tagged and released in proportion to the number arriving at the dam. The authors did not PIT tag any yearling chinook salmon (O. tshawytscha) in 1998 because sufficient numbers for survival estimation were PIT-tagged and released from Lower Granite Dam for the Transportation Evaluation Study and from Snake River Basin hatcheries. PIT-tagged smolts were detected at interrogation facilities at Lower Granite, Little Goose, Lower Monumental, McNary, John Day, and Bonneville Dams. PIT-tagged smolts were also detected using the PIT-tag trawl operated in the Columbia River estuary, and PIT tags were recovered from bird colonies in the Columbia River estuary. Survival estimates were calculated using the Single-Release (SR) Model. At McNary Dam, the authors evaluated post-detection bypass survival for yearling Chinook salmon (a test of a SR Model assumption).

Research objectives in 1998 were 1) to estimate reach and project survival in the Snake River throughout the steelhead and yearling Chinook salmon migrations, 2) to evaluate the survival-estimation models under prevailing operational and environmental conditions in the Snake River, and 3) to estimate post-detection bypass survival for yearling chinook salmon at McNary Dam.

This report provides reach survival and travel time estimates for PIT-tagged hatchery and wild juvenile steelhead and yearling Chinook salmon in the Snake and Columbia Rivers during 1998. Estimates of post-detection bypass survival for yearling Chinook salmon at McNary Dam are also reported. Results are reported primarily in the form of data tables and figures with minimal description of methods and analysis. Detailed information on the methodology and statistical models used for this report is provided in five previous annual reports on this study, which are cited here. BS064 
Smith, S. G., W. D. Muir, G. A. Axel, R. W. Zabel, J. G. Williams, and J. R. Skalski. 2000b. Survival Estimates for the Passage of Juvenile Salmonids through Snake and Columbia River Dams and Reservoirs, 1999. Prepared for the Bonneville Power Administration, by the National Oceanic and Atmospheric Administration, National Marine Fisheries Service, Coastal Zone and Estuarine Studies Division, Northwest and Alaska Fisheries Center, Seattle, Washington.

Objectives were 1) to estimate reach and project survival in the Snake and Columbia Rivers throughout the yearling Chinook salmon and steelhead migrations, 2) to evaluate the survival-estimation models under prevailing operational and environmental conditions, 3 ) to estimate post-detection bypass survival for subyearling fall Chinook salmon at McNary Dam, and 4) to estimate reach survival for subyearling fall Chinook salmon from the McNary Dam tailrace to the tailrace of John Day Dam.

For the transportation study, PIT-tagged smolts were recorded at detection facilities at Lower Granite, Little Goose, Lower Monumental, McNary, John Day, and Bonneville Dams. PIT-tagged smolts were also detected using the PIT-tag detector trawl operated in the Columbia River estuary and additional PIT tags were recovered from bird colonies in the Columbia River estuary. Survival estimates were calculated using a statistical model for single-release, multiple capture data. Post-detection bypass survival was estimated for river-run subyearling fall Chinook salmon at McNary Dam during the summer migration (test of a single-release model assumption) and reach survival for subyearling fall Chinook salmon from McNary Dam tailrace to the tailrace of John Day Dam.

Estimated survival probabilities from the tailrace of Lower Granite Dam to the tailrace of Little Goose Dam averaged 0.949 for yearling Chinook salmon and 0.926 for steelhead. For individual reaches, average estimated survival probabilities were as follows for yearling Chinook salmon and steelhead respectively: from Little Goose Dam tailrace to Lower Monumental Dam tailrace, 0.925 and 0.915; from Lower Monumental Dam tailrace to McNary Dam tailrace, 0.904 and 0.833; from McNary Dam tailrace to John Day Dam tailrace, 0.853 and 0.920; and from John Day Dam tailrace to Bonneville Dam tailrace, 0.814 and 0.682 . The average overall estimates of survival probabilities for yearling Chinook salmon and steelhead from Lower Granite Dam tailrace to Bonneville Dam tailrace were 0.557 and 0.440 respectively. At McNary Dam, average post-detection bypass survival probability for subyearling fall Chinook salmon was $0.988(\mathrm{SE}=0.027)$, and survival from the tailrace of McNary Dam to the tailrace of John Day Dam was $0.775(\mathrm{SE}=0.019)$. The results are reported primarily in tables and figures with minimal explanation of methodology. Methodology and statistical models used in the analyses were the same as in previous study years, and details are provided in previous annual reports cited in the text. $\underline{\mathrm{BS} 073}$

\section{Snelling, J. C. and S. A. Mattson. 1996. Movement and Behavior of Juvenile Salmonids at Three Lower Columbia River Dams. Year-end report for 1996. Oregon Cooperative Fishery Research Unit, Department of Fisheries and Wildlife, Oregon State University, Corvallis, Oregon.}

The primary objectives of this work were to 1) determine the optimum outfall locations to exit juvenile salmonids from the Bonneville tailrace, thereby reducing vulnerability to predation, and 2) determine the migration behavior of radio-tagged juvenile Chinook salmon from their passage at John Day to a point about $18 \mathrm{~km}$ below The Dalles Dam, thereby providing an estimate of migratory success. The major findings of the study were as follows: 1) juvenile Chinook salmon released from the Bonneville first and second powerhouse outfalls or at the proposed outfall location followed the shipping channel; up to $10 \%$ of fish released from Powerhouse II and the proposed outfall location used the side channels around Pierce and Ives Islands, which nearly doubled their travel time in the $8 \mathrm{~km}$ study area; 2) $3 \%$ to $4 \%$ of the fish held for more than 30 min within the same $400 \mathrm{~m}$, apparently unrelated to where 
they were released; 3 ) about $25 \%$ of the subyearlings released from existing outfalls were immediate mortalities, probably eaten by northern squawfish; 4) yearling Chinook salmon released at the proposed outfall traveled more rapidly than did those released from either powerhouse; the benefit to subyearlings only accrued from comparisons with the $2^{\text {nd }}$ powerhouse; 5) juvenile Chinook salmon released above Bonneville Dam by USGS and electronically intercepted by receivers used in this study below behaved similarly to those released above the dam; 6) yearlings moved through The Dalles pool directly, following the shipping channel; subyearlings spent more time at the river margins; 7) the more direct route through the north Miller Island channel was not a chosen route; 8 ) the authors documented $65 \%$ of yearling and $39 \%$ of subyearling Chinook salmon released above John Day Dam as migrating past Lyle Point below The Dalles Dam; 6\% of both age classes succumbed to predation, with California Gulls in The Dalles tailrace being the dominant predator; and 9) results represent fish behavior under exceptionally high flow conditions; thus results may be quite different in another year with a different hydrograph. BS127

\section{Stansell, R. J., R. A. Magne, W. T. Nagy, and L. M. Beck. 1990. Hydroacoustic Monitoring of Downstream Migrant Juvenile Salmonids at Bonneville Dam, 1989. Prepared by the U.S. Army Corps of Engineers, Portland District, Fisheries Field Unit, Bonneville Lock and Dam, Cascades Locks, Oregon.}

During hydroacoustic monitoring in 1986, 1987, and 1988 it became evident that the ice and trash chute (ITC) at Bonneville Dam second powerhouse was passing large numbers of juvenile salmonids (Magne et al. 1986, 1987, 1989). Dual-beam target strength estimates in 1988 indicated that fish entering the ITC averaged eight decibels (dB) higher than fish entering the turbine units (Magne et al. 1989). This could have been caused by differences in fish orientation, multiple fish passing through the hydroacoustic beam at the same time at the same range, or because the dual-beam method may not work when ranges between the transducer and target are short. In order to determine the behavior and orientation of fish entering the beam, underwater video cameras, situated in a manner to view the area ensonified by the acoustic beam, were deployed.

The results of the 1988 Bonneville study comparing the National Marine Fisheries Service (NMFS) Fish Guiding Efficiency (FGE) and hydroacoustic Theoretical Fish Guiding Efficiency (TFGE, those fish detected at an elevation greater than that of the bottom of the Submerged Traveling Screen and assumed to have been guided into the gatewell, divided by the total number of fish detected in the slot) at turbine slots 13A and 17B were promising, and showed a good correlation over the entire spring period, but varied greatly day to day (Magne 1989). This day-to-day variation was thought to be due to small sample sizes resulting from short sampling periods. Comparison with a sampling technique that collects data over a longer period of time should show better day-to-day correlation. The Portland District Corps of Engineers Fisheries Field Unit proposed a study to address these concerns in 1989. BS050

\section{Thorne, R. E. and E. S. Kuehl. 1989. Evaluation of Hydroacoustics Techniques for Assessment of Juvenile Fish Passage at Bonneville Powerhouse I. Final Report Prepared for U.S. Army Corps of Engineers, Portland District, by BioSonics, Inc., Seattle, Washington.}

The COE contracted BioSonics, Inc. to determine how a hydroacoustic system can be deployed and operated so that a routine monitoring program can be conducted at Bonneville Powerhouse I. The eventual goal will be to estimate total juvenile salmonid passage at the powerhouse and the relative distribution of these fish among the various passage routes. This information will then be used to evaluate fish bypass systems at the powerhouse.

Hydroacoustic data were collected at Turbine 3 of Bonneville Powerhouse I from June 28 to July 27, 1988, using two in-turbine transducers mounted to the trash racks. Sampling was concurrent with fish guiding efficiency (FGE) studies at Turbine 3 conducted by the National Marine Fisheries Service 
(NMFS) using fyke nets and gatewell dip nets. Turbine 3 was operated only during FGE sampling, which was generally $2000 \mathrm{~h}$ to $2245 \mathrm{~h}$. After successful application at Turbine 3, additional transducers were deployed in a similar fashion at Turbine 7, which is a noisier location because of turbulence associated with an adjacent wing wall. Sampling took place during both daytime and nighttime periods at Turbine 7 from July 20 to 27,1988 . The objective was to evaluate whether the deployment and sampling techniques used at Turbine 3 could be applied to other, noisier sites at the powerhouse.

This study focused on the relationship between acoustic target strength and system noise thresholds, since that is the most critical factor for successful operation of acoustic systems in this noisy environment. $\underline{\mathrm{BS} 047}$

\section{Thorne, R. E. and G. E. Johnson. 1993. "A Review of Hydroacoustic Studies for Estimation of Salmonid Downriver Migration Past Hydroelectric Facilities on the Columbia and Snake Rivers in the 1980s." Reviews in Fisheries Science. 1 (1):27-56.}

Hydroelectric development on the Columbia and Snake Rivers substantially impacted salmonid populations. The 1980 Pacific Northwest Electric Power Planning and Conservation Act mandated development of a program to mitigate these impacts. Hydroacoustics was one of the techniques that were applied to study the temporal and spatial characteristics of the downstream salmonid migration. Over 60 hydroacoustic studies were conducted at the various hydroelectric facilities on the Columbia and Snake Rivers during the 1980s. The primary objectives were measurement of run timing, vertical distribution, horizontal distribution, diel distribution, spill efficiency, and bypass efficiency. The techniques provided a cost-effective, non-lethal, and accurate means to study passage rates, migration paths, and efficiencies of various operational and bypass mechanisms. In at least one case, the techniques were instrumental in the development of a successful bypass procedure. The development of hydroacoustic techniques for the Columbia and Snake Rivers contributed to successful applications of these techniques throughout the world, although more widespread application is hindered by the complexity and lack of understanding of the techniques. (This is the original abstract). Permission was not granted by the publisher (Taylor and Francis Group) for us to provide a PDF of this copyrighted article.

\section{Toner, M. A. and E. M. Dawley. 1995. Evaluation of the Effects of Dissolved Gas Supersaturation on Fish and Invertebrates Downstream from Bonneville Dam, 1993. Annual Report of Research for the U.S. Army Corps of Engineer Division, Portland, Oregon by the National Oceanic and Atmospheric Administration, Northwest Fisheries Science Center, Seattle, Washington.}

During the period of high spring flow in the Columbia River in 1993, the occurrence of gas bubble disease (GBD) in migrating juvenile salmonids and other aquatic biota residing in the Columbia River downstream from Bonneville Dam was monitored. Fishes and invertebrates were collected with a 50-m beach seine, a 7.5-m seine, and a Ponar bottom sampler at 18 locations from Columbia Rkm 228 to 62 . Dissolved gas saturation values at the U.S. Army Corps of Engineers' Warrendale, OR, monitoring station (Rkm 226) reached $128 \%$ on four days, with daily mean values above $120 \%$ on nine days. However, the dissolved gas concentrations measured at the sampling locations from 27 April through 14 June averaged $112 \%$, with a range from $103 \%$ to $122 \%$; concentrations above $120 \%$ occurred upstream from Rkm 179 from 11 May through 21 May. External signs of GBD were infrequent. A low prevalence of GBD occurred in 6 of the 20 species that were examined. Mild signs of GBD (small blisters between fin rays) were observed in less than $1 \%$ of the juvenile Chinook salmon $(n=1,648)$ and peamouth $(n=238)$, in $3 \%$ of the juvenile coho salmon $(n=711)$, and in $2 \%$ of the juvenile steelhead $(n=50)$ examined. Moderate to severe signs of GBD (large blisters on the body and exophthalmia) were observed in less 
than $1 \%$ of the sticklebacks ( $\mathrm{n}=906)$ and prickly sculpins $(\mathrm{n}=174)$ examined. No evidence of GBD was observed in invertebrates collected from monitoring sites. (This is the original abstract). BS121

\section{Toner, M. A., B. Ryan, and E. M. Dawley. 1995. Evaluation of the Effects of Dissolved Gas Supersaturation on Fish and Invertebrates Downstream from Bonneville, Ice Harbor and Priest Rapids Dams, 1994. Annual Report of Research for the U.S. Army Corps of Engineer Division, Portland, Oregon by the National Oceanic and Atmospheric Administration, Northwest Fisheries Science Center, Seattle, Washington.}

This study involved monitoring the prevalence of gas bubble disease (GBD) in resident fish and invertebrates in four river reaches: downstream from Bonneville and Ice Harbor Dams, and upstream and downstream from Priest Rapids Dam, during the period of high spill in 1994. Visual examinations were made of fish and invertebrates using 2.5- to 5-power magnification lenses to assess external signs of GBD (subcutaneous emphysema on fins, head, eyes, and body surface). Authors examined 2,082 salmonid fishes, 11,976 non-salmonid fishes, and 4,133 invertebrates for signs of GBD. Signs of GBD were prevalent downstream from Ice Harbor Dam, but were rare in the other river reaches sampled. Downstream from Ice Harbor in early May, TDG levels reached 136\% for of saturation for three days and were higher than $130 \%$ for 7 to 11 hours each day. Signs of GBD were observed in 5\% to $10 \%$ of resident fish captured during the month of May. Half of the 22 species captured displayed signs of GBD. When TDG levels at the sampling sites dropped to a daily average of $110 \%$ of saturation with peaks no higher than $115 \%$, GBD signs among fish disappeared. Signs of GBD among invertebrates were few. $\underline{\mathrm{BS} 120}$

Uremovich, B. L., S. P. Cramer, C. F. Willis, and C. O. Junge. 1980. Passage of Juvenile Salmonids through the Ice-Trash Sluiceway and Squawfish Predation at Bonneville Dam, 1980. Annual Progress Report, Prepared for the U.S. Army Engineer, Portland District, by the Oregon Department of Fish and Wildlife Portland, Oregon.

The goal of studies in 1980 was to determine operating criteria for passing the maximum number of juvenile salmonids possible through the ice-trash sluiceway. The three objectives under this goal were to (1) Determine the sluiceway bypass efficiency for yearling salmonids when sluice-gates 4A, B, C, 5A were fully opened, (2) determine the horizontal distribution and abundance of juvenile salmonids passing through penstocks with the sluiceway operating at optimum criteria, and (3) determine the best sluice-gate openings or passage of subyearling Chinook salmon (Oncorhynchus tshawytsca) through the sluiceway after July 1. BS051

Ward, D. L., J. H. Petersen, and J. J. Loch. 1995. "Index of Predation on Juvenile Salmonids by Northern Squawfish in the Lower and Middle Columbia River and in the Lower Snake River." American Fisheries Society. 124:321-334.

The authors developed a predation index to describe the relative magnitude of predation on juvenile salmonids by northern squawfish (NS) throughout the lower and middle Columbia River and lower Snake River. The predation index was the product of an abundance index and a consumption index. The authors evaluated various catch indices and found that catch per unit effort best reflected differences among NS abundances. NS abundance was higher in the lower Columbia River than in the middle Columbia or Snake rivers and was highest in Bonneville reservoir and the Columbia River downstream from Bonneville Dam. The consumption index was based on the concept of meal turnover time for a sample of NS. Variables needed to calculate the consumption index (CI) were water temperature (T), mean weight of the NS (W), mean number of salmonids in each gut (S), and mean weight of the gut contents $(\mathrm{GW})$ : $\mathrm{CI}=0.0209 \mathrm{~T} 1.60 \mathrm{~W} 0.27$ (SGW-0.61). Generally, NS consumption of juvenile salmonids 
was highest in tailraces downstream from dams and higher in the Columbia River than in the Snake River. Predation on juvenile salmonids was much higher in the lower Columbia River than in the middle Columbia or lower Snake River and usually was higher in summer than in spring. Predation was highest in the Columbia River downstream from Bonneville Dam and in John Day Reservoir. The predation index identified areas where predator control efforts can be most effective. Angling for NS at dams should be concentrated in tailraces. Removal efforts concentrated in the lower Columbia River would have the greatest effect on predation. BS135 PDF reproduced with permission of www.fisheries.org.

\section{Willis, C. F. and B. L. Uremovich. 1981. Evaluation of the Ice and Trash Sluiceway at Bonneville Dam as a Bypass System for Juvenile Salmonids, 1981. Annual Progress Report, Fish Research Project, Oregon, Prepared for the National Marine Fisheries Service, by the Oregon Department of Fish and Wildlife, Portland, Oregon.}

The Columbia River Fisheries Council (1981) has established a goal that bypass systems should pass at least $70 \%$ of the available juvenile salmonids. Submersible traveling screens (STS) are being installed in the second powerhouse to bypass juvenile salmonids. The study reported here was designed to determine the best system for bypassing juvenile salmonids around the first powerhouse.

In 1981, tests were conducted to determine if STSs or the ice-trash sluiceway should be used to bypass juvenile salmonids around the first powerhouse. The National Marine Fisheries Service (NMFS) evaluated the guidance efficiency (proportion of juveniles collected in gatewells) of the STS system and the Oregon Department of Fish and Wildlife (ODFW) evaluated the bypass efficiency of the ice-trash sluiceway (proportion of juveniles passing through the sluiceway). This report describes the finding from the ice-trash sluiceway evaluation. The goal of our 1981 study was to develop final criteria for operating the sluiceway at Bonneville first powerhouse as a means of bypassing juvenile salmonids and to evaluate the bypass efficiency of the sluiceway when operated according to optimum criteria. To achieve this goal, the authors had three objectives: (1) Determine the best sluice-gate openings for attracting maximum numbers of juvenile salmonids. (2) Determine the efficiency of the sluiceway, when operated under optimum conditions, for bypassing juvenile salmonids. (3) Determine the factors other than the location of gate openings and flow per gate, that influence the effectiveness of the sluiceway for bypassing juvenile salmonids. BS062

\section{Zabel, R. W., S. G. Smith, W. D. Muir, D. M. Marsh, J. G. Williams, and J. R. Skalski. 2001. Survival Estimates for the Passage of Spring-Migrating Juvenile Salmonids through Snake and Columbia River Dams and Reservoirs. 2000 Annual Report, DOE/BP-10891-10, Prepared for Bonneville Power administration, by the Fish Ecology Division, National Marine Fisheries Service, Seattle, Washington.}

Objectives were 1) to estimate reach and project survival in the Snake and Columbia Rivers throughout the yearling Chinook salmon and steelhead migrations, and 2) to evaluate the performance of the survival-estimation models under prevailing operational and environmental conditions.

The Single-Release (SR) Model was used to estimate survival for releases of PIT-tagged yearling Chinook salmon, sockeye salmon, and steelhead from Snake River Basin hatcheries and traps and from Lower Granite Dam in 2000. Hatchery steelhead were tagged with PIT tags and released at Lower Granite Dam, and yearling chinook salmon PIT tagged by other studies, were used for reach survival and travel time estimation. PIT-tagged smolts were detected at interrogation facilities at Lower Granite, Little Goose, Lower Monumental, McNary, John Day, and Bonneville Dams. Smolts were also detected in the PIT-tag detector trawl operated in the Columbia River estuary. 
Estimated survival from the tailrace of Lower Granite Dam to the tailrace of Little Goose Dam averaged 0.938 for yearling Chinook salmon and 0.901 for steelhead. From Little Goose Dam tailrace to Lower Monumental Dam tailrace, estimated survival averaged 0.887 and 0.904; from Lower Monumental Dam tailrace to McNary Dam tailrace (including passage through Ice Harbor Dam), estimated survival averaged 0.928 and 0.842; from McNary Dam tailrace to John Day Dam tailrace, estimated survival averaged 0.898 and 0.851; and from John Day Dam tailrace to Bonneville Dam tailrace (including passage through The Dalles Dam), estimated survival averaged 0.684 and 0.754 for yearling chinook salmon and steelhead, respectively. The overall estimates of yearling Chinook salmon and steelhead survival from Lower Granite Dam tailrace to Bonneville Dam tailrace (7 projects) were 0.486 and 0.393 respectively. Results are reported primarily in the form of tables and figures. BS072

\section{Zimmerman, M. P. and D. L. Ward. 1999. "Index of predation on juvenile salmonids by northern pikeminnow in the lower Columbia River Basin, 1994-1996." Transactions of the American Fisheries Society. 128:995-1007.}

The authors estimated relative abundance of northern pikeminnow Ptychocheilus oregonensis and relative consumption of juvenile salmonids Oncorhynchus spp. by northern pikeminnow at standardized sites in the lower Columbia and lower Snake rivers from 1994 to 1996. Indexes of abundance and consumption were compared with indexes measured from 1990 to 1993 to evaluate changes in predation concurrent with a predator control program in the lower Columbia basin. Reductions in indexes of northern pikeminnow abundance, consumption, or both resulted in mean 1994-1996 predation index values that were 44\%-91\% lower than mean 1990-1993 values through-out the lower Columbia basin. Consumption of juvenile salmonids by surviving northern pike-minnow has not decreased in response to predator control efforts. Spatial patterns were consistent among years, being greatest downstream from Bonneville Dam, intermediate in lower Columbia River reservoirs, and lowest at Snake River sites. Reductions in relative predation were consistent with changes in northern pikeminnow population structure associated with harvest, although annual variation in river flow, dam spill, and juvenile salmonid passage may have magnified reductions in predation. (This is the original abstract). BS066 PDF reproduced with permission of www.fisheries.org. 